An examination of money in the real economy, with particular reference to the interpretation of monetary activity in alternative theoretical formulations of macroeconomic activity.

THESIS

SUBMTTTHD FOR THE DEGREE

OP DOCTOR OF PHILOSORHY

IN ECONOMICS

at the

VICTORIA UNIVERSITY OF WEIIINGTON

MARCH 1974 


\section{THE MONETARY NEXUS}

Recent debate on monetary theory has probed increasingly into its fundamental conceptualisations, and some far-reaching proposals for reform have emerged. This study is an attempt to contribute towards such a reform. It begins with an appraisal of the theory in order to evaluate its status as an empirical theory, and finds that the ideas of money as a nexus between producer and user, of economic processes as occurring through time, and of the absence of general equilibrating tendencies, need substantial reformulation if the processes of a modern pecuniary economy are to be adequately represented. The study devotes its major effort to structuring these ideas into a form capable of sustaining the required theoretical development while maintaining contact with the world of experience. 


\section{ACKNOWLEDGMENTS}

During the course of this study I have benefited from interchanges of views with colleagues and with advanced students, although as my own thinking has developed it has become increasingly difficult to separate individual influences. I should, however, like to acknowledge a specific debt to my colleague Mr. M.J. Pope, with whom some of the ideas expressed here have been hammered out in discussion. I should also mention the encouragement given during the course of this study by colleagues Professor L.F. Jackson and Professor B.M. Niculescu who have been entirely constructive.

I should like too to thank Mrs. Margaret Smith, who has made a fine job of the typing and of preparing the computer graphs for photocopying.

Any erroxs and inadequacies which remain are entirely my own responsibility. 
Many people working in the field of monetary and nacroeconomic theory have been struck by unsatisfactory features of this field. The following are not uncommon complaints: (a) many of the terms and propositions of the theory are either so loose and ill-defined as to leave obscure what is being said, or else so highly artificial as to oblige one to make some nonsensical statements about the way the world conducts its business if any translation into ordinary language is attempted; (b) the internal structure of the theory is marked by lack of cohesion, particularly evident in the compartmentalisation of monetary theory, theory of money and banking, theory of production and growth, and theories of inflation; (c) despite the enormous amount of empirical work that has been done in recent decades, and the bright promise held out by the development of econometric techniques, the gain in accurate information and in understanding of the system has been meagre and disappointing; (d) despite the faith that many modern economists still have in their model, its performance in practical application is at best patchy, even when the various schools can agree on what the problem is and what needs to be done.

While the state of economic theory has often been the subject of complaint during its history, in recent years the note of dissatisfaction seems to have taken on a perceptibly sharper edge. Modifications and suggestions for reformulation have been proposed, but despite a considerable fellow-feeling for their authors I cannot feel that such proposals really go to the heart of the matter; a much more fundamental investigation appears to be necessary before any significant progress can be made.

This study is an attempt to make a contribution in that direction. In essence, the task here undertaken is that of carrying out a diagnosis and following that up, as far as possible, with the development of an appropriate line of treatment. The concentration is to be on monetary theory, but since that cannot meaningfully be dealt with in isolation from the general context of macroeconomic activity, the field necessarily extends beyond purely monetary matters. 
We cannot, however, embark at once on a diagnosis; the tools do not lie ready to hand, and we need first to find and assemble them. In the process, we shall have to deal with some misconceptions which may stand in the way of the job in hand. We start, then, with a search for criteria by which theories may be evaluated, and by which the process of theory construction may be given definition and purpose; that is to say, we start with methodology. 


\section{ONTENTS}

1. Issues in Methodology.

2. The Interpretation of Macroeconomic and Monetary Theory.

3. Towards a Conceptual structure of Macroeconomic Activity.

4. Simulation of Macroeconomic Transmission Mechanisms.

5. Interactions in a Market System.

6. The Macroeconomy as a Control System.

7. A summing - Up.

Footnotes.

References.

Printout from computer simulation. 
CHAPTER 1

ISSUES IN METHODOLOGY

Most practising economists tend to avoid methodological debate mainly, it is to be supposed, because they see no need for $1{ }^{2}$ In the normal course of economic debate, however, when particular models are being discussed, reference is frequently made to the "realism" of the model under discussion, and since this question of "realism" is a central toplc of debate among those economists who do interest themselves in questions of theory formation and use, it makes an obvious starting-point for this study. 
1.1 The Debate on "Realism in the Assumptions"

1.11 The Course of the Debate

We begin with an argument from Robbins which contains, by implication, most of the issues with which we shall be dealing in this chapter. It is now some forty years since Robbins argued as follows:
"The propositions of economic theory, like all scientific theory, ere obviously deductions from a series of postulates. And the chief of these postulates are all assumptions involving in some way simple and indisputable facts of experience relating to the way in which the scarcity of goods which is the subject-matter of our science actually shows 1tself in the world of reallty." (Robbins, 1935, p. 78.)

Citing the main postulates of value theory, he continues:

\begin{abstract}
"These are not postulates the existence of whose counterpart in reality admits of extensive dispute once their nature is fully realised. We do not need controlled experiments to establish their validity: they are so much the stuff of our everyday experience that they have only to be stated to be recognised as obvious." (op.cit., p. 79.)
\end{abstract}

He goes on to argue that the laws of economics are quite general, and independent of spatio-temporal anchorage:

"No one will really question the universal applicability of such assumptions as the existence of scales of relative valuation, or of different factors of production, or of different degrees of uncertainty regarding the future.... and no one who has really examined the kind of deductions which can be drawn from such assumptions can doubt the utility of starting from this plane. It is only the failure to realise this, and a too exclusive preoccupation with the subsidiary assumptions, which can lend any countenance to the viev that the laws of Economics are inmited to certain conditions of time and space. (op.cit.. p. 81.)

He goes on to attack the operationist view, at that time made fashionable by the Watsonians in psychology, that: 
"scientific method.... demands that we should leave out of account anything which is incapable of direct

observation." (op.cit., p. 87.)

on the grounds that:

"we do in fact understand terms such as choice, indifference, preference and the like in terms of inner experience".

(og.cit., p. 87/8.)

On the foregoing basis he concludes:

"The nature of economic analysis should now be plain. It consists of deductions from a series of postulates, the chief of which are almost universal facts of axperience present whenever human activity has an economic aspect." (op.cit., p. 99/100.)

from which he deduces that:

"Economic laws describe inevitable implications. If the data they postulate are given, then the consequences they predict necessarily follow... If the 'given situation' conforms to a certain pattern, certain other features must also be present, for their presence is "deducible" from the pattern originally postulated.... Granted the correspondence of its original assumptions and the facts, its conclusions are inevitable and inescapable." (pp. 121-2.)

The importance of the position taken by Robbins is that, while few economists would be willing these days to defend this method as a sound precept of economic theorizing, it is much closer to what economists actually do, particularly in polley discussions and recommendations, than what the more 'scientific' economists say ought to be ane, and what they sometimes claim to be doing. It is not alvays clear that the postulates used in modern theory are as firmly rooted in experience as Robbins' argument requires, or that the economic conclusions therefrom are vallaly deduced or legitimately applied. But $I$ shall nevertheless argue that Robbins' position is not nucressarily false, and that the contrary view which advocates an ostensibly more scientific procedure is not necessarily valid.

To Robbins' view may be opposed that of Friedman (1953): 


\begin{abstract}
"Theory is to be judged by its predictive power for the class of phenomena which it is intended to 'explain'... the only relevant test of the validity of a hypothesis is comparison of 1 ts predictions with experience." (p. 8)
\end{abstract}

This assertion is plainly meant to be taken in conjunction with Friedman's discussion of the difficulty in setting up valid empirical tests of hypotheses, much of which stems from the difficulty of specifying the 'class of phenomena which it is intended to explain': this difficulty, says Friedman (op.cit., p. 14):

\begin{abstract}
"makes it tempting to suppose that other, more readily available, evidence is equally relevant to the validity of the hypothesis - to suppose that hypotheses have not only 'implications' but also 'assumptions' and that the conformity of these 'assumptions' to 'reality' 1 s a test of the validity of the hypotheses different from or aditional to the test by implications".
\end{abstract}

Although Friedman himself makes no reference to Robbins in this context, Koopmans and Papandreou sea the connection and juxtapose the relevant quotations; ${ }^{2}$ both find no difficulty in accepting Friedman's view. But such acceptance has not been universal; Rotwein, for example, assails the view that the testing of predictions is the only relevant test of a hypothesis. ${ }^{3}$ It may not be entirely fair to Friedman to Ignore his view that the postulates need also to be empirically based, but he obviously invites attack with :

"truly important and significant hypotheses will be found to have 'assumptions' that are vildiy inaccurate descriptive representations of reality, and, in general, the more
significant the theory, the more unrealistic the assumptions." 4

Nagel (1963) makes an attempt to sort out the confusion by distinguishing three senses in which an assumption may be said to be unrealistic:

(1) It does not give an exhaustive description of some object; every model - indeed, every perception of the world - must be unrealistic in this sense, since no finite number of statements could exhaust the characteristics present. 
(ii) It is believed to be either false or highly improbable on the available evidence;

(iii) It is a 'pure' or 'ideal' case - the commonest example cited being that of Galileo's law formulated for the pure case of bodies falling in a vacuum.

Io the extent that Friedman is referring to the unrealism introduced by the process of abstraction and simplification inherent in the construction of the model, it is unrealistic merely in the first sense, and no objection can be raised; that there is a considerable element of this in Friedman's argument is undoubted; but this does not entirely dispose of his difficulty; he rests considerable weight upon the example of bodies falling in a vacuum as providing a parallel to what he evidently wishes to classify as a pure case - the maximization of returns hypothesis. But Nagel will not accept his argument (op.cit., p. 217);

\begin{abstract}
"Professor Friedman"s proposed paraphrase which omits all mention of a vacuum thus rests on the supposition that theoretical terms can in general be replaced by non-theoretical ones, without altering the meaning and function of the statements containing them. But the possibility of such a replacement is dubious on formal grounds alone; and what is more important, the suggestion that unless theoretical terms can thus be eliminated the statements containing them are scientifically otiose overlooks the rationale for stating laws in terms of pure cases."
\end{abstract}

On the maximization hypothesis itself, Nagel finds an ambiguity in Friedman's formulation, and suggests two possible interpretations:

\footnotetext{
"the behaviour of firms brings them returns equal to a magnitude called the maximum of expected returns" or "firms behave as if they were attempting to maximize returns".
}

The first is merely a loose empirical generalization about what returns firms receive, and is not unrealistic if, as Friedman claims, "it is in good agreement with experience". 5

The second interpretation reduces to an attempt to construct a pure case "requiring the use of theoretical terms in its 
formulation which cannot be replaced by nontheoretical expressions". Friedman, he says, is wrong in attempting to eliminate the theoretical terms, so too is Koopmans, 6 who attempts to rework Friedman's hypothesis so as to forrulate it in operational terms: referring to the Friedman-Alchian 'survival' test, he comments:
"here a postulate about individual behaviour is made more plausible by reference to the adverse effect or, and hence penalty for, departures from the postulated behaviour. But if (the observed penalties, as e.g. bankruptcy) are the basis for our belief in profit maximization, then we should postulate that basis itself and not the profit maximiation which it implies in certain circumstances".

As Nagel comments: this amounts to "a recommendation that would replace the theory by the eapirical evidence for the theory".

It may be that a main source of confusion in Friedman's argument is some ambivalence of purpose; both Rotwein and simon accuse Friedman, under the guise of expounding a methodological principle, of in fact attempting to defend two major dogmas of orthodoxy: the maximization-of-returns model and the perfect competition model. There is something to be said for this explanation, and what Nagel (op.cit., p. 218) renders gently as: "the essay is marked by an ambiguity that pexhaps reflects an unxesolved tension in his view on the status of econoric theory" perhaps has been put more bluntly by Friedman himself (op.cit.. p. 300):
"A man who has a burning interest in pressing issues of public policy.....is not 1ikely to stay within the bounds of a thethod of analysis that denies him the knowledge he seeks. He will escape the shackles of formalism, even if he has to resort to illogical devices and specious reasoning to do so."

With the entry of Samuelson into the lists the debate takes a new turn. Designating as the "p-twist" the following proposition:

\footnotetext{
"A theory is vindicable if (some of) its conseguences are empiricaliy valid to a useful degree of approximation the (empixical) unreallsm of the theory "itself" or of its "assumption" is quite irrelevant to its valldity and worth",
} 
Samuelson goes on to irmpove the shining hour:

\begin{abstract}
"At points, the F-twist seens to go even farther and claim: it is a positive merit of a theory that (some of) its content and assumptions be unrealistic since only if it is not tailoxed closely to one small. bit of reality can it give a useful fit to a wide spread of enpirical situations. Unless we explain complex reality by something simpler than itself we have accomplished little (period or by theorizing)."
\end{abstract}

Samuelson concedes a germ of truth in the extension he provides, but comments on the basic F-twist:

(it is) "fundamentally wrong in thinking that unrealism in the sense of factual inaccuracy even to a tolerable degree of approximation is anything but a denerit for a theory or hypothesis".

The rest of Samuelson's critique is taken up mainly by a formal demonstration of the fallacy of the $\mathrm{F}$-twist, which it is hardily necessary to reproduce here.

Machlup ${ }^{7}$ charges Samuelson with rejecting all theory when he denies that the assumptions are wider than the theory, and the theory wider than the consequence. Machlup says :

"A theory, by definition, is much wider than any of the consequences deduced. If the consequences were to imply the "theory" just as the theory implies the consequences, that theory would be nothing but another form of the empirical evidence, (named 'consequence') and could never "explain" the observed, empirical facts."

It is interesting to see Samuelson here - not unjustly - charged, as Kooprasas is charged by Nagel, with trying to replace the theory by the evidence for the theory; since this is, in each case, a direct consequence of an attempt to formulate the theory directly in observational terms, is there perhaps a warning here about a particular trap that operationalists may be specially tempted to set for themselves?

Machlup then introduces a new element into the debate: 


\begin{abstract}
"We never deduce a consequence from a theory alone. We always combine the postulated relationships (which constitute the theory) with an assumption of some change or event and then we deduce the consequence of the conjunction of the theoretical relationships and the assumed occurrence."
\end{abstract}

This must surely be accepted as a fair statement of what is done in practice. But it leaves ertirely open, and hence impenetrable to analysis, the place of this assumed "change or event" in the formal structure; is it another assumption, or part of the specification of the "class of phenomena which the hypothesis is intended to 'explain'", or part of the deduced hypothesis?

At this point Machlup goes on to compare Samuelson the methodologist with Samuelson the practising economist:
"let us confront Samuelson's judgment with Samuelson's pattern of theorizing when he discusses, not methodology, but substantive propositions of economics. Let us choose the brilliant performance with which he demonstrated an important proposition in the theory of international trade".

Machlup lists the highly artificial assumptions of the theorem, and quotes the conclusion, that real factor prices are the same in both countries; (an excellent example, one would have thought, of patently false predictions derived from patently false assumptions); however:
"at the end of his discussion Samuelson evaluates some important qualifications.... which furnish Samuelson with the causes of factor-price differentials.....by the divergence of real conditions from the ideal ones which form the basis of the theorem".

Now this, like Friedman's discussion of the vacuum and profitmaximizing examples, can only be an attempt to claim the status of Nagel's third type of unrealism for the assumptions, i.e. the use of the pure or ideal case, which is capable of yielding information about the real world provided that the divergences of the real world from the pure case can be specified and their influence accounted for. Once again, the emperor has no clothes; as in the profit-maximization example, a method which stakes all on the conformity of the predictions with the observations entirely fails to produce the evidence. 
In replying to Machlup, Samuelson reiterates his view that:

\begin{abstract}
"the whole force of my attack on the F-twist is that the doughnut of empirical correctness in a theory constitutes its worth, while its hole of untruth constitutes its weakness".
\end{abstract}

Ee concades, by the way, that in respect of his factor-price theorem neither postulates nor consequences were valid. One contribution he does make is to give - what is long overdue in this debate - his definition of 'explanation':

\footnotetext{
"scientists never "explain" any behaviour, by theory or by any other hook. Every description that is superseded by a 'deeper explanation' turns out upon careful examination to have been replaced by still another description".s
}

Lerner (ARR DEBATE, 1965) takes the view that: "realism' and 'unrealism' constitute a trap. They sound like contradictory qualities, but they mean nothing more than 'applicability' and 'generality'....'realism' furthermore easily comes to stand not only for being subject to empirical testing, but also for the ability to survive such a test; and 'unrealistic' to mean either 'not subject to empirical testing' or 'failing in an empirical test" " One could wish that the other discussants had been clearer about this important distinction.

But Lerner's view of 'realism' is ambiguous:
"the 'realism' of the theory depends upon allowing accurately enough for the differences between the actual world and the abstract model. It does not mean that the abbreviated hint at the infinitely complex relationships.....must consist of, or contaln, an accurate description of reality."

This leaves wide open which of Nagel's three senses of unrealism Lerner has in mind. He concludes that Samuelson is not serious about the F-twist, and that there is no real difference between Friedman, Machlup and Samuelson, a conclusion which it is difficult to sustain except by a feat of re-interpretation which Lerner does not supply. 
An important contribution to the debate is made by Massey (AER DEBATE, 1965), who distinguishes three structural components of science:

(a) The postulates (or 'assumptions') from which, "by way of logical and mathematical implications, flow all the remaining propositions of the sciance which are called its theorems or derived propositions.

(b) The theorems together with the rules of inference by which they are derived. "A theorem is simply a sentence which is the last nember of a proof, where a proof is defined as a finite sequence of sentences each of which is either a postulate or is inferrable from earlier sentences in the sequence by means of the rules of inference."

\section{(c) Serrantical Fules (or 'rules of interpretation')}

"These rules confer meaning, either partial or full, on the postulates and theorems of scientific theory. Without interpretative rules, a theory would reduce to an uninterpreted calculus which points to nothing beyond 1tself.... the prime function of interpretative rules is to render fact germane to theory. They stipulate, in terms of facts, partial or full truth conditions for the sentences of the theory, i.e. for all sentences that can be written in the notation of the theory. In virtue of the semantical anchorage effected by interpretative rules, the acceptance and rejection of the sentences of a theory become functions of observations and experimentation."

In investigating further the semantical anchorage of scientific theories Massey distinguishes between "basic" sentences, directly linked to observation, and "theoretic" sentences not so directly 1inked; the problem, then, is to "clarify the manner in which experience is germane to the acceptance (as true) or the rejection (as false) of theoretic sentences". This point cannot be dealt with sumarily here, and we shall reserve it for the fuller discussion below. 
We conclude the debate with a rejoinder by Samuelson (AFR DEBATE, 1965). He dismisses Garb's and Lerner's contributions as mere misunderstandings of his position, which enables him to assert that: "There has been no successful demolition of my view that science consists of descriptions of empirical regularities; nor of my insistence that what is called an explanation in science can always be regarded as a description at a different level". On the distinction between 'basic sentences' and 'theoretic sentences' he comments that: "this is a monstrous perversion of usage" and cites four examples from physics. 9

The easy appeal to the practice of scientists is much overdone by economists, and frequently not only rests upon a false analogy between physics and economics, but also reflects a misconception about the nature of scientific enquiry.

A good illustration of the use of this analogy with science is given by Krupp (AER DEBATE, 1963), who argues that the "composition laws" governing the extension of relationships from the micro units run into difficulties when factors are luxpy and the "law of constant returns" ceases to operate; he asserts: "thus, composition laws may cease to apply at certain levels of conplexity or aggregation.....it is obvious, therefore, that the laws of composition may at some point stop yielding significant results. In physics, for example, theorems based on the independence of mass and velocity are no longer useful as velocities approach the speed of light. In econouics, theorems based on the independence of firms are no longer useful when firms enter into collusion".

Since the "composition laws" cited appear to reduce to a simple assumption of additivity, their breakdown is predictable; where the 'law of constant returns' comes from is not stated. The facile parallel drawn with physics surely needs no formal demolition; one can interpret 1 t as showing a complete disregard for tiz auccess of Newtonian mechanics in predicting and explaining a wealth of observations for which velocity does not approach the speed of light; or one can interpret it as evidencing 
a wildly optimistic view of the power of the perfect competition model to predict and explain. Either way, the analogy has the effect of claiming a status for economic theory which cannot be supported.

The paper by Papandreou (AER DBBATE, 1963), which i.s directed to a formal examination of the domain of applicability of economic theory, is more conveniently dealt with in a later section.

\subsection{Lessons of the Debate}

The debate is notable for its inconclusiveness and a considerable amount of talking at cross-purposes; a comon source of confusion, for example, is the fallure to distinguish between that set of assumptions which specifies the situation to which the model (or theory, or hypothesis) is held to apply, and that set of assumptions which by implication asserts something about behaviour within the given situation. A main bone of contention is the question of whether the emphasis is to be upon testing the assumptions, or the predictions, or both; associated with this is the question of the extent to which hypothesis testing is to be independent of whatever validation procedure is applied to the assumptions.

Let us try to set out the basic issue more clearly. A hypothesis is a conjecture about the facts; it adds to our information when it is tested against the facts, even when the test, by refuting the hypothesis, serves to exclude rather than to confirs one possibility. Provided that we have adequate and reliable procedures for deciding when a conjecture is in conformity with the facts, it should not matter where the conjecture comes from as far as its validity is concerned; it is either a true statement or not, regardless of how it came to be made. Even in this case there is much to be said for economising on tests by confining them to hypotheses where there are some grounds for expecting regularities on the basis of previous experience, as a matter not of validity but of efficiency. 
There are, however, two major reasons why this simple and direct view of hypothesis-testing fails to apply in the examination of any activity much more complex than that of verifying departure times of trains. In practice, the procedures for testing conjectures against the facts turn out to be neither reliable nor adequate; the results, taken on their own, are usually so inconclusive that a need is folt to supplenent them by other criteria. In addition, the search for information carries with it some need for understanding, for 'explanation' in some sense different from that provided by statistical tests for conformity; this need has in any case to be met when an experimenter seeks acceptance by his colleagues of his experimental results. Partly because of this the intuitive plausibility of an argument is a considerable factor in how it is assessed, and where the testing procedures are distinctly unreliable and inadequate this may lead to an assessment by consensus rather than by evidence. 10

In the final upshot the 'principle of unreality' of assumptions, the F-twist, and the associated ldeas can all be dismissed as frivolous. The reguirement that a hypothesis, in addition to being checked against observations in respect of its predictions, must first be shown to be in accordance with coumon experience - which is what now appears to be meant by 'realism in the assumptions' - cannot be ignored. ${ }^{11}$ At least, however one assesses Friedran's own position, his arguments cannot now be regarded as providing any warrant for accepting assumptions known to be unrealistic in some non-technical, everyday sense. 12

Most of the economists contributing to the debate appear to subscribe to the view that a scientific approach is by goneralization from observations. ${ }^{13}$ This is a crude and much oversimplified view of the scientific process; it depends upon a paxticular theory of knowledge that may or may not be tenable on formal grounds, and its status as a description of what scientists do is even more dubious. But, even taking it at face value, carrying such a procedure into effect would require rules and criteria whose specification, in economics, is wholly lacking. 
A key phrase is "the class of phenomena the hypothesis is intended to explain". The argument may be saved in a purely formal sense by this qualification: given that we have indeed succeeded in identifying the requisite class of phenomena to which the theory or hypothesis is held to be relevent, the problems of assessing the "realism of the assumptions" and the verificatory power of the hypothesis tests may be open to solution. But, as Friednan rightly insists, it is preaisely In the provision of such specifications that the major practical difficulties arise; in their absence this qualification, so far from solving the problem, becomes a mere question-begging device.

Nagel's threefold classifiation of types of unrealism does offer some help; in a purely formal sense it distinguishes clearly: that form of unrealism which is inherent in the process of abstraction as a consequence of the impossibility of arriving at complete description; that form of unrealism which patently contradicts the facts and calls for correction or rejection; and that form which is acceptable provided that certain conditions linking the pure case to the real case can be met.

But how, faced with a concrete example, do we go about determining into which category it is to be put? What is 'perfect competition'? A legitimate abstraction, unreal in the first sense only, is that no essential particulars have been omitted or falsified? or is it so at variance with the facts of a modern economy as to merit rejection out of hand? or is it, while not directly valid as description, nevertheless acceptable as a pure case, towards which the economy has an inherent tendency to converge, or from which it diverges only in specified particulars whose divergent effects can be accounted for? It is not difficult to find proponents of each of these views.

Where are we golng to put models which, without any explication of the underlying theoretical preconceptions, start off w:th a baldly-stated list of "assumptions" comprising: "static equilibrium, two country, two good case, under certainty and perfect knowledge"? And when we come to monetary theory, the case becomes even more desperate, what are we to make, for 
example, of: "Suppose that an initial stationary equilibrium is disturbed by a feat of magic th at suddenly doubles all money wage rates and all prices" ${ }^{14}$ since this sort of invitation to accompany the author into Fantasyland is all too common in monetary economics, some way will have to be found of dealing wth 1t.

Another bone of contention is the question of the admissibility or otherwise of nonobservational terms. There is a case to be made for operationalism in one at least of its avatars, although it is not the case that Samuelson makes. A strong jease can also be made for the contrary view, although that wust rest upon something more solid than the ground commoniy advanced, which is simply an appeal to what is taken to be scientific practice. In fact, to go by the debate, the issue turns merely upon which of two contradictory views one accepts about what scientists do. There is much more involved than this, and we shall have to look more closely at what we are to understand by "scientific explanation". But there are some loose ends that ought to be tidied up first.

\subsection{Rlgour versus Realism}

Moving along the spectrum of opinion from those who think that economics already is a 'sclence' in some narrow sense, through the central position of those who think that while economics is at present unscientific it ought to be developed along proper scientific lines, ${ }^{15}$ we find at the other extreme some who think that economics never can be a 'hard' science like the physical sciences. 16 Contributing to the attitude to economics as an area of study not open to scientific encuiry there is a view that the fleld of study itself forces upon us a conflict between rigour, in the sense of formal, deductive argument, and realisia, in the sense of descriptive verisimilitude. This point of view was sumed up by wiles (1963, p. 195) as:

\footnotetext{
"It is of the nature of the social sciences that the more rigorous the demonstration, the less interesting or important the point demonstrated."
} 
Two major ideas tend, in general, to get bound up with this attitude: (a) a distinction between quantitative and qualitative aspects of economic activity, and (b) the Idea that "science" means "controlled laboratory experimentation", which is usually denied to economists.

As a rough first approximation pending the more detailed discussion below, we may begin from a view of science as the application of logic to fact. This does not obviously imply either of the above ideas; but since to most economists "logic" means the elements of linear algebra and differential calculus which are the traditional tools of economic analysis, while "fact" means measurement, the association of "gcience" with "mathematics" (In this narrow sense) becomes more direct. Opposed to it one finds the ldea that economics is the study of Man, and of his behaviour in a given set of situations involving motives, practices and policies in the context of institutional frameworks, and that of the elements of this field of study, those which are susceptible of quantification are the least important. Associated with this opposed view is a dissatisfaction with the actual performance of quantitative studies in economios.

Arising directly from a narrow interpretation of "logic" as "algebra" is a distinction between 'rigorous' and 'non-rigorous' argument or analysis, which usually implies a distinction between mathematical models and verbal discussion. No one, I thinls, could quarrel with the view expressed by rinbergen (1950, pp. 71/2):

"What, now, is the sort of knowledge we can obtain by mathematical business cycle theory?... We are forced to state clearly what relations we assume to exist", particularly as his stated example, the need to specify whether one is talking about stocks or about changes in stocks, makes it clear that he is talking about relations already conceived in a specific quantitative form, and $\mathrm{his}$ assertion that algebraic formulation removes some major ambiguities from the exposition of such relations is surely unassailable. But, because a general acceptance of this view seems to have led to the confused 
supposition that algebraic formulation extends a similar assurance to the conception and formulation of the relations in the first place, Bodenhorn (1956) has felt it necessary to demonstrate the difference; he coneludes that:

\footnotetext{
"There is nothing inherent in the mathematical technique itself which requires a mathenatical economist to state his economic assumptions either clearly or correctly." (p. 32)
}

More specifically, it already seems to be doubtful whether the narrow range of wathematical techniques traditionally used by economists does not cormit them to a type of problem-structure badly suited to accomodate the more interesting and irportant economic problems. 17 They tend, as in the standard marginalist approach, to direct attention to deterainistic models within a largely static equilibrium Eramework, which wiles (1956) and, more recently, Culbertson (1968) find disabling; they are not at all well suited to examine problems of inter-industrial relations, as Leontief found some years ago; and yet, given their accepted probler-structure, they are not rigorous and general enough for Debreu (1959). It is for this sort of reason that Langholm (1969) asserts:

\footnotetext{
"Bcononists relying on deductive matheratical analysis are traditionally resigned to study rather simple problems, or, which may not always come to the same thing, to radically simplify the problens they want to study.... as thingr stand at present it seems as though we must follow sone other route if we are to get any further for some time to come."
}

Langholm's 'other route' is that of computer simulation, a growing technique in economic analysis. Schoemman (1966) finds computer sirulation more accomodating to the study of processes in contrast to the study of end states, and, as Holland and Gillespie (1963) comnent:

\footnotetext{
"It is especially usaful for studying mutually interacting processes which involve non-linearities and time lags. The studies on which this book is based could not have been done by any other technique known today."
} 
Since computex simulation opens up the range of techniques available to encompass a broader segment of logical relations within a flexible language, it provides a means of controlling the logic of the argument within a formal propositional structure without restricting it to the narrow range of relations capable of being handled by the linited equipment of standard economic analysis. In some ways, computer simulation could be seen as a substitute for controlled experimentation, but I am reluctant to push this argument at all far; there is already too much importance attached to the numbers extruded by computer processes to the neglect of the thinking which has gone into the conceptualization and construction of those processes; we should never lose sight of the idea that it is not the use of mathematics in general nor the use of one analytical or computational technique in particular which provides clear thinking in economics, but rather the prior ability to think clearly about economic problems that leads to a search for suitable means of expression and techniques of analysis.

The lack of laboratory experimentation is not in any case so crucial; if "sclence" is to refor only to that kind of field in which the experimenter may set up and physically set in motion the events that he wishes to observe under conditions that enable him to hold constant all but one of a small preselected set of variables, then the term must exclude most of what is now callea "sgierce" but may include much of the fine arts. As Nagel has pointed out so clearly, 18 the essential. feature is not that of the controlled and repeatable experiment, but that of controlled enquiry. It is true that observation in economics may involve complexities absent in physical experimentation, but it may be argued that this is a difference of degree rather than of kind.

But, In any case, it can hardly be doubted that an adequate enquiry into any field of knowledge must be systematic; that inferences must be explicit and controlled; and that if we are to draw usefully upon the lessons of experience we must find some way of organising the observations of singular events in ways which will provicie some guidance for present action. 
We need not remain content with present ways of selecting and making observations or of drawing inferences from them; indeed, if there is a conflict between "rigour" and "realism" in econonies, that may well be because both jobs are being done badly. 19 
1.21 The Problem

A major problem arising in section 1.1 may be described in Friedman's terms as that of specifying and identifying "that class of phenomena which it is intended to explain". This problem is given a more formal statement by Papandreou, ${ }^{20}$ who requires that a 'basic theory' be interpreted with reference to the appropriate class of phenomena, the "relevant social space', there may be many such 'augmented theories' corresponding to a single 'basic theory', and in order to refute the 'basic theory' it is necessary to refute each of the corresponding 'augmented theories". Papandreou continues: "It is essential, therefore, that the class of admissible interpretations be adequately characterized by the theorist. If he falls to do so, he ends up with an Inadequately interpreted theory - a theory which Is not ready to be subjected to any sort of empirical test. It will be argued that this state of things is typical of current practicen.

Nagel (1963) presents a similar view as follows: "A universal conditional neither asserts nor presupposes that the conditions explicitly stated in its antecedent clause are actually realised; accordingly, a theoretical statement having this logical form is not proved to be false by showing that the specifications in its antecedent are not enbodied in some given spatiotemporal region". Thus a demonstration that the specified conditions are not met in some given domain shows merely that the model is not relevant to that domain, although it may be relevant to some other domain. However, Nagel comments, "what can be said about a theory which is ostensibly unrealistic in every domain?"

In general, one would expect this consideration to be more important in economics than in the physical sciences; but although one can expect the properties of physical space to be invariant with respect to human actions or institutions, some propositions once thought to be generally true have to be modified for extreme velocities and temperatures, and the effects of human activity on the enviroment are now thought capable of producing 
irreversible changes in that environment; the problem of relevance, i.e. of the proper specification of the domain of applicability, is not one that scientists can always ignore. Nevertheless, the difference remains that physical properties that have been confirmed in, say, the United States, can be confldently expected to hold in, say, China or Russia; but economic propositions are much more dependent on their institutional setting, and there is no reason why one should expect, say, monetary or fiscal operations to have at all similar effects in these three countries. For economists, then, the extension of an economia theory from one context to another is a much more hazardous matter. Still more must the uncritical application of theories to policles in countries not remotely like those in which the theories were worked out be regarded with suspicion.

Warnings against this have been issued from time to time, but are often disregarded; for example, although John stuart M111 regarded rural poverty as a problem outside the application of his analysis of capitalist production, ${ }^{21}$ this did not prevent Lewia in a much-quoted article 22 from attempting what Mill clearly would have seen as a misapplication of the analysis. Both Cunningham (1892) and Seers (1963) have repeated this warning against the application of general theories about economic behaviour outside the context in which they were worked out; in particular, the mis-application of so-called 'Keynesian remedies' to backward economies may be seen to underlie much of the policy advice the latter have received. ${ }^{23}$

This direct result of the failure to specify domains of applicability is obvious enough; a subtlex result is that a given measurement, event or set of events may be ambiguously interpreted because of an uncertainty about precisely what are the conditions expressed in the antecedent, and hence what particular observations may be taken as lying within the domain to which the theory is held to be applicable. This has two results: (a) an uncertainty about what measuring operations relate to a particular term in the theory, ${ }^{24}$ and (b) a tendency to post hoc adjustment of the theory to accomodate a particular set of observations. 25 
The goal before us should, in my view, be to meet the speaification vtated by Braithwaite (1960, p. 257): "Statements expressing scientific hypotheses come to us with a well-defined meaning given by the class of observations which would refute then, or which would refute conjunctions of them with other scientific hypotheses".

Massey seeks the link between the theoretical construct and the observational domain to which it is to be applied in terms of linking specifications which he calls "semantical rules" or "xules of interpretation", 26 in Massey's words, "the prime function of interpratativa rules is to render fact gerrane to theory". Since the term "rules of correspondence" appears to be clearer we shall use it instead of Massey's terms. The general task, then, of "rendering fact germane to theory" which the required rules of correapondence must perform, may further be analysed into three coinponents:

(a) a specification of the characteristics by which a particular domain of applicablilty may be isolated, that is delinited and identified;

(b) a specifleation by which the observables in the given domain of application can be linked to corresponding terms in the theory:

(c) a specification of the extent to which the structure relating the terms or concepts of the theory is intended or is held to correspond to the processes by which the observables are produced in the given domain. 27

\subsection{Taxonomic Approaches}

One possible way of providing speciflcations of type (a) above might be to isolate particular domains according to some pre-existing taxonory of econonje problems and problen-contexts. Some rudimentary taxononies have been attempted in certain areas of economics. They have not dealt at all well with the task of identifying and classifying degrees of development in a macroeconomic sense, 28 Intriligator (1971) may be said to have attempted a tasonomy of problen-structures, but while his 
work can be very helpful in enabling one to piece together the bits of a particular theoretical structure, the appearance given, particularly in Part $I$, of providing interpretations of the symbols relating them to observational matters is 11lusory; the verbal terms are simply conventional names for the symbols.

The only area in which substantial attempts at a taxonomic approach can be found is that concerned with market structure. It is of particular interest here, for two reasons. In the first place, it is an area where ore would expect to be able to bring the main tools of economic theory to bear with great effect, since the fundamental ideas of price theory, markets and products are all directly relevant to the practical issues. In the second place the practical issues, of e.g. Industrial concentration and market power, are considered to be of major importance, and the specific attempts, in case after case, to seek from economic theory firm practical guidance in determining a 'market' and defining a 'product' should have brought out anything of use in this fundamental area of theory.

Singer (1968) cites some contributions from the theory towards the basic task of defining the extent of market power: the indexes of monopoly power from Lerner, Bain, Rothschild and Papandreou, and the alternative approaches through indexes of industrial concentration, from the earlier applications of Lorenz and Ginl to fierfindahl's summary index and the widelyused census concentration data. He discusses the bias and inconclusiveness of this sort of exercise, which he sees as arising from lack of homogeneity. 29

An even more central idea, that of elasticity, calls for examination. This is not only a key element in economic theory, but is also particularly suited, if anything in economic theory is, to the practical definition of a product, and it is no surprise that it has been called into use in those judicial cases where the definition of a 'product' has been an indispensable prereguisite for a judicial decision. singer gives an example: 30 
"The use of the term 'cross-elasticity' of demand by the Supreme Court marks a high point in the use of theoretical economic concepts in judicial antitrust opinions...."

This was in the Cellophane case, where the Court was not unanimous and the dissenting opinion attached importance to a difference of view on what the numerical value of the cross-elasticity of demand for Cellophane in fact was. Singer is led to comment: ${ }^{31}$

\begin{abstract}
"Only in the abstract world of economic theory can forces other than a change in the price of another good be held constant. Since the economic concept of cross-elasticity of demand presupposes such strict conditions as 'other things remaining equal', it is open to the danger that standard theoretical conclusions may be drawn when the concept is utilized in examining empirical data. In contrast, the legal concept of 'reasonable interchangeability', which considers factors other than price, such as quality and type of end-use, appears as a more suitable analytical tool for a court to employ in defining relevant product maxkets."
\end{abstract}

Massel (1962) comes to much the same conclusion about the operational value of the concept of cross-elasticity, and poses the question: 32

"Should we suspend the use of such a concept in antitrust until the economic analysis is on a firmer base and can be made clear enough to be employed productively by judges and lawyers?"

However, the other factors which may be taken into account to replace or buttress the dublous concept do not seem to lead to any definitions, in generic terms, that would be of use in actual identification. As Massel comments: ${ }^{33}$

"the market definition cannot be produced by a simple analytical exercise. It must be constructed with an eye to the purpose for which it is intended".

He goes on to consider various characteristics that have, in one antitrust case after another, been explicitly taken into account in jualcial decisions; taking as the simplest basis for defining a market as that of shared physical characteristics, he 
finds that that is not in practice so clear-cut or unambiguous, and goes on to consider other characteristics that have been considered. 34 He concludes that: 35 "The pollcy requirements are varied and complex. They do not lend themselves to simple classifications. They will not be satisfied by theoretical exercises in taxonomy."

Not only does the existing theory provide little practical help, but the quite impressive collection of observed judicial. decisions does not seem to have yielded any generalisations to the theory. Thus in this important area of applied econonic theory it appears that there is a gap between theory and observations which may not be crossed from either direation, as things stand.

Another feature is the tendency for taxononic approaches to be forced, before they have developed very far, into measurement. This does not, however, import any new element, since the first problem of measurement, that of specifying the characteristic to be measured, is already present in purely qualitative approaches, as the discussions by Singer and Massel suggest.

The fundamental problen is that any classisicatory aystem requires that the elements grouped into any one category have some identifiable characteristic in common that is not shared, or is not shared to a comparable extent, with elements in other categories. It cannot be required that all members of any group he homogeneous with respect to all characteristics, since even to speak of separate members implies that they are distinguishable in at least one respect, but it is required that they be sufficiently homogeneous with respect to at leas' 6 one characteristic. In practive such classifications as are required usually have to deal with elenents possessing a wide range of characteristics, and the elements may be grouped quite differently according to which characteristic is selected.

If the selection of the classificatory basis is not to be purely arbitrary, then some prior oriterion is necessary. Since classificatory exercises are not in general undertaken seriously 
except for some specific purpose, it is the purpose in hand which must provide the criterion. It seems inescapable, therefore, that a taxonomy, so far from providing a source from which we may derive a criterion of relevance, itself appears to need one as a prior construct if it is to be put together in a meaningful and operationally useful way.

\subsection{Operationalism}

The search for "operationally useful" theorles means, in a broad sense, no more than the obvious requirement that the theories be of empirical relevance; that we know what objects and situations of everyday experience they are talking about; and that we can distinguish clearly between those things for which the theories are or are not asserted to hold, and those for which they are or are not in error. But the term "oparational" is often used in a much narrower sense, in which it imposes specific restrictions on the type of theories which may be constructed, and 1 t is that narrower sense that we shall now look at.

One of the consequences of the persistent lack of oriteria of relevance and applicability in economics has been a tendency to evaluate a theoretical construct in terms of its own inner logic. This has led to a proliferation of activities described by Baumol $1^{36} \mathrm{as}$ :

\footnotetext{
"...the construction and manipulation of mathematical models for their own sake, where the ultimate criterion of success is the degree of entertainment provided to the model builder. Blaborate structures are created to show off spectacular applications of esoteric theorems with little regard for relevance or 11lumination".
}

This would not be very dangerous to economics if there existed a sound body of well-supported theory against which the substantive content of those structures could be evaluated. In practice, it is very often the compeling power of the mathenaties alone which is intended, as it is taken, to carry 
conviction, and as long merely as the variables have familiar names curiosity about the subject matter rests. As Bodenhorn (1956) has pointed out, not only does the corxectness of the algebra fail to guarantee the correctness of the economic argument, but not infrequently the verbal explanation accompanying the algebra differs materially from what is expressed by the algebra of the model; in such cases, Bodenhorn suggests, we generally tend to rely on the algebraic argument, for that is the source from which the conclusions are drawn. When this is done frequently, the situation described by Baunol is bound to recur.

To this, as to other problems of relevance in economic theory, Gordon is not alone in seeking a solution in operationalism:

\begin{abstract}
"In economics.....it has been found difficult in some cases not only to produce valid empirical propositions but even to distinguish empirical propositions from others. The development of the concept of operationalism is a contribution to this latter problem." 37
\end{abstract}

Although the term "operationalian" or its equivalent form "operationism" is usually attributed to Bridgman (1927), Bridgman himself later repudiated it, and in any case the ldeas in a broad sense have been present much longer. It was already evident in the Behaviourist approach to psychology made popular by Watson, and as Machlup comments a favourable climate for the reception of the operationalist approach was well established when Bridgman's "Logic of Modern Physics" appeared. Machlup says :

\footnotetext{
"Bridgman....pproposed "operationalism" as a universal program of scientific discourse.... This program was quickly endorsed by representatives of several fields .... It particularly suited the radical empiricists in their insistence on factual observations, the logical positiviats in their leanings towards physicalism, the behaviourists in their antagonism to non-observables." 38
}

In its modern form, operationalism has had many eritics. Machlup himself 1 ists six issues specifically ralsed by Bridgman's position and program; among them the following distinction is not only crucial but also throws light on what, among many people who 
use the term "operationalism" in a loose sense, is a source of confusion by those who have not grasped the distinction: "It is important to distinguish between three possible roles that may be assigned to the ldentifying or measuring operations: (1) the operations may be regarded as synonymous with the object; (2) they may be regarded as essential directions for finding the object; and (3) they may be regarded as a test or criterion of meaning. The third, in effect, implies a threat or attempted intimidation designed to obtain conformance: 'If you don't prescribe physical or statistical operations, your term and concept will be declared meaningless! " 39

Machlup goes on to cite some eminent authorities to show how decisively physicists themselves have rejected the operationalist programme, and discusses the more comprehensive views of theory construction offered by philosophers. His applications to method in economics axe germane to the whole question of realism and relevance in economics, particularly in his reference to econometric models, of which he says:

\begin{abstract}
"The fact that the numerical values of variables and parameters are derived from statistical operations may make some of us think that the terms in the equations are not pure constructs but operational constructs after al1." On the contrary, argues Machlup, an econometric model "consists of pure constructs..... Moreover, since (the econometrician) immediately proceeds to apply his model to data of observation, his model is always in the nature of a theory: it specifies the empirical (operational) concepts the magnitudes of which, he hopes, it can 'explain'",40
\end{abstract}

Philosophers have attacked the operationist position on formal grounds; 41 Nagel has repudiated it as a scientific procedure, in these terms:

"It is not reasonable to ask, as Bridgman appears to be
doing, that every theoretical term be associated with an
overt experimental procedure. It is even less reasonable
to reguire that each cormonent assumption of a theory be
capable of independent experimental tests." 42

Caws also argues on much the same lines: 


\begin{abstract}
"Operationalism is, undoubtediy, an extremely valuable aspect of analysis, but it can hardly be made a practicable method of science. One is constantiy turning to conceptual ideas in order to understand what operationism is saying." 43
\end{abstract}

As with the debate reported above, those leaning toward an operationalist position - as for example Samuelson - attempt to defend their position on the grounds that, whatever the formal grounds on which phllosophers reject it, scientists do in practice get their results that way. Some comment will be offered on that in the section following, but here it will suffice to cite the counter-argument given by Pap: 44
"The most important argument against operational definability of physical functors.... arises from reflection on the interplay between measurement and calculation which is characteristic of theoretical. physics. Suppose that, as consistent operationists, we....use different functors for temperatures that can be determined by calculation only and for temperatures that can be determined by measurement. But this analysis cannot be reconciled with the actual procedures of theoretical physics."

In 1954 a symposium on operational1sm held under the auspices of the American Association for the Advancement of Science, 45 was notable for a aisclaimer by Bridgran:

\begin{abstract}
"I have felt that I have only a historical connection with this thing called "operationalism"..... abhor the word operationalism, or operationism, which seems to imply a dogma..... It is often thought that there is a normative aspect to "operationalism" which is understood as the dogma that definitions should be formulated in terms of operations."
\end{abstract}

Margenau commented on this:
"Bridguan disavows its stacus as a philosophy and wisely so, for as a general view it would be vulnerable on two counts. First, it cannot define the meaning of "instrumental procedure" in a manner that saves the view from being either trivial.... or too restrictive...." 46

The rest of the symosium is also generally condernatory of operationalism, but Margenau's view sufflces to bring out the fundamental dilemna facing operationalists, a dilemma stenming 
from that unguarded aside by Bridgman, that included in his definition of "operations" some "mental" or "paper and pencil" operations. The dilema is briefly that if the theory be extended to mental operations, $1 \mathrm{t}$ allows in the whole of the structure of theoretical concepts that the critics of operationalism require a theory to have, and enus up saying nothing at all that positivists like iraithwaite, Nagel, Massey and Margenau, for example, are not saying, and the term is otiose. If, on the other hand, only physical operations are admitted, then operationalism ceases to be tenable as a theory of knowledge, as a criterion of meaning, or as a descriptively accurate account of what scientists do in practice. The dilema then, arises for those operationalists who, in the face of sustained criticism, still want to maintain an operationalist position without restrlcting themselves to the more vulnerable position; this is why the term has appeared, during its currency, to shuffle uneasily and confusirgly between the two senses.

Gordon settles bravely for the narrow definition, restricting himself explicitly to propositions implying only physical operations, thus avolding that dilema. But in his subsecruent search for examples in economic theory of operational propositions, particularly when he adduces the Leontief inputoutput structure as a parifal validation of the otherwise empirically false and therefore (on his terms) meaningless Walrasian system, his concept of "physical" operations becomes unclear.

Ackoff, however, while fully aware of the objections to operationalism (indeed, his first chapter could be adduced directly in support of the case against) nevertheless feels impelled to try to save something from the wreck:

\footnotetext{
"The notion of the operationists that scientific definitions should specify operations is one that we will try to preserve without incurring the difficulties in their theory. " 47
}

Is there, perhaps, an acceptable middle path here? since the specific reason for Ackoff's suggestion is that he is looking 
for a prescriptive rule which is intended to oblige researchers to keep the empirical relevance of what they are doing firmly in front of them, it is tempting for economists dissatisfied with the relevance of much of present economic theory to any ascertainable domain of observation to look for some way out along Ackoff's lines. Even Nagel, so critical of operationalism, does not reject behaviourism as a methodological orientation. 48

Where one of the dangers of this apprcach in economics appears to lie is in the temptation to believe (wrongly) that one is following this prescription by inspecting the numbers presented by some historical measuring operation, in the hope that direct induction from the inspected numbers will yield insights, and even theories, of economic activity. One example of this was the National Bureau approach to business cycles. Consider, for example, Roopmans' evaluation of this approach in a review of Burns' and Mitchell's "Measuring Business Cycles":

"The book is unbendingly empiricist in outlook...the decision not to use theories of man's economic behaviour ...linits the value to economic science and to the maker of policies, of the results obtained or obtainable by the methods developed. " 49

Both Ackoff and Nagel clearly reguire a firm structure of theory to start from, in which such isservations as may be made are defined and interpreted. What the advocates of operationalism in economics obviously intend is to ensure that economic theory be made subject to empirical testing as a condition of its being accepted as refutable and hence meaningful; surely no economist these days would dispute the desirability of a programme to carry out such an intention. A key statement from Gordon sets out the issue:

"Ror a proposition to be testable by some physical operation, it must predict that certain observations will not occur, so that, if they do, the proposition is refuted. " 50

Gordon could have cited almost any authority on scientific method in support of this statement. 51 
That economics does not in general meet this criterion is brought out by a number of writers, the most damaging criticisms being made by Culbertson (1968), and by Clarkson (1963). The former, in Part one more directly but in the whole work by implication specifically attacks economics on the ground of its general evasiveness in the face of evidence; his coments on "Kelly's constant" 52 reveal a popular device in economies by which the stern application of Braithwaite's criterion is evaded. clarkson, in a work which for some inexplicable reason appears to be little read, similarly spelis out the irrefutability of much of economic doctrine; his comments are addressed directly to the theory of consumer demand, but his demonstration is intended to have, as indeed it does have, more general applicability. clarkson, by the way, so far from being led by his critique to embrace operationalism, fastens his ideas of a proper structure of scientific theory to the logical structure expounded by Braithwaite as indeed does Papandreou (1958).

It appears that people who have thought about the state of method in economics and have sought diligently for guidance in the abundant literature on scientific method, so far from being attracted to operationalism tend rather to be attracted towards the positivists. This does not mean at all that they reject the need not only for empirical testing but for a firm criterion of refutability for the application of such tests; what they reject is the claim that operationalism can provide such a criterion. Culbertson throwa iight ${ }^{53}$ on the difference, in science as well as in economics, between the considerations which occur to those seriously enquiring into the state of their discipline, and the general act of faith by which others are content to perform their routine activities.

In spite, therefore, of the superficial appeal of operationalism as offering a guarantee of "relevance" or "realism" in economic theory, this guarantee is illusory; theory constructed on this basis remains perpetually prey to attacks on its formal status, if indeed it can in any case survive its own conceptual confusion; and it carries, in any attempt to apply it in practice, the danger that what is regarded 
as "empirical" work could degenerate into an erroneous and misleading process of blind manipulation of uninterpretable numbers. As a panacea for any present 111s of economics, operationalism cannot be accepted in its restricted form; no such cheap and easy remedy is at all likely to be effective.

The task of relating the constructs of economic theories to the world of observation remains. 


\subsection{OBSERVATION AND MEASUREMENT}

1.31 WHAT IS A "FACT"?

In an attempt to relate the logic of econoraic theory to the facts of experience we need to be cleax about what we mean by "the facts of experience", how we can "observe" them, and how we expect to recognise a "fact" when we meet one. Economists rarely treat the act of "observation" as anything but a quite direct and straightforward affair, they are not alone in this, to judge by Margenau's comment. ${ }^{54}$ Not too many economists have seriously questioned Robbins' term, 'the simple and indisputable facts of experience', although economists frequently disagree on what those facts are when the evidence of some particular model is under discussion.

As a starting-point, it may be useful to separate out two basic elements: knowledge, and the external world, in terms of the distinction made by Margenau between the C-domain (the set of mental concepts and their interconnections), and the $p$-domain (which provides the raw data of our senses). ${ }^{55}$ The initial question can thus be reformulated as: "what can we perceive of the p-domain?". Initially, "the process of perception includes the reption of changes in impinging energy, its transduction into electrical impulses, and the encoding of the impulses to prese ve the information which the impingements convey about events". 56

Sven this form of contact, as Day goes on to explain, is linited to a small segment of the spectrum of electromagnetic radiation; some creatures are equipped with receptors capable of registering slightly different segments of the spectrum, but in general we are confined to a narrow band of the totality of aspects which any given phenomenon is thought to be able to exhibit. Since we are not equipped to register, with our personal physiclogical capabilities, any manifestation outside this narrow kand, we clearly cannot derive any information about such events except indirectly, through the mediation of 
some apparatus capable of itself reacting to energy impingements outside this band, and recording them in a form within the band which we are equipped to register. Thus a large part of what are usually regarded as "objective" physical studies deal with essentially non-observable entities, whose presence and behaviour are not themselves observed but are at best inferred, and in the last analysis posited, by some personal conceptual act.

But even for those events which do produce energy impingements within our power to register, it is still not clear what could be meant by "direct" observation. For, even in the simplest kind of elementary visual perception, "...we do not 'see' objects directly, nor do we 'see' the retinal image, nor do we 'see' the excitation in the optic nerve. At most, we can say that what we 'see' is the final effect on the projection area of the cerebral cortex". 57 Further problems are involved in considering how the raw perceptions are structured or organised into an integrated perceptual whole, and how far the information required for this is present in the initial visual stimulus. It appears that seif-initiated visual feed-backs are important, and that the information from these is further supplemented by retention of impressions from previous events, so that we can refer to learned perceptual resolution. 58

The next stage in organising the raw sense data raises a problem expressed as follows: "In response to sensory stimulation, I experience a private parceptual world which is an interpretation of specific events in ky brain. Hence I am confronted by the problem of how this cerebral pattern of activity can give me a valid picture of the external world... Further problems are involved in attempting to understand how the brain events derived from the various sensory inputs can give me not only my private perceptual world, but also experiences that are shared by other observers and which, therefore, I have come to regard as manifestations of an external world." 59 
It is clear that even the simplest and ostensibly most direct act of perception already involves elements of learning and of conceptual organisation. When one carries on to consider the relation between perception and cognition, another question is raised: are the mental constructs, which are the closest we can come to perceptual contact with the P-domain, derived in some way from the operation of the raw sense data on the otherwise unstructured mechanisms of the mind, or are they imposed upon the raw sense data by the pre-existing neurophysiological structure of the mind? Eccles (1964) seems to settle for the second view. So, apparently, does Caws. 60 Since the way in which this question is answered has important implications for the way in which one sees the relation between " $\log i c "$ and "fact", it merits further enquiry.

That the fundamental relation between theory and observation involves a view of epistemology which ultimately, at least by implication, rests upon some prior view of the processes of perception and cognition, has not always been recognized by speculative philosophers, but two writers who have investigated the perceptual undorpinnings of epistemology are Piaget (1969) and Harris (1970).

Piaget, who had been working for many years on the study of conceptual development in children, hoped that it would be possible to devise a 'genetic' theory of knowledge by studying it as a function of its growth and development in the child. ${ }^{61}$ He had found that "step by step comparisons of the evolution of a concept and of corresponding perceptions.....always give rise to three supplementary questions. 'ihese are: (1) What information do notions obtain from perception? (2) What new elements (co-ordinations or new properties etc.) do notions add to perception? (3) What corrections, rather than additions, do notions make to the information they obtain from perception?"

He thus adopts as his aim: "to decide whether or not perception achieres that immediate contact between subject and object that empiricism has always considered to be the 
fundamental guarantee of objectivity: the particular problems to be tackled by a truly genetic analysis are whether that objectivity is built up or whether it is present from the beginning and, if built up, whether the prime instrument of its eventual elaboration (even in the so-called 'perceptual' verification made by the scientist at the end of a laboratory experiment) is an operational or a perceptual structuring".62

The bulk of the work following that introduction is devoted to a review and evaluation of a considerable body of experimentation, by himself and by others; he finds in this that the links between notion and perception yield not a simple linear or staçe by stage progression, but a continual process of reconstruction of knowledge, in which notion and perception are continually interacting through sensorymotor and representational activity. He comments: "The problem of tracing the perceptual or non-perceptual origins of notions becomes much more delicate when it is considered in terms of this perspective of continucus reconstructions than it would be if considered in terms of a concept of a stratified mental life in which stages are simply superimposed on one another".63

One major conclusion drawn by Piaget raises a large doubt about the positivist approach to theory construction: "The essence of the operational concept of intelligence is to negate the existence of any radical dualism between experience and deduction. It considers experience to be a progressive structuring rather than a simple recording, and deduction to be a co-ordination of operations rather than simply an exercise in logic: since experience consists in acting on objects, and deductive operations consist of interiorised and co-ordinated actions, there is only a difference in degree (functionally speaking) between the structures of experience and deductive constructions." 64 But positivism might yet be saved by Piaget's rider to this: "Nevertheless, a remarkable concordance does exist between the possible frameworks, or some of them, and the data of experience, so that one can 
always construct a logico-mathematical theory of the physical phenomenon".

Piaget rejects the idea that, even if perception did yield an adequate knowledge of the object, it could provide a source of all knowledge, ${ }^{65}$ and goes on to reject the idea that perception does provide an adequate knowledge of the object. 66 Finally, the exchanges between subject and object are not simply a matter of passively recording impressions from objective reality, but the result of purposive activity by the subject: "In the end, the relative adequacy of any perception to any object depends on a constructive process and not on an immediate contact. Duxing this constructive process the subject tries to make use of whatever information he has, incomplete, deformed or false as it may be, and to build it into a system which corresponds as nearly as possible to the properties of the object. He can only do this by a method which is both cumulative and corrective, and which, in perception, is based on decentration or on a consideration of successive centrations which correct one another's deformations. "67

Harris begins ${ }^{68}$ with an extensive critical survey of the development of science, from which he finds "an intimatc interdependence between observation and theory, which has now beer further illuminated by the realization that observation is always conditioned and directed by the operative conceptual scheme". This leads him to investigate perception as a source of empirical knowledge, and ultimately to "assess the claim of science to be knowledge of the real world and examine the notions of objectivity as attributable to science and of reality as imputed to the world it studies".69

He begins his study of perceptual processes by asking similax questions to those of Piaget, and although drawing upon different experimental repores arrives at much the same conclusion, 70 on which he comment': "If scientific procedure is one of evolving, testing and establishing hypotheses, the 
view that the touchstone by which they are tested is senseperception must be significantly affected by the discovery that sense-perception is itself a process of forming and testing hypotheses". 71 The close correspondence of Harris" argument with that of piaget is shown, e.g. by his discussion of the relation between perception and primitive sentience, and his denial that inference is merely the transformation of sentences or formulae in a deductive system. ${ }^{72}$

He finds, as does Plaget, that "observation is always, in its commonest and most everyday forms....parasitic upon a conceptual scheme". But he goes on to make a further connection which is not found in Piaget: "It is, then, no wonder that we found, when we examined the procedure of scientists and the course of scientific revolutions, that observation and theory were inseparable and interdependent". 73 only the most wilfully obstinate empiricist could ignore the substantial doubt thus raised about the 'immediacy' and 'objectivity' of observation, a further irplication of which is a weakening of the distinction between the laboratory sciences and other: fields. As Hochberg comments: "One recurring objection to the study of most of the phenomena of social perception is that they are so clearly the result of learning. The same argument would have to be made about the perception of physical objects and events, however. "74

When we move from consideration of the private perceptual world to our knowledge of an external or "public" world, we find that the 'external world' is itself a construct. 75 Associated with the development of a concept of an 'external world' is a development also of social interactions, attitudes and motivations. ${ }^{76}$ As with the initial conceptual development, these are not developed as a separable segment of activity, but are closely bound up with physiological activity. ${ }^{77}$

As the learning process continues, the child begins to tap the inherited stock of information, which includes not only 'facts' of some sort but social observances and attitudes, and also includes the acquisition of the schemata or organising 
conceptual apparatus of his immediate community. ${ }^{78}$ The schemata so transmitted through social interaction (including formal teaching) are not necessarily transmitted in unnodified form; there are losses and distortions in transmission, and for them to be received in any meaningsul way they have to be integrated into the schemata already available to the receiver. But all information transmitted through social interaction carries sanctions on the schemata employed, more subtly than the direct physical penalties arising from bad defects in elementary perception, but equally effectively.

To the extent, therefore, that contact with the world of public knowledge is made, it occurs mainly through social interactions which give a definite direction to the organising and interpretative schemata which collectively define what view of the world is adopted. What, therefore, is a 'fact' is not a matter alone of the direct transaction between subject and object (or observer and observed) but is also a matter of the social communications which shape and direct that view of the 'facts' is to be taken and, for complex events, what is a 'fact'.

When the field of enquiry is a highly orgariasis one, a student of the field laust acquire the accepted schematio used in that field, according to which the technical terms and relations of the fivld are concelved and the 'facts' of the field perceived, before he can acquire any of the 'known facts'. By the time he has arrived at the stage of knowing 'facts' about economic astivity, he has already acquired a considerable structure of schemata in terms of which to co-ordinate and organise his responses both to his general environment and to his special environment as a student of the field. The view, therefore, that ultimately objects such as chairs and tables which are taken as 'commonsense objects', and constructs such as G.N.P., do not differ in status since both are constructs, has to be modified by the view that a student trained in economics has usually learnt to treat G.N.P. as a comonsense object in exactly the same way as he has learnt to treat chairs and tables as commonsense objects. 
Thus, if we are to draw a line between the $\mathrm{C}$-domain and P-domain of economics (to apply Margenau's term) then both commonsense objects and economic objects must be on the same side of the line; either they are both to be treated as percepts, or they are both to be treated as concepts. If on the other hand we take the view on the grounds suggested above that no such distinction can be validly made in any way that would retain a P-domain of economic events, then what would economic theories have as their subject-matter? Certainly, it is hard to see what we would mean by 'testing hypotheses'.

Now, to the extent that the distinction between untested speculation and conjectures that are submitted to the risk of refutation is a sufficiently powerful organising or operational tool to economics to be worth retaining, some means of distinguishing between theory and observation in esonomics needs to by found. But. since there is no ground for supposing that there is a uniquely correct place to draw this distinction, precisely where the dividing line is to be placed becomes, not an objective matter to which an answer can be uniquely ascertained, but a matter of choice or convention.

One criterion for placing this dividing line is already given by the accepted paradigmatic structure of economics; since with a different paradigmatic structure we might well choose to draw the line in a different place, a discussion of what are to be taken as the facts of the field of enquiry turns into a discussion of the paradigrs which define what those facts are to consist of. This does lead to one highly important conclusion. Since the 'facts' against which conjectures are tested are a construct of the paradigm which defines them, the paradigm itself cannot be modified by comparison with the 'facts' of some other paradigm, unless suitable transformations between the two paradigms can be constructed. This is observable iri scme developments of science, where the supercession of the old by a new paradigm rreguently takes the form of providing more general constructs from which the old constructs can be derived as special cases. 
This point is pursued in section 1.4 below, but there are some minor consequences of the view arrived at which may be recorded here.

(i) Pure operationalism, as with other forms of empiricism, cannot be reconciled with the view arrived at of the perceptual basis of epistemology. 79

(ii) The crude form of empiricism which, rightly or wrongly, has been attributed to Friedman, cannot be reconciled with that view either; but Robbins' approach can. This does not entail as a logical consequence that Friedman is wrong or that Robbins is right. But it does raise a presumption in favour of Robbins; in short, Robbins appears to be on firmer ground than Friedman because Robbins' approach is closer to the way in which we do come to think about the events of the external world, even, perhaps, the only way in which we can think about them.

(iii) Doubt has been cast on the positivist framework in its rigid separation between the propositional calculus from which hypotheses are formed and the observables against which hypotheses are tested, since that would imply a divorce between deduction and perception which now seems inadmissible. But a place can perhaps be found for the framework as a metalanguage in which the components of particular theories may be analysed; and, beyond a certain point in conceptual organisation of a given field, the representational processes become more overt and may need to be more extensive; there seems to be no reason why their controlled extension may not for a while draw upon the positivist framework during a phase of temporary concentration on representational activity as such, as part of the more comprehensive processes of continuing reconstruction inherent in cognitive-perceptual development generally. 
It is sufficiently obvious from the foregoing that measurement involves some prior conceptual schema, and there is no need further to belabour the point that measurement requires prior definition of what is to be measured. But how can we be sure that what is defined and what is measured are the same thing? First, we need a sufficiently precise specification of the characteristic to be measured, formulated in metrical terms (functors), like 'length (of $\mathrm{x}$ cm.)', 'temperature (of $x$ degrees)', etc. Such metrical terms, or functors, have three components: the name of the characteristic (length), the pure number $(x)$ and the associated dimension (cm,). 30 The pure number may be of the form: $x=a$, or $a \leq x \leq b$, or $P(a \leq x \leq b)=a$.

With most simple characteristics the associated dimension is determined up to a linear transformation as soon as one knows the characteristic; its units (cm., in., ft.) and origin $\left(0^{\circ}\right)$ may still need to be specified. With the compound characteristics frequently used in economics, this is not the case and even more care is needed in defining the functors and the way in which the measuring operations have to be conducted. Another complication is that the compound characteristics of economic entities frequently defy unambiguous identification, owing to lack of homogeneity in the observables or to imprecise formulation of the theoretical term. 81 .

One requirement of definitions is set out by Caws: "An internal definition is any statement which sets an entity in unambiguous relation with one or more entities of the same group, and an external definition is any statement which sets an entity in unambiguous relation with one or more entities of another group. The word unambiguous means not merely that the form of the relation shall be unambiguous but that no other entity shall enter into the same relation with those to which the defined entity is related by its definition." 82 since, in 
its context, this definition of definition is offered as an alternative to the constitutive/operational distinction, it must be meant to apply to all terms, whether they are theoretical or metrical.

The view that Caws takes of the connection between the empirical and the theoretical is similar to that taken above in section 1.31; he regards measurement, not as a link between percept and concept, as Margenau appears to be dolng, but as "a link between physics and mathematics". ${ }^{83}$ But were one to set, according to the positivist view, a dividing line between empirical observation and theoretical deduction, Caws" definitional requirements would still have to hold, except that in this case one would have to apply them separately to both empirical or measurement terms and theoretical terms, being then further required to specify the rules of correspondence linking each observational term to a corresponding theoretical term (though not vice-versa). Since Caws still requires the mathematical formulation to be related to the language of ordinary experience if it is to have any meaning, he cannot be said to be making the physical entities consist of numbers.

We appear to have two major tasks in economic measurements. In the first place, let us suppose that our measuring operations yield numbers in the forn $x=a$. These can be substituted in the theoretical propositions containing $x$ to yield, in conjunction with other such number-substitutions, numerical tautologies. But they do not thereby produce an economie statenent or piece of information, in the absence of separate and complementary statements interpreting them in economic terms. As Caws puts the matter in regard to physics: "Physical properties, as a group, must have their own links with sense experience, independently of the links belonging to mathematical properties; and clearly, since measurement leads first to the mathematical, it cannot provide a direct path to experience. "84 
In the second place, "measurements' in economics (as the term is usually used) frequently yield, instead of the definite number, as $x=a$, a result in probabilistic form, $P(a \leq x \leq b)=c$. Taking from this some derived value $\bar{x}$, we may use this as though it were a definite measurement equivalent to $x=a$, associating with it a confidence interval derived from the probability $c$ of $x$ falling within the closed interval $(a, b)$, and accepting it in any case as contingent upon certain conditions being met in respect of the unexplained residual term.

Such measurements do not arise because the events measured axe thought to consist necessarily of processes occurring stochastically (i.e. indeterminately) in the real world, but arise from a variety of operations performed on data already collected, in raw form, as definite numbers. Econometrics is not usually concerned with measurements directly on economic events, but with further mathematical operations 1.e. deductions, performed on such measured numbers. It also tends to concentrate attention on the properties of the pure numbers, neglecting either the dimensions of the functor selected for the initial measurement, or the relation of that functor to the theoretical term of which the number is sald to constitute a 'value'; both aspects of the number are taken for granted once the number, and the label attached to it, are known.

Thus econometrics, even if one could meaningfully speak of a link between economic observations and the theory, could not itself claim to provide such a link. It is not a process of measurement, but a part of the deductive apparatus of theory, and is meaningful only when considered in the context of the rest of the conceptual and deductive apparatus.

Consider, for example, the important set of 'real' variables. These sound, and are treated in many theoretical propositions, as though they were meant to have the dimensions of physical (as opposed to monetary) functors, e.g. weight (of × lbs.) or capacity (of kwt.-hrs.); the actual measuring 
operations yield something entirely different, which in its simplest form is 'value of sales at constant prices (of $x$ dollars/price deflator)'. Frequently the rationale of treating the one as measuxing the other rests implicitly upon some universal conditional of the form: "if the firm (industry, economy) is in equilibrium then..........", where the conditions specified in the antecedent fali to hold for the domain in which measurement is made, nothing can be sald about how the number obtained by measurement relates to the theoretical term in the absence of further enquiry into the theoretical basis upon which the measurement is made. 85

Thus econometrics, so far from providing a link between deduction and observation, itself requires the prior establishment of such a connection if its results are to be interpreted.

It would be premature at this point to assert that the failure to specify dimensions of the variables itself provides a source of error, although it does indicate a general sloppiness of procedure. There is, of course, one genuinely dimensionless number, since any term expressed as an elasticity is by construction dimensionless. On enquiry, it turns out that a price index of the Laspeyres form is dimensionless provided that the same commodities are used and providea thact the monetary standard can itself be accounted for, where the index Itself does not provlde a measure of variation in the monetary standard. 86 The term now commonly used, i.e. "measurement at constant prices" is thus a reasonably good description of what is being done. The accuracy or appropriateness of the deflator used is a different matter, but raises no new problens that people who use deflators are not in general well aware of. The use of accounting-type relations in input-output analysis merits closer attention to the dimensions of the terms which will be given in due course (in Chapter 4 below).

The fundamental problem is still that arising from a confusion between the mathematical formulation of a relation and its semantic interpretation. The practice of naming 
variables in terms which, while used in the equations merely as identifiers, carry through to the conclusions their ordinary meaning in the English language, suggests that the strict relations of the mathematical formulation hold for any collection of things that can be brought within the looser definitions of the terms in oxdinary language. "Investment", "savings", "income" and "expenditure" are but a fev - though centrally important ones - of the terms so used.

For example, where 'savings' and 'investment' are held to be identical, this derives from the following process of definition: during a given period, a net total of goods and services have been produced over and above that needed to maintain the existing capital stock; a large subset of this net total has been used up, termed 'consumption'; the residue or complement has been saved, 1.e. not used up, and hence is 'real savings' ; but equally, the same complement may be sald to have been an addition to the conmuntty's wealth, and so is 'real investrent'.

This relation may be extended by the insertion of terms for goverrment and foreign trade, but the course of the argument remains the same. 'Investment' thus defined has then to be related to production, which implies that increments to the net stock of goods of all kinds be treated as increments to capital (fixed and working) 2.a. as additions to productive capital in a physical sense. But when it comes to measuring either 'savings' or 'Investment', the impossibility of measuring 'real investment' or the same entity in 1 ts guise of 'real saving' leads to a more general search for surrogates arong objects regarded in looser usage as 'investment', 1.e. increments, at the firm or individual level, in assets. Where the measurement is not conducted even at the micro level directly on the physical assets, but uses as a surrogate some collection of monetary values of assets (at constant prices) the connection between 'investment' in this loose sense and 'Investment' as the rigid formulation of the theory requires it becomes decidedly tenuous. The position with 'savings' is even worse, 
since attempts to measure savings inevitably have to deal with holdings which largely consist of financial assets, whose connection with 'real savings' is not merely a matter of defining terms but requires an extensive chain of reasoning about economic processes.

This does, in fact, turn out to be generally the case, at least in macroeconomics. The measurement of 'real variables' initially at current prices needs a statement of how the 'real variable' of the theory relates to the variable measured in monetary terms. which is used as data, and this cannot be done without spelling out the processes through which monetary activitiss giving rise to monetary records make contact with the real processes of the theory. The use of deflators, while innocuous in 1 ts aim of correcting for variations in the monetary standard, cannot provide any substitute for an account of these processes.

There is something to be said for tidying up procedures in empirical analysis. The specification of dimensions would reduce some of the sloppiness in theoretical discussion, and might have some valuable insights for us, although direct measurement in physical terms presents its own problems. 87 There is also a case for recognising the conceptual and measurement problems in the data by writing down such numbers as GNP with an associated confidence interval, which would prevent some of the misuses that Morgenstern was talking about. ${ }^{88}$ But it is not enough that the problems of the data be tackled; however refined the data, unless we know how it relates to the terms of the theory in which it is interpreted nothing can be made of it. And indeed, unless the theory itself can specify precisely what sorts of observation are germane to it, what could 'refinement of the data' mean? 


\subsection{THE DEVELOPMENT OF SCIENTIFIC THEORY}

\subsection{Concept and Experiment in Scientific Change}

The question is raised of what scientific advance actually consists of, and how it happens. This question is raised in the first place by the fact that economists themselves offer programmes designed to improve methods of enquiry in economics on the grounds that "this is the way things are done in science". This line of argument is explicit in, e.g. Friedman, Samuelson and Gordon, discussed aborc, although as it appeared in section 1.1 such economists frequently disagree about what precisely is scientific method. Hence any dubiousness about their claims to present an accurate view of Sclence reflects also on the arguments for adopting any of their programmes, and thus may reinforce any doubts about a proffered programme already present on other grounds.

But the question has also been raised in a different and more fundamental way by the discussion of Section 1.3. If observation and measurement arise from and are contingent upon prior theory, and more particularly if the observations and measurements which would refute a theory are prescribed within the terms of the theory and its conceptual structure, how can a different conceptual structure ever overthrow and replace an existing one?

Let us look again at the nice, tidy view Friedman has of how enquiry is conducted in science:

"The approach that is standard in the physical sciences is to use theory to derive generalizations about the real world. The theorist starts with some set of observed and related facts, as full and comprehensive as possible. He seeks a generalization that will explain these facts.... He tests this theory to make sure that it is logically consistent, that its elements are susceptible of empirical determination, and that it will explain adequately the facts he started with. He then seeks to deduce from his theory facts other than those he used to 
derive it and to check these deductions against reality. Typically some deduced 'Eacts' check and othors do not; so he revises his theory to take account of the additional facts." 89

Friedman is not alone in believing, or at least suggesting, that scientific enquiry develops by inductive generalization from observed facts, and indeed so common is this viev that Popper was impeljed to denounce it in no uncertain terms. 90 Eut at least, it may be sald, scientists do put their theories to the test, and Popper certainly required of a proper standard of investigation that theories should be subjected to $x$ isk, in that thoix predictions should not only be refutabie ir principle but that observations refuting them should be actively sought. Galileo is a popular witness called to support a view of the prominence of observation in science, by e.g. Northrop as an example of observed anomalies casting doubt on an existing theory, 91 and by Margenau, who couples him with Newton as examples of outstanding practitioners whose "significance lies not only in their discoveries but in their adoption and formulation of a new method of physical research, the method of controlled experimentation".92 Margenau, in citing the fanous Leaning Tower experiment, is moved to comment that "the strange thing is Galileo's reticence about this matter".

Galileo's reticence ceases to be strange if crombie's account is to be believed, casting doubt on the whole episode and the thesis which it is advanced to support, he records that:

"Two other scient1sts, Giorgo Coriesco in 1612 and Vincenzio Renieri. In 1641, did actually make such experiments from the Leaning Tower, and they found that even with bodies of the same material the heavier welght reached the ground first, if they were dropped from a sufficlent height." Their results disagreed, but Renleri subritted his results to Gall1eo, who "had cone to assume that all bodies of any material would fall with the same velocity. Unimpressed by the disagrement of experiment with theory, Galileo made an abstraction from erapirical actuality and said that the theory 
applied to free fall in a vacuum.... It has long ceased to be possible to regard the Leaning Tower experiment, even supposing Galileo made it, as in any sense crucial, or even new. " 93

From the internal evidence of Galileo's own argument, 94 and without having consulted contemporaneous historical record, it is hard to belleve that Galileo's experiments were not largely "thought experiments". They carried conviction to the extent that they offered descriptions of, and explanations of events arising from, the properties of communsense objects in contexts open to everyday observation; that, is to say, Galileo's arguments, so far from resting upon the results of laboratory-type experiment, were more in the nature of appeals to the world of public experience or common knowledge, which anyone else could observe as well as he. In short, while reading Galileo, one feels that Robbins' account: seems to be much closer to what Galileo is doing than Friedman's alternative. An important difference between the approaches of Robbins and Galileo is that the world of monetary events that Robilins appeals to is considerably more elusive and uncertain than the world of commonsense objects which Galileo had in mind.

But even the public world of commonsense objects does not provide an unequivocal guide, and it may be that observation (in an obvious, everyday sense) may itself be more misleading than thought-experiments, as Popper's reference to Anaximander asserts. 95 Even when experimentation had taken on a more modern laboratory-operational form the simple-minded account of the process as hypothesis - controlled test - result conviction is still wrong as a description of how it all happened. Consider, for example, the simple-minded account of Lavoisier's refutation of the phlogiston theory in 1772 followed two years later by an experiment proving the oxygen theory of combustion; the facts, according to Musgrave, were not at all so simple. ${ }^{96}$ 
Musgrave goes on to say "Many things have been said about the relations between experiments and scientific theories and most of them are wrong".

"The great Newton said that experiments could prove theories to be true. Since everybody worshipped Newton's science, they admired his philosophy of science too. No theory was thought respectable unless it could be claimed that it had been 'deduced from experiments'."97 But the chemical experiments that proved the phlogiston theory false did, in the long run, conduce to the acceptance of new theories which themselves came in for attack. It is only with hindsight that it can be seen which were the crucial experiments, after the smoke of battle betweer rival theories has died down.

There are many reasons why a single experimensal test is not in general conclusive; the result may be dismissed as a stray observation requiring more extensive support, and may even raise a doubt about the methods of the experimenter. Where the result is probabilistic in concept, the confidence intarval within which it is statistically significant may be wide enough to support several interpretations, or no clear one. Understanding of what is being observed may not yet have advanced sufficiently for the result to be adequately interpreted; and it has in any aase considerable resistance to overcome, particularly when a rival theory has been accepted as providing satisfactory explanations over a wide area, not to mention reputations at stake. In the long run the body of scientific theory is progressively modified in the light of experimental evidence, but not as a one-way process; the accumulation and refinement of experimentation is carried out in conjunction with and as part of a progressive modification and codification of the conceptual structure within which it is directed and understood. It is only with the hindsight of later generations that earlier work can be seen as progressing from milestone to milestone.

The simple-minded view of science as a sertes of crucial experiments which decisively confirm or reject particular 
theories is in any case bound to be wrong, since it leaves entirely out of account the whole context of thought within which even the most important experiments are conceived, conducted and evaluated. As kuhn puts it: ".... nature is vastly too complex to be explored even approximately at random. Something must tell the scientist where to look and what to look for, and that something, though it may not last beyond his generation, is the paradigm with which his education as a scientist has supplied him". Such a paradigm tells scientists "about the sorts of entities with which the universe is populated and about the way the nembers of that population behave; in addition it informs them of the questions that may be legitimately asked abcut nature and of the techniques that can properly be uscd in the search for answers to them". 98

Not only does the comprehensive conceptual system within which specific theories are enunciated and evaluated provide the framework of thought for those theories; by its status as a system of principles organizing the experience of the world it modifies and directs the course of perception itself. Harris gives examples of three ways in which this interdependence affects perception: (1) perceived phenomena may be simply suppressed and overlooked for lack of a conceptual scheme in which to place them; (2) perceived phenomena are seen differently in different conceptual schemes; (3) there may be a complete failure to perceive what no concepts iead one to expect. 99

Even where the experimenter and those to whom he reports his results, agree thai the result of the experiment is at variance with what the theory asserted, the rejection of the theory is only one of the options open. An experiment consists in confronting a predicted result with an observed result, their conformity being judged in the light of a rule for evaluating the comparison. An experimenter may choose to reject the theory; or he may reject the observation; or he may reject the rule which says that, having accepted the observation he must reject the theory. Sometimes the anomaly is allowed to stand pending further investigation. 100 
Thus the isolated experiment which consists of a decisive confrontation of a conjecture with a fact is a myth; even where with hindsight high points in scientific advance can be indicated, they are invariably the culmination of a long sequence of conjectures, trials, anomalies and puzzles. But this is not at all to say that the paradigms within which this sort of process happens operate merely as a negative, inertial resistance to the emergence of truth; the paradigms have in fact a quite positive and important place in the process, as Kuhn spells out. ${ }^{101}$ Their chief function is to provide a body of received knowledge together with a set of rules for using and extending it; its great. virtue for the practising scientist is the guarantee $1 \mathrm{t}$ provides that certain problems, which have not hitherto been sulved, are nevertheless problems to which a solution exists, so that he may proceed from a firm base to the task of extending the periphery.

Can a major reason for the inadequacies of economics be seen in the lack of this secure base? As kuhn puts it, when discussing the immense amount of knowledge to be picked up by workers on the periphery: "That sort of work is undertaken only by those who feel that the model they have chosen is entirely secure. There is nothing quite like it in the arts, and the parallels in the social sciences are at best partial. Paradigms determine a developmental pattern for the mature sciences that is unlike the one fanjliar in other fields."102

But economics has its paradigmatic structure; in the general sense, economists do share a common "disciplinary matrix" although "relative unanimity of their professional judgements"103 is hard to find. In a more detailed sense, certain paradigms persist. 104 But, more importantly, the workers at the periphery who appear to feel that their model is sufficiently secure are numerous and their papers prolific; if there is not a firm central core of theory then certainly a considerable number of the profession think there is. But Kuhn's main point cannot be dismissed. One must agree with Grundberg ${ }^{105}$ that economics has not even begun to show the sort of advance that science has, 
although one has to discount Grundberg's apparent blurring of the distinction between the isolated refutation of a theory and the progressive development of the body of scientific thought; the first is not a characteristic of science, and the latter consists, we are told, of successive extensions of the periphery of knowledge round a given paradigmatic core until so many unsolved problems and anomalies have accumulated that a crisis results and brings about a major change in the conceptual base.

But where is all the information that has been thus picked up at the.periphery?, Wheypare the solved problems.

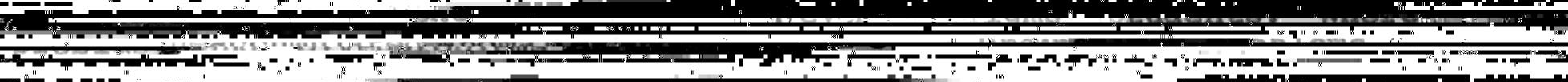

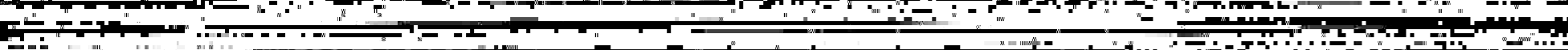
:

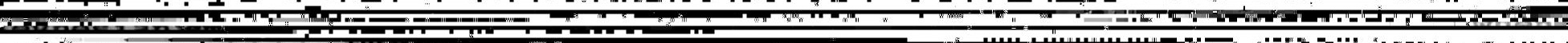

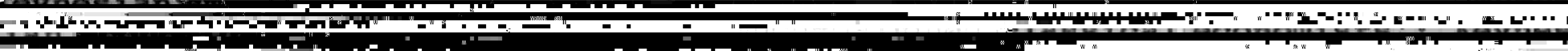

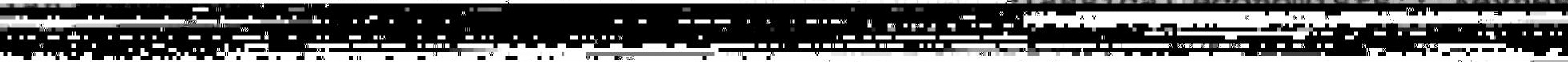

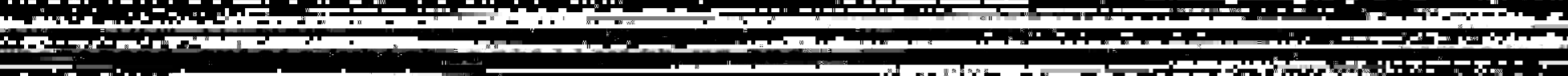
F : : r ; i

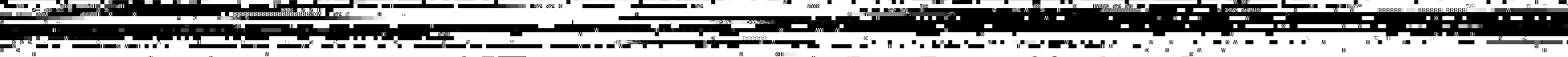

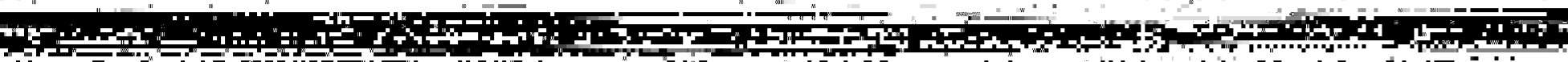
:

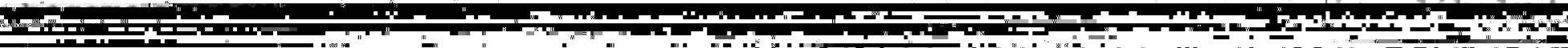
(2) -

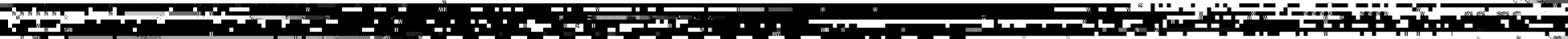
1,

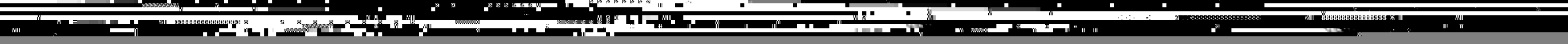


Economics not only has its paradigms; some, at least, of the main core of economic theory is expressed in formal axiomatic reasoning, and the expression of econouics in increasingly sophisticated mathematical models is a generally accepted part of economic research. Economics can make shift to exhibit some of the forms and appurtenances of a fullyfledged scientific discipline; nor does it lack 'facts', of an elementary sort. 109 Given the elementary facts, and the organising principles expressed in the not inconsiderable paradigmatic structure of economic theory, why does all this not add up to a science?

Let us try a slightly different point of focus.

1.42

\section{Stages in Enguiry and the Organisation}

OF KNOWLEDGE

The discussion in section 2.3 attempted to show that the sort of 'knowledge' that a physicist has of some of the more esoteric properties of the world is at bottom no different in kind fror the sort of 'knowledge' that a carpenter may have of the timber he works with, although there is a difference of degree. This difference of degree may be ignored when one is talking about the relation between 'fact' and 'concept', involving the basic epistemological questions, but it does become important when we set out to evaluate the status, as a science, of economics.

Northrop analyses three stages in the developrent of enguiry: (1) the problem, and its analysis; (2) the natural history stage, consisting of the collection and classification of facts; and (3) tise stage of deductively formulated theory. The first stage designates the facts which must be known in order to resolve the problem, the second stage comes to an end when "the facts designated by the analysis of the problem in the first stage are immediately apprehended by observation, expressed in terms of concepts with earefully controlled 
denotative meanings by description, and systematized by classification". The third stage involves the use of formal logic, and yields relevant and fruitful hypotheses for experimental testing. 110

This analysis can be faulted at many points. The designation of the problem cannot precede the conceptual scheme which provides the awareness of a problem; the hypothetico-deductive element has already been active and fruitful during the whole course of perceptual and cognitive development; the example chosen (Galileo) is highly dubious as a historical account; and the separation of the whole process into definitive stages is a mistaken view of how cognition and perception, it now appears, in fact interact through a continuing process of construction and reconstruction.

Yet I cannot believe that Northrop is talking nonsense when he says: "The natural history stage...is a necessary prerequisite for the third stage. Otherwise, the inductively given relevant data for which the hypothesis of the third stage must account, if it is to be effective, are not known.

"In fact, if one proceeds immediately to the deductively formulated type of scientific theory which is appropriate to the third stage of inquiry, before one has passed through the natural history type of science with its inductive Baconian method appropriate to the second stage, the result is immature, half-baked, dogmatic and for the most part worthless theory."111

The 'inductive Baconian method' as a pure empiricist epistemology has been demolished often enough on the infinite regress argument of philosophers, and more substantial evidence against it appears available on physiological grounds. But are these arguments relevant to induction in the context that Northrop intends? Once one has passed through the developing cognitive experiences of childhood and adolescence, considerably extensive and complex schemata are firmly established to direct and control the cognitive-perceptual acts, and observation as an initial source of knowledge is no longer in question. 
If we are to speak meaningfully of refuting theories, then there must be some sense in which we can apprehend the existence of a body of facts existing independently of the theories under scrutiny; what is more natural - or more useful than to separate out the conceptual acts which determine those facts from the conceptual acts which set up specific theories? ${ }^{122}$ This seems to require a distinction between two levels of knowledge at least; one is the body of knowledge which is more immediately apprehended, in the sense that the schemata we bring to it are largely automatic and unconscious, being the schemata we use in ordinary day-to-day transactions and which we have therefore come to take for granted. The other is the formal, axiomatic structure which we erect to deal with more complex and less immediate facts, and which can hardly be used otherwise than consciously and overtly. In between these we may interpose a certain level of organisation, more finely structured and overtly used than the commonsense schemata, but not going beyond detailed description and olassification. It is this intermediate level of knowledge that Northrop seems to mean by "the natural history stage of knowledge", and as suck. it makes a good deal of sense.

Scientific theories may also be discussed in terms of the distinction Bunge draws between 'black box theories' and 'translucid box theories'. 113 The former involve treating systems in terms purely of manipulations and observations at the input and output terminals of a box which, for the purposes of the theory, is regarded as devold of internal structure. 'Black-boxism' makes the false assumption that the sole aim of scientific theorizing is to systematize directly observable phenomena. It is easier and moxe attractive, since black box theories can always be constructed to fit any possible data, given enough uninterpreted paramerers, and they simplify the task by dispensing with the internal structures which would be needed in a representational theory offering interpretations of the facts. As a result, they come dangerously close to irrefutability, the mark of nonscience.

The task of scientific theory, then, is to move on from 
black boxes, which serve a useful purpose at an eariy stage in the construction of theory, to the construction of translucid box or representational theories. The internal mechanism cannot be deduced from the events at the input and output terminals alone: "...no double column of input data and output data ever points unambiguously to the mechanism symbolized by (the black box). If it is beyond our senses.... such mechanism must be invented. And such an invention does not call for more or even better observation but an effort of the imagination - and this has often been a source of distrust of representational theories. "114

The result is frequently a commitment to black-boxism, whose worst effect is "noc the multiplication of black box theories but the philosophy that praises phenomenological theory as the highest type of scientific systematization and abuses representational theory".

It is quite absurd to suppose that an investigation may become 'scientific' only if we begin by throwing away all the knowledge that we have accumulated on the way to maturity; since the mental furniture that we have gathered about us before beginning any scientific enquiry is not in any case so easily ignored or disposed of, there is obviously some sense in trying to make what ever use we can of this "background knowledge". Whether one sees this in Robbins" terms as "simple and indisputable facts of experience", or as the raw material for Northrop's "natural history stage", or to some extent as the source of the imaginative exercises entering into the construction of translucid box or representational theories, this mental furniture is bound to enter into any subsequent cognitive-perceptual act, and while parts of it may from time to time be refurbished or even replaced, it is in the process of fitting a new idea into this existing mental furniture that an explanation may be said to "make sense".

This does not, of course, require that an explanation be immediately intelligible to a layman, although economics deals more directly with human behaviour than the physical sciences and consequently faces more direct demands for it to make sense. 
There is, however, something to be said for the positivist separation between the $\log i c$ and the facts, with the rules of correspondence serving to make sense of the logical exercises.

One can see the distinction between Robbins and Friedman as relating to different stages in the development of enquiry; Robbins' approach, which goes directly from background knowledge to deductions whose validity is guaranteed by the reliability of the knowledge and the adequacy of the logic, is placsd thus in the natural history stage of enguiry; Friedman, whose initial conjectures come, not at random, but out of a well-structured prior knowledge, and are formulated in an axiomatic scheme and subjected to more formal tests, is defining a programme for the third, or hypothetico-deductive stage.

There may, however, be a snag in thus distinguishing them, but discussion of this is deferred to the summing-up of the next section. 


\subsection{SUMMARY}

ihis chapter set out with the idea of trying to assess the nature of economic enquiry in terms of what some economists who have directed their own attention to this question have thought about the matter. It turned out that aconomists themselves do not, in general, appear to have given the question sufficient thought to provide an adequate basis for discussion, and it was necessary to look further for more adequate tools in which to conduct an assessment.

Some preliminary points can be disposed of now. In the first place, most of the arguments about induction and the pre-eminence of observation, about the place of the hypotheticodeductive method in conceptual structurings, and about the confrontation of conjecture with fact, can be sufficiently resolved for our purposes (though not necessarily for a more fundamental enquiry into epistemology) as soon as one accepts that any research worker in economlcs has already, through his own cognitive-perceptual development in the context of social interaction, become well-endowed with considerable conceptual schemata. The genesis of knowledge itself is not in question, any more than the question of which came first, chicken or egg, is meaningful either for the modern poultry farmer who is amply supplied with both, ox for the evolutionary biologist who can refer to the complevintary development of both.

In the second place, in comparing economic enquiry with scientific enquiry, it is silly to compare economics as it is with an idealized view of natural science which appears to rest on some simple-minded view of a steady accumulation of certain knowledge from a progression of decisive experiments. ${ }^{115}$ Even on a more sensible view of science, however, it cannot be denies. that econonics completely lacks any signs of a similar development or comparable achievement.

In the third place, since it appears that for economics 
all our 'facts' are rather elaborate constructs then 'empirical testing' in economics comes down ultimately to the evaluation of one conceptual structuring in terms of another. If we are to attempt to draw a line between $\mathrm{P}$-domain and C-domain for the purposes of economic research, as we surely must if we are to speak meaningfully of theory refutation, then this line has to be drawn by choice or convention between two certain types of conceptual structuring. In drawing this line, it becomes necessary to be very careful about which side of it we place "income", "expenditure" and similar terms: associated with this is the question of whether national income accounts, production functions, and similar macroeconomic 'data' can be taken as objectively (for our purposes) arrived-at facts, or whether they need to be examined as conceptual schemata whose worth is in question.

Two possible approaches to the diagnosis have been suggested; if we take the Northrop view of a broad development through stages, then Robbins is talking about the second or natural history stage, and Friedman about the third, hypothetico-deductive stage, and the question then becomes: have we tried to pass too rapidly to the formal, axiomatic stage without having laid an adequate foundation for it at the natural history stage? If, on the other hand, we apply the Bunge distinction, then Robbins again becomes important when we try to move from the black box to the translucid bos or representational stage, and the question is then: is economics suffering from an excessive commitment to black-boxism?

The two approaches may be reconciled if one accepts that black-boxism is surely a predictable consequence of a premature incursion into axiomatisation, since the internal processes of the black boxes cannot be even posited, let alone subjected to formal hypothesis tests, in the absence of any clear set of ideas whose source is ultimately found in that general background knowledge which, in any developing field, should have been supplied at the natural history stage. Even the limited usefulness that Bunge sees in black boxes in physics 
may be denied to economics, if the black boxes themselves are unrelated to the world of experience, so that the measurements applied to the output terminals yield no information. 116

We have now reached a point at which enough ground has been cleared and adequate equipment assembled for present purposes, and we may now proceed directly to the major task in hand. In presenting the corpus of monetary theory for diagnosis, we shall concentrate attention on two aspects: the ideas about economic behaviour present, and the form in which they have come to be expressed. 


\section{CHAPTER 2}

\section{THE INTERPRETATION OF MACROECONOMIC AND}

\section{MONETARY THEORY}

In this chapter we examine some of the more important conceptualizations common to the hard core of macro-monetary theory; some provisional line has to be drawn here between terms understood in ordinary usage, treated as though their meaning is transparent, and other terms and relationships whose conceptual structuring is the subject of enquiry. For example, "bank deposit (demand liability)", "specie", "Banknote" are treated as objects of common knowledge requiring no explicit definition, while "liquidity" calls for more explicit treatment. "Money" is initially treated in a loose sense as understood in common usage, but it becomes clear during the course of the discussion that it needs very careful definition owing to ambiguities and shifts in its intended denotation. The context should make it clear in which way a term is being used. 


\subsection{THE BASIC IDEAS}

Money is relevant to macroeconomics in three major ways: (i) in the monetary element of, e.g., prices, interest and exchange rates, and wages and incomes generally, which are of direct interest in their own right as objects of study and of policy; (ii) in money's function as a nexus of exchange, carrying in a market economy also some onus for transmitting information and stimuli to action; and (111) as the dimension in which measuring operations on the physical entities are carried out and aggregated. Money in the third sense is now commonly elided by the use of deflators, 1.e. by dividing through by a price index. A rationale for this can be found in Ricardo's development of the ldea of 'sone invariable measure of value', 1 although Leijonhufvud considers that this procedure removes the essential monetary element (i1) from macroeconomic analysis. ${ }^{2}$

Taking (1ii) in isolation, it is arguable how far the derivation of ostensibly 'real' measurements by applying deflators to money measurements does yield the information it is taken to yield; but a case can be made for continuing this practice at least for those undeniably real variables whose direct measurement in physical terms would otherwise present severe difficulties. ${ }^{3}$ The question is what effect this practice has had on the structure of macroeconomic analysis and consequently on the terms in which current thinking about macroecononic activity proceeds.

One obvious consequence of the confidence placed in deflators is their extension to purely money variables; such a pure money variable as bank deposit liabilities is now brought into this 'real' framework to yield that curious entity a 'real money balance' and its macro aggregate 'the real quantity of money'. "The extension to 'desired real money balances' follows as a matter of course. 
But there also follows the elevation into an analytical tool of what might otherwise have been treated on its own merits as purely a measuring device; it is one thing to use some broad concept of 'purchasing power' as a commonsense approximation in relating money to goods; it is quite another to anchor formal. propositions about behavioural. factors underlying the money-goods relation in such shifting and uncertain ground. Is a result, a one-to-one correspondence between the money measurements and the 'real' variables derived therefrom by deflating has to be assumed in order to validate the procedure, and itself is further buttressed by the view of a money economy as simply a basically barter economy better lubxicated by money, which is in real exchange equilibrium, and in which cextain tautologies are said to hold. 5

The shape of this framework of thought is seen easily enough in the fact that the basic macroeconomic aggregates, $Y, S, I, M$ etc. are asked to carry monstrous loads of interpretation. $Y$ has to do duty for 'income', 'expenditure' and 'output', s for amounts of money recelved and not spent, for the excess of goods produced over those used up during a period, for amounts lent to borrowers or to users of money capital, for increases in productive capacity, within this rather unpromising framework, questions have to be formulated so as to elieit information which will throw light on the important topias of jobs, prices, standards of living, foreign trade and the rest. The formulation of such questions, involving as they must an economy in which the large majority work and borrow to get money to meet their personal and social commitments, is rendered extremely difficult by a theoretical structure which is not even defined for the differences between the acquisition and spending of money and the production and distribution of goods. The desperate atterapt to relate $y$, $s$ and $I$ through $M$ and $x$ is a direct consequence.

Why the franework for thought should have taken this form rather than some other is not inmediately apparent; in order to throw light on this we must examine the sort of ideas that 
have been selected for expression within the formal framework.

Many of the ideas which, modified and elaborated, still provide the basis of modern monetary theory were given the form in which they are now recognisable in the period of Hume, Smith and Ricardo, and developed into modern dress via Walras, Fisher, Pigou, Keynes and Hicks. Schumpeter ${ }^{6}$ and some recent commentators ${ }^{7}$ provide more comprehensive accounts of the relevant developments than can be attempted here. By way of bringing the accepted ideas into sharper focus we shall, at suitable points, contrast them with the different approach of Henry Thornton, who in many ways offered a sounder basis for the development of monetary theory than that which the discipline in fact adopted.

\subsection{HUME TO RICARDO}

We pick up the threads by looking first at some ideas in Hume and kicardo: chronologically, Thornton falls neatly between the two. ${ }^{8}$ Some differences between Hume and Ricardo reflect changes over the intervening period in the nature of the monetary scene, in particular the growth of English banking and the suspension of cash payments by the Bank of England in 1797. For example, whereas Hume would not admit bank money as 'money', calling it 'paper credit', 9 Ricardo acknowledges the use of bank paper as money, although its status as money he does see as traceable to its convertibility to gold. 10

Hume is these days often mentioned as a Quantity Theorist; ${ }^{11}$ Ricardo also accepted this idea, in a particularly rigid form. Hume was also able to posit a direct relation between the domestic money and the international money, since, as he saw 1t, the two were physically identical. ${ }^{12}$

The key element in these ideas was the specie-flow view of money, which provided a basis for three elements still important, in a less direct way, for current discussions of money. These are: (i) the idea of money as some tangible thing, which is deposited in banks and which they lend out again; (i1) the quantity of gold being determined in total 
by its physical production, gold once produced remained in general in existence, although not necessarily in circulation; and (i1i) the idea of an "equilibrium" stock of money, reached for the domestic stock of money by the occurrence of equilibrating international gold flows.

Hume's (i) is in modern guise the "uloakroom theory" of banking, spelt out by $\operatorname{Cannan}^{23}$ anc. accepted until very recently by practical bankers, although it was a practical banker, Thornton, who over a century before had understood and explained why this did not hold. The cloakroom theory, while formally rejected by modern theorists in respect of the aggregated banking system, is still in essence applied to the individual banks 14 Reynes himself had thought the refutation worth spelling out again in the rreatise, ${ }^{15}$ even though Crick (1927) had recenciy done so.

Hume's (1i) made obvious sense at a time when, with the quantity of gold being subject to identifiable restrictions on its production, the means of payment was observably specie; the theoretical concept derived therefrom of "the given stock of money" presented little difficulty in the absence of alarms and panics. Ricardo, however, put it into a rigid framework of barter exchange and equilibrium, which is a possible explanation - although not a justification - for its persistence today long after the specie-flow basis has disappeared. It is not only in the modern Quantity Theories that one finds the analysis resting on the concept of "the given stock of money"; Liguidity Preference approaches in general depend on it, and the concept is a key one in pretty well all of modern theoretical work in money.

Huxe's (iii) was adapted by Henry Thornton and transmitted by John Stuart Mill, coming to be known as the 'classical transfer theory' or the 'gold-flow, price-adjustment theory' 16 Thornton undoubtedly understood the difference made to Hume's specie-flow argument by a consideration not only of flows of what we would now call 'hot money' but also of the effect of a 
weakening of confidence in bank paper, and the feed-back effect between this and international finance flows, communicated, and measured, by the observed divergence between the mint and the market price of gold. 17

Henry Thornton combined an intimate practical knowledge of banking and commerce with a great analytical power, thus combining into a conceptual structure two elements of which so many writers on money, theorists or practical men, miss one. It is instructive that Thornton began his formal inquiry not fxom barter but from credit. ${ }^{18}$ When he did introduce barter, it was without the key element of the Smith-Ricardo analysis, the exchange equilibrium. 19 He explained in detail the process by which bills of exchange and pronissory notes came into being, treating them not just as guestionable substitutes for specie but as instruments desirable in their own right, being preferred for some purposes to holding either goods or money. ${ }^{20}$ He was definitely not a Quantity Theorist, as is shown generally by his argument and specifically by his criticism of Smith. ${ }^{21}$

Thornton disposes of one proposal for remedying the gold shortage: "It has been supposed by some, that the pressure on the mercantile world which a great diminution of notes must cause, would, especially if it were a severe one, induce the merchants to send Icr gold from abroad, in order to supply their own want of money". But, asks Thornton, what merchants? Not those without exportable goods; they must first exchange their own goods, 1.e. sell then for money. Thus they have to get hold of the very thing, from domestic holders, for which the proposal required them to send abroad. ${ }^{22}$

Thornton's argument leads up to a conclusion that "there may be an error on the side of too much diminishing bank notes, as well as on the side of too much increasing them". 23 He provides and explains a balance sheet of the Bank at 25 th Feb. 1797,24 and goes on to exarine the processes, i.e. transactions, through which the items are causally related. His description of these processes is clear; the bank cannot just increase its notes unilatera1ly, and the corresponding entry may be in a 
reduction in deposits, or in the acquisition of an asset in the form of a loan or of more bullion. But when bullion flows out due to an adverse balance of payments, the Bank, which must increase $1 \mathrm{ts}$ notes $1 \mathrm{n}$ order to provide sufficient means of payment for City transactions, can do so only by increasing its loans. Thus the loans are not a cause of the deficiency of cash, but a conseguence.

The difference between the rigid view of equilibrium and Thornton's more practical view is shown by his argument on the balance of trade; ${ }^{25}$ an imbalance must either run down bullion or extend debt, neither of whlch is practicable to any great extent persistently.

In Chapter 7, Thornton discusses the advantages and disadvantz; of country banks, and in so doing explains in detall the relation between the various means of payment on the one hand, and the institutions - country, London banks, Bank of England - on the other. Continuing this argument in Ch. 8 , Thornton analyses market factors in terms of supply and demand; as in his initial discussion of barter, he repudiates the 1dea of some exact equivalence, basing himself on a looser concept of a buyers' or a sellers' market, with prices set accordingly (but with, typically, no mention of a 'market-clearing' price). ${ }^{26}$

Thornton is extremely careful about causal connections. Having established the correspondence (an inexact one, hedged about enough to repudiate the quantity Theory formulation) between the increase of paper and the rising prices, Thornton then asks which is cause and which effect. ${ }^{27}$ In Chapter IX he first expounds the precise relationships in the banking structure important for his analysis, and proceeds with his tracing of cause and effect relation. Is it too much to see a statement of the 'inconsistent case' of Mundell in his argument? ${ }^{28}$

In Chapter $\mathrm{x}$ he brings the threads together. He answers first the argument that the rise in prices is a cause of increased paper, demonstrating that (a) a rise in paper will 
lead to an increase in expenditure, and (b) the increase in expenditure may call forth some new output, but since only a. moderate expenditure can be directed to existing unemployed factors, any further increase must lead to price riges, further aggravated by a feed-back mechanism remarkably similax to the Schumpeterian 'secondary wave'. 29 His explanation of this adduces a specific multipliex effect, ${ }^{30}$ which provides a causal. effect from paper to prices.

Thornton then, in arguing that bank credit, extended for each loan according to sound banking principles, j.s still not necessarily self-liniting, draws a firm distinction between the micro transaction, as seen by banker and customer, and the macro aggregates to which such transactions give rise. $^{31}$ He considers other ways in which demand for loans night be selflimiting without intervention by directors, and points to the impossibility of this while the Bank is willing to lend at below market rates. 32

The foregoing has attempted to indicate how clearly Thornton, applying his analytical and deductive faculties to his observations, could grasp and expound the monetary activities of his time. How important, then, was Thornton as a contributor to monetary theory? Hicks, In his essay on Thornton (Essay 10 of Hicks (1967)), Hayek in his prefatory essay to-the reprint of Thornton's major work (Thornton (1802)) and Schumpeter (1954) are all laudatory of the quality of Thernton's analyisis. Hicks, in particular, comments on Paper Credit that "It incorporated some of the chief things which Keynes, 130 years later, was to rediscover". The key ideas are Liquidity Preference, the downward rigidity of wages, and the marginal efficiency of capital; Hicks also adds that "Thornton is arguing, (in a very modern manner) against the use of deflation for the rectification of an adverse balance of payments" a point noted above. But Hicks makes the following astonishing statement "HIs argument is deficient because of his lack of a multiplier theory (in this respect, it must be admitted, he falls seriously short of Keynes)". But Thornton not only had a multiplier theory; (see note 30): his multiplier theory was superior, in one sense, 
to that of Keynes, in that he distinguished more clearly between the real and monetary aspects and effects; it was so much superior to the version produced in Hicks' interpretation of Keynes (in the 'Hicksian cross' model which is the authentic basis, rather than Keynes directly, of modern post-Reynesian theory) that Hicks completely failed to recognise it as a multiplier at all.

In fact, Hicks wants to make Thornton out a Keynesian although he does concede that this is truer of the short-run analysis than of the long, and that on the whole Thornton is closer to Robertson. But he also sees Thornton as a Ricardian, which does not stand up to the evidence produced above. In short, just as Schumpeter wanted to see Thornton as speaking in terms of an equilibrium analysis, which Thornton plainly was not doing, so Hicka wanted to see Thornton in terms of modern Keynesian analysis.

But, although many of the ideas in Thornton can be forced into the framework of modern post-Reynesian analysis there are, it seems to me, two major differences in the thinking based upon them. The first is in the expression of these ideas in a rigid, mechanistic framework, particuiarly that of equilibrium; I hope I have shown above that Thornton was concerned, all along, to avoid precisely that, which he would clearly see not as a more but as a less precise formulation, since it omitted those imbalances and exogenous disturbances which were what the crises were all about. The second is that the clear distinction, which Thornton drew at every point, between the real and the money is wholly absent from the Hicksian cross and from the whole of postKeynesian theory.

In spite of a performance which has recently drawn such plaudits, Thornton seems to have had no influence on the development of actual monetary theory, and certainly his ideas have had to be rediscovered subsequently. There are several possible explanations for this: the assimilation of Thornton to Ricardo, as e.g. by Hicks; the acceptance generally of 
Ricardo's analysis as in some way more scientific or precise, whlch schumpeter adduces; or it may be simply that Thornton's eminence in public affairs at the time prevented him from being taken seriously by economists as a theorigt. ${ }^{33}$ He was, it seems, influential in his own time; but such mark as he made on economic theory was tranmitted through the rigid, mechanistic structure that economic theory increasingly developed.

Now, I will concede that, just as Schumpeter and Hicks, with their own axes to grind, read into Thornton interpretations in terms of their own theoretical preconceptions, so might I be dolng, with a different axe to grind. I suggest a simple test. Put Thornton's analysis in terms of any of the rigid formulations, current then or now, and weigh the information and insights lost against what gains there ray be from so doing; I suggest that the losses greatly outweigh the gains.

By way of developing a different angle of view, let us now pass to some current formulations of monetary ideas.

2.12 The Development of Keynesian Economics

Classical views carried forward into the 20 th century gave monetary theorists, as a fundamental basis for their thinking, two Ricardian concepts of a real exchange equilibrium and the Quantity Theory. These were related through a specie view of money, as either itself specie or as a suxrogate validated by its claim to represent specie. Money in this form could be viewed in either of two lights, as a commodity freely exchangeable for all other commodities, or as a stock to be held as an asset. This is easily trans Istable into modern terms as the two major functions of money, that of acting as a medium of exchange, and that of acting as a store of value.

The real exchange equilibrium of Ricardo was more firmiy structured into the General Iquilibriun model of Walras, 34 further reinforcing the idea, already entrenched in Ricardo's formulation, that, Independently of variations in the value of 
the monetary standard itself, the real exchange equilibrium determined the relative prices, 1.e. ratios of goods-exchange. The task of accounting for variations in the value of the monetary standard (expressed today in terms of 1 its reciprocal, the 'general level of prices') was left to be dealt with by the guantity Theory resting as that did on the specie-based concept of the aggregate 'stock of money'. 35

The result was, as Keynes saw it, a dlehotomy in the inherited classical analysis between monetary and value theory. 36 He proposed to remedy this separation by treating money as primarily an asset, thus bringing it within the theory of choice. Whereas in the rreatise he retained enough contact with the classical view, transmitted through Marshall and Pigou, to bring this element in via a eash-balance approach, 37 he moved far enough avay to alter his stress, in the Genezal Theory, to the liquidity Preference approach, leaving the exchange function of money to be dealt with in terms of a transactions demand. The two together yielded a demand for money function as a more refined version of the demand for money function developed through Fisher and Pigou. This demand for money function, particularly as presented in the "Hicksian cross" 38 and subsequently construed as providing, on the LM side, a locus of equilibria in the money market, forms the core of modern monetary theory; at one time one would have autonatically excluded the 'monetarists' or modern Quantity Theorists ${ }^{39}$ from this reference, but it is not olear that such a division is accurate today; certainly, the lines are less definitely drawn.

In the form in which the "transactions demand for money" has been preserved in the theory its comnection with the simpler and more rigid form of the Quantity Theory is apparent, although in Reynes' own exposition complications and important differences are set out: but even in that exposition, there is warrant for supposing that Kreynes himself saw it as a logical development from the Quantity Theory. The remainder of the value basis the Ricardian real-exchange aquilibrium - is subsuted in the Is relationship, now construod as a locus of equilibria in 'the goods market' standing for the real side of the analysis. 
Thus to take the elements of the Hicksian cross as comprising a real side expressed in the Is relationship and a money side expressed in the LM relationship, while it may or may not adequately convey the substance of the General Theory, (the debate set off by Leijonhufvad is far from settled), 40 is a fair flrst approximation to how it has been transmitted to post-Keynesian analysts.

On the real side, we thus have two main mechanisms; the investment function, resting on a comparison of two interest rates, one notional and one actual; ${ }^{41}$ and a multiplier or incomeexpenditure function, relating investment to aggregate income. Now, a direct view of these mechanisms as they operate in practice would undoubtedly see them first in monetary terms. Where investment is said to depend on a comparison of the prevailing market rate (cost of borrowing ox return on lending) with the expected rate of return on airect investment expenditure, all the essential elements are conceived and calculated in monetary dimensions; viewing them in 'real' terms is an artificiality which obliterates the distinction between a liability or asset specifled and enforceable as a "sum certain in money", and a liability or asset specified as a title to goods or to a share in the proceeds of real processes. Since the sum borrowed for investment expenditure and the interest payable on the loan are of the first type, while the expected return is of the second, 1 t is not clear that the underlying behavioural relations can be understood when this distinction is removed, since the lender is usually dealing in money claims on both sides of his balance sheet, while the borrower is frequently incurring money debts in order to acquire real assets.

Where, as in the common case, the money standard is variable, this may in actuality be an important causal factor in borrowers' behaviour although it is less important for lenders (it may enter into their general assessment of particular borrowing propositions); but when the transaction is translated into 'real' terms it either obliterates this causal mechanism altogether or falsely represents the side of the transaction on which it occurs. 
A specific case in point is shown by Thornton's argument against the restraint on bank lending supposedly provided by either the application of 'sound lending' principles to individual bank loans or by the falling rate of profit to borrowers; 42 these arguments might apply in 'real' terms, but so long as bankers are content to keep creating money through their loans they are supplying the very means by which both the due repayment of money Cebts and the maintenance of money profits are assured, thus invalidating the conclusions of the 'real' analysis about tha self-limiting character of inflation. An attempt to recapture the monetary effect through the Quantity Theory $2 x$ the real-balance effect is unable to come to grips with live causal processes involved.

The multiplier mechanism sits even more oddly on the real side. As a money expenditure phenomenon (as it is in Thornton), it makes sense; through the chain of successive expenditures, an initial sum spent into the transactions flows increases the total in a definable way, which leads easily from the idea of an increase in total expenditure to a discussion of price, inventory and production effects. Alternatively, tracing through the effect on the goods side yields a chain of successively-derived demands. Whatever names one attaches to these two effects, they are distinct because money and goods pass in opposite directions between buyer and seller; the chain of money expenditures differs significantly from the chain of derived goods transactions, and may involve substantially different sets of transactors. Owing to ambiguity in the term "income", which has to stand for both expenditure and output, these entirely separate flows are not distinguished, with the result that we have to try to think of the real multiplier simultaneously in terms of both money and goods, while at the same time neglecting the differing paths of the effects.

Keynes' own exposition is not free from this ambiguity, since he clearly wants to speak both of the effect of the propensity to consume on the division of output between consumption and investment goods, and of the effect of increments in receipts leading to increments in expenditure. His analysis is saved formally by restricting the phenomenon to the case where only 
production effects of the increased expenditure are involved, i.e. the case of an advanced economy in a depression, in which the system has ample productive capacity and stands poised to produce the extra output provided only that the producers can get the new orders in. Thus each item of extra expenditure, i.e. each term $c^{n} r$, impels producers to produce corresponding increments of output. It is just a special case of the more general Thornton multiplier analysis.

In the less restricted uses of the multiplier concept in post-Keynesian analysis, the real multiplier appeals to the Ricardo-Walrasian real-exchange equilibrium reached independently of money, so that deflating the money terms to correct for variations in the monetary standard yields a "real multiplier relation" simply as a computation performed on numerical aggregates measured ex post, and the analysis is silent about the processes of which those measured numbers are taken to be the result.

Thus the suppression of the monetary aspects of the capitalinvestment relation and the multiplier relation removes that account of monetary processes which needs to be supplied in order for the behavioural aspects of real processes to be understood; it abolishes the view of money as a nexus between buyer and seller (or between lender and borrower), which as the important characteristic of a money economy requires a central place in the anazysis; and in consequence of removing this market nexus between demand and supply in both current and capital goods markets it renders the crucial income-expenditure relation impenetrable to analysis, which now is no longer defined to distinguish between 'income' and 'expenditure', except in the trivial sense that any two (uninterpreted) variables in the algebra may be so labelled.

The money side suffers from this defect too. That aspect of money as a market nexus which ought to enter into the goods market as the means by which would-be buyers make their demands effective in the market, is left to be dealt with on the money side as the 'transactions demand for money' which although 
vaguely related to 'income' has no ascertainable connection with the processes of buying and selling goods. Thus isolated, by assimilation to the money side, from the goods market, the 'transactions demand' performs only the formal function in the Hicksian cross - apart from the ritual bow it makes towards the 'medium of exchange' notion - of carrying a relation between 'income' and interest into the money side; this it does by providing a portion of the money stock to be deducted from the total money held, the absolute size of the portion deducted being determined by the level of 'income", so that, of the 'given stock of money' tise residue available for people to hold in performance of the asset function is determined.

This amount, M2, that people will want to hold as an asset is given as soon as one knows the interest rate, and since ex hypothesi the 'given money stock' does not change in response to any of the mechanisms of the model, the intereat rate must, if equilibrium is to be achieved on the money side. Since the whole analysis is dedicated to the proposition that equilibriws can and $w i I 2$ be achieved, a determinate locus of interest rate/ incoike paixs is derived by finally eliding money from this side too, thus providing a locus expressed in terms of the same two variables as the complementary locus on the real side (the SI locus): the two loci are then brought together on the same interest rate/income space, to determine a grand equilibrium for 'money' and 'goods' markets jointly.

The separate construction of the two 1.001, the IS and the LM curves, cuts clean across the fundamental relationship between money and goods: in a market economy, we begin from a view of a maxket as a congunction of buyers and sellers, the buyers coning with moruy to exchange for goods, the sellers coming with goods to exchange for money, on the buying side, the predicated basis of decision is the desire of buyers to achieve the best bargain (in their bwn estimation) in the basket of goods they buy, in the light of their personal preferences for goods qua goods as constrained by the amount of money they have to spend; the notion of an "effective demand" 
i.e. a denand that is effectively expressible in the market, is that of a desire for goods gua goods given substance by ability to pay; ultimately, then, the expression of a market demand is conveyed through the monetary expenditures of buyers. (This is nodified, but not destroyed, by a considcration of deferred peyment.)

On the selling side, the predicated basis of decision is the desire of seliers to achleve the best return, i.e. che most noney, for the goods they offer for sale. The confrontation of the two types of transacicor determines the price at which a gcod is sold, anc the quantity which is sold at that price. The effective demand, communicated through buyers' expenditures, is itself the medium through which buyers' preferences anong goods are communicated to sellers, and thus to producers who thereby are influenced in how they dispose the productive resources; the selling prices for the guantities sold communicate to buyers the relative scarcities and costs expressible in the production possibilities of the economy.

To the extent that the maxket also requires the transmission of information in order to arrive at determinate prices and quantities, 44 the expenditure flows carry a considerable onus - In pure price theory the whole onus - for the transmission of all the information roguired to organise econoric production and exchange. Thus the monetary nexus between producer and consumer rests upon a market nexus between money and goods. A macroeconomic structure which cannot take cognisance of this nexus because it lacks the requisite concepts - cannot analyse the market processes by which prices and quantities change, and is hence powerless to comnent upon either the causes or the effects of price changes or of changes in demand and supply oonditions. When the market analysis is axtended to factor markets, similar market processes are required to explain movenents in wage rates and levels of employment, axd the connection between those and the expenditures on goods that the factors are employed to produce, lacking cognisance of the requisite processes, the macroeconomic theory is hence powerless to comment on wages and employment. 
This does not prevent "explanations" being offered about. movements in prices, incomes, money, interest rates, exployment and other macroeconomic entities, although the atatus of such "explanations" remains conjectural. It ought to be a meaningful cuestion whether the monetary nexus as an element in explanation needs to be present in the macroeconomic structure if it is to be successfully integrated with value theory, or whether on the contrary the integration with value theory could be relied on to supply the missing element in macro theory; but since orthodox value theory itself falls to provide such a nexus the question does not: arise. 45

What 'the integration of monetary with value theory' means appears in practice to involve three ideas. Most importantly, it involves dealing with money in terms of theory of choice, which appears to mean: in terms of consuner equilibrium; it also leads to the notion of a demand-and-supply mechanism for money, exactly on the lines of the market analysis of equilibrium in the goods market; to a considerable extent it involves treating money as though it were simply a numeraire good, which associates it quite clearly with the specie view of money, both through its status as a commodity and through the importance attached to the size of the 'given stock'.

Thus monetary analysis consists of a demand function for money intended to reflect the influences arising from the private sector, while the supply of money may be taken as constant or as an exogenous $1 y$ determined variable, or may be more elaborately concelved in terms of a functional relation designed to relate the exogenousiy determined money base to the cxeation of trading bank money, possibly fuxthex elaborated to take specific note of the part played by non-bank financial intermediaries. The market conjunction of supply and demand functions is taken to determine the level of money stock and the finterest rate, and is one of the major influences on the 'level of activity' which comprises the behaviour of the major aggregates of income, employment, etc.

Where the supply function is dealt with in terms of monetary policy, the relation between money supply and general economic 
activity usualiy relies, implicitlY or explieitlY, on the underpirnings provided by the analyeis of money markets and goods markets; thus the whole relation between monetary stock, monetary activity and the associated variables, is left to be provided by the 'cienand for money' anelysis, and it is this that we shall. mainly deal with.

Different contributors stress different aspects of the 'demand for money'; as Johnson commented in 1962," 16 "contemporary monetary theorists, whether avowealy 'Keynesian' or 'Quantity', approach the demand for money in essentially the same way, as an application of the general theory of cholce, though the former tend to formulate their analysis in terms of the demand for money as an asset alternative to other assets, and the latter, in terms of the demand for the services of money as a good". Since the concept of a 'given stock of money' (though not an immutably fixed stock) in the context of real-exchange equilibrium is also practically universal, all the essential elenents of the Ricardian speciebased view of money are present.

What Johnson refers to as the 'Quantity' school is that associated with Friedman and is also known as the 'Chicago school'; this rather loosely associated group is said to have attempted (by some, is credited with having achieved) a 'monetarist' counter-revolution to the 'Keynesian revolution'. Thorn, (1966), lined up the major proponents as follows: quantity Theorists represented by Friedman, Latané and Meltzer; Asset Preference Theorists represented by Baumol, Tobin and Duesenberry: and then a category of writers, most of whom use the concept of the 'demand for money' but who do not IIt bo easily into this line up, since theix 'demand for money' functions give weight to both approaches. One might add, on the quantity side, Cagan, Meiselman, Meigs and Wolman, but since the Quantity theorists themselves incorporate asset effects in their models, while the asset preference theorists at least make the ritual bow 
to the exchange function of money by adnitting a transactions demand, it is difficult now to find anyone to occupy the extreme positions that this categorisation suggests. Dissent between differing caraps, however, persists. 17

Patinkin, who shared Keynes' view of the classical dichotomy, proposed to remedy it by returning to the use of the 'real balance effect", (which Keynes had discarded when he moved from the Treatise to the General Thecry), as the rain engine by which to integrate money and value theory. Despite the widespread view that the 'real balance effect' or, as some put it, the 'pigou effect', while an interesting analytical tool was of no practiral importance, Patinkin latex received substantial support from Pesek and Saving, who have ald what can be said in defence of the notion. 48

Since Patinkin's use of the real cash balance notion was by way of introducing it into the demand and supply functions for goods, this brought money into the utility funetion along with goods, thus linking money into value theory at two points: the cash Dalance approach being seen by Eatinkin as a type of wealth effect, it necessarily incorporated some elements of asset choice, and since bonds as well as money were brought into the general utility function, the whole asset spectrum was thereby encompassed within Patinkin's formulation of the utility or preference analysis of cholce. The conjunction of this general utility function with the posit of general narket equilibrium enabled Batinkin to sumarize his chain of argument into the relation between excess demands in goods and money markets, as e.g.: excess demand for goods necessarily implies a corresponding excess supply of money. 49

There is a good deal to be said for Fatinkin's formulation; it does capture one element of the tioney-joods exchange relation, in that, for any individual. an excess demand for goods must necessarily imply an excess supply of money, sinde he adjusts his holdings of money and goods through market exchange. But Patinkin nevertheless still finds it necessary, by aggregating up the individual demands for money, to arrive at some equilibrium 
relationship between the total stock of money that people want to hold and the 'given stock of money'. Moreover, his version of the money-goods exchange is distorted by a failure to recognise an essential difference between money and goods in an economy where money is not merely a numeraire commodity, as clower has forcefully pointed out. 50

But, before Clower, Gurley and Shaw had already taken issue with Patinkin on his 'neutrality of money' element, which implied that variations in either the 'given stock of money' or in the 'desired real balances' led to aujjustment processes which worked through price effects only, so that, after the equilibrating price changes which restored equilibrium between actual and desirec 'real money' (or, more generally, 'real wealth') the real exchange equilibrium emerged unchanged from its former state.

Gurley and Shaw's work 51 was based upon a more detailed view of the structure of financial institutions and of the associated financial assets marketed through non-banking financial intermediaries, dealing with the more liquid end of the financial asset spectrum as affecting the supply, demand and use of money as narrowly defined, through portfolio adjustment, interest rate and velocity of circulation effects. Their main tool was the concept of 'outside/Inside money' distinguishing between government or central bank debt, and commercial bank debt; (this distinction parallels a conceptual tool of the 'monetarists', the highpowered/ordinary money dichotomy).

One effect of the Gurley-Shaw work was to reinforce the growing uneasiness generally felt about the very concept of 'money'; the increased importance attached to 'near-moneys' and the work of the asset preference theorists of the Tobin-Yale persuasion stressed the portfolio adjustment mechanism as the main tool of analysis, which inevitably led to examination of money'g place in the asset spectrum with a consequent playingdown of the medium-of-exchange function of money, already weakly enough represented in the 'transactions demand' of the Hicksian cross. The concept of 'money' also ran into difficulties in the 'monetarists' work, partly because Friedman had felt 
obliged to include in his definition of money tine as well as demand liablilties of banks, thus obscuring one aspect, thought to be inaportant, of the interest effect on asset-holdings: 52 and partly because of the general tendency of the 'monetarists' to attach importance to wealth and interest effects in their 'dernand for money' functions. 53

Thus the concept of 'money', which had seened clear enough in pre-Keynesian ilterature while 1 t was being approached mainly from its means-of-payment function, became vaguer and more obscure as, from the introduction of Iiquidity Preference on, the increasing emphasis on the asset function led to a growing confusion between the concepts of 'money' and 'Iiquidity'; this confusion - which is largely unresolved today, led to attempts to define 'money' in terms of 'Iiquidity', so that no definite meaning could be attached to elther term, 54 to attempts to measure money in its narrow means-of-payment aspect, while using it in a theoretical context stressing asset preferences, which placed all the burden of explanation on to the velocity of circulation; to a concentration on simple-minded high-powered money concepts; 55 to a general disgust with monetary theory and a concentration on the income-expenditure side of the Hicksian cross, which led to a preference for Ilscal as against monetary policy in a context in which nelther 'income' nor 'expenditure' could be given any definite meaning, in the absence of a monetary nexus concept. 56

One important development steming most directly from the concentration on the asset function of money was a series of detailed investigations of the gtructure of interest rates: 57 this field is germane, not only to the Iiquidity Preference approach, but to the other side of the Hicksian cross reflecting the importance in Reynes" General Theory of the relation between short and long rates. Whe latter has also received some attention in examinations of evidence bearing on the question of how important interest rates are as factors in actual investment decisions, a crucial point in Reynes' own formulation.

The 'monetarist counter-revolution' developed more airectly from the older tradition of the cuantity Theory, seen by modern 
Quantity Theorists in the 'denand for money' aspect of the Carbridge formulation. Despite continued skimishing between 'Keynesian' and 'guantity' schools, and however differing their assessments of what importance attaches either to monetary behaviour in the private sector or to monetary policy, they have in common the formulation of monetary activity in termas of the 'demand for money' and its counterpart, the 'supply of money'.

Studies in 'The Demand for Money' are now a staple of monetary theory, ${ }^{58}$ in Britain as well as in the United States. The spread to Britain is no doubt due to many factors, but two influential ones can certainly be seen in the emplczment in Britain (ús elsewhere) of American-trained econometricians, and in the dissenination of "Amerlcan" approaches by some teachers, notably K.G. Johnson.

In a broad view, demand-for-money approaches may be seen as generally asking the question: what determines the amount of money that people, in the aggregate, want to hold? Differences of opinion arise from the answers offered to, and the relative weights given to, the following two questions:

(i) If the amount that people want to hold differs from the amount of the 'given stock of money', what adjustment mechanisms operate to restore equilibrium?

(ii) What determines the 'supply of money'? or, in the form that some prefer, what scope and power has the monetary authority to control the supply of money?

There is some difference in the implications for policy in the way in which these questions are seen and the way in which answers are formulated, since if the answers rest upon some direct relation between the 'given stock of money' and the level of prices (either directly through the Quantity Theory presuming some relatively stable velocity, or through the expenditure-price adjustments generated by the real balance 
effect) then the efforts of monetary pollcy are seen as requiring a manipulation of the money stock so as to arrive directly at an 'equilibrium stock" (or rate of growth) of money, if, on the other hand, the answer rests upon an adjustment occurring through interest rates, preaicated upon some non-neutral view of money which reguires that aggregate demand - particularly investment demand - should not be regarded as independent of the level of Interest rates, then this implies that the monetary authority should manipulate the supply of money in order to control interest rates.

Putting together with this the income-expenditurs echool operating minly on the real side of the Hicksian cross, the current state of monetary theory offers at best a conflict of views about how monetary policy needs to be conducted, and at worst an unrelated series of conjectures based upon a theoretical framework which is not even defined for, and hence cannot take cognisance of, the very entities (prices, monetary effects on real investment and output, wage levels and employment) that it purports to be examining. We consequently have only a 'black box', whose input terminals are the instruments of policy and the choice-theoretic basis of asset-holders' behaviour, and whose output terminals are the behaviour of the familiar macro aggregates derived from national income and finaneial data and the indexes associated therewith. The processes that the theory is ostensibly set up to analyse all take place within the impenetrable concealnent of the black box. We have thus to rely for what passes as evidence upon statistical correlations between the observations made upon events at the input and output terminals, which may serve for ahort-term predictions but can offer no observation of the interconnections, causal processes and transmission channels whose nature and action remain subject only to untestable conjecture.

There have at most times during the period under revisw been some who, imbued with the idea that economics ought to make sense before rigorous formulation is attempted, have remained apart from the rigid formalisms of the monetary mainstreami Robartson in particular preserves more of Thornton's type of approach, and 
cextainly carried on his tradition of distinguishing clearly between money and goods in an explicit institutional setting: Hayek and Hawtrey may also be seen as carrying on this tradition. 59 But in the normal course of events any contribution to thought in an area of study is interpreted and assessed in the terms of the currently accepted paradigm, and 1f, with whatever distortion, it cannot be seen in terms of that paradigm it inevitably gets overlooked, and any valuable insights it may have had neglected. 60

When that current paradigm is a stereotype of obsolece ideas fixed in a rigid framework, which is innocent of institutioial context or internal processes, whose accepted status as a theoretical structure rests ultimately on an appeal to the algebra, and whose methods of hypothesis testing consequentiy rest on applications of the (mainly regression) techniques of econometrics to the highly guestionable numbers used as data, even where there are some useful ideas initially present their expression in that paradigm cannot fail to squeeze out. any substantive content.

It is therefore a hopeful sign for the future of economios that so many misgivings about the current paradigm itself are being expressed. 61 But misgivings are not enough. If they are not to suffer the fate of all well-intentioned platitudes, they must be substantiated by alternative views and practical suggestions.

Before we can advance, it seems to me, or even before the currant post-Keynesian work can be properly, interpreted and assessed, we shall need to go bark to a more adequate view of the monetary nexus in a modern economy. Once we have apelt out the fundarental notions which are to be expressed in the theoretical structure we can begin to develop a view about which of the functions of money are to be taken as most important for analysis and empirical examination; this will need to take note of the alte-native views of Hicks and clower according to whether the key function of money is to be taken as 1 ts asset function or its means of payment function, supplemented by discussions from Newlyn, Yeager and Clower about the characteristics by which what is money may be unambiguously identified. 


\subsection{THE MONETARY NEXUS}

2.21 Monetary Expenditures and the Stock of Money

The distinction which received monetary theory makes between the 'supply of money' and the 'demand for money' may be seen as attempting to separate out two different areas in which the corresponding monetary mechanisms of adjustment are said to operate. The first concerns the mechanisms through which the instruments of policy operate on the proximate objects of control, of which interest rates and the stock of money may be taken as examples. The second concerns the mechanisms through which these proximate variables are thought to operate on the ultimate objects of monetary policy, of which prices and employment are examples.

It is arguable how far this separation can usefully be followed, and there is a good deal to be said for giving more attention not only to the mechanisms on the supply side, ${ }^{62}$ but also to their interaction with the mechanisms on the demand side. Certainly, when this separation is carried to the point of neglecting altogethex the process by which money gets into the hands of firms and employees ${ }^{63}$ one wonders whether the models so constructed may not be dismissed at once as purely frivolous. More than this is involved, however, and the point is taken up below.

For the moment, it is impossible to centre attention on all the cetails at once, so we begin by looking at the mechanisks of the second type, whose theoretical underpinnings have been set out by Hicks. ${ }^{6}$ Hicks sets his analysis in terms of the paradigms of equilibrium and of value theory, placing explicit stress on the idea of choice involved in the second. He begins, as did Keynes, by separating the money stock into two comprrerts; the first is that component required for transacilons, and the second is the residue available to be held as an asset. 65 His key argument, within 
this framework, is that the transactions component, while it may be "quantitatively much the larger part", is not held as a deliberate act of choice on the part of the holder, whereas the other part is held as the result of a deliberate act of choice, "and this voluntary part, whatever its size, is tremendously important. For it is through the voluntary part that monetary disturbances operate, and it is on the voluntary part that monetary policy must have its effect ${ }^{n}{ }^{66}$

This leads at once to the view that, of the functions of noney, that of being held as an asset is the analytically important one, while the other main funotion, that of operating as a medium of exchange, is analytically of no great significance. To put it another way, the important aspect of money is seen in its relation to other forms of asset holding to which it is an alternative, rather than in relation to goods or services for which it might be exchanged. A theory so concelved can obviously have no major role for the monetary nexus of the market to play, except in the speculative market for financial assets.

What is involved in rejecting Hicks' argument and the theoretical position to which it leads? one can, while accepting the framework of equilibrium and value theory, reject Hicks' vien that no important choice elements are involved in the use of money in transactions; but it is not easy to see how one could then apply to the transactions component all the apparatus that choice-theoretic approaches have applied to the asset component, involving ideas of liquidity, risk and return. Moreover, one cannot deny that in practice the bulk of an enployee's aisposable income is held in cash to meet disbursements between pay-days. At first sight it may appear that the Monetarists offer an alternative view to that of Hicks; but, as Weintraub argues, 67 the monetarist view is, at bottom, a view that money does not matter except when the monetary authority uses the wrong rule. The monetarists have in fact common ground with Hicks in that they regard the mechanisms operating through the transactions component as no more than transitory disequilibrium phenomena. 
J1timately, then, we are brought to the question of abandoning the paradigt of equilibxium, if a more important place is to be given to the use of money in goods-market transactions. Since economies are frequently observed in periods of disturbance and rarely, if ever, in periods of equilibrium, there is in any case much to be sald for abandoning a paradign which must lead to a neglect or a distortion of most of the economic events which occur. In the terms of either the asset approach or the monetarist approach, a concentration on aisequilibrium would undoubtedly focus more attention on the transactions conponent, but since these approaches have shown little interest in disequilibriun the models are not well defined for adjustments auring aisequilibrium, other than those required to return the system to equilibrium, and can offer little help in examining paths of adjustment auring persistent, and changing, diseguilibrium.

One might feel more reluctant to part with the asset approach to money if it led proved fruitful in yielding wellconfirmed explanations of the mechanisms at work, or if it had at least givan rise to a coherent body of theory. In fact, it has not even achieved a reliable and unambiguous definition of 'money' and it is becoraing increasingly clear that an operational definition of 'money' cannot be based upon its asset function. Certainly, if 'money' is defined in tarts of 'llquidity' then no definite meaning can be attached to either term. 68

Newlyn (1964) sees cleariy the need for an operational definition of money, 69 and is surely correct in asserting that a distinction between money and near-money is much more definite if the line is drawn on the basis of the means-ofpayment function; but his analysis runs into difficulty when in looking for some method of identification he develops the 'neutrality' aricerion, which he states as follows: "Assets can be uniquely identified as noney (medium of exchange) if, in financing payments, they are neutral, that is to say, the aggregate of the class of assets to which they belong remains the same and there is 130 repercussion in the market for loans".70 
This is confusing, because it seems to rest upon a prior identification of 'money' in terms of its asset function: how else could its neutrality with respect to the rest of the asset spectrum be established? It comes alose to distinguishing money as a non-interest-bearing asset, which places the analysis under fire from the arguments ${ }^{71}$ with which Hicks rejects this distinction; it is not even necessary, since what is in fact used in any particular place at any particular time is surely open to more direct observation by anyone acquainted with the commonsense facts.

As Yeager (1968) comments: "....no mere definition should deter us, when we are trying to understand the flow of spending in the economy, from focussing attention on the narrow category of assets that actually get spent". Since Yeager, despite this, goes on to embrace the neutrality criterion, and indeed to demonstrate how capable it is of detailed application, one can only suppose that he attaches priority to his evident preference for a definition of money which is constant from time to time and from place to place. But that battle is lost before it is begun; it can hardly be questioned that in meansof-payment terms what is 'money' does vary from time to time and from place to place; even for the same country at. the same time, what is ased as a means of payment between individuals is not what is used as a means of payment between banks, and except in the special case of a country whose domestic currency is also an international intervention currency, both differ from what has to be used to settle international debts.

Yeager is right, too, when he attaches importance to the manner in which people acquire and dispose of assets (in terms of actual market processes), but misdirects our attention when he associates this with a demand for cash balances. This tendency for spending to be associated with cash stocks rather than flows is widespread, and is given more attention below.

Clower (1967) seems to come closest to an analytically sound definition of money which is also operational, and his 
arguments in support of basing this definition on the means of payment function of money are surely convincing. He shares the prevailing view that money needs to be brought explicitly into the domain of value theory, which constrains him within the equilibrium structure developed along marginalist lines. His basic disagreement with Hicks' view of money (as expressed in the discussion of the two triads in Hicks, 1967) appears at rirst sight to be about whether the individual's utility function can be applied to money spent as well as to money held, although this point will be examined in the light of the ldeas explained below.

First, this is a convenient point at which to exanine Clower's later suggestion ${ }^{72}$ that the definition of 'money' should include trade credit. This suggestion is usually met in the confused discussions of 'liquidity' approaches to money; Clower's discussion is on the contrary so lucid that the anatomy of his analysis - along positivist lines - is worth highlighting.

The analysis begins with a definition of the theoretical term, relating it to the way in which it is to be used in the propositions of the theory: "money will be defined ${ }^{73}$ theoretically in terms of explicitly postulated restrictions on trading alternatives that assign a special role to certain commodities as payment media in organized markets". (These commodities might depend upon custom, as well as upon law.) From the theoretical term we have to pass to the corresponding observational term, which reguires a specification of interpretative rules or rules of correspondence: "It is one thing, of course, to establish a theoretical definition of money and quite another to decide what collection of objects in the real world should be considered to correspond to this definition". Two questions are raised, requiring us to ascertain (a) what, in the area to which the term is to apply, constitute the 'organized markets' and (b) which comodities 'routinely serve as means of payment in such markets'. Though difficult, 'both can be answered satisfactorily in relation to the objectives of any given 
investigation by direct inspection of trading patterns and payment procedures in various sectors of the econony'. Finally, in order to guide us in deciding whether a given object does or does not 'routinely serve as means of payment' we have the rule: "whether the tender of any given financial instrument permits a buyer to take delivery of a commodity from a seller".

This leads him, applying the given criteria, to conclude that: "For the United states and the United Kingdom, for example, it seems clear that for most practical purposes, 'money' should be considered to include trade credit as well as currency and demand deposits".

Two difficulties are immediately apparent: the interpretation of 'financial instrument' requires a distinction between instruments of security, instruments of title, and instruments of transfer; whatever may be said about these in general, what is germane to the issue here discussed is bound up with the status of a promise to pay; and the interpretation of a 'cormodity' usually extends in economic discussion to services, particularly those of labour. This similarly involves the status of a promise to pay, but in addition raises the question of whether labour markets ought to be included in the 'organised markets' to which the rule set out above is meant to apply.

The status of a promise to pay is directly relevant to the delivery criterion, and so lies in the heart of the matter. In trying to guess why clower acopted this rule, one can see a possible train of thought in following up the logic of $\mathrm{his}$ formulation of the income and expenditure constraints. ${ }^{74}$ Key statements axe: "The expenditure constraint asserts that all (net) purchase offers must be backed by a readiness to supply money in exchange" and "... the total value of goods demanded cannot in any circumstances exceed the amount of money held by the transactor at the outset of the period. Our definition of choice alternatives thereby captures the essential meaning of the traditional (but curiously nonmodern) contention that 
demand in a money economy is effective only if it involves a combination of desire with money purchasing power".

In terms of common background knowledge of the economies specified, it is an undeniable fact that purchases are quite widely raade on credit; if the theory is to 'make sense' in terms of that background knowledge, it must accomnodate the fact; presumably clower takes this to imply that 'effective demand' must include demand for goods bought on credit, which in turn requires credit to be brought within the definition of money.

This rescues the theoretical formulation from an apparent conflict with fact, while preserving the concept of "effective demand" in a more adequate view of a modern economy. But it now seens to be at loggerheads with the view of money as something which may be used to settle a debt, for in terms of the same background information it is also an undeniable fact that this difference does exist between 'money' narrowly defined and credit: that when money is paid over, it extinguishes a debt, whether in respect of goods now delivered or goods delivered in the past against a promise to pay; but when a good is sold on credit the execution of a promise to pay creates a debt, which is Jater to be extinguisisec by the payment of money narrowly defined.

In the normal course of business, the extension of credit is conditional upon the expectation that the purchaser will be willing and able to meet his obligations, which is not a matter of the transaction alone but of the purchaser's general probity and solvency. ${ }^{75}$ In the long run purchasers on credit must acquire enough money (in a narrow sense) to meet their obligations. Thus, apart from fraud and theft, credit operates only as a means of deferring the offer of money, not as a substitute for it.

To make matters clear, two points ought to be made explicit. The first is why we distinguish between a claim on a bank in the form of a demand deposit and a claim on an individual in the form of a promissory note or an acceptance 
on a bill; we call the first 'money' on any definition seriously considered, while the second is usually called 'borrowing', although both are debts. Now there is no a priori reason to distinguish between the promise to pay of a private purchaser, a goldsmith, a bank, a finance company, or a central bank; the only possible basis of such a distinction Is what, in some given domain, transactors do in fact accept as extinguishing a debt. And the plain fact of the matter is that if I buy a suit and proffer a cheque, provided that this is duly honoured by the drawee, the sale is treated as a 'cash' sale; whereas if I gign a prcmissory note a debt is recorded until payment is received.

This brings us to the second point. A cheque is not itself 'money', i.e. a claim on a bank; it purports on the face of it to transfer such a claim, implying that such a clain exists; if the claim does not exist, then on presentation the drawee will dishonour $1 t$, answering 'no account' or 'insufficient Eunds' or whatever is appropriate, in such a case, although the vendor might have recorded a cash sale on receipt of the cheque, he will have when the cheque is dishonoured to recognise that he has unwittingly extended credit, and to record a debt still to be collected from the purchaser. Thus while the acquisition of an actual bank claim is unequivocally a cash receipt, the aqquisition of a cheque in payment may be recorded as a cash receipt contingent on the drawee bank's concurrence and the actual receipt of the claim on a bank which the cheque in effect promises.

This seens to suggest that, although the actual business procedure which distinguishes in its records between 'cash sales' and 'credit sales' is an important source of a criterion, it is not alone sufficient where businesses tend to accept chegues and other purported forms of cash payment without, on the face of it, overtly recognising their highly contingent nature as actual cash payments. Some firms do recognize this, and are reluctant to accept cheques except 
from customers they know well; but it would be a rare firm that is reluctant to accept a bank deposit in a reputable bank as payment, provided it is sure that that is what it has got.

Credit cards can be dealt with along the same lines. Where they do not carry some undertaking by the credit card company, their main force is in providing support or corroboration to the purchaser's claim to be trustworthy. But where the credit card carries some independent undertaking by the credit card company to meet the payment, then the purchaser's ability to pay is no longer a factor, since the vendor now reposes his confidence in the probity of the credit-card company. In these circumstances, the credit card company is performing a financial service parallel to that provided by an acceptance house or by a bank confirming a letter of credit.

In short, a vendor who has, sufficient reason to believe that the cash will be forthcoming, i.e. that someone - whether it be the purchaser or not - has the money to meet and will be willing to meet the obligation, may record the transaction in his books as 'cash', although he knows, as a strict matter of fact, that he has not yet been paid. And in this context, what is meant by 'money' is unambiguous; it reduces to legal tender or to an actual claim on a reputable bank, 1.e. to 'money' as narrowly defined.

There is one final polnt in this connection. There is invariably, in such transaction $s$, an element of waiting, and during these periods of waiting credit is in fact involved; the normal business practice in New Zealand is to require an obligation to be met by the following 20 th of the month if it is to be treated as a cash payment; after this the debt becomes overdue, although not usually attracting an interest charge. There may thus, even in the most reliable cash transactions, be a considerable amount of very short-term credit operating, some of it extended involuntarily by the vendor. 
In all of this, it appears that the distinguishing characteristic of a means of payment is more clearly seen in relation to its ability to extinguish a debt than in the ability of holders of a means of payment to get possession of goods; that is to say, if we define a means of payment as "that which is generally accepted, in the transactions under observation, as extinguishing a debt" then the delivery criterion reduces to dropping the restriction that the exchange of money and goods requires simultaneity, and delivery may be made either against immediate cash payment or against a deferred cash payment when the vendor has sufficient grounds for confidence that the obligation will he honoured in due course. If, on the other hand, we require simultaneity of money-goods exchanges, then clower's delivery criterion does require trade credit to be called 'money', and we can no longer regard money as something able to settle a debt; this would, in my view, be a great loss to the theory and a source of confusion and obscurantism.

Moreover, since trade credit does not, in any form, provide an adequate substitute for cash in paying wages, it is still necessary to retain the narrower definition of 'money' as a means of payment in the factor market; factor markets would hence have to be excluded from the 'organized markets' to which the monetary theory so constructed was held to apply. ${ }^{76}$

The concept of 'effective dernand', then means a demand that can be made effective in the market either by immediate cash payment or by convincing the vendor that the debt can and will be discharged in due course of business. We thus return monetary theory to the point at which Thornton started his analysis; 77 just as the 'double coincidence' of wants is not a necessary pre-requisite for exchange, so the simultaneity of money-goods exchange is not a necessary pre-requisite for the market nexus; both in fact can be seen as sides of the same coin, whose unifying idea is that economic processes occur over time, and nothing but the comitment to a simultaneousequations approach in the paradigm of statio equilibrium could prevent us from seeing this. 
Thus the major drawback to Clower's expenditure and budget constraints, and the reason his logic appears to have forced him into this awkward position, is that his model is not defined for a time dimension. The richness of variety in economic processes cannot be well captured in any simple period analysis, but for the purpose in hand a simple reformalation of Clower's suggested budget constraint is adequate to bring out the point at issue. Taking as our 'period' something fairly short, as e.g. a inonth, we have in essence:

writing the $f^{\text {th }}$ transactor's net purchases for a period as

$$
\theta_{j t}=\sum_{i} p_{1 j t} x_{1 j t}
$$

and his available money for the period (money held at the beginning plus money recelpts during the period) as $M_{j t}$ we would, in the absence of credit, formulate his budget constraint as

$$
Q_{j t} \leqq M_{j t}
$$

the equality holding only when no money is held by the $f^{\text {th }}$ transactor at the end of the period. With credit, however, we have

$$
Q_{j t} \leqq M_{j t}+D_{j t}-R_{j t}
$$

where $D_{j t}$ is his new debt incurred during the period and $R_{j t}$ is his old debt repaid during the period. Since, in practice, $D_{j t}$ is a function of some previous history of debt behaviour, then for some $n, R_{j, t-n}$ would in part determine the size of $D_{f t^{*}}$

We can accommodate the fact of credit purchases, therefore, without being obliged to call credit 'money'; we have, moreover, now brought in explicitly the idea of credit itself involving the creation of a debt which can be extinguished only by paying over money, in the narrow sense. This opens 
up the analysis for an enquiry into some pertinent aspects of credit, for example the extent to which the need to meet currently due debts might restrict the effectiveness of trade credit as a means of evading a tight monetary policy. This may, in part, underlie the results found by Coates (1967). It is true that the lengthening of the period of indebteaness, measured by the volume of deferrals of repayment (whether voluntarily granted by lenders or not), does seem, in the short run, to be associated by some observers with monetary restriction. But this does not contradict the assumption made above that $D_{g t}$ degends in part on some $R_{f, t-n}$ since however the volume of overdue debts may reduce the $f^{\text {th }}$ transactor's credit-worthiness and hence $D_{j t}$. if he is simply not getting the money in there is no way in which repayment can be made; without driving hira into bankruptcy, all the lenders can do is to refuse to lenä híi any more.

But there is anothex reason which may be in practice more significant. Whatever scope a businessman has for getting round a tight monetary policy by using trade credit more extensively, he still has to meet his payroll in cash. This fact is easily dealt with in the budget constraint as amended, since although he cannot evade the need to find cash for his payroll, he may be able to get this from his bank or from some other lending agency, provided again that his credit remains good; or he ray, again if his oredit is good, accept on credit goods that he would otherwise have paid cash for, thus diverting to wage payments cash normally kept or borrowed for other expenses. Either is a short-term expedient, since if his cash does not come in at a rate sufficient to service his debts and maintain his credit status he will soon find himself turned away and thus unable to meet his payroll.

Clower is, of course, looking at the micro or behavioural basis of monetary behaviour, while the exclusion of labour markets and factor payments from the analysis has more serious consequences when viewed from a macro standpoint. But, even from the point of view of micro aspects of consuner behaviour, the concept of 'money' as something used to extinguish a debt is surely important enough to merit retention. 
The amendment suggested above does succeed in retaining this important concept, and does so without forcing us either to relinquish clower's idea of a 'pure money economy' or to pretend that debt does not exist. That, in doing so, it imposes two inescapable requirements, that the analysis be referred to a context of monetary institutions, and that it. be dynamic, seem to me to be gains rather than losses.

In view of the difficulties of moving from an analysis of money at the micro level to an integrated macro approach, there is something to be said for tackling the problem of money from both macro and micro standpoints, as simultaneous and complementary enquiries; there is certainly no reason why the two approaches need be regarded as mutually exclusive, and the task of providing suitable transformations between the two constructs, so that what makes sense in one may be required also to make sense in the other, may well be the most useful goal of monetary theorists at present.

Similarly, there is finally no need to oppose the asset preference view to the transactions view of money as though they were mutually exclusive constructs. If the 'Demand for Money' based on the asset function had referred to Keynes' $M_{2}$ only, as Hicks implies it ought to have been, ${ }^{78}$ we might have been spared much fruitless squabbling. Thus to see $M_{1}$ as requiring more detailed spelling out in terms of the processes of exchange in the goods market need not be taken to imply that the decision functions relating to $N_{2}$ are not worth studying, merely that they cannot alone describe the whole of monetary behaviour in a macro context. Since, in such a view, more detailed study of the market nexus in money-goods transactions might suggest the need for a similar extension of enquiry in money-bonds transactions, a complementary development of the two main uses of money would be attainable.

But the two markets must be closely intertwined through the use of money in both. In the first place, we may defer to the views of Hicks' $\operatorname{critics}^{79}$ and decline to separate out two identifiable components of the total money stock, so that $M_{1}$ and $M_{2}$ are seen, not as different sums of money, but as 
alternative and competing uses for the same sum of money. In the second place, the amount of goods produced depends, among other things, on the extent to which producers can finance the necessary operating expenses; in the search for alternative methods of finance, they must encounter the effects of financial operations relating to $M_{2}$, not only in interest rate effects but in the amount of loanable funds, in the form of money as narrowly defined, accessible to them at the time required. But the amount of loanable funds is not dependent only on the $M_{2}$ activities, since the amount of money available to producers depends not only on what people save and make available through lending, but also what money they pass over in the $M_{2}$ activities.

We thus come to accept a view not unlike that of Reynes, in that from the point of view of the monetary effect on producers' decisions it is ultimately less important to distinguish between money spent and money lent back into circulation, than to distinguish these fxom money hoarded by someone who will do neither. The difference is that this effect is not necessarily transmitted through interest rate effects; its transmission through credit availability may be more important.

A more adequate view of money's place in economic activity is thus seen to require a more detalled inspection of the vay in which monetary flows occur in all types of transaction, from the initial way in which expenditures, not only by consumers but by producers, are Iinanced, to the way in which the monetary proceeds of maxket exchanges are used by the razipients.

2.22 Transaction Flows and Money Stocks

An economic transaction consists of an exchange of money for goods (and services); ostensibly, orthodox value theory recognises both sides of the transaction in 1 ts separation of producers and consumers, but it makes no attempt to separate 
out the things exchanged, which would require an explicit distinction between the goods that are sold and the money that is paid for them. This does not at all imply that 'real' theories of production and exchange can be developed independently from a theory of money, since the behavioural functions governing the real processes cannot ignore the question of financing. But, since the flows of goods and the corresponding flows of money occur in opposite directions, it does imply, among other things, that we must know at any point in the analysis whether we are talking about goods or whether we are talking about money.

We are not precluded from concentrating attention from time to time on monetary or real aspects alone, and indeed some preliminary separation in order to fabricate the several parts of the whole structure is necessary, provided we are careful to bear in mind that no explanation of economic activity can make sense in terms of any one part alone. At this point, therefore, we concentrate on the flows of money expenditure.

In oxder to study the flows, we need a more adequate concept of 'flow' than can be provided by the uswal interpretation which sees a 'flow' as equivalent to the net change in a stock variable between two end-period states, which has the effect of defining out of the model the whole intervening course of events. This requires a repudiation of Johnson's view: 0 that any new development must be conducted within the same equilibrium structure that orthodox theory binds itself to, for a reason expressed by Leifonhufvud as follows: "comparative static experiments with the standard simultaneous equation model cannot yield any statements relating to the process connecting the initial and terminal 'equilibria'".81

What is required is spelt out more positively (in a migroeconomic context) by Schoenman: "....the essential interest is not in the rinal consequences which, through mathenatical deduction, flow from the initial premises, but in the economic 'solution' per se, 1.e. the specific path 
(over time) of the economic adjustrent. This process would be specifled and then followsd in 1 ts own terms; one would account for each step because, as we have said, each step has a specific bearing on the adjustment as well as a meaning per se". 82 The actual place of time in the analysis involves greater difficulties on the real side of economic processes, and a fuiler discussion of the time element is deferred until Chapter 4 ; it is mentioned here to indicate that the basic concepts of monetary activity under examination need to be expressed in a form which will permit a more detailed account of monetary processes through time in a non-equilibrium framework. In particular, more explicit attention needs to be given to the process by which money enters and leaves the circular flow, and to the fact that in a modern economy money is typically created as the result of an expenditure.

Instead of beginning from a micro study we shall proceed directly to the task of opening up the black boxes of macro theory. In particular the black box designated $M$, or 'the stock of money', needs investigation. In order to keep our ideas tidy we shall construct a simple schema in which to order them.

We begin with two simple tautologies. First, when money is paid out in the course of a transaction it must either have been previously held by somebody as money or have been newly created. Secondly, when money is received in the cource of a cransaction it must aithar be held by somebody as money or be destroyed. We can therefore classify the money expenditure of a period, written as $\mathrm{g}$, into two groups: those siade in old money, i.e. money previously held as money, written as $B M$, and those from new, 1.e. newly-created money, written as ES. Similarly, the money receipts in a given period, written as $R$, can either continue to be held as money, writter as $R M$, or be disposed of in some way which reduces the money supply, written as RS. We have thus the basic tautologies of the system: 


$$
R \equiv R S+R M
$$

and, of course, $B \equiv R$.

The components of $S$ and $M$ clearly depend upon the definition of money: provisionally, we shall define money in the orthodox way as comprising notes and coin in the hands of the public together with demand deposit liabilities of the commercial banks. This definition will require examination, but for the moment let us examine the sources of payments and the disposal of receipts in terms of this definition.

In New zealand additions to the money supply as provisionally defined can arise in government expenditures, in the acquisition by the commercial banks of an asset, or in the drawing down of time deposit liablitties of the cumercial banks. We can therefore express $E S$ as the sum of its components, i.e.:

$$
E S \equiv E G+E O+E A+E B+E T
$$

where EG: Payments increasing liability to or decreasing deposit with the Central Bank. ${ }^{83}$ Open market purchases by Central Bank.

EO: Purchases of foreign currency or gold by the banking systam.

$E A$ : Payments to the debit of overdrawn or loan accounts at the commercial banks; bills discounted with commercial banks.

$B B$ : Payments by commercial banks for purchase of bonds.

ET: Repayment of time deposits by commercial banks.

Similarly, we show Ek as the sum of its two components:

$$
E M \equiv E D+E N
$$


where: $E D$ : Payments to the debit of demand deposits with commercial banks.

and: $\quad E M$ : Payments from notes and coin held by the nonbank public.

Receipts from these transactions can be disposed of in ways that may reduce the money supply, viz.:

$$
R S \equiv R G+R O+R A+R B+R Z
$$

where: $R G$ : Recelpts used to reduce liablilty to or increase deposit with Central Bank. Open market sales by Central Bank.

RO: Sales of foreign currency or gold by the banking system.

RA: Repayment of overdraft or loan accounts; payment of bills held discounted by commercial banks.

$R B$ : Purchase of bonds from commercial banks.

RT: New time deposits and time deposits renewed at maturity with commercial banks.

The remainder of receipts are disposed between the two forms of money-holding:

$$
R M \equiv R D+R D
$$

where: $R D$, Receipts held in the form of demand deposits at commercial banles.

RN: Receipts held outside the banking system in the form of notes and coin.

Thus both ends of a transaction impinge upon the money supply' no statement can be made about whether a given transaction actually increases or decreases the money supply until one knows both the source from which the spender, or buyer, finances his expenditure and the disposal which the recipient, 
or seller, makes of his receipts. The flow from various sources can be set out in the following matrix:

\section{TRANSACTIONS MAZRIX}

(Sources of expenditure and disposal of receipts)

\begin{tabular}{|c|c|c|c|c|c|c|c|c|}
\hline & $\begin{array}{l}\text { Diaposal of } \\
\text { receipts }\end{array}$ & \multicolumn{5}{|c|}{ RS } & \multicolumn{2}{|c|}{ RM } \\
\hline $\begin{array}{l}\text { Souxces of } \\
\text { expenditure }\end{array}$ & & $\begin{array}{l}\mathrm{RG} \\
\text { (1) }\end{array}$ & $\begin{array}{c}\text { Ro } \\
(2)\end{array}$ & $\begin{array}{l}\mathrm{RA} \\
(3)\end{array}$ & $\begin{array}{l}\mathrm{RB} \\
\text { (4) }\end{array}$ & $\begin{array}{l}\mathrm{RT} \\
(5)\end{array}$ & $\begin{array}{l}R D \\
(5)\end{array}$ & $\begin{array}{l}\mathrm{RN} \\
(7)\end{array}$ \\
\hline \multirow{5}{*}{ ES } & EG (1) & & $x$ & $\mathrm{x}$ & $\mathrm{x}$ & $\mathrm{x}$. & $\mathrm{x}$ & \\
\hline & EO(2) & $x$ & & & & & & \\
\hline & $E A(3)$ & $\mathrm{x}$ & \multicolumn{3}{|c|}{ duadrant I } & & \multicolumn{2}{|c|}{$\begin{array}{l}\text { Cwadrant } \\
\text { II }\end{array}$} \\
\hline & $E B(4)$ & $\mathrm{x}$ & & & & & & \\
\hline & $\mathbb{E T}(5)$ & $x$ & & & & & & \\
\hline \multirow{2}{*}{ EM } & $E D(6)$ & $\mathrm{X}$ & & & & & \multirow{2}{*}{\multicolumn{2}{|c|}{ guadrant }} \\
\hline & $\operatorname{EN}(7)$ & & \multicolumn{3}{|c|}{ guadrant III } & & & \\
\hline
\end{tabular}

Inspaction of the transactions natrix raises an immediate doubt about the definition of the money supply as bank deposit liabilities plus notes and coin in the hands of the public. We are combltted to the view that the importance of money lies in its function of acting as a means of payment; now this surely implies that money changes hands in the course of a transaction. With money as we have defined it, only the transactions of guadrant IV fully satisfy this requirement. In guadrant II, the payment does not become money, as defined, until it is in the hands of the recipient, in fact, it is precisely because of this that transactions in Quadrant II have the effect of increasing the money supply. In puadrant 
III, the opposite occurs; a payment out of the existing money stock ceases to be money in the hands of the recipient, and it is because of this that transactions in Quadrant III have the effect of reducing the money supply! the net increase in the money supply over the period is simply the difference between the transactions in Quadrant II and those in Quadrant III. In Quadrant I, no money at all as defined changes hands. Let us inspect Quadrant I more closely.

If row 5 of Quadrant I were to contain a significant volume of transactions, distributed over the columns, this would imply that time deposits are widely used as a means of payment, without first requiring to be exchanged for money in the form of $D$ and $N$. This would be the case if cheques were freely drawn directly upon time deposits. This would surely imply that time deposits ought to be brought within the definition of money, which would remove $E T$ from $E S$ and include it instead in $E M$; similarly we should have to make $R r$ a component of RN rather than of RS.

Given the theoretical definition and the rule of correspondence, the question is an empirical one: whether time deposits are money reduces simply to the question: are time deposits widely used as a means of payment, 1.e. as checking accounts? In countries where the answer is "yes", then time deposits are money. Where the answer is "no", time deposits are not money and we must attribute to the public some power to create money unilaterally by moving from time to demand deposits. 84 Consider now row 3 in Quadrant I. Under the overdraft system this must contain significant elements in all columns. In fact, there is no a priori reason to suppose that payments against overdraft would be used for substantially different purposes from payrents against demand deposits, so that wo would in general expect $B A$ to be distributed over the columns in very much the same way as $E D .^{35}$

Could this be eliminated by taking bank overdrafts out of guadrant I by including them in the definition of the money supply, on the lines suggested above for dealing with 
time deposits? This would at once involve us in a contradiction. For, transactions in which a bank loan of $\$ 100$ created a deposit of $\$ 100$ would now appear in Quadrant IV, which would oblige us to say that the money supply remained unchanged. But in adding up the components of the money supply we would include the $\$ 100$ in both advances and deposits, so that we should have to say that money supply had increased by $\$ 200$. This contradiction does not arise in the case of time deposits, since they appear on the same side of the balance sheet as demand deposits. One way out of this would be to include unexercised overdraft limits in the money supply. On an analytical level this would be perfectly simple to do; but it would require placing an interpretation upon unexercised overdraft limits which they could not bear. It is frequently forgotten that they operate primarily as an instrument of advance supervision and control from the bank's point of view, rather than as a definite assessment of the drawings on overdraft to be made. Moreover, the increase in the money supply would then be recorded at the time the limit was granted, rather than at the time money was spent, which would distort the connection between money creation and money spending. And certainly banks prefer to draw a firm distinction between actual and contingent liabilities. 86

We therefore have the situation that we have some means of payment which is not money as so far defined yet which cannot be included in our definition of the money supply for reasons given above. This problem is soluble if we conceive of two types of money, the stock of money is clearly money as originally defined, and changes in this stock occur as a result of the decisions by the recipients of payments about the disposal of their receipts. The transaction by which a payment increases one overdraft and reduces another clearly must be regarded as involving a medium of exchange, which we must call money, distinguishing it from the other type of money by calling it flow money. It is of the nature of flow money that it exists only briefly during the course of a transacition; whether it yields an increase in stock monsy depends entirely upon the disposal of receipts which the recipient may make at his pleasure. Flow money, then, becomes 
equivalent to $E S$, and stock money to $M$, where the increment to stock money over any period is simply $R M-B M$. In broad terms, 'flow money' consists of undifferentiated claims on the banking system, not given specific form until the transaction is completed by the recipient.

No separate matrix for indicating changes in bank reserves is necassary: they involvo those elements in the matxix above which are marked by $x$. Clearly, over any given period of record the net increment to bank reserve balances will be the difference between the first row and column totals respectively, less any government or central bank payments made directly to or by the private sector in hand-to-hand currency, which in a New zealand context refers to notes and coin paid across the counters of the Reserve Bank other than by way of encashment of or deposit to trading bank reserve balances.

Writing elements of the transactions matrix as $t_{1, j}$ where the rows and columns are numbered as shown above, then trading bank balances will be increased by the amount

$$
\sum_{j=1}^{6} t_{1, j}-\sum_{i=1}^{6} t_{1,1}
$$

and banks' vault cash will increase by the amount of hand-tohand currency paid over trading bank counters in the purchase of some asset from the banks, less the proceeds of asset acquired by the banks (by purchase or lending, extended to include bank expenses paid in currency) encashed over the banks" counters, i.e. by

$$
\sum_{j=2}^{7} t_{7, f}-\sum_{i=2}^{7} t_{i, 7}
$$

then bark reserves, from both components, will increase by

$$
(E G-R G)+(E N-R N) \cdot 87
$$


It is at once apparent that any observed movement in $M$ over some period, measured directly by the difference between the two values of the stock variable at successive end points, may be explained by a variety of combinations of $R N$ and $E M$, which would therefore need to be examined however short the period intervening between the two end points. Since, moreover, it is $E M$ only that relates directly to expenditures, while $R$ relates to receipts, then it is to $S M$ that attention should be given if we are interested in expenditures.

It should be made clear that the introduction of behavioural assumptions would be entirely premature at this stage. The process of enquiry is seen as consisting of the exploration of a succession of problems; what is offered as an "explanation" at an early stage becomes itself the explanandum of a later stage; in the order here chosen, behaviour is seen as entering only at a late stage in the process, when the mechanisms of the black boxes have been sufficiently explored to set up definite explananda requiring behuvioural expldnations.

The first task of opening up the black boxes, which in this context implies finding transmission mechanisms relating the course of the stock variables to the ultimate variables of enquiry, is to describe the course that, in the aggregate, expenditures have taken over the period under review.

Once we have "explained" the course of sone major monetary stock variables in terms of the flows, we may then be able to look at the monetary flows themselves as requiring explanation, which undoubtedly will require consideration of the real flows, the institutional context and the initial states of both real and monetary stock variables. Only then, when a firmly specified explanandum is to hand, is it meaningful to ask why, in the specified setting, do people respond in this way rather than some other, having regard to the options previous ly established as being open to them at the desigrated points of decision. 
The simple schema of money flows set out above does enable us to get some trivia out of the way. For example, it is sometines said that people don't have to pay cheques into banks, since they can instead deposit them with nfi. Perfectly true, but what are the nfi thought to do with the cheque? The cheque is not a claim on a bank but an instrument purporting to transfer such a clain. The transfer is not conswamated, 1.e. the nfi has not received any money, until the cheque has been presented to the drawee bank and honoured by them. The matter of the nfi, as of trade credit, we look at below.

The implication that money is created usually in the course of an expenditure follows directly from the above analysis. To bring it out more clearly, we look at some other aspects of money in terms of the concepts of monetary orthodoxy.

The Demand for Money

If the "demand for money" is to mean anything at all, it is clear that it must be at least three-dimensional, by which I mean that it cannot be analysed in terms of less than three separate types of transactor, necessarily involving three separate and independent behavioural functions. To illustrate this, the transactions matrix may be cut down to simplified form, comprising two rows, $E A$ and $B D$ as defined, and the corresponding two columns, $R A$ and $R D$. The, money stock then becomes simply the sum of bank demand deposit liabilities, $D$, and increments in this figure reduce to:

$$
\Delta D=R D-E D \equiv E R-R A
$$

EA itself will involve two transactors, the borrower from the bank and the lending bank.

On the supply, or lending, side, the familiar bank multipliex applies, resting on these assumptions:

(a) bank demand deposit liabilities are generally used as a means of payment; 
(b) either by regulation or by convention, a fractional reserve requixement holds;

(c) A triangular interdependence holds among bank deposits, advances and reserves. 88

We may therefore construct a supply function for bank credit on the ordinary constrained maximisation principle, the maximand or objective function being supplied by some utility or profitability concept, and the constraint being supplied by the liquidity requirement. On the demand side, there will be a real demand for the goods and services upon which the proceeds of the loan are to be spent, and probably financial variables from the customer's profitability and liquidity functions. This yields a type of market framework for the determination of $B A$ as the equilibrium amount of bank advances derived from the conjunction of the bank credit supply and demand functions. I am not very fond of this type of approach, but it does seem to be a natural theoretical 
of the previous day, the gross flows $E D, E M, R D$ and $R M$, and in whose hands any particular bank claim may lie at the close of business; the change in $M$ over one day merely reflects the course of expenditures and the general state of accounts into which payments are made, than any specific desires about what Nought to be.

Hicks: undoubtedly takes this point, ${ }^{90}$ but does not seem to feel impelled to explore the implications for his "voluntary" component if the "transactions" component, which is in any case larger, is subject to fortuitous elements. Moreover, it seems to be fairly olear that if the "Demand for Money" refers at all to $D$ (bank deposit liabilities) it cannot mean a temand directly for $D$ as such, but must mean: given the expenditure flow, what w11l decide the allocation of receipts among the various forms of disposal, including $R D$ ? In the simplified model this will necessarily depend on whether the course of transactions directs the receipts into the hands of people whose accounts at the bank are in aredit or are overdrawn.

As soon as we introduce the idea of the nfi, however, we have the possibility that where the recelpts tend to get into the hands of people already in credit, they may well decide to lend their surplus funds to an interest-paying ingtitution, who in turn will lend the deposits to someone disposed to spend thern. Since the banks cannot lend out thair own deposit liabilities, the presence of a third party, the nfi, is necessary if idle funds are to be used for expanditures. By the same argument, in the context of a tight monetary policy, the activities of the nfi may be stimulated to the extent that no idle funds remain in the system, all of them being channelled into the hands of spenders.

In the more general model, the simple triangular relationship determining the money stock ceases to apply, and we really have to know more about the elements of the transactions matrix above. 
is long as we tend to think in terms of a given stock of money going around the circular Llow from hand to hand, the velocity of circulation seass to mean something, it also has associations with the very cormon idea that there is some thing which the banks borrow in order to lend out again. rhese idsas might have been valid when the thing was ascertainably specie, and may still be properly applied to nfi. It is true that a specie view of noney becomes more understandable when it is developed in the context of a country whose domestic currency is also an international intervantion currancy, since then for sone purposes it may be traced analogously to specie. But this still wili not do in relating the flow of domestic expenditures to the stock of money, since the creation and destruction of noney are continuously operating; anyone with even a passing acquaintance with the internal operations of a bank must be aware of the immense difference in order of magnituac between the gross daily flows of debits and credits to current accounts, and the net residual change that their difference bxings about in the levels of deposits and advanoes.

There seens to be some point in the idea when we consider the effect of the nfi in ahanneliling otherwise 1dle balances into the hands of the willing spenders. But since we can not only analyse this effect but also inspect $1 \mathrm{t}$ much more directly by looking at idle bank deposits and the shift between the damand and time deposits we really have no use for the term. It is a particularly dangerous term to use in conjunction with a single-dimensioned demand for money concept, since the fallure to take the gross flows into account leads to inevitable problems in relating the stock of money directly to the level of expenditures, and this in turn leads to a reliance on "changes in the veloaity of circulation" to explain discrepancies which otherwise cannot be explained. Ultimatoly, then, the function that this concept performs in the theory is purely that of a Melly's constant. 91 
Liquidity and the Real Balance Effect

There is in this area of discussion a considerable tendency to confuse the micro variables with the macro aggregate. At the micro level, an individual may meaningfully reckon into his available purchasing power any money as narrowly defined together with any easily realisable assets plus any credit available to him personally, but even the narrowly defined component of his "Iiquidity", i.e. his bank deposit, may be treated as fully liquid if and only if not all bank customers demand encashment of their deposits simultaneously. Individual liquidity, even in this narrow sense, hence is meaningful only on the specific condition that it is not aggregable into macro liquidity. Similarly, while an individual may meaningfully assess the worth of his "11quid" assets in terms of what they can be realised for, and what their proceeds will buy at current market prices, his justification for dolng so is necessarily that not all of such Iiquidity is actually realised and spent, for in that case he could hardly expect prices to remain unaltered, even were his initial assumption justified that his liquidity denands could in fact be satisfied along with those of everyone else. 92

Thus, if the "demand for money" is associated with either of these concepts, it is meaningful at the micro level only, and even then only upon the speaific condition that it is not aggregated. If, therefore, there is any macro significance in the concept of a voluntary demand for money, this can refer only to a tendency on the part of expenditure recipients to dispose of their bank clairs in cne way rather than another. and hence refers to the deterraination of $R M$, given the current level of monetary expenditures; no information about $M$ can possibly yield information about $R M$, unless in conjunction with information about the other gross flows involved. This seems to have the effect of removing the apparent aifference of opinion between Clower and Hicks, referred to above; both have in mind the individual (partial) equilibrium, but whereas Clower is talking about the determinants of $E S$ and $E M$, Hicks is talking about the determinants of RS and RM. 
The "High-powered Money" Concept

The concept, though not the name, may be traced at least back to Meade (1934); it was presented by Friedman and schwartz (1.963) as an independent 1dea developed from first principles, and used as the basis of his analysis by Cagan (1965), who referred it to both of the previous works (and also to Brunner and Metzler); it aay be said to have been given its definitive statement, as it is embodied in the theoretical basis adopted by the Chicago-st. Louis axis, in Meigs and Wolman (1971).

On the basis of a common construct, in which the money system comprises a specie foundation, a monopoly note issue by the Central Bank, and deposit liabilities of conmercial banks holding at least some of their reserves with the central. Bank, the works cited have the folloving two aspects in cormon: a set of tautologies derived from this monetary structure, and a warning about the status of these tautologies and their power to "explain" monetary processes.

This warning, however, seems to have been progressively less stressed from Meade to Meigs and Wolman. Meade ${ }^{93}$ says that his figures "must not be interpreted as measuring the change in the amount of money which would, in fact, have folluwed a given change in one of the proportions during the years 1925-30; but rather they are simply measures of the sensitiveness of the English banking system during those years (i.e. measures of what would have occurred if everything else had remained the same)". Cagan, while insisting that the ratios of his basic tautology "are only proximate determinants .... The behaviour of the three determinants alone does not 'explain' changes in the supply of money" seems, in the body of the work, to want to push it rather further, 94 and in view of their assertion that "Changes in three variables - the volume of high-powered money, the currency-money ratio, and the reserve-deposit ratio - therefore, can account for all changes in the money supply", Meigs and Wolman ${ }^{95}$ are clearly reading a causal effect into the basic tautology, despite their acknowledgement that "This is the accounting statement - 
the $C+I+G=Y$ or the MV $=P T$ of the monetarist view of the money supply process".

We take here tie identity as given by cagan: the crucial relationship is that between htgh-powered money, $n$, and total money supply, $H$, We have $H=C+D$, where $C+D$ is the sum of currancy and comercial bank deposits held by the public; $R / D$ is the bank reserve/deposit ratio, so that $H=C+R$, from which the following identity is derived:

$$
M=\frac{I}{\frac{C}{M}+\frac{R}{D}-\frac{C}{M} \cdot \frac{Q}{D}}
$$

It is immediately clear that the status of this tautology depends upon whether there is:

(a) any reason to suppose that there is a causal connection from the variables on the right hand. side to $M$, and

(b) any way of establishing the processes by which $H, C / M$, and $R / D$ are set, independently of the constraint imposed upon them by the tautology.

(This is guite apart fron the more fundamental question of whether there is any reason at all for attaching importance to the size of $M$. As the foregoing attempted to show, only the processes whose interactions lead to the residual end states of the several stock variables are capable of explaining them.)

Since the transactions table is defined for flows rather than stocks, the ratios of the tautology have to be expressed as changes in order to interpret them in this model. Making these amendwents, then, we have:

$$
\Delta M=R D+R N-(E D+E N)
$$




$$
\begin{aligned}
\Delta C & =R N-E N \\
\Delta R & =(B G-R G)+(E N-R N) \\
\Delta D & =R D-B D \\
\Delta E & =\Delta C+\Delta R \\
& =(R N-E N)+(E G-R G)+(B N-R N) \\
& =E G-R G
\end{aligned}
$$

Thus "high-powered" money is the net cash flow from the Central Bank into the private sector. This may in part be taken as autonomous with respect to the private sector, in the sense that gross payments to meet state and Marketing Board operations are so, while receipts into the Central Bank from the private sector, $R G$, will in general be partly autonomous; but since tax payments constitute a large component of $R G$, this presumably will be dependent upon the general level of incoines, given the tax rates; certain other receipts, e.g. the beer and betting taxes and customs and excise generally, may be supposed to depend on levels and patterns of expenditure. But, until some of those variables can be shown to be influenced by the pattern of monetary flows (as indeed they might be), they mist, in the direat sense, be taken as autonomous with respect to private sources and disposals of payments.

We have:

$$
\frac{\Delta C}{\Delta H}=\frac{R N-E N}{R D-E D+(R N-E N)}
$$

It surely cannot be supposed that $R N$ and $R D$ are independent of the other forms of disposal; apart from anything else, when a cheque is deposited to an account, whether that transaction enters into $R A$ or $R D$ is entirely a matter of whether the account is in credit or debit at the time, which must depend at least in part on the previous course of transactions. It therefore appears that an explanation of this ratio would require a knowledge of the other elements of the transactions matrix. 
The $R / D$ ratio is considerably trickier than the elementary 'bank multiplier' makes it look. Central Banks have usually operated on the free reserves rather than total reserves: in many countries it is not the cash reserve ratio but the I.G.S. ratio that is operative; even where the L.G.S. ratio is not used explicitly, banks' holdings of bonds presurably enter into their attitude to the holding of free reserves; other asset holdings, particularly of foreign exchange reserves, are also likely to be important. The actual, ex post $R / D$ ratio thus is an extremely collapsed summary of a complex of factors, as indeed are the other terms in the tautology.

The knowledge of the flow variables, for a given period, of all the cells of the transactions matrix would only provide the first stage in an explanation of macro events in any case; but the "high-powered money" tautology does not even get that far, and does not, as the transactions matrix does, Indicate the next step in the explanatory schere to be explored. It therefore appears that the "high-powered money" concept lacks analytic power, and that in the presence of the information about the transactions flows which is in any case needed to "explain" its ratios it is otiose.

Morecver, since for any period one can find numbers to insert as ex post values of $M, R, C, D$ and $R$, there is a temptation to suppose that by putting the numbers into this form they constitute a piece of information about behaviour. 96

"Manna" Theories of Money Creation

Given the part expenditures play in money creation and destruction, what are we to say of constructs that begin with a view of money as dropping indiscriminately from Heaven? ${ }^{97}$ The key seems to me to lie in the fact that money does not in general get into a man's hands unexpectedly or without deliberate intention on his part. Consequently, it seems odd to pose the question: "Now that he's got this money, what mechanisms need to be brought in to give him a motive for spending it?" If he hadn't already got some expenditure 
motive for getting it, why did he go to the trouble of working for it, or selling an asset, or borrowing it? secondly, once we know how a man got his money we may be able to restrict the range of possibilities.

If he got the money as wages, we presume his household or subsistence needs will claim most of 1 t; if he got it by selling goods in the normal way of business, he needs the money to pay his working expenses, either those previously incurred or those to be incurred in replacing the stock sold. Now, once these things are recognised, it is true that, for the average businessman or wage-earner, he needs not and does not consider where the buyers or employers got the money from, 98 so that to that extent his own expenditure decisions are independent of the source from which his receipts were financed. If this is all the "manna" construct intends to convey, the exclusion of the source is innocuous and need not prevent the construct from sustaining a useful job of analysis.

But if we are concerned with a broader picture of the economy, the general pattern of monetary flows is not so easily dismissed. If the factor payments from one set of firms are used by recipients laxgely to buy the produce of other firms, where does the money to make those payments come from? This has obvious implications for the analysis of inflation with its discriminatory sectoral effects, of general wage demands, and so on.

It is surely evident that if we are speaking of money in a macro context, then we have to enter the eircular flow of transactions at some point, and 1 t can be no criticism of any approach that it does not attempt to enter simultaneously at all points. But of all possible approaches, that which obliges us to speak of money as operating independently of transactions and of transactors is surely the worst; it renders us quite incapable of saying anything meaningful about the way in which money enters into transactions. 99 
Now, it may not be wholly inappropriate to apply 'manna' constructs to the specific case of windfall gains, although the transactions approach would have to include explanations of any windfall gains. On the whole, it appears that macro theory is bettex off without pennies from Heaven, and if used at all the construct is more appropriate to micro theories where it is less likely seriously to mislead us.

Trade credit and NFI

There are two obvious types of credit which need to be distinguished: (a) credit extended directly by vendor to purchaser, so that little or no money changes hands at the time of the transaction (even in the 'flow' sense described above): (b) credit extended as a cash loan, involving three parties, lender, borrower-cum-buyer, vendor.

The second is dealt with easlly enough under the general rubric of nfi (which would include credit card companies, nonbank moneylenders, finance companies, etc., but exclude hire-purchase arrangements where the buyer is a debtor directly to the vendor). The nfi, in this sense, in general operate to bring idle balances into circulation; as the bank cannot lend idle balancez, and the owners don't in general deal directly with borrowers who borrow for their own business or consumption needs, if the idle balances are to be used in general financing they need to be airculated by some intermediary, who may give the owners some asset in the form they want in exchange for the balance, while being able to provide the borrowers with money on the quite different terms they are willing to accept.

Thus the second type of credit (here called "nfi. credit") involves a contemporaneous financial transaction as an ancillary to the money-goods transaction, which then becomes indistinguishable from any other transaction for which the buyer already had his own cash.

The first type of credit, in which goods are sold but no money changes hands at the time of the sale, which involves 
that the vendor himself exchanges an asset (goods) for another asset ( $a$ debt) on his books, is what we shall mean by "trade credit". It involves a temporal element, in which a unilateral transfer of goods at one point of time involves unilateral. transfers of money between the same two transactors at subsequent points of time. Two of the most important cases are consuner hire purchase and interfirm credit.

It should be made quite clear that this separation between two types of credit is a separation of function; there is no implication that it requires a corresponding division of institutions; indeed, some institutions, like stock and station agents, P.S.I.S.. petrol flrms and foodstuff firms (financing outlets) are quite active in both types of credit.

In order to keep in mind that not all transactions involve a simultaneous exchange of goods and money a convenient record of unilateral goods transfers can be kept in an eighth row and column bordering the transactions matrix, the unilateral money transfers appearing in the main body of the matrix as before. (rhe relation between this and the real transactions, and the specification of a more detalled record of credit transactions, are discussed below in Part 2.) The concern at the moment is simply to indicate that we can make sense of nfi and srade credit elements in modern activity without having to abandon or obscure the basic money-goods relation. 


\subsection{THE ANALYSIS OF MONETARY MECHANISISS}

In this chapter we have been concerned with exploring some of the basic ideas in macroeconomic theory, particularly those to which monetary analysis is relevant. Here the findings must be put together.

At the heart of modern macroeconomic analysis lies the real-exchange equilibrium of Ricardo and Walras. This essential core has not conspicuously changed during the 20th century, although on the real side production and capital theories have been progressively modified. The main modification with which we are more directly concerned, however, is what has happened to the monetary part of macro analysis aince Wieksell's conclusion in 1898 that the Quantity Theory was the only theory of money available at that time. 100

For the English-speaking world (apart from some mentioned above in the Ihornton tradition) the basic conceptual schema of money rests, however elaborately decked out, upon what Keynes described as the "fundamental proposition of monetary theory" i.e. "the proposition which harmonises the 1iberty, which every individual possesses, to change, whenever he chooses, the amount of money he holds, with the necessity for the total amount of money, which individual balances add up to, to be exactly equal to the amount of cash which the banking system has created. In this latter case the equality is brought about by the fact that the amount of money which people choose to hold is not independent of their incorres or of the prices of things (primarily securities), the purchase of which is the natural alternative to holding money. Thus incomes and such prices necessarily change until the aggregate of the amounts of money which individuals choose to hold at the new level of incomes and prices thus brought about has come to equality with the amount of money created by the banking system." 101 
The only modification to this basic schema has been the general acceptance of the idea that purchases of goods as well as purchases of financial assets are to be regarded as the alternatives to holling money. A direct expression of Keynes' "fundarental proposition" is found, e.g. in the exposition by Kavanagh and Walters 102 of the demand for money. Their micro function axpresses a demand for roney of the $i^{\text {th }}$ transactor (their equation I.6) as:

$$
\frac{u_{1}}{p}=f_{i}\left(x_{b}, \frac{x_{i}}{p}\right)
$$

explicitly stated to express the causal relation, 1.e. that the 'real cash balance' the $1^{\text {th }}$ individual desires to hold is determined by the bond rate and the level of the $1^{\text {th }}$ individual's 'real income'. For all transactors, the $n_{1}$ must satisfy the relationship

$$
M=\Sigma_{i}{ }_{i}
$$

But this - again explicitly - does not mean that the sum of the individual stocks of money held, 1.e. the aggregate stock of money, $x$, is determined as the sum of the individual demands, since $M$ is instead determined by the banking system, operating on the monetary base determined by the government. At the macro level, $a$ becomes exogenous to this model, and may variously be expressed as determining the level of income, or bond rate, or prices. (As equations I.7 through I.10 express.) 103 Exercises on 'The supply of money' are directed to finding determinants of o outside this structure.

There are two aspects of this to be brought out; the first is the aditive element, in a timeless context; the second is the task now set up of finding what mechanisms ensure that the aggregate condition is satisfied. The first is trivial, since if money is in existence at any given instant it must be held by somebody, so that the total amount 
held by all must be the arithmetic sum of the amounts held by each. What may be important is whether the total amount $M$ is determined in the way described, that is to say whether individual transactors, by their responses in adjusting their own holdings, are able to alter $Y, r$ and $P$, but not $M ;$ in any case it is accepted that the processes of adjustment are important. Ultimately, then, this schema of money has to be judged on the questions which it leads to.

In practice, the question that it leads to is: "how do individuals react to a divergence between desired and actual money holdings?" which leads further to an encuiry into how individuals structure their decisions about relative moneybonds-goods holdings. Now at the individual level an intelligible set of problems can be isolated by this approach. A man who is in the process of deciding how to allocate his income (or wealth) may quite reasonably be viewed as weighing up the alternative alaims on his purse of consumption, investment and asset-holding opportunities, and at the individual level the 'demand for money' approach, particularly as now usually elaborated, is capable of talking a good deal of sense.

This is because, at the individual level, it is neither necessary nor usual to consider questions such as : If I spend more, does this mean you have more or less to spend? If I get a salary raise, does this mean that there is less money to pay you or more? If I buy more goods, on cash or credit, does this make it easier or harder for you to buy more? If I buy more from you will my exployer have to pay me more or will he pay me less? Does my having a job depend on your having or not having one? If I can't meet my household expenses do I want you to spend more or less?

But macroeconomic theory cannot evade guestions of this sort if it is to find out anything about why the important macro aggregates behave as they do; in particular, it needs to be able to trace the interactions between individual transactors (or, to make it easier, groups of transactors) 
in order to find out anything about how the spending or borrowing of one affects both the money available to another and the goods available to be bought with that money. Some broad statements are achieved by macroeconomics in its present state, but there is a specific reason why such broad statements do not relate in any definite way to monetary mechanisms. The archetypal question of money, underlying all of the questions asked above, may be seen as:

"How does money get out of my pocket into yours; and, having got into yours, how does it get back into mine again?" This an surely be geen only in the course of transactions, not in the aggregate tautologies that, in the end, have somehow to be satisfied. Certainly, in the crude concepts of "velocity" and "hoarding", we can see the rudiments of an appreciation that it matters whether the money that I spend comes back to me in circulation or whether it piles up like a snowdrift in some inaccessible corner of the system. But while the orthodoxy is preoccupied with questions of why a man spends or lends and what he buys, it does not seem to be in the least interested in the questions of where he got the money from or where he spends $i t$, and whom he got it from and whom he pays it to; and it is questions of this type that provide the means of linking wp the individual transactors into the interaction mechanisms of the monetary system.

If it be accepted, then, that current monetary orthodoxy fails to do its job because it is preoccupied with questions that are not of key importanse, and does not ask the questions that need to be asked, where does the fault lie? Is it that the basic ideas about monetary behaviour are all wrong, or that the rigid theoretical frameworks prevent the right questions from being formulated? This firm separation between form and substance is not easy to make, and the argument of chapter 1, particularly section 1.3, suggests that we would be wrong to make it. Nor is it easy to set out the shortcomings seriatim, for much the same sort of reason. Some broad heads of criticism may, however, be attampted in order to sumarize the discussion. 
At various points of the analysis one can detect a frequent tendency to tackle macro problems in micro terms, this has already been discussed above in the question of liquidity, in which an assumption of additivity is not rerely questionable but is definitely wrong. But the same has to be said of many of the constructs of macro theory, in respect of asset, consurption and utility functions on the consumer side, and in respect of production, investment and employment functions on the producer side. In general, the view appears to be taken that the aggregate functioms can be validated as behavioural functions by their plausibility as individual behavioural functions. Where some link between the two is attenpted, it takes one of two forms either "simplifying" assumptions of homogeneity and independence are inserted to Justify straight additivity, or the market is left to provide the necessary reconciliations.

kither approach has cone through custorn to ba accepted; but despite the permissiveness of the profession in this respect and regardless of the credibility of the justifying assumptions, they are sinply not sufficient. The micro bohaviours are connected in a variety of ways; factor and goods markets are necessarily connected because much the same people trade in both; receipts from one market are largely the source of expenditure in another; one man's income is another man's cost; and so on. In these interconnections, time is of the essence; what one man coes depends clusely on what other people have been doing, because in general what he does is conditional upon or is a response to what other people have done. The construction of aggregate relations cannot alternatively be rationalised as a direct approach to group behaviour, since as human behaviour is conceived in economics it is essentially the behaviour of individuals. Whatever other social sciences may have to say about group behaviour, macroeconoric theory has no concepts or analytical tools at all to deal with this. 104

While light may be thrown on micro behavioural functions, the aggregate relations to which they give rise require consideration of how individual actions interact over time, and in the 
absence of an account of these interactions the macro aggregates remain unexplained. The problem is further pushed into limbo by the association of the timeless, static framework, into which individual actions are frozen, with a framework of equilibriur.

\section{Static Equilibrium}

A static framework, in which time is not mentioned, obviously cannot deal with the question of deferred payment, nor with the question of the timing of transactions, nor with the way in which these timings affect both the need for cash to make payments and the supply of loanable funds at the requisite points of time; but its association with equilibrium leads further to the view that an inspection of such details is unnecessary, since if the general equilibrium is achieved. then these problems of timing and momentary liquidity must somehow have been solved by the operation of the economy in reaching equilibrium, and interest in how this came about lapses.

The problem is not resolved by modifying the construct to a pseudo dynamic form, which in the type of periodic simultaneous equations approach used is no more than a comparative statics form; since this is essentially a movement from one equilibriun to another, almost all the faults of the static aqiilibrium analysis are retained. All the comparative statics aproach can do, then, is to crunch out solution states for the successive terminal points, and is no closer at all to examining or even evincing interest in the course of transactions between terminal points.

Finally, macro theory loses interest in the behavioural factors as meaningfully related to the actions of people, and deals directly with the macro aggregates themselves. 
The result, inevitably, is an attempt to collapse the enormously complex interactions of transactions processes into simple 'behavioural' links directly between the macro aggregates, as e.g. between the money stock and the level of output, without any attempt at all to spell out those interactions in any way that connects with the ongoing processes of economic activity of which we all obtain, from a micro standpoint, a partial view. Theory construction in macroeconomics, then, consists wholly of the construction of black boxes, whose internal mechanism cannot be deduced frora the events at the input and output terminals alone. The application of sconometric deductive techniques to the events at the input and output terminals, in a context in which, within the current paradigmatic schemata, such deductive technigues are accepted as the only true type of 'empirical' work (which is then taken to mean 'contact with the facts') leads further; we have, not meraly the multiplication of black box theories, but blackboxism itself, i.e. "the philosophy that praises phenomenological theory as the highest type of scientific systematization and abuses representational theory".

Since the phenomena observed are elaborate constructs produced within a variety of conceptual schemata, their status as 'facts', even in the sense in which commonsense objects may be taken as 'facts', is dubious. Ultimately, then, not only are the black boxes of macroeconomic theory incapable of providing explanations of or even of evincing interest in the economic processes connecting the input and output terminals, but it is not certain whether the terminals or the events at them are as factual as we are asked to believe.

If we vant to make sense of macroecononic activity, we have to gat closer to the processes which yield the macro results. This will oblige us to distinguish more sharply between propositions which are held to apply at the micro 
level, and the entirely different sorts of propositions which are held to apply at the macro level, since the lattex are contingent not only on our being right about the micro behavioural aspects but also on our being right about the way in which those mloro aspects interact through the transactions in which they axe expressed.

The study of purely micro behaviour, particularly that of microecononic cholce or decision-making, is thus relevant to the macro propositions in the specific requirement that the macro propositions have to make sense, in whatever they assert or inply about behavlour, in terms of the micro studies as well as in terns of the nacro aggregates. But it does not appear posslbje that the interaction mechanisme can be agyeregated up from Individual behaviour alone, since for the study of such behaviour the feedback mechanisms have to be definec out of the study. The connection with the micro propositions must be seen most impertantly in terms of the information content of micro decisions, the connecting link between micro and macro being seen in terms of the continuing responses of individuals to those changes in theix economic enviroment of whose impingements they are aware.

It is also necessary to distinguish yuite sharply betiveen the real and monetary siaes of interaction processes, since these interaotions comprise, to a very large extent, interactions between real and money elements, and we cannot hope to investigate these in a language which never makes clear whether one is talking about money or about goods.

We shall also need to pay more attention to the element of time, which inevitably pushes us outside the static equilibrium framework. The time element may be seen in two ways: as a matter of duration, or as a matter of sequence. In the discussion of liguighty above, it seems clear that the sequential ordering of transactions is likely to be the key element in the money-goods relation, and this may have important implications for the way in which time is treated in the analysis. 
Wother in a static vien or not, the concept of 'equilibrium' is surely a stifling framework for thought, it obliges ue to say some rother silly things ahout how econonja activity progresses, and nantfestly ignores the. basto fect that mogt eaonomic problems arise because disturbances occur in situations whlch are alrandy out of equilibrium. But its worst effect seems to ne to be in the things that it is used to save us the trouble of saying, or even the trouble of thinking about. Once we have expressed an economic situation as a set of equations, the next step is to find a solution to the equations, since that is all that can be done with them, the study of economic activity reduces to a blind faith in an econony's ablilty to solve the equations itself, since if the comparative static simultaneous equations models are not saying that the economy itself acts as an algorithm which can and does solvo the equations, what are they saying?

It is not the case that the concept of 'equilibrium' and its assoclated constrained extremum problem structure need be the only tool of analysis open to us, or that we are hound to distort our viev of the world so that we can force it into that Examework. It may be that a structure of economic activity at once more flexible analytically and more meaningful in comonsense terma is avaliable if wo discard it. 


\section{CHAPTER 3}

\section{TOWARDS A CONCEPTUAL STRUCTURE OF}

\section{MACROECONOMIC ACTIVITY}

In the previous chapter we explored the hard core of monetary theory in an attempt to find out why it falls short of adequacy. In doing so, we found it necessary to bring out some ideas about the place of money in economic activity, about some important aspects of money neglected in the received theory, and about the type of questions that need to be asked. Here we attempt to organise those ideas into a form more suitable for theoretical analysis. 


\subsection{ECONOMIC PROCESSES AS TRANSUISSION MECHANISHS}

Macroeconomics is the study of a system; as a condition of being a system, an economy has functional relationships between its parts, and it is those relationships that are the object of study. That is to say, macroeconomics is not the study of the system as a single body in relation to other economies, nor the study of the several parts in isolation from one another, but a study of the system itself in terms of processes internal to itself. These processes may involve responses of the system either to impulses received from outside or to internal stresses set up within; but this distinction does not, for our purposes, lead to separate types of enquiry, since both external events and internal stresses operate on specific areas of the system, and in order to explain the consequent behaviour of the system it becomes necessary in either case to examine how the adjustments made by some parts in response either to internal stresses or to external impingements are transmitted to other parts of the same system.

We shall thus concentrate attention on the processes themselves mainly in terms of the internal stresses of the system, since external events impinge upon the system in ways that, for a private enterprise system at least (and also for a socialist system where there is decentralization of decisionmaking) must share the same transmission mechanisms. The sort of questions asked in 2.3 above arise and need to be answered whatever the source of the events whose effects are being stualed.

More importantly still, the behaviour of the system at any time is a product of its past history, and at any time there will usually be going on processes of adjustment and response in some parts of the system arising from past impingements from other parts of the system, and leading to further impingements on other parts in the future. In order to examine this highly complex behaviour of the systera, we have to isolate those elements which appear to be of key 
importance in the transmission mechanisms, and to organise those elements into a schema which will enable us to keep track of the transmission processes as they occur over time. It will also be necessary to indicate, at various convenient points in what follows, where the organising schemata already available in orthodox macro-theory become inadequate to cope with the elements here considered to be important.

In general, we can see that in a modern pecuniary economy any individual (or firm) has at any one time a stock of wealth and of information, together with some idea of what in a more or less efficient way he is trying to achieve, and which therefore directs and circumscribes how he behaves in any given situation, and hence the ways in which he in turn will affect others through his own adjustments. Now it may be that a truly comprehensive approach to the problems of interaction in an economic system needs to take account of extra-market interactions of a socio-political type; but although at some stage an integration of market and non-market interactions must become necessary, that formidable task is not undertaken here, and we restrict attention to the more traditional areas of economics concerned with activities conducted through organized markets.

This implies a concentration on market transactions, i.e. exchanges between buyers and sellers: the buyers come to the markets with money to be exchanged for goods, the sellers with goods or services to be exchanged for money. Since most people are buyers and sellers (in the commonest case being sellers in the factor market and buyers in the goods market), the general course of transactions activity can be seen as one of selling goods or services for money, using the money to buy different goods or services, and so on through time. Tracing the transmissions through such transaction flows involves asking both where the money comes from, and where it goes to, and where the goods come from and where they go to, and finally asking what connection there is between the two. Some common elements may be abstracted from the general course of transactions. 
Every individual firm or person may be seen as a node at which three flows converge, and from which three flows diverge. These are the flows of goods and services, the flows of payments, and the flows of information. At each node, at any instant of time, there is interposed between the inflows and outflows a configuration of stock variables; changes in these stock variables arise from the impingements on them of events in the inflows, and in conjunction with the individual's own purposes consequent responses are initiated in the form of events in the outflows. Microeconomics deals with the processes internal to the nodes, whereas macroeconomics concentrates attention more directly on the internodal flows.

The relevant configurations comprise stocks of goods of all kinds, stocks of money, and assets and liabilities consisting of claims upon and obligations to other nodes with whom market transactions are conducted. Stocks of information are not easily put into a comparable form, and to a large extent relate to the intranodal processes of financial and production management or of household earning and spending which are not dealt with in any great detail for macroeconomic purposes; for our purposes, it is easier to take account of them in terms of effects on the response mechanisms stimulated by external impingements. Since in any case both stocks and flows of information involve the socio-political framework from which it is here necessary to abstract, it will not within the scope of this study be possible to say much about information flows.

The money and goods flows are closely related, since in general an inflow of goods will require an outflow of money, which itself will require a prior inflow of money together with an outflow of goods or services. These requirements need not be strictly adhered to at any given instant, since stocks of cash, ability to borrow cash and ability to arrange deferred payment may modify them. The importance of the temporal sequence is apparent. For if a firm has to pay for inputs before it has received the proceeds of previous sales, its cash holding at the time of payment is important; moreover, even although a firm's receipts may be due and expected, if its 
customers can't find the money it won't get paid, thus reducing its ability to meet its own payments.

This may further affect its own production, and although it may later be able to catch up it may, while it is waiting for payment, have to turn away other customers and perhaps restrict labour payments, with consequent effects on the demand for the goods they buy. Since factor payments are commonly spent on products other than those they were incuxred in making, this may lead to a shortage of demand and supply elsewhere, although not necessarily in the same market. Thus, through the chain reactions so set up, as a consequence of a shortage of money in one sector, other sectors may be affected asymetrically, some feeling the demand effect more, others the supply effect. Thus the money and goods sides of transactions are not symuetrical, but interact through the course of transactions.

Temporal sequences are thus important in two ways. In the first place, the events impinging on any node's configuration must precede the consequent events initiated in that node's outflows. (This does not exclude such elements as anticipation and expectation, since if these are iriportant they must be represented in the configuration at the node at the time they enter into responses, and indeed some events in the outflow may be initiated in response to some change in the expectational elements in a node's configuration.) In the second place, a configuration at any instant of time is the result of the node's entire past history, and since this configuration is being continually changed by events in the inflows the corresponding events stimulated in the outflows may vary according to the sequence of the impingements.

In any such economic system there must be a finite number of nodes, but the transactions flows are more properly seen as unbounded. However far back through the chain we trace the source of a given set of impingements, there will always be a further set of nodes acting as prior sources; and however far forward we trace the effects of such events, there will always 
be, beyond the nodes considered, a further set of nodes which will be subsequently affected. ultimately, of course, as we track through in either direction, we meet for a second time nodes already met. But they will not be entirely the same nodes: the point of time relevant will be different, and their configurations hence different; their behaviour may or may not be signifleantly affected by these changes in configuration.

Since the money-goods nexus involves that money and goods are moving in opposite directions through any particular node, the analysis of the reflexive effects on a given node of its own actions requires the tracing of two separate flows. If money spent by a particular node comes back to it, it does not come back to it at all by the same path that the goods it bought came to it from the services it sold. In general, tracing the effects of any given disturbance necessitates tracing two separate paths, since although the money and goods flows will frequently intersect they will not in general follow the same paths.

The organising schemata that orthodox macro theory imposes on this system depend in their most restrictive form upon two radical simplifications. The first is to treat the system as timeless and unchanging, so that once a reconciliation of the desired with the possible has been arrived at for one set of configurations the system is 'explained' and curlosity rests. In these terms, the system may be treated as bounded, at one end by the given factor inputs which limit the possible, at the other end by final products or output which designate the desired. Some contact with the unbounded nature of the nodal system proper may be maintained by interpreting this structure in terms of the 'circular flow', the opposite flows of money and goods being expressed in the following way: households provide factor inputs to the IIrm, which produce the goods, which the households consume; in the other direction, firms pay the factors, providing incomes to households, who use the incomes to buy the goods from the firms.

But, in the timeless, unchanging pattern of the circular 
flow, there is less need to keep account of both flows separately; thus the analysis may be conducted in what are called 'real terms' which is an attermpt to speak in terms of the goods flows alone, although any actual measurements are applied in the first instance to the money flows. Thus the sumarizing concepts of 'income' and 'output' are measured as follows: in the circular flow, the cost of the final goods produced (after netting out interfirm transactions) is taken to be equal to the sum of factor input costs; thus the recorded factor incomes are said to 'measure' the cost of output, which 'measures' the value of output, so that ultimately the total of household income (net of transfer payments and so equal to factor incomes) is identically equal to the total of output 'measured' in value terms.

Although in strict terms this 'measurement' is definable only for the circular flow, it is in practice applied to economies not characteristically in the timeless equilibrium of the circular flow, with the single modification that variations in the monetary standard itself are allowed for by deflating the factor income sum by a suitable price-index in order to arrive at a measurement of final output at 'constant prices'. This returns the analysis to the conceptual basis of the Ricardian goods-exchange equilibrium, so that the circularity of economic processes is eliminated by their expression in the Walrasian static equilibrium. The whole process of measurement can in practice be reconciled with data from any economy whatever its situation, since the ex post accounting identities yiald the requisite correspondence between costs and receipts through the balanding residual of profits.

The timeless circular flow construct may be extended in two ways. Pirst, it is modified to include savings and investment, as follows: saving is a deduction from household incomes, being equal to the excess of their income over their purchases of consumption goods. This leaves a discrepancy which is accounted for in the total of goods as investment goods. Thus the saving by households, seen first as a monetary phenomenon, provides loanable funds, which are lent to investors who use the borrowed funds to buy investment goods, thus maintaining 
the corresponding levels of income, expenditure and output.

Secondly, it is modified to take account of changes in the nodal configurations from time to time. The comparative statios or simultaneous equations approach proceeds as follows: the reconciliation of one set of desires and possibilities provides a solution in the form of a set of conflgurations for the system. This may, at time $t$, be contrasted with the set of configurations which were desired by individual transactors, thus setting in raotion a number of adjustments leading to changes in the events lmpinging in the flows from node to node, so that at time $t+1$ a new set of conflgurations is needed to reconcile the desires with the new possibilities, which raay involve sinilar discrepancies between the actual and the desired configurations with consequential adjustments.

But the comparative statics approach does not in fact encuire into what events are aarried by the flows or how they are passed from node to node or by what path they are transmitted from one part of the system to another. All it provides is the solution set of configurations at times $t, t+1$, etc., and rules for determining each set from parameters deterained by previous sets.

Now, the interactions among the nodes, seen more properly as a finite but unbounded system in which the nodal configurations are continually changing over time and acting and reacting upon one another, yield too many details to be described by enumeration, and even if that were possible the result would be too complex for analysis. Some sumarizing concepts are needed; but if we sumarize the reticulated system in the aggregate concepts of the orthodoxy, we lose contact altogether with the transmission mechanisms which are the source of the information we seek.

the raacro aggregates in order to provide an appropriate sumarization ought to combine the information from the internodal transmissions; instead they throw away all the information about these transmissions, attempting to retain contact with 
them by adding together the configurations at particular points of time, so that recovery of the information about the transmissions is impossible.

Moreover, it is guestionable whether the addition of the stock varlables of the configurations always yields a meaningful sur, Consider, for exarnle, the micromacro liguidity. aggregation problem mentioned in Cha teer 2, Additional 11ght can be thrown on that problem as 1 t appears in the aircular flow formulation. Consider that point at which household savings are lent to investors, thus completing the clrcular flow. The perative word here is 'lent', in lending their savings, households do not reduce their wealth but exchange money for some other asset, 1.e. some form of clatm on the investors. These claims will be of all types, from money claims to ordinary shares; but a substantial part of them will be the type of assets reckoned into the individual's liquid assets, some perhaps even into his 'real balance'.

Now, the money so lent to investors out of current income fully absorbs, when spent back by investors into the aircular flow, all the excess of goods produced but not bought directly by households. In the unlikely contingency that all micro liquidities are in fact realised and the proceeds in fact spent, since ex hypothesi. there are no extra goods to be bought then the prices of those that were already being bought must rise. Real income thus remains the same. Now we can get round this by removing the requirement that factor incomes be just sufficient to buy the total of output at curreat prices but what in that case happens to the equivalence between "real income" - measured at factor receipts, and "real output", of which it is taken as the measure?

The attempt to deal with the unbounded nature of economic transmission processes by the simultaneous equations approach thus ?eads to a substantial doubt about what is being measured and hov it relates to the terns of the theory; it is only possible in practice to retain this measurement at all by heavy zeliance on the purely accounting convention by which 
the residual, profit, by entering Into the factor payments sum automatically adjusts so as to preserve a numerical equivalence of factor receipts with output. It is movements in the aggregates so measured that constitute a major part of the explanandura of atandard waoroeconomic enguiry; thus the problem is not only that lack of lnterest in the transmission mechanisms prohibits explanation of the aggregates which their collective interactions yleld, it is not even decidable what it is that is to be explasned. The poverty of present theory is evidenced by the frequent resort to labels such as "stagflation" with the policy goal set as that of "shifting the Phillips curve" which might serve as a useful shorthand for more conplicated descriptions if the detailed technical knowledge required to give them more definite statement could be supplied.

A moxe samsible approach, thexefore, is not to proceed from the standard macroeconomics aggregates in an attempt to uncover the causes of their movements, but to go directly to the transmission flows and try to see what useful sumnarizations can be made of these. Only when a meaningful macxoeconomic explanandum has been found is there any point in looking for explanations. 


\subsection{THE FORM OF THE STRUCTURE}

3.21 CHOICE OF TECHNIQUES

Whatever conceptual structurings are inherent in the discussions up to here, the processes of further abstraction and conceptualisation an now be made more overt and explicit. In this deliberate attempt at representation there is a place for the positivist framework, which may be valuable in helping to prevent us from misunderstanding what we are doing with numbers in econoruics.

It is already clear that further dsvelopnent necessitates finding some guantitative expression for the transmission mechanisms; the initial background knowledge already involves sums of money, quantities of goods, stocks and balance-sheet items, all of which are expressible as numbers; and the immediate purpose of the exercise, to define a meaningful macroeconomic explanandum from interactions between these sets of numbers, suggests rather strongly that what we are looking for is some representative set of numbers in which an economic situation or course of events can be expressed. It will. undoubtedly be the case that explanations of economic events äraw importantly upon elements not adequately expressible in numerical form, but that issue will not arise until we know what it is we want to explain.

This immediately puts out of consideration the option of direct recourse to empiriaal work on available data, particularly in the form of applying econometric techniques to published macroeconomic aggregates, which can result only in an attempt to force out of them information which they may not contain and whose interpretation would in any case remain purely conjectural. Nor is the study of individual transactions a very promising line of approach for present purposes. The major task in hand is to look for some way of connecting up the individual transactions, that is some way of summarizing them 
so that descriptions and analyses of macroeconomic systerns can be arrived at. Neither the simple addition of data available on micro events nor the direct manipulation of available aggregates in pseudo-reduced form is $1 i k e l y$ to provide any reliable access to these.

It may be that when this work has made some progress a place may be found for some at least of the standard aggregates, but we need a more intelligible way of interpreting them than is at present available, and it is likely to be the case that interpretation of existing macro aggregates will require additional information of a sort not usually collected; the transactions matrix set out in Chapter 2 already suggests one type of information we may need. In short, in the absence of direct data on transaction flows, the first problem is not that of fitting into a given conceptual scheme "observations" already available, but the prior problem of defining what observations - and measurements - will need to be made.

We can also dismiss the use of traditional techniques to build a mathematical model of the structure of interactions; in the present state of macroeconomics such techniques lead inevitably to a search for equilibrium solutions and their properties. This approach does freat violence to the facts of a modern economy and will not permit us to try to capture those elements of a modern economy taken to be important for practical purposes; two such elements are the impingement of macro constraints on individual transactors, and the ordering through time of individual transactions. Both involve considerable nonlinearities and lags, and while any way of structuring these is bound to involve enormous simplifications, we do want to avoid simplifying the essential elements out of the model altogether.

We shall accordingly resort to the cruder technique of numerical simulation, which does have drawbacks of its own but which at least gives us a freedom not attainable within the rigid framework of a deterministic model. Given the limited 
number and range of numerical operations feasible with pencil and paper, there is an obvious economy in using a computer to carry them out. Apart from the greater bulk and cormlexity of numerical operations that can thus be undertaken, there is an additional benefit in using a computer for this; the syntax of a programing language provides an admirable vehicle for expressing the propositional calculus of the theoretical. structure, and is certainly a clearer way of comunicating to others the structure of the numerical operations performed in the simulation. If the programe is properly written, i.e. if it faithfully conveys the ldeas in mind in an internally consistent and well-defined way, then the main work of setting out their logical structure is completed.

Further, the process of actually writing the programme is a considerable aid in putting together the logical structure in the first instance, the progxamer is continually faced with such questions as: what happens in this case? How many alternatives need be considered? What happens next? since these are the sort of questions which we want to be able to ask of economic transaction processes there is a lot to be said for using a technique which will throw up such questions in specific contexts. Thus writing the programe is not only a way of expressing the ideas, but way be used as an instrument in their finer articulation.

It is not easy to check directly whether a programme of some complexity is correctly expressing the relationships intended, whether it is internally consistent, or whether all possible situations that can arise in the defined operations have been catered for. The process of de-bugging the programme through successive runs, with adequate checks inserted to monitor the operations performed, is the most effective way of doing this. Testing runs will from time to time produce 'results' which in terms of some prior interpretation of the numbers are regardint as odd or nonsensical, this will usually turn out to be a programing fault, but sometimes it may instead reveal an oddity in the ideas expressed. This raises 
a doubt about the initial ideas, and the consequent re-thinking may thus make a useful contribution to the programmer's conceptualization of his field of study.

The simulation approach enables us to start from individual transactions, and by running sequences of such transactions try to build up summarizing ideas which retain the essentials of the information sought but represent it in a small enough compass for us to survey the gross behaviour of the system intelligently. Since interpreting the results presented by the summarizing ard organising processes necessarily makes some use of inference, the value of computer simulation is that a given run may be exactly reproduced, but with such additional information printed out as necessary about the detailed. operations at any point of interest. Any inferences necessary in interpreting the summary can thus be checked against a fuller knowledge of 'what actually happened'. We thus retain full control of the summaries actually printed out, since information suppressed in the summaries can always be recovered if necessary.

Given that some intelligible macro aggregates can be produced, certain problems become open to investigation. Not only may some basis of assesment be attainable for evaluating the macro aggregates currently coilected, but light may also be thrown upon the interpretation of relations between them as posited by orthodox theory. It may also be possible to comment further on the view that the economy does in fact operate as an algorithm to solve the equations of the equilibrium states. But these are not the problems of major interest.

By separating out real and money flows, a more direct approach is opened up to examining the money stock in relation to the processes of producing and distributing goods, and the modifications brought about by the nfi and trade credit. One aspect that may be of key importance in considering the information required to interpret the aggregates is that of the extent to which the transactions matrix needs to be known; will row and column sums tell us what we want to know, or must we 
have data on the individual elements? In view of what may be important differences in the feasibility of collecting various numbers erapirically, this sort of question needs to be looked into.

Another question arises fror a consideration of how macro constraints operate. Certainly, it is true that the total expenditures in an economy cannot buy nore goods than exist to be bought, and that goods cannot be produced in excess of the productive capacity of the economy. But how do Individual transactors becoine avare that a macro ceiling has been reached?

Now as long as we are content to sumnarize the course of activity in a set of simple variables of which ${ }_{t}$ has to stand for the total of goods produced or bought, we can express this sort of constraint quite directly, as e.g. $Y_{t} \leq r_{t}^{*}$, where $r_{t}^{*}$ is some exogenously determined celling, set perhaps at a trend rate $Y_{t}^{*}=Y_{0} e^{x t}$. But this leaves entirely impenetrable the process through which the macro constraint becomes operaitive, 1.e. known to and enforced upon individual transactors. If the collective intentions of the individuals determine a ${ }_{t}$ violating this inequality, how does that situation impinge upon individual. transactors in such a way that the total is reduced to comply with the constraint?

We shall not here delve much into the motivational basis of the way in which individual transactors respond to the presence of constraints, but shall concentrate on the means by which the macro constraints are expressible in the micro decisions, and the limits that they set to the options open to any particular transactor at any point of time. The first intimation that an individual has of a macro constraint will not usually be in the form of direct knowledge of the macro tautologies; it is necessary that some transactors at least be frustrated in their intentions, and the investigation of the processes through which this comes about is logically prior to the analysis of policy effects. 
A possible drawback to numerical simulation is that some varlables have to be assigned specific numerical values in order to specify initial states and some initiatory activity. This may make the structure quite sensitive to the precise numerical values assigned to determine the initial configurations, so that anything found out about the behaviour of the structure occurs in the first instance not as a generally-derived consequence but as a special case valid only for the assigned numbers. This sensitivity can however be compensated for to some extent by comparing many different runs starting from different initial states, since one may hope to elininate from consideration the stray guirks and develop some view of significant magnitudes and relations as experience of the model develops; this is what one means by "getting the feel of the model". This must, of course, be directed and controlled if it is to be fruitful.

In one sense, sensitivity of a model to initial states may not ultimately be a drawback at all, and 1 t $x$ ry be that this property is more characteristic of actual economies than a lack of such sensitivity. As Thornton percelved, an economy subjected to an external disturbance while already in a disturbed state may react quite differently from the same economy relatively settled, and this idea ought to have a more important place in the theory. It is obvious enough that what an economy suffering some external impact on 1 ts foreign trade must or may do is heavily dependent on its domestic posture at the time and its holdings of foreign reserves. Is it not equally obvious that the examination of disequilibrium is more fruitfully begun from some arbitrary initial state than from some set "equilibrium" position?

3.22 THE MODEL

The conceptual structuring present from the discussions of Chapter $2 \mathrm{~cm}$, mav be taken in a loose sort of way as constituting a 'model'. We shall reserve the term, however, to refer to the more definite expression of those 1 deas $\ln$ a 
form suitable for numerical simulation, and it is the "model" for simulation that is now discussed.

The focal element is that of a transaction, 1.e. of the exchange of money for goods modified for deferred payment and borrowing. A transaction involves two transactors, a quantity of a good, and a sum of money; the sum of money is further defined in respect of the source of payments and the disposal of receipts in terms of the transactions matrix of chapter 2 . Each transactor is vieved as a node in a network of flows, and a transaction consists of exchanges conveyed through the internodal flows. The flows into a node act upon a configuration of stock variables at the node, which reacts in some determinate way conveyed by the outward flows.

The engineering basis of the production processes implicit In this schema are taken as internal to the nodes, and are not the object of study, being represented only in transformations of the intranodal configurations and the internodel flows. Thus the nodes themselves will be left as the black boxes of the structure; the result is to replace the macro black box by a collection of micro black boxes, with the intention of exploring the processes internal to the former but mainly external to the latter, leaving details of the bshaviour within nodes to be spelt out by microeconomics. An advantage is that this approach provides an intelligible transition between microeconomics and macroeconomics.

Although the definition of a separate set of information flows is not here attempted, some influence of such flows is impliait in the internal configurations and the money and goods flows, and it is clearly important to prohibit any designated events from depending upon the use of information, as e.g. about general equilibrium solution values, not sensibly taken as knowable by individual transactors.

Excluding for the moment considerations of credit, the view of a transaction is taken to involve a simultaneous money-goods exchange. Thus a transaction has the following 
characteristics: a quantity, $r$, of good $k$ is passed from the $i^{\text {th }}$ transactor to the $j^{\text {th }}$ transactor; a sum of money, $m$, passes from the $j^{\text {th }}$ transactor to the $i^{\text {th }}$ transactor: the sum of money is further characterized by the elements of the transactions matrix, i.e. In terms of the source from which the $j^{\text {th }}$ transactor finances his payment (the $s^{\text {th }}$ row of the matrix) and the form in which the $i^{\text {th }}$ transactor disposes of his receipts (the $d^{\text {th }}$ coluran of the matrix); each transaction will also relate to a particular point of time, $t$.

The introduction of credit into the money-goods relation can take one of two forms: (i) sales of goods on credit, where the vendor himself extends credit directly to, i.e. accepts a promise to pay from, the buyers; and (i1) sales of goods for cash, where the buyer had first to borrow the money from some third party. (The combination of the two, where the vendor first delivers goods against a promise to pay, and forthwith discounts the obligation to a third party for cash, will be subsumed into the second, since the model is not defined in sufficient detail for this difference to be significant.) We exclude from (i1) borrowing on bank overdraft since this is already dealt with in terms of the "flow money" concept inherent in the transactions matrix, and hence (ii) refers to borrowing from nonbank financial intermediaries.

Case (i), which involves the non-simultaneity of moneygoods exchanges, is designated a "goods-credit" exchange, and case (ii) is designated a "money-debt" exchange. Case (i) clearly involves a goods-credit exchange at one point of time, succeeded, after some interval, by a money-debt exchange in which the liability is extinguished. Case (il) involves an ordinary money-goods exchange between buyer and vendor, preceded by a money-debt exchange between buyer/borrower and lender, and followed by a reversed debt-money exchange by which the debt is extinguished. The recording of such liabilities and assets is already available within the stock variables, but may further be recorded by suitable amendments to the transactions matrix. Details of these are postponed to Chapter 4. It is also convenient to designate a separate 
transactor, the nfi, to stand for the intermediary lender, who will derive his loanable funds from surplus cash in the hands of vendors through corresponding money-debt exchanges.

A number, $k$, designating the type of good, will not here be defined; we shall adopt the simplification of taking there to be a one-to-one correspondence between goods and transactors, so that the $i^{\text {th }}$ good is simply a good supplied by the $i^{\text {th }}$ transactor. This is much the sare convention as that adopted by the ordinary input-uutput type of structure, which is able further to distinguish classes of goods as between internediate and Einal goods, and as between consumption, investment, export components of final goods, by defining separate "sectors" or groups of transactors dealing in such goods. Macro theory in general does not further distinguish types of goods, and although there is rauch to be said for going beyond standard theory and giving more importance to what makes a loaf of bread different from a coat-hook, we shall not do that here except to the rudimentary extent that that idea is captured by distinguishing different intermediate sectors. Thus for our purposes any particular transaction will be adequately defined as soon as the numbers $r, 1, j, m, s, d$ and $t$ are determined. That is to say, a transaction is defined as an nxdered septuple of numbers $(x, 1, j, \mathrm{~m}, s, d, t)$.

Each transactor at any given tirae has a configuration defined as a set of stock variables, which will include assets in the form of inventory and cash, and may include other assets in the form of trade debtors and deposits with nonbank intermediaries, and liabilities in the form of overdrawn accounts, tracie creditors and loans fxom nonbank intermediaries. Although production processes are not explicitly dealt with, they affect transactions through the purchases of imputs, and since they are constralned by the fixed capltal stock and labour force avallable to each transactor, these elements also have to be included in the consiguration.

Thus at tine $t$ the $1^{\text {th }}$ transactor will have a guantity, $g$, 
of ( $i$ type) goods held on inventory, a quantity, $k$, of fixed capttal, an available work force, $l$, a sum of money, $c$, and financial assets in the form of claims to amounts $a, b$. He may also have financial liabilities in the form of claims to amounts $u, v, w$. His configuration is thus expressible as the ordered set of numbers $(i, g, k, l, c, a, b, u, v, w, t)$.

Transformations between the two classes of set need to be specified. For a single transaction two configurations will be directly involved, and in the first instance this is a simple mattex of up-dating the appropriate stock variables. Once initial values have been assigned to the elements of the $1^{\text {th }}$ transactor's configuration any subsequent changes will occur only as a result of a transaction involving the $i^{\text {th }}$ transactor, with an occasional exception; exceptions will occur where some variables are taken to be exogenously determined, as for example labour force and bank reserve balances. Thus the numerical values in the configuration sets are fully determined, given Initial values and exogenous values, by the transactions which alter them.

We could specify all transactions exogenously as singular events, which would give enough naterial for the problems of aggregation and sumarization for macro purposes to be examined. But that would not capture the structure of sequences of transactions, in which any exogenous transaction gave rise to effects expressed through consequential transactions. It is also necessary, in an examination of market processes, to consider the part played in initiating transactions by the transactors therselves, i.e. by events within the node giving rise to external events, so that some sequences of transactions at least would originate within nodes.

There are some obvious ways in which direct effects are spread through the system. The interindustry structure suggests how the demand for one sector's final output leads to demanda by the supplying sector upon other sectors for inputs and demands for primary inputs, and sequences of transactions may 
thus be generated through the production structure of the system. There may also be feedback effects through factor incomes to demand for goods, and monetary effects initiated through real balance or interest rate mechanisms. Any of these may be used, since all may be meaningfully applied at the midro level; on the other hand a direct quantity relation between the stock of money and the level of output is inadmissible, as are all other direct effects between macro aggregates. In general, it is not necessary for monetary variables to have initiatory effects through the real balance and interest effects for money to be important, since in the structure of the transactions flows money must in any case operate as a constraint in some way as yet to be specified.

The basis of the relation between one transaction and subsequent transactions which occur as a consequence is the active part played by transactors in initiating transactions. Thus a transaction, as well as altering the conflgurations of the transactors involved, will in some cases at least set up internal stresses within the nodes which are resolved by the initiation of the consequent transactions. This is the nearest approach in the structure to microeconomic behaviour; it could be seen as a more general statement of equilibrating mechanisms, but in view of the long association in economics of "equilibrium" with constrained extrema or simultaneous equations frameworks, it is better to avold the term, so as to stress the departure from those frameworks. Whus, from time to time, the configuration at a node may be compared with some target configuration, and discrepancies lead to further transactions. An important case of this will be the comparison, from time to time, between target and actual inventory as the main source of intersectoral demands for inputs to production.

The sequence of operations representing a chain of events will thus have the following form: the assignment of initial numerical values to the elements of the configurations; setting up transformations between transactions and configurations; processes for initlating transactions, both exogenously and arising 
out of configuration discrepancies between actual and desired states; rules by which constraints on the supply of transactable resources have to be irmosed upon transactors. All operations will have to be given a definite place in the timing of activity. Finally, the structure has to provide a means by which the individual transactions can be recorded and. surmarized.

\subsection{Semantic Interpretation of THE MODEL}

We begin by setting up the convention by which, for the purposes of this enguiry, a line is to be drawn between the c-domain and the p-domain. The p-domain of econorics may be seen as consisting of all the activities involved in production, distribution and consumption including the relevant financial and administrative activities. But no direct contact is made with those activities; contact is made primarily through books of record, although the information from those might have to be supplemented by the more evanescent traces left during the course of data processing and not usually preserved in permanent books of record; such evanescent traces, to the extent that they are recoverable, are information at a comparable level of observation. (Elements of the transactions matrix are likely to be of this type.) A different convention is required for micro economics, which wil1 have to be entrusted with the task of exploring the relationship between the actual activities and the representations of them which constitute the basic "facts" of macroeconomics.

But the traces left by individual transactions cannot themselves provide the macroeconomic entities directly; thus between the macroeconomic entities - yet to be defined - and the microecononic traces, is interposed a link provided by the summarizations sought. stage 1 of this enquiry thus is required to provide - in lieu of the presently unobtainable empirical "facts" - simulated populations of such "facts", in order for stage 2 to have some material to work on. 
In a computer simulation exercise, all the numbers need to be distinguished and their 'names' or 'addresses' specified. For this purpose identifiers are used, for ease of recognition by the programmer frequently in the form of words like 'inventory', 'bank', 'deposit' etc. But these 1dentifiers carry no semantic interpretation merely on that account; any collection of distinguishable alphanumeric symbols would do as well. If, therefore, we require the simulation exercise to carry a semantic significance, we have to attach one to the terms explicitly. This is required in the first instance if the exercise is to have any economic, as distinct from purely numerical, significance; but it is also required in terms of the second stage, for if we are to designate data which needs to be collected then we need to know what collection of objects we are talking about and where we are to get the empiricallymeasured numbers from.

What are to be taken as basic "facts" for our purposes comprise entries on various books of record; but the inspection of individual transactions as recorded in individual transactors' books is quite impossible to undertake for the system as a whole, and macroeconomic observations cannot be conducted at this level. of detail. What we must use as the basis of observation therefore cannot be the individual entries themselves, but summaries of them produced during the processes which give rise to the individual facts. This is true not only of an actual economy, but also of the much more linited population of transactions simulated in a computer run; a sequence of simulated transactions occupying, with limited printout, some ten minutes of computer time, would yield an enormous volume of printout if each defined characteristic of each transaction were printed out.

Given that a transaction is defined as an ordered set of seven numbers, this constitutes a seven-dimensional array whose elements can be sumed over any required dimension; such sums can, for particular purposes, be further added to produce another stage of summarization. The raw material, i.e. the basis of observation, for the sirulation exercise will thus consist not of individual transactions but of such sums derived from them. The second stage of the exercise will hence consist 
of enquixies into what information is communicated by such sums, and which of them, supplemented where necessary with additional information recoverable from the simulation, prove most useful in interpreting the behaviour of the system. This, in turn, will raise the question of the feasibility of collecting such sums from the actual processing and recording operations connonly conducted in the economy, with perhaps some suggestions for supplementary information or for the construction of surrogates where the actual sums are not accessible. There is no doubt at all that in practice it is the monetary data that are most accessible, and indeed data on the real side are very hard to come by: while we shall not restrict attention to the money side alone, it is clear that any practicable search for data will require real. event:s to be deduced largely if not exclusively from monetary data, and that must be kept in view throughout.

In linking up the terms of the theory to the actual observations (measurements) to be made it is necessary to specify the functors or metrical terms in which the observables are to be measured. Attaching dimensions to the pure numbers produced by simulation is part of the process of interpreting the results and cannot be made a part of the simulation itself; this means that computer simulation provides no control over the dimensions of the numbers, and this control has to be provided separately by the programmer. The distinction between money and real variables required by the theoretical discussion above implies a distinction between numbers interpreted as "a sum of money (of $x$ dollars)" and numbers interpreted as "a quantity of $1^{\text {th }}$ goods (of $x$ tons) ${ }^{*}$. The more formidable problems of dealing with dimensions on the real side are considered in the following chapter; here attention is restricted to the money variables which raise no difficult problems.

The definition of "money" itself has been dealt with in Chapter 2 in terms of money as a means of payment, the criterion of identification being "what is in practice accepted in settlement of a debt". Confining our attention for the moment. 
to stock money, it is taken to comprise, in the New Fealand economy, demand deposit liabilities of the trading banks together with notes and coin in the hands of the public. (Certain other things, as e.g. deposits in stock and station agents, may for limited classes of transactions be accepted as extinguishing a debt, but their use in this way is judged to be insufficiently general to warrant their inclusion in the money stock; it is usual for claims passed in this form to be realised as claims on the trading banks.)

Associated with the "means of payment" characteristic of money is that of "unit of account". Once stock money is defined then the "unit of account" is the unit in which the components of the money stook are expressed, 1.e. for our purposes \$N2. Thus the "unit of account" relates directly to the "sum certain in money" which characterizes payments. There is more than a definitional tautology involved here. The 'NZ' is usually suppressed in domestic transactions, but it becomes important to specify it when two different currency units are being discussed. The distinction between e.g. \$Nz and \$us involves more than the trivial arithmetical operation of converting at the current rate, since the sus unit designates not only the amount but the means of payment required. A New Zealand resident incurring an obligation to pay $x$ (US\$) must first buy the $x$ (US\$) with, at the ruling rate, $y$ (NZ\$), for which a meaningful business transaction is required. Any such transaction involving the means of payment of two countries is possible only as long as sufficient holders of both currencies are willing to trade in them. Thus the "sum cextain in money" for which a bill is drawn designates simultaneously both unit of account and a specification of what is accepted in discharge of the obligation.

"Financial assets" can now be separated out from the whole collection of assets as that subset of them comprising claims designating an obligation to pay "a sum certain in money", i.e. an obligation to pay a definite amount stated in \$NZ. It follows that an asset in the form of a claim axpressed in foreign currency and held by a New zealand resident is not treated as 
a financial claim but as a different type of asset. The fact that in N.Z. a market for foreign claims is readily available should not obscure the fact that as far as the domestic economy is concerned foreign currency is on a par with inventory rather than cash; whereas a bank can create domestic money, it can accuire foreign currency only by buying it from some holdex, and part of its business consists of buying foreign currency for resale at a profit much the same as a grocer buys and reselis household goods. It tends to create money when it buys Eoreign currency not because of the monetary aspect of foreign currency but because the purchase of any asset by a bank tends to create money, and the circumstances under which the purchase does actually create money are the same whatever the asset.

"Liquid assets" comprise a different subset of assets. Broadly, these are any assets, real or financial, which may be readily sold for money. Inevitably a subjective element is involved here, since the ease with which an asset may be sold depends upon what price the seller 1s willing to accept for 1t; it will also depend in an important way upon a particular transactor's knowledge of and contacts with the markets in which particular types of asset are sold: it will also depend upon the state of the relevant market at the time the asset is offered. Thus under some circumstances and for some transactors, inventory might be a highly liquid asset, whereas long-dated securities might not. These factors affect both the ranking of assets in relative degrees of liquidity and the determination of the particular segment of the liquidity spectrun which is readily realisable. Both will differ from transactor to transactor at the same time, and from time to time for any given transactor. One may distinguish some particularly 11quid assets, as e.g. bank time deposits, P.O.S.B. and other nfi. deposits, which do not require either capital loss or special knowledge to realise, but clearly no general concept of "liquid assets" can be defined.

Since the liquidity of an individual would also have to be defined to include what he could borrow and what he could buy on credit, even at the micro level "liquidity" could only 
mean in a very loose sense the maximum money and credit an individual thinks he could raise if he tried and if most other people were not simultaneously trying to realise their "Iiquidity" in this sense. We already know that this last condition prevents micro liquidity in any case from being aggregated up into macro liquidity. In a very broad sense, the monetary base can be expected ultimately to set some upper limit to the expenditures and purchases that can be made at any one time, but an extensive chain of interconnecting activities would have to be established in order to make any use of this idea. It is not impossible that some light can be thrown upon this by the simulation results.

We thus have the easier problem of dealing with "financial assets", which cannot however be equated with "liquid assets", are further removed from individual "liquidity", and carry no definable implications for "macro liquidity". Financial obligations may include all sorts of verbal or even tacit acknowledgements of debt, but we confine the term to those written down either in books of record or on pieces of paper which are recognisably debt instruments; these will include the records of trade credit extended, of loans outstanding, promissory notes, bills of exchange, cheques held for presentation, and in general any instrument which entitles the holder to present it for satisfaction by some stated sum of money either on demand or after a stated term.

When we take account of flow money as well as stock money we find that we do not need to amend the analysis of the "unit of account" aspect or the consequent implications for obligations expressed in foreign currency units, since the elements of the transactions matrix all represent payments whose vehicle is some form of voucher expressed as an entitlement to a "sum certain in money" where the money is in units of $\$ N Z$; the elements $B O$ and $R O$ are themselves implied by the discussion of units in foreign currency. Nor does it make any difference to the definition and analysis of the "financial assets". It must, however, enter into both causes and effects 
of changes in the financial asset stock. For example, the mere fact that a stock of money exists provides no assurance that any given transactor will hold money at the time he needs to make a payment; he must be able to get his hands on it by borrowing or by the sale of goods. Both will involve money flows, i.e. payments in one form or another which are represented in the transactions matrix.

For a transactor to borrow out of the existing stock of money, someone must previously have transferred an ldle bank deposit to nfi. Alternatively he may acquire flow money arising from ES, particularly by drawing on bank overdraft. His access to bank overdraft will depend, not only on his own general creditworthiness but also on the bank's free reserve position, and this in turn will depend partly on previous overdraft boxrowing and repayment by other transactors. In general, a transaction financed through $E R$ provides an increment to the money stock generally available if the recipient pays it into a creditor account, which he subsequently transfers to NFI, if the deposit is not thus transferred there will be an adition to the money stock which is not available to any other transactor, but which still reduces credit available from the bank; a payment out of one overdraft used to reduce another leaves credit availability unaltered. The effect of these transactions will also be modified where there are differences between the standards of oreditworthiness required or between the cash reserve against deposits held by banks and nfi.

As with money itself, the importance of financial assets at the macro level lies not in their aspect as a stock of wealth but in their relation to the payments flows, which are in any case needed to explain changes in the total stock. Whatever difference interest rates may make to individuals' asset preferences and portfolio adjustments, these differences must be traceable through payments flows if they are to affect the mal side of activity through the money-goods nexus.

This does not imply that the asset aspect of money or of 
a claim on money is of little importance, since the money available at any given time to particular transactors will depend directly or indirectly on the asset preferences of other transactors; it implies merely that the study of asset effects through the stock variables alone is not very illuminating even in respect of asset preferences, let alone in respect of their impact on spending. If the existing work on portfolio adjustment were supplemented by a more adequate analysis of the transmission mechanisms the conjunction of the two ideas might be very fruitful. Indeed, since the analysis of flows attaches importance to the responses and adjustments of individuals to their aaset configurations, a study of asset preference at the micro level is already implied.

In looking at the transactions flows in terms of moneygoods, money-debt and goods-credit exchanges, and in distinguishing numbers measured in money terms from those measured in real (physical) terms, we capture the essentials of the elements abstracted for study. But at this point we need to reverse the process in order to consider briefly how the representational form of the abstract structure relates to the actual economic activity whose selected aspects it is intended to represent.

Ackoff (1962) distinguishes three types of model, as follows:

Iconic: models representing the relevant properties of the real thing by those properties themselves, with only a transformation in scale; thus iconic models look like what they represent. For example, road maps and aerial photographs represent distances by distances and relative positions by relative positions, differing only with respect to scale. Another example is provided by the theoretical analysis (in money and banking texts) of bank operations in terms of $T$ accounts, since actual bank operations consist of entries to books of account.

Analogue: models in which one property is used to represent another; for example, colours or contours may be used on a map 
to represent height; on a slide rule quantities are represented by distances proportional to their log. Analogue models in hydraulic or electrical form have been used to simulate nacroeconomic flows; the flow charts in which such models may be represented may also theraselves be used directly as analogues of the same economic relations.

Symbolic: models in which properties are expressed symbolically; where the syrabols represent quantities, we have the traditional type of mathematical models.

One may discern elements of all three types in the simulation model under discussion. Transactions are represented as records of quantities of goods delivered and sums of money received or paid; stock variables in general are treated as entries in books of record. On the real side, there is thus no explicit representation of goods as goods, although the stock variables "inventory" may be seen as referring not to the goods directly, but to that tally or list of them (kept, as it were, by an actual tally clerk) which is kept up to date so as to show, at any instant of time, the actual 'stock in hand'. The stock of fixed capital on hand, treated in exactly the same way as inventory in the simulation model, is in practice however on a different footing; an actual inventory of fixed capital equipment is not usually kept, and the record kept by accountants is much more indirect and conventional.

\section{Physical processes of production are not directly} represented at all. To the extent that they give rise either to transactions, in the form of inputs delivered and paid for and output sold and pald for, or to additions of the produced goods to the stock on hand, they are implied by the corresponding records. Thus the events on the factory floor, in warehouses and between loading bays are represented only to the extent and by the sarne means as they are represented by events in the accountant's office. To the extent that the latter events may be taken as constituting an analogue of relevant aspects of the former, the simulation model may be seen as an iconic representation of the accounting analogue of some effects of production, at the point where those effects impinge on the external flows. 
Some parts of the model, as e.g. response mechaniams, may be represented symbolically in the ordinary way. The alphanumeric syrabols in which the whole programme is written constitute a symbolic representation of some aspects of economic activity; the programme may alternatively be reduced to a flow chart, which would then constitute an analogue of the economic processes symbolised in the programme.

This mixed form of representation suggests a rather different status for the money and real terms of the model. since the actual payments of money in transactions, the moneydebt exchanges, and the stocks of assets and liabilities, all consist in actuality of entries to various books of record or at least, as for example in the case of some flow money transactions, of lists of voucher amounts, the money side of the model is iconic, and hence corresponds closely enough to the events in the pudomain for the requisite measuring operations to be apparent. The real side of the model is more removed from the events it is intended to represent, and hence exhibits a further degree of abstraction inherent in analogue representation.

Thus to the extent that the money measurements indicated by the summarizing ideas of the simulation can in fact provide a reliable basis for tracking the monetary events in the model, then we can have some confldence that when such measurements are made in an actual economy they will measure what the theoretical structure calls for then to measure. What sort of contact they will enable us to make with the real flows remains to be seen, but at present we can expect that some information from the real side will be needed properly to interpret them. 
CHAPTER 4

SIMULATION OF MACROECONOMIC

TRAMSMISSION MECHANISIS 


\section{I IITRODUCTION}

An initial attempt to develop the detailed structure of the model along the Iines indicated by the discussion of the monetary nexus was carried some way beEore two major problems became apparent.

It had originally been thought that once the money elements had been separated out from the real or goods elements and related to the transactions natrix, the real side could be dealt with in terms of the ordinary input-output structure, supplemented where necessary by conceptualizations from orthodox capital and production theory; the essential place of the monetary nexus would hence be apparent as interactions between the real and money sides.

However, as the procedures defining the operations to be carried out were developed and the model progressively refined, questions arose on the real side which either could not be answered at all within the avallable conceptual structures of input-output, capital or production theories, or to which the answers provided by standard real theories were seen more and more to be unsatisfactory. This necessitated an encuiry into some aspects of the real side that I had not originaliy realised would be necessary, particularly concerning the treatment of thine. The consequent re-thinking reguired a substantial reformulation of the model and a complete rewriting of the programme, recorded by labelling the new formulation as "Mark 2 ".

Mark I will not be directly discussed, but section 4.2 below gives an account of some major difficulties found in the standard real theory, while section 4.3 gives the details of Mark 2 at a particular stage in its development. While the chapters of this encuiry are presented in what I take to be the correct logical oxder, it ought to be mentioned that in strict chronology the development of Mark 1 and the discussion of 4.2 preceded and in some ways gave rise to some of the fdeas mentioned earlier. 


\subsection{PROBLEMS IN REAL. SECTORAL ANALYSIS}

Since the problems examined in this section arose from an attempt to use standard input-output analysis to represent the ideas about the real processes set out above, a suitable link between the discussion of chapter 3 and the frameworks available from standard theory can be provided in that context. We firat discuss how input-output analysis deals with the idea of time; the separation of money and goods variables then requires a discussion of how input-output deals with the ainensions of the numbers it useg; this in turn raises the question of primary or factor inputs. Throughout this discussion the unifying idea is that of economic processes as physical activities occurring over time.

4.21 Time and Causation in Interindustry EConomics

As soon as we start thinking in terms of physical processes we immediately have to consider the fact that typically the intake of input supplies and the outward delivery of produced output ocour at intervals during the period over which the purchases and sales are aggregated into input-output tables. It is already obvious that the simultaneous equations approach completely neglects facts of this sort. ${ }^{2}$

Consider, for example, the basic equation set of inputoutput analysis, $x=y+A x$, where $x$ and $y$ are vectors of, respectively, total and final output, and $A$ is the matrix of intermediate input coefficients. If the requisite conditions are met, this has solution $x=(I-n)^{-1} Y$, which may also be expressed in terms of the recursion

$$
x=y+A Y+A^{2} Y+A^{3} Y+\ldots+A^{n} Y+\ldots
$$

Usually these two formulations are taken as equivalent, which involves that the recursion is understood as occupying computational time only and hence is simply an alternative way 
of producing the timeless solution directly obtainable by using the inverse. This is unexceptionable if the solution is understood merely in terms of an existence theorem relating to the numerical properties of the system, thus telling us only what numbers are to appear in the solution if it happens to be attained by an econony, not how, or indeed whether, the economy will actually work in such a way that its totalled weights and volumes of goods produced and used during the period agree with the calculated numbers. If the recursion is intended to carry a semantic interpretation, as implying a sequence of processes through which an econony progresses over calendar time so as to converge on the solution, then the individual terms of the recursion need to be dated.

It is apparent that the term $A^{x} y$ must occur in point of time between the terms $A^{x-1} y$ and $A^{x+1} y$, and we thus consider two possibilities: either the time subscripts run forward from $y$ to $A^{x} y$, or they run forward from $A^{x} y$ to $y$. Either choice presents difficulties. If we take the processes to run: $y_{t}+A Y_{t+2}+A^{2} y_{t+2} \ldots \ldots$ then the tenporal sequence makes sense in causal terms, in that the presentation of the final demands $Y$ gives rise to derived denands $\Delta Y$ in the following period, further derived demands $A^{2} y$ in the next period, so that the dispersion of derived demands for inputs initiated by the demands in time $t$ for final outputs, $X$, occurs successively in subsequent time intervals. But then we have the problem that the final output, $y$, is supplied before the outputs from other sectors, $A Y$, used as inputs in the production of $Y$, are available from production, and so on through the sequence. We thus have the additional task of explaining how the inputs are provided at the times called for.

If, on the other hand, we take the series to run the other way, i.e.: $y_{t}+A_{t-1}+A^{2} y_{t-2}+\ldots \ldots$ then the provision of input supplies follows the correct temporal ordering, but the so-called "derived denands" precede in time the initiatory demands for $\boldsymbol{y}$ from which they are presumed to derive. We thus have the additional task of explaining how the producers in 
times $t-1, t-2$ etc. are presumed to know what will be required of them.

Superficially, the first problem can be dealt with merely by regarding the demands as each supplied in the first instance out of inventory, the production of the amounts required at each interval being undertaken for inventory replacement, the inputs for such production being again supplied out of inventory. As we shall see later, this raises further problems when inventory is inadequate to supply the requisite demands at the time they are made, and suggests a rather more explicit structuring of denand and inventory responses as a necessary condition of the viability of the system, even when the numerical structure satisfies the mathematical conditions for the existence of the solution mentioned above.

The second can be dealt with by assuming some anticipation of final demands, which then raises the question of how the system behaves when demands are anticipated wrongly, or when correctly anticipated demands cannot physically be met. Certainly, trade cycle theory suggests rather strongly that any divergence from the "equilibriur" values will tend to produce strong positive feedback effects away from the solution path. ${ }^{2}$

In the case, therefore, of an input-output model constructed from data on the processes of a market aconomy, the relation $x=y+A x$ may stand as an ex post accounting statement of the results of aggregating over purchases and sales, but provides no basis for an analysis of the processes whose results are so aggregated, thus, in the absence of a specification of the ways in which the activities of transactors are brought into conformity with the macro solution, the sense in whlch the numerical solution $x=(I-A)^{-1} Y$ is interpretable also as an economic solution remains inpenetrable.

This is in any case only the beginning of the matter. Once the dating of input supplies in relation to demands for output is under question, further problems are raised by a 
consideration of any one term in the recursion, $A^{x}$. This stands for a complex of activities in which all sectors of the economy are, by impliation, sinultaneously involved. But in practice, the production activities of one establishment do not commonly all occur together; production takes time, and during the period involved inputs may be called at intervals depending on how they are used in production, and for some types of industry output is coming off the production line during the course of the period. All establishments do not in general begin production at identical dates, nor call for inputs together, nor augment the supply of saleable outputs together. Thus some groups of industries may be able to pass through several terms of the recursion in the tire that it takes a sector with a longer production period to finish one. The conformity of input supplies and demands may aghin place heavy reliance on inventory in order to cope with these differences in timing.

In general, the simultaneous eguations approach yields merely the simple time schera as follows.

solution solution solution solution solution solution

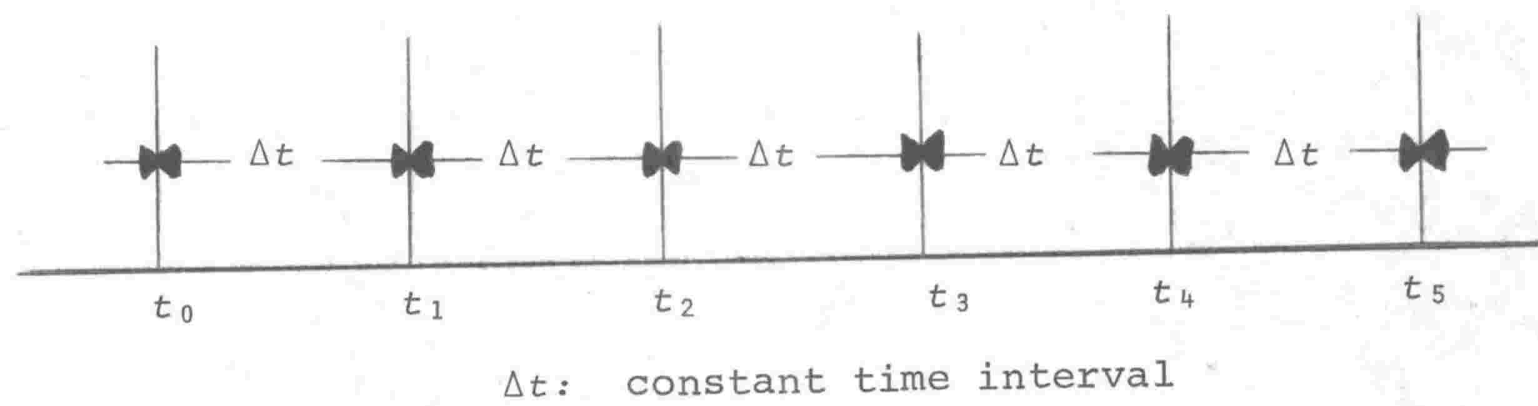

Where the time interval $\Delta t$ is referred to the individual terms of the recursion, 1.e. to the interval between $\lambda^{x} y$ and $A^{x+i_{y}}$, rathex than to the interval between successive solutions $x_{t}=(I-A)^{-1} Y_{t}$, and $x_{t+1}=(I-A)^{-1} x_{t+1}$ some minimal approach to economic sense is made, but it does not go far enough and there is no reason why it should stop there. Moreover, there is inevitably a tendenoy to confuse the period over which data 
are aggregated into the ex post accounting schema, with the period over which the actual processes physically take place. In fact, some effort is usually made to reconcile the ex post record with the actual timing of production periods particularly for long-period and seasonal production, but it is obviously more meaningful to divorce the ex post aggregation period from the timing of physical activity altogether. Given the ideas of duration of econoric activity and of the sequential ordering of transactions Ilows which need to be allowed for, the reguired time schema is moxe adequately presented as follows.

aggregation aggregation

aggregation

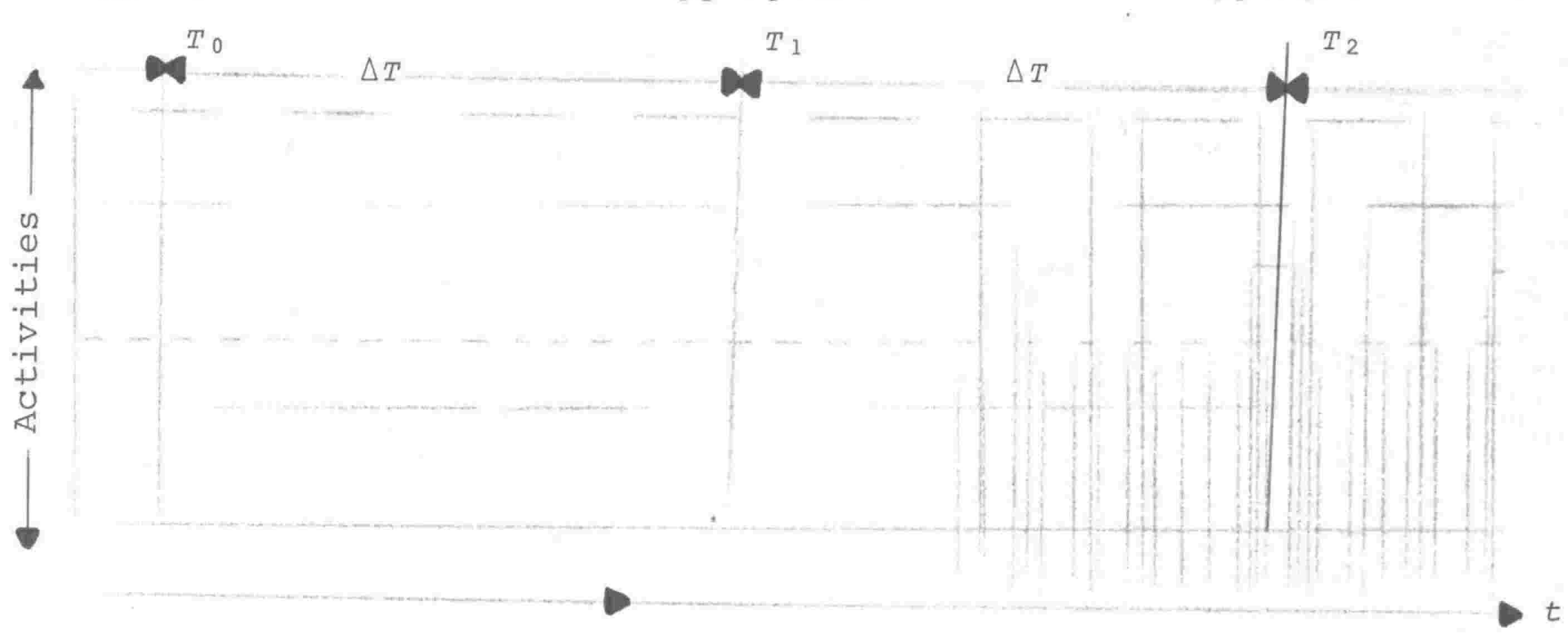

The actual duration of time is represented by the length of the lines representing different types of activity; the sequential ordering is represented by the time instant t, which may be seen as sweeping over the time surface from left to right. Every time it impinges on an element of any transactions process, it represents the instant of time at which that activity occurs. Since the time elements captured by the sequential ordering are thus reduced to a linear relation, it 1 s necessary that each impact of $t$ with a particular activity should carry to the linear representation a signal recording the transactor affected and the activity occurring.

This enables us to separate out the aggregation period as a different sort of time interval $\Delta r$, which for comparability is kept uniform in length but otherwise may be arbitrarily 
chosen with respect to calendar time. No general relation between $T$ and $t$ is definable, ance $t$ is not inspected except in terms of the instants at which something of interest is happening, and the number of such instants, determined by the number of impingements during a given aggregation period, may vary. Any particular $\Delta F$ may however be related to $t$ through regarding the operation of aggregation as itself an activity occurxing at a particulax point of time, and hence representable in the linear representation of the time instant impingements on the activities of the system. Thus the emphasis is on sequential ordering rather than duration, as long as we are looking at the macroeconomic aystem of flows, but it may well be that a more explicit treatment of cilendar time will need to enter into mieroeconouics as it tries to make contact with the physical facts underlying the accounting analogue.

This treatment of time raises obvious questions about the prinary inputs - particularly capital, which available theory does not appear to have gone into, but as additional questions will be raised by the consideration of dimensions we turn first to that consideration.

\subsection{THE DIMENSIONS OF THE HUMBERS}

The requirement that we must be able throughout to distinguish clearly between numbers standing for quantities of goods and numbers standing for sums of money raises questions about standard input-output analysis, which in principle is defined for real transactions but in practice is based on measurements of money transactions, the inputs being measured as purchases and the outputs as sales. This ambivalence of meaning is generally recognised ${ }^{3}$ but its implications are not usually followed up. An obvious reason for this is the widespread attachment to empiricism, which dictates that where measuring operations specified by theory cannot be carried out surrogate measurements which are feasible are used instead. One can have some sympathy with this practice when, as in the 
measurement of physical inputs and outputs, the difficulties are so great. Nevertheless, the substitution is defensible only if the surrogate numbers can be adequately connected with the terms of the theory, and we therefore need first to consider the problem in terms of the conceptual structure defined for numbers measured in physical dimensions.

The questions that need to be asked are as follows:

(i) To what extent are the operations carried out on the puxchases-and-sales table also definable for the input-output table?

(1i) To what extent may genuinely dimensionless numbers be constructed from the dimensioned numbers with which the table begins?

(iii) Is the difference between purchases-and-sales (in sums of money) and inputs-outputs (in physical quantities) a matter of the definition of the monetary standard only, or is something more fundamental involved?

(iv) How far does the money dimension of measurement provide a genuine escape from the index-number problem which is bound to arise in using physical dimensions?

An article by Augustinovios appears to offer sone help in tackling these, and we shall relate the discussion to that article. We first define the input-output structure as follows:
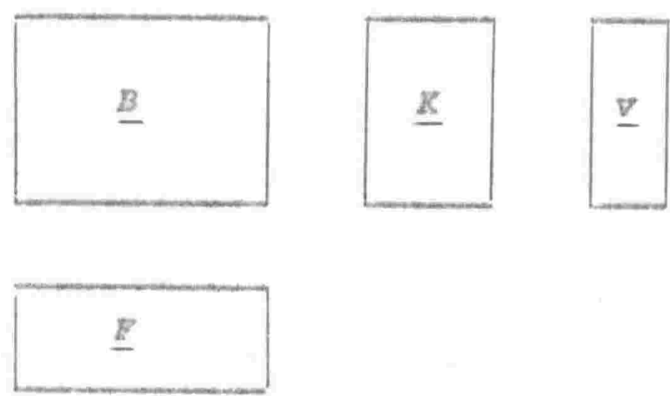

$$
\begin{aligned}
& \underline{B}_{(n, n)} \approx\langle\lambda>B . \\
& \underline{K}(n, z)=\langle\lambda>K . \\
& \underline{V}_{(n, 1)}=\langle\lambda>v . \\
& \underline{F}_{(s, n)}=\langle\alpha\rangle F .
\end{aligned}
$$


$\underline{B}$ is the matrix of intermediate inputs and outputs, specified with respect to the dimensions of measurement. $\underline{x}$ is the matrix of final demands or goods supplied to final users, and $\underline{v}$ is the vector of total outputs. It is evident that in this structure the dimensions of measurement chosen are those in which output is specified; taking each sector's output as specified in 1 ts own appropriate units, as it might be tons, gals, kwt-hrs, etc, we form the vector $\lambda, 1 . e$.

$$
\lambda=\left[\begin{array}{c}
\text { Tons } \\
\text { Gals } \\
\vdots \\
\text { KWt-Hiss. }
\end{array}\right]
$$

Adopting the convention that frora any such $n \times 1$ vector of dimensions may be constructed an $n \times n$ diagonal matrix from corresponding elements, we separate the dimensioned numbers of measurement into their two couponents, the unit of measurement being shown in $\langle\lambda\rangle$, and the pure numbers as above. With these amendments we adopt the remainder of Augustinovios' notation.

The first lmportant point about the structure as defined is that we can no longer rely on the accounting convention by which the column sums yield a vector identical with $v *$, as in the corresponding teras of Augustinovics' analysis. This is implied by the designation of a separate set of dimensions for the elements in $F$, the primary input matrix. It is the intention here to convey that primary inputs are measured in dimensions appropriate to the types of input, not in output dimensions. This is obviously necessary if we are to retain any concept of e.g. labour productivity, since that concept requires us to think of output per unit of input, which cannot be done if the unit of input is the unit of output.

But, even for those matrices whose elements are defined in units of output, column sums are not definable. By construction, $B_{1}+k_{2}=v$, since $v$ is defined as the sum of 
intermediate plus final goods sold. This identity carries over into the dimensioned numbers, for

$$
\underline{B}_{1}+\underline{\underline{K}}_{1}=\langle\lambda\rangle B_{1}+\langle\lambda\rangle K_{1}=\langle\lambda\rangle=v=\underline{v}
$$

The operation $I^{* B}$ may be carried out on the pure numbers, but 1 I. is semantically uninterpretable in any way that makes economic sense unless $\underline{B}$ is defined as $B<\lambda>$, which would obviousiy be inconsistent. If we were to adopt the definition of $B$ in input rather than output terms, then $1 * \underline{B}$ would be meaningful but a similar problem would arise for $\underline{B}_{1}$.

Thus Augustinovics' (2) cannot be defined if the semantic interpretation is required, although $2 * B$ can always be defined for the pure numbers. As $E$ has been specified here, not only would a similar problem arise with $2 * \underline{F}$, but it is hardly 11 kely that the reguired identity, $2 * B+2 * F=v^{*}$, would hold even for the pure numbers since the measurements of the elements of $\underline{E}$ are conceived in dimensions appropriate to the primary inputs, as e.g. man-hours of labour; own units of capital would 
Writing the dimensionless constructs to correspond:

$$
\begin{aligned}
& \underline{B}=\langle\lambda\rangle B \downarrow\langle\lambda\rangle^{-1} \\
& \underline{\vec{B}}=\langle\underline{\nabla}\rangle^{-1} \underline{\underline{B}}=\langle v\rangle^{-1}\langle\lambda\rangle^{-1}\langle\lambda\rangle B=\vec{B}
\end{aligned}
$$

On a simizar argument to that concerning $\underline{\underline{B}}, 1 * \underline{\underline{R}}$ ls excluded, and thus (4a) is without dimensioned equivalent.

$$
\begin{aligned}
& \underline{\vec{K}}=\langle\underline{\underline{\underline{K}}}\rangle^{-1} \underline{\underline{K}}=\langle v\rangle^{-1}\langle\lambda\rangle^{-1}\langle\lambda\rangle K=\vec{K} \\
& \left.\underline{E}^{\dagger}=\underline{F} \underline{\underline{v}}\right\rangle^{-1}=\langle\alpha\rangle p\langle\nabla\rangle^{-1}\langle\lambda\rangle^{-1}=\langle\alpha\rangle F \downarrow\langle\lambda\rangle^{-1}
\end{aligned}
$$

Thus $E \downarrow$ is a dimensioned matrix of primary input coefficients; if the $i^{\text {th }}$ row of $\underline{F}$ contained labour inputs (in man-hours) and the output of the $\bar{f}^{\text {th }}$ sector were measured in tons, then $F^{4} 1, j$ would show the labour input in man-hours per ton of sector $f^{\prime} \mathrm{s}$ output.

$$
\begin{aligned}
E=\langle\underline{F} I\rangle^{-1} \underline{E} & =\langle\langle\lambda\rangle F I\rangle^{-1}\langle\lambda\rangle F \\
& =\langle P I\rangle^{-1}\langle\lambda\rangle^{-1}\langle\lambda\rangle F=F
\end{aligned}
$$

Although $\underline{\underline{b}}$ is not dimensionless, $\underline{\underline{v}} \underline{\underline{v}}=\underline{B} \mathbf{2}$, so that substituting into (1b) we obtain

$$
\underline{B}+\underline{v}+\underline{\underline{Z}}=\underline{\nabla}
$$

whence $\underline{R} I=(1-\underline{E}+) \underline{V}$, and a dimensioned equivalent (7c) can be wxitten for (7a) if the inverse is definable. We assume that the Hawkins-simon conditions ${ }^{5}$ are met for the dimensionless numbers $B \downarrow$, so that the series $I+B \downarrow+B t^{2}+\ldots+B t^{n}+\ldots$ converges to the limit $(I-B \downarrow)^{-1}$.

In the case that $\underline{B}^{T}$ has the dimensions of $\underline{\underline{t}}$, $1 . e$.

$$
\underline{B} \downarrow^{2}=\langle\lambda\rangle B \downarrow^{2}\langle\lambda\rangle^{-1},
$$


then

$$
\left.\underline{B} \downarrow^{x+1}=\langle\lambda\rangle \underline{B} \downarrow\langle\lambda\rangle^{-1}\langle\lambda\rangle \underline{B} \downarrow^{x}\langle\lambda\rangle-1=\langle\lambda\rangle B \downarrow^{x+1}<\lambda\right\rangle^{-1}
$$

This case holds for $x=1$, and so for all terrs of the series, so that $I+\underline{B} t+\underline{B} t^{2}+\ldots \underline{B} t^{n}+\ldots$ can be written as $\left.\langle\lambda\rangle\langle\lambda\rangle^{-1}+\langle\lambda\rangle B \psi\langle\lambda\rangle^{-1}+\langle\lambda\rangle B \psi^{2}\langle\lambda\rangle\right\rangle^{-1}+\ldots+\langle\lambda\rangle B \psi^{n}\langle\lambda\rangle^{-1}+\ldots$ which converges to the limit $\langle\lambda\rangle(I-B t)^{-1}\langle\lambda\rangle^{-1}$, which may be written as

$$
\begin{aligned}
{\left[\langle\lambda\rangle^{-1}\right]^{-1}(I-B \downarrow)^{-1}\langle\lambda\rangle^{-1} } & \left.=\{\langle\lambda\rangle(I-B \downarrow)<\lambda\rangle^{-1}\right\}^{-1} \\
& =\left(I-\left\langle\lambda>B \downarrow\langle\lambda\rangle^{-1}\right)^{-1}=(I-\underline{B}+)^{-1}\right.
\end{aligned}
$$

Thus:

$$
(1-\underline{B}+)^{-1} \underline{\underline{K}} \mathbf{I}=\underline{v}
$$

and, writing $\underline{\text { Q }}+(1-\underline{-B})^{-1}$

we re-write (7c) in the form

$$
\underline{Q} \underline{\underline{K} Z}=\underline{v}
$$

liaving prohibited (2), then we cannot derive dimensional. equivalents for $(6 b)$ and $(7 b)$, and conseguently for $(8 b)$ and (9b). Since equivalents for (4a) and (3b) are excluded, so are equivalents for $(10 a)$ and $(10 b)$. Thus neither $Q \$ \underline{k}$ nor $F Q$ can be defined, and since the point of the article's main argument is to relate these the analysis cannot be pursued further.

We may now atterpt answers to the questions asked above.

(i) The basic relation $x=y+A X$ continues to hold for dimensioned input-output tables specified as above, and the solution $x=(I-A)^{-Y} Y$ is meaningful in dimensioned form. While we cannot move directly to a relation between inputs and outputs by constructing $\underline{\underline{F}} \downarrow \underline{Q}+\underline{K}$ and $\underline{\underline{O Q R}}$, a meaningful relation can be constructed to find primary input reguirements for any given array, $\underline{\hat{K}}$, of final outputs. The required total outputs are given by $\hat{\underline{V}}=\underline{Q} \downarrow \underline{\underline{X}} I$, whence $\hat{\underline{F}}=\underline{\underline{F}}+\underline{\hat{v}}$ 
$=\langle\alpha\rangle F+\langle\lambda\rangle^{-1}\langle\lambda\rangle \hat{v} \equiv\langle\alpha\rangle P+\hat{v}$, which yields the result expressed in the reguired primary input dimensions. The remainder of the operations defined for the accounting identity do not appear to survive in any meaningful way in dimensioned form.

(11) Sme dimensionless numbers may be constructed, as e.9. $\underline{\underline{E}}, \underline{\underline{E}}$ and $\underline{\vec{E}}$, but these do not relate to anything useful in the absence of the derivations from them for shich they were constructed. We may also, for most purposes, prefer in this context to deal with the dimensioned numbers, which not only play a more useful part analytically but also carry meaningful interpretations in their own right. It is not clear that $\underline{Q}^{+}$will in fact be relied on if, as the abandonment of a simultaneous equations approach suggests, it is operations of the form

$$
\hat{B}_{t}=\underline{F}_{t} \underline{B}^{\downarrow} t \hat{K} I_{t}
$$

that will be more important. In this case, the Identity (Ib) will relate to the ex post record of activities over some aggregation period $\Delta r$, so that if (90) is used at all it would be only as a means of checking the procedures by which $\underline{B}$ and $\underline{x}$ were derived. It is apparent that once we drop the accounting identity the basis of measurement of the numbers inserted in $\underline{Z}$ becomes more important, and we examine that in section 4.23 below.

(iii) The definition of a monetary standard, providing a uniform dimension of measurement, would make sense of the entities formed from $I^{*} \underline{\underline{B}}, t^{*}$ and $2^{*} \underline{\underline{Z}}$ as totals of money expenditures on certain subsets of inputs and outputs; this alone would not, however, rescue identity (2) which is dependent directly on the accounting identity. The quastion, ultimately, is whether the money expenditures constitute an 
accurate measure of the real inputs and outputs, and this question has to be answered before it can be known what operations are admissible. It therefore precedes the argument ${ }^{6}$ which supports the conclusions that "the 'output approach' model expressed in value terms is independent of the price and valuation systems" stid that "In the 'input approach' model the ratios between two types of inputs used in two absorbing sectors are incependent of the price and valuation systems".

To the extent that questions about the price and valuation systems arise from purchasing power parities in international and intertemporal comparisons, then the definition of an appropriate monetary standard would suffice to deal with them. But if the questions are more fundamentally a matter of the basis of valuation, i.e. of the relation between the money measures in terms of the monetary standard and the real measures in terms of the technically-determined physical requirements of production, then Augustinovics' constructs depend upon a prior and independent settlement of those questions and cannot offer a way round them.

(iv) The index number problem can thus be seen to have two elements. The first is concerned with adding up incommensurables, 1.e. the operations as e.g. I"B, the second is concerned with the functors of measurement.

Consider the money sum: $s_{k}=\Sigma_{i} p_{i k^{q}}{ }_{1 k}$. The choice of $q_{1 k}$ is obviousiy a matter of what is to be measured, in terms of what characteristics are required of the theoretical term. Now, if the functors selected for measuring the $g_{i k}$ are based upon the technical characteristics important for production, and if the weights attached to them for summing, the $p_{i k}$, are correctly chosen, then the production function in 
money terms $p_{k}(\$)=f_{k}\left(p_{i k} q_{i k}\right),(1=2,2, \ldots n)$

differs from the function expressed in physical terms only by some constart: arising from changes in the value of money in which the $p_{i k}$ are measured, and this is dealt with adequately by appropriate choice of deflator. In this case, the operation $p^{*} \underline{B}$ is a legitimate way of getting round the inabilicy directiy to perform $1 * \underline{B}$, and the deflated money sums resulting are able to be construed as measures of the "real" aggregates. But supposing that the money sums are all that can be observed? That is, suppose that what is actually measured in the fixst instance is $s_{k}$, and that neither the $p_{1 k}$ nor the $q_{i k}$ are known? or that data may be collected on some prices and quantities, but that the production function is not known, and the relevant characteristics of the physical components of the arguments of the production function are not known? Both of these cases reduce to the same result, since the analysis has no basis to enquire beyond $s_{k}$.

In this cass, two paths are open. The first is to deflate the money sums $s_{k}$ in order to correct for variations in the unit of money dimension, but instead of treating the result as "real" entities to regard them sti11 as money sums. Thus $B \downarrow$ would be interpretable only as indicating the proportionate expenditure on inputs, not the technically-derived input coefficients. Sintlarly, it would not be possible to derive $\underline{\underline{Z}} \downarrow \hat{\underline{v}}$ expressed in required manhour input, but only $p \downarrow \hat{v}$ as a statement of factor expendituxes required out of given total sales receipts. The accounting identity would obviously be applicable here.

The second path is to suppose, by what must under the circumstances be a blind act of faith, that the money sums actually pald over are a good measure of what, if one had been able to start from 
a specification of the requisite functors and aggregation weights, one would have arrived at. Given this act of faith, no objection is raised to regarding the result of deflation as a measure of the real inputs. Where the money sums paid out are determined by the processes of a market economy, stis nltimately reduces to the validation of this interpretation by an appeal to the Ricardian realexchange equilibrium, and gdaing to this the Risardian basis of valuation of labour imput a direct path to the Augustinovics input-output analysis is open.

It is always possible to construct, on some such basis, a special case as follows:

IF we restrict the vectors $x_{1}$ of inputs to welldefined production functions, continuous in the $x_{i}$, so that the veator of outputs might be written $y=y\left(x_{i}\right)$ $(i=1,2, \ldots n)$.

AND IF we add also the restriction that the $y$ are linear homogenous, so that $y=\sum_{i}\left(y_{x_{1}} \cdot x_{i}\right)$.

AND IF we add further the restriction that

$$
\frac{{ }^{y} x_{i}}{p_{x_{i}}}=\frac{y_{x_{j}}}{p_{x_{j}}}=k \quad(1, j=1,2, \ldots n)
$$

THEN

$$
y=k \Sigma\left(p_{1} x_{1}\right)
$$

With these restrictions the cost of output is a valid measure of the amount of output. There may be other such spacial cases, but such cases are clearly mathematical curiosa only. Certainly theze is no reason to suppose that the balancing residuals arrived 
at in practice can be justified on any such grounds, and the accounting identity is devoid of economic significance.

In the general case, if the $q_{i k}$ entering into the sum $s_{k}$ are meaningful then their meaning derives 2xore their connection vith production processes; an input of $x$ gallons of milk is not the same measure as an input of $y$ 1bs. of butterfat, and it is no accident that the processing works measure these inputs differently according to whether the required output is whole milk for town supply or butter, cheese etc. What is the appropriate functor in which to measure car output? ${ }^{7}$ We can, for example, measure the output of electric drills in numbers of machines, horsepower rating etc. Consider, say, the suming of two types of drill into one output figure; suppose that we have 800 drills of thp e $\$ 20$ and $200 \mathrm{drills}$ of $3 \mathrm{hp}$ a $\$ 30$.

These can be aggregated as either 1,000 drills or $300 \mathrm{hp}$. Since the value sum is the same, the aggregation in value terms is thus 800 a $\$ 20+200$ e $\$ 30$, or $200 \mathrm{hp}$ a $\$ 80+100 \mathrm{hp} \theta \$ 60$. But these two formulations are not simply different ways of saying the same thing. They offer us a genuine cholce between two mutually exclusive ideas of what are the relevant and significant aspects of economic activity for the purpose at hand, the usual practice of ignoring this difficulty altogether is evidence not of the superior merit of aggregation in value terms but rather of 3 ts power of obfuscation.

The mexe fact that, once the money sum $s_{k}$ has been determined, any selection of the $q_{i k}$ and $p_{i k}$ must combine to give the same result, so that for any alternative $g_{1 k} q_{i k}$ alternative prices rist be found so that 


$$
\Sigma_{1} p_{1 k} \cdot q_{1 k}=\sum_{1} p_{1 k} \cdot q_{1 k}=s_{k}
$$

does not make the choice of the $g_{i k}$ less significant. The importance of this point cannot be overstated. If the real variables defy measurement then there is no feasible measuring operation in terms of which observable counterparts for the real variables in the theory can be defined, which surely renders the real side of economic processes impenetrable to observation and description. Moreover, fallure to find meaningful functors for the real terrs necessarily implies also a fallure to find an economically meaningful basis of aggregation in value dimensions; for how can we speak meaningfully of the price per unit of input or output: if we cannot derine meaningfully the unit of input or output?

Thus aggregation in value terms only gets round the minor part of the index-number problem, i.e. that concerned with the surs $2 \mathrm{~B}$. It is still dependent for its maning on a satisfactory interpretation of the elements $\underline{n}_{1 f^{\circ}}$. Thus, where the $\underline{B}_{1 f}$ are measured, in the first instance, as money sums of the type $s_{k}$ ' then their meaningfulness is dependent on a proper choice of the $q_{1 k}$ entering into these money sums. In respect of intermediate inputs and outputs there is probably less occasion for concern, since the firms supplying data for, e.g. Industrial production statistics, may be supposed to know why they want the inputs and how they enter into the production process. This does not aispose of the matter, for if the production functions are such that inputs have to be combined in specific proportions then market power may affect their relative prices. On the other hand, fixed proportions would make the technical combinations easier to arrive at directly through some volume index. But what can be said of the primary or factor inputs, 1.e. the components of $\underline{p}$ 
4.23 CAPITAL IN InPUT-OUtPut Amalysis

The concept of "capital inputs" is not at al.1. well-defined in the theory, and is generally no more than a hazy conflation of several quite distinct ideas. As the model is generally constructed and as the data put into it is variously interpreted in terms of the model, it fecomes quite impossible to separate out the following rather important concepts:

(a) The capital stock actually employed at any one time by a given sector.

(b) The aifference between the capital stock which a given output requires and that which is actually used.

(c) The entirely different decision periods required respectively to set a level of output, according to current targets, within the capacity of the capital, and to make substantial changes in the capital stock itself.

(d) The concept of "Inputs of capital", if any, which would carry the same current connotation as "inputs of raterial".

(e) The concept, defined technically, of the 'length of the period of production".

Where the actual numbers used in "empirical" work are the accounting residuals preserving the required productexhaustion identity, their contact with any of these concepts becomes decidedly tenuous. Since such numbers do not even connect with actual factor payments for capital inputs, they cannot be saved by the ultimate resort of treating all payments for inputs as direct neasures - validated by the Ricardian/ Walrasian framework - of factor inputs. While one may have considerable sympathy with those pragmatists who use the ex post accounting data for want of anything better, it is clear that. the contact that input-output analysis in 1 ts usual form can make with capital and production theory is negligible. Iven 
1f we were to interpret the accounting residual, without much justifleation, as actual payments for the factor, capital, any connection with capital and production theory would have to asstme quite definite restrictions on the methods and the periods of production for which the model is defined.

The capteal-output ratio is normally defined in annual teras, by sector. The observable which if actually measured is the ex post book return to oapital for the period of aggregation, which need have no ascertaluable connection with either the shareholders' rate of return on their money eapteal, or the technically determined physieal capital-output ratio. In practice, this ex post accounting residual has to do the Lollowing jobs:

(1) to provide a "capltal coefficient", Inserted in the computation to provide a nuaber for "capital" Input to the eonuputed output:

(1i) to provide a neasure of "capital usage",

(11i) to provide a measure of "capital reguirement", both to operate as a constraint in the short run on the output level that can be sustained with a given capital stook, and to operate in a longer run as an argurant in investwent functions.

If the period over which oftea is aggregated is ohosen axbitraxily, or, what amovnts almost to the same thing, in terms of annual accounting records, then we are forced to assume that all production periods throughout the econony correspond to the same choice of calendar year. If the period of aggregation is insteal chosen according to sone "representative" production period, then the model is a little less restrictive but is atill subjeat to the presupposition that all activities in the econony can usefully be represented, not only as occupying the same length of time, but also as starting and Iinishing at identical initial and terninal dates. 
Regarding production as essentially a matter of applying physical transformations to raw materials in order to sult thers to final uses, we draw on some initial ideas from Chenery ${ }^{8}$

"2he concept of production as the appliation of energy to materials leads to a division of economic inputs accoraing to their technological function. The basic distinction is between inputs which form part of the final product (materials) and those which do not (services)... the material inputs 'receive' energy while the service inputs supply 1t. The lattsx will be callea 'processing factors'."

"Processing sactors may have one of three functions: to supply enexgy! to transform the energy which has beon supplied into another form, or to control the process."

"Process variables include both the quantity of an input or output and 1ts other dimensions or "qualities"."

For our purposes we designate materials and fuel sources as 'intermediate' inputs, and equipmont and labour as the 'prinary' Inputs from 'capttal' and 'labour force'. Since, as the discussion in chapter 3 indicated, the actual physical processes will not here be represented, we shall not try to incorporate the main constructs from Chenery. It is, however, necessary to define the recuisite terms into the conceptual structure if the macro thecry is to malntain contact $w$ th the wicro theory, particularly in respect of the recording of primary inputs and in respect of the operation of physical constraints on production. 'Capital', then, may have any of the 'qualities' of size, welght, horsepower, speed, kilowatt capacity etc. Any of these qualities, which ever is appropriate, may be defined as the attribute with respect to which the units are reguired to be (sufficiently) homogeneous within a given sector, thus defining the functor of measurement in the first instance.

We now distinguish an entirely different concept, that of 'production capacity', as follows. It is understood that 
some physical quality is to be sought in respect of which intersectoral material inputs and outputs may be taken as homogeneous, thus constituting the basis of their measurement in physical dimensions, Defining also a time dimension (which as the discussion in 4.21 indicated would require a concept of 'auration' in microeconomics) then a 'production capacity' has the form: physical untt $x$ time unit, as we right speak of, e.g., a production capacity of 'm tons per ala', which is clearly equivalent, as a measure of 'production capacity' to ' $6 \mathrm{~m}$. tons per 6-day week'. In such a neasure, the cholce of time period in thich 'production capacity' is to be expressed is obviously arbitrary. There 1s, hovever, at least for some types of proâct, a sense in which there is a minimun time pariod for which it is meaningful to define 'producsion capacity'. This is most easily seen in ono-off, custombullt projects, as e.g. Awokland Harbour Bridge. While, if this takes 500 days to construct and erect, we can express the 'production capacity' of the labour and capital used as 1/500 Aucikland Harbour Bxlages per day, this is not particularly meaningful; clearly, we may designate the 'period of production' of A.H.B. as 500 days as the minimur period of time for which the 'production capacity' may be meaningfully defined.

In this case, the concept of 'corpleted output' is unequivocal. In such a case, the minimun time period is clearly definable as that for which a given amount of equiprent is tied up, 1.0. committed to the production of a given output, from which it cannot be diverted without forgoing the output. In some industries, examples are easy to find: in agriculture, land used for a particular crop is tied up in the production of that crop during the perlod between sowing and harvesting; in ceramies, the kilns are consatted to particular batches for the duration of the firing process. As long as the production process is one which takes place in identiflable segments of output in 'runs' or 'batches' or 'crops', no problem occurs in isolativg a unique time interval.

There are obvious affficulties where output is continuous, 
or nearly so, as e.g. in electricity and beer production; it is doubtful whether there can be isolated a uniquely meaningful time period for car production; is the unit of output a car, in which case the relevant period would be the time between the arrival of the materials actually going into one aar, and the completion of the finished product? It is not in any case clear that this direct identification of given input materials with specific units of output could be made. Is it the entire run of one model? But there is plenty of opportunity to make minor modifications without changing either the wajor structural and engineering characteristics, or the main body pressings. It does seem to be the case that where the unit of product is hard to define, so too is the 'production period'; accordingly, it appears that the empirical specification of the production periods for different industries must rest upon a great deal of work, yet to be done, of fincing some measure of output in physical terms.

As that work would require a major research prograrune itself, it is outside the scope of this enquiry; we can here only present the definitions and implications of a view of production as a process occurring through time, and hence related to a definite duration.

One obvious implication follows directly. Given the cooperating inputs of labour, energy and materlals, if $n$ machines can produce a batch of $x$ unlts of output in one week, the sane machines can produce $2 x$ units of output in two weeks. If there are a such production periods in a year (or other period of ex post aggreqation), than if the capital is kept enployed throughout the year we should find a total output of ax produced by $n$ machines. On the usual basis of computing technical coefficients, we should then have to say that the capital output ratio (or capital coefficient) was $\mathrm{n} / \mathrm{ax}$; if for some other industry, there were is periods of production in a year, and if in each of those $m$ machines were used to produce $y$ units of output, the capital coefficient, ex post, would similarly be m/by. As long as both capital inputs and outputs are measured in theix own physical dimensions, these ratios are strictly non-comparable; 
in value terms a quite spurious corparison might be made, and if the difference between $b$ and $a$ were not reckoned into this comparison, an antirely misleading view of the relative sizes of capital coefficient in the two industries would result.

The exror is compounded if the capital in either industry is not fully employed throughout the pariod. Whether, in the first example, full batches of $x$ are produced for the first half of the year, and none at all, for the second, or whether the capital is kept working for the whole perlod at half capacity, the total output from the $n$ machines for the year will be kax, the capital coefficient thus becoming greatly overestimated as $2 n / a x$.

If this ex post capital coefficient be interpreted also as the capltal requirement, then as between two successive periods, in which capital is underutilized in the first but fully employed in the second, the computation will indicate a reduced capital requirement, which presumably will be 'explained' in some catch-all term as e.g. 'technological progress'. It may also suggest the presence of a constraint where none exists.

If the correct production periods be used as the basis for calculating capital coefficients, they then may properly be interpreted also as capital requirments, provided that the capital is fully used. If, therefore we have a clearly defined production process, such that the conpletion of all transformation processes within the given plant applied to an identifiable batch of $*$ units of output occuples $d$ days and $1 f$, within the production period so defined, $n$ machines are able to produce one batch of $x$ units within this production period when they are fully employed, then clearly we have:

Production period: $a$ days. Capital coefficient: $n / x$. production capacity of $n$ machines: $x$ units per $d$ days. 
Capital usage cannot be measured in these variables alone. Let us suppose that duxing a given production period, $x_{1}$ units are in fact produced. The capital requirement provides the constraint:

$$
x_{1} \leqq(x / n) n
$$

The capital. Input is measured as (n $x$ days employed), so that one measure of unemployed capital is immediately available as n.d - capital input. Fhis is not the only measure required, however; it would be an appropriate measure where, for the production period, either less than $n$ machines were employed, or the machines wexe used for less than $d$ days. Nelther of these seems consistent with the definition of a production period, but there may be some cases in which the size of the 'batch' is a matter of general practice rather than technical necessity; for some processes, the plant may have to run at the same speed or operating teraperature whether the batch is full-sized or not, and in those cases the capital input is iikely to be largaly independent of the size of the batch up to maximure cagacity, in others, some scope may be avallable for reducing the capital input when the batch is reduced for other reasons; since these different technical considerations w111 undoubtedily affect production decislons under some circumstances, they ought at least to be definable in the model.

If the 'production period' concept had to do the work of providing the above varlables only, it vould obviously be possible, by appropriate definition of the 'batch size', to eliminate this distinction. But the 'production period" concept has also to convey some notion of a decision period; and if, in some given industry, general practice is to conmit capital in larger batch sizes than would be strictly necessary on technical. grounds, then this becomes the operative period for short-run production decisions.

We may then directly define the two important decision periods: that over which $x$ may be varied, for given $n$, and 
that - in general a much longer period - over which $n$ itself might be varied.

Neither decision period is dependent upon which period is selected as the basis for aggregation, and indeed this is now free to be arbitrarily chosen, provided the concepts are first defined for each sector in terras of its own production period, then the common period of aggregation need present no problems, as long as due care is taken to provide for inventory and work in progress elenents when incomplete portions of production periods are included.

It is not necessary for this model to use the concept of a "production function", but since that concept is undoubtedly reguired fox other areas of production theory, we ought to be able to see how it relates to the model. Consider first the following problem. Let us suppose that a given transformation process, as it right be the operations of drilling and shaping the engine block in the process of producing car engines, is automated. Now tinis will elearly involve the substitution of capital for labour in some way. How is this change to be regaxded? As a change in technology, to which discussions of innovation are germane, as a change in the production function within a given technology, or as a substitution of capital for labour within a given produation function?

At first sight the problea is easily resolved by requiring that, sinee Innovations are generally embodied in sone change in eapital stock we distinguish between a 'short' run, in which capital stock. is Iixed, and a 'long' run, in which capital can be varied. But this implies that the way in which the production function is generally written, as

$$
Q=f(x, L), \text { continuous in } x \text { a } L \text {, }
$$

Is essentially a long run concept, and is not defined for the short run. If thexe is to be a corresponding 'midale' run concept, which is long enough for capital stock to be increased 
- or reduced by usage without replacement - but not long enough to define "Innovation", this uust imply a clear distinction between 'widening' and 'deepening'.

It is far from clear that modern technology can be represented as one in which any of these distinctions can be meaningfuliy made, Whthout at all attempting to settle this point, we shall here indicate the variables in which alternative Lormulations of the 'production Iunction' concept may be interpreted in the model.

Any technical change in the materials processed, the source of energy used to process them, ox the equipment used to convert the energy and/or conduct the operations upon the materials, must be expressible as changes in any or all of:

(a) The choice of physical qualities defining the dimensions of $n, *$ and the quantities of materials inputs and of outputs.

(b) The length of the production period, $d$ days.

(c) The numerical ratio, $n / x$.

(d) The production capacity of $n, i . e . x$ units per d days.

Any concept of a 'production function' has to bo expressible in these tarms if it is to make contact with actual production processes, even in the cookbook recipe sense in wich such Functions are used to specify the type and guartities of ingredients to be used without speoifying the physical. transformations to be applied to them; any such function that is well enough defined to be translateable into these terms is definable vithin this general nociel. structure. A production function which does not speoify either these variables or the changes in them which it encompasses must surely have a rather doubtful status in any case. 
Labour is obviously not definable solely in terms of total numbers employed, the following distinctions are needed: levels and types of skill, employees of various types on the payrol1; and the quantity of labour input to a particular quantity of output. If the usual assumption of fixed proportions is carried throuyh strictly, then we would expect any underemployment of capital to be reflected elther in reduction in men employed for a production period or in hours worked per man, or both, so that the net effect retains the full-utilisation ratio of machina-hours to labour-hours. Any change in this ratio would thus be independent of the degree of utilisation of capital, and hence would be attributable to a change in at least one of the parameters defined in the production function.

For simplicity, we shall here restrict the definition of labour to a single dimension only, aistinguishing only between the laboux input coefficient, 1.e. the labour requirement in man-days per production period for the required output $z$, and labour usage, in terms of actual man-days used. But it should be emphasized that this iimitation is not an assuraption which is basic to the model in the sense that the fomal structure of the rodel reguires or depands upon it. It is on the contraxy a recognition of the ilmitations on present data avaliabie on a sectoral basis.

Imports, and government-provided goods and services, to the exterit that either is not incluaed in a category previously mentioned, are easily incorporated as aditional primary inputs. Their dimensions are arrived at in precisely the same way and on precisely the same grounds as the dimensions of the intermediate and capital inputs. In fact, there is a good case for designating government real activity and real imports not as primary but as intermediate sectors. This would bring out clemrly the dependence of imports and government-provided services on the inputs from exports and government-used goods and services, and vice versa. For sone real purposes this is 
highly desirable. The main reason for not doing it here is that it is dasixed to malntain some close correspondence between the real and monetary moals, and the alotinction between primary and intermediate goods becomes more important when its other aspect in terms of the flow of funds is exanined.

It should be strassed that the developoent of production and capttal theories has nevex been part of the object of this enguiry, and that we have only gone into them as far as we have in order to find some basis for linking the real structure into the internotal transmissions.

4.25 FINAL DEMAND

Final demand is to be given the major initiatory role in the structure; it is both to set in motion the sequences of transactions, and to give, subject to constraints and response mechanisms, a steady growth trend to the general course of activity. The final demand array is expressed as net final demand, comprising sales to consumption and investment, governient expenditure (if any) and changes in inventories. Any such component of final demand way, froxu time to time, be purely exogenous or it may be wholly or partly governed by responss mechant.sms.

These response mechanisas may operate on either the rcal side or the money side. There is an obvious choice with the consumption or income-expenditure multiplier; in general, the 'expenditure' idea suggests money rather than real demand response mechanisms, but the idea is not incorpatible with a 'real' demand; the fact that maxket demand, in the sense of effective derand, depends upon the ability to pay (currently or later), does not imply that market demand is necessarily determined by the ability to pay, in the sense that demand arises from possession of means to pay as its prime cause: it is entirely consistent with the monetary view of demand to suppose that real demands are generated through real mechanisms, and that the monetary element enters not as a causal factor but as a constraint on the operation of causal ractors. 
However, there is something to be said for distinguishing the treatment of the income-expenditure relation here frora 1 ts normal expression wholly in 'real' terms with no money element defined, and we shall hence treat any income-experditure relation explicitly in money terms.

We shall need to difine investment falrly carefully, since as capital is treated here the difference between gross and net investuent is not prinarily a matter of accounting-type depreciation allowances but of physical using-up, which may be unxeguited in money terns; thus the depreciation element cannot be simply 'netted out of both sides', 1.e. deduated from both outputs and imputs, since it will have different 1raplications for these in real and money terias. But that problem, as with any others, will be dealt with as they arise in the context of the siralation. 


\subsection{THE STRUCTURE OF THE HODEL}

4.31 Mierarchy of Concepts: Generality

As the formulation of the general ideas is put into increasingly specifle form, so the range of possibilities is restricted until their expression in the programe set up for a particular simulation run encompasses only a small subset of the possibilities infeially open. We may isolate some basio elements in this process.

The paradigm broady defines the view of economic activity as one in which both money and physical processes are important: and need to be distinguished; equilibrium is not regarded as the fundamental oxganising idea, and rather irregular movements over tire are held to be more accurate as a description of how economies actually bahave. The ideas are given some formal structure intended to be defined according to canons of erapirical theory construction, although since part of the object of the enguiry is to devise speaficitions of data to be observed no actual empirical testing of hyootheses is envisaged within the present work. The formal structure is expressed in terms of a model.

The model defines a set of transactors each with a stock configuration, and a set of transactions; the main object of the rodel is to investigate flow mechanisms connecting transactors through transformations between txansactions and nodal configurations.

The programe is the expression in programing language - here Algol - of the model and 1 tg operation. The programme must be continually modified as the work develops, but it is convenient to distinguish rufnox from major changes. A major change vill usually imply the insertion of a new procedure, the definition of a net set of vaxiables, and/or substantial changes in existing procedures. 
The run will refer to a particular run of the programme through the computer; setting up the programe for successive runs will reguire minor changes in the programe, usually requiring only a small number of cards to be inserted or changed. Within one run, repetitions with one single modification to permit direct comparisons will be referred to as "sequences". The details of the programe now set out refer, of course, to the programue as set up for a particular run.

4.32 SPECIFICATION OF TRAMSACTORS AND TRANSACTIONS

The ordered sets representing transactions and configurations could be translated directly into computer terms as seven- and eleven-dimensional arrays, and any particular set of numbers could always be recovered in this form. But for convenience in recording and printing out, these are summarized and presented in the form of a nuaber of two-dimensional arrays, wilch in general show separately the real and money slearnts.

Thus a single transaction $(x, i, j, w, s, d, t)$ is split into two sets, $(x, 1, f)$ being the representation of a supply of goods, and $(u, f, y)$ being that of the payment of money. Thus we designate two arrays, $R$ and $\pi$, so that the number representing goods (in physical output dimensions) delivered by the $i$ th transactor to the $f^{\text {th }}$ transactor, is the number $\pi(/ 1, j /)$ and the roney sux paid by the $j^{\text {th }}$ eransactor to the $i^{\text {th }}$ transactor is the number $M(/ 1, j /)$. A sequence of transactions expressed as such numbors is accumulated, so that although as far as a single transaction is concerned $t$ does not reguire recording, it being the "now" of the simulation, the actual arrays $R$ and M when printed out contain the sets $(x, i, j, t)$ and $(x, i, j, t)$, whose elements are summed over the $t$.

We also incorporate in $u$ the information conveyed by $s$ and $d$. We could, of course, show this as a separate transactions array, say $w(/ s, d /)$, but this is not done, partly in the hope that the row and column sums, 1 . e. totals for the sources and disposals, will suffice, and partly because the precise location 
of a particular transaction may be undecidable when the transaction is financed from a combination of sources and the recelpts are distributed over disposals. We thus add the sources and disposals information to $M$ as a border, so that a money payment also appears in $\|(/ s, j /)$ and in $m(/ 1, d /)$. These similarly are surumed over the $t$.

Purther sumaarizations are immediately obtainable by surming over rows and columns of $R$ and $M$, whenever these are adrissible. (Since the dinensions in which $R$ is interpreted as being expressed are output dinensions, row sums are adraissible but not column sums.)

Corresponding real and money stock configurations could be constructed, but in fact the elements of real stocks are fow enough to be tolerable as a border to $R$, so that the real stocks are represented as, e.g. $R(/ g, 1 /)$, representing the $1^{\text {th }}$ transactor's inventory at the instant $t$. The financial stock variables are shown in a separate array $F$, so that the number $P(/ 1, f /)$ represents a sum of money (ox an obligation expressed as a sum certain in money) due from the $1^{\text {th }}$ transactor to the $j^{\text {th }}$. This can be a debit/credit relation, or a record of cash, in the case that it represents a cash stock held by households, the number will be that designated by the value of $p(/ b n k s$, hhld/). Thus, in general, $F$ records both an asset and a liability as one element, the number $F(/ i, j /)$ serving as a record both of $L^{\prime} \mathrm{s}$ liability and $f^{\prime} \mathrm{s}$ asset. Thus $l^{\prime} \mathrm{s}$ net worth can be arrived at by sumwing the rows and colums of $F$, and deducting the $i^{\text {th }}$ row sum from the $i^{\text {th }}$ colum sum.

A.1. stock variables, of course, are not sumed over $t$ as a cumulation over a period, but are printed out at whatever values they happen to have at a given $t$, the simulation "now" at which the operation of printing out the array takes place.

There are $n+2$ transactors, comprising $n$ producing sectors and households; the latter sell labour to the producing sectors and buy consurption goods fxom them. Investment goods are produced and sold intersectorally, but are distinguished from 


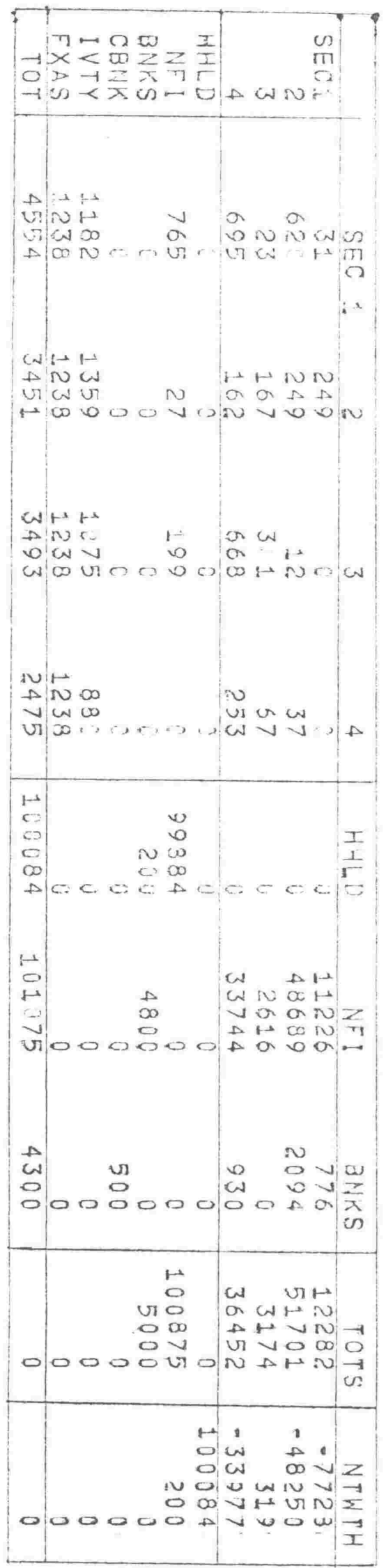

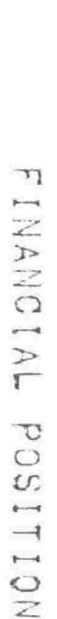

is n nim

HN V U H U I- W $1+\infty$

ir

Ca

nom nits.

UINATU NUGANO

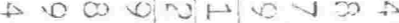
A an anda a via bon

Nan

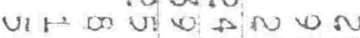

UI $A$ W W $\rightarrow$ U! Ul

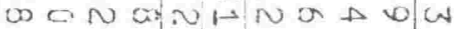

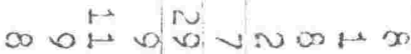

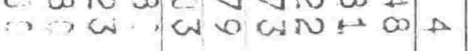

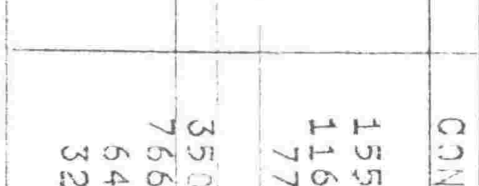

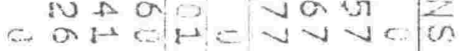

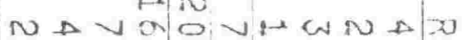
0 O VII OU. U N D A I D a ow Uro, vor ura o vi a vivera viun

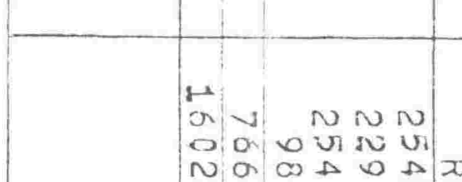

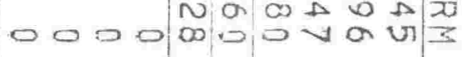

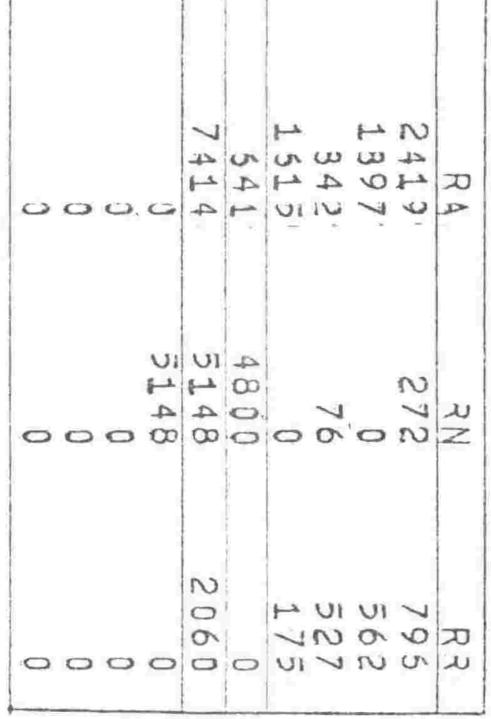

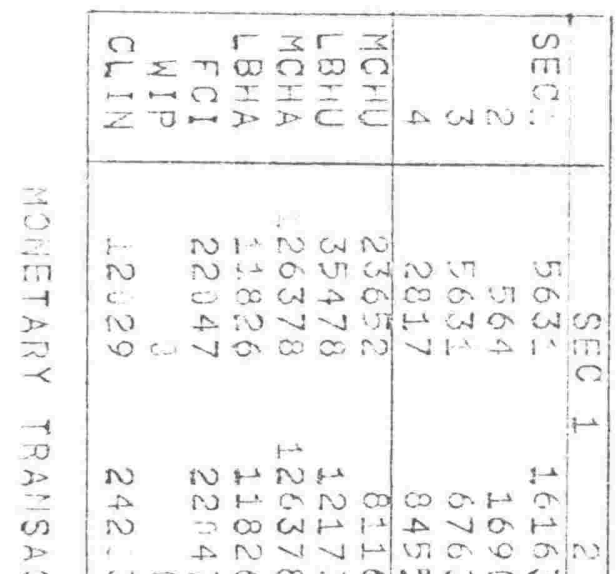

$\approx$

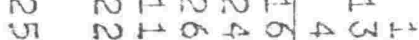

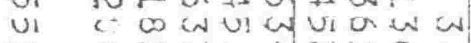

is A NV A.CHito

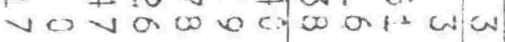

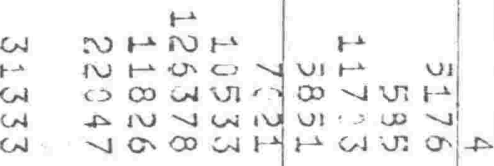

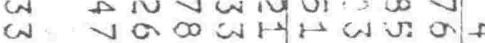

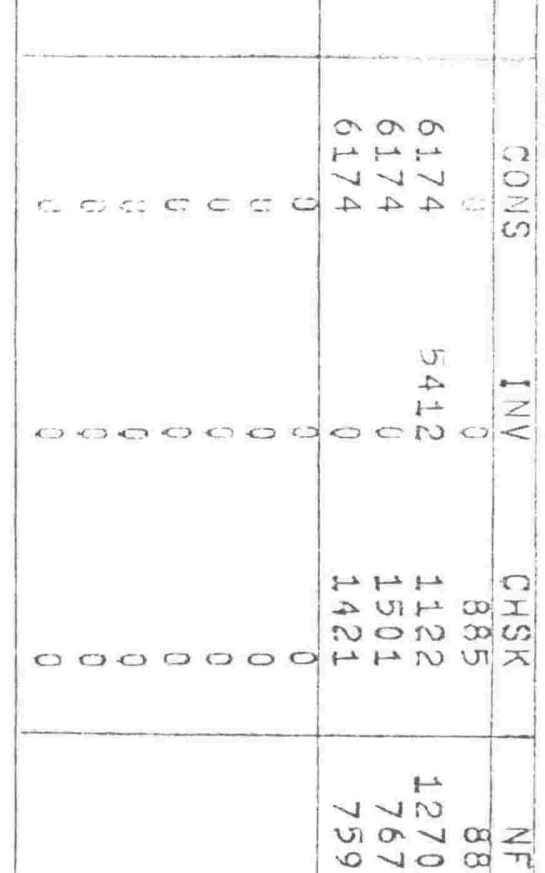

$=\infty=0 \mathrm{sed}$ U

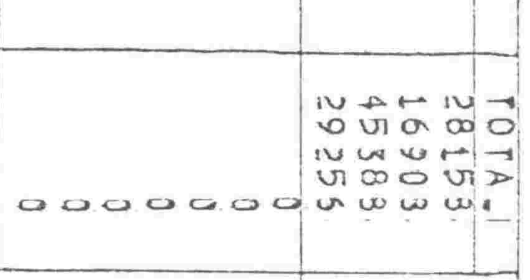


current inputs by being recorded in a separate $(n+2 n d)$ colum of $R$, and of course by producing changes in the fixed capital of the purchasing sector. Financial transactors include also banks and nfi, entering in a flow sense into money-debt transactions and in a stock sense through the asset-1iability structure in $z$.

Sources of payment distinguished are payments to the debit of bank current accounts in credit, to the debit of bank accounts overdrawn, and to the debit of loan accounts with nfi. Goods-credit exchanges are recorded as a fourth source.

An exaruple of the three arrays $R, M$ and $F$ is appended, witl a description of their labelling and interrelations.

\section{NOZES ON MATRICES}

\section{R. Real Transactions}

Sec $1,2,3,4$, producing and using sectors.

mohu, lbhus primary inputs, capital and labour, reckoned in machine-days and labour-days respectively.

ACHA, LBHA, machine and labour days available.

PCI: fixed capital stock.

wIP; work in progress.

CIIIV inventory of produced goods held after production by producing sector.

CoNs, INV: final goods, consumption and investment respectively.

CHSK: change in inventories, equal to $C L I N_{T}-C L I N_{T-1}{ }^{*}$ AFD: net final demand; sum of CONS, INV and CaSK. тогAL: row sums of goods supplied = output to intermediate goods $+N P D$.

\section{If: Monetary Transactions}

Sec $1,2,3,4$; receipts by sector.

aHLD, payments to households for labour input.

coss: total payments by sector. 
EN : payments made to debit of current account in credit.

$E A$ : payments made to debit of current account in overdraft.

$E N$ : arawings or borrowlings from $N F I$.

ER. purchases on trade credit (incl. hire purchase of consurer goods).

coNs, INV: payments for consumption and investment goods. Consumption goods are bought by households, investment goods by using from producing sector. In this run, investment was allocated to intersectoral payments, and hence $I U V$ column of $A$ is sero.

Rows: rowsums, first six colums. $R A, R A, R N, R R$, disposals of receipts symmetrically defined with sources.

\section{E: Financial position}

Sec $1,2,3,4$ : intersectoral trade credit outstanding. UHLD: liabilities of households. BNKS: liabilities of banks = current accounts in credit. CBNK: liabilities of central bank; only trading bank reserve balances, so this is in fact trading bank reserves. rVFY, FXAS; a balance sheet valuation of inventory and fixed capital stock, in this run no valuation has been placed on these items; if it were required, WIP would be added to IVTY (at valuation).

ror: colum sums, total assets by transactor.

Fors: row sums; total liabilities by transactor.

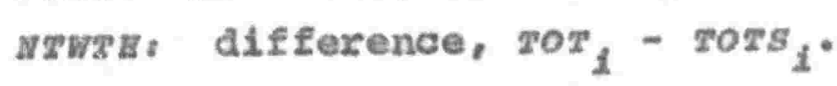

Bank advances to producers and consumers thus appears in the column of assets of the banks, by rows of 11ability by transactor. NFI are similarly treated.

A transaction will thus involve, in general, one entry per transaction in the $R$ matrix, three in the $M$ matrix (one denoting transactors, two denoting sources and diaposals). and, except for direct trade credit, two in $F$. (Each transactor having one entry, giving the change in asset or 
liability, the corresponding entry for each being shown by the same element, which is e.g. both a liablitity of the bank and an asset of the deposit holder.)

What transactions occur is determined as follows: final demand by households is mainly though not wholly, exogenous, in this run as an initially assigned set of final demand purchases, set thereafter according to a steady exponential. growth rate. (This is modified for sone runs by the user of a multiplier feed-back relation.! without a multiplier or induced final demand, this assigned rate of growth sets a ceiling to final demand, which it cannot exceed but from which it ray fall short owing to the operation of constraints on either the supply of goods or on the monetary denand side. It should be made clear that, even when wage income is not an argument of the consumption function, it may ultimately act to depress consurption expenditure if desired demands cannot be flnanced.

Goods so supplied to households for consumption are supplied in the Iirst instance from sectors invertories of finished goods. This sets in train a series of production transactions, according to sectoral production targets for inventory replacement, which may include some desired increase in inventory. Fach sector's production will require inputs from other sectors and from primary factors; wage payments have to be met, but no monetary payment for the use of capital is recgulred. Where capital stock is increased according to some investrent function, this new capital stock is a finished good purchased from the producing sectors, and has to be financed.

Thus the exogenous Inal demand acts as the primam mobile of the dynamies of the model, and all other transactions follow from. the response mechanisms acting through both real and monetary linkages. 
4.33 ThE TIME ELEMENT

Transactions can arise in the model from a number of different activities; in addition to these, there are some house-keeping activities, concerned with aggregation and updating, and storage of time series. The programme designates the following activities:

1. Set production target.

2. Call for inputs.

3. Completed production to inventory.

4. Consumption purchases.

5. Fixed capital investment.

6. Mdjustments: liquiaity (adjustraent of financial assets); physical depreciation of fixed capital stock' growth of labour force.

7. Short-period aggregation and updating.

8. Long period aggregation for time series.

Bach of the first six activities has to be specified with respect to sector, so that in general for $\mathrm{m}$ such activities undertaken by $n$ sectors, we have an $n$ by $n$ matrix of sectoral activity.

The structure adopted was based on the modal time period, a "day". This mainly is a way of carrying the instant, $t$, but sone realistic interpretation in relation to a cnronological day is meaningful. For almost any financial purpose, a day is the minimur period for which transactions are recorded, and in some cases, the minimum period for which they are defined. For example, one can always ascertain the day on which a cheque was debited or credited to an account, but rarely is 1 t meaningful to refer to the time of day at which this transaction occurred.

This does not mean that, within a day, the order in which ovents occux can be neglected. It does not natter whether a customer a, of a shop, cones in ten minutes or three hours 
before $B$, if only the first-comer can be supplied, but the order in which they appeax is crucial. Inventory and financial transactions have generally the same feature in this respect: money that has just been spent on one thing cannot be spent again by the same person on something else; goods emptying inventory to supply one customex cannot be used to supply a subsequent customer. We must therefore be careful not to neglect the order in which events axe occurring, although we have to accept that the data will never record this in sufficiently short periods for the actual seguence of events to be ascertainable ex post.

A particular run of the programue is thus set to continue for a specified number of "days" ( in the run shown as an exampla, we have a run of 894 days, covering 8 activities for 4 sectors). The tiraing sequencing mechanism thus comprises three elements:

(1) A "clock" to keep count of the days; this is provided simply by a variable $d$, which takes successive values from 1 to (in this case) 894; the date of the curxent day, for any day, is therefore given by the value of $d$ at that point in the running of the programme.

(ii) A matrix, a by $n$, of inftial dates (DA), thus $D A_{1, j}$ designates the number of the first day on which activity 1 is carried out by sector $y$.

(11i) $\mathrm{A}$ matrix, $w$ by $n$, of assigned intervals (DY), thus $D x_{1, f}$ designates the interval in days between successive occurrences of activity 1 by sector $f$.

As the $i^{\text {th }}$ sector completes the $f^{\text {th }}$ activity on the $d^{\text {th }}$ day, the interval $D x_{1, j}$ is added to the date given by $D I_{1, f^{\prime}}$ which then becomes the next date due for that activity by that sector. Two different runs of the programae, then, can be given radically different patterns of timing and sequencing by adjusting $D A$ or $D Y$ or both. sinse, in this programue, exogenous final demand is the prirum mobile, the first activity 
has to be a consumption demand, which then sets in train response mechanisms, timed according to the assigned dates and intervals. The programe thus has as its main organising principle a search over $D A$ to find the lowest number, whose subscripts will indicate the next activity due. Several activities may be carried out in one day, and there may occur some intervals during which no activities are scheduled.

The production sequence is split into three activities as shown above, it is not inherently unreasonable to suppose that in some industries production targets are set before current production is finished, but there seens little point in doing this in the model. It is therefore taken for granted that the activities: set production target; call for inputs; completed production to inventory; occur in that order for any one sector. (This is, of course, quite independent of the timing of any other sector.) It is also taken for granted that the production period defined here by the interval between setting production targets and taking the completed production to inventory, is constant so that for each sector the intervals between the two activities will be equal. This is not an unarguable assureption, since some constraints may well bo net in practice by extending the period of production, but the model is not defined for that response. Since inputs may be required throughout the period, the programme provides for the total inputs reguired to be split up, where desired, into instalments provided at more frecuent intervals.

The investment, asset adjustment and aggregation can be timed as desired, independently of each other and of the production and consumption activities. Two periods of aggregation are set, designated a "month" and a "year". These periods are, unlike the "day", intended to bear no relation to chronological time, and are merely a convenience for aggregation.

The "clock" carries one further feature; it provides a convenient device for introdueing trends over time; for this 
purpose, a variable gw is defined, assigned a value $(1+r)^{d}$, and this enables any desired variables to be given the same trend by making them functionally dependent on the parameter $\mathrm{gw}$.

4.34 INPUT TO THE SIHULATION

The general structure of the model is expressed in the details of the programe, which are set out below. Without here considering those things which generally remain unchanged in the programme, we here refer to those elements in the structure of the inodel which are open to variation between runs.

1. Input as data (i.e. in response to a RRAD signal): The technical coefficient matrix, designating the inputs to be called for by each sector in producing a given target production, both from other sectors and from capital and labour.

The inverse of the square (intermediate) portion of the technical coefficient matrix. This is not used in the actual course of transactions (outside the simultaneous equations framework, it would be considered guite illegitimate to use the inverse actually to determine any transaction), but is handy to have available as a checking device. The matrices of first due dates and assigned intervals, $D A$ and $D X$.

Names of row and column elements to be printed out in the output matrices.

2. Numbers assigned in the body of the programme. Since many of the procedures are written in terms of the general parameter $n$, and arrays are also specified in terms of $n$, this has to be assigned early in the heading; $n$, the number of activities, is also assigned at the same time. These assigned numbers must, of course, tally with the size of the 
matrices read in as data. Other parameters, as $g w$, day (the number of days for which the programme is to run), are also assigned in the body of the progranme. There is no reason why such parameters could not be read in as data, and indeed in an earlier trial of the model, that was done. But very often, in changing a parameter value certain other minor changes are desirable, and in total there is less inconvenience involved in changing either programe or data cards but not both at once.

In assigning paraneter values used in decision functions the opportunity might be taken to change the decision function, by introducing another argument or changing a lag. Thus simple changes in the response mechanism, which are one means of differentiating runs, are better regarded as input rather than as structural components of the model.

Initial positions: clearly, there has to be some starting inventory, or the model would never be able to start producing. rhere will also be needed some money in the system. Other characteristics of initial positions are more open to choice. Many variations of run are able to be produced by quite simple changes in initial positions, since these may well dictate the point at which constraints operate. In general, the initial positions are determined by the values assigned to the stock variables; ( $P$ for money; the last five rows of $R$ for the real variables). All other elements of the three matrices (as of any other arrays used for other purposes) are assigned a value of zero.

4.35 Time Paths of Transactions

Given the assigned vector of final demands at their first due dates, which sets the whole model in operation, the suiseguent course of transactions is determined by four factors:

(i) The initial position, which in part determines the operation of the other factors; 
(ii) Exogenous transactions;

(iii) The response mechanisms,

(iv) The constraints within which the response mechanisms operate.

One example will illustrate how these combine. A feature of the transactions in general is that a purchase can be made only if both the supply, in terms of real variables, can be provided, and if the purchaser is able to make payment. A constraint may operate from either the real or money sides, if the full amount cannot be supplied, or paid for, a lesser amount which satisfies the supply and payment conditions is provided, if any positive quantity can be supplied and paid for at 411 .

The ways in which a purchase may be Iinanced are: bank deposit (cash); bank overdraft; borrowing from nfi; for some purchases, credit may be extended by the supplier. The sources of finance are called upon in the order stated: a payment that can be met only in part from one source may be made up from any of the other sources. Let us suppose that a payment of 200 is required at some point, and that the purchaser has no cash; he then uses bank overdraft if available; creditworthiness is not defined in the programme, and the only constraint that operates on bank lending is the required reserve ratio. If this ratio is to be important in one run, the amount of bank reserves determined in the initial position aictates the point at which the banks become fully lent, and further overdraft is not available, except as some outstanding overdrafts become repaid. If such a payments constraint operates, subsequent constraints on the real side may become operative through repercussions on the real variables. Further, if a constraint on bank lending is to operate, the initial cash holdings of the transactors are important.

\section{空}

A major purpose of the model is to relate the terminal positions of the stock variables (for each "year" of aggregation) 
to the course of transactions during those "years", with the object of throwing light on the relation between the two; one reason for this is to examine what information can be deduced about the course of transactions from a knowledge of the stock variables alone, in terms of their values at terminal points. This is expected to demonstrate chat, in the absence of information about the flow vaxiables, the stock variables by themselves resist interpretation in any conclusive way. Accordingly, the prime output comprises the three matrices recording both types of variable (i.e., $R, M$ and $F$ ), printed out at the end of each "year" of aggregation. This is standard for a..2 runs, regardless of the length of run. For a long run (the axample used here, which ran for 894 days $=50$ "years" is an example of a long run), it is convenient to store some of the yearly values, and print them out at the end of the run as a time series; while this is done, a quick survey of the course of events is provided by a graph of the time series, which is accompanied by a running vector designed to signal the point at which various constraints operate. Where a particular feature of one run appears to merit closex enquiry, that portion of the sexies is run again, with more detailed print-out to trace to the required degree of fineness the operation of the response mechanisms and the constraints.

Flow charts are appended to illustrate the main structure of the model. 
MAIN PROGRAMME

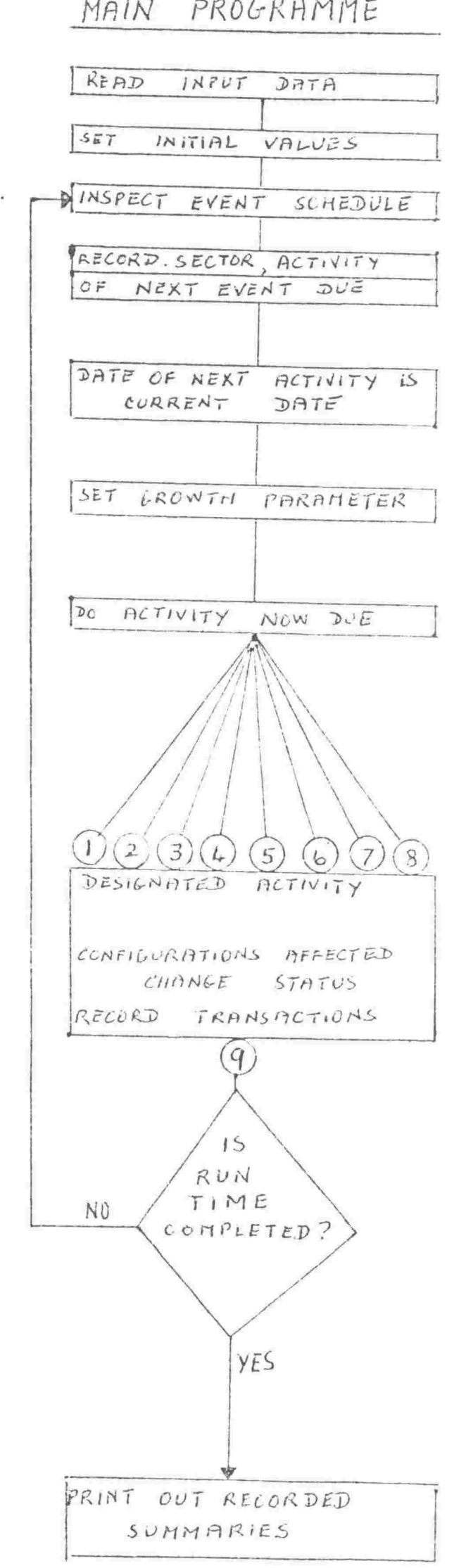

ACTIVITY 1: SET PRODUCTION

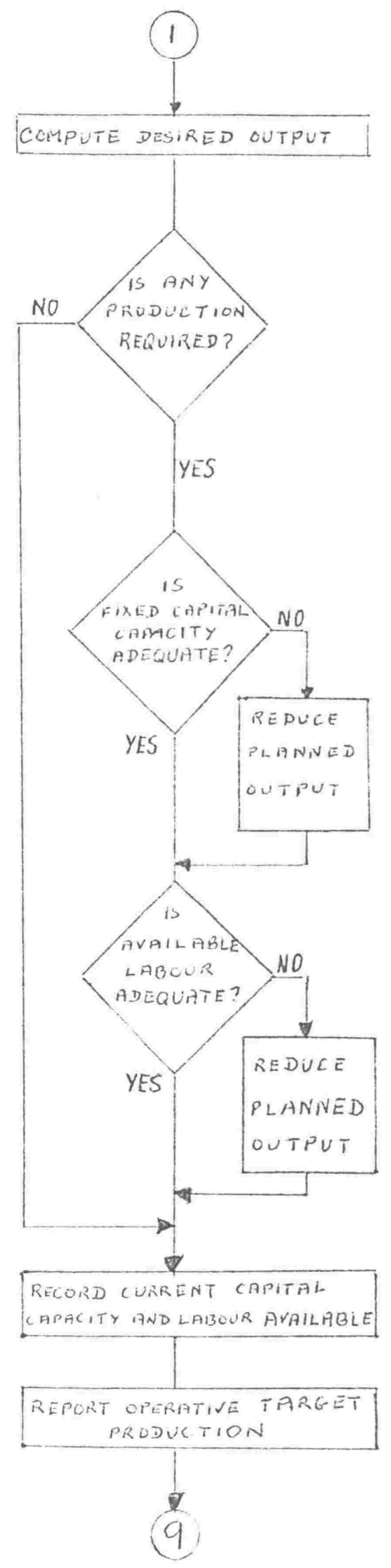


Activity 2. Call for Inputs

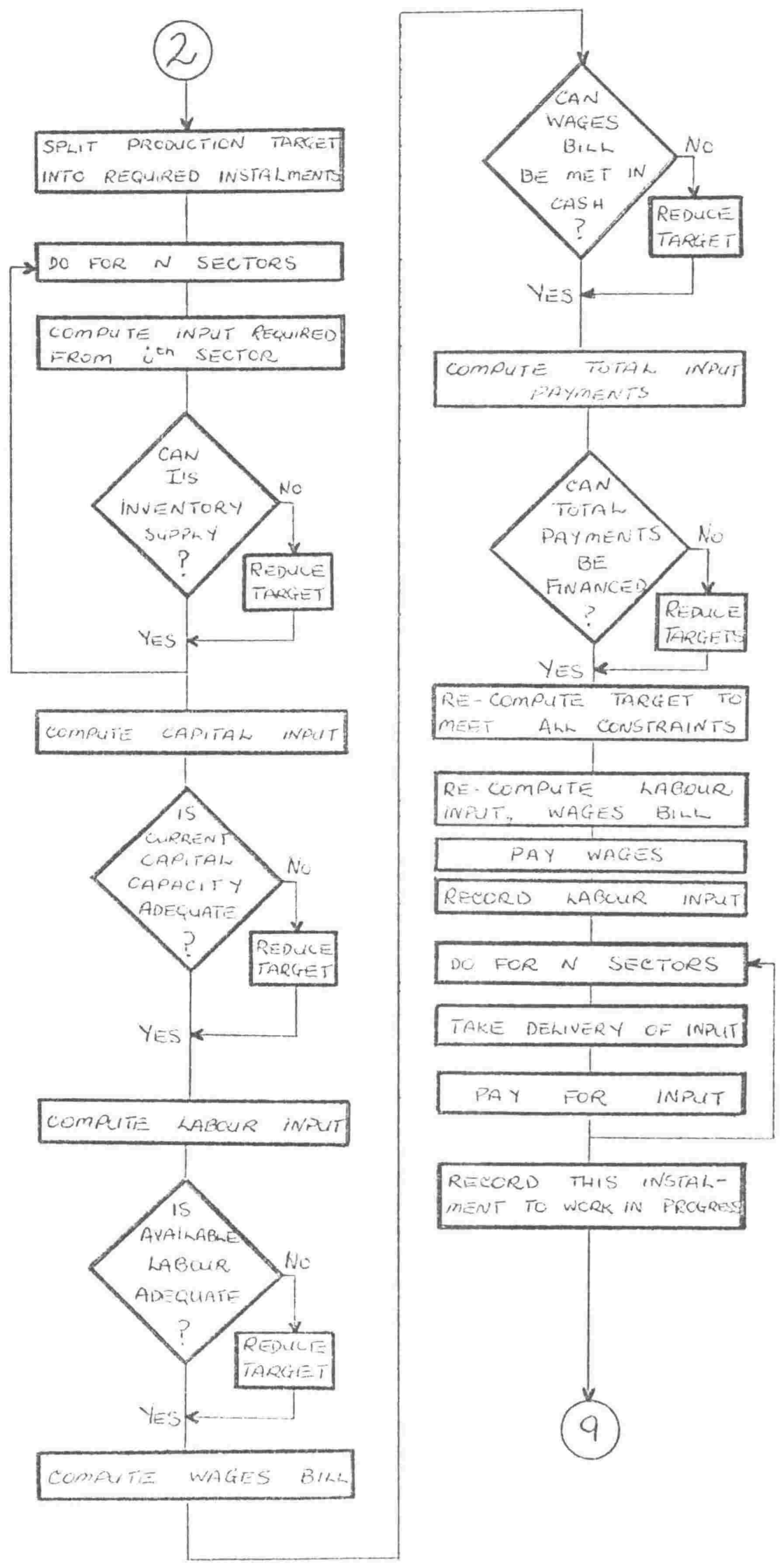


Activity 3 : completed

PRODUCTION TO INVENTORY

(3)

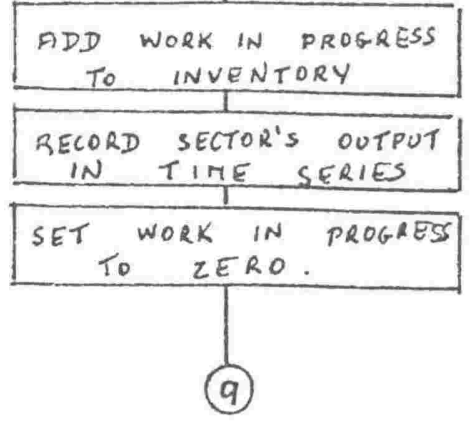

Activity 4: consumption

(4)

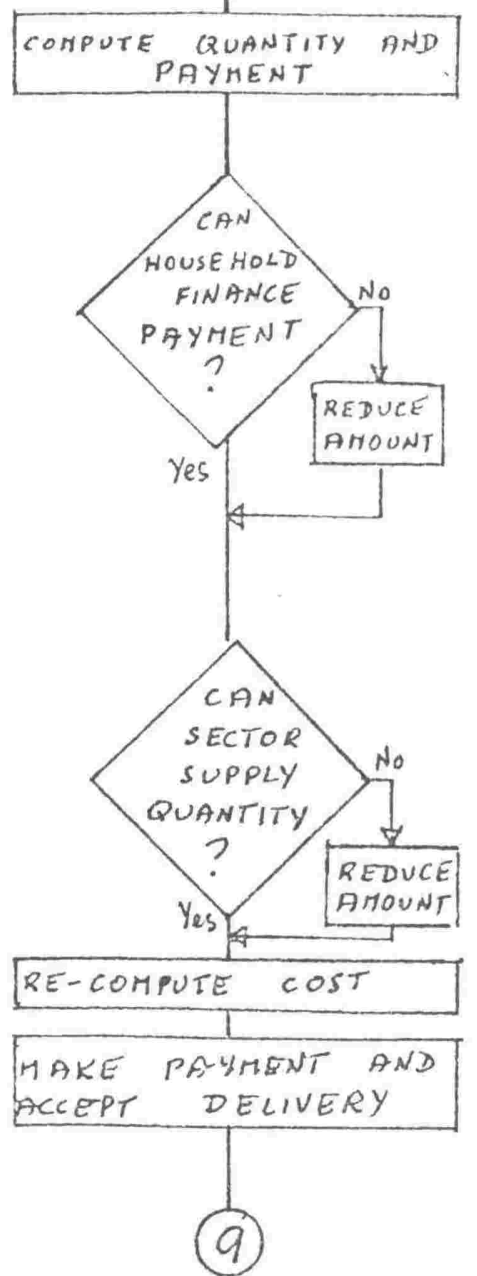

Activity 5: Fixed

CAPITAL INVESTMENT

(5)

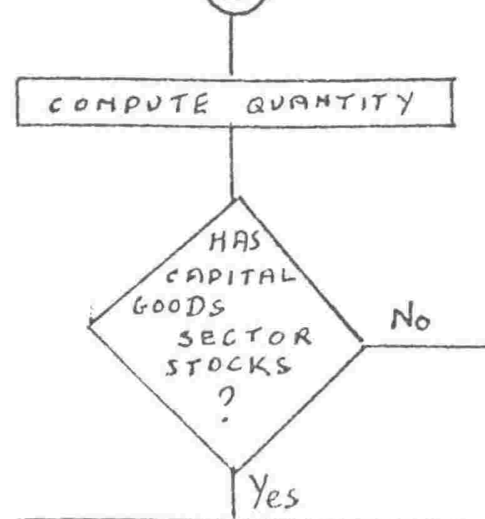

COMPUTE COST

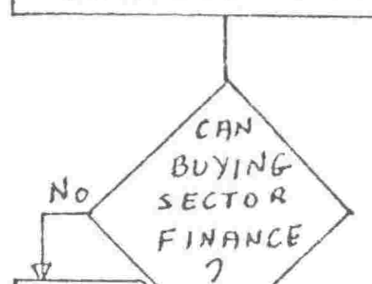

REDUCE

AMOUNT

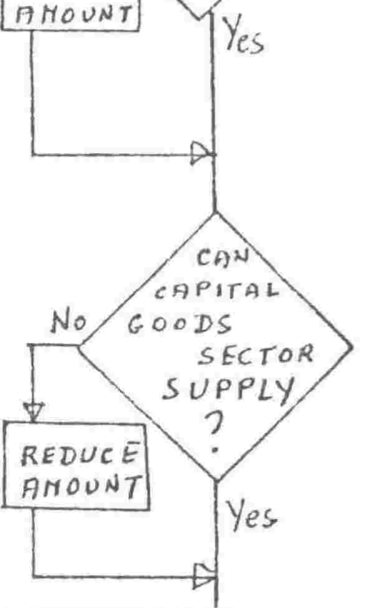

HMONT TRANSFERRED

FROH SUPPLYINC SECTORS

INVENTORY TO BUYER'S

FIXED CMPITAL STOCK

REAL INVESTMENT RECORDED

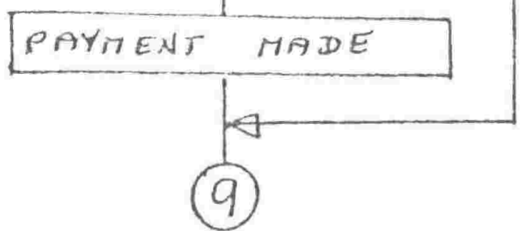


Activity: 6 .

ADSUST ASSETS

6

DECAY SIXED CAPITAL STOCK

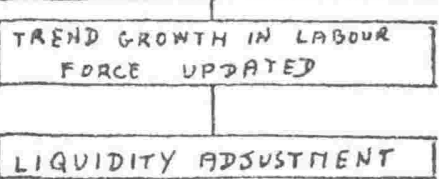

(9)

Activity 7: ShORT PERIOD AGEREGATION

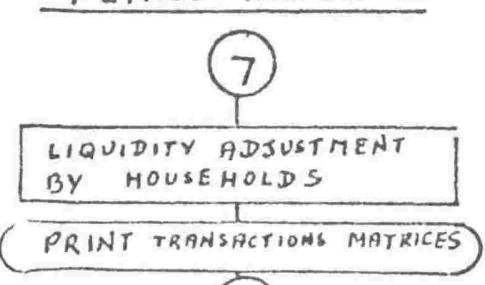

(9)
Activity 8 : LONG $_{\text {peniod }}$

(8)

WQUNDITY ADSUSTMENT BY HOUSEHOLDS.

PRINT TRANGACTIONS MATRICES

STORE VALUES FOR TIIEE SERIES

SET TRANSACTIONS MATRICES

TR ZERO

VPDATE "YEAR" SALUE

(9)
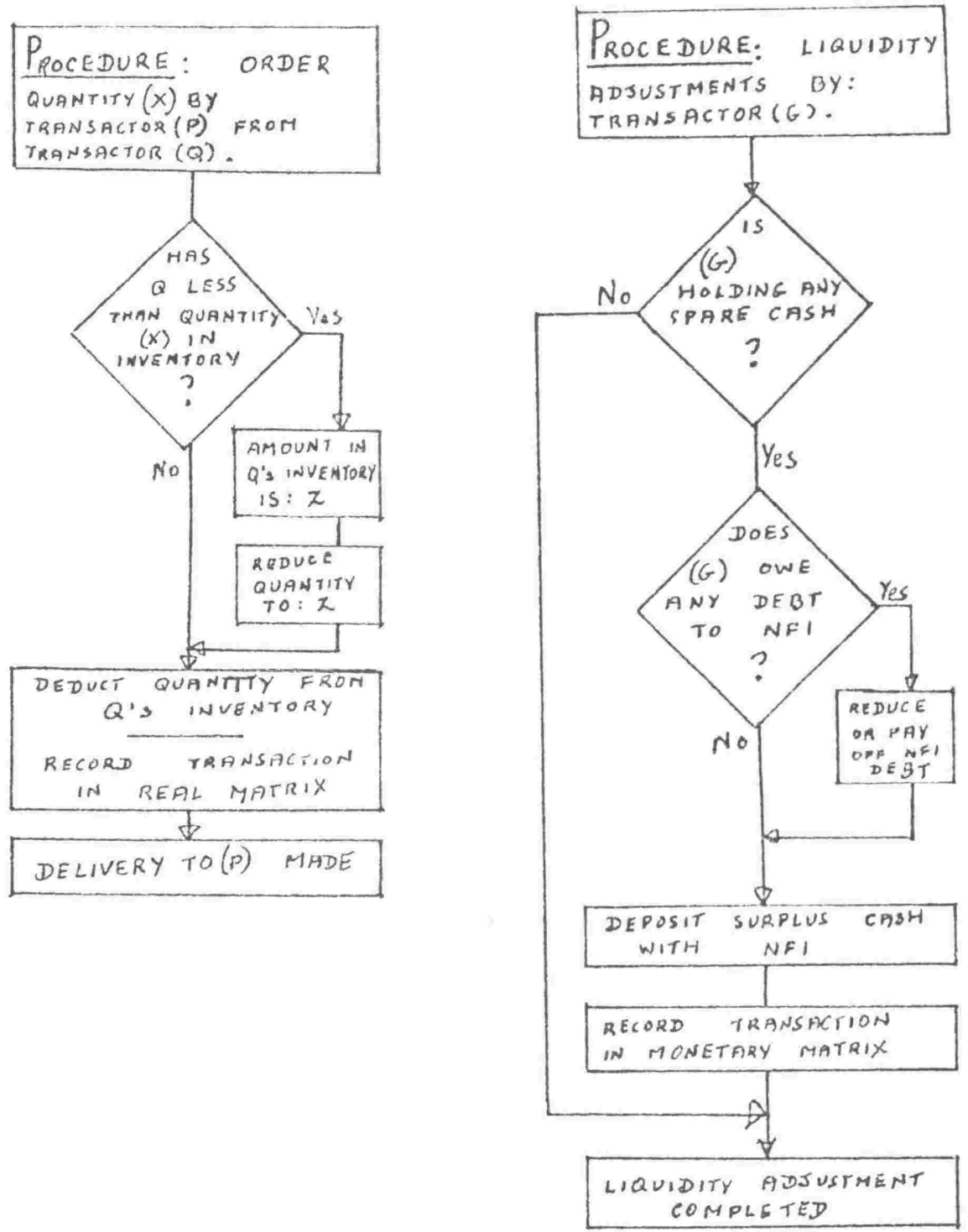


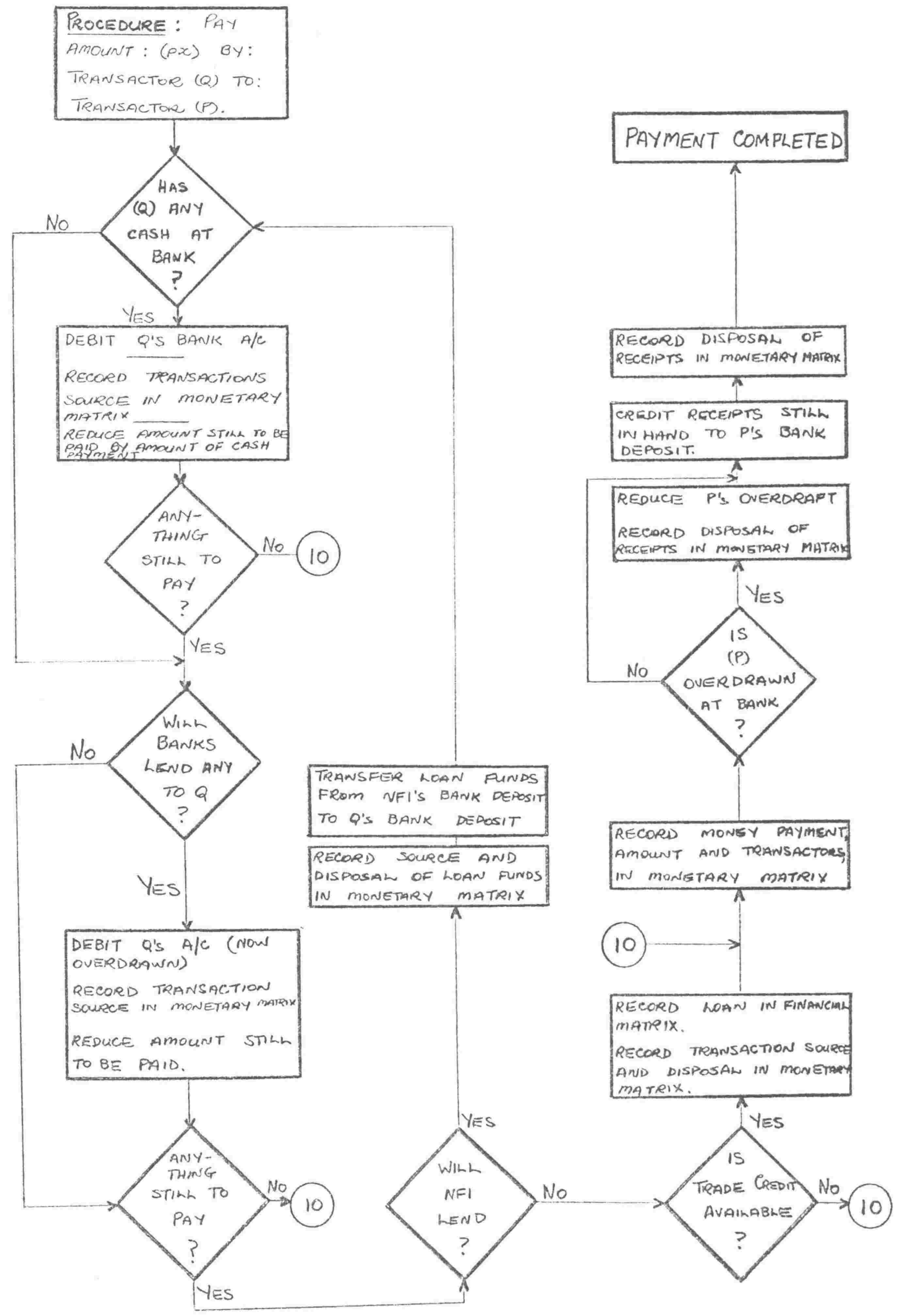




\section{CHAPTER 5}

\section{INTERACTIONS IN A MARKET SYSTEM}

In this chapter we consider the interactions between the real and money flows in a market system, with the main idea of defining and investigating the gross behaviour of the system as it arises from various types of internodal transmissions.

Some considerable development of the model preceded its presentation in the previous chapter, but the course of development up to that point was not discussed. From this point on, the progressive steps in the development will be made more explicit and some points of interest will be discussed in terms of the particular simulation run from which they arose. Runs discussed in detail will be numbered in sequence for easy reference to the illustrative charts appended. 


\subsection{THE MONETARY SIDE OF THE CIRCULAR FLOW}

A preliminary run was tried in which the real side was set on a steady growth path as a basis for the money flows. A fixed autonomous rate of growth was assigned to real consumption, gross fixed capital investment and target inventory, and sufficient stocks and primary inputs were provided for the real side to be unconstrained on the assigned growth path. On the money side, banks were given a fixed reserve balance, but credit facilities were available. Prices were set arbitrarily, and as a consequence wage payments persistently outstripped household expenditure, with the obvious effect of piling up cash in households. Since most of the households' excess cash was deposited with nfi, who re-lent it to firms when the firms had exhausted the banks' lending capacity, expenditures remained unconstrained in the event. The assignment of autonomous real variables together with the absence of constraints ensured that the imbalance in cash flows did not prevent the system from continuing along its steady growth path, which meant that firms were continuing to trade although making persistent losses with a consequent steady deterioration in their net asset positions.

This occurred because of the passive behaviour so far defined, no response mechanism being available to firms to correct their position. It is not however at all certain that the immediate introduction of feedbacks to deal with losses would achieve this satisfactorily, or that it would do so without upsetting the steady real growth, and we shall first examine the imbalances in the money flows in a context of exogenously-set paths for the real side. Obviously, in this context the prices are the key element; since the quantities of goods and services bought and sold are predetermined, the amounts paid are also determined as soon as prices are known. This isolates for study a simple relation on the money side from prices to profit and liquidity via the amounts paid and received in transactions and the consequent net money flows. 


\subsection{Profitability AND LIQUIDITY}

These two are connected, but their relationship needs careful definition. Outside the elementary micro theory, profit is not simply the excess of sales receipts over payments for the cost of production, but an accounting residual into which enter imputations and subjective valuations which interpose arbitrary and indeterminate elements between profit and the net payment flows. Liquidity is also separated from direct contact with the payments flows not only by the credit a firm receives but also by the credit it. extends. It is thus hardly surprising that one finds in practice that firms continue to trade despite book losses, or that they sometimes encounter liquidity problems despite a satisfactory profit performance, as a result of tying up too much of their working cash in inventory and fixed assets. Liquidity, in the general sense discussed above, ${ }^{1}$ is also constrained by the credit available in the system to a particular transactor at the time he needs to make a payment, and an unexpected tightening of credit or an unusually large demand elsewhere for credit or a shortage of loanable funds from owners of bank deposits may give some firms liquidity troubles despite a generally sound position.

On the other hand, there is ultimately a closer relation between profit and liquidity than short-term considerations would suggest. In general, a firm that is making persistent losses is likely to come under increasiag pressure from its oreditors, its suppliers and its shareholders as they become more anxious to protect their own interests, and this is bound to aggravate any difficulties the firm may have in meeting its own payroll. The connection becomes even closer where the firm's profitability enters explicitly into its own financing decisions and also into its customary lenders' decisions, and may hence become important even in the short run.

On the whole, profitability and liquidity are not independent in the long run; but it does appear that if they are 
so closely related in the short run as to make them important for the operation of the monetary mechanism, then this is not a consequence directly deducible from the payments structure, but a possibility contingent upon the presence of a particular type of behaviour by the transactors involved. Thus the effect of an imbalance in the payments flows operates more noticeably at the micro level, and the macro system may continue to operate quite well for a time despite imbalances provided that sufficient credit is available; ultimately, however, if large imbalances persist then the viability of the whole system becomes dubious. We shall consequently attach importance to the achievement of some approach to balance in the payments flows, initially under fairly stringent conditions.

The first step requires the establishment of a macro relation between real flows and payments flows; we therefore pick up again the analysis of 4.22 , which we shall now re-work in monetary terms. The matrix structure is defined as before, i.e. with the pure numbers as:

B: $n \times n$ matrix of intermediate inputs and outputs.

$K$ : nXz matrix of final use outputs.

$v$ : nxl vector of total outputs.

F: sXn matrix of primary inputs.

Measurements are assumed to be made in output dimensions, so that the corresponding arrays of dimensioned numbers are:

$$
\begin{aligned}
& \underline{\underline{B}}=\langle\lambda\rangle B . \\
& \underline{\underline{K}}=\langle\lambda\rangle \boldsymbol{R} . \\
& \underline{\nabla}=\langle\lambda\rangle V . \\
& \underline{\underline{E}}=\langle\alpha\rangle F .
\end{aligned}
$$

We shall suppose that each sector sells its output to other sectors at a uniform price, designated a trade price; thus all intermediate sales and purchases take place at trade prices. A different price will be set by each sector for sales to final output, and this price will be referred to as a retail price. 
We shall also assume that each factor, or primary input, is sold at a uniform price to all sectors. We thus define the price vectors in pure number form as:

$$
\begin{aligned}
& \text { m: } n \times 1 \text { vector of trade prices. } \\
& p: \quad n \times 1 \text { vector of retall prices. } \\
& \text { w: } \quad s \times 1 \text { vector of factor prices. }
\end{aligned}
$$

Each price is a sum of money divided by a quantity, so that in dimensioned form the price vectors are:

$$
\begin{aligned}
& \underline{m}=\langle \$\rangle m\langle\lambda\rangle^{-1} \\
& \underline{p}=\langle \$\rangle p\langle\lambda\rangle^{-1} \\
& \underline{w}=\langle \$\rangle w\langle\alpha\rangle-1
\end{aligned}
$$

In purchases and sales form, the matrix structure is now:

$$
\begin{aligned}
& \langle\underline{m}\rangle \underline{B}=\langle \$\rangle\langle m\rangle\langle\lambda\rangle^{-1}\langle\lambda\rangle B=\langle \$\rangle\langle m\rangle B \\
& \langle\underline{\underline{R}}\rangle=\langle \$\rangle\langle p\rangle\langle\lambda\rangle^{-1}\langle\lambda\rangle \mathbb{K}=\langle \$\rangle\langle p\rangle \mathbb{K} \\
& \left\langle\underline{W}=\underline{F}=\langle \$\rangle\langle w\rangle\langle\alpha\rangle^{-1}\langle\alpha\rangle=\langle \$\rangle\langle w\rangle\right.
\end{aligned}
$$

On the assumption that the monetary standard is the same for all transactors, ${ }^{2}$ we may leave the dollar sign to be understood, and confine attention to the sums of money defined by $<_{m}>B$, etc. since, by construction,

$$
B I+K I=V
$$

then total receipts from sales by sectors of intermediate and Iinal goods can be represented as an $n \times 1$ vector $r$, where

$$
r=\langle m>B I+\langle p>R I
$$

Total expenditures on intermediate and primary inputs can also be represented as an $n \times 1$ vector $e$, where 


$$
e^{*}=1 * 2 n>B+1 *<W>F
$$

The column sums which were inadmissible in physical terms can be defined for purchases since we are now dealing in sums of money. But the accounting identity between $e$ and $x$ still does not apply, since $F$ is a direct measure of factor inputs and is not defined for a balancing residual. The following putative equalities are relevant:

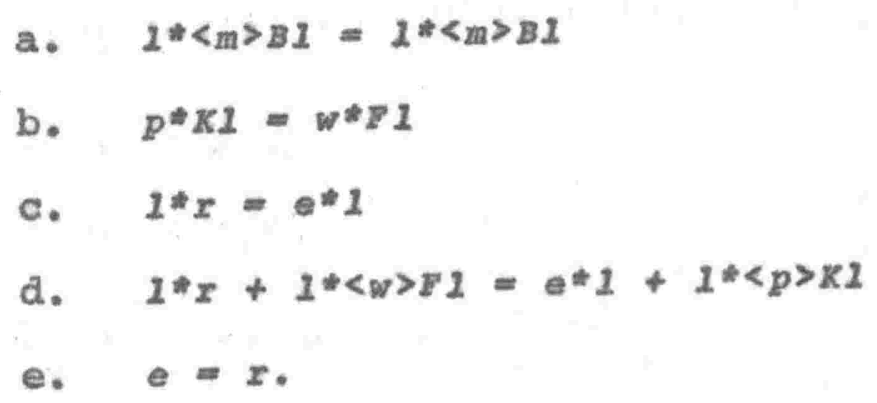

The question is which of these five equalities are true tautologies; (a) obvious Iy is; it expresses the fact that total intersectoral recelpts, obtained by pre-multiplying $\langle m\rangle_{B 1}$ in (5.1) by $1 *$, must always equal total intersectoral payments, obtained by post-multiplying $1 *<m>B$ in $(5.2)$ by 1 ; (b) expresses the fundamental relation between total expenditures on final goods, i.e. $p^{*} K 1$, and total factor payments, $1 . e, W^{* 1}$. This 1 s the equality between GNE and GNP which in the orthodox statement of the circular flow is regarded as a tautology. It rests upon either of two arguments; the first is that (e) is tautologically true, 1.e. simply that each sector balances its books, and requires both that imputed items be treated as actual payments or receipts, and of course that any discrepancy is accounted for in the balancing residual; the second is that (c) must be tautologically true, on the intuitive basis that since one man's payment is another man's receipt, the two totals cannot differ. But, as $r$ is defined, it does not include factor receipts; similarly, e does not include payment for final goods; in order to arrive at the equality which intuitively we can see ought to hold we have to add these in, to yield (d) which is a true tautology. 
An alternative basis for (b) is that it is presented, not as a tautology, but as an equality which happens to hold in a particular case because payments for final goods are in fact, after netting out intermediate transactions, all distributed among the factors employed in their production; thus (b) becomes an empirical statement which might or might not be true, and the assertion that it is true imposes specific restrictions on the way in which prices are determined in the economy, so that observations which would refute the statement are definable. But if (b) is defined as a tautology in the theory then the question of its empirical confirmation or refutation cannot arise. This is commonly accepted on the level of methodological generalisation, but its implication is often neglected once empirically measured numbers are inserted into the tautology, since their apparently observational character as "facts" is taken to confer indisputably empirical status on the theory. On the contrary, if data from empirical observation are selected according to a tautological framework then discrepancies between the theory and the fact cannot be observed, and the theory ceases to be empirical. 3

Given (a), (b) would guarantee (c), but (c) although necessary is not sufficient for (e), which is the zero profit condition for equilibrium in the circular flow. As such, it. imposes definite restrictions on the structure of prices, and we now look at those. We shall need some definitions used earlier, viz.:

$$
\begin{aligned}
& B \downarrow=B<V>^{-1} \\
& F \downarrow=F<\nabla\rangle^{-1} \\
& Q \downarrow=(I-B \downarrow)^{-1}
\end{aligned}
$$

Since the Hawkins-Simon conditions are assumed to hold for $B \downarrow$, then

$$
v=Q \downarrow K I
$$


From (5.1), (5.3) and (5.6)

$$
\begin{array}{cc}
x=\langle m\rangle B \downarrow Q \downarrow K I+\langle p\rangle K I=\langle m\rangle(Q \downarrow-I) K I+\langle p\rangle K I \\
x=\langle V\rangle m+(\langle p\rangle-\langle m\rangle) K I & \ldots(5.7)
\end{array}
$$

From $(5.2),(5.4)$ and $(5.6)$

$$
\begin{gathered}
e^{*}=m^{*} B \downarrow\langle\nabla\rangle+W^{*} F \downarrow\langle V\rangle \\
e=\langle v\rangle B \downarrow^{m}{ }_{m}+\langle V\rangle F \downarrow^{T}{ }_{W}
\end{gathered}
$$

From (5.7) and (5.9), the condition for (e) is:

$$
\langle V\rangle^{-1}\langle K I\rangle(p-m)+\left(I-B \downarrow^{2}\right) m=F \downarrow^{2} W
$$

It does not affect the structure of the problem whether we start from factor prices as given and solve for $p$, or whether we solve for $w$, given $p$. We shall assume factor prices as given, so that (5.10) specifies $n$ equations in the $2 n$ variables $p$ and $m$. Of the many possible solutions, two are of particular interest:

$$
p=m=Q t^{T} F t^{T} w
$$

and

$$
p=\langle K 1\rangle^{-1}\langle\nabla\rangle B \psi^{T} m+m \text {, when } m=F \psi^{T} w \ldots(5.12)
$$

(5.11) is the simplest and most appealing; it has two features: no distinction is made between trade and retail prices, and prices of all products are set equal to direct plus indirect unit factor costs; it may be interpreted as a Walrasian general equilibrium. This idea has been fastened on to the general input-output structure by way of validating the national income identities; notwithstanding that the satisfaction of (e) arises in practice from the fact that the figures derived from empirical measurement are structured into an accounting framework 
in which (e) is tautologically true, it is nevertheless treated as though the measurements were made in an economy whose system of price determination met the condition (5.11), in that the figures derived from the numerical tautology are interpreted as a measure of factor costs, 1.e. as a measure of $Q \downarrow^{T} F \downarrow^{T} w$. As the foregoing argument attempts to show, this interpretation is quite inadrissible; indeed, if factor input costs were independently defined and measured, we should be in principle capable of commenting on whether the numbers measured could or could not validly be structured into this form.

(5.12) does not assume a knowledge of indirect factor costs in setting trade prices, and the basis of $m$ is more relevant to the product exhaustion theorem, which at the micro level does not usually consider the place of materials costs, although it is sometimes used to buttress the argument for (b); but if (b) is to hold in this case, then $p$ must be calculated on the basis of a considerable knowledge, which includes a knowledge of $\boldsymbol{K} \boldsymbol{I}$. Since prices have to be set ex ante, while $k l$ can in general be known only ex post, this is asking the impossible. Nevertheless, (5.12) is of interest in a liquidity context, in which direct factor costs are more crucially a problem than the indirect ones included in materials costs, since the intermediate inputs may frequently be acquired on at least short-term trade credit and hence are not quite so urgent in the short run. Moreover, they are more directly known, and it might well be sensible in practice to set prices on a basis of dirsct factor costs with a conventional mark up to take care of the rest.

In both cases, there is no warrant for supposing that producers actually conspire together to set prices in order to achieve the equilibrium of the circular flow, and the mechanism by which the market would actually get individual producers to conform to this result would still require spelling out.

Thus tire designation of any such conditions as "equilibrium" conditions does not solve the problem of the missing auctioneer, but raises it in a more acute form, particularly wisun account is 
taken of the fact that in order to derive $(5.10)$ most of the conplexities of a modern economy were omitted.

On the other hand, the consequences of not achieving some sort of balance in the monetary flows, even as a rough approximation to (e), cannot be disregarded. An imbalance with prices illivd must lead to persistent net flows from some transactors to others, the losers' 11quidity and possibly their net asset position steadily deteriorating. The efxects need not be confined to them, for if their flnancial position gets so bad that they can no longer finance, from any source, their normal production or consumption expenses, then their purchases from other transactors must fall off, with depressing effects on production, employment and incomes generally. If prices are able to be varied, then some competitive raising of prices might ensue from efforts of producers to protect their relative inflows, with consequent inflation and possibly union or government intervention. The possibilities are many; anong the least likely is that such corrective action as may be taken converges on a price vector that would restore equilibrium. Progressive disturbance is much more likely, since under such eircuitstances no one could have much 1dea of what the equilibrium. prices would be.

The lag in effect of a payments imbalance on the real. variables would in part depend on the extent to which credit provided an alternative source of finance, and this would be important in estimating how closely payments flows would have to approximate to balance to be tolerable. In general, if substantial imbalances persiated the nfi would be bound to play a more important role, since there would be a large amount of cash piling up in one part of the system with a corresponding need for credit in another part, so that an nfi would have both a large supply of potential depositors and a large demand for loans. Where the flows were more in balance, the banking system would be less stretched, since short term overdraft would tend to be fully revolving and new advances continually avaliable; cash would tend to be re-spent rather than hoarded or re-lent, and one would expect the nfi to be less active. 
The static equilibrium of the classical circular flow can be approximated by assigning, without rationale, prices computed directly to satisfy (5.10). A direct representation of the timeless equilibrium familiar in simultaneous equations form is not, however, attainable in the model, since although the timing differences may be eliminated in respect of duration, the sequentias ordering of activities and transactions remains. The "static" element therefore is expressed as a zero rate of growth, with essentially the events of one aggregation period being repeated in subsequent periods.

\section{$\underline{\operatorname{Run} I}$}

A simulation of the circular flow in this sense was based upon a vector of real demands assigned exogenously, constant from period to period except for discrete changes at $z=20$ and $T=35$, where $T$ is reckoned in aggregation periods; the model ran for 50 such periods, Retail prices were calculated initially, at $T=20$ and at $T=35$ directly from the equilibrium condition (5.12) according to the known K1. Resources were set so as to leave the real side unconstrained.

The sequence of 50 periods was run three times, in order to compare the effect of differences in timing, ceteris paribus. (In thif sontext, "ceteris paribus" is given a clear meaning; it implies that no elements of structure, initial conditions, or response rules are changed between sequences except those specified, but that where the thing changed affects the rest of the model such changes are allowed to work themselves outy thus we do not risk impounding in ceteris paribus any of the logical consequences of the change made. For example, in RUN 1 under extensive timing differences the real side did not, in the event, remain unconstrained.)

Sequence 1 approximated "simultaneity", in that due dates for all activities were set uniformly for all sectors; sequence 2 retained "simultaneity" in production but varied timing in final demands over sectors; sequence 3 varied production 
activitles as well. The effect of the third variation was fundamental; since $F \downarrow$ is defined with respect to the production period of each sector, the measured primary input coefficients have a time element. Production activities are thus also defined for a given production period, and when this changes this directly affects input usage for any given level of output. Thus L.njwening the production period increases total labour and total capital usage for given output (and thus provides a means of conveying the effect of inefficiencies arising from breakdowns, go-slows and strikes), while shortening the production period reduces total usages for given output (and may thus be used to represent the effect of increased efficiency). Materials inputs are not defined in terms of a time dimension, being taken to be directly proportional to output regardless of the production period. Changes in production efficiency could alternatively be represented by changes in the required input coefficients, leaving the production pariod unaltered. Which is more appropriate, once the production period has been defined in terms of 4.23 , becomes a question of fact.

The course of real output for sequences 1 and 2 is shown on charts $I .1 / 1$ and $I .2 / I$, the first shows the orderly pattern of the circular flow, with verz ilttle time needed to adjust output to discrete changes in final demand in an otherwise static situation. The second is basically similar, but with some cycling; this cycling arises from timing differences in the sectoral final demands with consequential variations in the production undertaken for inventory replacement.

Sequence 3 turned out to be non-viable, in that the system could not sustain the demands made upon it. The changes in timing of production activities had the effect of lengthening some production periods considerably; orders from final demand and other sectors continued to be met during the long production periods, thus running down inventory to low levels; this increased the amount of production needed for inventory replacement when the cycle of production eventually came round again, and the amounts needed were more than the available 
capital could produce, so that in the event capital constraints operated rather early. The effect was pronounced enough to run down inventories and thus bring in supply constraints on intermediate supplies, which fuxther restricted inventory replacement. The result was that three sectors ceased production at $T=11$, and althouch some consumption could still be supplied from inventory remaining, all real flows ceased at $z=20$. Thus the unconstrained growth path intended turned out in the event to be impossible with very luapy production.

The equilibritm prices set by direct computation according to (5.12) were the same in sequence 1 and 2 , but differed in sequence 3 owing to the changed production periods, as follows:

\begin{tabular}{|c|c|c|c|c|}
\hline \multirow[t]{2}{*}{ RERIOD } & \multirow[t]{2}{*}{ SECTOR } & \multirow[t]{2}{*}{$K I$ (DAILY) } & \multicolumn{2}{|c|}{ RETAIL PRICES } \\
\hline & & & Seg. $1 \& 2$ & Seg. 3 \\
\hline \multirow{4}{*}{$1-19$} & 1 & 20 & .4243 & .5472 \\
\hline & 2 & 40 & .2584 & .3739 \\
\hline & 3 & 60 & .1588 & .3151 \\
\hline & 4 & 80 & .1977 & .3304 \\
\hline \multirow{4}{*}{$20-34$} & 1 & 80 & .2363 & .2818 \\
\hline & 2 & 60 & .2403 & .3480 \\
\hline & 3 & 40 & .1945 & .3858 \\
\hline & 4 & 20 & .4908 & .7662 \\
\hline \multirow{4}{*}{$35-50$} & 1 & 50 & .2739 & .3349 \\
\hline & 2 & 50 & .2475 & .3584 \\
\hline & 3 & 50 & .1731 & .3434 \\
\hline & 4 & 50 & .2563 & .4175 \\
\hline
\end{tabular}

(The setting of required final output in daily amounts means that the total demanded over a period is independent of the frequency with which purchases are actually made, although the implications of varying this frequency, as in sequence 2, may under some circumstances have significant supply and payments effects.) 
The effect on prices is in accord with common sense. If a sector lengthens its production period while 1 ts alily wage rate remains unchanged then its total labour cost must riso, and since ex hypothesi it is taking longer to produce the same output, its labour costs per unit of output must rise. This will raise its price to other sectors, whose retail prices will thus be pushed up although theix own labour costs might not be affected.

The illustrations of effects on the money flows provide a convenient way of introdueing some of the summarizations of monetary data whose appraisal is a major objeot of study.

\section{Sequence 1}

Despite the assignment of equilibrium prices and other devices to determine a static system, the process of starting up the nodel fron rest, and the transition periods when the final demand vector changed, gave $x$ ise to very short-run lag effects which could be negleated in examining the broad pattern of flows but which had irreversible effects on some of the stock variables; some minor imbalances occurred through rounding, which also could be neglected in flow terms but whose cumulative effect on the stock variables was more noticeable. During these adjustment pericas, short though they were, a number of transactions occurred at the "wrong" prices, since the assigned prices were valid only for the equilibrium state.

The result was that although firms were throughout able to meet their expenditures in cash, housoholds ran out of cash so early that after the first period all their purchases were made out of bank overdraft; nevertheless, bank advances remained constant for ruch of the run, being reduced in total duxing the middle of the run, since the households were able continuously to repay overdraft from cash recelpts by way of wages. The importance of this short term bank finance is wore apparent from the flow figures of the transactions matrix than from the stock figures fox bank advances outstarding at end-points. (See 
chart I.1/2 for the sources of expenditure, i.e. the row sums $E M, E A, E R$ and $E M$ of the transactions matrix.) Pinpointing the slight income-distributive effect of the rounding imbalance requires supplementary information from the more detailed transactions matrix printed out during the course of the run, but not summarized and not shown here.

The slight net cash drain from households to firms gave the latter small excess cash balances whtch were transferred to nfi. This movement cannot be directly deduced from the relative movements in bank and nfi deposit liabilities, although chart I.1/3 makes it look as though it can. What are shown there as "bank deposits" are adjusted in line with the usage in the Reserve Bank's table "Money Supply and Selected Iiquid Assets of the Public", i.e. net of trading bank deposits held by nfi. But although it makes sense at the micro level to speak of a transactor "transferring" a deposit to nfi, in total the trading bank liabilities are unaffected thereby, only the ownership of the deposit being transferred.

It happens that for this sequence total bank deposit liabilities can be arrived at by adding nfi-owned deposits to the net bank deposits shown, but there are reasons why this would not normally be the case. Where nfi lending occurs, since such lending loses cash at the bank equal to the amount of the loan, it can become large only if the nfi are receiving cash from new depositors; the process thus implies a recycling of deposits of the following form: A receives a payment initially by cheque which he presents to the drawee bank, with whom he accepts a demand deposit in satisfaction; subsequently he deposits his own cheque with nfi, who thus acquire a trading-bank demand deposit equal in amount to the debit to $A$ 's account. The nfi lends to $B$ by giving him a cheque on this demand deposit, upon which $B$ draws to make payment to $A$, who again passes it through his account in the process of depositing a like amount with nfi.

There are two ways of treating this process analytically. One is to cancel out, i.e. neglect, the passing through $A$ 's bank 
account of $B^{\prime} s$ second cheque to $A$, so that we should directly connect the nfi loan to $B$ with the acquisition of A's second deposit, i.e. we should say that the nfi has created the second deposit through its own lending; only the first of $A^{\prime}$ 's nfi deposits would count as a shift between assets on $A$ 's part, the second subsumed into the deposit creation by nfi. The other way is to refuse to distinguish between the first and second of $A$ 's deposits, treating them both equally as portfolio adjustments by $A$, in which case we should not speak of the nfi's ability to create deposits through its own lending, but of its continued ability to lend being dependent on this continued asset-shifting by owners in the first instance of bank deposits.

The first way has considerable merit, since the nfi would have acquired both of A's deposits while maintaining only an amount at the trading banks equivalent to the second; it would thus be operating on a fractional reserve ratio, and a tidy analysis adding a third tier to the high-powered/ordinary money structure would follow immediately. Nevertheless, it is the second way that has to be accepted. In the first place, the elision of the transaction through A's trading bank account is inadmissible if the definition of money as a means of settlement be retained, since in the light of that definition the elided transaction is of importance in its own right and may not, without inconsistency, be neglected. In the second place, we have been able here to distinguish A's first from his second deposit by appropriate labelling; we should not be able to distinguish them in practice, since no one could tell whether a given deposit with nfi arose as a consequence of nfi lending or not; finally, the analysis implies a beginning and an end to the transactions sequence, which in the context of the unbounded transactions flow are meaningless. Nevertheless, since nfi do in fact operate on a fractional reserve ratio, the total of their deposit liabilities does not correspond to an equal amount of bank demand deposit liabilities, and it is not clear what meaning, if any, could attach to the sum of nfi and trading bank demand deposit liabilities, whether or not the latter be adjusted for nfi-owned deposits. 
The cycling of deposits brought about by $B^{\prime} \mathrm{s}$ getting further into debt to nfl in order to pay to $\mathrm{A}$, whose continued deposits with nfi are providing the loanable funds from which B's payments to $A$ are financed, may appear implausible when we think of $A$ and $B$ as two people but becomes much more believabla when we regard them as two sectors or groups of transactors. Indeed, some such process is necessary if transactions are to be sustained in a context of laxge and continued irbalances in the monetary flows.

It also appears that a persistent growth in nfi liabilities and assets requires equally persistent imbalances. Depositors with nfi can acquire the idle funds to deposit only if their receipts remain above their expenditures; borrowers, who must be forthcoming if the nfi are willing to incur the expense of attracting such idle funds, can need to borrow only if their current expenditure needs exceed their current receipts. An imbalance thus appears necessary for the nfi to be important. That this may be more than a means of adjusting payments to timing discrepancies may be seen in the fact that nfi deposits and loans are in general longex term than bank deposits and advances and cannot, like the latter, have the function parely of absorbing short term discrepancies between expenditures and receipts.

When trade credit, i.e. deferred payment directly, enters, and when in general the timing of recelpts and disbursements differ, the designation of some period over which money flows should balance becomes arbitxary, there 1s, of course, no "proper" period over which money Elows should balance. In the static equilibrium of the circular flow, it would be possible to specify some condition for any arbitrary aggregation period, e.g. thit each transactor's outstanding debts owed by or to him shouid remain unchanged between teminal dates, or that 211 ner worths remalned constant, but difficulties would still axise for the formal relationship if aggregation periods contalned unequal or split periods of income recelpt. 
In a dynamic context balance conditions could not hold as rigidly, and there would be nothing intrinsically wrong with the existence of persistent imbalances and strongly active nfi; indeed, this seems to be required if the money side of activity is to be consistent with the neo-classical concept of finance for business investment being derived from household saving. But imbalances could occur in the other direction, so that some business surplus receipts would be used, via nfi, to finance household consumption expenditure, and elements of this can be seen in most economies today.

Chart I.1/3 also shows the close correspondence, in this sequence, between $E M$ and $R M$, and a similar relation holds for advances. The relatively stable levels of deposits and advances seen in the stock variables gives no clue to the very active nature of the accounts, which can be deduced only from the flow variables of the transactions matrix. If one is at all interested in sources and uses of finance, the stock variables are not very informative.

\section{Sequence 2}

The relationship between stock and flow variables is brought out more clearly in the cyclical pattern of sequence 2 , the money flows naturally reflecting the cyclical movements in the real flows. Charts $I .2 / 2$ and $I .2 / 3$ show the interaction between bank current accounts, payments shuttling between advances and deposits as the fluctuating course of transactions dictated. (No other sources of finance were used; deposits with nfi were made but, after the first period the amounts were again too small to be significant.) Thus, even in the circular flow, there is a need for short term finance, and a continuarion of activity would be very difficult without it.

The relation between stock and flow deposit figures is shown in I.2/4, the fluctuation in outstanding deposit liabilities of banks being directly related to the activity seen in the previous two charts rather than to nfi activity. 
Because of the limited number of sources and disposals defined so far, the close relation between bank deposits and advances is inevitable, but in a more extended range of possibilities other sources of changes in deposits would arise from government and foreign exchange transactions.

Sequence 3

The very lumpy production, which brought in real constraints in this sequence, also produced greater demands on the monetary system. The creation of money in the form of additional bank deposits ceased when the bank reached its lending celling, but since alternative finance was amply available from the nfi, who had plenty of cash from the firms, no general finance constraint reduced any transactions. After real activity had ceased altogether money did not disappear from the system, since bank and nfi loans to households could not be repaid once wage payments had stopped, so that the money stock variables remained thereafter at constant, nonzero levels $(I, 3 / 1)$.

More could be found out about the properties of the static equilibrium circular flow; for example, the monetary effects of replacement investment to maintain a depreciating capital stock would bear examination. An attempt has been made to provide some link with General Equilibrium analysis, but it is clear that once we modify that analysis to distinguish real and money sides in a context of time, we already depart from the simplifications available within the usual specification of the Walrasian structure, whose properties become less accessible to formal analysis. Since a static economy is not interesting from an economic point of view, we shall not pursue its analysis any further; it is preferable to move into an attempt to develop a dynamic analysis, which nat be expected to present more severe problems.

Two such problems have already been suggested by Run 1. 
The first is that of disequilibrium trading and production during periods of adjustment, which in a dynamic economy can be expected to occur frequently, if not continuously, with consequent irreversible effects on the stock variables; the second is the possibility that inventory may run down to a point where production ceases altogether. These will obviously require attention in a dynamic setting. 


\subsection{THE CIRCULAR FLOW IN A GROWING ECONOMY}

Translating the static equilibrium of the circular flow Into a dynamic context raises a number of problems; on the real side "equilibrium" can be represented as a steady expansion path with a constant rate of growth, $(1+x)^{T}$, where $r$ refers to aggregation periods. But this trend rate cannot be assigned directly to total outputs since these are endogenously determined; it can be assigned to final demands for consumption, which at present are treated as exogenous, and provided that no constraints operated and that any other components of final demand had the same trend rate, then total outputs would also have the required trend rate. In this case, prices set exogenously according to (5.12) would be "equilibrium" since the trend rate would cancel out between $\left\langle K{ }_{1}\right\rangle^{-1}$ and $\langle\nabla\rangle$.

Complications are introduced when capital and inventory accumulation occur, since both may cause divergences on the real side between the ex post rates of growth of final demand and total output; these would not be serious if investment were assigned exogenously with the common trend rate, when in the absence of constraints the real equilibrium conditions would still apply. Problems on the money side would be more troublesome.

Inventory accumulation comprises unsold stock for which production expenses have been incurred but for which no payment has yet been received; reduction of inventory involves actual transactions in goods which are not included in current output and for which no current production expenses are incurred. If equilibrium, in the sense defined above, were maintained on the real side, movements in inventory could be kept constant and these problems would not arise; but even a steady trend of inventory accumulation would still provide a source of monetary imbalance, production payments always running ahead of sales receipts.

Investment in fixed capital involves money transactions between the sellers who produce capital goods and the buyers who use them in production; at the time of sale, the capital goods 
are treated as ordinary produced goods, being distinguished from consumption by classifying the real quantities in a separate demand vector. Once the purchase is completed, the buyers add them to their own capital stock thus expanding the primary capital inputs available for subsequent production. This follows the broad lines of the standard treatment, apart from the fundamental. differences made by the timing mechanism and the money/real distinction of the model; here purchases of capital goods and their subsequent use in production are not formulated directly in terms of aggregation periods but in terms of the sequential ordering in which all transactors' activities are expressed. Depreciation involves the physical reduction of existing capital stock without an actual sale and purchase being involved. This need not present problems on the real side, since it is gross investment which enters into the final demand vector regardless of what rate of depreciation is applied. It could raise a problem if the usual dynamic equilibrium condition specifying the uniform growth rate in terms of net investment were applied, since in that case there would be a discrepancy between the final and total growth rates.

Increments in the labour force affect production only in the supply of primary inputs which in the absence of shortages do not affect the real equilibrium condition; no capital cost of expanding the labour force is defined and no monetary effects of such expansion can thus occur. 4 It is thus inventory and capital accumulation that raise the question of how much of current expenditure by producers accumulating these assets is to be passed on in current prices to buyers of final goods, since if these costs are not passed on in current prices then the payments and receipts of producers must differ in each period. There is nothing intrinsically wrong with this, and indeed it may reflect the situation referred to in 2.12 and 5.1 , in which producers commonly incur money debts in order to acquire real assets.

But it does make it rather hard to see how we would then define "equilibrium" in the money flows, since as soon as we admit the extension of credit into an equilibrium state most of the characteristics which would otherwise provide possible criteria of demarcation between equilibrium and disequilibrium become equivocal 
or misleading. For example, when a payments imbalance persists the net payments arain must result in net transfers of cash, but where the surplus receipts are lent back through nfi, transactions might be able to continue even in persistent monetary imbalance; it would be necessary to distinguish this situation from an equilibrium one in which household saving is used (via nfi) to finance anticipatory expenditure by business in the normal sourge of growth. Ostensibly the required distinction is provided by the traditional equilibrium condition of the equality of savings and investment, but when real and money flows are distinguished it needs to be made clear what the relation between real and money saving would be, and how imputed money values would enter into the equality in the absence of some prior notion of "equilibrium".

Where goods are bought on credit for further processing, only the value added needs an immediate cash payment, and the sale of the finished goods for cash may involve significant trangfers of liquidity. Ultimately trade credit must be settled, but there need be no ascertainable period over which, in general, this must be done, or any definite point at which all outstanding debts have to be cleared. On the other hand, the grand total of claims arising out of all activity would cancel out between debits and credits in the consolidation of balance sheets at any point of time regardless of the prevailing state of the economy. Since the distributive effect of imbalances has wealth effects, the static equilibrium condition becomes simply that all net worths remain constant. But in a dynamic context we would expect total. wealth to be increasing, and someone must hold the new wealth; this would be further complicated by the mixture of real and money variables involved in the notions of "wealth" and "net worth". Finally, the aggregation period, while it may or may not be arbitrary in every sense, is certainly arbitrary with respect to any particular transaction or to the receipts and payments totals of any particular transactor.

In general, it becomes doubtful whether a monetary equilibrium, in a dynamic economy actively using credit, can meaningfully be defined in any exact sense. But before we can 
explore the problems raised in this area, another problem supervenes, and this calls for prior attention. This problem arose in sequence 3 of run 1 , in which the whole system came to a stop. It occurred in a subsequent run, in which the system stopped in all three sequences. The course of events on the real side in that subsequent run merits a brief statement, since it gives an example of the sort of chains of causation that we shall want to establish.

The transition to a dynamic system was approached through assigning a constant growth rate of $1.04^{2}$ to gross investment in fixed capital, to the labour force, and to consumption demand, with an allowance for a constant proportional rate of fixed capital decay. In the event the operation of a labour constraint at an early point on the time path resulted in a rapid running down of the system, which thus had no chance to reach equilibrium in any sense. The constraint operated in sector 1, which had the highest laboux input requirement, and did not at first prevent output generally from continuing to rise. The continued supply of intermediate and final goods was met out of inventory which, with sector l's production held down by the labour constraint, could not be replaced quickly enough and so progressively ran down to nothing. The cumulative effect was to restrict supplies to other sectors, inducing a rapid complementary feed-back in all sectors between production and inventory. The effect of this phase was most severely felt in sector 4 , where the reliance on intermediate supplies was greatest, and production activity first ceased altogether in sector 4. Sector 1 was in fact the last sector to go out of production.

Given adequate short-term data on real sectoral outputs some nint of tinis coulâ have been picked org from looking at leauling and lagging sectors, but more direct information on the sequence of constraints operating is necessary to establish causation with any precision. The ability to trace such chains of cause and effect must play a key role in following through the transmission of disturbances throughout the system. The disturbance must arise somewhere, i.e. it must first affect some particular group of transactors; if it is significant for the system as a whole, some rational explanation must be found of the way in which 
the primary phase, i.e. the initial impact and the beginning of the spread to other groups, leads into the secondary phase, in which the effects have become general and consequential disturbances are arising throughout the system.

As it stands at present the model has an inherent tendency to respond to an encounter with a constraint by setting in motion a series of events which, instead of reducing activity to a lower path consistent with the constraints, stops it altogether. This is directly due to the lack of any response mechanisms to restrain demand, which is met willy-nilly out of inventory as long as there is any inventory at all; thus, although the presence of a real constraint ultimately becomes enforced upon users of output, they are confronted with it only when it is already too late to halt the downturn.

It is hard to believe that a supply shortage in one sector is at all likely in the normal course of events to bring about such a definite cessation of all production activity, since one would expect a modern economy to be more resilient. The model is thus unrealistic in this important respect. ${ }^{5}$ It is, of course, bound to depart from descriptive faithfulness in many ways, and the question arises of specifying which general characteristic of a modern economy has been omitted or falsified in a way that leads to this result as a necessary consequence of an encounter with a real constraint.

The model could be made less sensitive to disturbances by reducing the extent of the interdependencies; the number of sectors is small and the technical coefficients unrealistically large. However, the idea of sectoral interdependence is important to discussions of feedbacks and of the effects of inflation and unemployment, and there is someting to be said for exaggerating this characteristic in order to bring out its effects more clearly; what is involved is mainly a matter of emphasis and it does not appear that, within the model structure, the downturn can be prevented by reducing this emphasis unless the intersectoral interdependencies are made analytically insignificant. 
The model is also unrealistic in the omission of price, income and demand feed-back effects. These will undoubtedly need examination in their own right, but any particular feed-back effect between money and real variables ultimately implies a specific type of behaviour, which cannot be dragged in as an ad hoc device to get rid of an embarrassing structural defect.

In short, the problem is one of fundamental structure, and needs to be tackled on that level. It axises in the operation of constraints, and what is required is either some guarantee that constraints will not operate, or some check to the irreversible downturn that comes into play when constraints do operate. Thus what is required is either the complete elimination of the primary phase, or isolation of this to eliminate the secondary phase, or some means of mitigating the effects before the secondary phase takes over from the primary phase in importance.

That constraints must operate from time to time follows from the fundamental notion of "economic activity". Economics, in any form recognisable to modern economists, is the study of scarcity of means relative to ends. Both means and ends are ultirately functions of knowledge and social organisation, and hence are not permanently set. But for any given structure of living patterns and of resource use within a given material technology, the usable resources are relatively scarce, each use having its opportunity cost, and in this sense a "real ceiling" is implied as a first characteristic of any modern economy. If real constraints are operative in any significant way, they must be experienced by sonebody; thus the system, as a condition of its being an economic system, must be defined for the operation of constraints in some way that makes sense in terms of people's behaviour.

If a system encounters constraints in the normal course of events then it presumably does so in such a way that total disaster is not the inevitable outcome of aii such encounters. (Abnormal encounters, as for example a general shortage of customary energy sources, or some natural cataclysm, might well be decisive.) The primary phase cannot reasonably be eliminated if the model is 
to be an economic model; since real constraints must be communicated in some way to all users of whatever output is affected by the constraint, not all of the secondary phase can be eliminated; we are thus left with the remaining option of mitigating the effects on the system as they occur during the two phases. We shall refer to the general concept as a "real floor" to production corresponding to the real ceiling set by resources limitations; an important characteristic of this real floor must be a means of holding back some inventory from immediate consumption in order to protect at least some minimum reserve supply of inputs to sustain further production. This calls for two things: a distinction between those produced goods available for supplying intermediate inputs, and those available for immediate consumption; and a priority ordering to ensure that intermediate supply overrides consumption supply whenever depleted inventory makes it necessary.

One of the falsifying simplifications of the model is that only one inventory variable is defined for each producing sector, and while the process of aggregation into sectors involves lumping together many kinds of good as one good, a broad distinction between raw materials, semi-finished goods and final goods is still meaningful. The distinction may, of course, be conveyed by allocating goods in these three categories to different sectors, which accords with the identification here of kinds of goods with sectors, but not with the technical coefficient matrix which in that case ought to be triangular as a basic structural characteristic.

Where the different stages of processing of goods is not conveyed by the distinction between groups of transactors into sectors, then each sector may have to be seen as carrying goods of more than one type; strictly, this would call for the specification of two or more separate inventory variables for each sector, each variable having its own dimension of measurement, and a priority rule for allocating production between the different types of inventory. Pursuing this line of thought further would lead us into a consideration of whether similar producers could properly be seen as producing goods at various stages, and 
ultimately into the whole basis of sectoral classification. since, in such a consideration, we should have to take account both of the elements in tiered form in manufacturing and distribution, and of the different structure in which such goods as oil, building materials, transport etc., were subject in some ways to competing demands from consumers and manufacturers, we should be led much too far afleld for present purposes.

We shall apply two criteria in deciding how much it is necessary at this point to approach descriptive reality more closely. First, macro ceilings cannot be known directly to individual transactors, and even if they were there is no reason to suppose that transactors would alter their behaviour until obliged to do so: shortages of supply, within the market framework adopted, can be known by and enforced upon individual buyers as a rule only when specific demands are refused by sellers owing to actual shortages of goods known at the point of sale. ${ }^{6}$ Secondly, considerable simplification must be accepted, and it can be said to have gone too far only when its analytical consequences are destructive of or misleading for the purpose of the model.

Both criteria would be met by the expression of an adequate set of priority orderings, which could be conveyed quite simply by restating the supply condition so that only a set proportion of inventory is available for supplying consumption demands. In this restatement, it is necessary to consider the relation of current inventory to target inventory, in order to measure the extent to which inventory is being replaced through production. This calls for an amendment to target inventory, which would, if held constant, place an absolute ceiling upon consumption thus eliminating the main growth factor from the path of events. (Target inventory was held constant in the previous run in order to meet one condition for equilibrium in the monetary flows,) This merely implies that, in a demand-oriented economy, growth is impossible unless producers generally are willing to plan for their production and their inventory holdings to grow. 
The constant trend rate of growth was retained for gross capital investment, the labour force and consumption demand. It was extended to inventory, and a limit on supplies to consumption was set arbitrarily to reserve from current inventory an amount equal to half the current target inventory. The allowance for fixed capital decay was also retained. No other changes were made from the previous (trial) run, and together these modifications describe the transition from run 1.

The labour constraint operated early as in the previous run, but in sequences 1 and 2 the limitation on consumption supplies protected production and avoided the zero downturn which had occurred without the consumption supply rule. As a result, sector l's supply to consumption was restricted to a lower path than that assigned, but other sectors continued to be supplied with their required inputs, and thus were able to continue to meet production demands in full. Production thus continued to grow (charts II.1/1 and II.2/1).

With timing differences in production now added in sequence 3, the much larger production needs of sectors with longer production periods drained inventory; the consumption limitation, which did not apply to intermediate supplies, no longer sufficed to provide a floor, and all production soon ceased through the process previously described.

A comparison of flow and stock variables on the money side is shown for sequence 1. Charts II.I/2 and II.I/3 show respectively sources and disposals flows (i.e. row and column sums of the transactions matrix); II.1/4 show the time series for some associated stock variables (loan assets of banks and $n f 1$, and trade debtors), together with drawings on overdraft (EA) which are repeated to provide a comparison of scale between II. $1 / 2$ and II. $1 / 4$.

In II.1/2, cash payments (1.e. EM, debits to bank deposits) include cash payments to nfi (recorded separately as $R N$ ) and cash 
payments from loans made by nfi (EN). $B M$ has not been adjusted by deducting these, since raw data on debits to bank deposits would include such money-debt exchanges as well as money-goods exchanges, a direct implication of the definition of "money" as a means of settling a debt. Thus in order to arrive at the money-goods exchanges financed out of buyers' own cash holdings, we should have to adjust the bank flow data by similar flow data, as e.g. $E N$ and $R N$, derivable from nfi, and from all similar transactors involved in money-debt exchanges.

Making these adjustments to $E M$ does give a greater relative importance to $E M$ than the uncorrected $E M$ suggests, but even so II.1/4 greatly overstates the importance of nfi finance relative to other sources of funds for payments. The tendency to turn to trade credit towards the end of the simulation period shows that both bank and nfi lending abilities had become fully extended. This does not, of course, imply that when the money supply created by bank lending had reached the ceiling imposed by the fixed reserve balance and fixed reserve ratio this produced an immediate end to bank lending. An active and growing turnover of existing overdraft continued after money supply had reached its ceiling, as one would expect when fixms continued to receive cash through their sales. It does suggest that the fixed monetary base (i.e. bank reserve balance) is becoming inadequate as the volume of transactions grows.

Sequence 2 differed in no major respect except for the cyclical effect produced by events on the real side, and a slightly greater use of trade credit towards the end. The more pronounced movements between overdraft and bank deposits are shown in the sources of expenditure, chart II. $2 / 2$.

While the floor has worked well enough up to a point, it has clearly not been developed far enough, since a more general statement of the basic relations between real and monetary activity needs to take account of possibly extensive timing disparities, and the floor will need further modification before we can return to the outstanding major problem of first defining and then finding a way to reach monetary balance. 
5.21 THE FLOOR

Where the floor, which at present is provided only by restraints on consumption supplies, fails to halt the downturn it is because of the exhaustion of inventory in one or more producing sectors by the supply of intermediate inputs to other sectors, and this is most noticeable under extensive timing disparities. The diagonal elenents of the technical coefficient matrix are nonzero, so that intrasectoral inputs are needed for production, and when these are not forthcoming the deficient sector cannot replenish 1 ts own inventory; its own production and that of using sectors hence cannot be revived.

Unlike the distinction between semi-processed and final goods, this could not be remedied by restricting attention to triangular matrices, since even triangular input-output tables commonly have nonzero elements in the diagonals, so that the problem is more fundamental. Only a few cases can be found where an industry actually uses its own produced output as a further input, seedcorn and breeding livestock being extreme cases; parallel cases are hard to find in manufacturing, and the nonzero diagonals arise in practice from different stages of manufacturing being aggregated into one sector. Nevertheless, on a similar argument to that before we shall extend the supply constraint to differentiate also between intersectoral and intrasectoral supplies, with a corresponding three-stage priority ordering.

It must be conceded that this three-tier classification and priority ordering is only tenuously in contact with the complexity of stages of processing and of types of inputs, but it does at least recognise the need to make such distinctions. That they ought to be carried further, with whatever implications for orthodox input-output analysis, can hardly be denied. But we shall not do that here unless the analytical consequences of not doing so become too severe to be ignored.

At all events, whatever form of representation is used, the basic principle remains: if the resources devoted to immediate 
consumption are at the expense of the supporting production needed to maintain that consumption, then production must, at least temporarily, take precedence over consumption if economic suicide is to be avoided.

There is another feature of modern economic activity which might conveniently be introduced at this point. When suppliers are unable to meet demands immediately, very often they will try to retain customers by accepting orders for deferred delivery. This is also a characteristic of some firms' ordinary practice, when production is undertaken to meet specific orders rather than for some general market. For these reasons, longer order books and extended delivery dates are frequent signs of shortages of supply. Although order books are sometimes used in consumer as well as in intermediate transactions, their use is rather more general in interfirm transactions, and in introducing them into the model we shall restrict them to that use. Thus, in the model, consumer demands that cannot be supplied within the restraint on consumption supply will not be carried forward, but where firms cannot be supplied with the full anount ordered the remainder will be placed on order books pending the replenishment of inventory. Outstanding orders will be taken into account in setting production targets, and delivered when available. Since there is no point in allowing orders to accumulate indefinitely when demand remains above the real ceiling, an arbitrary limit is to be placed upon the total of outstanding orders any sector will retain on its order books.

We shall not attempt at the same time to introduce monetary feed-backs to the real side, but some preparation may be made, without affecting the course of real events, by changing the basis of pricing. This, initially, is to be based upon direct labour costs, with some arbitrary markup to take account of other production expenses, including inventory and fixed capital accumulation. Obviously, this cannot except by accident yield "equilibrium" prices in any sense. By way of preparing for an examination of profit and liquidity relations, valuations of inventory and fixed capital assets need to be included in balance sheet assessments of net worth. 
The floor was modified by adding to the existing constraint on consumption supply a constraint on intersectoral supplies to reserve an arbitrary $20 \%$ of target inventory for intrasectoral supply. Unfulfilled intersectoral orders were retained up to an arbitrary limit on order books, and supplied when inventory permitted. On the money side, prices were set according to an arbitrary markup on direct lahour costs, of $30 \%$ and $250 \%$ for intersectoral and final sales respectively. Book profit included some valuations (at $60 \%$ of cost) of fixed capital assets and inventory. Tile main effect of the floor modification was evident in sequence 3, but some minor diversion of output from consumption to intermediate supplies appeared throughout. Details are given below.

In sequence 1 , the combination of laboux constraints and order books produced some cycling, but otherwise the general course of output was much the same as in run 2 , the main difference being in its disposal. The production of sector 1 was devoted almost entirely to the provision of supplies to other sectors. Sales of intermediate supplies kept close to the labour ceiling, at times exceeding it when inventory permitted; consumption supplies remained very low unt1l period 21, after which they ceased altogether. This made all sector 1 's output avaliable to service the other sectors, which although at times forced to restrict some consumer supplies managed to keep them growing at a relatively slow rate. The labour celling was not operative in the other sectors, which were nevertheless restrained by input supplies from sector 1. (The course of real output, the effect of the ceiling and the floor on disposition of supplies, and the consequent effect on sector 3 , are shown in charts III.1/1, III. I/2 and III.I/3 respectively.)

In sequence 2, output again followed the same course as in run 2 , but with more pronounced cycling, except in sector 1 whose output was identical with that of run 2. (Chart III.2/1.) The supply restrictions operated much the same as in the first. sequence, except that consumption supplies from sector 1 ceased 
earlier, and in sector 4 the timing difference in consumption produced more marked interaction with the consurption supply constraint. (Charts III.2/2 and III.2/3.)

In sequence 3 , the main impact of the adjustment to the floor became evident. Instead of ceasing early, as in the corresponding sequence of run 2 , activity continued throughout on a generally rising trend. (III.3/1.) Sector 1, instead of ceasing to supply consumption as in the first two sequences of this run, actually continued to supply consumption intermittently throughout. (III.3/2.) This was because the staggered production periods allowed sector 1 to build up inventory enough at times to supply some consumption demands before heavy intersectoral demands came in. Sector 3 now also encountered the labour ceiling from time to time. (III.3/3.)

In the absence of monetary feed backs, monetary flows naturally followed the general pattern of real flows, with similar cycling. The arbitrary prices set up a significant imbalance in the monetary flows, with a persistent net cash flow to households. Sources of expenditure were cash, bank overdraft and nfi loans, with more reliance on nfi in sequence 2. In all three sequences, bank overdraft continued to be an important source of payments after bank lending had reached its absolute ceiling, owing to the operation of nfi which allowed the continual repayment of overdraft. (III.1/4, III.2/4 and III.3/4.) Further imbalances in the monetary flows arose from a considerable investment in fixed capital and inventory by firms, which owing to the conservative balance sheet valuations reduced profits a little, although the misaligned prices would in any case have enforced losses on producers.

The modification to the floor appears to have resolved the problem arising from the impact of constraints; problems remaining on the real side are those of excessive capital accumulation and of substantial unemployment.

In general, monetary imbalances can be expected when prices 
are fixed and arbitrary, and it should be borne in mind that the problems of defining and reaching a monetary equilibrium remain to be solved. Although it is traditionally acceptable simply to assume that prices, in some unspecified way, become set according to (5.11), which does raise fewer problerns than (5.12), and that they axe so set before any trading takes place, so that trading at Ealse prices is eliminated, we shall not do that. As behavioural assartions these need such better justification than Is yet available, and we oertainly cannot legltimately seed a general eguilibrium ex post solution into micro ex ante decision sunctions. A novement towards introducing sone flexibility into prices wi.11 be started in the next run.

The unstable and internittent course of consuraption has as its proxinate cause the operation of the floor in diverting resources from consumption to intermediate supply, and although this mechanism is fundamentally necessary in order to maintain any consumption at all in the long run, it is associated in run 3 with excessive capttal accumulation. This high real saving is coraplemented by high financial saving by households. This could be adjusted by raising prices, but in the absence of monetary feedbacks this would merely transfer the monetary saving to producers without affecting the real saving.

The iale capadity resulting is also complemented, in some sectors, by high unemployment, and ultimately the prime source of a large part ố these undesirable features is the labour bottleneck in sector 1. Thus the labour ceiling, which does not operate directly on other sectors, restriats the production of sector 1, and is felt indirectly through the consequential. restrictions on supply to consumption and to other sectors, which give rise to idle capacity and unemployment in those other sectors. Some real saving is enforced upon all sectors by the laboux ceiling in sector 1 (in conjunction with exogenously-get investment), and it is a fortuitous consequence of the particular prices set that the associated monetary saving ends up in the hands of households.

Even after allowing for this, the level of real saving is 
still too high, and is not only inappropriate from a social point of view but is hardly reconcilable with behavioural factors at the micro level, since only the most pig-headed of producers would continue investing at this rate when both falling profits and persistent idle capacity would suggest caution. On the other hand, the general level of unemployment, while obviously inappropriate from a social point of view, is quite consistent with behaviour by individual producers, who do not usually regard the general level of unemployment as requiring their personal action.

At this point it becomes apparent that the notion of full employment is equivalent to the notion of the labour ceiling being encountered generally, which in the model must mean that some employers are experiencing, from time to time, actual shortages of labour which enforce temporary restrictions on their output. This notion is much closer to the rough, practical guide already used, that of excess of unemployed over notified vacancies, than some "equilibrium" notion of a level of employment in which neither unemployed labour nor shortages of labour exist. But as soon as we look at it in the context of the theoretical apparatus provided by the model, the rough practical guide gives us another measure; while the difference between unemployed and vacancies indicates the extent of unemployment, the absolute level of the lesser figure may indicate the extent to which the economy provides insufficient flexibility in shifting factors. This point is deferred for discussion until the following chapter.

In the meantime, we shall continue to follow up the discussion of the monetary factor. 


\subsection{THE MONETARY FACTOR}

Money has been passive in the model so far for two reasons: (i) direct feedback mechanisms from money to real variables have been omitted, in the sense that there have been no money arguments in real response functions; in their absence monetary variables could have affected the actual course of real output only through acting as a constraint on purchases, with consequent effects on production from the demand side; (ii) money did not in fact act significantly as a constraint, since although the monetary base formed by bank reserve balances has been held constant, the operations of the nfi kept enough cash circulating, although towards the end of the simulation period in some cases the system was reaching the end of its ability to keep this up as the volume of transactions grew; trade credit was further available as a back-up. There are a number of ways in which the model is descriptively unrealistic on the monetary side, and we shall now look at some of those.

The unconstrained nature of trade credit, which except for wage payments is freely available on demand without limit, neglects considerations of creditworthiness, cost, and both borrowers' and lenders' current liquidity. Bank and nfi lending are constrained in the model by the state of the lender's liquidity, but by no other consideration; yet in practice wouldbe borrowers are often refused on the grounds of their own liquidity or solvency position, even when the lender is in a position to lend. Cost of borrowing may not have the overriding importance that orthodoxy attributes to it, but that does not imply that it can be neglected altogether. A consideration of cost would require the introduction of interest rates; this in turn would open up the model to considerations of portfolio adjustments by lenders and by transactors generally, of the structure of interest rates, and of the relative importance of the cost as against the availability of credit as restraining factors in expenditure. Since these are all behavioural elements, they are essentially micro, and suggest different ways in which monetary adjustment responses could generate disturbances in the internodal flows. 
On the consumption side, the exogenously-set final demands remove any direct correspondence between spending and income. Two concepts of orthodoxy are relevant: (i) the income constraint; this does not operate as such in the model, since the payments constraint may be considerably extended by the use of credit beyond current income; as a behavioural factor it would be alternatively related directly to income through some effect of (ii) the consumption function; this would provide some obvious means by which higher household incomes would be reflected in higher consumption spending; if it worked in both directions, it might also supplement or replace the budget constraint proper by reducing spending when incomes fell, although some concept of a budget constraint might still be necessary if a particular specification of the consumption function were at times to run households into liquidity difficulties. ${ }^{7}$

On the investment side, there are reasons for relating the rate of accumulation of producers assets, fixed and working, to monetary variables; but, equally, there are good reasons for relating them more directly to real variables. In either case, the place of "the interest rate" ought at least to be commented on.

We shall not be able to follow up all of these ideas; limitations of time and computer space would in any case supervene. A choice has to be made.

Although many features of a modern economy have been played down or excluded from the model altogether simply because of the impossibility of dealing with everything at once, the exclusion of interest has been quite deliberate. In the Keynesian analysis and post-Keynesian derivations therefrom, "the" interest rate has been given a quite crucial place. The result is a heavy commitment of the whole paradigmatic structure to a particular view of how interest rates enter into economic activity. One can without inconsistency accept the view that the concept of "the" interest rate is grossly overplayed, while still attributing importance to the effect of relative interest rates both on portfolio adjustment by lenders and on financing decisions by borrowers. An approach to 
the analytical effect of the second effect is as follows: as a behavioural factor, relative interest rates are basically a matter of arranging priorities in sources and uses of funds; as soon as alternative sources and uses were defined in the model, such priorities had in any case to be defined in order to provide a basis of selection. The present schedule of priorities is a simple ordering, any payment being financed from own cash, bank overdraft, nfi loans, and trade credit (for other than wage payments), in that order; the introduction of interest rates into this mechanism would have the same analytical effect if cost of borrowing were the sole criterion and the cost ordering of the various sources followed the existing choice ordering. It would allow a refinement of the priority orderings if relative interest rates were allowed to vary.

Such a refinement could be brought in by stressing the portfolio effect of relative interest rates without attaching importance to "the interest rate" or to some "general level of interest rates"; nevertheless, in view of the prime importance that attaches in Keynesian theory to the notion of "the interest rate" - in conjunction with that of "the money supply" - as a primum mobile of the system, an importance rather greater than experience warxants, it seems wiser to try to find some alternative view of money in economic activity that does not commit the whole structure to this dubious notion; certainly we want to be free to bring in interest rates at points where they are known to be important, without being obliged to bring them in simply in default of any other organising or reconciling principle of the system. The underlying purpose of providing an alternative is more sharply brought out if interest is not defined at all in the model.

The unlimited availability of trade credit, for which no repayment mechanism is defined, is a definite fault of the model as currently formulated, particuiarly in view of the discussion of pp. 96-98 above.

This fault has not so far resulted in severe analytical consequences, and with both consumer demand and producers' prices 
being independent of income and payments flows it is hardy likely to be. Under these conditions, a monetary imbalance sets up persistent net cash flows in one direction, so that cash would not in any case be available to the heaviest borrowers since they would remain the losers on the flows; the bulk of trade credit could thus not be repaid as long as the given imbalance in the one direction persists. The discussion (pp. 96 -98) did point out that, regardless of undertakings or creditworthiness requirements, no borrower can discharge his debts if he is not getting money in. Until, therefore, some monetary response mechanisms are available to reverse net cash flows, surplus cash to repay credit is unlikely to be sufficiently available to debtors.

In the meantime, there is some advantage to be gained, since while trade credit is freely available to all purchasers of goods it is not available for payments of wages, which must be met in cash (borrowed from banks or nfi if necessary). If this requirement is sufficient to impose a ceiling on production relative to the monetary base, then its effect is more easily isolated if we ensure that other obstacles to the extension of vendors' credit do not modify or obscure it. Moreover, the introduction of significantly tighter restrictions on credit of all kinds would undoubtedly yield a monetary downturn which might bring about a real downturn regardless of the real floor, and since the conjunction of the two would be highly complicated we cannot deal with them both at once; we should certainly want to distinguish sharply between primary disturbances arising on the real side and those arising on the money side, particularly since the first is structural and the second is a matter of specific behavioural mechanisms.

Two monetary response mechanisms call for Immediate attention: those on the consumer demand side, and those on the producers' side involving profits and prices.

Consumer Demand

Standard preference analysis, formulated in terms of the constrained extremum problen structure and the simultaneous 
equations approach, requires us to accept the proposition that all consumption decisions, given an income or a budget constraint, are made with all possible spending opportunities simultaneously present in the mind of the purchaser, so that the best bargain can be made over the whole range. In this context, as we have stressed above, the current paradigm is generally silent about actual encounters with scarcity and provides no explicit machinery for analysing them. We therefore need to provide some alternative organising idea and problem structure for consumer choice as the source of demand.

The general organising idea is already given by the designation of the nodes in 3.22 above. It is implied there that a transactor will respond in the same way to the same external stimulus each time it is received, unless either some other stimulus or some internal stress changes the configuration at the node. A rationale for this as a cyps of consumer behaviour is found easily enough when one considers the array of factors that enter into an individual's felt needs. Apart from the general influence of social interaction, consumer needs differ sharply according to family and other commitments, income, job status, social class and so forth, and these factors are generally changing over time for any individual. Knowledge of consumption opportunities also varies, and given the cost and effort of experimenting outside their immediate experience and felt needs, consumers in general are forced into economising on buying and budgeting decisions in two ways: (i) by adopting a system of priorities so that they cover their most urgently-felt needs first and meet others as and when they can; (ii) by settling on particular goods, particular shops and particular sources of finance to supply their customary needs. It cannot be supposed that consumers take the trouble to ascertain the price of everything before buying anything, and inevitably mental attention at any point of time is concentrated on one aspect only of the whole field of consumer decisions, much as visual attention is concentrated on a part only of the whole visual field.

The simplest representation of these ideas appears to be as follows: we shall assume that there is some minimum requirement 
for goods, exogenously determined, ${ }^{8}$ these are defined in real terms as physical quantities, to be bought at whatever prices are currently being asked as long as any means of finance or credit permits. Any residue of current income remaining is then allocated in money terms over the branches of consumption in accordance with some preset scale of priorities, the actual amounts of money to be spent on each good being decerained first, the quantitios that these will buy from each sector being determined by that sector's price; at this point sufficient wages might not have been retained if some wages have been used to repay overdraft (or some other debt), 9 so that a monetary constraint could still operate; otherwise the total amounts deranded will be determined; the amounts actually supplied will still be contingent upon supply conditions.

This results in a consumption function in two stages; income is first used to buy committed or customary purchases; the remainder - the truly "discretionary" income - is allocated from the residue. 10 The small number of sectors used in the model for simulation obliges us to use the same sectors - and by implication the same goods - for discretionary as for customary expenditure, so that the distinction between committed and disnetionary income is not specifically represented as a difference between types of goods. Many of the major difficulties of a thorough-going demand theory have noi been tackled here. 11 Nevertheless, demand does here enter in a meaningful way into the internodal transmissions.

Profits and Prices

Signals communicated through profit records are by no means the only stimulus to corrective action by firms; all of the real and money stock variables in a node's configuration are within its knowledge, at least ex post, and may convey signals; there is already one response mechanism defined, 1.e. the inventory replacement rule for production. This happens to be a response on the real side to a signal on the real side, but there is no reason why real responses should be confined to real signals, or monetary responses to monetary signals; there is also no reason why the stimulus-response relation should be one-to-one. 
We cannot discard the inventory-replacement rule, since it plays the fundamental part set out in 4.1. But it could still be modified, so that the amount of inventory-replacement is altered by some additional signal, as it might be profits, or some broader set of signals conveying some assessment of the relative strength of demand. We shall, however, confine attention here to the two main tasks immediately in hand, the correction of net payments outflows arising from monetary imbalance, and a means of preventing excessive build-up of idle capital through overinvestment.

While a monetary signal could be used in defining a response mechanism to deal with overinvestment, there are several reasons why it would not be a good idea for producers to use a monetary signal. The relation between investment and capital needs for expanding output is surely a direct one in real terms, not only in underlying causation but also as it can be seen by producers, who would surely be more directly and immediately aware of the presence of idle capacity than could ever be deduced from their profit and loss account, even if they could afford to wait for it. While the presence of large or persistent idle capacity ought to be a clear signal to restrain investment, high current profits may occur from reducing inventory and failing to replace depreciating capital stock; but low profits might occur when capital stock has been allowed to run down and is inadequate to sustain the level of production required; on the other hand low profits could arise from overinvestment beyond the amount warranted by current or prospective sales. Profits are thus an equivocal guide to investment decisions, and offer no clear signal in the absence of the more direct knowledge about the relation of current capital stock to current and planned production, which should in any case be directly knowable by individual producers. We shall therefore use the simple rule of allowing investment to grow autonomously along its usual trend, with a direct bar to new investment when excessive idle capital is directly observed.

Equally direct information about payments imbalances is not. usually available, in the absence of some definable period over 
which payments figures should balance, particularly when new money capital is being raised and when external finance for current operating expenses is also involved. Cash-book type data is not in practice given the importance in management that balance sheet data is, ${ }^{12}$ and certainly in a context of generally available credit the associated liquidity problems may not be forced upon the attention of producers. In these circumstances, poor profits are probably a clearer signal that prices are "wrong".

There are, of course, a number of responses that a firm may make to falling profits: selling campaigns, internal reorganisation, product diversification, amalgamation, reduction of inventory, etc. But that wide range of responses cannot be dealt with here, and is left to micro theory to tackle (with whatever consequent effects for macro theory). We shall therefore define a simple profit-price mechanism, in which a falling-off of profits is taken as a signal that prices are "wrong" and need adjusting. It is not immediately apparent which way the response would work; for example, when firms experience a falling-off of profits would we, in general, expect them to raise or lower prices?

There is some warrant, with fixed input proportions and a relatively inelastic demand (given by the committed expenditure) for expecting firms to raise prices when profits weaken. This is more generally likely in a context of continuing boom or inflation, since in such circumstances lower profits are frequently attributable to rising production costs, and firms do usually pass such increased costs on when they can. There is no corresponding rationale to justify a symmetrical fall in prices when profits rise; it may be that some products will tend to fall in price as they become outdated, or when increasing concentration brings economies of scale, or when government intervention or the fear of it impels producers to avoid unusually high profits. There seems to be no particular reason why producers should actually want to pass on lower costs to consumers, and an appeal to the notion of "competition" requires much more careful spelling out in terms of the internodal transmissions if it is to be meaningful. We shall stop short of this, and simply assume that firms trading successfully will not in general feel impelled to 
lower prices except in response to external pressures from government or from other firms. Government pressures are not yet under consideration, since the emphasis of this chapter is on the rules by which a market economy finds its own reconciliations through the markets, i.e. through transactions. Pressure from competitors falls within this rubric, but since no form of substitution is defined that is part of a larger problem which cannot here be attempted.

We shall therefore define price rises in response to profit falls without symmetrical price decreases when profits rise; it would be desirable to have some notice taken of the level of profits as well as their direction of change, and we shall incorporate this. Trading has to take place before any profits can be reckoned, and some "initial" price base needs to be set. By far the commonest practice is to take a fixed figure for unit current costs in production, and some fixed markup to cover overheads including servicing of fixed capital. We shall approach this from the present basis in the model of arriving at prices initially by applying an arbitrary markup to labour costs. Since we already know that this does not in general give "equilibrium" prices, we shall be able to see whether the profit-price response does in fact move towards a better balance in the monetary flows.

The pricing rule clearly cannot lead towards stable prices; if one sector raises its prices to correct its profit position, costs to other sectors must increase, and their prices are likely to have to rise accordingly to protect their own profits. This is bound to be inflationary; the main brunt must be taken by households, since with rising prices and constant wages one can expect substantial losses to households, unless the multiplier effect mitigates them. It may be, that with wages and prices so defined, there is no way open to households through which they can reverse income flows in their favour, since any temporary success must bring further price increases in retaliation.

A trial run in which households were provided with a means of 
retaliation by raising wage rates was attempted; this predictably, in the structure of the model, led to such rapid inflation that it became obvious that the more pervasive type of wage-price spiral which stops, or is stopped, short of hyperinflation cannot be defined in these simple mechanisms. It is, in fact, extremely likely that the same sort of ceiling and floor mechanism that had to be developed on the real side will also be needed on the monetary side. We shall first see how the relative price and income flows, and the real variables, react to the monetary feedbacks described.

\section{$\underline{\operatorname{Run} 4}$}

The following modifications were made for this run:

\section{Investment constraint:}

The autonomously growing investment rule was maintained, but modified by a bar to new investment when $50 \%$ idle capacity was reached.

Multiplier:

Consumption expenditure was defined as the sum of two components, autonomous and induced. The autonomous expenditure was specified in physical quantities of goods to be bought, and given the common growth trend. (It would hardly have been consistent with the growing labour force to keep total basic needs constant.) This was costed at current prices, and the money amount deducted from household (wage) incomes of the previous aggregation period. (There is no theoretical basis for this choice of period; all that is required is some determinate period over which income has been received; but since this is arbitrary, it might as well be the aggregation period for programing convenience.) The residue was apportioned in money terms according to fixed weights of $.1250, .1875, .2500, .3125$ for purchases from sectors $1,2,3$ and 4 respectively. This left a residue of .1250 of discretionary income saved in money terms ex ante; ex post money saving then became conditional on prices, and on supply and financing conditions; no direct connection with real savings is 
established, and indeed there need be none since there is no direct connection between costs, inputs and payments. The discretionary expenditure allocated to each sector then determines the quantities purchased when divided through by the appropriate prices.

Mankup Pricing:

This used two argument, the direction of movement of profits over the two previous aggregation periods, and the sign of profits for the previous aggregation period. (This was selected on the same basis as the period used in the consumption function.) The rule adopted is that prices increase by $2 \frac{2}{2} \%, 5 \%$ and $7 \frac{1}{2} \%$ respectively according to whether profits have been falling and positive, not falling and not positive, or falling and not positive. For profits not falling and positive no price change is made. This rule applies individually to sectors as each enters a new production period.

\section{Variation:}

Timing was kept for all three sequences to the "simultaneous" timing of sequence 1 of run 3 . In order to compare the effects of the two monetary mechanisms within the constraints defined the first sequence used the multiplier with prices constant, the second used price adjustments without the multiplier (leaving only the autonomous component of demand), while the third combined price adjustments with the multiplier added. Results were as follows.

Broadly speaking, in the first sequence the system bumped along under a sectoral labour ceiling with considerable unemployment in some sectors and steadily growing net cash imbalances. The second sequence was much quieter and more orderly, with rising prices, a lower rate of growth and higher unemployment; the third sequence began in the early periods to follow the real path of the first sequence, but rising prices prevented this and led to a downturn, from which the system emerged and continued along the lower growth path of the second sequence in real terms, with prices still rising. Details are given for each sequence. 
Sequence 1:

After some early periods when activity was getting under way all real constraints (on capital, labour and materials) were operative throughout; there were minor fluctuations, due partly to these constraints, transmitted through materials shortages; sector 4 was noticeably affected by these from time to time. Total output was generally increasing until monetary constraints operating on labour payments (and so directly on production) brought about the beginning of a general downturn, near the end of the simulation period. (Chart IV.1/1.) The impact of the fall in production is apparent in total wage payments (IV.1/6).

It is evident that the effect of the ceilings on production, deliveries to intermediate and final use, and investment, cannot be deduced as a system aggregate but need to be conceived at sectoral level. (Charts IV.1/2, IV.1/3, IV.1/4 and IV.1/5.) In sector 1 the labour constraint was operating almost throughout; production finally started to fall below the ceiling as the downturn got under way, although consumer supply was still being restricted. In sector 2, output was so far below the ceiling that considerable idle capital accumulated; the highly intermittent and lumpy nature of investment under these conditions is apparent, and must be responsible in part for the fluctuations in output. Sector 3 has much the same pattern as sector 1, with the final downturn more clearly evident. Sector 4 was well below the labour ceiling, mainly as a result of materials shortages from sectors 1 and 3. The impact on consumption operated sectorally, and is therefore not directly deducible from the aggregated consumption expenditure despite the fact that prices were held constant throughout. While it follows from the structure that supply restrictions when real ceilings operate must fall first on consumption, only direct sectoral data yielding time series for quantities delivered to consumption would permit direct inspection of this effect.

On the monetary side, the constant prices and supply constraints combined to bring a large and irreversible net cash 
flow towards households, evident in the excess of household wage income over expenditure (Chart IV.1/6); the effect of this on the terminal asset position is shown in Chart IV.1/7, which also suggests considerable sectoral imbalance. Deposits by households with nfi provided ample loanable funds for use by firms, who were able to meet payments for a while by borrowing from nfi; recourse to trade credit became necessary in period 31 and was increasingly used thereafter. (IV.1/8 shows the general course of financing expenditures; the structure of payments flows during the last aggregation period, $T=50$, and the terminal financial positions are shown in IV.1/7.)

The growing volume of payments, even at constant prices, placed increasing strain on the fixed cash base, and eventually cash from all sources was insufficient to finance wages and this induced a general downturn towards the end of the run. Total wage payments were thus reduced, and via the money income-expenditure multiplier reduced final demand. This demand effect interacted with the supply effect of the reduced production, and in the last few periods this interaction in the context of still operative real and monetary constraints produced a complex of feed-back disturbances in the transactions flows. The timing of relevant events can be picked up from IV.1/1 and IV.1/8. The real downturn occurred during $T=43$, when total expenditures were also reduced. Trade credit became significant during $w=32$, and $i$ ts growing use implied a general shortage of cash before the downturn actually occurred. The mechanism is clear enough; when general recourse to trade credit is necessary, the cash base is insufficient, not only because buyers who need to buy on credit must be short of cash (with the priority ordering as set), but the sellers who extend credit are not getting so much cash in from sales, and if this is carried to any lengths such sellers are likely to be forced to borrow cash for their own wage payments at a time when the available bank and nfi credit has already become scarce.

There would be problems in 1dentifying this sort of process in practice; the priority ordering in the model ensures that trade credit is used as a last resort, but with the more general use of trade credit as a usual practice it would be necessary to 
find some way of separating out the abnormal substitution of trade credit for cash from the normal use of trade credit. It would also be necessary to distinguish a difference in financing due to emergency borrowing from genuine innovations in financing methods, since customary financing procedures are usually changing and developing continually. The structure of timing used, in which all sectors conduct similar scheduled activities on the same day, makes it easy to see that, as sectors 3 and 4 always call on both supplies and finance after the other two sectors have been accommodated, they are more vulnerable to restrictions on either side. This would be much complicated in practice.

It is not clear that extensive information on the course of interactions after the downturn had got under way would be necessary for policy; it is already too late, by about $r=45$, to remedy matters by increasing the cash base, since by then the real effects have become important. If the data on abnormal use of credit had been correctly interpreted by about $\mathrm{gra}^{\mathrm{a}} 40$, an immediate increase in the cash base could have averted the downturn in general, although with sectoral monetary imbalances this would not preclude the possibility that some firms would still be encountering liquidity difficulties. But it would have staved off depression of any magnitude.

Two separate primary phases and their effects can thus be distinguished.

(a) The persistent operation of labour constraints in sectors 1 and 3 did not prevent output from growing at a relatively good rate, as far as the exogenously increasing labour force available to the sectors permitted, but the consequent operation of supply constraints on inputs to other sectors kept employment in those sectors well below full employment (i.e. ceiling) levels. The floor alone did not keep the rate of growth up to the level it in fact reached; it was the strong upward pressure of demand, in the context of fixed prices and the money-income multiplier, that ensured that, given the basic protection afforded by the floor, production did press against the ceiling most of the time. 
The extent of unemployment remaining was thus due - until the final downturn - to the lack of any mechanism to redistribute labour from sectors with unemployment to those with full employment, 1.e. those constrained by the labour ceiling. 13

(b) The money stock provided by the fixed monetary base was progressively put into the hands of nfi as a consequence mainly of the large imbalance in the payments flows. With the rate of real growth achieved the expenditures became progressively largex for individual transactions, and some prospective borrowers had increasing difficulty in getting their hands on it at the time they needed it for payments. The unprofitable sectors, i.e. the net losers on the payments flows, had to wait for households and the profitable sectors to increase their cash holdings from receipts and then to re-deposit with nfi before it became available for lending. (Again, this is a matter not of lags as such, as would be suggested by the old idea of an "institutional ceiling to the increase in velocity of circulation", but of the sequential ordering of transactions, although this itself may perhaps be seen as a matter of institutional structure.) In the absence of some other disturbance or some corrective action, the eventual downturn when payrolls could no longer be met as desired was bound to happen. ${ }^{14}$

The following considerations thus arise:

(i) If the employment situation had been eased by transferring labour from sectors with unemployment to those with labour shortages, the total labour situation would have been relieved and a higher rate of growth attainable, until all sectors had full employment, i.e. were all constrained by the labour ceiling. But since total payments would consequently have been higher the monetary ceiling could have been expected to operate earliex, thus starting the downturn earlier.

(1i) To sustain a higher rate of growth and to prevent the downturn from getting under way it would have been necessary to increase the supply of loanable funds, and/or correct the payments imbalance. Since the money stock first reached its ceiling in $T=7$ while the impact on wages causing the downturn 
started in $\mathrm{T}=41$, a direct relation between money stock and "Iiquidity" - In the broad sense of ability to finance payments would not be derivable in the absence of a proper understanding of the course of expenditures and the parts played by nfi and trade credit.

Sequence 2:

No constraints operated throughout the sequence; the absence of a multiplier effect removed the impetus to a high rate of growth and also made real demand independent of price rises, so that a moderate but steady rate of growth was attained, with some minor cycling due to the derived demands arising from intermittent and lumpy investment. (IV.2/1.) Investment in total was lower than in the previous sequence, and even sectors 1 and 3 remained well below their labour ceilings. (IV.2/2 and IV.2/3.) Owing to the lumpy investment, terminal capital stock is a less meaningful datum than the course of capital investment. (CF. FCI in $R$, IV. 2/4 with the ceilings charts.)

The exogenous real consumption demand in a context of increasing prices naturally increased household expenditure, which overtook wage receipts later in the sequence (IV.2/5) thus progressively reducing household networths. The sequence ended with all networths positive (IV.2/4) although some imbalances remained. Thus the ability to increase prices in response to profit performance did permit some tendency for relative prices to approach a more reasonable relationship, although clearly not an "equilibrium" one in any sense. The consumer price index (IV. $2 / 5)$ tended to overstate the scale of price rises, but the broad picture of prices increasing monotonically with money stock constant or falling is correct.

No serious problems of instability arose and any corrective mechanism or intervention in the system would need to have been directed to raising the rate of growth in an attempt to relieve the considerable unemployment. A fiscal policy to raise the level of demand through deficit spending would have been effective to 
some extent, but in order to deal with the sectoral unemployment reraining after sector 1 had reached its labour celling some transfers of labour would also have been needed, at this point the discussion of sequence 1 would be relevant, although the absence of constant prices would modify the analysis.

Without such prior action to raise the rate of growth, monetary policy would not have affected anything, since the system had ample money for the low level of transactions; indeed, total overdrafts outstanding began to be progressively reduced, as the complementary reductions in money stock (IV.2/5) indicate.

Sequence 3:

The conjunction of rising prices with an income-expenditure multiplier led to a combination of the effects of both earlier sequences. In the beginning of seguence 3 the multiplier effect vas stronger than the price effect, and resulted in a pronounced upsurge of activity which was soon restrained by the labour celling (first peak of IV.3/1), as in sequence 1. The price effect made itself felt and the lower demand reduced output below the ceilings (IV.3/2 and IV, 3/3). No constraints operated thereafter, and after a pronounced downswing output converged on the lower growth path of sequence 2. (Remainder of IV.3/1; cf. IV. $3 / 1$ with IV. $1 / 1$ and IV.2/1.)

Charts IV. $3 / 4$ and IV. $3 / 5$, together with IV.3/1, show the related money flows. Although total money expenditures were magnifled by the price increases, wage income and consumer expenditure were much lower in relation to the money stock. (Cf. IV.1/6 and IV.3/5.) The end period transactions for $r=50$ (cf. IV.1/7, IV.2/4 and IV.3/6) give some idea of the relative scales of activity, and show that sequence 2 , with a steady rate of growth on a generally low real path, achieved the best approach to balance in the money flows.

Sumary of results of run 4:

Labour redeployment to remove the sectoral misallocation of labour in sequence 1 would be expected to raise the rate of real 
growth and to correct the unemployment, since the multiplier in a context of constant prices provides a strong upward pressure to demand; eventually, this strong rate of growth would reach a monetary ceiling and a timely increase in money supply would be needed to sustain the attainable real rate of growth.

In sequence 2 labour redeployment would merely shift the distribution of unemployment, and measures to raise the pressure of final demand would be needed. With rising prices, however, this would produce the effects of sequence 3 rather than those of sequence 1. Direct deficit spending would raise the problem of liquidity, since the absence of a multiplier prevents additional cash receipts to households from returning to the sectors through additional consumption expenditure, although rising prices must tend to correct this.

In sequence 3, labour redeployment would not help unless household incomes were increased or prices held down.

It is plain from all three sequences together that, while each appears on the face of it to have different problems, they are all different phases of a succession of problems, so that solving one problem brings the next into play. Once demand pressures are adequate to bring the economy on to its sectoral labour ceiling, labour redeployment would then become necessary to remove the remaining unemployment, since however strong the demand pressures the sectoral ceiling would impose supply constraints which would prevent other sectors from attaining their labour ceilings. 15

Given that demand pressure is kept up and that labour redeployment is brought about to prevent sectoral unemployment, the economy should move along the celling imposed by aggregate labour supply. A further problem is then encountered. If prices are frozen, then intersectoral prices have no chance to correct liquidity flows. If prices are allowed to correct liquidity flows, then apart from the general problem of inflation household demand, and hence the pressure of demand generally, must weaken the main stimulus to growth. 
Full employment of labour, which implies real growth along the labour ceiling, generally implies the operation of labour constraints as a normal matter of course. This must operate in conjunction with some mechanism, like the floor, to prevent a total downturn. But the floor alone would not prevent unemployment. In order to maintain full employment, both sectoral redeployment of labour and high demand pressures to keep real growth up to the ceiling are necessary, in addition to the floor. 


\subsection{THEORIES OF AN UNREGULATED PRIVATE MARKET ECONOMY}

In this chapter we have moved further and further from the idea of a private market economy under total laissez-faire, particularly one which solves its own problems and attains both individual and general equilibrium solely through the homeostatic mechanisms operating in 1 ts markets. We have not been entirely fair to orthodoxy, in that the shifting of factors, consumer demand and money capital in response to changes in relative wage rates, prices ani interest rates has been excluded. But the orthodoxy, while including such mechanisms as "behavioural assumptions" has nothing to say about the transaction processes through which they are supposed actually to go about achieving the desired general concordance among individuals' market actions.

It is, of course, clear that setting prices according to the "equilibrium" specification of $(5.11)$ would enable us to finesse the problems of monetary imbalance and of depressive effects of inflation on demand thus maintaining a more orderly monetary context in which demand pressures could be kept high without undesirable liquidity effects. It would not solve the problem of sectoral unemployment. Moreover, (5.11) is the solution to an equations system, which can be formulated only from the standpoint of an overview of the macroeconoray; it strains credulity to suppose that Individual producers could or would calculate the required "equilibrium" prices on the basis of such an overview, or that they would all necessarily think that it would be in their own best interests to conform to the prices so calculated.

One problem is whethex producers would be receiving the signals, through events impinging on them through the transactions Elows, adequate to convey the direction and extent of required price movements, or to tell them what their own prices would need to be if the collective tendency were to be equilibrating. In view of the divergences between liquidity, profit and net cash flows discussed above, it is by no means certain that producers would interpret these in the reguired way; when the timing of activities is taken into account further opportunities occur for 
producers to go wrong; for example, if they are using different periods for their flow data base they may well disagree on what the relevant liquidity or net cash flows are.

Another problem is that response mechanisms available to, and used in practice by, producers include other than price responses. Many such decisions have in any case to be made, since someone must make up his mind what inventory is to be held, what production level is to be set, what supplies are to be ordered, and so on. The general problem is to relate the $\mathrm{mix}$ of inputs signals to the range of responses available. In doing this producers have many opportunities to go wrong, particularly when one considers the complicating factors of unforeseen inventory changes, the operation of supply or other constraints, industrial disputes, external disturbances of all kinds, and the actions of government itself.

Moreover, even where a producer behaves rationally in terms of his own goals, those goals need not be appropriate to the society's ends; even, perhaps, as the trade cycle models suggest, producers' search for their own equilibria might collectively be disequilibrating. While, therefore, the search for response mechanisms which would bring the system here constructed into conformity with some prior macroeconomic notions of "orderliness". and "social appropriateness" has not been carried very far into the extensive repertoire of orthodox constructs, further attempts to develop along the same lines while not neglecting all the complicating factors must increasingly strain credulity, if the mechanisms are to be interpreted as the behaviour of free agents bounded only by the context of the markets in which they operate.

But while the search for "appropriate" response mechanisms may be totally misconceived as a statement of "equilibrium" conditions in a laissez-faire private market economy, it makes much more sense as a search for signals for corrective action to be taken by some external agency which accepts responsibility for the behaviour of the macroeconomy. In the presence of such a macroeconomic agency, capable of placing bounds on individual 
behaviour, some problems which appear insuperable in a laissezfaire context become more manageable.

For example, the choice of period for the flow data base becomes quite easy, since it is essentially arbitrary as long as all individual transactors conform to it, not necessarily in their actual operations but simply in the data they provide to the central agency. This will at once call to mind the operation of government policy and the data collected by the Department of Internal Revenue and the Department of Statistics, and may suggest a discussion of the familiar equipment of Central Bank and Treasury instruments and resort to the data collected by government departments generally.

This would be a mistake. The logic of the operating requirements of a complex macroeconomic system calls for a macroeconomic agency to set macro goals and to find ways of getting the system to conform to those goals. But there is nothing that logically requires this purely economic agency to operate as an organ of government; historically, the Bank of England provides an example of a private, autonomous institution which increasingly accepted responsibility for underwriting the stability and solvency of the financial system in which it operated. There is nothing conspicuously political about such activity. But in view of the general presence of already existing firm central governments, and the fact that they have generally been forced by practical events to accept increasing responsibility for providing a macroeconomic overview, there is much to be said for continuing to expect government to discharge this responsibility.

That no private market system operates in fact without considerable intervention from government is recognised at two points within the accepted paradigm. The activities of government are tacked on as variables or parameters to the theoretical constructs devised for the private market economy, as for example by tacking a shift parameter on to the IS curve to "stand for" government expenditure. And economists using private market equilibrium systems as their basic tool of analysis are rarely 
reluctant to draw conclusions and recomendations for pollcy interventions. Indeed, such pollcy recomnendations are almost enforced upon a model-builder by the requirements of the current paradigm, if he is to avert the charge of amusing himself with "unrealistic" models.

But since the theories of the private system, closed or not, are black boxes devoid of internal structure or processes, the addition of government can merely add input and output terminals to the black boxes. Since there are no transaction processes or any other explicit mechanisms connecting the input and output terminals, none can be defined to connect in the government terminals. Moreover, the basic technique of analysing systematic behaviour sanctioned by the paradigm is in terms of equilibrating mechanisms, which are all that are availabie both to draw policy conclusions and to analyse the effect on the private system of government policy measures. Thus a considerable feat of doublethink is involved. The policy conclusions are drawn from a model. in which the equilibrating mechanisms work as a matter of course; yet the recommendation for government policy suggests that the government is being asked to do something that the private econony cannot or will not do. But despite this plain implication that the private market mechanisms have not worked in the way that they were supposed by the theory to work, precisely the same mechanisms are invoked in order to analyse the effects of the policy recommended. There aurely cannot be any phrase more abused in the context of government planning than "optimal resource allocation".

Thus despite the recognition that current theory ostensibly gives to government action, its conceptual framework is quite unsuited to deal with the actual presence of government intervention. A private economy model that is not even defined for the processes 1t purports to be examining cannot be expected to perform better when the same model is put into a political setting. These remarks also bear on the data collection undertaken by government agencies. Some of this data, of course, is collected for specific purposes, as e.g. tax, lmport control, building permits, on bases not directly germane to economists' purposes, 
some is collected on a pragmatic basis, more or less because it is there; the remainder, like input-output tables, financial data, and national income accounts, are collected on a conceptual base deriving from the constructs of private enterprise economics. All of it, nevertheless, is grist to the empirical economist's mill.

Obviously, any attempt to speak in terms of "macroeconomic goals" or of "socially appropriate actions" implies some global view taken outside of private market activity. We shall therefore abandon the fiotion that macroeconomics is an attempt to represent equilibrating transactions flows among private transactors only, i.e. that it attempts to describe the behaviour of a closed market system with its own equilibrating or homeostatic mechanisms, and consider the problems of "balance" or "stability" as problems of external intervention. Thus we move on to a more adequate notion of a macroeconomic system as a contrcl system. ${ }^{16}$ 


\section{CHAPTER 6}

\section{THE MACROECONOMY AS A CONTROL SYSTEM}

In this chapter, the view of a macroeconomy as conducting its main producing and consuming activity via the operation of private transactors in private markets is retained; the difference is that we now move to a more explicit examination of the problems and techniques of controlling such a system from the basis of a macroeconomic overview operating in the light of macroeconomic goals, rather than of trying to find ways in which an uncontrolled private market system might, through its own homeostatic mechanisms, be able to reach such macroeconomic goals unaided. While some mechanisms examined will clearly be functions of government, some may involve bounds to or requirements for private actions; but we shall not here discuss the political relations between government and private transactors, restricting the analysis to the exploration of such economic mechanisms as appear to be necessary or desirable for the proper functioning of the system. 


\subsection{THE BASIS OF CONTROL}

Some of the ideas developed in previous chapters ${ }^{1}$ may now be summarised as follows:

(a) The homeostatic mechanisms upon which theories within the accepted paradigm rely to bring the independent and conflicting actions of private transactors into concordance with one another and with the macroeconomic goals of adequate provisioning and of furnishing means for the attainment of other social ends, in a regular and orderly way, are at best unreliable and may not even exist at all; in any case they do not, and probably cannot, work in the way that would be necessary for the social goals to be met in an orderly and reliable economic context.

(b) A modern economy is not in general left to the unfettered operation of independent private enterprises, and even in those countries most dedicated to the "free market system" governments are obliged to accept considerable responsibility for correcting maladjustments arising in the system. The practical necessity for macroeconomic intervention is beyond dispute.

(c) But government or other macroeconomic intervention cannot replace the markets system or make it unnecessary. The presence of extensive division of labour implies the existence of a structure of interpersonal obligations for goods and services provided, a structure now too extensive and complex to function except by the use of some common nexus of settlement. Whatever is used to settle these obligations, while it need not be at all like the money we know, is nevertheless money in terms of our basic theoretical definition of "money". Interpersonal transactions, with money as the nexus, hence coexist with the presence of extensive division of labour. Only a total abolition of the interpersonal obligationg themselves would vitiate this; this in turn would require a radically different view about the 
nature of social organisation (including the ownership of property), which would not apply within the possible domains of applicability of the concepts of this study. Even where the means of production were comaunally or state-owned, interpersonal obligations would still arise as long as individuals had title to their own labour and to the consumables they enjoyed.

(d) Given a transactions system necessitated by the provision of inputs to production, the distribution of the output therefrom, and the settlement of the interpersonal obligations thence arising, the operation of a system of markets follows immediately. Whether the operation of such a system is adequately represented by some particular schema or not, that it operates in some way or another cannot be doubted. To the extent that macroeconomic intervention becomes necessary because of problems the system has in reaching its own reconciliations, with important consequences for the course of production and consumption, it has to be recognised that such external intervention must evoke its own market responses, and these must be taken into account when intervening.

(e) Government or other intervention in the market system cannot be expected to be effective in providing the required control unless the controlling body is able to conceive its intervention policy according to adequate schemata of the processes in which it proposes to intervene; when the organising schemata available for analysing both the sources of maladjustment and the putative effects on them of various policy instruments stem from the conceptual framework whose fundamental basis 1 s still to be found in the ideas discussed in section 2.1 above, a framework which is not even defined for operative transaction processes, this precondition is not met.

(f) This does not at all imply that the aim of intervention is to preserve some status quo or basic regularity in the uncontrolled market system; it is more likely to be the case that intervention is required to provide some regularity or some purpose that the private and uncontrolled mechanisms are incapable, or at least have failed to show themselves capable, of achieving 
unaided; the task is thus not to restore the system to some hypothetical "ideal" state, but to modify or adjust it in the light of some definite purpose which the system is required to fulfil.

(g) It is not the case that the only or the best type of test of the adequacy of understanding of the system at our disposal is that specified by the traditional hypotheticodeductive paxadign, which prescribes conformity tests applying the tools of inferential statistics to the black boxes of Ricardian-Walrasian equilibrium economias. Such tests on theix own are compelled to silence on those questions of transfer mechanisms which are crucial to understanding, and still more to effective control, of the processes observed. If it be accepted that the perception and understanding of macroeconomic events involves a process of successive construction and reconstruction, then some type of activity mediating between the external events and their understanding is essential. It is not to be expected that for all flelds of enquiry overt operations on the actual object observed will be possible; but in the control of a macroeconomic system the interlorised actions constituting representational activity may be conjoined with exteriorised actions through the intervention instruments used by the controlling body of the system. What could more directly constitute "acting on the object" than intervening in the observed system in a definite way to produce a specified effect on the behaviour of the system? Thus, attempted control of a set of processes is itself a form of observation of them, and successful control is an assurance that they have been adequately understood. This assurance is of course provisional, in exactly the same way that predictive success is a provisional assurance of confirmation within the hypothetico-deductive paradigm.

(h) Since the "specified effects" intended to be produced in the system by control may easily be seen as a form of "prediction", the test of "successful" control may after all be seen to reduce to the general conformity tests prescribed by the positivist view. But control is not a single experiment, and allows for the fact that dealing with a particular effect of the 
system may produce unintended and possibly unforeseen effects on the system in addition to that intended, thus making continuing thought and intervention necessary. Moreover, for much of the time it will not be a question of verifying particular predictions but of frustrating the event predicted, so that whether it would or would not have happened in the absence of intervention becomes untestable. Most importantly, the control approach here is based upon an understanding of causal effects in the system, alternatively to the prediction tests which deal with statistical regularities rather than with the causes of singular events.

(i) The economic events under examination here are not themselves ultimate but are the proximate ains which must be attained if many of the social goals are to be met. These economic aims, being themselves means to an end, need not initially be specified in detail as the aims of control; once we have adopted as the major proximate goal that of providing adequate provisioning in an ordexly way with full employment, the subsidiary requirements, as for example in respect of monetary behaviour, that may suitably be set as desired means to those economic ends may be left to emerge from the analysis of the system.

Two approaches to control

A control system has been spoken of so far in terms of macroeconomic intervention. This suggests a "trovble-shooting" approach, in which the network of nodes is left to provide its own motive power and individual action-directives at the nodes, intervention becoming necessary only in the presence of some malfunction of the system. Intervention may, on the other hand, be carried beyond this to an extreme which presents an alternative approach, in which macroeconomic control assumes a "supermanagement" role, replacing individual action-directives by a system of central direction, compulsion and prohibition. In this extreme case, the macroeconomy is regarded by controllers as a single producing entity in which individuals are not autonomous actors whose actions are to be reconoiled after they have become overt, but sub-units of the system whose prescribed 
actions have already been subjected to a macroeconomic reconciliation exercise by the controlling authority before being promulgated.

The logical distinction between the two extremes does not present a meaningful choice between two practicable alternatives in a modern technology. That technology, resting on extensive division and specialisation of labour, needs equally extensive division and specialisation in its management function, implying a considerable decentralisation of decision-making, whether by delegation or by ownership. On the other hand, there are many goods of communal consumption whose benefits may not be captured and sold for profst, or for soise other reasun have to be left to government responsibility, so that the existence of social ends implies that some action-directives have to be attributed to government.

Since we have confined ourselves to one major component of total activity, that concerned with market transactions between independent decision-makers, we shall restrict ourselves to the trouble-shooting approach, 1.e. to dealing with malfunctions of the market system when they become apparent. This gives us a major difference of approach from that of the recelved paradigm. The theories of the current paradigm attempt to describe the behaviour of a market system when 1 t operates perfectly, and for this reason are completely at a loss when it goes wrong. Here, we are content to leave the gystem alore when it goes right, our main concern being with what needs to be done when it goes wrong.

Mechanisms of control

The mechanisms of control fall into two categories, those operative through the transactions flows and those using other means of communication not here defined. This sounds like, but is not, equivalent to the more familiar "market versus direct controls" distinction familiar in discussions of fiscal and monetary policy. But taxation here involves actual transactions through the banking system, and so do social security payments, state house rentals and subsidies, so that the mechanisms of the first type cover a more extensive range than those which involve 
the control authority in private markets as itself a buyer or seller of assets and services. But control of the second type. which does not operate through transactions, must operate on them, i.e. must have effects discernible in the transactions flows, if it is to impinge upon the individual transactors' production and consuaption activity in any significant way.

For example, one type of control which may have to be given importance would be necessary to redeploy labour where the private markets themselves cannot provide sufficient flexibility of factor movements between sectors. This would operate outside the transactions flows, requiring an apparatus of communication and administration only peripherally involving transactions (for example, in payment of transfer or interview expenses). But if operative in a time of sectoral unemployment and restrictions on production due to sectoral labour ceilings such intervention should have a major effect on the extent and direction of transactions flows. Price control is another type of external control which while administered without transactions would be expected to have a direct effect on transactions flows.

Criteria for control: the identification of malfunction

The trouble-shooting approach means that control action is seen as a response to a stimulus received from the nodal network rather than as an initiatory activity, although this does not deny that some initiatory actions may arise from other purposes of the controlling authority. But since we are dealing only with the response to a malfunctioning of the market syster, the search for criteria for control action reduces to the specification of signals indicating the presence of a malfunction or conveying warning of an impending one.

The presence of sectoral unemployment or vacancies ray properly be taken as directly perceived from data and notifications to the administering body from both employers and unemployed. But some other malfunctions may be more difficult to identify. At what point, for example, does a monetary imbalance become 
sufficiently Important to require attention? This will obviously call for further enquiry in due course. In general, we shall continue to seek to construct a set of charactaristics which may collectively constitute an array of signels to be kept under view, through a process of dealing with problems as they arise in the singular events of simulation and assessing any further problems as they then appear through market responses to earlier control actions.

If the course of events in run 4 is anything to go by then malfunctions probably do not occur singly, but in succession as the sulution of one tands to bring others in=o prominence. Thus successful control is likely to be, not a matter of single adjustments to deal with single problems, but a matter of a seguence of adjustuents to deal with side effects of previous control actions and subsequent disturbances. clearly, if a sequence of control adjustments is to converge on some notion of "orderliness" then oycling between two malfunctions by reversing the previous control action mast be avolded. (The sort of sequence to avoid is 1llustrated by the sequence: deflation to correct a balance-of-payments defleit - Inflation to correct unemployment resulting Erom the deflation - deflation to correct the balance-of-payments deficit arising from the inflation......) 


\subsection{MALFUNCTIONS}

6.21 UNEMPLOYMENT

Unemployment has a variety of possible sources. Those arising outside the market system, as for example from an inadecruate technological base which is a symptom of imperfectly industrialisel societies, or from major industrial dispute, which may be associated with market factors but involves major social factors as well, will not be dealt with here. We shall also have to exclude input shortage arising from extornal market factors, since we have not so far extended the model to deal with foreign trade, although it really needs to be brought into the transactions flows. For our purposes, any constraints arising from those source: would have to be treated as real ceilings imposed by exrogenous factors.

Those sources of unemgloyment arising within the market system may be dealt with in two categories: deficiency of demand or deficiency of production. As a preliminary basis, it appears from previous runs that we can approach these in the following ways:

(a) Deficiency of demand: this would be identifled by generally low output with no real constraints oparating, with plenty of stocks available to consumption and considerable idle capacity; thus there must be a lack of pressure to keep production up to the ceiling. It could arise from:

(i) I.ack of strong desire for goods qua goods. This suggests consumer satisflcing in respect of basic needs, with no multiplier effect; this would be apparent when no spending response occurs in the presence of surplus income available for discretionary spending, and would suggest a high propensity to save. This ought to be identiflable from considerable monetary saving by households arising from an excess of income receipts over expenditure, beyond that needed to finance real saving to 
sustain the existing rate of expansion. This need not imply any real saving, since producers' 1.de capacity might involve some real dissaving, and certainly their 11quidity positions must be deteriorating through cash losses on the payrants flows. If they were to recoup their losses by raising prices, this would reduce household monetary saving and the situation would merge into that of (ii) below. Before this, the situation cannot be corrected by putting wore money directly in the hands of households. since in this case the extra income would go to incraase hougehold saving rather than spending, although it would indirectiy heip in financing any necessary borrowing by producers. A direct cenand for output by the control authority entering the maxlect da a buyer would be needed, and this would be consonant with the use of the unused real resources for other social purposes. This would be particularly appropriate if the consumer spending resistance stermed from a general oxpectation of depresalon and lower incomes and prices.

\section{(1i) Inadegruate conauner incone. A elear indication of this} would be a persistent excess of expenditure over income, but it st1.11 would not be clear whethex additfonal income woule bring a multipliar into play or whether it wovld merely ifnance basic needs with any suxplus going to saving. Further information would be needed. Inadequate income could arise from:

- Monetary imbalance, with substantial losses to households on the monetary flows. This could occux with fixed prices set arbitrarily so that relative prices were "wrong", a direat connection would require money inome to be an argument of the demand function, an indiregt effect might arise through licuidity constraints operating.

: Inflation with fixed wage rates or inadequate wage increases, there might for a time remain some household saving in a situation there the inflation arose from the efforts of firms to correct a monetary imbalance in houscholds" Iavour, which sooner or later must lead to an imbalance in the other alrection.

: The operation of a monetary constraint directly on conswer expenditure, arising from a basic inadequacy in the 
monetary base. (The case where the monetary constraint operates on production reverses the causal effect, since then the demand deficiency is a secondary effect of the unemployment, discussed in (b) below.)

These require, respectively: correction of the monetary imbalance, control of firms' pricing practices and/or wage increases, and expansion of the monetary base. Since all three sources tend to merge, and could not easily be distinguished in practice, corrective action might have to comprise all three elements. In the case that corrective action led to a levellingoff of household expenditure, with the remainder going to saving, case (i) would then apply.

(b) Deficiency of production and demand for labour: these could arise and would be directly identifiable from:

(i) The operation of real constraints, on:

- Materials supply from other sectors; this normally would be part of a secondary phase when found in connection with unemployment, and a prior source in the primary phase needs identifying, possibly in sectoral unemployment. As a genuine primary disturbance, it would indicate that producers were setting target inventories too low, a problem that we have not dealt with.

: Capital inputs; this would also tend to be a symptom of a secondary phase since capital is ex hypothesi produced domestically, although with imported capital it could operate as a primary disturbance. Otherwise, as a primary disturbance it would indicate that investment targets were being set too low.

: Labour supply; if this is to operate persistently in one sector, with unemployment remaining elsewhere, this is clearly a problem in sectoral rigidity, although general unemployment inight persist after sectoral rigidity has been dealt with, as a secondary symptom of some other primary malfunction. 
In general, the operation of real constraints needs interpreting with care, since when the economy is growing along the full employment ceiling real constraints must operate from time to time. It is when they occur persistently in a context of substantial unemployment that they become significant symptoms of malfunction.

(ii) The operation of monetary constraints. Where these operate directly on production, they may arise from:

: Imbalance in the monetary flows; in this case producers are net losers, and a situation similar to that of (a) (i) is evident; it may also be associated with:

: A deficiency in the monetary base.

The foregoing suggests that where sectoral rigidities or monetary imbalance are present, their effects tend to mask other sources of disturbance, and where they occur together other sources resist identification. They need to be dealt with first before any other problems present can be identified and dealt with. It is also clear what a hit or miss affair monetary restriction must be if applied whenever rising prices and general shortages of supply are present. It is crucial to know whether monetary restriction operates first on production rather than consumption, and whether the rising prices are a consequence of markup pricing practices rather than directly a response to excess demand, since in these circumstances monetary restrictions must increase unemployment before reducing inflation. ${ }^{2}$

We shall approach the problem of unemployment from two sides. The sectoral rigidity needs direct administrative attention, since where it exists the existing market mechanisms are clearly ineffective. The administrative means for redeploying labour require in practice extensive organisation, but since that 
Is an extra-market matter the difficulties of doing so are not here examinable. We shall have to assume that it has been done, and that an organisation exists capable of matching up unemployed labour in one sector with job opportunities in sectors constrained by labour shortage.

This deals only with that section of the total unemployed for which corresponding vacancies exist elsewhere. Any unemployment. remaining is net unemployment for the system, which in a modern economy will frequently - though not necessarily - arise from a demand deficiency, as in sequence 2 of run 4 , which is observably case (a) (i) above. We shall attempt to deal with this by introducing a government demand for goods in the market; since government expenditure in the goods market necessarily increases the monetary base, this might itself dispose of the problem of unemployment due to a monetary constraint, and we shall not at this point introduce a separate mechanism to deal with that.

None of these measures is $11 \mathrm{kely}$ to make such impact on monetary imbalance, and consideration of that will have to be deferred.

$\underline{\text { Run } 5}$

Modifications to the model as it had stood for run 4 were as follows:

\section{Labour Redeployment}

This took the form of transferring unemployed labour to a central pool (up to half the labour unemployed in any sector at the time of transfer) with transfers out of the pool to sectors encountering labour constraints. It was thought that, while this might leave significant numbers of unregistered unemployed, if the rate of growth were high enough it would progressively reduce unemployment without causing cycling due to fluctuating labour demands. It should also be recognised that where very great unemployment exists, large scale transfers cannot be made at once, and some administrative lag must in practice be accepted. 
Government Expenditure on Goods

Where net unemployment was large, the government was to enter the market as a buyer of goods (from sector 4, whose derived demands on other sectors are relatively large, so that the accelerator effect is given as much leverage as possible). This automatically operates to expand bank reserves through the necessary transactions flows.

\section{Variation}

This was kept as in run 4, i.e. multiplier with constant prices, price increases without multiplier, and price increases combined with multiplier for the three sequences respectively.

In the event, the only substantial effect on the real flows of the two employment measures introduced was in sequence 1 , operating mainly on sector 1; a minor effect on the real side occurred in sequence I from the government expenditure on goods; whereas the shortage of money had resulted in a marked downturn in run 4 , this was largely prevented in run 5 by the extra monetary base thus provided. The other two sequences were broadly the same as before. Details are as follows.

\section{Sequence 1}

Real output was, as expected, much higher in sector 1 owing to transfers of labour from other sectors. This enabled sector 1 to maintain intersectoral and consumption supplies, thus enabling other sectors to keep up their production and providing a strong stimulus to growth, in the context of the multiplier-induced demand. But an unexpected effect reduced sector 4's output: Unemployment was zero after the first few periods during which the system was absorbing its initial unemployed labour, and thereafter vacancies grew as the system pressed against the total labour ceiling. Sector 4, which had lost a good deal of 
labour to sector 1 in earlier periods, soon found itself increasingly short of labour as a direct consequence of the extra production from other sectors, providing both demand stimulus and less restricted supplies. Its growing notification of vacancies could not be met since the labour pool was empty, any new additions to the labour pool from increases in the labour force being taken by sectors ahead of it in the queue. Whether this is a good or a bad thing depends entirely on how one values the various sectoral outputs; but certainly the actual attainment of the total labour celling must leave some sectors short of labour in terms of what jobs they could then offer, ${ }^{3}$ particularly when, as in this case, labour is transferred to a labour intensive sector.

The course of real output is shown in $\mathrm{V} .1 / 1$; a datum line is put into $V .1 / 1, V .2 / 1$ and $V .3 / 1$, which shows how the same pure number is scaled on each chart, in order to give some comparison of scale. The real cellings $(\mathrm{V} .1 / 2, \mathrm{~V} .1 / 3, \mathrm{~V} .1 / 4$ and $\mathrm{V} .1 / 5$ ) illustrate the movements of labour into and out of sectors, including accretions from new entrants to the labour force. All. labour ceilings are generally operative, since unemployed labour is transferred fairly quickly to the central labour pool, and it is the operating constraints that signal vacancies to the pool.

The higher level of production and the attaimment of the full employment ceiling resulted in higher wages, which operated via the multiplier to increase household expenditure. Thus, in the absence of some external disturbance arising from, for example, resource scarcity or industrial dispute, the basic conditions were met for steady growth along the labour ceiling. The level of money stock, which has hitherto acted as a datum line in order to assess the scales of successive income-expenditure charts, varies between IV.I/6 and V.1/6, owing to some initial government expenditure on goods when the initial unemployment was still significant. This minimal expenditure increased the money base by some $5 \%$ and enabled a corresponding increase in the money stock to take place. After the first few periods unemployment was absorbed, no government stabilising expenditures were necessary and the monetary base thereafter remained constant. 
It is worth emphasising that, while the pressure of consumer demand is needed to keep up the growth path, increased production is also necessary. Any increase in demand not arising fron Increased employment would not have permitted production to increase to the extent that it did.

Comparing V.1/7 with IV.1/8 it is apparent that trade credit is used later and to a smaller extent in run 5, and also that the nfi played an important part, through the recirculation of bank deposits, in making maximum use of the marginal increase in money stock. The active nfi, as one would expect, were associated. with substantial imbalance in the money flows. This vas aggravated by the fortuitous circumstance that the labour transfers increased the receipts of sector 1, which was already a net gainer on the payments flows, at the expense of other sectors, particularly sector 4 which had already been a net loser. Sector 1 recelved a double benefit; on the markup basis used, consumer sales are more profitable than intermediate sales, and since sector I's production was now high enough to enable it to supply consumer demand, its aditional sales were also more profitable.

Sequence 2

Real output remained below the datum line for most of the running time (cf. $V, 1 / 1$ and $V .2 / 1$ ), and unemployment remained significant after labour redeployment, which in fact made very little difference by comparison with IV.2/1. Despite the general unemployment, labour constraints operated internittently throughout. This intermittent operation when the labour pool is fairly full can easily be recognised as the operation of the transfer mechanism alone and not a consequence of the system having reached $1 \mathrm{ts}$ labour ceiling. (This is a simple matter in the model since no distinction has been made between various types of labour, in practice, a redeployment agency would have to run different pools for different types of skill, each pool being treated as we have here treated the general pool). The general picture is suggested by $\mathrm{V} \cdot 2 / 2$.

The persistent unemployment led to continual government 
purchases, which did not bring about full employment but did yield a rapid growth in the monetary base. Advantage was taken of the freely available overdraft resulting, and money stock rose correspondingly. As a result, consumer income and expenditure are rather flattened in $\mathrm{V}, 2 / 3$ by the scale needed for the money stock. One effect of the money mechanisms is shown by a comparison of $v_{0} 2 / 3$ and $v_{0}, 2 / 4$ with $v_{0} 1 / 6$ and $v \cdot 1 / 7$. When the money stock has reached the celling set by a fixed money base, and imbalances call for a good deal of credit (apart from bridging finance needed), the nfi tend to be more active, shown both by $E N$ in $V .1 / 7$ and by the general use of cash to finance payments (EM), obtained mainly from the nfi's recirculation of bank deposits. When the monetary base is ample and growing, and would-be borrowers are in evidence, the main source of payment is bank overdraft (EA in $V_{*} 2 / 4$ ), which of course increases the money stock $(\mathrm{V}, 2 / 3)$ as long as it exceeds overdraft repayments. (The condition of an increase in money stock is not, of course, that $E A$ is growing, but that $E A$ exceeds RA; this condition was in fact met, but sirce ti.s "disposals" data was not collated, to leave room for something else, this had to be verified by cheaking the running printout.)

Thus, in some circumstances, an increased money base may not stimulate increased expenditure on goods but merely substitute overdraft for some other source of finance for payments that would in any case have been made. The real balance effect would not vitiate this, since until the extra overdraft has been used, no one has an increased deposit arising from the increased money base. Given this prior substitution of overdraft for other finance, there would then be something for the real balance effect to work on. Thornton's aprroach is more direct; the knowledge that additional bank finance is available is a stimulus to spending when there are enough would-be borrowers for new expenditure hitherto frustrated by monetary constraints.

The labour redeployment and government expenditure, while not getting to the root of the matter, did have minor effects on the distribution of production and the course of payments; the conseguent effects on profits and thus prices further affected the 
payments flows. But these were minor matters which are not of interest to macroeconomic control.

Another minor natter arising from the inventory replacement rule was that of inventory, which with the low rate of growth accumulated to excess. This accumulation was not only excessive in terms of social use of resources, but could not be afforded by the losers on the payments flows (sectors 2 and 4 ) and would have been improvident on their part if indeed the banks had permitted the accumulation of excessive inventory on bank overdraft. Apart from the general question of creditworthiness standards, this is purely a matter of the decision rules at the nodes, exogenous to the model.

\section{Sequence 3}

The course of real output followed the general pattern of run 4. The three phases (marked in $\mathrm{V} .3 / 1$ ) were as follows: in phase 1 the multiplier effect was strong, and real consumption, production and employment were high; in phase 2 the multiplier effect progressively weakened as higher prices left smaller residues of discretionary incone once basic needs had been met; in phase 3 the multiplier disappeared, basic consumption in real terms being identical to that in the corresponding periods of sequence 2. The peak in sector $3^{\prime} \mathrm{s}$ output is higher than at the corresponding point in run 4 (which affects the scaling of the charts). The effect on the cellings is most marked in sector 3 $(v .3 / 2)$, in which the impact of phase 2 on the labour and capital ceiling can be distinguished. There are differences: the capital celling reduces owing to physical decay of capital stock which is not being replaced in the face of idle capacity resulting from the downturn, and real dissaving is involved; the labour deiling reduces owing to transfers of labour out of the sector to the labour pool, and must go to swell the unemployment figure as no vacancies exist elsewhere.

On the monetary side, the plateau which the money stock reached in phase 1 can be distinguished in $V .3 / 3$, the rapid growth thereafter being a consequence of the progressively growing 
monetary hage, wan affert nf vorernment expenditure rising in response to the growing unemployment in phases 2 and 3 . The monetary effects occurring separately in sequences 1 and 2 axe both discernible in sequence $3($ in $\% \cdot 3 / 4)$. In phase 1 the fixed money base and monetary imbalance led to a very active nfi, with a rapid turnover of bank deposits evident from both $E N$ and $E M$. In phase 3, the growing money base - still with gubstantial imbalance, substituted bank overdraft for nfi credit, which led to the growth in money stock. Phase 2 actually exhibited similar Eeatures to phase 3 , but this is not clearly shown in $\mathrm{V} .3 / 4$; it cair be deduced, given the known structure of the model, that since money stock is rising while wawings on overdraft are falling, then repayments must be falling faster than new drawings. In the greater generality of the model, information from the disposals data would be necessary to establish this point.

\section{Sumary}

No outstanding problems, except that of monetary imbalance, appear to remain from sequence 1. Sequence 2 has a demand deficiency, reminiscent of the "underconsumption" and "oversaving" theories of depression. If this could be overcome, the next problem that earlier seemed sure to arise, that of sectoral rigidity, has already been dealt with, and there seems to be nothing but demand deficiency to prevent the system from achieving full employment and the associated high rate of growth. But in the absence of government use of the idle resources, which would be sensible in view of the absence of a multiplier to prevent the demand feed-back from getting out of control, and which could in any case be expected to be willingly undertaken by government, there seems nothing in the control mechanisms currently available to solve the problem. Sequence 3 , which has a multiplier which cannot operate when prices are s.jo high, presents a problem of low production and unemployment arising from demand deficiency due to iradequate incorne (at current prices). 
There are many mechanisms available for dealing with inadequate income as a source of unemployment; price control, wage increases, correction of the monetary imbalance, and social security payments are the most obvious. (Other less familiar devices, as for example government entry as a competitive producer, or the use of lump-sum redistributions of money could be considered, but there seems to be little point in trying those in preference to mechanisms for which practical administrative procedures have already been developed by most modern governments.)

It is obvious that with pricing practices as at present formulated in the model, wage increases, particularly if tied to a consumer price index, would lead to runaway inflation; this would be a worse malfunction than the one it replaces, and might not eliminate that one either. Price control would be more sensible, and could be devised in conjunction with an attempt to deal with the monetary imbalance. It therefore has much to recommend it. Before doing that, there is something to be said for introducing unemployment benefits as a familiar feature of modern economies with obviously important implications for the transaction flows, and we shall see what problems that leaves us with.

Run 6

The following modifications were made to the model as set up for run 5:

Unemployment Beneól:

This introduced a direct payment by government to households of an amount equal to $60 \%$ of the going wage rate for each man registered as unemployed (i.e. held in the labour pool).

Taxation on Próats:

In order to provide some offset to the increases in the monetary base resulting from government stabilising expenditure, 
a tax rate is applied to profits for the current year, calculated and payable at the year's end. This is set at a rate of $50 \%$ of net profits, with some allowance for sectors on low profits.

\section{Inventony:}

In order to find out whether the system is better off with a lower target inventory in order to prevent excessive accumulatIon of inventory, a lower rate of growth of target inventory is set exogenously at $(1.02)^{T}$ instead of the $(1.04)^{2}$ set previously.

Variation:

The three sequences as before were retained; nothing interesting was expected in sequences 1 and 2 , and they were retained (in terms of the "convergence" notion of control), in the interest of seeing whsther, when malfunctions are tackled, previously solved problems stay solved.

In the event, what had been seen as a minor change to inventory overrode the system; output over all three sequences was affected, although the effect was partially offset in sequence 3 by the boost to money incomes from uneraployment benefit, which via the multiplier strengthened the demand stinulus. Details are as follows.

Sequenee 1:

A conparison of the datum Iine in VI.1/1 with that in V.1/I shows how substantialiy output fell. Within the model, a simple process of elimination suffices to identify the cause. Monetary constraints did not operate in VI.1/1, so that the introduction of taxation did not restrict output through liquidity effects, and aince net proflts do not here enter into either production planning or price setting, there are no other mechanisus through which the taxation effect could enter. It is also difficult to see how unemployment benefit could actually reduce output (even within the mechanisms of the model sone chain of feed-backs might produce such an effect, so it cannot be 
forgotten), but since the full employment rate of growth of V.1/I would eliminate this payment it could not in any case have been primarily responsible. This suggests that the lower production path is the result of lowering the target inventory.

Although this sort of diagnosis can be made within the known structure of the model, it would be much harder in practice. First, because although we can exhaust the possibilities here through a prior knowledge of them, in practice an exhaustive list of possibilities might be a meaningless thing to ask for. Secondly, the direct inspection of nodal response mechanisms possible here might have to be replaced by a much less certain chain of inferences. We accordingly need to consider how we should be able to draw, from the information likely to be available to the control authority, sufficient assistance in pin-pointing the cause of malfunction. We cannot expect a clear set of deductions yielding a definitive and logically necessary conclusion; we shall be content with finding some means of progressively narrowing down the possibilities requiring investigation. A basic tool in the identification of primary and secondary phases is data on the constraints. The simulation printout provides constraint data in the form shown below: 
RUN 5

Sequence 1
RUN 6

Sequence 1

$\begin{array}{llllll}\text { PERIOD } & \text { CAP- } & \text { LAB- MATER- } \\ \text { ITAL } & \text { OUR } & \text { IALS } & \text { MONEY } & \text { CAP- } & \text { LAB- MATER- MONEY } \\ & \text { ITAL OUR } & \text { IALS }\end{array}$

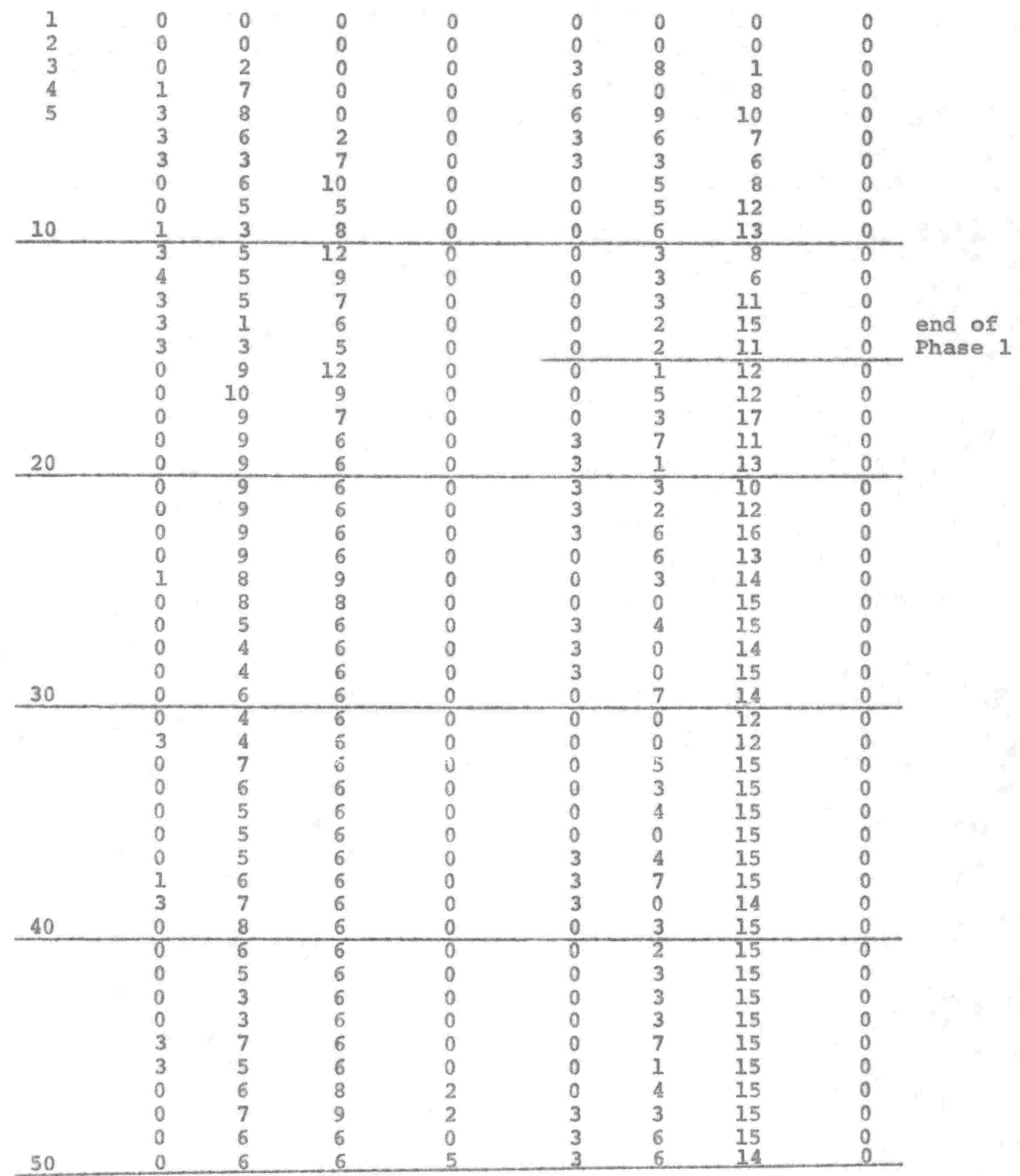


Each number records how many times the indicated constraint operated during the course of a particular aggregation period. Neither the individual. sectors affected nor the sequence of operation within an aggregation period is identifled, and these details may have to be investigated before the course of a primary phase can be established. Where the inception of a secondary phase occurs slowly over several aggregation periods, the relative frequency of constraints may give sufficient information. Since in the full employment growth situation constraints are expected to operate in the normal course of events, information from this type of data has in any case to be supplemented from other sources.

In run 5, unemployment was zero after the first few periods, and this information (direct from the labour posl figure) enabled the labour constraints to be interpreted purely as the typical symptom of restraint by the full employment celling, with the materials constraints as an inevitable consequence of this which served to communicate the existence of the labour ceiling to consumors and intermittently to other producers: the capital constraints were easily interpretable as indicating the normal decay of capital and signalling that new investment was needed.

In run 6 , disregarding the unemployment in the starting-up periods we can easily distinguish (in VI.1/3) two phases: phase 1, with full employment, and phase 2 in which unemployment was growing. It is thus clear that the materials constraints in phase 2 are not caused by the labour constraint, and equally cannot be caused by capital constraints. Thus, in the absence of monetary constraints, the materials constraints must be a primary source of disturbance, and this suggests strongly that production targets are too low, particularly as the excess of household income over expenditure (VI.1/3) in conjunction with the materials constraints suggests that consumption is being held down by supply shortages.

The behaviour of money stock in phase I of VI.1/2 calls for comment. Owing to the large increases in money stock, the scaling 
effect has flattened the reserve balance so that its reduction in phase 1 is not apparent in the chart. It is nevertheless a legitimate piece of information to use - being already published periodically - and from the running printout it can be directly seen in the time series that the reserve balance was in fact reduced owing to taxation recelpts in a time of full employment: this lowered the money stock celling and necessitated a reduction in new lending. Reductions in the money stock itself could not be effected unless overdrafts were being repaid at the same time. As VI.1/4 suggests, in the corresponding part of phase $1 \mathrm{cash}$ payments were sustained as nfi credit was substituted for bank overdraft, and through the general transactions flows enough of this cash got into the hands of borrowers with outstanding overdrafts and so enabled them to reduce their overdrafts, thus reducing the money stock. Owing to the availability of alternative finance from $n f 1$, the operation of the bank ceiling did not in the event affect production; but it could have done, and in that case an immediate and drastic lowering of the required reserve ratio would have been necessary to prevent a deprescion. (Iowering the required reserve ratio in order to relieve the pressure on bank reserves of the March-April tax drain was for some years standard practice in New Zealand.)

Sequence 2:

As a comparison of $\mathrm{V} .2 / 1$ and $\mathrm{VI} .2 / 1$ indicates, reducing target inventory weakened further an already weak stimulus to growth. In the event, no materials constraints operated, because the rate of growth was so low that the inventories available were adequate. This makes the low target inventory understandable from individual producers' point of view, since under these circumstances when production for inventory is a major part of the whole denand stimulus to production, inventory expectations become largely self-justifying, and producers would have no reason to suppose that they were setting theiz target too low. If there is anything in the notion of "stagflation", VI. $2 / 3$ must surely depict a classic case. 
Sequence 3:

VI. $3 / 1$ is separated into phases to correspond with those of $\mathrm{V} \cdot 3 / 1$. In phase 1 the stimulus from additional household incone, in the context of the multiplier, isas tended to outweigh the reduced stimulus from production for inventory, although more frequent operation of constraints on materials in a context of growing unemployment (VI.2/3) towards the end of phase 1 suggests that the low inventory target is also constraining input supplies, particularly to sector 3 , although some materials constraints would in any case have been due to the labour ceiling as in V.3/1. But output is generally higher in phase 1 in VI.3/1 than in $\mathrm{V} .3 / 1$, so that the net effect is expansionary.

The stimulus from increased income, at a time when prices have not yot hecome too high, is decisive in phase 2 ; in phase 3 the multiplier is still operating enough to maintain consumption demand, since with high unemployment the additional incomes are more or less keeping pace with prices. (This can be seen by a direct check on the course of real consumption in both runs; this would not be open to direct inspection in practice, but a ussable measure might be derived from quantity indexes of retail sales.) The price increases do, however, exercise some depressing effect, and since unemployment benefits are not as much as full wages, for both reasons the multiplier is much weaker than the full employment multiplier at constant prices.

since no constraints are operating, except the labour constraints purely in connection with the transfer mechanism, it is apparent that the generaliy stagnant character of output in phase 3 arises from a weak demand stimulus to growth. The conjunction of a weakening multiplier and a reduced inventory demand is thus responsible for the lack of impetus to growth.

It is evident that to the lack of demand for consumer goods must be added deficiencies of demand for producers goods as possible sources of unemployment; this is just another instance 
of the importance, in an uncontrolled market economy, of producers making the "right", i.e. macroeconomically appropriate, decisions. Inappropriate decisions about inventory and investment can, of course, lead to restrictions on output and employment from capital. and materials constraints, as well as reduced wage incomes, and It does become rather important that they are appropriate to the technically attainable rate of growth. There is no way of guaranteeing this in an uncontrolled system. Even in a control system, it is not clear, in terms of the "trouble-shooting" approach, what could be done to change producers' responses, particularly when they tend to be self-justifying:

A distinction raust be made between deficiencies of private enterprise which act as a positive obstacle to adequate provisioning, and those which appear simply in a lack of impetus. The second can always be supplied by government if necessary, since there is no reason why it should not enter the private markets. It is doubtful how far the first is amenable to economic controls, or how far it is accurately classified as an economic malfunction.

We shall leave the question of unemployment, for the present, although it will no doubt arise in other contexts, and return to the study more directly of malfunctions on the money side.

\subsection{Imbalance in the Payments Flows}

The model structure as it now stands penalises lack of liquidity on the part of individual transactors considerably less than would be the case in practice, since neither creditworthiness nor onerous re-payment requirements are operating to restrict credit. Even so, the system cannot stand persistent imbalances in the payments flows without meeting some difficulties. On the supply side, shortage of money may eventually make some payrolls hard to meet and hence restrict production, employment and wage incomes; this in turn must affect the demand stimulus to the economy $v i a$ the income-expenditure multiplier, and may add supply constraints. On the demand side, only the presence of virtually 
unlimited trade credit may prevent the direct impact on the demand stimulus of shortage of money in households; where trade credit is freely available, its use replaces the cash receipts from retail sales and hence transfers the liquidity problem to producers.

Payments imbalance also raises difficulties for control, since its presence increases the difficulty of identifying and dealing with malfunctions arising from other causes. When the correction of payments imbalance is left to producers to deal with through price adjustments, the result is likely to be inflationary. (The particular type of response defined here for producers is necessarily inflationary, but, in general, it is difficult to see how any response could fail to be, since the losers on the payments flows would have no hope of correcting the imbalance by reducing prices in the context of fairly inelastic basic demand.)

It is fairly clear that the profit-signalled response used so far is not a very successful one from the producers' point of view; it does seem to correct the grosser distortions produced by completely arbitrary prices, but seems rapidly to exhaust the possibilities of improving the balance after this has been done. It is even worse from the households' point of view, since the competitive price-raising has a tendency to continue long after any possible benefit to producers has been exhausted, as a result of feed-back effects from earlier price rises.

A more sensible basis for pricing might be direct costing. Once the system is in operation, information about past unit costs is available, and there is no reason why this should not be made use of as the basis of setting current prices, since although it may not give an accurate calculation of current costs it is still likely to be the best approximation to them. If control intervention in pricing practices became necessary, this might also provide the only administratively practicable basis of controlling prices, and the only avallable criterion for assessing whether individual producers" prices were "too high". 
In terms of the analysis of section 5.1, then without either trade or retail markups this would imply simply that

$$
p_{t}=e_{t-1}\langle v\rangle \frac{-1}{t-1}
$$

which would not satisfy condition (5.10) in general. Nevertheless, it is worth investigating in this context, since what we are now looking for is not some rigid equilibrium but some way of removing unacceptable payments imbalances without causing perpetual

inflation as a necessary consequence. Since producers must make some allowance for capital depreciation and inventory accumulation, we will retain trade and retail markups but apply them to direct costs arrived at in the above way.

\section{Run 7}

Pricing:

This set arbitrary prices for the first aggregation period, and thereafter prices were set equal to total unit direct costs of the previous period, calculated from actual purchases of intermediate and factor inputs, with a markup of $10 \%$ on cost to other sectors, and $20 \%$ on trade price to retail.

\section{Variation:}

Four sequences were used: sequence 1, to provide a bench mark, used arbitrary constant prices and no multiplier; sequence 2 , direct cost pricing also with no multiplier; sequence 3 , arbitrary constant prices with multiplier; sequence 4 , direct cost pricing with multiplier.

In the event, the direct cost basis for prices worked rather well for the mechanisms used, although the weak demand stimuli to growth tended to keep the rate of growth very modest. The effects were as follows. 
The low rate of growth without multiplier effects and with low production targets is shown in VII.1/1. Owing to the low growth rate no constraints operated, except the intermittent labour constraint due to the transfer mechanism. Uenmployment fluctuated around a constant trend in absolute terms (VII.1/2), although since the labour force was growing this represented a steady improvement in percentage terms. As VII.1/2 indicates, the steady rate of growth of basic consumption expenditure rapidly outstripped the growth of household income, which included some unemployment benefits but was held down through the low level of production. The cumulative effect on household asset position is shown in $F$ (HHID, NTWTH) in VII.1/3. Both from the sectoral terminal net worths and the course of sectoral profits (VII.1/3) it can be seen that even the arbitrary prices were not as serious for firms as in previous runs, the expenditure amounts with the low rate of growth not being large enough to bring out the full effects of monetary imbalance, and all sectors finished with a reasonably liquid and solvent position. The general liquidity position is apparent from $\mathrm{F}$ in VII.1/3, and clearly is supported by the large monetary base resulting from sustained payments of unemployment benefit; (see $F$ (CBNK, BNKS) in VII.1/3).

The periodic fluctuations apparent in VII.1/1. and VII.1/2 arise from two factors on the real side: (a) as the percentage rate of unemployment is reduced, govermment stabllising purchases of goods are automatically reduced, thus offsetting to some extent the expansionary effect of increased production; (b) as the ceilings charts for previous runs have shown, when the rate of growth is very low new capital investment becomes very intermitten and lunpy, and this produces intermittent boosts to production when investment does occur.

It is evident in VII.1/2 that there is a positive correlation between household money incomes and unemaployment, instead of the negative corxelation one would expect. This is mainly a consequen of the timing differences both in the labour transfer mechanism an 
in the payment of unemployment benefits. The latter are paid in a lump sum to households at the end of each aggregation period, calculated on the numbers of unemployed held in the pool at that point of time. Thus although the daily unemployment benefit per man is only 608 of the daily wage rate, it is paid for the whole period; a man transferred out of the pool in mid-period is paid wages for fewer days than his forgone unemployment benefit would have been paid for, and when relatively large transfers in or out of the labour pool are involved this effect appears to be decisive.

Sequence 2:

Since this sequence also had no multiplier, the substitution of direct costing for arbitrary prices produced effects on the monetary side which were not transmitted to the real side; thus sectoral outputs were identical for sequences 1 and 2 , and unemployment was consequently the same. Household income remained the same, both wages and unemployment benefits being unchanged. Consumer prices remained fairly steady at a level which substantially reduced household expenditure on the autonomous basic purchases; (VII.2/1). The course of trade prices is shown in VII. 2/2; retail prices differ by a constant percentage markup.

The different pricing basis and consequent lower expenditure reversed the net payments flow, which previously had been unfavourable to households, and the effect on household terminal worth was substantial (VII.2/3). Intersectoral prices were much better in balance, indicated by sectoral profits and the sector terminal net worths in VII.2/3. Although government stabilising purchases of goods remained the same in quantity terms as in sequence 1 , the lower prices set reduced government expenditure in total, and some minor variation in profits and tax payments resulted from the altered payments flows. The net effect was to keep bank reserves slightly below their previous level (cf. F (CBNK, BNKS in VII. $2 / 3$ and VII.1/3), although at the modest level of expenditures called for the monetary base was still more than adequate. 
The cycling effect on the real side was repeated as a result of the same two factors, and the variation in sectoral prices introduced a consequential effect on the money side. The intermittent and lumpy investment caused price variations due to the way the cost base is calculated: the costing calculation sirply divides the total expenditure on intermediate and factor purchases by the total quantity of output produced, both for the preceding aggregation period. This is taken to be the direct unit cost of production, to which fixed percentage markups are applied to arrive at trade and retail prices. The purchase of investment goods involves an intersectoral expenditure which is included in the numerator of the cost ratio, whereas to the extent that the new capital gives rise to equivalent output (it will usually not be fully used immediately) the effect is spread over subsequent periods. Thus substantial price rises occur in investing sectors, and through their effects on costs to other sectors tend to push up all prices. This effect is reversed when investment demand is satisfied for the time being and direct cost is reduced.

The periodic effect on prices is seen in VII.2/2, and although in the absence of a multiplier quantities of goods bought by households remained unchanged, money expenditures on them were obviously affected (VII.2/1).

Sequence 3:

Despite the addition of the multiplier to produce an extra stimulus to growth, the return in this sequence to the arbitrary prices of sequence 1 kept prices too high for incomes to provide much discretionary income, after purchases of basic goods, for the multiplier to have much effect (VII.3/2). Some very minor variations in output are apparent between VII.1/1 and VII.3/1, but unemployment, household income and expenditure remained substantially as in the first sequence.

seouence 4:

The multiplier stimulus, when direct cost prices were substituted for arbitrary prices, raised output substantially 
(VII.4/1). 5 Prices were generally stable (VII.4/3), and from the course of sectoral profits together with the final liquidity and solvency positions (VII.4/4) the payments flows are well in balance. There is no theoretical presupposition that equality of income or wealth distribution is aimed at, although other social ends might well attach importance to the relative distributions; from the viewpoint of macroeconomic stabilisation this balance must be well within the range of variation that the system could tolerate without $i 11$ effect.

The nfi have accunulated large working deposits for which they are unable to find borrowers. This is obviously not a good thing from nfi's own point of view, and in this balanced context they would be unlikely to operate, unless they could compete on loan interest or ancillary services with banks. From a macro control standpoint it hardy matters whether they do or not. since with a large monetary base and general payments balance private transactors might as well hold cash assets directly as bank deposits; no monetary malfunctions are at all likely to arise.

The cyclical effects previously mentioned are here much more definite, as can be seen in VII.4/1, VII.4/2 and VII.4/3. The primary phase due to the previous three factors, government stabilising expenditure on goods, intermittent investment, and the effect on prices, has been transmittea to a secondary phase by the effect on household money incomes in the context of the multiplier, and since this now has reedback effects through purchases of consumption goods, output, employment and household incomes, the complicated feedbacks of the secondary phase are well intermixed. Thus the initial stimulus to real output by investment purchases subsequently, through their effect on prices and household expenditures, sets in motion the secondary phase which depresses output. The process is reversed when investment demand is satisfied and prices revert to their lower level.

The pricing basis and the administrative mechanisms which set off the primary phase could all be changed. Government stabilising purchases could be kept up a little longer after unemployment has begun to fall, and unemployment benefit could be 
tied more closely to the actual timing of labour transfers. But there may be a case here for not making control stabilisation measures too automatic, and leaving some scope for discretion. It should also be recognised that, however well-intentioned and well-conceived control intervention can be, its practical execution cannot be expected to be perfect, and some anomalies must be accepted. In any case, whatever is done, various sources of untidiness are bound to appear in the data.

The costing basis is easily dealt with in the model. But there are two things worth mentioning. First, the distinction between capital and current inputs is not so easy to make in practice as it is in the model. Secondly, the measures used by the orthodox techniques are not well-defined as measures of capital input or capital accumulation, and much of the trouble here comes from defining for the model a rather more accurate view of the way in which capital enters into production. Nevertheless, if new capital investment is to be taken into account in setting prices, the more or less rule-of-thumb markup more commonly used in business is superior, from the point of view of control stabilisation, to either the orthodox approach or the alternative discussed here.

In general, all these problems might become less important if the rate of growth could be raised to the ceiling by strengthening the demand stimulus. But there is a point to be cleared up first. The course of events ias been made rather simple in the last few runs by, among other things, the "simultaneity" of activities.. This has enabled prices, with fixed wage costs, to remain on the whole fairly steady, and has facilitated identification of primary and secondary phases. With varied timings, it is not clear that either feature would be retained, and this needs examination.

Run 8

Prices:

In moving to a more complex timing it has to be recognised that some production periods will not fit exactly into aggregation 
periods; this has to be taken account of in the costing basis of pricing, for where work in progress has incurred production expenditure but has not been finished and taken to inventory, it would not be included in the actual produced output figure. How work in progress would be measured in output terms is not clear, but in the fixed proportions structure used we can reckon it simply in proportion to quantities of inputs used. Inputs, in the model, are called for at intervals during the production period, and paid for at the same time. The estimated contribution to output can thus be calculated on the number of instalments in a production period, and recorded as work in progress; this we shall include in the denominator of the cost ratio.

\section{Variation:}

We shall retain the mechanisms of sequence 4 of run 7 , (i.e. direct cost pricing with a money income multiplier), and vary the timings over four sequences. In the first sequence, each activity will generally be scheduled for a different time for each sector, and in subsequent sequences the same timing schedules will be rearranged among sectors.

Monetary Policy:

Some attempt to rernedy an inadequate monetary base was made through providing increments to reserve balances when money constraints were operating. This is analytically the effect produced by direct transactions between govermment (or Reserve Bank) and the trading banks.

In the event, the timing variations produced much more pronounced fluctuations on both real and money variables, and in general output was below that of the corresponding "simultaneous" path of sequence 4 , run 7 . The timing differences also brought in operative constraints due to various secondary effects of the timing variations. Major difficulties arose for control in the identification of primary sources of malfunction, since in this untidy context the basic indicators were no longer sufficiently clear and informative on their own. We first discuss sequence 1 
and then compare all the sequences.

Sequence 1:

One obvious consequence of the varied timings was that the production perioas did not fit tidily into aggregation periods; VIII.1/1 would in any case have had a scattered look since different combinations of terminating production periods in different aggregation periods result in variations in the extent to which output is recorded as taken to inventory and so reckoned into aggregate output for the period. These variations did not produce a disturbance in the pricing mechanism owing to the inclusion of work in progress in the costing basis. Some hint of this is seen in the reference points, indicating those aggregation periods in which the maximum number of terminating production periods occurred, (in VIII.1/1, VIII.1/2 and VIII.1/3), which are not systematically related to the upswings and downswings. Although a time series of investment by sectors has not been collated, from uncollated data the association between fumps in trade prices in VIII.I/3 and the occurrence of investment is quite direct. But the actual causes of variation can be reliably established only on the basis of a direct knowledge of the costing basis of pricing.

It may appear that the required causal connection could be established by applying sophisticated statistical analysis to the time series. A minor difficulty might be that, since the time series serves only as explanandum, the additional information required might not be available from published data to a passively observing economist, and it might be only in the context of control that the required infornation can be sought and obtained. But, most importantly, the search is not for a statistical "explanation" in terms of the relative quantitative importance, on average, of the various factors involved, as a basis for predicting future movements of the cycle. What we are looking for is an identification of the singular events which can be shown to be causally responsible for the primary phase of the disturbances, in order to provide a basis for eliminating the cycle. Thus instead of lumping all contributory factors together 
as "explanatory" variables, we want to separate out those that operate as secondary responses to the initiatory events, from the initiatory events themselves. Certainly we shall want to know how the secondary feed-backs operate, and given this information the statistical analysis may be able to give us some estimate of theix net guantitative effects. But control requires identifying and dealing directly with the initiatory disturbances if that is at all possible.

Additional sources of cyclical disturbance in the model could arise from the selection of the aggregation period as the arbitrary period used in the argument of some response functions, as for exanple it has been used as the period determining the income argunent of the demand function. Thus, although the aggregation period is as good for the purpose as any other in the context of "simultaneous" timing, its use in other contexts is less innocuous, and the choice of base period needs more care. In the event, this consideration did not seriously affect run 8 , it can be seen from VIII.I/2 and VIII.1/3, together with information from the constraints (set out below), that the low level of production not only reduced the multiplier component of demand via the employment-income relation, but also reduced the supply of goods so that materials constraints operated from time to time. Since this weakened the multiplier effect, so that basic demand became more important, the effect was to overshadow any cycling arising purely from choice of income period.

In VII.1./2 the relation between employment and consumer prices suggests a typical "Phillips curve" relationship. But the mechanisms are different; the causal chain usually adduced is of the form: ermployment - consumer income - expenditure - market. effect on prices from raised demand curve, or of the associated form: consumer demand - market effect on prices - production stimulus - employment, with or without a further effect on wage rates. Here price and employment effects arise, independently of each other, Erom the Iumpy investment; this affects prices directly through the costing basis of pricing, and employment directly through the lrupact effect on production in the primary 
phase. In the secondary phase, of course, all the feedbacks are intermixed and it becomes idle to ask which is causing which.

Comparison of sequences:

Since the different timings of production periods, varying over sequences, affect the points at which investment occurs, and through the operation of materials constraints from time to time affect the levels of production, the time paths of output tend to differ over sequences. (Cf. VIII.1/1, VIII.1/2, VIII.1/3 and VIII.1/4; owing to the lower level of output in sequence 3 a "semi-datum" line is shown, indicating the relative position of half the pure number represented as the datum line otherwise used.)

While all sectors are both providers and users of intersectoral inputs, sectors 1 and 3 are relatively more important as providers than as users of intermediate outputs; sectors 2 and 4 as users rather than as providers. This distinction becomes important when the main providers have longer production periods than users, since inventory is being rapidly run down during the course of the long production periods, which must make production lumpy and may bring in materials constraints. The length of production periods were in the ratio $5: 16: 18: 20$. The effect of allocating these production period lengths to different sectors over successive sequences did not produce generally clearcut results owing to the interlocking relations between sectors; in sequence 3, however, both input-providing sectors had the longer production periods while the using sectors had the shorter. It is thus not surprising that intermittent materials constraints and a somewhat lower rate of growth occurred.

The effect of odd combinations of terminating periods on the output summarized in the time series is observable in VIII. 4/1. Sector 4 has no terminating period in one out of every ten aggregation periods, and sector 3 has two in one out of every eight. Similar effects can be seen for other sectors in other sequences. 


\section{Sequence 1}

年

$\begin{array}{llll}0 & 0 & 0 & 2\end{array}$

$\begin{array}{llll}0 & 0 & 0 & 4\end{array}$

$\begin{array}{llll}1 & 2 & 0 & 4\end{array}$

$\begin{array}{llll}1 & 4 & 2 & 0\end{array}$

1560

1360

$\begin{array}{llll}1 & 3 & 5 & 0\end{array}$

$\begin{array}{llll}0 & 3 & 4 & 0\end{array}$

$\begin{array}{llll}0 & 5 & 3 & 0\end{array}$

$\begin{array}{llll}0 & 2 & 2 & 0\end{array}$

$\begin{array}{llll}0 & 1 & 0 & 0\end{array}$

$\begin{array}{llll}0 & 1 & 0 & 0\end{array}$

$\begin{array}{llll}0 & 0 & 0 & 0\end{array}$

$\begin{array}{llll}0 & 0 & 0 & 0\end{array}$

$\begin{array}{llll}0 & 0 & 0 & 0\end{array}$

$\begin{array}{llll}0 & 1 & 0 & 0\end{array}$

$\begin{array}{llll}0 & 3 & 0 & 0\end{array}$

$\begin{array}{llll}0 & 3 & 0 & 0\end{array}$

$\begin{array}{llll}0 & 7 & 0 & 0\end{array}$

$\begin{array}{llll}0 & 2 & 1 & 0\end{array}$

$\begin{array}{llll}1 & 2 & 2 & 0\end{array}$

$\begin{array}{llll}1 & 1 & 1 & 0\end{array}$

$\begin{array}{llll}0 & 3 & 0 & 0\end{array}$

0410

$\begin{array}{llll}0 & 2 & 1 & 0\end{array}$

$\begin{array}{llll}0 & 1 & 1 & 0\end{array}$

$\begin{array}{llll}0 & 0 & 0 & 0\end{array}$

$\begin{array}{llll}0 & 1 & 0 & 0\end{array}$

$\begin{array}{llll}0 & 2 & 0 & 0\end{array}$

$\begin{array}{llll}0 & 0 & 0 & 0\end{array}$

$\begin{array}{llll}0 & 3 & 0 & 0\end{array}$

$\begin{array}{llll}0 & 4 & 0 & 0\end{array}$

$\begin{array}{llll}0 & 3 & 1 & 0\end{array}$

$\begin{array}{llll}0 & 4 & 2 & 0\end{array}$

$\begin{array}{llll}0 & 3 & 2 & 0\end{array}$

0420

$\begin{array}{llll}0 & 1 & 2 & 0\end{array}$

$\begin{array}{llll}0 & 0 & 1 & 0\end{array}$

$\begin{array}{llll}0 & 1 & 0 & 0\end{array}$

$\begin{array}{llll}0 & 0 & 0 & 0\end{array}$

$\begin{array}{llll}0 & 1 & 0 & 0\end{array}$

$\begin{array}{llll}0 & 4 & 0 & 0\end{array}$

$\begin{array}{llll}1 & 3 & 0 & 0\end{array}$

$\begin{array}{llll}0 & 4 & 1 & 0\end{array}$

$\begin{array}{llll}0 & 4 & 3 & 0\end{array}$

$\begin{array}{llll}0 & 5 & 2 & 0\end{array}$

$\begin{array}{llll}0 & 3 & 6 & 0\end{array}$

0250

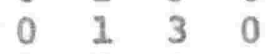

0120
Sequence 2

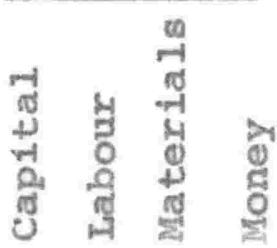

00002

$\begin{array}{llll}0 & 0 & 0 & 6\end{array}$

$\begin{array}{llll}1 & 2 & 0 & 3 \\ 1 & 1 & 1 & 0\end{array}$

$\begin{array}{llll}2 & 4 & 2 & 0\end{array}$

2320

1430

0420

0420

0110

$\begin{array}{llll}0 & 0 & 1 & 0\end{array}$

$0 \begin{array}{llll}0 & 0 & 1 & 0\end{array}$

$\begin{array}{llll}0 & 0 & 0 & 0\end{array}$

$\begin{array}{llll}0 & 0 & 0 & 0\end{array}$

$\begin{array}{llll}0 & 0 & 0 & 0\end{array}$

$\begin{array}{llll}0 & 2 & 0 & 0\end{array}$

$\begin{array}{llll}0 & 6 & 0 & 0\end{array}$

$\begin{array}{llll}0 & 3 & 0 & 0\end{array}$

0310

$\begin{array}{llll}0 & 6 & 1 & 0\end{array}$

0220

$\begin{array}{llll}0 & 2 & 1 & 0\end{array}$

$\begin{array}{llll}0 & 2 & 1 & 0\end{array}$

00110

$\begin{array}{llll}0 & 5 & 0 & 0\end{array}$

$\begin{array}{llll}0 & 1 & 0 & 0\end{array}$

$\begin{array}{llll}0 & 2 & 0 & 0\end{array}$

$\begin{array}{llll}0 & 2 & 1 & 0\end{array}$

$\begin{array}{llll}0 & 1 & 1 & 0\end{array}$

0510

0210

0210

$0 \begin{array}{llll}0 & 0 & 1 & 0\end{array}$

$\begin{array}{llll}0 & 1 & 1 & 0\end{array}$

00110

0100

$\begin{array}{llll}1 & 5 & 1 & 0\end{array}$

$\begin{array}{llll}0 & 3 & 1 & 0\end{array}$

$\begin{array}{llll}0 & 3 & 2 & 0\end{array}$

$\begin{array}{llll}0 & 3 & 3 & 0\end{array}$

$\begin{array}{llll}0 & 1 & 3 & 0\end{array}$

01110

$\begin{array}{llll}0 & 3 & 3 & 0\end{array}$

$\begin{array}{llll}0 & 0 & 2 & 0\end{array}$

$\begin{array}{llll}0 & 3 & 4 & 0\end{array}$

$\begin{array}{llll}0 & 3 & 1 & 0\end{array}$

$\begin{array}{llll}0 & 2 & 2 & 0\end{array}$

$\begin{array}{llll}0 & 1 & 2 & 0\end{array}$

02120

$\begin{array}{llll}1 & 4 & 2 & 0\end{array}$
Sequence 3

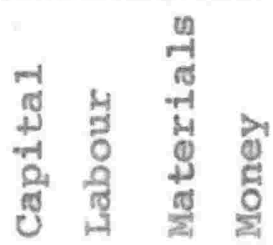

$\begin{array}{llll}0 & 0 & 0 & 2\end{array}$

$\begin{array}{llll}0 & 1 & 0 & 6\end{array}$

$\begin{array}{llll}1 & 2 & 0 & 5 \\ 0 & 2 & 1 & 9\end{array}$

$\begin{array}{llll}1 & 3 & 2 & 0\end{array}$

$\begin{array}{llll}3 & 7 & 1 & 0\end{array}$

$\begin{array}{llll}1 & 1 & 3 & 0\end{array}$

$\begin{array}{llll}1 & 3 & 5 & 0\end{array}$

$\begin{array}{llll}0 & 6 & 6 & 3\end{array}$

0248

$\begin{array}{llll}0 & 1 & 1 & 7\end{array}$

$\begin{array}{llll}0 & 1 & 0 & 0\end{array}$

$\begin{array}{llll}0 & 2 & 3 & 0\end{array}$

$\begin{array}{llll}0 & 1 & 4 & 0\end{array}$

$0 \begin{array}{llll}0 & 1 & 3 & 0\end{array}$

$\begin{array}{llll}0 & 3 & 2 & 0\end{array}$

01310

$\begin{array}{llll}0 & 1 & 0 & 2\end{array}$

$\begin{array}{llll}0 & 6 & 0 & 0\end{array}$

$\begin{array}{llll}0 & 1 & 1 & 0\end{array}$

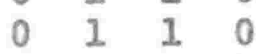

$\begin{array}{llll}0 & 2 & 0 & 0\end{array}$

$\begin{array}{llll}0 & 2 & 0 & 0\end{array}$

$\begin{array}{llll}0 & 1 & 0 & 0\end{array}$

$\begin{array}{llll}0 & 3 & 1 & 0\end{array}$

$\begin{array}{llll}0 & 3 & 1 & 0\end{array}$

$\begin{array}{llll}0 & 2 & 3 & 0\end{array}$

0130

$\begin{array}{llll}0 & 6 & 2 & 0\end{array}$

$\begin{array}{llll}0 & 0 & 3 & 0\end{array}$

$\begin{array}{llll}0 & 2 & 3 & 2\end{array}$

$\begin{array}{llll}0 & 0 & 1 & 0\end{array}$

$\begin{array}{llll}0 & 3 & 1 & 0\end{array}$

$\begin{array}{llll}0 & 0 & 2 & 0\end{array}$

$\begin{array}{llll}0 & 2 & 0 & 0\end{array}$

$\begin{array}{llll}0 & 1 & 1 & 0\end{array}$

$\begin{array}{llll}0 & 3 & 1 & 0\end{array}$

$\begin{array}{llll}1 & 5 & 3 & 0\end{array}$

$\begin{array}{llll}0 & 3 & 3 & 0\end{array}$

$\begin{array}{llll}0 & 2 & 3 & 0\end{array}$

$\begin{array}{llll}0 & 3 & 4 & 0\end{array}$

$\begin{array}{llll}0 & 1 & 3 & 0\end{array}$

$\begin{array}{llll}0 & 3 & 3 & 0\end{array}$

$\begin{array}{llll}0 & 0 & 3 & 0\end{array}$

$\begin{array}{llll}0 & 0 & 3 & 0\end{array}$

$\begin{array}{llll}0 & 0 & 1 & 0\end{array}$

$\begin{array}{llll}0 & 1 & 3 & 0\end{array}$

$\begin{array}{llll}0 & 3 & 3 & 0\end{array}$

$\begin{array}{llll}0 & 4 & 3 & 0\end{array}$
Sequence 4

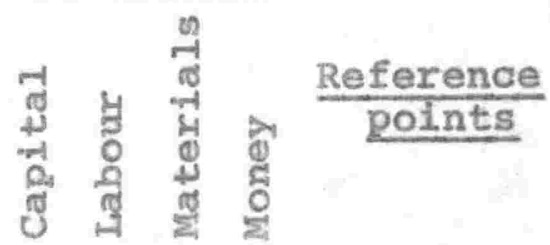

$\begin{array}{llll}0 & 0 & 0 & 1\end{array}$

$\begin{array}{llll}0 & 0 & 0 & 7\end{array}$

$\begin{array}{llll}0 & 4 & 0 & 0\end{array}$

$\begin{array}{llll}0 & 2 & 1 & 0\end{array}$

1220

1330

1450

$\begin{array}{llll}0 & 2 & 3 & 0\end{array}$

$\begin{array}{llll}0 & 1 & 3 & 0\end{array}$

0120

$\begin{array}{llll}0 & 2 & 1 & 0\end{array}$

$\begin{array}{llll}0 & 2 & 2 & 0\end{array}$

$\begin{array}{llll}0 & 2 & 1 & 0\end{array}$

$\begin{array}{llll}1 & 2 & 0 & 0\end{array}$

$\begin{array}{llll}0 & 1 & 0 & 0\end{array}$

$\begin{array}{llll}0 & 1 & 0 & 0\end{array}$

$\begin{array}{llll}0 & 3 & 0 & 0\end{array}$

$\begin{array}{llll}0 & 1 & 0 & 0\end{array}$

$\begin{array}{llll}0 & 4 & 0 & 0\end{array}$

$\begin{array}{llll}0 & 2 & 0 & 0\end{array}$

$\begin{array}{llll}0 & 3 & 0 & 0\end{array}$

$\begin{array}{llll}0 & 7 & 0 & 0\end{array}$

0120

$\begin{array}{llll}0 & 1 & 2 & 0\end{array}$

$\begin{array}{llll}0 & 0 & 0 & 0\end{array}$

$\begin{array}{llll}0 & 1 & 0 & 0\end{array}$

$\begin{array}{llll}0 & 4 & 0 & 0\end{array}$

$\begin{array}{llll}0 & 1 & 0 & 0\end{array}$

$\begin{array}{llll}0 & 1 & 0 & 0\end{array}$

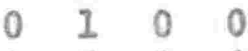

$\begin{array}{llll}0 & 5 & 0 & 0\end{array}$

$\begin{array}{llll}0 & 2 & 0 & 0\end{array}$

$\begin{array}{llll}0 & 4 & 1 & 0\end{array}$

$\begin{array}{llll}0 & 5 & 2 & 0\end{array}$

$\begin{array}{llll}0 & 0 & 2 & 0\end{array}$

$\begin{array}{llll}0 & 1 & 0 & 0\end{array}$

$\begin{array}{llll}0 & 1 & 0 & 0\end{array}$

$\begin{array}{llll}0 & 0 & 0 & 0\end{array}$

$\begin{array}{llll}0 & 2 & 0 & 0\end{array}$

$\begin{array}{llll}0 & 0 & 0 & 0\end{array}$

$\begin{array}{llll}0 & 2 & 0 & 0\end{array}$

$\begin{array}{llll}0 & 5 & 0 & 0\end{array}$

$\begin{array}{llll}0 & 2 & 0 & 0\end{array}$

$\begin{array}{llll}0 & 5 & 2 & 0\end{array}$

$\begin{array}{llll}0 & 2 & 3 & 0\end{array}$

0320

$\begin{array}{llll}0 & 0 & 2 & 0\end{array}$

\section{1}

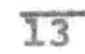

$\begin{array}{llll}0 & 0 & 1 & 0\end{array}$

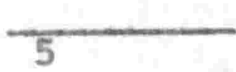


Capital constraints are almost absent; the low rate of growth produced substantial idle capital for much of the time, and reinvestment was only occasionally needed. Labour constraints are not unusually active, although at a higher level of employment the large fluctuations in output would clearly necessitate much more frequent transfers of labour than a more orderly growth path at the same average level, and 1t appears that the transfer system would need, in such circumstances, a considerable element of anticipatory transfer.

In sequence 3 , the generally low growth path explains the frequency of materials constraints, but makes the operation of monetary constraints surprising. These derive from the effect on the monetary base of differences between government receipts and government expenditure. The profits tax is not directly related to the level of output in general, but depends also on the net payments flows and the distribution of profit, since a high tax payment may as well arise from high profits in one sector due to losses in another, as from a high level of production with profits more evenly distributed. (The course of profits is shown in VIII.4/4.) Unemployment was also a little lower in sequence 3 at a time when tax payments were high; the net effect was to reduce the reserve balances substantially from time to time, so that the monetary base which initially would have supported a much higher growth path, was reduced below even the amount necessary for the lower growth path, and thus introduced an additional primary source of a depressant to production.

The effects on production, employment and incomes lead into secondary effects, but an obvious task of control would be to intervene before the monetary effects had become significant and so prevent the secondary phase from starting. This could have been done directly either by lowering the reserve ratio or by increasing actual reserve balances.

Household variables and trade prices shown in the charts for the last three sequences indicate broadly similar patterns to the first; the causal sequences are similar, although the 
timing variations introduce a different pattern to the secondary phases.

The disturbed course of production obviously brings about very large payments imbalances from period to period, but on the whole they tend to cancel out between sectors in the long run. Households are generally in deficit except in the last sequence. (Cf. VIII.1/4, VIII.2/4, VIII.3/4 and VIII.4/4.) since in sequence 4 the two output-providing sectors have the shorter production periods, there may be some connection between monetary imbalance and the time structure of production, but we shall not be able to follow up that idea here.

Indeed, we have already puxsued this enquiry rather further than was originally intended, and it is becoming time to sum up. In the nature of the enquiry, whatever point we choose to stop at must leave us with a sense of unfinished business; even when a stage is reached at which all outstanding malfunctions appear to have been dealt with, further developments to extend the range or to refine the detail must introduce further complications. Before attempting a summing-up, some indication ought to be given of the lines on which work can proceed from here, and what other major malfunctions need to be tackled.

The next step is to remove the cyclical feedbacks produced by the costing basis in a context of lumpy investment, and to produce a more orderly arrangement for costing investment into prices; this then raises the question of growth, and a revision of the production targets is called for. If the problem of low production targets is mainly a matter of their place in the demand stimulus, a substitute could be found in a direct autonomous demand for goods by government, growing at a steady rate, as possibly an administratively more practicable method. If, however, this did not prevent limitations arising out of materials constraints due to low production targets, more direct intervention in production planning would become impossible to avoid. 
Given that a full employment rate of growth were attained by raising production targets and without autonomous government expenditure, this would be bound to bring about excesses of tax payments over government expenditure, with consequent reductions in the reserve balances and progressively increasing monetary constraints. The feedbacks operating as a result of this might operate quickiy so as to yield no more than a harmless minor cycle at near full employment, but we might on the other hand find that the impact effect of the monetary constraint on production produced a downturn on tire real side through the effect on derived demand. If this secondary phase develops too quickly, the monetary response might be too slow to remedy the problem. ${ }^{6}$ This is what appears to have happened in run 8 , when the increases in reserve balances made in response to already operating monetary constraints did not prevent the real downturn.

Thus the increases in the monetary base would either have to be anticipatory or independent of current monetary states. The normal method of increasing the monetary base, as far as the textbooks are concerned, is by open market operations. This might be a harmless way of doing it; the finance market might take the side effects of open market purchases in its stride, depending upon how much increase in the monetary base had to be provided; but as a general rule, it would be desirable to find some way of increasing bank reserves without entering the general finance market. For example, the Reserve Bank might, for this purpose, either deposit funds on time deposit with the trading banks, or buy a specially devised interest-bearing bond from them. This would restrict the initial effect purely to the monetary base.

Once these problems had been successfully dealt with, it would then be possible to introduce some of the structural modifications required to improve the representational adequacy of the model; those of particular importance are refinements in the credit mechanisms and the definition of international transmission mechanisms. It may look as though the lattex could be analysed in the model as it stands, simply by re-interpreting 
groups of sectors (using a larger number in total of sectors) as "countries", and something of this basic structure must inevitably appear when international transmissions are defined.

But on the money side there would be a major change brought about by the difference in monetary standard and unit of account between countries; since this is accompanied by significant trading in the domestic currencies themselves, associated also with international capital flows, the monetary flows would acquire greater importance. They would give more point to the introduction of interest rates; in general trading in foreign currencies between trading banks and central bank have consequences for the monetary base, and exchange rates and overseas trading in goods have consequences for internal real and money flows; thus the redefinition of the transaction flows to link foreign trade to particular domestic nodes would require much more extensive development of the model.

In an attempt to tidy up some of the loose ends left over from the last run, the modifications suggested for that run have been applied and the results are briefly presented.

Run 9

The modifications made were as follows:

Pricing:

Investment expenditure was excluded from the costing basis of prices; this was not compensated for by increasing the markups, which were left unaltered.

Inventory:

Target inventory was given the rate of growth of the common trend, from which it had previously been reduced. 
Monetary Base:

Bank reserves were freed of the earlier response to constraints and instead were given the common trend rate of growth, assigned directly to $F$ (CBNK, BNKS). This was to operate as a minimum, and any increase in the reserve balance above this was left untouched.

In the event, these modifications cleared up the major problems outstanding, and no signs of malfunction appeared. The pattern of growth varies between the four sequences due to timing differences, but the modifications worked equally well in all four sequences; it is necessary to present only one.

Given the inevitable raggedness, the growth path was wellbehaved. (IX.1/I.) Labour constraints operated mainly on account of the full employment situation, although slight unemployment tended to recur. (IX.1/2.) This was, however, fairly promptly corrected by stabilisation policies, which in the absence of other destabilising factors were able to work as designed. The spasmodic production brought in materials constraints from time to time; their effect can be seen on household expenditure (IX.1/2).

Trade prices settled down to a fixed level, after the initial periods, and clearly were unaffected by the vagaries of output and investment. (IX.1/3.) It should be noted that, whereas in a normal model fixed "equilibrium" prices are an automatic consequence, in this type of closed system, of fixed wage rates and fixed input-output proportions, in the more complicated feedback and time structure of this model it is by no means a foregone conclusion that the mechanisms will produce or allow a convergence to constant prices from an initial arbitrary price vector. That these were, if not "equilibrium" prices, at least in a tolerable relationship is shown by IX.1/5.

The major source of expenditure was bank overdraft. (IX.1/4.) This is not surprising, in view of the extensive availability of bank credit due to the increasing monetary base. It is clear that the monetary base, and the money stock derived from increasing 
overdraft, are quite excessive; the system could manage with much less, particularly as the considerable capacity of nfi to lend remains almost untouched. But it seems to be doing no harm.

The behaviour of the system as it stands is now suitable for our purposes, and the stage is set for further structural modifications (although those will be left to some other occasion as far as this study is concerned). In addition to structural modifications, further enquiry is needed into types of malfunction not so far given attention in their own right. We shall indicate briefly some major topics needing study.

\subsection{Dther Malfunctions}

The Monetary Base:

It is clear that an inadequate monetary base can bring in monetary constraints and so initiate a real downturn, and that this needs anticipatory correction to prevent the secondary phase of deepening depression from getting under way. But is there a sense in which a more than adequate monetary base can itself constitute a source of disturbance requiring control intervention?

Clearly, unless additions to the money stock occur as a consequence of the increasing monetary base, it is a matter purely between the trading banks and the central bank and makes no difference to the system; these additions to the money stock cannot occur unless there are credit-worthy borrowers forthcoming. It makes little difference to the system if these borrowers are merely substituting bank overdraft for nfi credit, and for the extra monetary base to make any significant difference to transactions some of the additional bank lending made possible by the enlarged reserves must go to finance expenditures that would not otherwise have been made. In short, it must either remove an existing monetary constraint, or it must give rise to expenditure decisions which stem from the existence per se of credit availability. 
It is easy to see how, in a situation that is already persistently inflationary, the existence of ready credit may itself stimulate speculative activity, since in such circumstances the prospective gains, from financial or land speculation, for example, would be bound to exceed the cost of borrowing. But while this might well aggravate inflation already present, it cannot explain how it could set off the inflation in the first place. In the absence of such an explanation, any inflationary stimulus from an excessive monetary base would be a secondary phase phenomenon.

Inólation:

By this we mean generally rising prices. It will usually be necessary to trace causal effects through expenditures, but clearly the first thing to look at is the mechanism by which the prices at which goods are actually sold is determined. We need no mysterious auctioneer to explain these. Most goods are sold without haggling or chaffering according to the price marked on the ticket, ${ }^{7}$ and the question becomes one of the basis on which sellers arrive at the prices they 1ist. In most cases this will be based on a cost plus markup allowance as in the model. This leads quite easily to the analysis of inflation through examining the components of prices.

There are two obvious cases where the pxice-setting exercise itself may be a primary source of disturbance. Where employers are offering much higher than award rates in order to tempt key men from other firms in a time of labour shortage, this is clearly a primary source. (Apparent, for example, in the very high rates that some builders have been offering for carpenters and blocklayers.) The cost effect is quite direct, and there may be a secondary effect on consumer demand as well. Wage rises resulting from employer-union negotiation have a parallel effect.

On the consumer denand side, the pressure of demand is conveyed through the consumer expenditures, which from the seller's point of view increase sales receipts and deplete inventory. So 
far in the model we have looked at this purely from the point of view of inventory; but there is no reason why a seller, faced with rapidly increasing sales, might not respond by raising his markup as well as by increasing his orders or his production target for inventory replacement. In the secondary phase of the wage-price spiral, cost and sales effects are intermixed. Similarly, a slackening of demand might result in reduced markups in order to clear unsold stock.

A cost-push effect initiated by increased import prices needs examining, and would provide a useful basis on which to begin an assamination of wage-price spirals. But this requires the fntroduction of a foreign trade sector, and since many inflationary problems are associated in some way or another with balance of payments problems, a full enquiry into inflation would have to be deferred until the structural modifications had been made.

International Payments Imbalances:

These obviously would have to be given major attention. The structural modifications required would be very extensive on the monetary side, since the introduction of trading in currencies would bring in pervasive complications, and ought to be associated with the definition of interest rates and capital funds markets.

Those developments lie in the future, and for the present we will merely sum up on where we have got so far. 


\section{CHAPTER 7}

A SUMMING - UP

The undertaking at the outset of this study was to attempt to diagnose the deficiencies of a particular area of economic theory, and to develop a course of treatment for those deficiencies. The diagnosis has been completed and the indicated course of treatment carried as far as it can be carried within the scope of this study; at this point we review progress so far. 


\subsection{REVIEW OF THE COURSE OF THE ENQUIRY}

7.11 The CONCEPTUAL BASIS

In approaching the task of finding out why the analysis of macroeconomic monetary systems has so much difficulty in making contact with problems of practical importance in the behaviour of such systems, and why it has such dubious status as "science" we found it necessary to cast around for 1deas not usually given much attention by the majority of practising economists. ${ }^{1}$. We then tried to apply those ideas in the examination of some fundamental conceptualisations in monetary theory, as a result of which we concluded that the root of the trouble lies in the following characteristics :

(a) The common conceptual structure of macro-monetary theory is not even defined for those transactions processes which lie at the heart of the questions to which economists address themselves. Very often it cannot be decided whether a particular discussion is about money or about goods, and frequently one cannot help thinking that the author himself is unclear about which he means to discuss.

(b) The paradigm governing the formulation of propositions in economic theory prescribes their embodiment in a formalistic structure, which becomes increasingly devoid of semantic content as it becomes elaborated. Sanction for this might be found in the positivist paradigm of theory structure, but only if certain other requirements are met.

(c) The structure which the positivist paradigm requires a well-formed theory to have, in which the propositional calculus is formaliy separate from the domain of observation and experience, has as an indispensable component the rules of correspondence or interpretation; these mediate between the deductions and the experience, serving both to make sense of the propositions of the theory and to define what it is that is to be measured, i.e. how numbers are to be selected for insertion as values in variables of the theory. Without these rules, there is no basis for translation between the two modes. 
(d) As one result of this lack, the economic paradigm fails to provide criteria for deciding which numbers are validly inserted as values of the variables of the theory, and thus cannot specify which set of observations would refute any particular hypothesis under test.

(e) As another result of this lack, policy conclusions tend to be deduced directly from the formal models without benefit of any definite criteria which would enable the conclusions from the rigidly circumscribed context of the model to be modified so as to account for divergences of the domain of applicability from the conditions specified in the model from which the theoretical conclusions have been drawn. When the formal models assert that the system is in equilibrium, that it is free from external disturbance, and that certain things are held constant, and the policies have to be applied in contexts in which none of those assertions holds, one of two things must happen; either the policy conclusions are legitimately drawn from the axioms of the model, in which case they can have no bearing on the actual situation; or the policy conclusions are intuitively oriented to the actual problem, in which case they cannot be legitimately deduced from the axioms of the model and the theoretical argument becomes irrelevant, - mere window-dressing.

(f) While a further articulation of the accepted economic paradigm so that it came closer to meeting the requirements of the structure provided by the positivist paradigm could do much to improve the state of the art, it is not clear that much of the present theoretical structure of macroeconomics could survive the required modification, or that the positivist structure itself is fully satisfactory as a framework for economic theories. Hayek (1964) has rather convincingly argued that the complex phenomena characteristic of the social sciences cannot be successfully worked into this hypothetico-deductive method, and the argument of 1.3 above suggests that the formal distinction between deduction and observation may be mistaken.

(g) We have attributed the current state of affairs in economic theory to premature axiomatisation, whose effect on 
economic method has been to encourage, if not to impose, a professional commitment to black boxism.

In the light of this diagnosis, a course of treatment was based upon the need to modify the existing structure of macromonetary theory in order to meet the two major requirements suggested by (a) and (c), which required us: (i) to place the concept of a "transaction" at the heart of the analysis in such a way that it would always be clear whether we were speaking of money or of goods, and that we should be able to analyse in a direct way the working of the monetary nexus; and (ii) to attempt to provide interpretative rules for those parts of the formalist theory carried over into the modified structure. This we described as an attempt to open up the black boxes, i.e. to construct from them translucid boxes by providing their internal mechanisms. ${ }^{2}$

After some investigation upon these lines, it became necessary to deal with other problems that progressively arose; in particular the element of time needed much more care, and the definition of the real or goods side of the system needed sharpening. At first the investigation had been limited in intent to opening up the existing black boxes of macro-monetary theory, i.e. to linking up their input and output terminals by internal mechanisms expressed in the transactions flows. Ultimately it became apparent that the formalist structure resisted this development, chiefly because as the internal transmission mechanisms became better defined doubt increasingly arose about the status of the input and output terminals of the traditional black boxes; finally it became clear that, rather than trying to provide internal mechanisms connecting the input and output terminals "given" by the existing theory, we should be trying to work from the opposite direction, i.e. to specify the transaction processes first, then to develop interactions and transmission flows within the system, and finally to look for convenient points at which to place input and output terminals devised for use in macroeconomic analysis. This involved going back to the beginning and starting again; the results of this fresh start are embodied in chapters 3 and 4 . 
Once the structure set out in those chapters had been expressed in a working simulation model, the two main jobs could be put in hand. The first involved exploring the internodal flows directly rather than attempting to deduce their behaviour solely from events internal to the individual nodes or from the properties of macroeconomic systems of pseudo-reduced-form equations; this had to be done in a context in which the logically implied effects of any events introduced were allowed to override any ceteris paribus conditions attempted. The second raquired looking at various ways of recording, summarising and presenting information from the operation of the system in a sufficiently condensed way for it to be readily comprehensible as a schene of the gross behaviour of the system, while trying to maintain enough contact with the details to provide sources of explanation.

In chapter 5 we restricted attention to the closed private economy. Once the conceptual basis of the Ricardo-Walrasian real exchange equilibrium had been abandoned, and with it the faith that the actual attainment of this equilibrium would be assured by the operation of the invisible hand of the markets, two questions arose: what could be said to designate a "satisfactory" state of affairs towards which the internal homeostatic mechanisms of the markets ought to conduce? And what consequent constraints on behavioux would, in the hypothesised absence of government intervention, have to be imposed by the market procasses themselves?

A concept of "monetary equilibrium" could be defined in a static context, although even then it seemed to impose rather onerous restrictions on the market determination of prices; in a dynamic context it became much harder to define, although the gross imbalances which tended to appear in the payments flows were so obvious that a formal definition was not needed, since no sensible definition could have encompassed the situation generally arising in the earlier runs. We did find a use for the term "liquidity" in the miaro sense set out (on p. 114 above), and it may serve as a rough shorthand for describing the state of the finance stock variables in the individual nodal configurations. 
Monetary and real constraints were not defined as acting on the system-as-a-whole, since this would be meaningless in terms of actual economic activity, but operated on individual transactors so that any effect on the gross behaviour of the system of the impact of constraints on particular transactors arose from effects transmitted through the system by the transactIon flows. Certain bounds to market behaviour needed to be introduced to prevent the operation of constraints from causing a downturn ending in total cessation of all activity, and this led to the development of the floor; thus the real side of the econorny became subject to the ceilings and floor which together provided a broad corridor within which the otherwise irregular path of activity could, in general, be held.

The introduction of feed-backs between the money and real sides of activity brought in further destabilising effects, and it became increasingly clear that the difficulties of getting a private market economy under total laissez faire to provide an orderly path of growth at or near full employment were becoming severe, and thus imposing restrictions on individual behaviour that a consideration of the requisite information flows alone suggested would be beyond the ability of unregulated private markets to enforce. We therefore abandoned the attempt to represent the unregulated market economy as able to solve its own problems and thus attain both individual and general equilibrium solely through the homeostatic mechanisn's operating in its own markets, and turned our attention to the role of control intervention in securing order in a market economy.

This was approached in chapter 6 through a "trouble-shooting" approach to control, in which intervention to achieve macroeconomic stability was undertaken in response to the presence of or a warning of some specific malfunction. This led to a convergence of the three notions of: equilibria in the goods and money markets, general macroeconomic stability, and specific criteria for control intervention, upon the simple operational idea of the identification of actual or impending malfunction. From this developed the task of separating out various broad types of malfunction, and 
for any given malfunction the task of separating primary from secondary phases. We have attached importance to the Identification of primary phases, on the grounds that in the secondary phase the feed-back effects are completely intermixed with secondary disturbances arising through the system, and the situation has become too unsettled for individual effects to be meaningfully separated out.

This raises three questions:

(a) There appears, on the face of 1t, to be an inconsistency between the original theoretical position taken in chapter 3 , in which economic events were regarded as the resultant of all that had gone before, expressed within the limited time-span of practical interest to economists as the unbounded transactions flow, and the idea introduced in chapter 6 of "primary" causes of disturbance. Now, if we were attempting, within the more familiar hypothetico-deductive framework, to deduce the total behaviour of the system from the first principles of its organisation embodied in the axioms, there certainly would be a formal inconsistency if we were to introduce into the deductive sequence a "primary source" not mentioned in or deducible from the axioms from which we started.

But that is not what we are trying to do at all. Within the "trouble-shooting" approach to control, intervention becomes necessary because of some interruption to a system which had previously been operating satisfactorily. ${ }^{3}$ In general, we can usually know quite directly that something is wrong; where we need more formal rules for guidance is in moving from the general. impression to specific statements of what is wrong, and what needs to be done about it. Thus the separation between primary and secondary phases is first a matter of particularising the trouble by tracing it back to a time when the misbehaviour began, and second a matter of finding a useful point at which control may be applied; thus it becomes, not another "assumption" smuggled in to supply a need during the course of a deductive analysis, but simply a way of finding a point d'appui for the operation of control. 
Once the primary phase has been identified, it provides a useful starting point for the analysis of the succeeding chains of causation which provide an explanation of the particular behaviour, not from the beginning of tirne, but merely from the beginning of the period of the disturbance in which we are interested.

(b) By the time the secondary phase has got under way and has begun to override the primary phase, is it not too late to go back to the primary phase to correct the original source of the trouble? This may in fact be the case; but apart from the contribution of an analysis of primary phases to a general understanding of the system, there are specific reasons why it is worth while to identify them. In the first place, the primary phase might itself be a recurring phenomenon (as for example that produced by lumpy investment in the context of runs 7 and 8), and when it has been identified it should then be possible to eliminate it, and with it the attendant secondary phase, the next time it occurs (as suggested by run 9).

In the second place, a proper understanding of the ways in which primary phases begin might permit control to anticipate them and eliminate them or reduce the likelihood of their occurring. A definite form to the whole problem is given by the case of operating monetary constraints on production. In the primary phase, their impact reduces production and employnent, and is transmitted to the secondary phase through the falling off of derived demands for inputs on the real side, and consumer demands falling as a result of reduced income on the money side. It is too late when the secondary phase is under way to correct matters by increasing the monetary base, as runs 7 and 8 suggested, since neither derived inputs demands nor consumer demand can be directly revived by the monetary base itself. The only way to deal with the problem is either by very prompt action on the monetary base or policies to eliminate monetary constraints by ensuring a steady growth in the monetary base.

It is true, of course, that some primary phases might be set in motion by external events beyond the control of the system, 
and these would have to be accepted. But it must be remembered that they will, in the first instance, affect particular transactors; thus there will be a distinguishable primary phase, before the general disturbances of the secondary phase are transmitted from those first affected, and it might be possible to operate on that. We cannot tell at this point.

(c) The approach in general replaces the technique of identifying the relative quantitative effects of all contributory factors operating together by a technique of tracing the operation of causal chains through time. This imposes rather onerous information problems on control, although these are by no means as onerous as those imposed by the Ricardo-Walrasian framework on private transactors. We shall consider in 7.2 below the problem of informational requirements.

As an aid in developing the conceptual structure, we have made use of numerical simulation, and it is time to look again at the relationship between the number manipulations and the concepts of economics.

\subsection{THE NUMERI CAL SimULATION}

In chapters 5 and 6 we have reported a number of numerical exercises each of which began with the discussion of a previous run, and in the light of that discussion evolving further modifications of the programme, which was then run again and so provided the starting point for the next discussion. The results are examined in the following way.

After a broad survey of the raw output, 1.e. the graphical presentation of the sumarisations collated during the running of the programme, an explanandurn is set up by comparing the behaviour of different variations with one another, in terms of some preconceived notions of satisfactory behaviour, expressed in terms of levels and rates of growth of output, employment, household income and expenditure, and prices. An explanation 
for discrepancies and for what, by comparison with the set of preconceived ideas, are taken to be unsatisfactory features, is then sought in terms of the internal structure of transmission mechanisins through which one part of the system relates to another, and which therefore provide a key to the causal chains.

Purely as a collection of investigations into the numerical. simulation as such this work would be otiose; the simulation merely derives one set of numbers by elementary operations on another set of numbers arbitrarily (though not randomly) selected and input to the simulation. All that would thus be necessary would be to present the printed output as the "explanandun", and the programme listing as the "explanans". " The question is, then, what revelations the construction and examination of such number patterns have for us in terms of actual economic systems.

In setting up an algorithm to produce certain number patterns we started from the idea that economic activity itself, in one of its aspects, acts to produce numbers in various relations, and that for various personal purposes, as of earning a living, running a business, etc., it is frequently useful, by conaucting further numerical operations on selected subsets of these numbers, to construct number patterns which enter into our thinking about what has happened and what we are to do next. The semantic interpretations attached to the numbers in the course of discussion of the simulation exercises are a link between the number patterns produced by the simulation and the number patterns generated in the course of actual economic transactions. They serve to ldentify certain subsets of numbers of the sort produced by an economic system in the course of its operation.

Some manifestations of economic activity consist in actuality of numerical operations; sums of money and quantities of goods are numbers which stand in the same relation to transactions in actuality as numbers in the sinulation labelled "suns of money" and "quantities of goods" stand to the theoretical term "transactions". Thus although we have repudiated the idea that actual economies can or do act as an algorithm to solve the 
Walrasian or any other equation system of the black box theories, that the transaction aspect of economic activity can be validly represented as a numerical structure there can be no question. It is therefore meaningful to represent the structure of transaction flows occurring in economic activity in terms of a numerical structure whose modular component is a "transaction" as derined for the simuiation. Wheiner the particular numerical structures produced by the simulation are "realistic" is a matter of the extent to which their form is isomorphic with the numerical structures of actual transaction flows.

This we have attempted to achieve, not by comparing the number patterns of the simulation with corresponding number patterns produced by actual events, but by trying more directly to achieve a conformity between the simulation and actuality in respect of the way in which the numerical structures are built up from the modular component of a transaction. We have therefore given attention, not to the question of what particular numerical structures are in fact observable, but to the question of how such numerical structures are produced.

If this be granted, the process of then forming ideas about which number patterns most usefully, judged by the preconceptions from which we started, epitomise the total outcome of the course of individual simulated transactions, is a way also of forming ideas about which aggregated number patterns would perform a similar service for us in the observation of actual aconomic systems. The process of forming ldeas about which particular numerical operationg can be inserted into the simulated system in order to remove or to modify certain pattern relations is similarly a way of forming ideas about what mechanisms or bounds would be necessary or helpful in the control of actual economic systems. The extent to which such ideas can validly be extended to actual transaction systems is again a function of the extent to which actual transaction processes are validly represented in the simulation model. 
Thus the question of the "relevance of the model" reduces to two criteria: (i) the extent to which the operative processes governing the transaction flows conform to those of the economy in question; this raises the question of "the class of phenomena which it is intended to explain", which does not become undecidable as it does in black box theories, since the nature of the transaction processes in any particular econony is open to direct commonsense observation $;^{5}$ (ii) the extent to which the practical control or policy problem is expressible within the defined transaction processes of the model; since the terms used in the interpreted model to specify malfunctions, to analyse their primary and secondary phases, and to identify the underlying causal chains, and the terms used initially to describe the problem, are terms of the same language, no translation from ordinary into formal language is necessary. The task of expressing the problem in details of the transaction flows affords opportunities both of controlling the precision of the initial formulation of the problem and of checking the model's suitability for handling the problem.

Some problems, of course, it would not be able to handle, even after extensive development. The isolation of problems with which it could deal is done directly by ascertaining whether they are expressible within the transaction mechanisms defined (although it could not be claimed that this eliminates an element of judgement). At present, the model has not been extended far enough to do more than develop and indicate a particular technique of analysis, and at this point it can deal only with a limited and crude set of problems; its further articulation is thus a matter of extending the range and fineness of the problems which can be expressed in the transaction mechanisms.

\subsection{TECHNIQUES OF ANALYsis}

The hypothetico-deductive technique of analysis places prime importance on the formulation of the problem in an axiomatic framework in order to arrive by mathematical deduction at an 
answer (a "conclusion" or a "hypothesis") as a logically necessary consequence of the axioms. The technique of investigation and explanation developed here departs from that method in two major ways.

(i) The axiomatic approach requires that all that is known (and known to be relevant) about the field of enquiry has to be expressed in the initial axioms if the process of logical deduction is to be validly carried out. The non-axiomatic approach does not attempt this, for three reasons:

(a) The correction of malfunctions may need to be undertaken in sequence, since the presence of one type of malfunction may obscure the signals indicating others, and until the first has been dealt with the others resist identification and hence treatment.

(b) The informational needs of successful control cannot all be met by the preliminary examination, and the investigation of malfunction cannot proceed directly from the initial question to the final answer; it usually starts with a fairly broad and tentative first question, to which the answer is a preliminary specification of more detailed information which needs to be ascertained before the question can be reformulated in more precise terms, and this involves a process of successive construction and reconstruction akin to that of the elementary processes of perception. Thus the movement is not from preliminary explanandum, derived from the gross behaviour of the system, directly to final explanans, but from preliminary explanandum to preliminary explanans, which narrows the problem area down to a more restricted and specific explanandum and explanans, and so progressively to a fine enough understanding of what has gone wrong for the purpose in hand.

(c) It cannot be asked of policy makers that they foresee the unforeseeable, and considerable room must be left for accommodation to new problems that arise during the course of dealing with a previous one. This implies a flexibility of approach in which control has to be ready to deal with 
contingencies as they arise.

For these three reasons, the control of an economic system by the identification and treatment of malfunctions is not a matter of once-for-all adjustment, but requires continuing adjustment in the light of information sought and obtained; the finality of a formally deduced conclusion is not attempted.

(ii) The identification of malfunction through the recursive process described in (i) (b) is a matter of tracing causal chains. These provide the explanation of the malfunction, and hence occur at or near the end of the investigation. The axiomatic approach tries, on the contrary, to start from postulates about the underlying causal mechanisms and attempts, through establishing their logically necessary consequences, to deduce what gross behaviour of the system must arise. This then becomes the hypothesis, and its conformity with the gross behavlour that does arise then provides the validation test for the initial axioms about the causal mechanisms.

I can see nothing wrong with this approach in principle. But in our present state of knowledge of the system, the gross behaviour of the system at any particular time is much better known, in a very broad way, than the causal mechanisms which gave rise to it; using the axiomatic approach in the way in which it is applied to economics thus implies basing our logical deductions on a set of axioms which embody the most uncertain part of our economic knowledge. Now if proper scientific method is sought, we should surely have regard to the fact that the axioms of a scientific field embody a distillation of the facts of the field as they are known, the kasic principles that are secure, at least as far as present knowledge goes. The need in economics to present the axioms of the field as though they had this status leads to an inescapable ambivalence of view which perhaps explains why the economists taking part in the debate discussed in section 1.1 had so much trouble with the status of "assumptions" and the question of "relevance" in economic theory. 
Once the axiomatic base, i.e. the first principles of the system, are sufficiently secure, then the axiomatic method provides a very powerful technique of analysis. But until our understanding of the causal mechanisms is very much more secure, we should be wise to resist being seduced by the charms of the axiomatic method. And 1f, in doing so, we have to relinquish the impressive theorems and elegant formalisms of the axiomatic approach, that is the price we pay for having previously disdained the messier business of getting to grips with the system.

We discard along with the axiomatic approach the complementary statistical testing of detailed generalisations in favour of a concentration on the investigation of singular events. Some very broad and unsurprising generalities have emerged, their unsurprising nature being due to the requirement that the analysis makes sense in ordinary language, but before more specific "laws" and "theorems" are attempted we need to accumulate much more extensive knowledge of the causal mechanisms underlying observed singular events. It is in the controlled enquiry into such causal mechanisms that the techniques of analysis here developed are intended to have tiheir force. 


\subsection{THE INFORMATIOMAL NEEDS OF CONTROL}

A good deal of the analysis of the gross behaviour of the system, and the search for causal mechanisms which explain the gross behaviour, has had to be supplemented by additional information not available from the summaries collated and reproduced, and in some cases needing recourse directly to the programmed structure itself. This raises the question of what administratively practicable sources could be specified from which comparable information would be available for control purposes.

To consider a particular example, in run 8 the key to an understanding of the causal mechanisms at work lies in a knowledge of the timing and of the parameters of production decisions, and also in a knowledge of the costing basis of price-setting. The former ultimately derives from the physical basis of production, but the details of this need not be known to control to the extent that the production managers themselves would need; an indication of the time distribution of inputs and outputs could be briefly added to the forms on which raw data for the industrial production statistics are collected; information on changes in production and employment levels could be collected in a form similar to that of the quarterly survey of business opinion conducted by the New Zealand Institute of Economic Research, (with some modification in coverage and formulation); these surveys also provide a convenient vehicle for information on the operation of constraints, which plays a key part in the interpretation of the gross behaviour of the system.

Information on the costing basis of price-setting would not in general be disclosed by firms, although the operation of a price justification scheme does require the provision of such information whenever a price rise is contemplated. The required cost breakdown would have to distinguish between increases in materials costs (indicating, usually, a secondary effect), factor costs (which could indicate primary or secondary effects, and 
would need supplementary information) or changed physical inputoutput relations (usually a primary effect).

We indicated in 3.23 that on the money side the iconic representation of monetary processes offers a relatively direct path between the simulation and the actual world, and measurements made according to the definitions of 3.23 would yield observed values of the money variables which could be validly inserted into the monetary model. The actual process of measurement could still involve difficulties, but the definition of what is to be measured is sufficiently clear for the purpose.

Details of the monetary variables are discussed in terms of the two matrices $M$ and $F$ (see, e.g., IV.2/4). M has two main components, the payments flows between firms and households, and the additional rows and columns showing the sources of payment and the disposals of receipts. It is not expected that we would always be able to fill in the elements of the full sources and disposals matrix (as set out on p. 105 above), since a single payment may be financed from several sources, and the recipient may allocate his receipt among several different forms of disposal. It does appear in fact that the row and column sums of that matrix are usually all we need for analytical purposes. The requisite figures would be collectible within the ordinary structure of bank book-keeping operations, although they are not at present collected in the form used here; it would be necessary to distinguish credits and debits to current accounts according to the credit or debit state of the account.

When the sources and disposals matrix is extended, as it would need to be, to include currency, a difficulty would arise, since many transactions involving hand-to-hand transfers of notes and coin would not leave any traces on books of record; we should, however, expect figures for notes and coin passing between banks and their customers, or over the counters of the Reserve Bank, to be collectible, and in principle some sampling of shops" transactions in notes and coin could be made, so that we ought to be able to get some idea of the movements in notes and coin. 
A really difficult problem would be the separation of money-goods and money-debt exchanges. As indicated in earlier discussion, in order to separate these out in the raw data on $E M$ and $R M$ we should need comparable information on $E N$ and $R N$, which should be collectible from nfi, but undoubtedly there would also be in the raw bank figures a good deal of "fluff", arising from transfers of money within households, or from asset excinanges on the share market or on financial markets. Some of this might be sorted out by subsidiary information from markets invoived, but problems must obviously remain. Further problems arise in goods-credit exchanges, since although in principle figures for sales on credit are collectible, there might be administrative and political problems in attempting to collect them.

In general, the problems that would arise in practice in collecting the figures, and the various ways in which sources of additional information might be devised, can be properly seen only in the light of experience in attempting the collations. In view of the progressively uncertain nature of information collected in the subsidiary figures, the place to start is obviously with the more reliable bank data. In practice, one cannot expect these to be made avallable to any except an official body, and they would probably have to be sought within the powers already available to the Reserve Bank. The remainder of $\mathrm{K}, 1 . e$. the inter-transactor payments flows, would be available in principle from the same source as the input-output tables already published, although some modification might be needed to bring them into line with the definitional basis of $M$, and figures taken once every few years would be of little use for the purpose. It might be that major payments flows collected annually for the industrial production statistics might have to be used as the main base, with interpolations on the basis of best information about other sectors.

On the money side we should be able to make a useful start by first confining attention to those figures already collectible; apart from the untraceable note and coin transfers not passing 
through banks, the sources of expenditures and the disposals of receipts should be possible to collate from existing raw data if this were made available; firm and household money income and expenditure are not, for national accounting purposes, collected in the "cash-book" form here defined, although the Inland Revenue data might yield a basis of estimating these. It is not clear how far we need attempt fully comprehensive coverage, and the technique of analysis adopted, which calls on occasion for progressively more detailed information about some parts of the system, never presupposes that all the relevant information is to hand at the start of the analysis.

Although practical measurement problems can be expected on the money side, those on the real side must be more severe, since the indirect form of the analogue representation leaves unanswered the question of precisely what it is that is to be measured. These problems may be rendered more manageable if, instead of attempting to deal with the very knotty problems involved in direct measurement in physical dimensions of all real variables, we restrict ourselves to the bare mintmun of information essential to the purpose in hand.

It is clear anough that if the theoretical terms on the real side are all required to have measurable counterparts, then we should need to find some common functor as a basis of measurement for those variables to be aggregated, and in terms of the theoretical definitions these would need to be specified in physical dimensions. This would involve us again in the index number problem discussed in 4.22 , in which it was pointed out that measures of real variables in money dimensions merely delude us that the problem is solved. But, as indicated in the discussion of "operationalism" in section 1.23 , it is not reasonable to ask that every term in the theory has a directly measurable counterpart. We need, in our fundamental structure of concepts, ti) distinguish sharply between money and goods if we are to keep our minds clear about the nature of the processes under discussion; but this does not imply that we must always have an accurate measurement procedure for baskets of goods. 
And when we look at the problem, not from a general theoretical. standpoint as would be necessary, for example, in an attempt at a "general theory of production", but frora the point of view specifically of the informational requirements of control, we find that we can get along with something much less rigorous.

From this standpoint, we can disregard the characteristic of "value in use" which clearly enters into alscussions of the physical relation of inputs to outputs, the definition and measurement of the social product, and the concept of "socially necessary labour". Thus restricting ourselves to "value in exchange" there is no reason why we should need to look further than the units already used to cesignate quantities in actual exchanges, For example, the goods side of transaction flows is a flow of goods; in this contest, the information contained in invoices and delivery dockets, where the quantities of each good are expressed in units customarily enployed in the trade, would suffice to determine an adequate basis of measurement si goods exchanged. Deriving from these basic moasurements the figures for materials used and goods produced in the way recorded in the Industrial production statistics would provide data on quantities of goods exchanged; supplementing these by inaications of the time distribution of input and output deliveries would thus provide the raw data for goods flows. The remaining problem would be in aggregating these for control purposes, and for this it would suffice to use a quantity index arrived at independently of nonetary valuations by some rule of thumb weighting. There is no reason why the financlal and services sectors should not be able if required to produce, again independently of monetary valuations, an analysis of services provided by similar rule of thumb weightings applied to different types of service measured in manhours. These rough measures would have to be limited in use; they could not be used, for example, to measure productivity.

It should be stressed that the comparative basis on which the initial rough and ready conspectus of the gross behaviour of the system is arrived at requires no more than a broad picture of goods Elows, and any additional details required on the real 
side as the investigation of a particular malfunction proceeds would be confined to specific areas; there is no reason why such details should be expected all the time for all sectors. In view of the dubious nature of the gross measures used, it would be necessary not to place any great stress on minor variations; certainly they should not be allowed to be treated with the same reverence as that accorded to the equally dubious figures for G.N.P. in the devotional exercises of planners.

Other key information on the real side is given by the operation of constraints, which as suggested above could be usefully communicated through surveys, although in view of the probable need for some operative agency for labour redeployment more information would probably be available from the agency's contact with business.

In general, the measurement and informational base on the real side cannot be said to be of the status that a rigorous theoretical structure would require. But it equally cannot be supposed that monetary measures of real variables are in any sense more accurate. It can at all events be claimed for the approach here adopted that an analysis which can distinguish, in both theory and measurement, between money and goods is both more meaningful and more useful than one which cannot.

The informational requirements of the approach adopted need not impose as onerous a burden on the data-collecting agencies as may appear at first sight. In the first place, most of the information required for control does seem to be, if not already collated on a national basis, at least accessible in a variety of institutions and agencies, and its collation could be carried out within the ordinary processes of the main statistical operations. Thus the informational requirements of control may be met, not by devising totally new methods of measurement, but more simply by bringing together and making use of information already present in one form or another within the system. 
In the second place, all the information that could concelvably be required on a particulax occasion need not be collected in the first instance as a normal requirement, but called for only as the narrowing-down of the expanaandum specified information in progressively detailed form. There would be no need, for example, to trouble about the problems of defining "output" for non-manufacturing sectors unless there has arisen some ground for supposing them to be an important source of primary disturbances or a main agent of transmission of primary to secondary disturbances. All that need be collected on a routine basis would be sufficient signals to characterise the gross behaviour of the system and to provide a preliminary explanans in the event of actual or impending malfunction.

In the third place, an enormous amount of information is already collected by a varlety of government agencies for the specific purposes of government information and control, particularly where any approach to macroeconomic planning is in evidence; in view of the inefficient use of much of this information, whether judged by performance or by the proliferation of variables needed to fill out the inadequate conceptual structure within which the information is interpreted, the adoption of a different conceptual basis may make it unnecessary to collect much of this information or to aggregate 1t in its present form, since if we can achieve a more precise understanding of what it is, on any particular occasion, that we realiy have to know, we may be able to get along with much less and in general rather cruder data.

Since the above assertions are together tantamount to a view that in general a great deal of effort is devoted to the collection and refinement of data not well suited to the effective management or control of the economy, while much that is collected or avaliable to be collected is not made use of for control although it appears, in the light of the foregoing analysis, to be much more centrally relevant, the question is raised of why the major statistical effort should be so misdirected. The answer lies in 
the conceptual structure which we bring to the perception of economic activity, for reasons set out in the discussion of pp. $53 \mathrm{ff}$. The orthodox paradigm does not prescribe the use in its formal structure of the sort of information specified here, and in fact has no terms in its theory which would relate to many of the observations here required; for that reason, while any such subsidiary information no doubt enters into the ininds of many purely pragmatic administrators, its use is confined to intuitive assessments since it has no assigned place in the overt analyses within the terms of the theory. Indeed, any atternpt to force the information about money and goods flows into the accepted theoretical structure can result only in serious distortion of the informational content initially present.

A further problem is raised when one considers that, while much of the needed data is already collected by some agencies for restricted use, many businessmen and labour organisations might be reluctant to provide data for a central control agency, particularly if they suspected that the provision of honest and accurate data would lead to their being penalised in some way. Quite apart from the political and administrative difficulties that this would raise, untrustworthy data would vitiate the purpose of collecting it; it is true that successful control would produce the general business climate most favourable to the stable management of firms, but promises to this effect have been too often made to cut much lce now, and some more positive inducement might be needed.

An efficient labour transfer scheme, while it could not claim to solve all the problems of unemployment or of specific labour scarcity, would nevertheless work directly to the benefit of both labour and employers, and one could expect them to appreciate the advantage of cooperation in this area. But direct information on matters of internal financing and production data is more sensitive, and some quid pro quo, for example in the form of accelexated depreciation allowances, or preference in imports or in finance, might have to be offered. In the specific case of the identification of a bottleneck sector, 1.e. one in which 
primary disturbances were operating and causing secondary supply and income effects elsewhere, the separate purposes of business and control would converge on the immediate need to remove the bottleneck, by the provision of adequate inputs or finance if necessary.

It is no argument against the use of such inducements that they would distort the price structure; the view that a given price structure adequately reflects both relative resource scarcity and production possibilities on the one hand, and relative "value in use" on the other, appeals within the axiomatic framework to the allozative effects of free market prices within the "assumptions" of the conditions of parfect competition equilibrium. What could be aaid of an economist who is willing to assert that these conditions in fact hold in the New zealand economy of the 1970's?

Within the conceptual structure and the analytical technique developed in this study there appears to be every reason to expect that, given experience in handing the different sort of data $1 t$ calls for, adequate information for the restricted purposes of the control of major malfunctions would be forthcoming, although it would never be adequate for minute statistical enquiry or as a basis for generalisations or "Laws". 


\subsection{A MATTER OF PARADIGM}

In the first two chapters, after establishing a basis for diagnosis we came to the view that major deficiencies in macromonetary theory, accounting at least in part for its inadequacy in prediction, explanation and policy application, stemed from its reliance on black box theories. Specifically, to put it in terms of the structure set out by Bunge, ${ }^{6}$ we saw the macro black box, $A$, as just a symbol performing the syntactical linkage among the input, $I$, (comprising micro behavioural propositions including the specification of boundary conditions, with or without additional policy instrumental propositions), and the output, 0, (comprising the ex post macroeconomic aggregates).

It appeared, therefore, that a useful approach to remedying the deficiencies of macro theory would be opened up by an attempt to supply a mechanism linking $I$ and 0 . It had already become clear that the separation of money and goods in the theory and the proper definition of a "transaction" were in any case needed in order to permit the theory to say the things about economic activity that economists had been trying to make it say, although the definitions and the axioms of the theory they had at their disposal did not permit the proper formulation of those aspects of market activity which the theory was ostensibly set up to analyse. This naturally led to a focus on the idea of a "transaction" as the modular element, and the derived idea of "transaction flows" as the main organising idea of the required mechanism.

Initially it was thought that the insertion of this refinement into the existing theory together with any consequential modifications would suffice. One important modification to the formal structure of the theory, the specification of rules of correspondence, had already been seen to be necessary in order to link the existing axiomatic theory to the observational base. This became more urgently required when the question of interpreting and explaining the black boxes by means of internal mechanisms provided by the transaction flows placed the matter of "relevance" among the central issues. 
But it also became easier in that context, since the separation between money and goods variables removed a major source of confusion. In fact, variables on the money side yielded rather readily to the specification of rules of correspondence. Variables on the goods side presented more difficulties, but by restricting attention to "value in exchange", which is all we needed to define the goods side of transactions, and since in any case the limited purpose of the theoretical structure required for control did not call for more than coarse aggregates of output, It appeared that we could ignore the less tractable problems that would need to be got round in the more accurate measurements needed for detalled analyses of productivity or of technical input. relations.

It appeared in this initial view that, given the required modifications, the existing black boxes could be made translucent and puzzles that from the black boxes alone appeared incapable of solution might in fact be solved. This was associated with a view also that the major reason for the weak discriminatory or verificatory power evident in econometric applications of the theory was mainly a matter of the inadequately or inappropriately formulated theoretical apparatus, which among other things placed upon statistical conformity tests also the onus for providing explanations, and that when econometrics was freed of this burden it could provide an effective means of assessing the quantitative significance of factors already known to be relevant on othex grounds.

Thus initially the intention was to work within both the received macro theory and the accepted paradigm, modifying the first in respect of the internal transaction mechanisms explaining the course of economic events, and the second in respect of the method of arriving at a solution of the black box equation, $0=M I$. The accepted paradigm required this equation to be solved for $u$ by direct computation of $I^{-I}$ by a process of deduction based upon the constrained extremum problem-structure in conjunction with the concept of "micro equilibrium" and upon the simultaneous equations structure in conjunction with the concept of "macro equilibrium". 
This was to be replaced by a process of investigation based upon the modular component, a transaction, which once the theory had been suitably modified was specified in $I$; $M$ was then to be constructed by combining the modular transactions into transactions flows, which would thus provide the explanation of 0 .

At this point the task appeared to be that of revising or of refining the received theory within the accepted paradigm, in such a way that the familiar constructs and terms of the theory would not in general be discarded but would, it was hoped, be better related and explained. The positivist approach to theory structure, sanctioning the formal separation of the axiomatic framework and the observational domain, was thought to be serviceable if the required interpretative rules could be specified; and it was thought that once the separation of goods and money had made this possible, the statistical conformity tests would be more meaningful since they would not have to be stretched in an attempt to provide corroboratory tests for both $I$ and $M$, and that as a result the hypothetico-deductive framework would have a better chance of providing a successful strategy for economic enquiry.

It was while work progressed along these lines that several ideas converged and led to a radical change of view, which showed I and 0 in a different light altogether. The initial attempt to use orthodox input-output analysis as the main organising idea on the real side led to an examination of some major components of the orthodox structure, as a result of which the need to revise them became ineluctable. In the process, the status of the major macroeconomic tautologies became dubious; this in turn cast doubt on the macroeconomic aggregates which, in the absence of any specified composition laws to enable them to be derived from the micro behavioural rationales invoked, depended for their definition on the tautologies; this further raised the question of the status of the observational and measurement techniques applied when data were inserted into the framework as values of the aggregate variables.

It soon became clear that, quite apart from any other needs or deficiencies of the received theory, the valid measurement of 
macroeconomic variables alone was not adequately based on the tautological framework in which the macroeconomic entities were defined, since whether expressed in input-output or in national accounting terms the accounting tautologies would ensure the conformity with the theory of any numbers inserted into the theory, whatever the actual state of affairs in the economy in which measurements were made. Thus, purely for the sake of making meaningful measurements, the inserted numbers would have to be selected on grounds other than those provided by the tautological framework. 7

This committed the enquiry, not to linking up the internal. mechanisms of $M$ directly to the familiar macro aggregates, but to looking for other bases of selection of numbers to be inserted as data. This immediately raised a doubt about whether, starting from the internal mechanisms of $M$, we should end up with the same output terminals as those of the received theory. This doubt was reinforced by considerations of an input-output structure expressed in physical dimensions, in which the balancing residual of the accounting framework was not defined, and of similar implications for the money flows corresponding to the real flows. On reflection, it became clear that if we were to take seriously the view based on Northrop's analysis, i.e. that we shoula have to provide a "natural history" base for the given axiomatic structure, ${ }^{8}$ it could no longer be taken for granted what axioms or macroeconomic terms we should end up with.

This had the effect of shifting the emphasis to the construction of $M$ as the main task of the enquiry, leaving 0 to be determined as one of the results of the investigation rather than as one of the initial "givens". On taking this line in an enquiry into the ways in which something approaching "equilibrium" might be defined in macroeconomic terms, it became apparent that, as long as we insisted on making contact with what we already know of the world. we live in, the analysis of "equilibrium" in an uncontrolled private market system, which we had previously had reason to regard as dubious, now became unacceptable on formal grounds as a basis of economic enquiry. This led us to attach importance to Lowe's thesis that order and regularity in economic behaviour was at 
best unlikely to be achleved in the normal course of events by an uncontrolled private market system, ${ }^{9}$ and that any order and regularity actually observable would have to be reached within the context of some form of organised control.

Once we had narrowed down the general search for suitable macroeconomis explananda to the specific search for explananda suitable for control purposes, questions about the techniques of analysis, of information-collecting and evaluation, and of forming and testing conjectures, became important. It was finally clear that the attempt to work towards an axiomatic framework implied that, since in this context we would be looking for an explanation of some malfunction already plainly observed, we should be forced to try to move from axioms based on the relatively less wel1-known facts, to deduce those already well known; this must import a considerable element of guesswork into the whole process, and considerable doubt is thus cast on the appropriateness of the axiomatic technique. Since that technique also requires us to state in the initial "assumptions" the details known to have a bearing on the malfunction under investigation, it asks nothing less than that we know the answer before we embark on the analysis; in the context of a search for explanations of known economic disturbances this can hardly be a sensible way to set about finding out facts that we do not initially know and need to know for some specific purpose.

Grounds for doubt about the appropriateness of the hypotheticodeductive technique as a strategy for economic enquiry had already been provided by Lowe, 10 in the context of the positivist paradigm of theory-structure, which as the arguments of Plaget and Harris suggest ${ }^{11}$ may in any case involve a fundamental error of epistemology, it suffers from two major defects. In the first place, when the body of facts known at the "natural history" level is inadequate and uncertain no secure first principles exist in which the axiomatic analysis can be anchored, and any conclusions reached by such an analysis must have a highly dubious status, and cannot offer much help in the major task of filling out the facts at that 
level; since economic theory, while accepting the formal separation between the observations and the deductions, has not met the other requirements of the positivist paradigm, any conclusions reached by deduction inust in any case remain strictly uninterpretable. In the second place, when the basic principles of the field are so insecure this method cannot cope with the problem of "relevance" to some particular domain of observation.

\section{of narrowing down the field of enquiry through successively better}

towards the possible explanation, thus postponing the question of relevance to the end of the analysis, instead of being obliged to decide the question at the outset on the basis of quite inadeguate infomation.

Finally, the requirements of explanation for control purposes concentrated attention on the causal mechanisms at work rather than on the relative quantitative importance of all variables entering into successive stages of malfunction, and on the analysis of singular events rather than on generalised trends common to a population of events. The first may be important ifs as looks at this stage to be likely, the secondary disturbances so magnify the effects transmitted from the primary disturbances that their quantitative importance could mate the primary disturbance appear insignificant. The second must be important when malfunctions at different times arise from different causes, and when the response mechanisms also are changing as a result of past events. In either case, a prior knowledge of the causal mechanisms is a prerequisite to the establishment of statistically significant factors and cannot be deduced from it. This tdea is further reinforced by a cogent argument from Hayek.

As a result of the conjunction of these ideas we have moved further and further from the structure of received theory, and in developing a different approach to the analysis of economic systems have moved away also from the techniques of analysis and of observation prescribed by the accepted paradigm. The 
points of correspondence between the approach here developed and that of the received theory are few, in choice of problem, in conceptual framework and in techniques of analysis; those that can be traced stem ultimately from the major idea in common, i.e. that macroeconomic activity can meaningfully be formulated in terms of a numerical structure, and this by itself offers no help in deciding how two different types of numerical structure may be reconciled as representations of the same thing.

It can, I think, be claimed that this study has developed a different way of looking at monetary activity, and I suggest that it is capable of providing insights not attainable within the received theory; it is to be expected that as we move to a different view of monetary activity we should expect some modification in our opinion about how problems in the area need to be formulated and what techniques of analysis and observation are appropriate. But this view of monetary activity has not been developed at all far, and has in any case been restricted to a very linited range of concepts; while the course of the enquiry has tended te lead to a groping towards a different paradigm, the search has only begun. And whether the organon developed here can ultimately be reconciled with the accepted general framework, or whether it is capable of being developed into a genuine alternative, cannot be decided at this stage. In the meantime, I suggest that our knowledge of monetary activity is not so thorough or so secure that we can afford to neglect alternative ways of thinking about it. 
1. Cf. "A practising scientist interested only in either the deductive oxganisation of his system or in the empirical conclusions to be deduced within it can 'use' his symbols without 'mentioning' them. But immediately he becomes self-conscious about what he is doing, and tries to connect up the terms occurring in his deductive system with the observables in its conclusions, he will have to think about what he means by the words 'electron' or 'wave-function' or 'mental energy', and thus will have to mention the symbols in order to explain how he proposes to interpret them." (Braithwaite, 1960, P. 87.)

2. Koopmans (1957), after a crreful interpretation of Friedman's view, says, "This entirely acceptable view would circumscribe and qualify Robbins' belief in the obviousness of the postulates, by requiring that not only the postulates themselves, but also thelx dexived implications meet the test of observation". (p. 138) Papandreou (1958, p. 7) is less cautious: "By now no one could doubt the outcome of this debate. The 'realism of assumptions' point of view has given way to the 'predictive power' criterion, is theory capable of being refuted by reference to empirical data".

3. Rotwein (1959) sees a confusion in Friedman's argument between the concepts of 'possibility' and 'probability', and rejects the consistency of the predictions with actual occurrences as providing a sufficient basis for validating the theory. He argues (p. 562) that "(explanation) is a function of the extent to which we may suppose that any entities denoted by the assumption are in reality associated with the event predicted, so that 'unrealism' of the 'assumption'..... and 'explanation' of the event are mutually exclusive".

4. Friedman (1953) P. 14. This view has obvious affinities with the 'instrumentalist' view, which provided a convenient formula by which the Church could have accepted Gallieo's 
(Footnote 4 etd.)

teaching had he agreed to the formula; cf. Osiander (quoted Popper, 1963, p. 98): "There is no need for these hypotheses to be true, or even to be at all like the truth; rather, one thing is sufficient for them - that they should yield calculations which agree with the observations".

5. Simon (AER DEBATE 1963) appears to be the only contributor to have perceived that the emperor has no clothes. He argues that "the logical fallacy in Friedman's principle of unreality has exerted so much fascination...that attention has been distracted from its other errors". He goes on to argue on the following lines: the assumptions that businessmen desire to maximise profits and can make the necessary price-quartity adjustments lead to the hypothesis that market prices and quantities are in fact at profit-maximising levels. Other critics have accepted that the observations on prices and quantities have confirmed this, whereas simon denies that such observations have been or could be made; in fact, such information as does exist relates to the assumptions rather than the conclusion (hypothesis), which reduces the argument to one able to be validated only if one accepts Robbins' view.

6. Op.cit., p. 141 .

7. Machlup, in a communication listed in AER DEBATE (1964).

8. Also in AER DEBATE (1964). Garb (AER DEBATE 1965) comments that "many eminent philosophers and scientists support the idea of explanation in science", instancing Einstein and Nagel. Ostensibly, Bridgman's view supports Samuelson: "I believe that examination will show that the essence of an explanation consists in reducing a situation to elements with which we are so familiar that we accept them as a matter of course, so that our curiosity rests". (Bridgman, 1927, p. 37.) But this does suggest a more subjective basis than Samuelson would appear to accept. 
9. Samuelson, in AER DEBATE (1965), cites: Galileo's analysis of a falling body, Newton's theory of universal gravitation, Einstein's special theory of relativity, and some theories from the classical thermodynamics; he comments: "I have checked with several physicists and find they agree with me that (these four) are expressible completely in terms of Massey's basic sentences alone". The place of theoretic sentences in the theories of natural sciences cannot be dismissed so easily; but in any case it cannot be taken for granted that the methods of physias should, or even that they can, be taken over into economics.

10. A major difficulty of economics is that what may appear to be merely a lay demand for an intelligible, non-technical explanation rests in fact upon the more fundamental thesis that it is not only the processes of hypothesis construction and testing that depend upon the prior basis of theory; the measurement operations and ultimately the designation of what are to be taken as "facte" are not independent of the conceptual structure in which they are defined and interpreted. This point is pursued in subsequent sections.

11. Although it is not immediately apparent that economists thereby avoid this type of absurdity: "The Freudian analysts emphasized that their theories were constantly verified by their 'clinical observations'! As for Adler, I was much impressed by a personal experience. Once, in 1919, I reported to him a case which he found no difficulty in analysing in terms of his theory of inferiority feelings, although he had not even seen the child. slightly shocked, I asked him how he could be so sure. 'Because of my thousandfold experience', he replied; whereupon I could not help saying: "And with this new case, I suppose, your experience has become thousand-and-one-fold" . (Popper, 1963, p. 35.)

12. Although one ought to bear in mind Papandreou's warning that a concentration on the "realism" of the model without 
(Footnote 12 atd.)

adequate attention to the prediction capabilities tends to result in constructions that "are in substance ingenious devices which take the form of general, flexible, ex post facto explanatory schemata". (Papandreou, 1958, pp. 138/9.)

13. The form in which this view has been expressed by Friedman would probably conmand wide acceptance among economists. See Friedman (1953) pp. 282/3.

14. Gurley and Shaw (1960) p. 35.

15. Clarkson (1963) and Papandreou (1958) have offered suggestions for improving the formal framework of economic theorizing so as to make it more adequately suited for empirical analysis. on widely acceptable positivist lines. Rornai (1971) has considerably refined some concepts whose general use would, in my opinion, greatly improve economic analysis as an intellectual tool; in some ways, Kornai's approach may be seen to have been foreshadowed by that of Schoenman (1966), whose is a substantial piece of work in its own right. Many other writers, working along more orthodox lines, have produced illuminating views on particular concepts; some of these will be referred to in other contexts below.

16. See, e.g., Schoeffler (1.955, p. 8): "Economists, in common with all social scientists, often complain that their inability to conduct controlled experiments is an almost crippling handicap in their search for useful facts and laws". Lowe (1965) provides an argument (in Part 1) showing how the hypothetico-deductive method of economics as this is expressed in the main tool, the extremum principle, is on its own of dubious use, he comments that, since progress has made direct testing less important, indirect testing has also proved unsuccessful; "the attempt is made to establish the validity of the extremum principle through the empirical confirmation of predictions derived from it. The striking failure of many of these predictions cannot but throw doubt on the actual or the heuristic significance of the premise". (p. 59). Lowe goes on to develop an interesting proposal which will be treated below in a different context. 
17. See, e.g. Baumol (1966) and cf. a comment by Balogh (1964, p. 167) on a paper by Tinbergen and Bos: "I put the blame for this confusion squarely on the shoulders of an overenthusiastic fringe of mathematical economists and econometricians. In their frantic efforts to arrive rigorously at quantitatively precise statements they have unreasoningly applied results based on primitive and unrealistic models of the economic system".

18. Nagel (1961) concludes that "The injunction that factors are to be varied one at a time represents a frequentily desirable but by no means universally indispensable condition for controlled inquiry". (p. 455). In considering how processes of controlled inquiry may be developed by the social sciences, Nagel offers the view that: "It is difficult to escape the conclusion that behaviorism as a methodological orientation (as distinct from behaviorism as some particular substantive theory of human behaviour) is not inherently inadequate to the study of purposive human action". (p. 480)

19. There may even exist a fundamental misconception about the required relation between the two; a modern economist may well feel some sympathy for Yourgrau's view: "I find this trend to use the term 'necessary' in a formalist, i.e. deduction-theoretic, sense as well as in a semantic context highly confusing.... I think that the idea of natural necessity leads to consequences that interfere with the code of logical rigour in formal deduction". (Yourgrau, 1964, pp. $379 / 80$ )

20. Papandreou (1958); his selected structure is basically similar to that of Przelecki (1969), although a trap for the unwayy is set by the different use made by logicians of the term 'model', which Harrod (1968) discusses.

21. Subsistence farming is an 'irregularity' that he specifically excluded from his discussion of the laws of rents, profits, wages and prices. (Principles, Book II, Ch. XVI, sect. 4) Mill saw rather clearly that the problem was by no means a 
purely economic one, as changing the Irish peasantry into receivers of wages without changing their mental habits would do nothing to improve their condition (Principles, Book II, Ch. X, sect. 1; cf. ibid, Book I, Ch. XIII, sects. 1 and 2).

22. Lewis (1954); his essay \&s explicitly stated to be "written in the classical tradition, making the classical assumption, and asking the classical question".

23. Rao (1952) examines in some detail the application of Reynesian economics to underdeveloped countries, concluding that the category of economic process to which Keynesian analysis belongs is that of moving from a low to a high level of employment, while that of underdeveloped areas is that of moving to a higher level of development, and that "The mixing up of these two categories and a conseguent blind application of the Keynesian formulae to the problems of economic development has inflicted considerable injury on the economies of under-developed countries and added to the forces of inflation". Rao's discussion is notable also for an acute analysis of the 'Keynesian multiplier', his conceptualization, as e.g. In "The multiplier principle, therefore, works with reference to money income but not with reference either to real income or employment". (p. 211), is worth bearing in mind in the discussions in Chapter 2 below on Thornton and on the 'Hicksian cross'. GeorgescuRoegen (1960) also looks at the question of the relevance of capitalistic models in other countries, and sees the alternative as "policy without theory".

24. In an abstract of a seminar paper, Coale says: "A frequent false assumption is one that identifies an intuitively defined concept with a whole range of connotations e.g. real income - with a measured property when the measuring operation in fact defines a much more limited property - e.g. value at some specified schedule of prices". The abstract is printed in Econometrica, Vol. 21, 1953, p. 338, but if the seminar paper has been published I have not seen it. 
25. Papandreou (1958, pp. 138/9), Nagel (1961, p. 509) and Culbertson (1968, partic. pp. 80/82), have drawn attention to this; Culbertson uses the term "Kelly's constant" to describe the device by which economic theories evade refutation, and hence lack explanatory power; he uses the term as follows: "How is Relly's constant applied in economic research? The typical case is that in which the researcher seeks notionally to test his theory, but in fact is seeking to support it....All that is required to do is to slip into the theory sonewhere a variable of unconstrained vajue. Then the theory will - after the fact - explain any experience". (p. 81). He goes on to suggest that "perhaps the most monumental and audacious modern employment of Kelly's constant is the Keynesian theory", the unconstrained variable in this case being autonomous investment.

26. Massey (in AER DEBATE, 1965), p. 1159. Papandreou (1958) uses the term "disposition rules".

27. Component (c) is included here for completeness. I have in mind here two analyses: the discussion (in Ackoff, 1962, Ch. 4) of iconic, analogue and symbolic models, and that in Schoenman (1966) of processes linking initial and terminal states. Othor writers are also relevant, but the whole discussion bears directly on what view of the nature of economic models we are to adopt and require, consideration of which is deferred until chapter 3. To put it in terms of a nautical metaphor, (a) is a matter of navigation, (b) of berthing and discharging or embarking, and (c) involves asking what the trip is for.

28. One may discern some development from Higgins (1959) pp. 1124 to Ginsburg (1961), but if this approach has been since carried to more advanced levels I am not acquainted with them.

29. "The problems analyzed in this section emerge from the lack of homogeneity between the sets of companies classified in an industry and the component subsets of the leading 4,8 or 20 companies. Differences in the economic characteristics 
existing between the two sets limit the use and reliability of concentration ratios as measuring devices. When concentration ratios are aggregated into broader classifications, the complexity of the problem increases." (Singer, 1968, p. 166)

30. Ibid, , p. 56.

31. Ibid., p. 59.

32. Massel (1962) p. 278.

33. Ibid., p. 239.

34. Massel (1962, pp. 241-253) gives a number of different criteria used. The physical basis yielded ambiguities: in the first Alcoa case, virgin aluminium alone defined a product, but several years later it was ruled that secondary and scrap aluminium should be included. In the Cellophane case, many types of flexible wrapping were held to be part of the same market, although in the du Pont-General Motors the court distinguished automobile finishes from paints used for other purposes. End uses of products sometimes overrode physical characteristics, as in the Brillo proceedings and in Reading $\mathrm{Co}$; the court held that the physically identical products (steel wool in the first, anthracite in the second case) were sold to different types of user, who constituted different markets. And similarly throughout the list; no single characteristic appears to have been found which is uniquely decisive or without counter-examples.

35. Ibid., p. 278.

36. Baumol (1966) p. 93.

37. Gordon (1955) p. 93. 
38. Machlup (1960) p. 553.

39. Ibid., p. 558.

40. Ibid., p. 573 .

41. "Operationalism adopted a fallacy that was almost a reversion to the idea of real definition - the principle that the physical identity in fact is the set of operations by which it is measured." (Caws, 1959, p. 5.) Northrop devotes a chapter to contrasting operationalism with a theory structure along positivist lines; he uses the term 'epistemic correlations' in much the same sense as the term 'rules of correspondence' is used above: "In an inferred, deductively formulated theory operational meanings are derived meanings obtained by way of the epistemic correlations". (Northrop, 1948, p. 123.) See also soo (1.954).

42. Nagel (1961) p. 270.

43. Caws (1959)' p. 16.

44. Pap (1959) p. 194.

45. See the symposium listed as soo (1954).

46. Introduction to soo (1954).

47. Ackoff (1962) p. 151.

48. Nagel (1961) p. 480 . See note 18 above.

49. Koopraans (1947) p. 172.

50. Gordon (1955) p. 150.

51. Cf. the quotation from Braithwaite (1960) p. 257, given in section 1.21 above. 
52. See note 25 above.

53. Ibid., p. 113 ff. Cf. Braithwaite (1960) p. 87, quoted. note 1 above.

54. "Most philosophers and many scientists regard measurement as a simple "look-and-see" procedure." (Margenau, 1959, p. 164.)

55. The distinction was described by Margenau as: "If observation denotes what is coercively given in sensation, that which forms the last instance of appeal in every scientific explanation or prediction, and if theory is the constructive rationale serving to understand and regularize observations, then measurement is the process that mediates between the two, the conversion of the immediate into constructs via number or, viewed the other way, the contact of reason with nature". (Margenau, 1959, p. 164.) The idea of the protocol domain was developed in the first two chapters of Margenau (1961), and the P-domain/C-domain dichotomy was made explicit in Margenau (1966).

56. Day (1969) p. 1.

57. Hochberg (1964) p. 14.

58. Ibid., p. 97. Cf. Day (1969) p. 134.

59. Eccles (1964) pp. 269-70.

60. "The mental equipment of ordinary men provides them as they mature with a large number of concepts, generalized, by a process that is largely automatic, from the diverse presentations of sense. These presentations are originally in apparent chaos, but are organised into simple concepts, which are irreducible and cannot be analysed, by an involuntary neural mechanism." (Caws, 1959, p. 9.) 
61. Hyde (1970) p. 3. Plaget's studies on this general fleld were published in many earlier works, of which one closely relevant was Inhelder \& Piaget (1958).

62. Piaget (1969) pp. xxvili-xxix.

63. Ibid., p. 351 .

64. Ibid., p. 358 .

65. The division between perception and reason is impossible "because action as a whole is both the point of departure for reason and a continuous source of organisation and of reorganisation for perception". (ibid., p. 361-2.). Perceptions, in fact, "are structured in the same way as notions because they share sensory-motor roots". (loc.cit.)

66. Piaget mentions the "empiricist's theory of the knowledgecopy, the copy being perception itself" and quotes with approval Pieron's "fundamental remark that sensation itself is only symbolic and provides a less accurate image of the object than mathematical equations do. The 'copy' has thus become an approximate translation". (ibid., p. 362/3.)

67. Ibid., p. 365 .

68. Harxis (1970) is referred to here; the work draws upon much of Harris's earlier work, particularly Harris (1969).

69. Ibid., p. 232-3.

70. "There is a marked convergence of psychological theories on the view that perception is a process of organizing and structuring the elements of what is often termed the sense-field." Ibid., p. 249.

71. Ibid., p. 251. 
72. Ibid., p. 284 ff. A particular statement of these two points is to be found on p. 285 .

73. Ibid., pp. 288-9. We pick this point up again in section 1.4 below.

74. Hochberg (1964) p. 101. This point had earlier been spelt out, though without experimental support, by Northrop (1948) Ch. 3. Northrop argued that the pure empiricists are the mystics, and that to restrict one's observation to sense-data alone restricts one to impressionistic art. In these terms, the pure empiricist thus remains in the pre-operational stage which, according to Piaget's findings, would be expected in a normal infant to be drawing to a close by about the age of 2 years.

75. Harris (1970) p. 289.

76. A concise schema of the stages of interaction between social influences and perceptual activity is found in table 10.1 of Miller (1969) p. 262-3.

77. Miller (1969) Ch. VI.

78. The environment in which a child grows up - and must learn to deal with - may involve the development of quite specific perceptual skills appropriate to that environment. See Serpell (1972).

79. One corollary is that, in general, the injunction to a research worker to approach his topic without preconceptions would be literally impossible to carry out; any worker who could achieve this humanly impossible feat would in any case have to begin by learning to control his sensory-motor operations all over again.

80. For a useful discussion of what is involved, see Pap (1959). 
81. Cf. section 1.22 above. But see also Nagel (1961) p. 505.

82. Caws (1959) pp. 6-7.

83. "What measurement does is to connect two parts of theoretical knowledge, the mathematical and the conceptual, imparting relevance to the one and precision to the other." Caws, op.cit., p. 13.

84. Caws, 1oc.cit.

85. Consider, e.g. Keynes' definition of his variables in the General Theory in terms of wage-units (Keynes, 1954, p. 41). If the argument in the Treatise (Keynes, 1930, Vol. I, p. 134) is anything to go by, some idea of price equilibrium is involved.

86. Consider a price index:

$$
\frac{\sum_{p} j i \cdot q_{k i}}{\sum_{i} p_{k i} \cdot q_{k i}}=L
$$
where $p_{j i} \cdot q_{k i}$ is the price of the $i^{\text {th }}$ good in the $j^{\text {th }}$ year
multiplied by the quantity of the $i^{\text {th }}$ good in the $k^{\text {th }}$ year. Writing in the dimensions, this becomes

$$
p_{j i} \cdot\left(\frac{\$ j}{a_{i}}\right) \cdot q_{k i}\left(a_{i}\right)
$$

where $s_{j}$ is the unit dollar of the $j^{\text {th }}$ year and $a_{i}$ is the dimension in units of which the $i^{\text {th }}$ good is measured; the $a_{1}$ cancel out leaving a sum of money,

$$
p_{j 1} \cdot q_{k 1} \cdot\left(\$_{j}\right)
$$

Whence

$$
L=\frac{s_{j}}{s_{k}} \cdot \frac{\sum_{j} p^{* q_{k 1}}}{i k 1 \cdot q_{k 1}}
$$

(Cont. on page $x T V$ ) 
$\frac{s_{j}}{s_{k}}$ is the dimension of the variation in the monetary standard, and since for a monetary standard of no intrinsic worth some such ratio of value sums is all that is available to measure changes in $i t$, the above becomes a definition. It may be necessary to decide whether, e.g., a wholesale-price index should itself be deflated by a consumer-price index. But all this rests upon the definition of the monetary standard. (Cf. Keynes (1930) Vol. I, p. $76 \mathrm{ff.}$ and Ch. 14; see also Mason, 1963.)

87. It might be very salutary for economic theorists to have to write down their relations explicitly in the form described by, e.g. Ipsen (1960) Ch. IV.

88. Morgenstern (1963) passim, but see particularly Ch. III on "spurious accuracy".

89. Friedman (1953) pp. 282-3.

90. "The belief that science proceeds from observation to theory is still so widely and so firmly held that my denial of it is often met with incredulity.... but in fact the belief that we can start with pure observation alone, without anything in the nature of a theory, is absurd". (Popper, 1963, Ch. 1, sect. v.) Further: "....science must begin with myths, and with the criticism of myths; neither with the collection of observations, nor with the invention of experiments, but with the critical discussion of myths, and of magical techniques and practices". (Popper, 1963, Ch. 1, sect. vil.)

91. Northrop (1948) Ch. 2 .

92. Margenau (1941) pp. 98-9.

93. Crombie (1952) Vol. II, pp. 150-1. Cf. Einstein's view, quoted in Harris (1970) p. 102. 
94. An English translation of "Dialogues Concerning Two New Sciences" is here listed as Galileo (1914).

95. "What prevented Anaximander from arriving at the theory that the earth was a globe rather than a drum? There can be little doubt: it was observational experience which taught him that the surface of the earth was flat. Thus it was the speculative and critical argument.... which almost led him to the true theory of the shape of the earth; and it was observational experience which led him astray." (Popper, 1963, p. 139.)

96. "For one thing, the fact that the volume of air is reduced, while the weight of the burned substance can increase, was well known to phlogiston theorists. For another, oxygen was first discovered by phlogiston theorists. And, for a third, great chemistslike Priestly, Cavendish and Kirwan, retained the phlogiston theory long after these two decisive experiments had been performed." (Musgrave, 1972, p. 152.) For additional examples, see Harris (1970) Part 2.

97. Musgrave, 1972, p. 159.

98. Kuhn (1963) pp. 359-363. Cf. Harris (1970) pp. 177-8.

99. Harris (1970) pp. 207-210.

100. As e.g. the Newtonian anomaly of the moon's perigee had to wait for Clairaut to resolve. (Kuhn, 1970, p. 81.)

101. Kuhn (1970) passim.

102. Kuhn (1963) p. 353.

103. Kuhn (1970) p. 182 defines 'paradigm' in 1 ts broad sense as having these characteristics. 
104. See, e.g., Gordon (1965). Loasby (1971) not only draws attention to the importance of the profit-maximising micro-equilibrium paradigm in the theory of the firm, but suggests that a new one - a behavioural approach - may not only be a useful alternative but may co-exist with the older approach. Along the lines of Kuhn's analysis, one would expect that, other than in a transition period, for two such competing paradigms to co-exist some integration is to be expected; an obvious source of integrating ideas in this field would be the formal analyses of decision theory under uncertainty.

105. ".... since the fifteenth century....there has been in the social sciences not one major breakthrough of the kind and nature of those which mark the development of physics, chemistry, biology, medicine...

.... In fact, the history of the social sciences shows no clearcut case in which a theory has been disconfirmed by contradictory evidence." (Grundberg, 1966, p. 148.)

106. Robinson (1972). Joan Robinson explicitly recognises the existence of earlier crises; these two are referred to her lifetime. But she could almost have made a case for supposing these to be a new and different sort of crisis. in that economists had not previously found themselves at once so well equipped with impressive theoretical structures and so 1ll-placed to deal with events.

107. Leijonhufvud (1968).

108. Cf. Leijoniufvud (op.cit., pp. 4-6).

109. By 'elementary facts' here is meant the sort of data, as output, employment, prices, etc., which economic theories attempt to predict and explain. Whether this sort of data can legitimately be regarded as 'factual' is an important question which will be examined below, but for the present it suffices to adopt the view generally taken, that, for

(Cont. on p. XVII) 
practising economists, these are the given facts of public knowledge. There may be some debate about precisely what ought to be included in such aggregates, but doubts expressed about the objective nature of the entities so measured cannot be taken seriously when the majority of the profession uses them as a matter of course in empirical exercises and policy recommendations. The absence of information about interrelations, particularly about causal connections, is another matter altogether.

110. Northrop (1948) Chapters II, III and IV. Bach of the three stages is given a chapter.

111. Northrop, op.cit., Ch. III.

112. Cf. "In accordance with Popper's criticism we state that the starting point of empirical science is not epistemologically absolute: At any stage empirical science is relying on a store of previous knowledge which contains many unanalyzed constituents, which however, may become assessible to analysis at further stages". Bernays (1964) p. 39. Cf. Heinemann (1948), particularly his conclusions on p. 632. Heinemann is talking about the essential modernity of Leibniz's doctrine of two kinds of truths, and the distinction is not the same as that made here. But it does show that philosophers trying to make sense of the theory-fact relation, however much aware they are that ' Eacts' are constructs, nevertheless cannot escape the need to separate out some subset of those constructs as being part of the 'real world'.

113. From Bunge (1964). Bunge's paper on Phenomenological Theories is drawn on here. (op.cit., pp. 234-254.)

114. Bunge, op.cit., p. 239. 
115. Economists' misconceptions about science may mislead them in another way; cf. "In the overall, a measurement in physics with 10 percent accuracy is a very good measurement. The reader should compare this with the alleged ability of the economist to measure changes in national income, consumers' spendable income, price level, imports, etc., to an overall accuracy of ten to one hundred times better - even in the average!

"Newton established the law of gravity and verified it with an accuracy of about 4 percent (it was later proved to be accurate to about $1 / 10,000$ of one percent). We conclude from such shining examples in the history of physics that the economist need not despair that good workable theory is impossible unless the data are of the presently alleged high accuracy which even the physicists now do not enjoy in general. But the theory will look different from what is now being advanced." (Morgenstern, 1963, pp. 97/8.) [Cf. the comment by $N$. Wiener: "economics is a one or two digit science" quoted by Morgenstern (op.cit., p. 116n).j

116. "It can aiso happen that a theory is in no perceptible way influenced by any additional and/or finer measurements. This will be the case when it is not related to the facts at all or only in such a hazy way that it deserves no consideration whatsoever as an empirical theory. It is likely that parts of accepted economics fall into this category. For example, no amount of improved observations of a modern economy will have any bearing upon the Walrasian system which, using the inadequate conceptual-mathematical notion of maximization, describes only a hypothetical case of economic orgarization, far removed from reality however coarsely or finely described." (Morgenstern, 1963, p. 97.) 
1. Ricardo (1951) Ch. I, section VI.

But since Ricardo has based his discussion on gold, which has its own intrinsic value based on its labour input, the variations in his standard's own value are analytically distinct from variations in the values of what the standard is to measure, and Ricardo is thus enabled to state explicitly what he is holding constant to dexive his 'Invariable standard'; his argument ceases to hold for modern money. (Cf. Mason (1963), particularly Ch. III.)

2. Leijonhufvud (1968) p. 80 (taxt and n.27).

3. This point is discussed more fully in Chapter 4.

4. See, e.g., Patinkin (1965), pp. 17 and 172, and Pesek and Saving (1967) p. 320, to cite two influential works. Keynes devoted several pages of the Treatise to this 1dea, although In the General Theory he moved still closer to Ricardo by basing his units on real wages. (See discussion in section 2.12.)

5. I have in mind particularly the Fisher equation of exchange and the Keynesian equality (identity) of savings and investment. These tautologies suffer from a confusion in many post-Keynesian writers between 'tautology', 'functional relation' and 'equilibrium condition'. Cf. Harrod (1968) p. 33.

6. Schumpeter (1954) Part III, Ch. 7 and Part IV, Ch. 8, to begin at the point where modern theory may be said to begin; Schumpeter also looks in detail at the earlier writers whose ideas, in many ways, found expression in flume and his successors.

7. Discussed in section 2.13 below. 
8. Specifically, we refer to Hume's essays of Money and of the Balance of Trade, both reproduced in Rotwein (1955); to Ricardo's Principles of Political Economy in the Sraffa edition listed as Ricardo (1951), particularly Chs. I and XXVII; and to Thornton (1802).

9. Or, (in Money, p. 35): "a counterfeit money, whlch foreigners will not accept of in any payment".

10. Although Schumpeter supports this view, listing Ricardo as a theoretical metallist, Ricardo does say (p. 354) that "it is not necessary that paper money should be payable in specie to secure its value;" which at first sight could be quoted as a disavowal of theoretical metallism, but Ricardo goes on to qualify this: "it is only necessary that its quantity should be regulated according to the value of the metál which is declared to be the standard". (Cf. schumpeter's argument p. 700.)

11. Although not, in Schumpeter's view, adding anything of consequence to Cantillon's statement. Hume does deduct hoarded money from the money supply in his analysis, referring the quantity relation to money actually in circulation, and further weakens the direct quantity relation by admitting increases in labour productivity and lags, (See Rotwein, 1955, pp. 38-9).

12. It may be argued that this is tautologically true in Hume's analysis on the grounds that his definition of 'money' appears to require international acceptability (see N. 9 above). But both the practice and the theoretical formulations up to Hume's time provided ample support for his specie-flow view of money, and it was still close to the truth in Hume's day; there does appear the difference, that whereas up to Hume the specie-flow basis was a simple matter of fact, to a minor extent for Hume and much more for Ricardo there was a growing shift towards the normative element of convertibility as a basis for control, i.e. as a policy. 
13. Cannan (1921) pp. 28-36. Cannan cites with approval a publication (a Political Dictionary of 1845) which expresses this view, and refers to Jevons as carrying it forward. But see Marget (1938) pp. 161-171, Vol. I.

14. See e.g. The Federal Reserve system, (1963) pp. 63-73, Samuelson (1970) pp. 335-6. Intermediate texts on money have in recent years become more careful on this point.

15. Keynes (1930) Vol. I, pp. 25-27.

16. See Fetter (1968) pp. 63-84, in which Fetter discusses some modern applications. The analysis of the exchange-flow seems to be the only substantial part of Thornton's analysis which became accepted into the mainstream of monetary theory, although the Ricardian commodity-view of international finance survived along with it. Schumpeter lop.cit., pp. 732738) questions how far a definite separation of these two views can be sustained, although the important article by Mundell (Chap. 26 of ahorn (1966), pp. 655-662) does appear to lean more towards Ricardo than Thornton.

17. Thornton (1802) pp. 191-2. His comments on the relation of the domestic 'value of paper' to the value of the exchanges is 11luminating. It must be conceded that Ricardo's Ingot Proposal (see Principles, p. 357-8) shows an awareness of these aspects, in a more simplistic view how much Ricardo owed directly to Thornton on this point I am unable to say.

18. "Even in that early and rude state of society, in which nelther bilis nor money are as yet known, it may be assuned, that if there be commerce, a certain degree of commercial credit will also subsist. In the interchange, for example, of commodities between the farmer and the manufacturex, the manufacturer, probably, will sometimes deliver goods to the farmer on the credit of the growing crop, in confidence that the farmer will come into possession of the fruits of his 
(Footnote 18 eta.)

labour, and will be efther sorpelled by the law of the land, or induced by a sense of justice, to fulfil his part of the contract when the harvest shall be over." (Thornton, 1802 , beginning of $\mathrm{Ch} .1$, in the edition used, on p. 75.) This contrasts sharply with the Smith-Ricardo-Mill basis, and shows a remarkable similarity to the much later view expressed by Elnzig (1966) on pp. 343-4, basing his findings on the reports of anthropologists on a wide array of field studies, Einzig is devastating about Mill's 'barassed tailor on the verge of starvation, trying frantically to find a baker who happens to be in need of a jacket', although Jevons' 'double coincidence of wants' still appears to be the staple of introductions to price theory.

19. See Ch. 2 (Thornton, 1802, p. 81).

20. pp. 82-84. These passages can be interpreted in terms of modern Isiquidity preference, but in order to do so some of the detailed information given in Thornton's analysis mut be dropped, and the analysis greatly simplifled; whether that improves matters in this case is arguable. The remainder of $\mathrm{Ch}, 2$ Thornton devoted to a refutation of the 'real bills doetrine', a hardy weed which nevertheless survived the refutation and re-appeared in the Federal Reserve Act of 1913.

21. See p. $94 \mathrm{ff}$. A specific repudiation of the Quantity Theory may be seen in: "The anount of what is called the circulating medium of a country has been supposed by some to beax a regular proportion to the quantity of trade and of payments. It has, however, been shewn that such part of the circulating medium as yields an interest to the holder will effect much furver payments, In proportion to its amount, than the part which yields to the holder no interest." (p. 94) Since rhornton does not believe in stable proportions obtaining between the components of the money supply, this astanot be reworked into the Quantity 
Theory by some simple extension of the high-powered/ ordinary money device. See also n. 25 below.

22. Thornton, op.cit., pp. $116 \mathrm{ff}$. This leads into the 'goldflow, price-adjustnent' theory; but as the latter proceeds, Thornton's grasp of a wider range of effects than a rigid equilibrium analysis can manage is demonstrated. See also note 28 below.

23. p. 124. The argument here is based on the maintenance of confidence in the Bank's notes: "There is an excessive Ilmitation of them, as every one must admit, which will produce falitures, fallures must cause consternation, and consternation must lead to a run upon the bank for guinaas". It thus depends on "the degree of alarm, and not on the maintenance of the greater or of the less quantity of notes, whether the guineas shall be more or less rapidly called for from the bank." Finally, then, the way to prevent an excessive run is to provide enough paper to prevent the alarin.

24. PP. $133 / 7$.

25. p. 141. That this implies no formal type of equilibrium analysis is elear. Ce. p. 143. A final statement, which sums up this non-equilibrium view in respect of some major coneepts, is (p. 224): "Let 1t, therefore, be carefully remembered, that I by no means suppose a limitation of Iondon paper to operate simgly by causing an equal reduction of country paper, and then such a fall in the price of goods over the kingdom as is exactly commensurate with the general diminution of paper; and, finally, also such a variation in the exchange as is precisely proportionate to the reduction of paper, and to the fall in the price of goods. Counteracting elrcumstances of various kinds may prevent these proportions fxcu being maintained: and the full effects may not follow their cause untll after the lapse 
of some pexiod of time". cf. (p. 197): "an exact correspondence between the quantity of paper and the price of commodities can by no means be expected always to subsist".

26. P. 293-5. "The price paid is not at all governed by the equity of the case, but entixely by the degree of command which the one party has over the other." Where an increase in 'eagerness' on the part of the buyer arises from an increase in $M$, this is not a 'real balance effect', since it is made abundantly clear that for the notes to be issued some people must borrow from the bank, which they are willing to do as long as the bank's lending rate is below the market rate. (p. 254/5) An Income effect may then be generated through the expenditure multiplier (pp. 239/40), and the whole process sustained by bankers, who are happy to keep lending since theix loans are also being repaid through the process. (p. 253)

This demand/supply analysis is extended (p. 194) to the demand for and supply of paper (money): "The principle which has been laid down as governing the price of goods, must be considered as also regulating that of the paper for which they are sold; for it may as properly be sald, on the occasion of a sale of goods, that paper is sold for goods, as that goods are sold for paper". Compare this with a parallel statement by Clower (1967) p. 5. "Money buys goods and goods buy money; but goods do not buy goods." clower is arguing against the opening proposition by Patinkin, that "Money buys goods, and goods do not buy money" (Patinkin (1965) Introduction, ק. xxiii). Thus, although at first sight Patinkin's view that (an excess) demand for money implies inx azsess) supply of goods is equivalent to Thornton's formulation, several differences are apparent. Thornton is concerned to distinguish types of transactor and of transaction (see p. 116) which Patinkin is not. Patinkin alse assumes that goods exchange directly

(Cont. on p. $\left.x x V_{0}\right)$ 
(Footnote $26 \mathrm{ctd}$.)

for goods - the point with which clower is arguing whereas Thornton explicitly states the opposite: "They must first exchange these unsuitable goods for goods which are suitable, that is, they must sell them, in the first instance, for money" (p. 116; eraphasis supplied). In addition, Patinkin is deducing this relationship from an "equilibrium" concept, which Thornton manifestly is not.

27. p. $197 / 8$.

28. p. 225. "We have lately been placed between two dangers: between that of a depreciated paper currency on the one hand, and that of an interruption to our paper credit, and a consequent stagnation of our commerce and manufactures, on the other."

29. pp. $230 / 9$.

30. See particularly p. 239/40, note that the multiplier is explicitly a money-expenditure multiplier; having explored the course of the multiplier, in terms of successive payments of the same notes from recipient to recipient, this yields a total of money purchases or expenditures; only arter establishing that, do we enguire into the real side: if expenditures thus increase, either the output of goods or prices must have risen; in general both effects will occur.

31. p. 253. "But it is here to be recollected, that the bank 1tself, if we suppose a progressive enlargement of notes, raust be assumes to furnish perpetually increasing means of effecting payments, and thus to render punctuality in fulfilling even the most extravagant engagements convenient and easy to the merchants." (Cf. Keynes' Treatise, Vol. I, p. 27: "Each Bank Chairman sitting in his parlour may regard himself as 
(Bootnote 31 cti.)

the passive instrument of outside forces over which he has no control; yet the 'outside forces' may be nothing but himself and his fellow-chairmen, and certalnly not his depositors".)

32. p. 255. "The borrowers, in consequence of that artificial state of things which is produced by the law against usury, obtain their loans too cheap. That which they obtain too cheap they demand in too great guantity." Thus the borrowers' interest diverges from that of the bank, which consequently cannot rely upon their moderation.

I cannot agree with schumpeter that this argument is interpretable as "the loan rate (money interest) tends to equal expected marginal profits of investment (maxginal efficiency of capital)". (Schumpeter, op.cit., p. 721 and $721 \mathrm{m.}$ ) In the first place, in view of Thornton's evident dislike throughout of simple-minded equalities and other exact quantity relations, he could hardly be supposed to have been willing to accept the idea of 'equality at the margin'; in the second place, Thornton's whole argument is that, while some approximate stabllity might be achieved if bank rate were allowed to rise, the whole trouble under discussion is brought about precisely because the necessary ceteris paribus conditions are not maintained. Time and time again he stresses the iraportance of the disturbing factors, particularly when the aisturbing factors act upon an already unstable situation. Thornton also goes on (p. 255/6) to give reasons why, in the situation under review, there would not be a falling rate of money profit, an indispensable premise of the 'falling marginal efficiency of capital. argument in a context of money borrowing.

33. The mistake attributed by Hayek (Esgay, Thornton, 1802) to McCulloch, of confusing Henry Fhornton with his eldex brother, Samuel, who was a director and, from 1799 to 1801, Governor of the Bank of England, may have subsequently contributed. 
34. That is to say, the formal structure was provided by Walras, but the basic ideas of exchange equilibrium were those of Rlcardo and Smith. Ricardo opens (Principles, Ch. 1) with the following statement: "In speaking then of commodities, of their exchangeable value, and of the laws which regulate their relative prises, we mean always such commodities only as can be increased in quantity by the exertion of human industry, and on the production of which competition operates without restraint.

"In the early stages of society, the exchangeable value of these commodities, or the rule which determines how much of one shall be given in exchange for another, depends almost exclusively (in lst edition, 'depends solely') on the comparative quantity of labour expended on each." He finds his rationale in Smith, quoting - with approval - "in that early and rude state of society, which precedes both the accumulation of stock and the appropriation of land, the proportion between the guantities of labour necessary for acquiring different objects seems to be the only circumstance which can afford any rule for exchanging ther one for another". Ricardo regards this as "a doctrine of the utnost importance in political economy".

A comparison of this with Thornton (and Einzig) becomes most revealing when one considers how the Idea of a "real-exchange equilibrium" prior to and independent of money has been carried on into modern theory. Cf. the comment by Morgenstern on Walrasian equilibrium (see Ch. 1 , n. 116 above).

35. Wicksell commented in 1898 that: "If the Quantity Theory is false - or to the extent that it is false - there is so far available only one false theory of money, and no true theory." (Wickse11, 1936, p. xxili.) The modern formulation of the Quantity Theory, usually ascribed to Irving $F$ isher, is presented nowadays as $M V=P F$. Much earlier formulations of this relation, neglecting the velocity term, are recorded by schumpeter. Reynes oites 
(Footnote 35 etd.)

other predecessors of Fisher. The earliest version explicitly in these terms is credited by Theocharis (1961, pp. 100/1) to an early German mathematical economist, Claus Krönke, writing in 1804. But, as Theocharis quotes it, Krönke's equation is written $x=\frac{\phi}{2}$, where $x=M, \phi=P T$, and in $=V$ (to match corresponding definitions) which is the modification usually called the 'Cambridge' equation. (See, e.g. Thorn, 1966, p. 59.) Pigou, (1917), In fact extends the 'Cambridge equation' to differentiate between currency and bank deposits, arriving at a formulation foreshadowing the high-powered-money relation of the Chicago-st. Louis axis (q.v. below).

36. Marget (1938-42) disagreed that such a classical dichotomy existed. His woxk is mainiy devoted to refuting this idea, his chief target being Reynes. Marget attacks the 'real balance effect', (Vo1. 1, pp. 433-458) particularly as that concept is dealt with by Keynes in the Treatise. His conments are relevant also to the discussion of patinkin, below.

37. See Keynes' discussion of the Cambridge and Fisher formulations in the Treatise (1930, Vol. 1, chapter 14), he sees the difference between them in the following terms: "Quantity Equations of the 'Cambilige" type lead up, as we have seen, to the Cash-balances Price-level, whilst Equations of the 'Fisher' type lead up to the Cash-transactions Price-level". Now Keynes guite clearly was speaking of the definition of a Currency standard, as we see from his earlier remark (op.cit., pp. 76-77): "An object of expenditure which passes straight from the original producer to the ultimate consumer, such as personal services for example, gives rise to a less volume of monetary transactions than an object of equal value which passes through many hands and through many 
stages of production, each of which involves a monetary transaction before it reaches the consumer".

But the association of this distinction with the definition of a Currency standard, directly related in both Keynes and Fisher to a preoccupation with the purchasing power of money and the construction of suitable Index-numbers, misses a more fundamental aspect: the cash-transactions approach suggests a concentration on the rmeans-of-payment function of money, and as Reynes describes it has obvious affinities with input-output approaches, whereas the cash-balances approach relates to money as an asset in conjunction with the incomeexpenditure approach as GNP, 1.e. as output with intermediate transactions netted out.

Money as a means of payment ought surely to be more closely identified with total transactions, and it is because of the stress on money as an asset that the 'demand for balances', i.e. the Cambridge form, has regrettably prevailed. A distinction is preserved in modern textbooks, between the income-velocity and the transactions-velocity, without leading to any apparent interest in the transaction processes associated with the latter. See also the discussion on "Keynes' second proposition" in Robertson (1933).

38. The article "Mr. Keynes and the Classias", reprinted in Hicks (1967) may be seen as a source of the fundamerital structure of modern monetary theory. Ostensibly, the article is purely an interpretation of Reynes' thought in the "General Theory", but a comparison with Hicks" earlier comments on the "zreatise, in his essay "A Suggestion for Simplifying the Theory of Money" (also reprinted in Hicks 1967 ) and with his subsequent use of the structure for the money model of his "Contribution to the Theory of the Trade Cycle" suggests that Hicks ' own thought tended to move in this direction independently. The fact that he came to monetary theory from a firm standpoint in value theory may have been decisive here. 
39. This is a very loose grouping; I have in mind particularly Friedman (1970) and Friedman (1971), the earlier theoretical chapters in Cagan (1965) and the article by Meigs and Wolman (1971). See also Thorn (1966) Part II.

40. Leijonhufvud (1968). The ground selected by Grossman (1972) for debate is the thesis that some dissenting analyses in the post-Keynesian era, which Leijonhufvud sees as a more valid interpretation of what Keynes had in mind, are rather, particularly in respect of the work of clower and Patinkin, the beginning of an attempt to axticulate a new paradigm.

41. Keynes, in the General Theory, repudiates his former attachment to Wicksell's formulation of this Idea, "I an no longer of the opinion that the concept of a 'natural' rate of interest, which previously seemed to me a most promising idea, has anything very useful or significant to contribute to our analysis". (1936, p. 243.) But see Hicks' coments, (1967) pp. 141 and 199 ff.

42. See note 32 above.

43. See note 30 above.

44. See Leijonhufvud (1968, Chapter II) and Kornai (1971, Chapter 5) for discussions of this.

45. It is not clear whether even clower (1967), although he undoubtedly sees the need, departs sufficiently from orthodoxy to provide this nexus.

46. Johnson, 1962, (in Thorn, 1966, p. 13).

47. See, e.g. the panel discussion "The Role of Money in Economic Policy", (Federal Reserve Bank of Boston (1969) 
(Footnote 47 otd.)

pp. 7/36), in which Samulson, the 'real' incomeexpenditure theorist conceded that money matters, but rejected monetarism, Meiselman and Meltzer, monetarists, took the view that while money was not all that mattered, it was sufficlently important to produce grave distortions if omitted from consideration; robin, the portfollo theorist, challenged the evidence for monetarism, on grounds not fundamentally different from those I have mentioned as constituting flaws in the Hicksian cross analysis; (Tobin renders what I would describe as 'the black box' as a 'pseudo-reduced-form'). Wallich, sumning up from the point of view of the user of policy recommendations, points to the differing views advocated and the problem of appraisal thus presented to the Pecieral Reserve, particularly when the differing views are presented with equal confidence.

48. Patinkin (1965) passim and Pesek and Saving (1967, Parts $I$ and II).

49. Patinkin, op.cit., Ch. II and the Appendix thereto, pp. $417 \mathrm{ff}$.

50. Clower (1967). Although Clower presents his argument as a criticism of Patinkin's view and as a necessary reformulation of Patinkin's budget equation, his argument seems to me to have wider and more important implications, as Leijonhufvud (op.cit.) appears to have seen.

51. Gurley and shaw (1960). Their argument is not put into the formal algebraic Iramework that other writers, particularly Patinkin, have selected (although there is a mathematical appendix by A.C. Er.thoven), and at first sight appears to be an atternpt in the genre of ThorntonRobertson-Hayek-Hawtrey. But it does not get at all as close to the money-goods nexus, and its rather artiflaial conceptual basis owes much more to the post-Reynesian orthodoxy than it does to the insights of the Inglish tradition of monetary analysis. 
52. Meltzer (1963) argues that, while Friedman's results appear to refute the theoretical arguments of Baumol and Tobin (that there are econorales of scale in holding cash) his definition of money leaves this question still open.

53. See, e.g., Friedman (1959) and Priedman (1970); see also Meltzer (1963) and Brunner and Meltzer (1963).

54. Syring (2968, pp. 35/6) refexs to Bronfenbrenner's approach in which 'monetary assets are distinguished from non-monetary assets on the basis of their degrees of Iiquidity', and comments that this definition "appears to be useful from a conceptual point of view, but it does not help the empirical worker to separate those assets which are money fros those which are not". Since Bronfenbrenner was conducting one of the earlier exercises in spelling out in more detail one aspect of the Liquidity Preference approach in the choice-theoretic terms of utility theory the work cited preceded the emplrical exercises on which syring was mainly comenting. The work referred to was Bronfenbrenner, 1945.) The point that exercised Bronfenbrenner was that the redium-ofexchange function was only a necessary condltion for 'moneyness', and that a sufficient condition needed recourse to the liquidity notion. But putting this into a utility framework inevitably made liquidity, and hence money, a matter of subjective estimate, which may differ anong asset-holders, and it is this which renders the identification of 'money' so elusive. Bronfenbrenner himself pointed out this difficulty (op.cit., pp. 412/3), which olearly has important implications for subsequent developments along choice-theoretic lines.

55. In a context of monetary policy, this does not replace the theories of money by a supposed alternative, but in fact may be presumed to rest on the general theoretical tenets of the "monetarists' who produced the concept in 
(Zootnote 55 etd.)

order to provide a supply function for the demand-andsupply analysis. See, e.g., Meigs and Wolman (1971).

56. The result of this was a gulf between propononts of fiscal policy and those of monetary policy; the entirely inconclusive debate between Friedman and Heller (1969) is symptomatic of this gulf. But the attempt to regard thera as separate policy instruments which may be combined to two different ends (as in Mundell's article in Thorn 1966) is no real improvenent, since in actuality fiscal instruments have money effects as well as inconeexpenditure effects, and monetary instruments are presumed to have some connection with expenditures, so that a proper $1 \mathrm{y}$-conducted analysis along those lines ought to be able to explain first how these effects interact and how they are concoptually distinguished.

57. Two major works are Melselman (1962) and Malklel (1966).

58. Out of the voluminous literature, the following are good representative treatments :

Books: Johnson (1.971), Johnson (1972), Laidlex (1.969) and Thorn (1966). See alsos Felge (1964), Syring (1968) and Croome and Johnson (1970).

Articles and contributions to symposia: Bronfenbrenner and Mayer (1960), Frandis (1972), Friedman (1959 and 1970), Haxxis (1968), Johnson (1962 and 1970), Meigs and Wolman (1971), Mel.tzer (1963) and Smith (1970).

Papers in Johnson (1972) of particular interest are those in the 'Demand for Money' section, particularly papers by the Bank of England research staff. The articles 1isted from flarxis to Snith contain surveys, assessments and sunuaries of the conventional wisdom in this area. 
59. Marget (1938, Pp. $120 / 3$ of Vol. 2) takes this view of Hawtrey's work generally. Marget comments (p, 123): "No one in our own generation has been more insistent than Hawtrey on the point that it is dangerous to talk of tearing aside the "monetary veil" in order to study the 'realities' of economic life which that 'vell' is supposed to hide. No one, by both precept and example, has started more explicitly from the proposition that, If it be granted that the function of 'general' economic theory is to explain the working of the economic process in the world we $\mathrm{know}$, then no description of economic processes in the world we know can be regarded as satisfactory if it abstracts from the effects upon these processes of the working of the monetary mechanism."

60. Harris (1970), Chapter 7 and Misgrave (1972). Kuhn's discussion (1970, Chapter 6) can, it seems to me, be read either way.

61. See Rornal (1971), and from two influential associations, the Presidential addresses by Hahn (1970) and Leontief (1972): Culbertson (1968), Clarkson (1963) and Papandreou (1958) have produced some reasons for believing economic theory to suffer from serious structural flaws. Johnson himself has voliced the odd doubt (1971, p. 117), and there are plenty of comments on the dependence of econometric exercises on the theoretical formulations to which they are applied; econometric textbooks usually stress this point, but the material available on econometxic exercises on the 'demand for money' leaves one in no doubt that the practitioners regard their results as capable of corroborating their theory, to the chagrin of their opponents.

62. See, e.g. Coppock and Gibson (1963), Crouch (1964) and Cramp (1966).

63. What may be generically described as "manna" theories of money creation carry this neglect to extremes. Consider, 
(Pootnote 63 otd.)

e.g. Gurley and Shaw: "Suppose that an Initial stationary equilibrium is disturbed by a feat of magic that suddenly doubles all money wage rates and all prices." (Gurley and Shaw, 1960, p. 35.) The "hellcopter" variant is popular: see Welntraub on Friedman (Weintraub, 1971, p. 39) and Thorn (1972, p. 480) on Mundell. Cf. these views with that of Hayek (1933, p. 46), who attaches importance to the process by which money is introduced into the economic system, referring to the "fundamental. diversity between a money economy and the pure barter economy".

64. Hicks (1967), particularly the discussion in the first three lectures, relating to the Two Triads.

65. L. Harxis (1969), Johnson (1970) and Perlman (1971) have taken issue with this separation, maintaining that any particular sum of money is neither in principle nor in practical measurement able to be categorised into one or other compartment.

66. Hicks (1967) p. 15.

67. Weintraub (1971) p. 49.

68. See note 54 above.

69. "Operational" here means simply "usable" in some practical sense, and has nothing to do with the rigid "operationalist" approach alscussed in chapter 1.

70. Newlyn (1964) p. 345-6 (conclusion 3.). The discussion leading up to this definition (on pp. 334-339) is addressed to a specific argument by Sayers, and is not fairly treated out of context. Moreover the Idea of differentiating between "investment financed by drawing upon money balances and investment financed by drawing 
upon claims to money". (p. 335) is an important one not well handled in the theory. Nevertheless, the neutrality criterion is proposed as having general application, and that is how it is looked at here.

71. Hicks (1967) pp. 18-19. If one could be sure that it would never be treated outside the whole context of Newlyn's argument this would be less of a danger.

72. Clower (1971) Part 1.

73. Clower (1971) p. 17. In its strict context, this is a forecast, not a statement of clower's position. But taking it together with Clower (1967), particularly pp. 35. I believe it to be a fair representation of his general theoretical position.

74. Clower (1967) p. 6 .

75. It may be realled that Thornton (1802) argued on much the same lines in refuting the real bills doctrine (see note 20 above).

76. I suppose an absolutely deternined model-builder could force wage-payments into this structure by regarding the working week as a period of purchases of labour services on credit, although the place of the wage-payment in discharging the debt to tine worker still needs explanation in terms of money's ability to extinguish a debt.

77. The opening passages of Thornton (1802). See note 18 above.

78. Hicks (1967). The whole discussion of the Two Triads needs to be taken into account, but a key statement is on p. 15: "I think that Keynes was absolutely right in 
(Bootnote 78 otd.)

the distinction which he drew between $M_{1}$ and $M_{2}$ : more exactly right than som of his followers (including myself) have been, when we have formulated the 'Demand for Money' in ways that blurred the distinction".

79. See note 65 above.

80. "(the demand for clarification of the mechanism by which results can be explained)...vill have to be answered satisfactorily.... and the attempt to answer it will necessarily involve the counter-revolutionaries in the opposing methodology of general equilibrium systems and multi-equation econometric models". Johnson (1971b).

81. ¿ejjonhufvad (1968) p. 31n.

82. Schoemman (1966) p. 15. To put the interpretation beyond doubt, this viev is further spelt out by Schoenman as follows: "The changes in the unit's liquidity is the most complex for it is the result of soverai different types of flows. There are inflows from delivery of the unit's goods at their average price, and also transfer. The outflows are in the form of amounts of the unit's current operation requirements at theix average cost and of fixed outlays.... One notes that in the simplest of the above position calculations there are at least two flows....to explain directly the change in position or the position itself, pre-supposes no interest in the separate flows wich constituted them." (ibid., pp. 578.) It will not be possible to produce in a macro structure the fineness of detail which schoenman applies to the micro structure, but an attempt to earry this approach as far as possible into both real and money sides of the macro structure is a major object of this enquiry. CE. also applications to the real side, in $\mathrm{Ch}$. 4 below. 
83. In New Zealand, important customers of the Central Bank are the maxketing organisations, particularly the Dairy Board, whose transactions would thus be included in EG. This has the effect of lumping e.g. Dairy Board transactions in with those of government, for the reason that, in monetary analysis, the basis of distinction is not that between government and autonomous organisations, but between those whose transactions directly impinge upon the monetary base and those whose do not. Thus both government and other customers of the Central Bank are seen, not as spending out of existing monay supply, but as adding to both money supply and money base through their expenditure.

84. Phus any major increase in the activity of nonbank financial intermediaries may lead, among other things, to actual increases in the money supply if bank customers shift from bank time deposits to nfi deposits, since nfi would be expected to channel these into demand deposits of the banking system.

85. In considering an application of this to the American econony an obvious aifference arises in that American banks operate mainly on loan account rather than overdraft lending. This cannot be dismissed as 'mere' bookkeeping, since money as provisionally defined is nothing but bookkeeping, and no one could dismiss the difference between a cheque drawn on a trading bank and one drawn on a central bank as a mere detail of bookkeeping. Nevertheless, it seems reasonable to suppose that people who borrow from a bank under elther system do so not to hold a deposit but to finance an expenditure; the difference in bookkeeping has obvious importance for the measurement of the stock of money, but not for the analysis of the relation between bank lending and money creation. That is to say, the important aspect is the intervening transaction and the act of money creation by the depositing recipient of the expenditure, not the trivial fact that the bank credits the proceeds of the whole loan to the borrower's deposit. 
86. Some importance ought to be attached also to the difference in status between Iigures recorded for 'unexercised overdraft' and those for 'demand deposit liabilities', the latter are an integral part of the bank's internal bookkeeping, subject to the battery of verificatory and inspection procedures needed to give such highly important figures the reliability and accuracy that the bank's business dexands; the former are not.

87. 'This brings to mind the 'high-powered money' concept, discussed below.

88. Even this simplified construct is not well handled in the textbooks, the place of bank clearings being entirely fudged over. It is easy enough to construct a multiplier for one bank of the system, and to derive the famlliar result that ach bank is able to expand without loss of reserves (other than through net encashments) as long as 1 ts gains on the settlements balance 1ts losses, and further that this depends in general on the relative rates of expansion of different banks rather than on their relative aize. Provided that the multiplier is expressed as an inequality, and is used as a rough generalisation, it is unexceptionable. cf. note 25 above on Thornton's view of this sort of relation.

89. While, therefore, one can see much mexit in Davidson's view (1967, D. 246) that "an increase in the demand for goods implies not only an increase in wants but also.... an increase in the ability to pay", when his argument continues: "an increase in the ability to pay means an increase in active balances" one wonders whether he has overlooked the nature of flows in the system despite his insistence on their Importance. (ibid., p. 249 n.1.) cf. Clower's approach, discussed above.

90. Hiaks (1967) pp. 14-15. 
91. Cf. Culbertson (1968) pp. 80-2. See also the discussion below on trade credit, where no money at all is paid when goods are delivered on interfirm credit, such expenditures would be measured into the 'velocity of circulation'; since they do not involve the money stocic there would be nowhere else for them to go.

92. For this reason, work such as that of Baumol (1952). Tobin (1958) and Gurley and Shaw (1960) is relevant at the micro level, where it reay throw considerable light on the way in which individuals finance expenditures and alspose of receipts, but is simply not defined for the macro aggregates, since if there is one thing we can be sure of it is that individual 'real balances' or 'Iiquidities" are not simply additive into macro aggregates. Lefjonhufvud appears to suggest (1968, p. 201, n. 23) that the requisite correction can be made in terms of 'the axpected price level', but the analysis of Marty (1961) to which he refers, in so far as it implies anything beyond a knowledge of current price changes, must require a much greater knowledge of macro events than Marty himself is villing to concede even to the monetary authorities.

93. Meade (1934, p. 82).

94. Cagan (1965) pp. 12-3. This may be unfair to Cagan; an alternative view is that Cagan intends this to be understood along the lines of the "successive explanation" approach which he mentions at the end of Section II, in which case the issue is one not of method but of choice of structure.

95. Meigs and Wolman (1971) p. 19.

96. Cf. Ackley (1961) on 'Tautological versus Meaningful Multipliexs' (pp. 309-312).

97. See note 63 above. 
98. In particular, he would neither know nox care whether the source lay in ES or EM, and even if he did this would certainly not affect his own disposal decision.

99. Cf. Thornton (1802) pp. $116 \mathrm{ff}$.

100. Wicksell (1936) p. xxiii.

101. Kaynes (1954) Pp. 84-5.

102. N.J. Ravanagh and A.A. Walters, The Demand for Monoy in the United Kingdom, 1977-1961, Paper 8 of Johnson (1972) pp. 151-180.

103. Ibid., pp. 159 and 162. Selecting this simplified schema does not do justice to Kavanagh and Walters' whole work, but it is not the intention here to comment on their work in particular, but on the core which is representative of the genre.

104. It is the "hard-core" theory which is meant here. Labour economics in particular has to deal directly with group behaviour, at least that of Trade Unions; nanagerial economics and the sociological approaches to economic development also have an interest in group behaviour. But these sorts of flelds are usually seen as "institutIonal" approaches or as "applied economics", not aivorced from but not integrally part of the hard core theory. Plck up any modern text on value or monetary theory, and see how far group behaviour enters into the formal constructs of the theory. 


\section{FOOTNOTES TO CH. 4}

1. See comments on pp. $101 / 2$ above, with footnotes 81 and 82 , and on p. 227.

2. The general view is surned up by Harrod: " $G$ is a quantity determined from time to time by trial and error, by the collective trials and errors of vast numbers of people. It would be great luck if their collective appraisals caused them to hit precisely upon the value $G_{W^{*}}$ But if they do not do so their expexience will tend to drive them farther and farther from it". (Harrod, 1948, p. 86.)

3. Ste, e.g. "Fundamentally, the flows that are represented in the transactions table are in physical units and the input coefficients represent physical production relations, but in practice they are derived from the value relations recorded in the transactions table. The conceptual gap between physical and value terms is bridged by defining the physiaal unit of each industry's output as being equal to that quantity which can be sold for the money unit." (N.Z. Stats. (1967) Part IV, P. 7.) An approach to the analysis of the physical processes is due to Chenery (1953), but although economists showed some interest in physical measures during the $1950^{\circ} \mathrm{s}$, their work does not appear to have had any significant impact on either the theory or the empirical work in macroeconomics.

\section{Augustinovics (1970).}

5. Hawkins and Simon (1949). Their concluding discussion on p. 248 makes it clear that, while it is not possible to demonstrate as a matter of natural necessity that the conditions must always be met, common sense dictates that economic analysis exclude consideration of technical coefficient matrices for which they are not met.

6. Augustinovics, op.cit., pp. 256-9. 
7. See Culbertson (1968) pp. 227-8. Cf. discussion in section 1.22 above on "defining a product".

8. Chenery (1953) pp. 300-2. 


\section{FOOTNOTES FOR CHAPTER 5}

1. Pp. $156 / 7$.

2. It often makes sense to consider using different deflators for each sector, which suggests that \$ should be treated as a vector rather than as a scalar, and so could not properly be cancelled out in the column sums. On the other hand the monetary unit actually used in transactions is homogeneous for the system, and certainly financial assets and liabilities do not call for sectoral distinction in the unit of measurement. In one sense, this is a dumy problem which appears to exist only because the theory continues to treat a nonintrinsic money as "an invariable standard of value" by the use of deflators; we are trying to use as a unit of measurement of goods and services something whose value can be reasured only in terms of what goods and services it will buy. This used to be well recognised by economists, but the need for quantitative measures of real data aggregable only in money terms, together with the failure to distinguish in the analysis between real and money flows, has led to a fudging over of this notion. The problem disappears in this structure; if the aggregation of real quantities is dealt with by means of some quantity index, different for different industry group, we may without inconsistency treat money both as a means of settlement and as a unit of account as homogeneous to the whole economy.

3. Cf.: "Mathematics receives its confirmation in virtue of the fact that any equation becomes a tautology if numbers, related to one another in the way prescribed by the functions involved, are substituted for the variable elements in 1t.... The equations used in physics must satisfy this requirement too, i.e. they must be valid mathematically before they can hope to be valid physically. But they are confirmed as physical statements in virtue of the fact that they reduce to tautologies, not when the numbers substituted for the variables already have the prescribed functional relation but when they are selected on other grounds." (Caws, 1959, p. 11.) 
4. This is not to deny that the capital cost of the labour force is large, or that the provision of social overhead capital is necessary, or that what government expenditure is used on is important. But it is doubtful how far a particular subset of government expenditure on social needs can be quantitatively related to output, particularly in a fixed proportions type of construct. The cost of an expanding labour force can really be dealt with only as a component of government expenditure exogenous to the private sector flows.

5. This relates to the discussion of "realism" in 1.1, particularly the remarks about the "three senses of unrealism".

6. The idea that the "market clearing price" is always and necessarily arrived at instantaneously without false trading, is of course quite inadmissible unless we can give a rational explanation of how individual transactors arive at one. Within the model structure, the "market-clearing price" would in any case not dispose of the problem since the problem is to leave some inventory unsold.

7. The form of a budget-cum-liquidity constraint could well be along the lines set out in pp. 96.98 above. A constraint in that form need not imply a specific attitude to thrift on the part of households, but may instead reflect the behaviour of firms dealing on hire-purchase, enforced on less thrifty consumers.

8. It will be recalled that consumer motivation, as with other intranodal mechanisms, is exogenous to this model.

9. This directly invokes the idea of sequential ordering of transactors' activities.

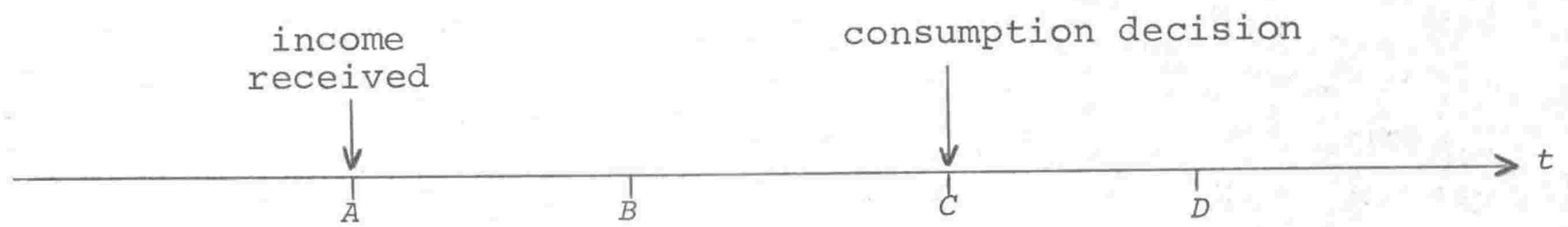


(Footnote 9 continued):

If debt repayment (other than overdraft) is at $B, i . e$. between $A$ and $C$, a monetary constraint could operate at $c$, but clearly this could not happen if debt repayment were not scheduled until $D$, in which case an operative monetary constraint might apply to the debt repayment. Overdraft is a different matter, since if the income received were credited to households' accounts at $A$, overdraft repayment would occur automatically at $A$, and a monetary constraint due to banks being fully loaned up would depend on the other borrowings and repayments between $A$ and $C$. This is not a matter of lags, the intervals $A B, B C$ etc. being undefined.

10. Cf. Strotz (1957, pp. 270-1) and Stone (1964, p. 203).

11. The difficulty of moving from micro, behavioural budget studies to some corcept of a macro consumption function does not deter us here, since it can be resolved without conceptual difficulty by designating several distinct groups of households, each with its own source of income and its own stock configuration including a demand schedule. While that level of detail is not sought here the model structure does provide a means by which the macro effect would arise naturally in the operation of time sequences, in which the aggregate consumption path would arise naturally out of the collective effects of the interactions of these distinct nodes with each other and with other nodes of the system, through the transactions flows.

12. This is not to deny that businesses do attach importance to the money flows in their day to day cash management; but policy decisions usually need to take account of the wider range of variables important to their total financial position. No doubt the "theory of the firm" could do with modification, which would have to be undertaken in any case to fill in the details of intranodal organisation. But that must be left to micro. 
13. Cf. "Before full employment is reached $G$ may have to be reduced owing to the increasing difficulty of transferring labour and other resources to their required uses as employment gets better. If $G_{w}$ is substantially above $G_{n}$, the $G$ curve may intersect the $G_{W}$ curve some time before full employment is reached, thus raking a vicious spiral of depression inevitable at this point." (Harrod, 1948, pp. $89-90$. )

14. Cf. the argument by Hawtrey (1952, pp. 308-310), which leads him to the conclusion that: "A vicious circle of declining demand is started, and traders fail to secure the reduction of stocks which they aim at. The vicious circle is set up only if a contraction of the flow of money is allowed to continue too long. It is not especially characteristic of a contraction initiated by the traditional methods of dear money and credit restriction, but might be an incident of any contraction, however caused, if too severe or too prolonged. If the contraction is started by dear money, it can be ended by cheap money promptly applied." (p. 310; emphasis in original.)

15. This corresponds to the idea of the "Phillips-Samuelson-Solow" curve, but the same effect could be produced by a variety of causal mechanisms. Sequence 2 had inflation, with substantial unemployment, due to pricing practices in the face of a deficiency of demand. In sequence 3 , demand was very strong, but significant unemployment was due to sectoral rigidities. If the PSS effect is meant to convey some sense of an anomaly: i.e. that increased expenditure should cure unemployment but for some inexplicable reason raises prices, then the reasoning depends on rather fine equilibrating responses of labour and consumers to wage and price movements, and presupposes that no intersectoral rigidities exist.

16. Cf. "We do have an economic theory, but it refers to situations in which there is no practical need for theoretical guidance, since the automatism of the system assures that all goes well. 
However, once this automatism begins to fail, scientific prediction turns into an indispensable condition for restoring the viability of the market process. But with the fallure of the automatism the empiriaal basis for such prediction - the regularity of micro- and macro-movements - seems lost.

Can this vicious circle be broken? We have come to understand that on the answer to this question depends more than the scientific status of Economics. What on the surface looks like a problem in methodology really concerns the future of decentralized decision-making in the framework of modern industrialism." (Lowe, 1965, p. 98.)

And: "Stated in the simplest terms the issue is now one of finding a substitute for the impersonal factors of the environment - pressures and resource mobility - a substitute capable of inducing motivational. and behavioural patterns which assure good working order under the changed conditions. Such a substitute can only be a personified force, henceforth denoted as Control." (Tbid, p. 130.) These two quotations do injustice to Lowe, taking him out of context, but this does seem to be roughly where the argument leads us. This has, of course, as little to do with communism as it has with Ricardianism; the concept of "socially necessary labour" is the socialist equivalent to the Walrasian condition (5.11). Both derive from Smith, via Ricardo and the labour measure of value, which has little to do with wage rates as currently determined. 
1. Influenced, it must be acknowledged, by some thoughts from Lowe (1965).

2. Cf. Thornton's view, discussed in footnote 28 to Chapter 2.

3. Although it. is a commonplace of srthodos theory that an initial stinulus or depressant to production must, through derived production demands, be augmented by a real employment mulifplier, the obvious corollary does not seem to be generally realised. Yet by the same logic, the final stages of an expansion of production to the labour celling must continue to generate additional employment opportunities which at the ceiling cannot be taken, and unfilled vacancies necessarily result.

4. This point emerges from the earlier discussion (pp. 68 ff.) of Thornton's exposition.

5. Reference points in the cycles are numbered by aggregation periods backward from the terminal period. Since the system of transactions flows is unbounded in time, we cannot, strlctly, start from a first period. (It is a drawback of simulation that there must be a first period.) The basis of enquiry into malfunctions which requires us to aistinguish primary from secondary phases, so that when we have traced back to a primary source of malfunction its identification marks the limit to how far it is necessary to go back in time searching for prior causes, is conveniently recalled in this way.

6. Cf, footnote no. 14 to Chapter 5.

7. If we need a more detailed account of price-setting situations, Wiles (1956) has provided a framework which is adequate for the purpose. Formal value theory, which like monetary theory knows no monetary nexus, is on that account - whatever its other merits - unusable here. 
1. Some distinguished exceptions are noted in this study.

2. Some terminological confuston could arise if the terms used by Bunge (1964) were carried over into economics with the same connotation that Bunge gives them in the context of physics, since whereas Bunge is speaking of representational theories about unobservables which are needed to explain the rechanisms internal to the black boxes of phenomenological theories, in economics the position is reversed; it is the macroeconomic variables of the black boxes which are unobservable (except in the broad sense that unemployment and price rises may be matters of general experience), and the internal mechanisms provided by transactions flows which are more directly observable, and hence it is the internal mechanisms which are phenomenological. It is to a fuller appreciation of this key point that the later shift of approach in this study is due.

3. This appears to exclude, as a general disturbance, an unacceptably low rate of growth. Yet rates of growth, levels of consumption and conditions of work that would be intolerable by the standards of many modern economies have frequently been tolerated by the system of the time, and it requires some development, of information or of social conscience or of technology, to make what was acceptable no longer acceptablc. In this case, the disturbance is not strictly the low rate of growth, but the realisation, for example, that it need not be so low.

4. The programe listing for run $9 \mathrm{is,}$ for what it may be worth, appended to this study. I regret that I have not found time to give it the tidying-up it needs. 
5. Cf. "In economics we are not, I believe, concerned with any entities that are merely posited; all the entities with which economics deals are, in principle at least, directly observable." (Harrod, 1968, p. 33.)

6. This initial view drew upon the following exposition:

"Any quantitative scientific theory concerning the transactions of a system with its environment may be summed up in the following symbolic relation:

$$
0=M I
$$

Where ' $I$ ' designates either the initial stage of the system concerned or the set of stimuli (input), and ' $M$ ' sumarizes the properties of the box. In black box theories the "mechanism" connecting $I$ and 0 will be left unspecified; that is, 'M' will be just a symbol (e.g., an operator) performing the syntactical linkage among the input data $I$ and the output data 0 . In translucid box theories, on the other hand, 'M' will concern the constitution and structure of the box - in short, 'M' will represent the mechanism responsible for the overt behavior of the box.

Three classes of question can be raised in relation with Equation (1):

(i) The problem of predictions given the input I and the kind of box (i.e., $M$ ), find the output 0 .

(1i) The inverse problem of prediction: given the output $O$ and the kind of box $(i . e ., M)$, find the input $I$.

(iii) The problem of explanation: given the input $I$ and the output 0 , find out the kind of box - i.e., determine $M$. 
(Footnote 6 continued):-

The contrast between representational and nonrepresentatIonal theories does not occur in connection with the first two problems as sharply as with the third one. If only a black box theory is available or wanted, the problem of explanation (iii) will be sulved by cumputing the inverse, $I^{-1}$, of the input since, in accordance with (1), we have

$$
M=O I^{-1}
$$

The completion of this task will coincide with the building of the black box theory; or, if the latter is at hand, the particular question will then be answered. But this is only a first stage in theory construction, and in the applications of the theory if the translucid box approach is adopted, in which the interpretation of $M$ in descriptive terms is wanted. This interpretation involves the hypothesizing of entities that make up $M$, and the assignment of specific (physical, biological, etc.) meaning to all the parameters, otherwise uninterpreted, that usually plague the phenomenological theories.

In other words, a 'mechanism' linking $I$ to 0 is wanted in the translucid box approach." (Bunge, 1964, pp. 238-9.)

7. This refers to the discussion on P. 212, and to footnote 3 to chapter 5 .

8. See above, pp. $57 / 8$.

9. See footnote 16 to chapter 5.

10. See footnote 16 to chapter 1.

11. See pp. $36 \mathrm{ff}$. 
12. "Because statistics is designed to deal with large numbers it is often thought that the difficulty arising from the large number of elements of which complex structures consist can be overcome by recourse to statistical techniques.

Statistics, however, deals with the problem of large numbers essentially by elininating complexity in the sense of a multiplicity of relations between individual elements and deliberately treating the individual elements which it counts as if they were not systematically connected. It avoids the problem of complexity by substituting for the information on the indiviaual elements information on the frequency with which their different properties occur in classes of such elements, and it deliberately disregards the fact that the relative position of the elements in a structure may matter. In other words, it proceeds on the assumption that information on the numerical frequencies of the different elements of a collective is enough to explain the phenomena and that no information is required on the manner in which the elements are related. The statistical method is therefore of use only where we either deliberately ignore or are ignorant of the relations between the individual elements with different attributes, i.e., where we Ignore or are ignorant of any structure into which they are organized. Statistics thereby enables us to regain simplicity and makes the task manageable by substituting a single attribute for the unascertainable individual attributes in the collective. It is for this reason irrelevant to the solution of problems in which it is precisely the relations between individual elements with different attributes thich matter." (Hayek, 1964, p. 339.) 


\section{REFERENCES}

ACKIEY, G.:

Macroeconomic theory, Macmillan, N.Y., 1961.

ACKOFF, R.I.:

Scientific Method, Wiley \& Sons, H.Y., 1962.

AMERICAN ECONOMIC REVIEW, IIII, No. 2, MaY 1963, Pp. 204-236.

(Introduction: F. Machlup.

Papers:

A.G. Papandreou,

E. Nagel.

S. Exupp.

Discussion: G.C. Arohibald.

H.A. Simon.

P.A. Samuelson.)

AMERICAN ECONOMIC REVIEW, LIV, HO. 5, Sept. 1964, pp. 733-739. (Comanication by F. Machlup.

Reply by P.A. Samuelson.)

AMBRICAN ECONOMIC REVIBW, LV, No. 5, Part 1, Dec. 1965, pp. 11511172. (Communtcations: G. Garb.

A.P. Ierner.

G.J. Massey.

Reply:

P.A. Samuelson,)

AUGUSTINOVICS, M.: Methods of International and Intertemporal Comparison of structure, Ch. 13 of A.P. Carter and A. Brody (eds.), Input-output Techniques, North Holland, Amsterdam, 1972.

BAIOGH, T.:

Comments on a paper by Tinbergen and Bos, pp. 180-187.

(J. Tinbergen and H.C. Bos, A Planning Model

for the Educational Requlrements of Economic

Development, O.E.C.D. Study Group on the

Bconomics of Education, The Residual Factor and Bconomic Growth, O.E.C.D., Paris, 1964, pp. $147-169.7$

BAUMOL, W.J.:

The Transactions Domand for Cash: An Inventory TheoretL Approach, Quarterly Journal of Economics, Vol. 66, Nov. 1952, pp. 545-56.

BAUMOL, พ.J.:

Economic Models and Mathematics, Essay 6 of S.R. Krupp, The Structure of Economia science, Englewood Cliffs, Prentice Ha11, 1966. 


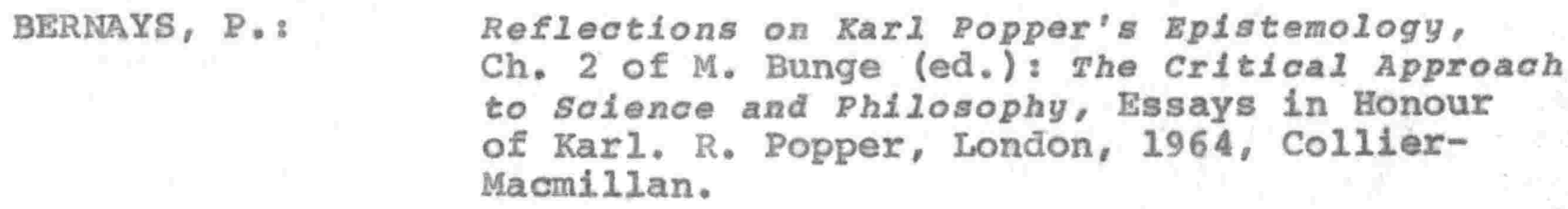

BODENHORN :

EConomic Assumptions in Mathematical Economics, Journal of Political Econony, Feb. 1956.

BRAITHWAITE, R.E.:

Scientific Explanation, Harper \& Row, N.X., 1953. Harper Torchbook edition 1960.

BRIDGMAN, P.W.:

The Logic of Modern Physies, Macmillan, N.Y., 1927.

BRONFENBRENNER, M.: Some Fundamentals in Liquidity Theory, Quarterly Journal of Economics, May 1945.

BRONF ENBRENNER, M. and

MAYER, T. :

Liquidity Functions in the American Bconomy, Econometrica, Vol. 28, Oct. 1960, pp. 810-834.

BRUNNER, K.
and
MELTZER, A. :

BUNGE, M. (ed.):

The Critical Approach to Science and Phllosophy, Free Press, New York, 1964.

CAGAN, $P_{0}$ :

Determinants and Effects of Changes in the stock of Money, 1875-1960, National Bureau of Economic Research, New York, 1965.

CANNAN, E.:

The Meaning of Bank Deposits, Economica, Vol. I, No. 1, 1921.

CAWS, P.:

Definition and Measurement in Physlas, Ch. I of: C.W. Churchman and P. Ratoosh, Measurement, Definitions and Theories, Symposium of American Association for the Advancement of Science, 1956, John Wiley \& Sons, N.Y., 1959. 


\begin{abstract}
CHENERY, H.B.:
CLARISON, G.P.E.:

CLOWER, R.:

CLOWER, R.W.:

COATES, J.B.:

COPPICK, D.J. and

GIBSON, N.J.:
\end{abstract}

CRAMP, A.B.:

CRICK, W.F.:

CROMBIE, A.C.:

CROOME, R.

and

JOHNSON, H.G.:

CROUCH, R.L.:

CULBERTSON, J.M.:
Process and Production Functions from Engineering Data, Ch. 8 of:

W. Leontief, studies in the structure of the American Economy, Oxford University Press, N.Y., 1953.

The Theory of Consumer Demand: A Critical Appraisal, Prentice-Hall Inc., Englewood Cliffs, N.J., 1963.

A Reconsideration of the Microfoundations of Monetary rheory, Western Economic Journal, Dec. 1967, pp. 1-8.

Theoretical Foundations of Monetary Policy, in: G. Clayton and others (eds.), Monetary Theory and Monetary Pollay in the 1970's, Oxford University Press, 1971.

Trade Credit and Monetary Policy, Oxford Economic Papers, March 1967, pp. 116-132.

The Volume of Deposits and the Cash and Llquid Asset Ratios, Manchester School, Sept. 1963.

Control of the Money Supply, The Economic Journal, (76), June 1966, pp. 278-287.

The Genesis of Bank Deposits, Economica (7), 1927, Reprinted in A.E.A. (1951) as Reading 4.

Augustine to Gallieo, Mercury Books, London, 1952 .

Money in Britain 1959-1969, Oxford University Press, Oxford, 1970.

The Inadequacy of "New-Orthodox" Methods of Monetary Control, Economic Journal (74), Dec. 1964, pp. 916-934.

Macroeconomic Theory and stabilisation Pollcy, MeGraw-Hill, N.Y., 1968. 
CUNNINGHAM, W. :

DAVIDSON, P.:

DAY, R.H.:

DEBREU， G. :

ECCLES, J.C.:

EINZIG, P.:
The Relativity of Economic Doctrine, Bconomic Journal, March 1892.

The Importance of the Demand for Finance, Oxford Economic Papers, July 1967, pp. 245253.

Human Perception, Sydney, Wiley \& Sons, 1969.

Theory of Values An Axiomatic Analysis of Economic Equilibrium, Monograph 17 of the Cowles Foundation for Research in Economics at Yale University, J. Wiley \& Sons, N.Y., 1959.

The Neurophyslological Basts of Experience in: M. Bunge (ed.), The Critical Approach to science and philosophy, Collier-Macmillan Itd., London, 1964.

Primitive Money, London, Pergamon Press, 2nd edition, 1966.

FEDERAL RESERVE BANK OF BOSTON: Controll1ng Monetary Aggregates, Monetary Conference, June 1969, Boston, Mass., 1969.

THE BOARD OF GOVERNORS OF THE FEDERAL RESERVE SYSTEM: The Pederal Reserve system, 1963, Washington D.C.

FEIGE, E.I.:

FETTER, F.W.:

FRANCIS, D.R.:

FRIEDMAN, M.:
The Demand for Liguld Assets: A Temporal Cross-section Analysis, Prentice-Hall Inc., Englewood Cliffs, N.J., 1964 .

The Transfer Problem: Formal Elegance or Historlaal Realism? Essay 4 of: C.R. Whittlesey and J.S.G. Wilson (eds.), Essays in Money and Banking in Honour of R.S. Sayers, London, 1968, O.U.P.

Has Monetarism Falled? the Record Examined, Federal Reserve Bank of St. Louis Review, March 1972.

Essays in Positive Economias, Chicago, University of Chicago Press, 1953. 
FRIEDMAN, M.:

FRIEDMAN, M.:

FRIEDMAN, M. :

FRIEDMAN, M. and

HELLER, W.W.:

FRIFDMAN, M.

and

SCHWARTZ, A.J.:

GALILEO, G.:
The Demand for Money: Some Theoretical and Empirical Results, Journal of Political Econony, August 1959.

A Theoretical Framework for Monetary Analysis, Journal of Political Economy, (78), March/ April, 1970, pp. 193-238.

A Monetary theory of Nominal Income, Journal of Political Economy, March/April, 1971.

Monetary vs. Fiscal Policy, W.W. Norton \& Co., N.Y., 1969.

The Stock of Money in the United States 1867-1960, National Bureau of Economic Research, princeton 1963.

Dialogues Concerning Two NeW Sciences, (Translated by Crew and Salvio) Macmilian \& Co., N.Y., 1914.

GEORGESCU-ROEGEN, N.: EConomie Theory and Agrarian BConomies, 0.E.P., Vol. 12, Feb. 1960, pp. 1-40. Reprinted in C. Eicher and I. Witt (eds.), Agriculture in Economic Development, N.X., 1964, MoGraw-Hill.

GINSBURG, N.:

GORDON, D.F.:

GORDON, D.F.:

GROSSMAN, H.I.:
Atlas of Economic Development, University of Chicago Press, 1961.

operational Propositions in Economic Theory, Journal of Political Economy, Vol. $63,1955$.

The Role of the History of Economis Thought in the Understanding of Modern Economio Theory, American Economic Review (55/2), May 1965, pp. 119-127.

Was Keynes a "Keynesian"? A Review Article, Journal of Economic Literature, Vol. $\mathrm{x}$, No. 1, March 1972, pp. 26-30. 
GRUNDBERG， E。:

GURLEY, J.G. and

SHAW, E.S.:

HAHN, F.H.:

HARRIS, E.:

HARRIS, E.:

HARRIS, L.:

HARRIS, L.:

HARROD, R.F.:

HARROD, R.F.:

HAWKINS, D. and

STMON, H.A.:
The Meaning and Scope and External Boundarles of Economics, Essay 10 of: S.R. Krupp (ed.), The Structure of Economic Sclence, Englewood Cliffs, N.J., Prentice-Hall, 1966.

Money in a Theory of Finance, The Brookings Institution, Washington D.C., 1960.

Some Adjustment Problems, Econometrica, (38/1), Jan. 1970, pp. 1-17.

Fundamentals of Philosophy, George Allen and Unwin Ltd., London, 1969.

Hypothesis and Perception - the roots of scientific method, George Allen and Unwin Lit... London, 1970.

Regularities and Irregularities in Monetary Economics, essay in: C.R. Whittlesey and J.S.G. Wilson (eds.), Essays in Money and Banking in Honour of R.S. Sayers, Oxford University Press, Oxford, 1968.

Professor Hicks and the Foundations of Honetary EConomics, Economica, May 1969.

Towards a Dynamic EConomics, Macmillan, London, 1948.

What is a Model? in: J.N. Wolfe (ed.), Value, Capital and Growth, Edinburgh University Press, 1968. Reprinted as essay 2 of: S. Mittra, Dimensions of Macroeconomies, Random House, N.Y., 1971.

Note: Some Conditions of Macroeconomic Stab111ty, Bconometrica, Vol. 17, 1949, pp. 245-8.

HAWTREY, Sir R.G.: Capital and Employment, Longmans, London, 1952 (2nd edition). 
HAYEK, F.A.:

HAXEK, F.A.:

HEINEMANN, F.H.:

HICKS, J.:

HIGGINS, B.:

HOCHBERG, J.E. :

HOLLAND, E.P. and

GILLESPIE, R.W.:

HYDE, D.M.G.:

INHELDER, B. and PIAGET, J.:
Monetary Theory and the Trade Cycle, trans. N. Kaldor and H.M. Croome, Cape, London, 1933.

The Theory of Complex phenomena, in: M. Bunge (ed.), The Critical Approach to science and philosophy, Collier-Macmillan Ltd. , Iondon, 1964.

Verités de Ralson et Verités de Fait, Library of the Tenth International Congress of Philosophy, Vol. I, 1948, Amsterdam, pp. 629-632. [A1so in revised form in: Heinemann, F.H., Truths of Reason and Truths of Fact, The Philosophical Review, Vol. 57, 1948 , pp. 458-480.]

Critical Essays in Monetary Theory, Oxford University Press, Oxford, 1967.

Economic Development, Constable \& Co. Itd., London, 1959.

Perception, Prentice-Hall, Englewood Cliffs, N.J., 1964.

Experiments on a simulated underdeveloped Economy, M.I.T. Press, Cambridge, Mass., 1963.

Plaget and Conceptual Development - with a cross-cultural study of number and quantity, Holt, Rinehart and Winston, Iondon, 1970.

The Growth of Logical rhinking - from Chlldhood to Adolescence, Basic Books Inc., U.S.A., 1958.

INTRILIGATOR, M.D.: Mathematical optimization and EConomic Theory, Prentice-Hall, Englewood Cliffs, N.J., 1971.

IPSEN, D.C.: Units, Dimensions and Dimensionless Numbers, McGraw-Hill Book Co. Inc., N.Y., 1960. 
JOHNSON, H.G.

JOHNSON, H.G.:

JOHNSON, H.G.:

JOHNSON, H.G.:

JOHNSON, H.G.:

KEYNES，J.M.:

KEXINES, J.M.:

KOOPMANS, T.C.:

KOOPMANS, T.C.:

RORNAI, J.:

KUHN, T.S.:

KUHN, T.S.:

LAIDLER, D.E.W.:
Monetary Theory and Policy, American Economic Review, (52), June 1962, pp. 33584, reprinted as Chapter 1 of Thorn (1966).

Recent Developments in Monetary Theory A Commentary, Ch. III of: D.R. Croome and H.G. Johnson, Money in Britain 1959-1969, O.U.P., Lonđon, 1970.

Macroeconomics and Monetary Theory, GrayMi1ls Publishing Ltd., London, 1971.

The Keynesian Revolution and the Monetarist Counter-Revolution, American Economic Reviev, Vol. IXI, May 1971, pp. 1-13.

Readings in British Monetary Economics, Oxford University Press, London, 1972.

A Treatise on Money, Macmillan, Iondon, 1930.

The General Theory of Erployment, Interest and Money, Macmillan, London, reprinted 1954.

Heasurement without rheory, Review of Economics and Statistics, Vol. 29, 1947.

Three Essays on the state of Economle selence, McGraw-Hil1, N. Y. 1957.

Anti-Equilibrium, Amsterdam, North-Holland, 1971.

The Function of Dogma in Sclentific Besearch, Ch. 11 of A.C. Crombie (ed.), scientific Change, Symposium on the History of Sclence, Eleinemann, London, 1963.

The structure of Solentifle Revolutions, International Encyclopedia of Unified Science, Vol. II, No. 2, Chicago, University of Chicago Press, 2nd edition, 1970.

The Dersand for Money, International Textbook Co., Scranton, Penn., 1969.

Pul1 Cost and optimal Price, Universitetsforlaget, Bergen, 1969. 


\begin{abstract}
LEIJONHUFVUD, A.: On Keynesian EConomics and the Economics of Keynes - A study in Monetary Theory, Oxford University Press, N.Y., 1968.
\end{abstract}

LEONTIEF, W.: LEWIS, W.A.:

LOASBY, B.J.:

LOWE, A.:

MACHLUP, F.:

MALKIEL, B.G.:

MARGENAU, H.:

MARGENAU, H.:

MARGENAU, H.:

MARGENAU, H. :

MARGET, A.W.:

MARTY, A.L.:
Theoretionl Assumptions and Nonobserved Facts, Anerican Bconomic Review, Jan. 1972.

Bconomic Development with Vnlimited Supplies of Labour, Manchester School, May 1954.

Hypothesis and Paradigm in the rheory of the Firm, Economic Journal, Dec. 1971.

On Economic Knowledge, Harper \& Row, N.X., 1965.

Operational Concepts and Vental Constructs in Model and rheory Formation, Giornale degli economisti e annale di economia, N.S., Vol. 19, Sept./Oct. 1960, pp. 553-582.

The Term Struature of Interest Rates, Princeton University Press, 1966.

Physics, Ch. III of L.L. Woodruff, (ed.), The Development of the Sciences, Yale University Press, New Haven, 1941.

Philosopilcal Problems Concerning the Heaning of Heasurement in Physics, Ch. 8 of C.W. Churchman and R. Ratoosh, Measurement, Definitions and rheories, Wiley, W.Y., 1959.

Open vistas, Yale University Press, New Haven, 1961.

What is a theory? Issay 2 of: S.R. Krupp (ed.), The structure of sconomic Sclence, Prentice-Hall, Englewood Cliffs, N.J., 1966.

The Theory of Prices, reprinted 1966 by Augustus $\mathrm{K}$. Kelley, K. Y.

Gurley and shaw on Money in a Theory of Finance, Journal of Political Econony, Eebruary 1961. 
MASON, W.E.:

MASSEL, M.S.:

MEADE, J.E.:

MEIGS, A.J. and

WOLMAN, W.:

MEISEIMAN, D.:

MELTZER, A.:

MIILIER, M.R.:

MORGENSTERN, $\mathrm{O}$ :

MUSGRAVE, A. E.:

NAGEL, E.:

NAGEL, E.:

NEWLXN, W.T.:
Clarification of the Monetary standard, Pennsylvania State U.P, 1963.

Competition and Monopoly, Legal and Economid Issues, The Brookings Institution, Washington, 1962.

The Amount of Money and the Banking system, Economic Journal, March 1934, pp. 77-83.

Central Banks and the Money Supply, Federal Resexve Bank of st. Louls Review, Aug. 1971.

The rexm Structure of Interest Rates, Prentice-Ha11, Englewood C11ffs, 1962.

The Demand for Money: The Evidence from the Time Series, The Journal of Political Economy, Vol. 71, June 1963.

Sense and Symbol - A Textbook of Human Behavloural soience, Staples Press, U.K., 1969.

On the Accuracy of Economic Observations, Princeton University Press, Prínceton, N.J. 1963.

The Role of $\mathrm{Exp}$ eriment in the Chamiaal Revolution, Chemistry in N.Z., Journal of the N.Z. Institute of Chemistry, $(36,5)$ Oct. 1972, PP. 151/162.

The struoture of science, Routledge and Kegan Paul, London, 1961.

Assumptions in Economic wheory, A.E.R., May 1963, pp. 211-219。

The Supply of Money and 1ts Control, Economic Journal, Vol. LXXIV, No. 294, June 1964, pp. 327-346. 
The Logic of the Sciences and the Humant ties, Macmillan, N.Y., 1948.
NORTHROP, F.S.C.:

PAPRATDREOU, A.G.:

PATINKIN, D.:

PERLMAN, M. :

PIAGET, J.:

PIGOU, A.C.:

POPPER, K.R.:

PRZELECKI, M.:

$R A O, V \cdot K \cdot R \cdot V \cdot:$
PAP, A.:
N.Z, DEPARTMENT OF STATISTICS, Inter-Industry study of the New Zealand Economy 1959-60, Wellington, 1967.
Are Physical Magnitudes operational1y Definable? Ch. 9 of C. W. Churchman and P. Ratoosh, Measurement, Definitions and Theorles, Symposium of A.A.A.S. 1956, John Wiley \& Sons, N.Y., 1959.

Bconoxies as a science, J.B. Lippincott \& Co., Chicago, 1958.

Money, Interest and Pxices - An Integration of Monetary and Value rheory, Harper and RoW, N.Y., 1965.

The Roles of Money in an EConomy and the optimum Quantity of Money, Economica, August 1971.

Money, Wealth, and Eoonomic Theory, Macmillan, N.X., 1967.

The Mechanisms of Perception, Routledge and Kegan Paul, 1969.

The Value of Money, Quarterly Journal of Economics, (32), Nov. 1917, pp. 38-65. Reprinted in A.E.A. (1951) as Reading 10.

Confectures and Refutations, Routledge and Kegan Paul, London, 1963.

The Iogla of Implrical Theories, Routledge and Kegan Paul, London, 1969.

Investment, Income and the MuItiplier in an Underdeveloped Bconomy, Indian Economic Review, Feb. 1952. Reprinted in:

A.N. Agarwala and S.P. Singh, the Economles of Underdevelopment, London, 1958, Oxford Univerฐiry Press, pp. 205-218. 
ROBBINS, L,:

RICARDO, D.:

ROBERTSON, D, H.

(Sir Dennis) :

ROBINSON, J.:
An Essay on the Nature and signiflance of Economlo Sulence, London, Macmillan, 2nd ed., 1935.

On the Principles of Political Economy and Taxation, Vol. I of: P. Sraffa (ed.), The Works and Correspondence of David Rleardo, Cambridge University Press, 1951.

A Hote on the wheory of Money, Economica (13), 1933, pp. 243-47. Reprinted in A. E. A. (1951) as reading 9 .

The second Crisis of Economie Theory, Richard T. Ely Lecture, pub. A.E.A. (1972), The Second Crisis of Economic theory, pp. 1-10.

ROTWEIN, E. (ed.): David Hume, Writings on Economias, Nelson, Edinburgh, 1955.

ROTWEIN, E.:

On the Methodology of Positive Economics, Quarterly Journal of Econoralas, Vol. 73, 1959, pp. 554-575.

SAMUELSON, P.A., HANCOCK, $\mathrm{R}$.

and WALIACE, R.: EConomfes: Australlan Edition, 1970, MeGrawHill, sydney.

SCHOEFFLER, S.: The Faliures of Economies, Cambridge, Mass., Harvard University Press, 1955.

SCHOENMAN, J-C,: An Analog of Short-Pexlod Economic Change, Stockhelm, Almqvist and Wiksell.

SCHUMPETER, J.A.: History of EConomic Analysis, Oxford University Press, N.Y., 1954.

SERRS, D.:

The Initeations of the spealal Case, Oxford Bulletin of Economics and Statistics, May 1963.

SERPEII, R. :

How Perceptlon Differs Among CuItures, New Society, Vol. 20, No. 508, 22 June, 1972, pp. 620-623. 
SINGER, E.M.:

Antitrust Economics - Selected Legal Cases

and Eoonomic Models, Prentice-Hall Inc.,

New Jersey, 1968.

SMITH, W.L.:

On Some Current Issues in Monetary Economlas,

An Interpretation, Journal of Economic

Literature, $(8 / 2), 1970, \mathrm{pp}, 767-782$.

Symposium on operationalism: Scientific Monthly, Vol. 79, No. 4, October 1954, A.A.A.S., Lancaster, Pa.,

pp. 209-231.

STONE, R., BROWN, A.

and

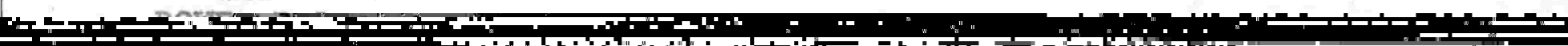
10.

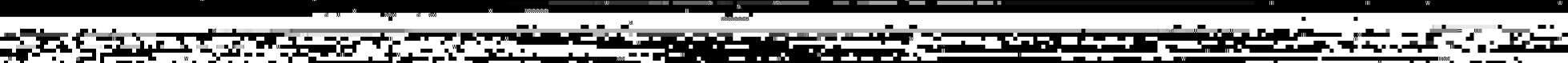

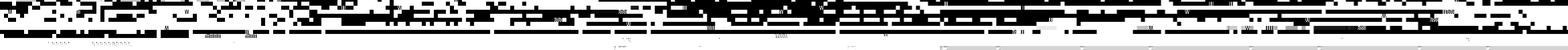

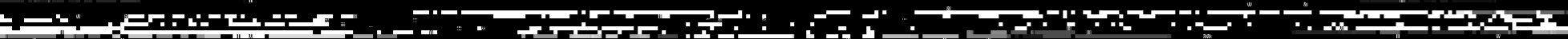
1

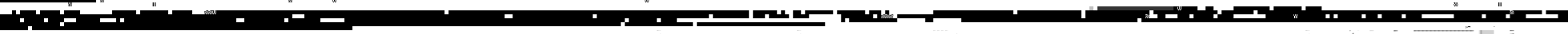

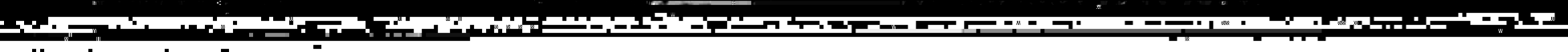

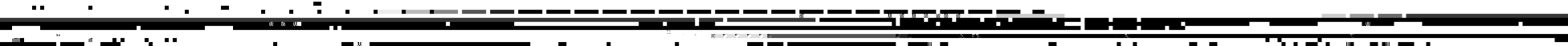

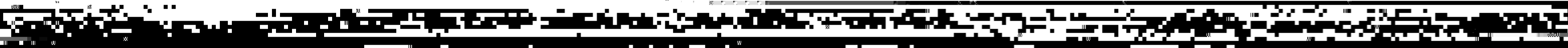

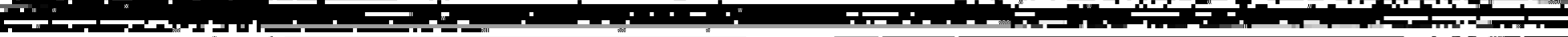

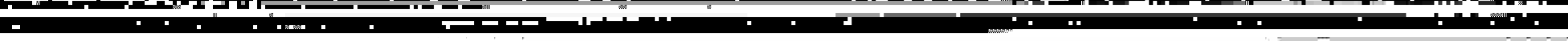

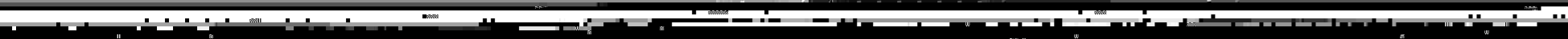

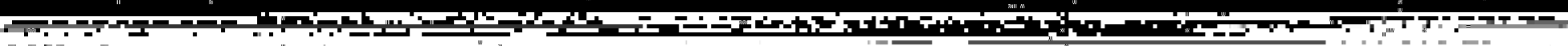
$=$

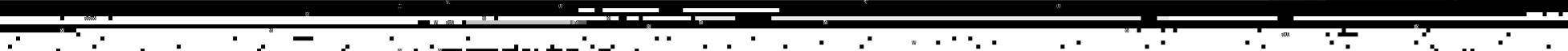
$\therefore$ : Pre Prin

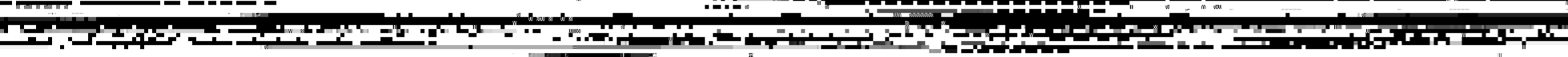

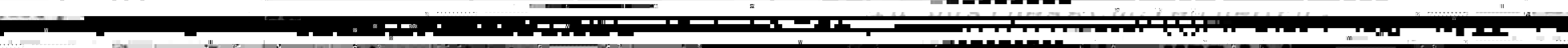

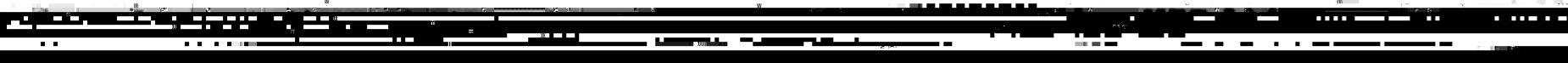

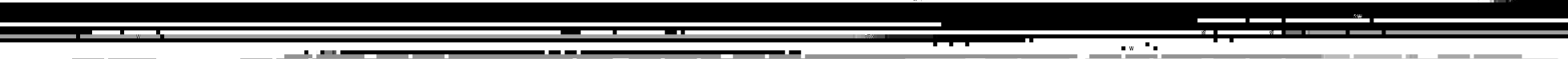

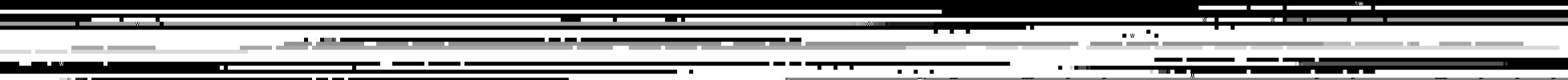
. : 달

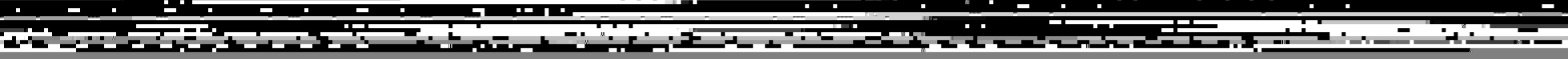


WICKSELI, K. :

TOBIN, J.:

WEINTRAUB, S.:

WILES, R.J.:

WILES, P.J.:

YEAGER, I.B.:

YOURGRAU, W.:
Interest and prices, trans. R.F. Kahn, in Reprints of Economic Classics Series, N.Y., 1965, Augustus M. Kelley.

Liquidity Preference as Behavlour Towards Risk, Review of Economic Studies, Vol. 25, Feb. 1958 , pp. 65-86.

Keynes and the Monetarists, Canadian Journal. of Economics, Eeb. 1971, pp. 37/49.

Price, Cost and output, Blackwe11, Oxford, 1956.

Pilkington and the Theory of Value, Economic Journal, 1963.

Essential properties of the Medium of Exchange, Kyklos, Vol. XXI, No. 1, pp. 45-68.

On the Reality of Blementary Particles, in

M. Bunge (ed.): The Critical Approach to science and Philosophy, Collier-Macmillan Ltd. , London, 1964. 

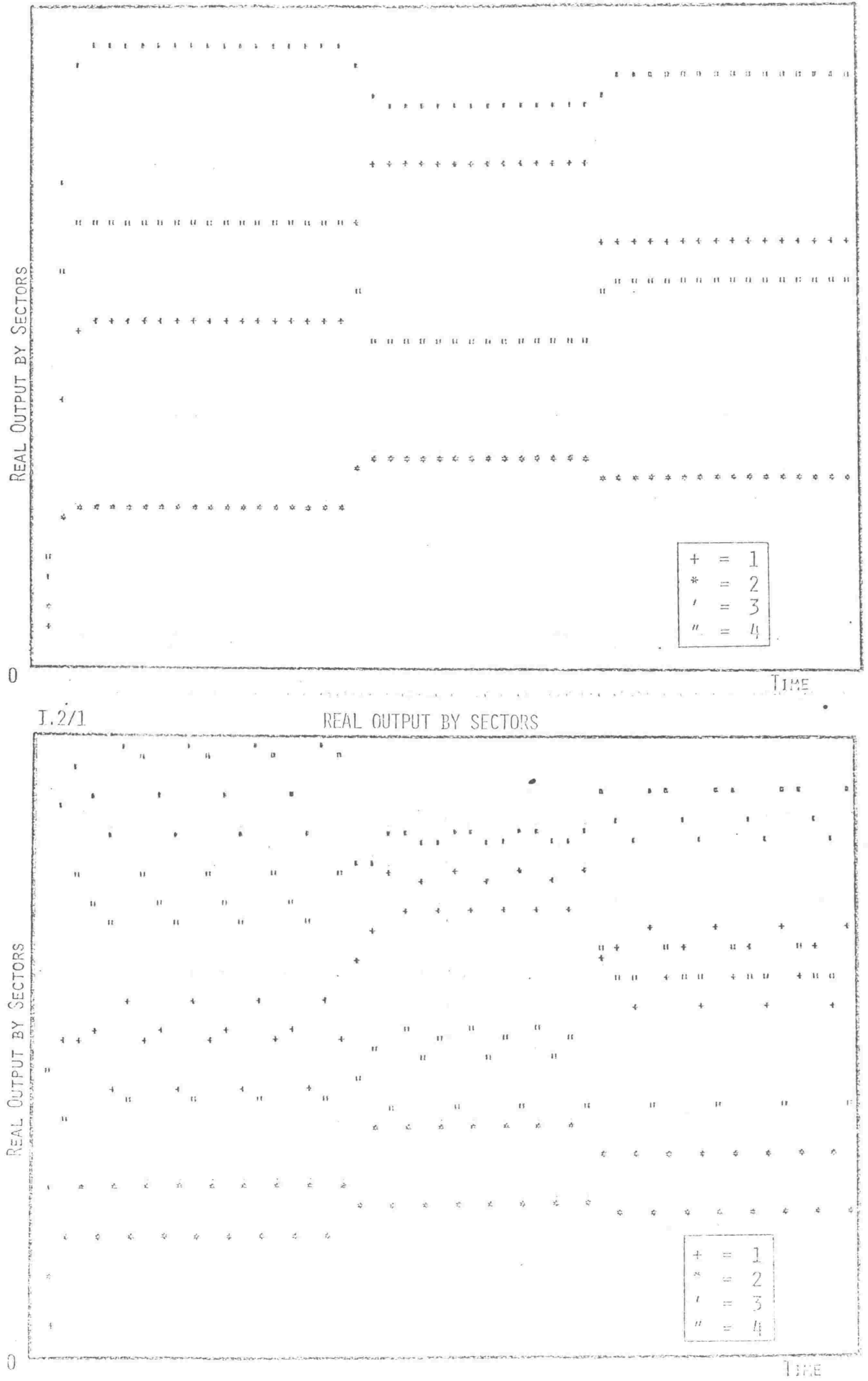


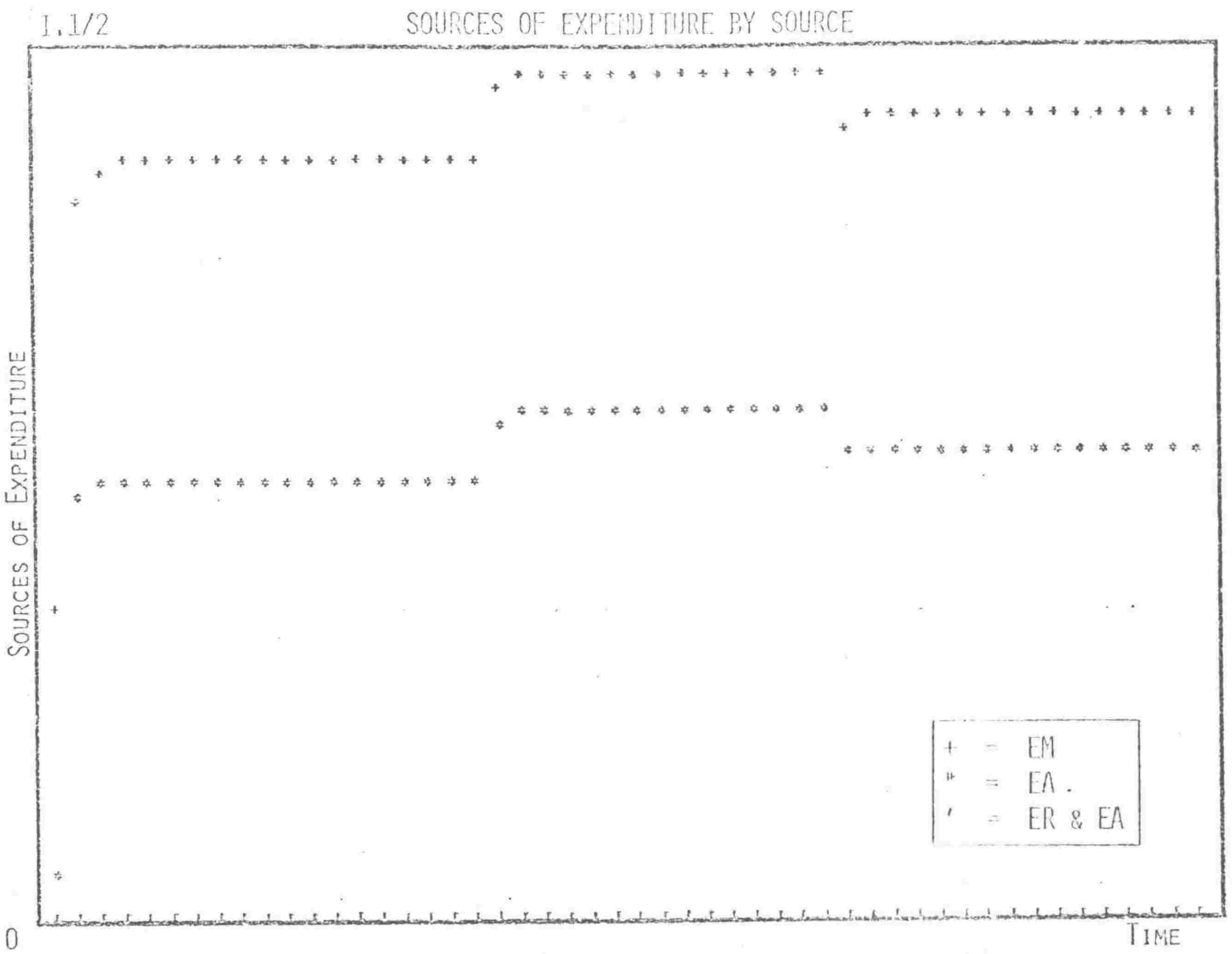

I. I/3 DEPOSIT LIABILITIES BAWS IEL AND DI MII

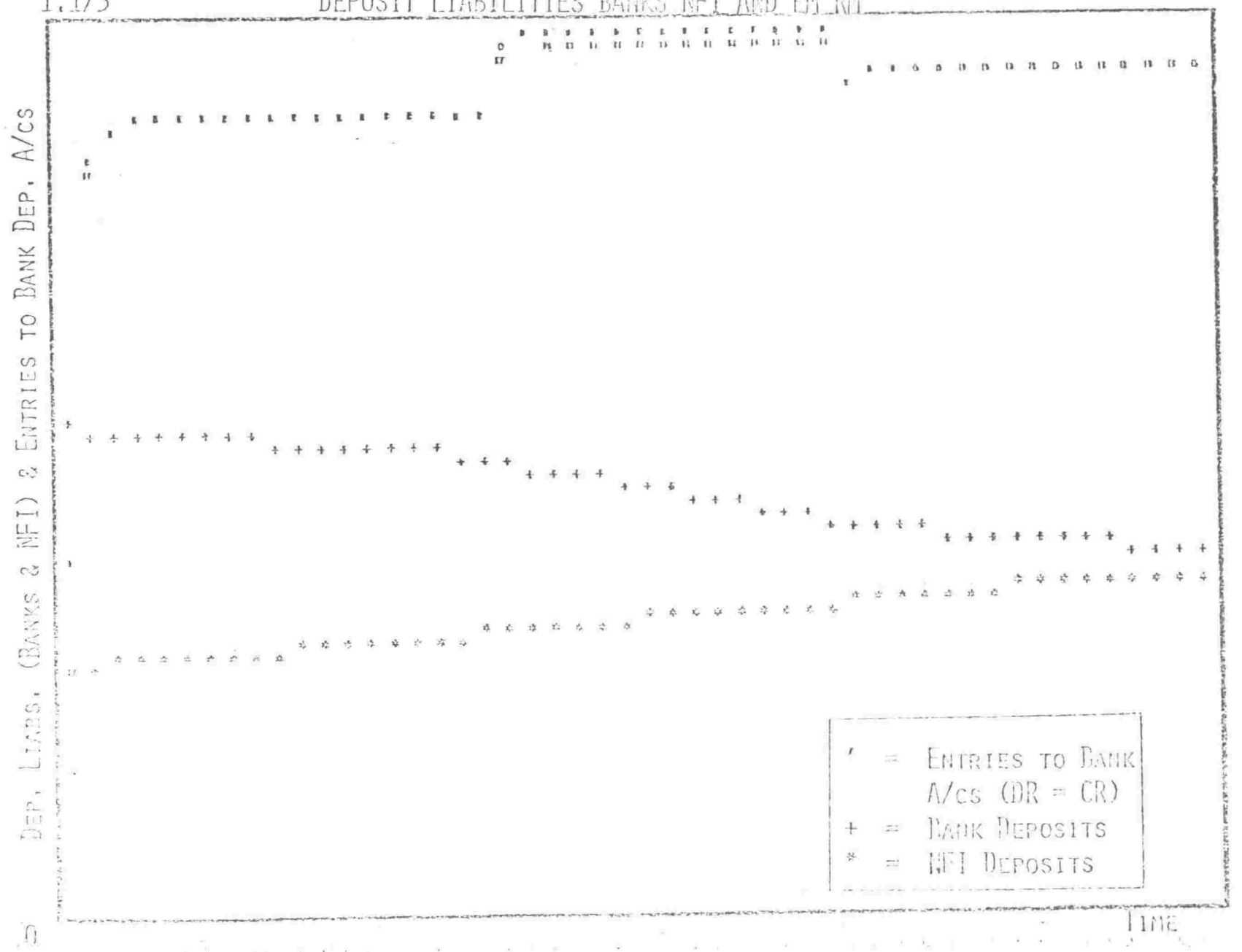



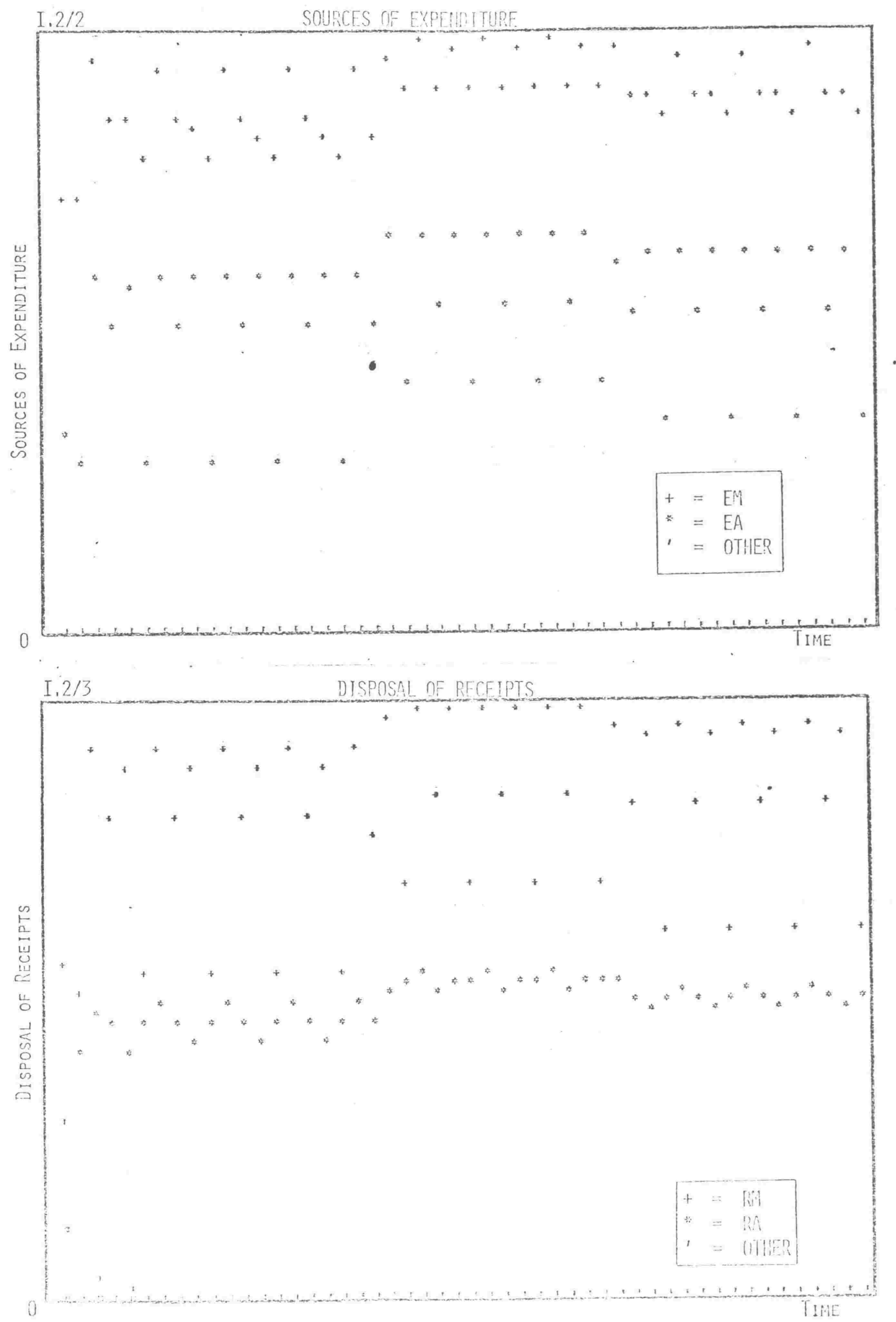

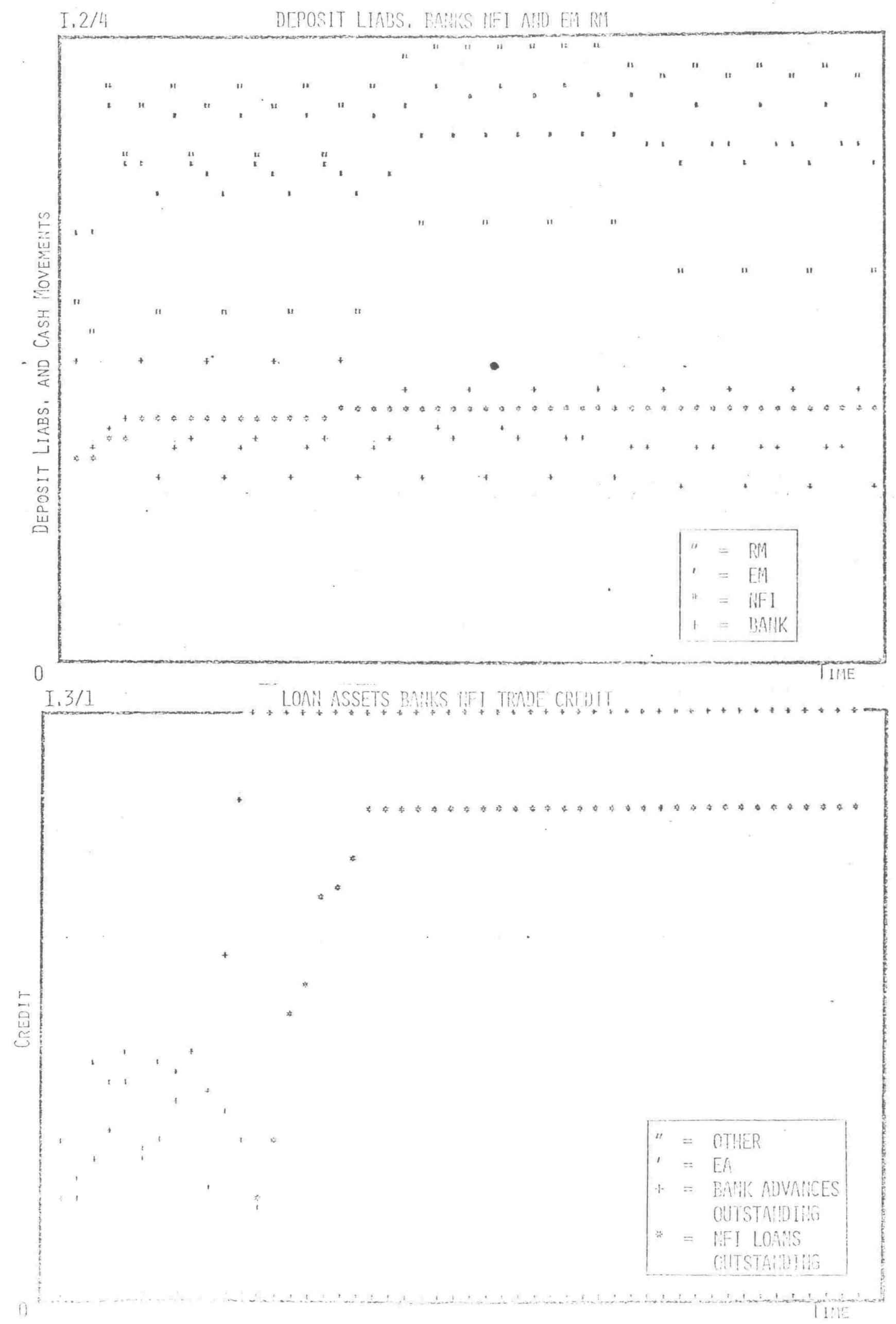

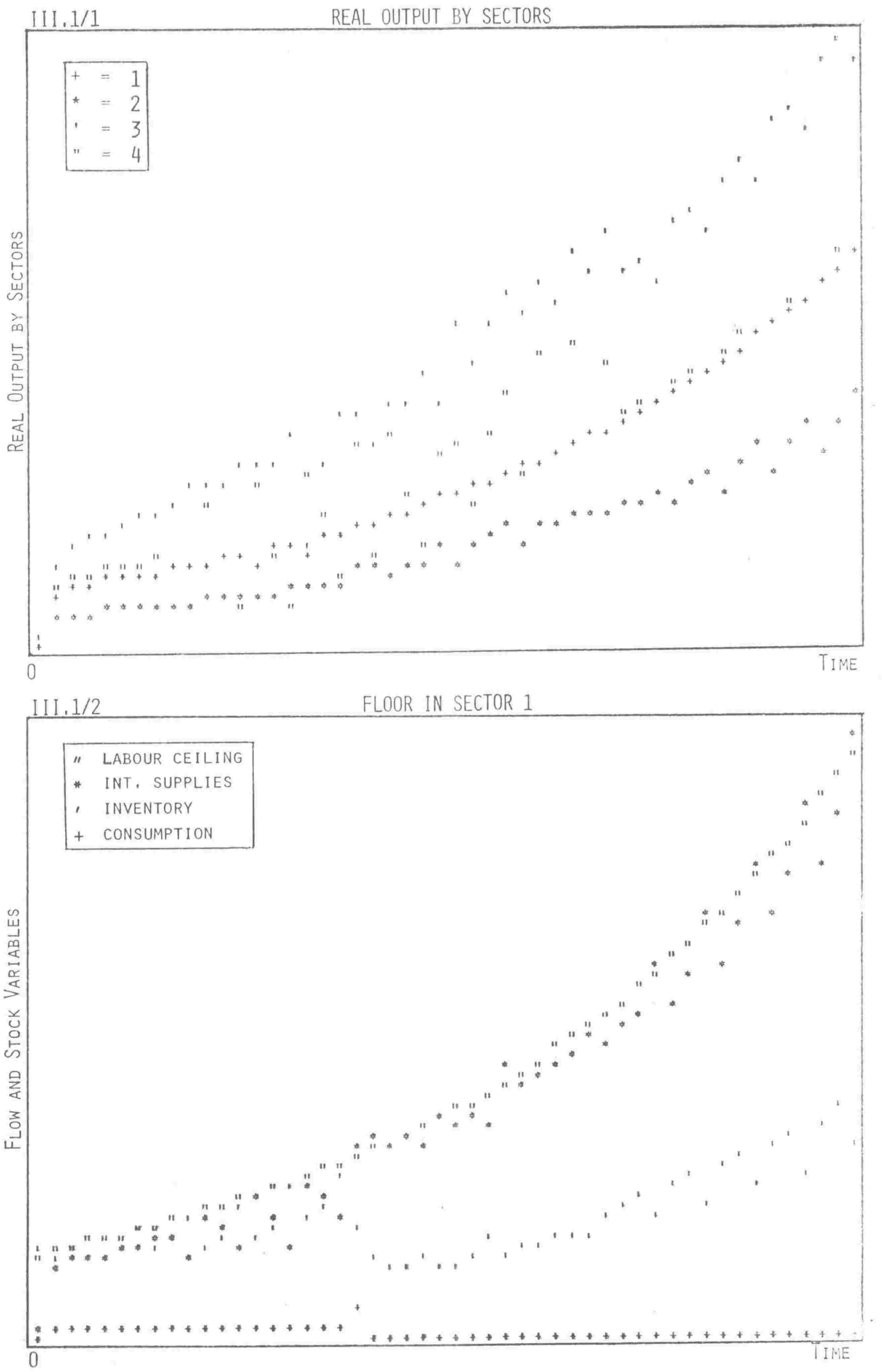

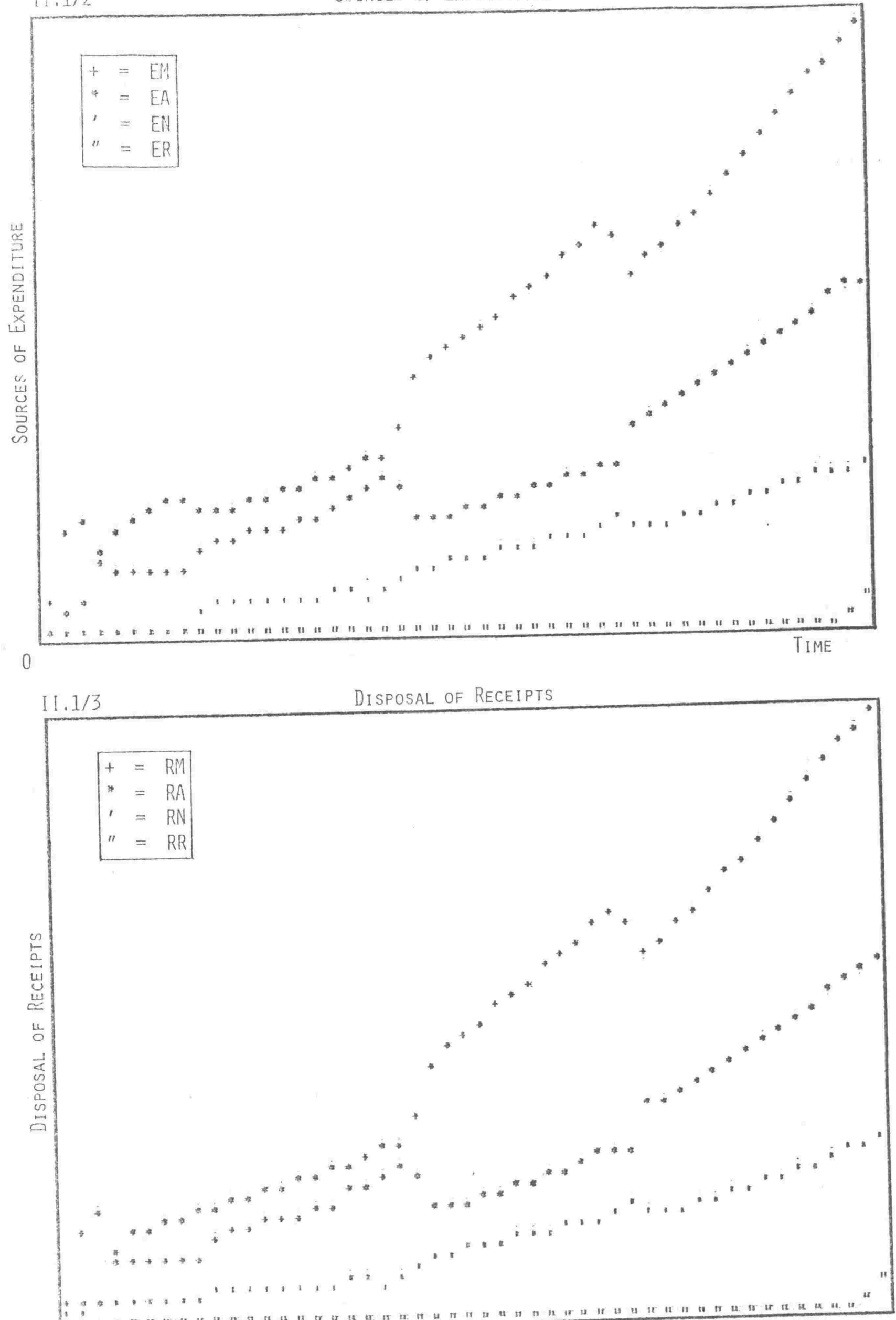
$\begin{aligned} & *=\text { NFI LOANS } \\ &=\text { DRAWINGS } \\ & \text { ON O/DFT } \\ &+\quad= \text { BANK ADVANCES } \\ & \text { OUTSTANDING } \\ &=\text { TRADE CREDIT }\end{aligned}$

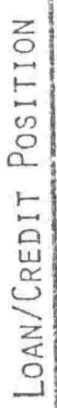

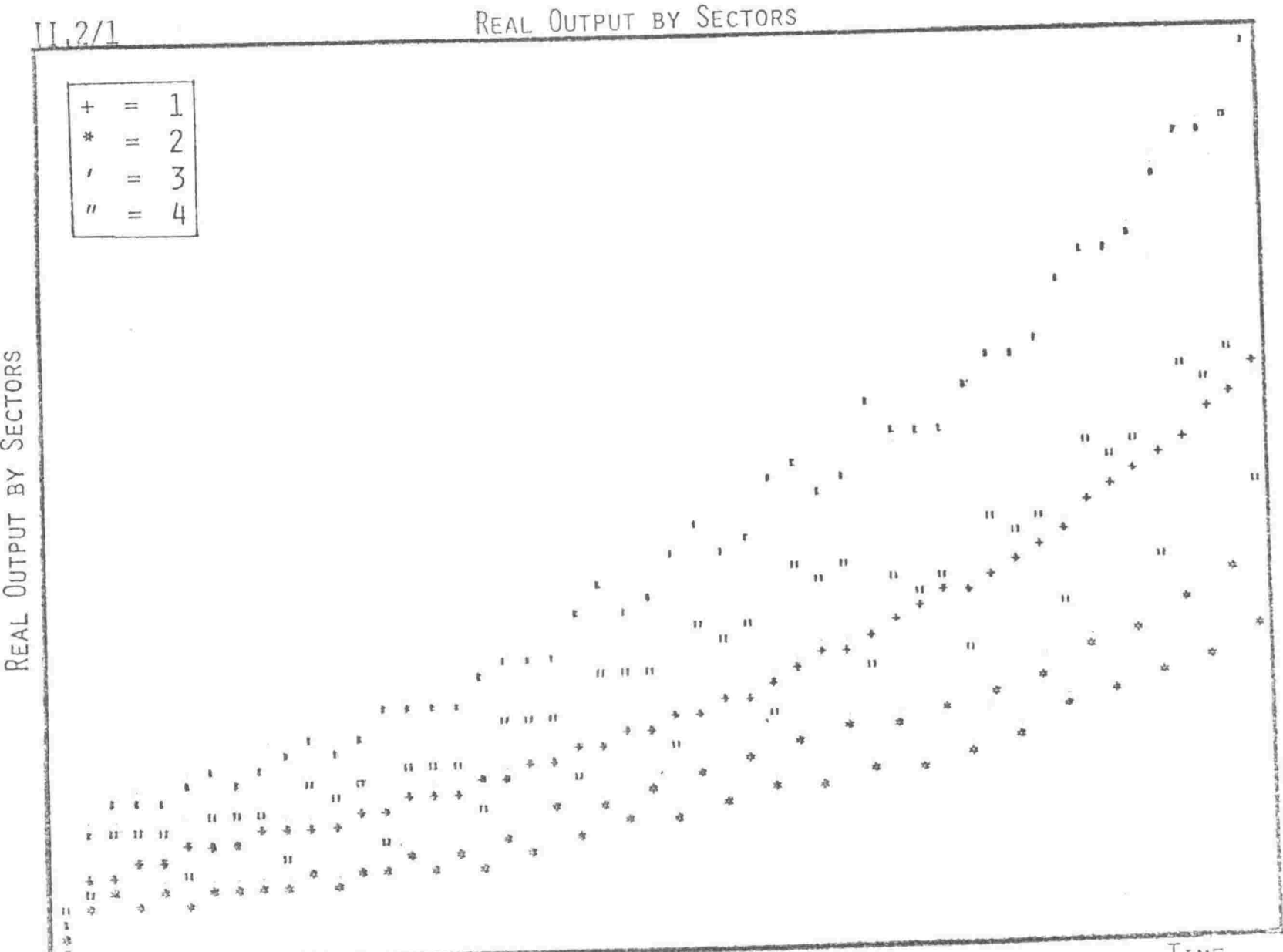




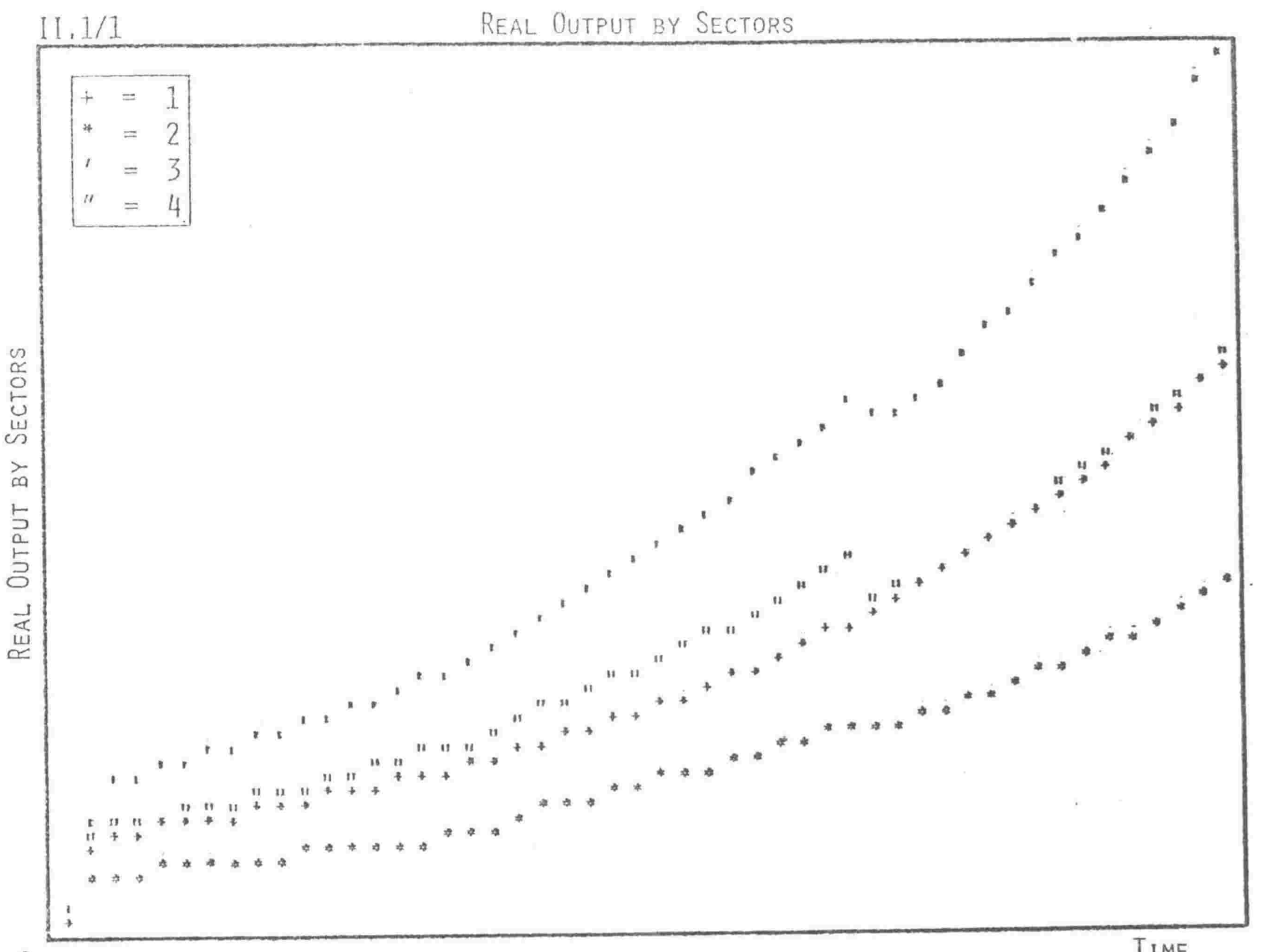

0

SOURCES OF EXPENDITURE

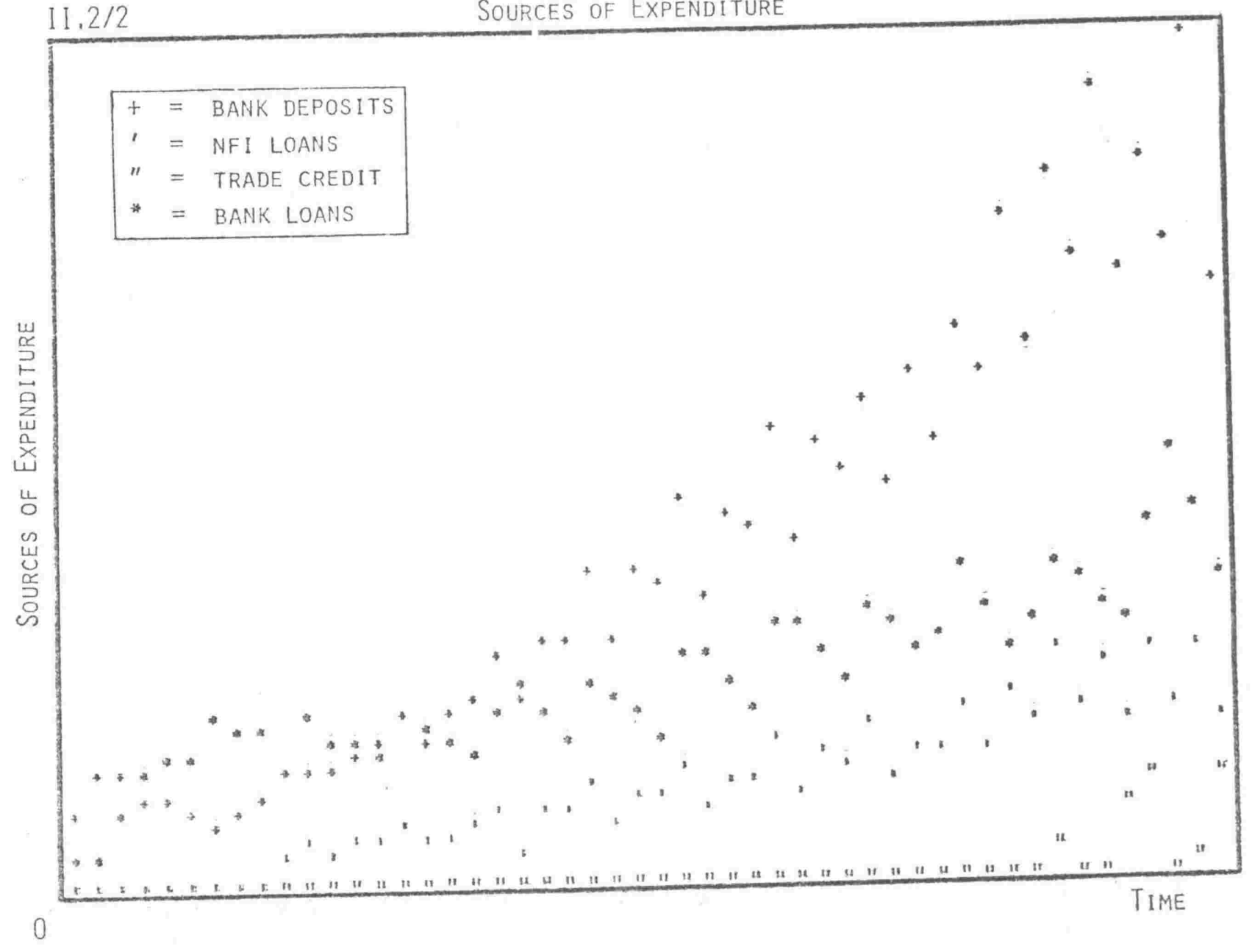




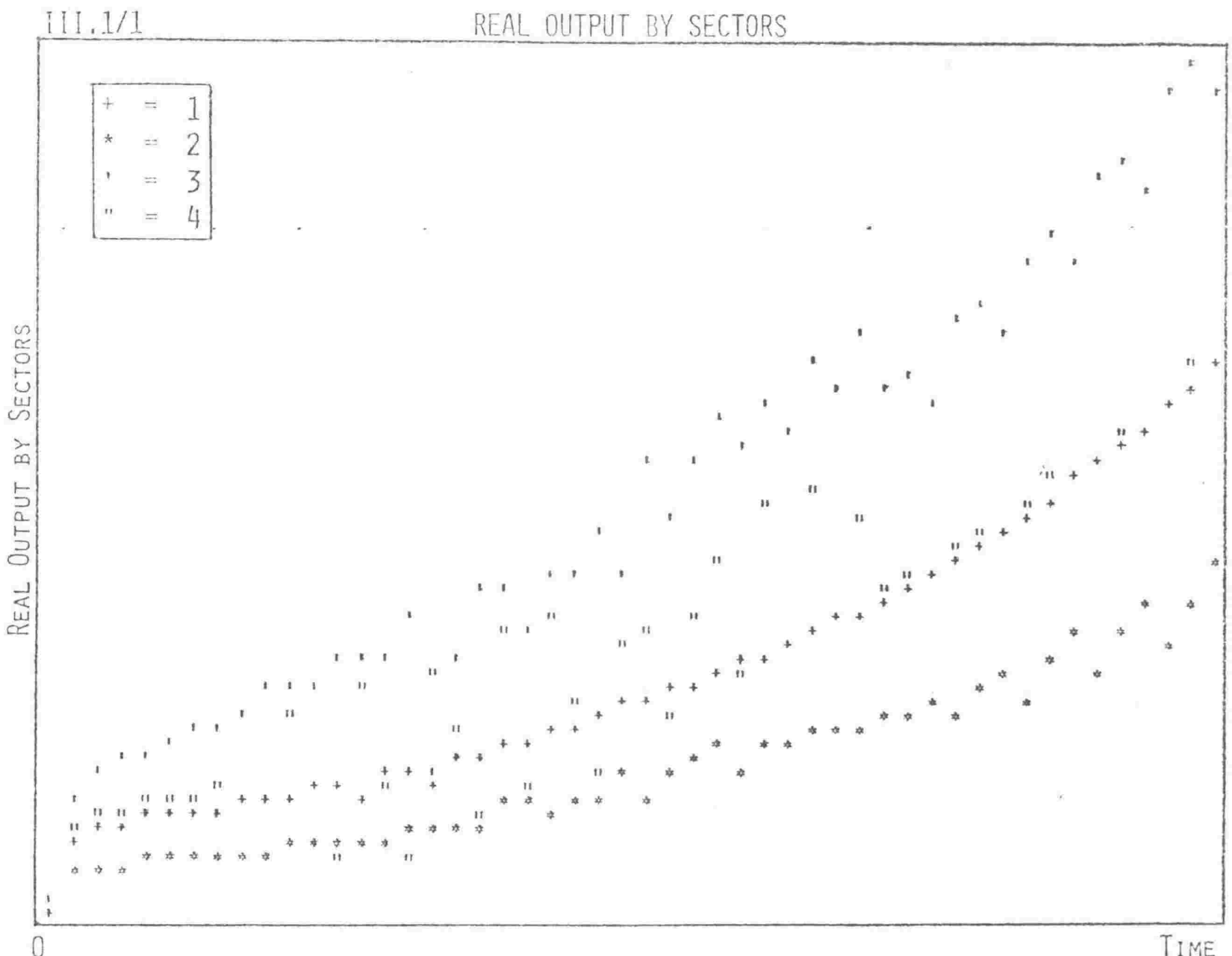

TIME

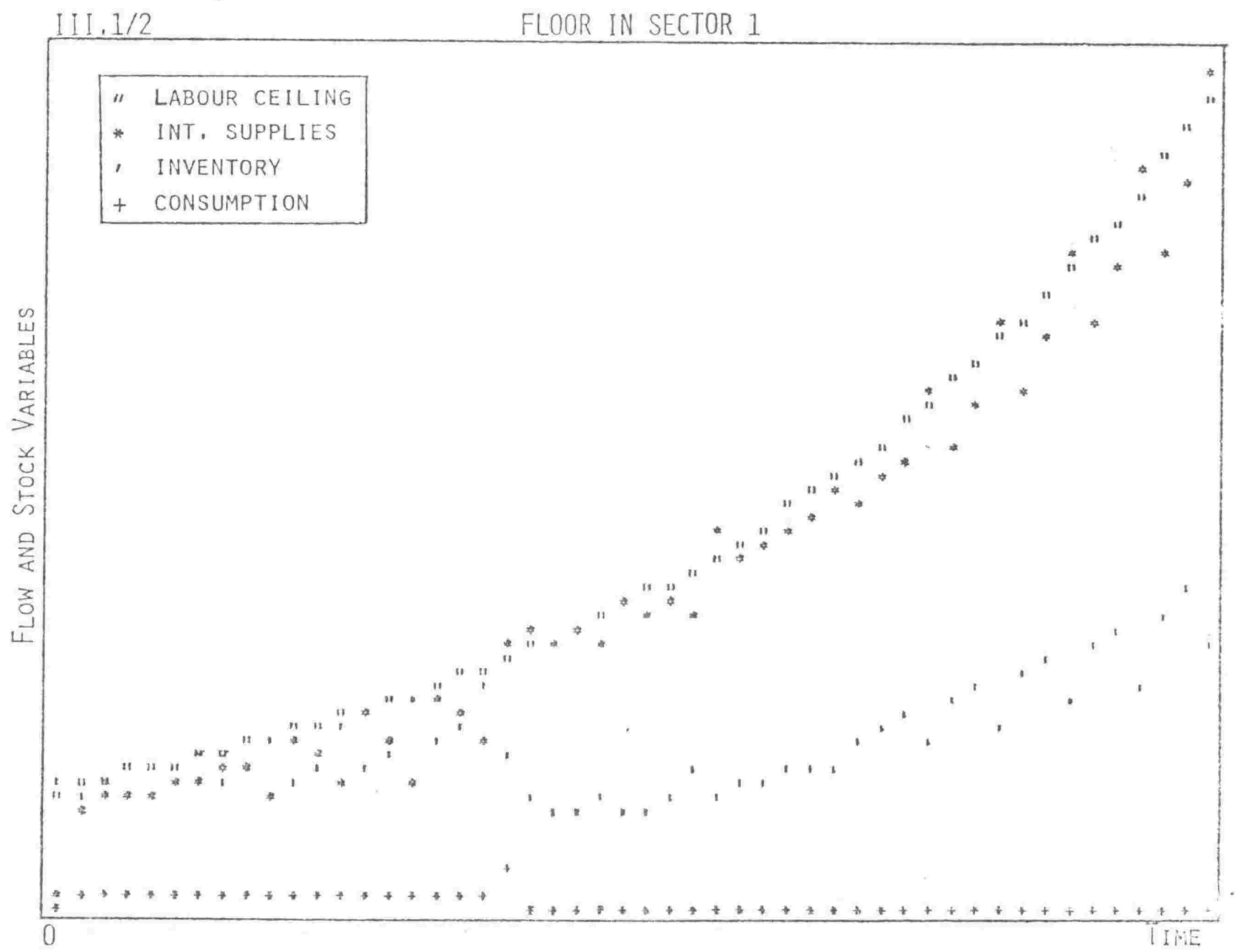



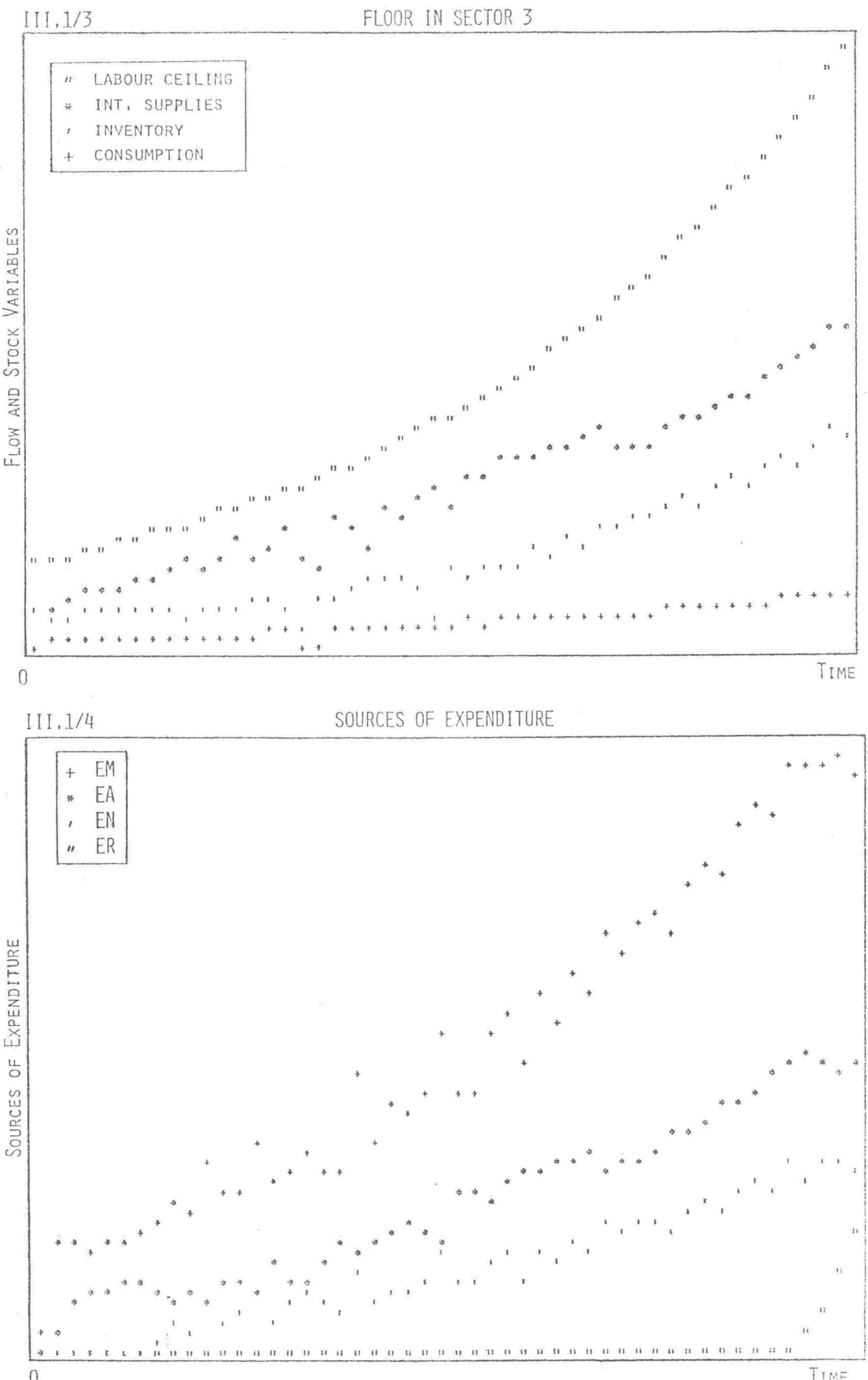

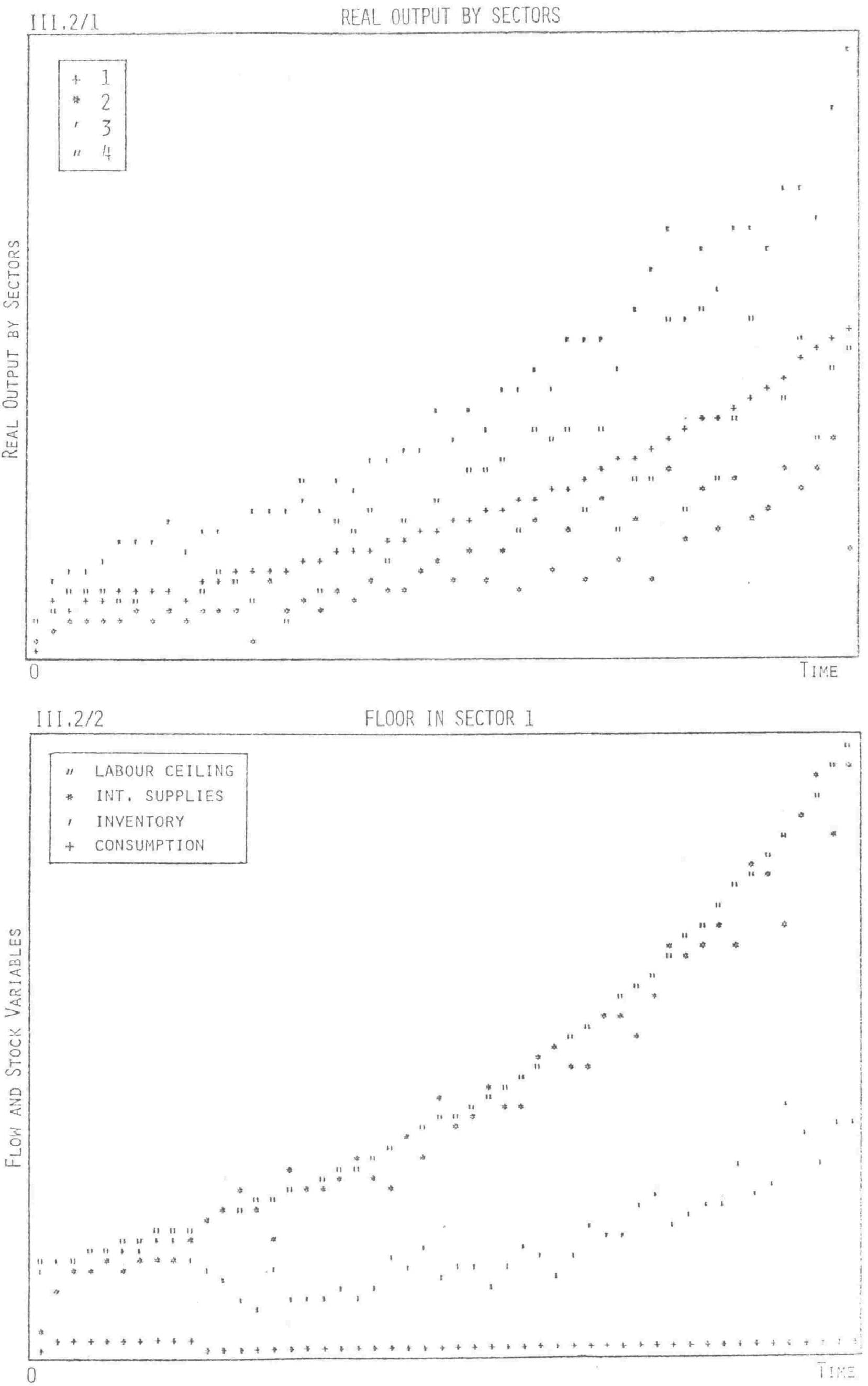

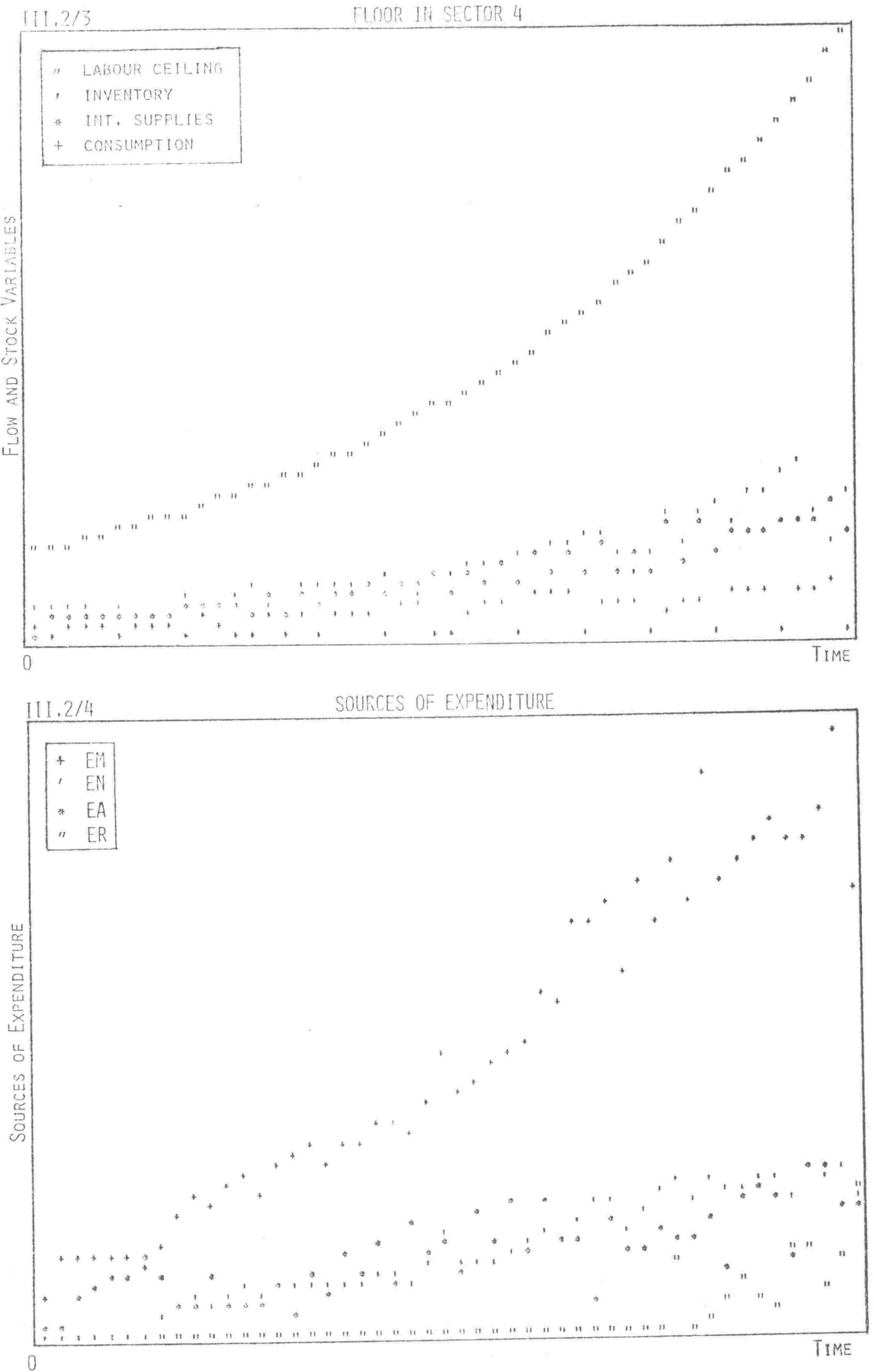

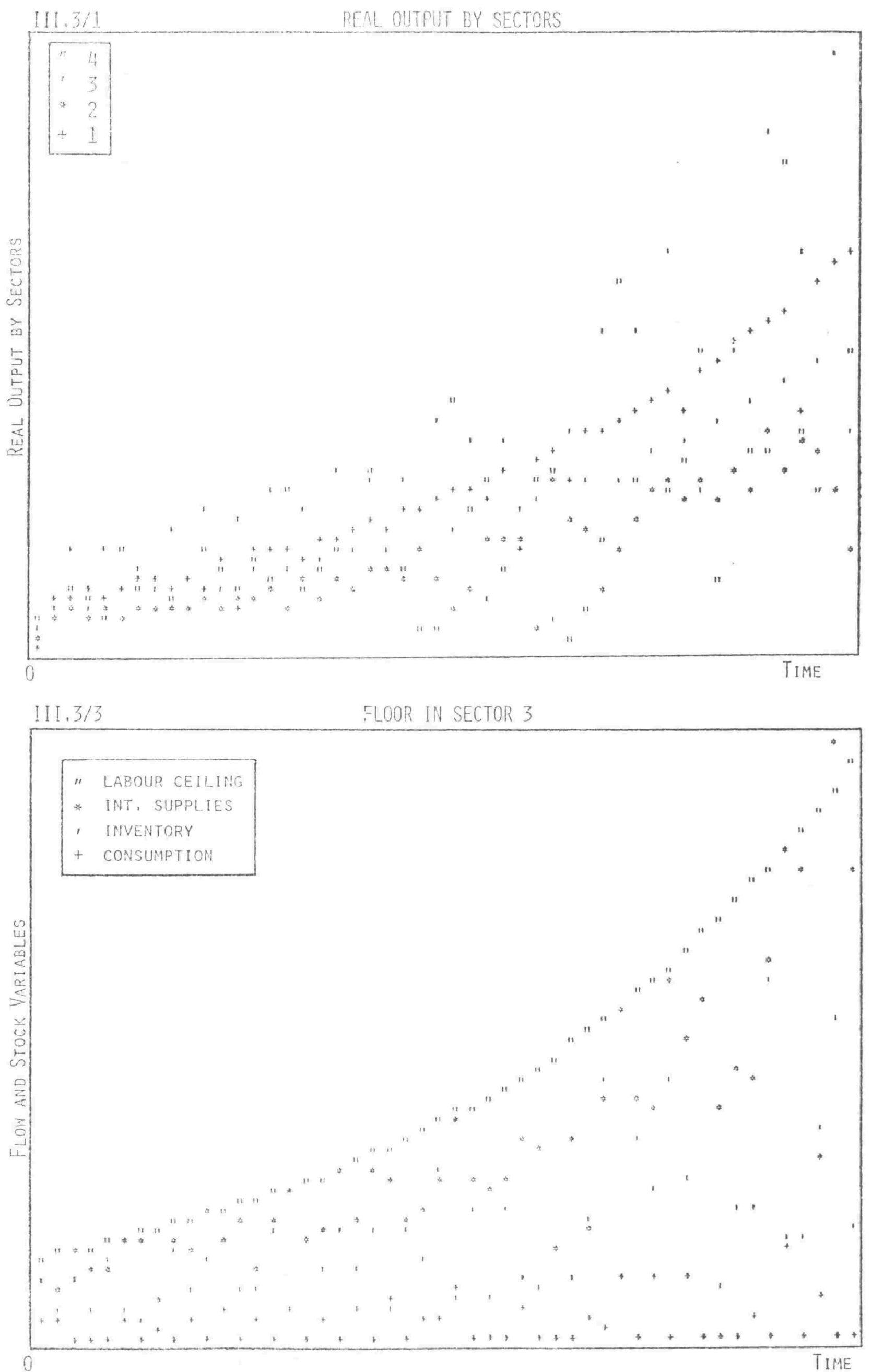

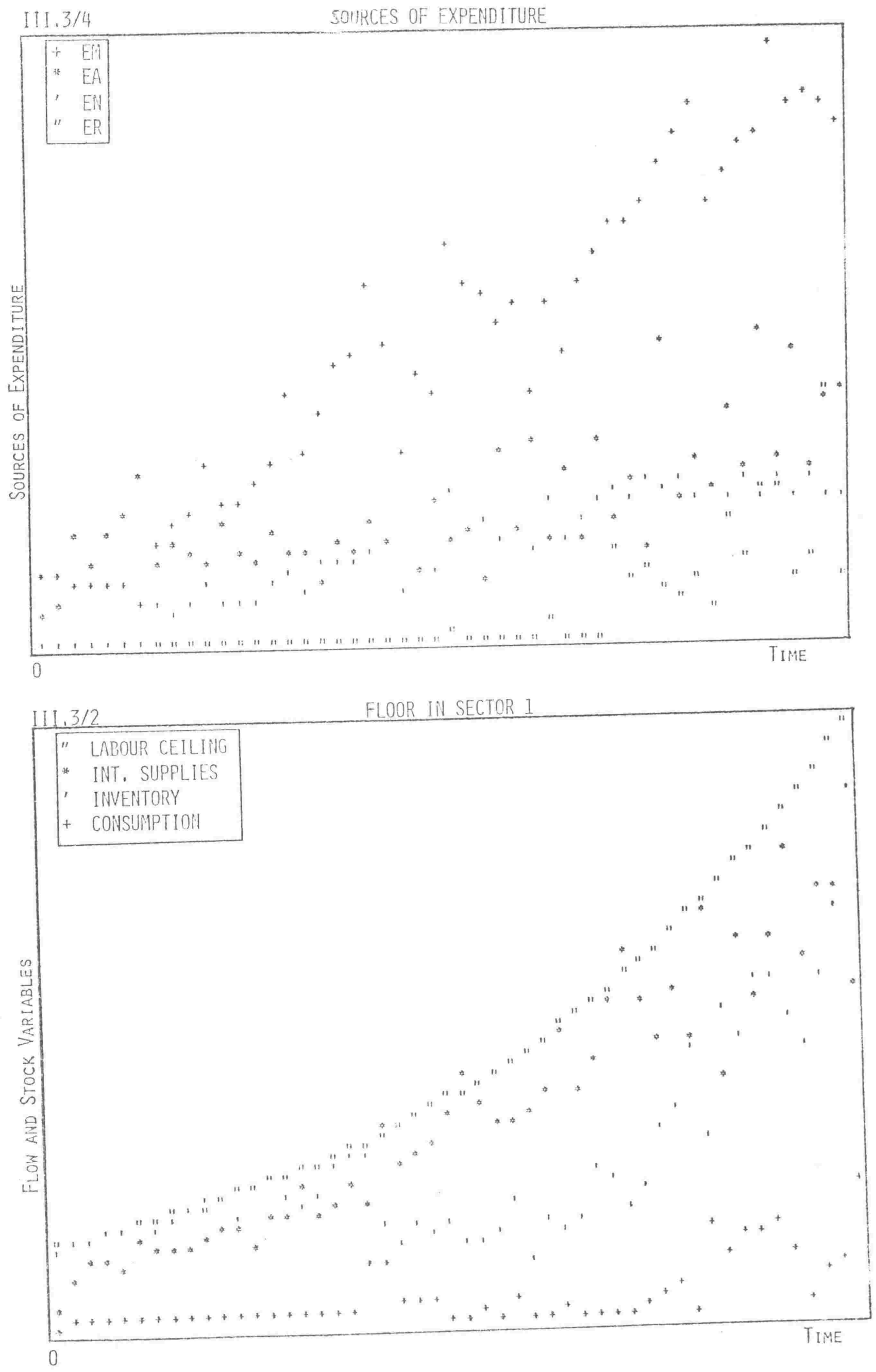


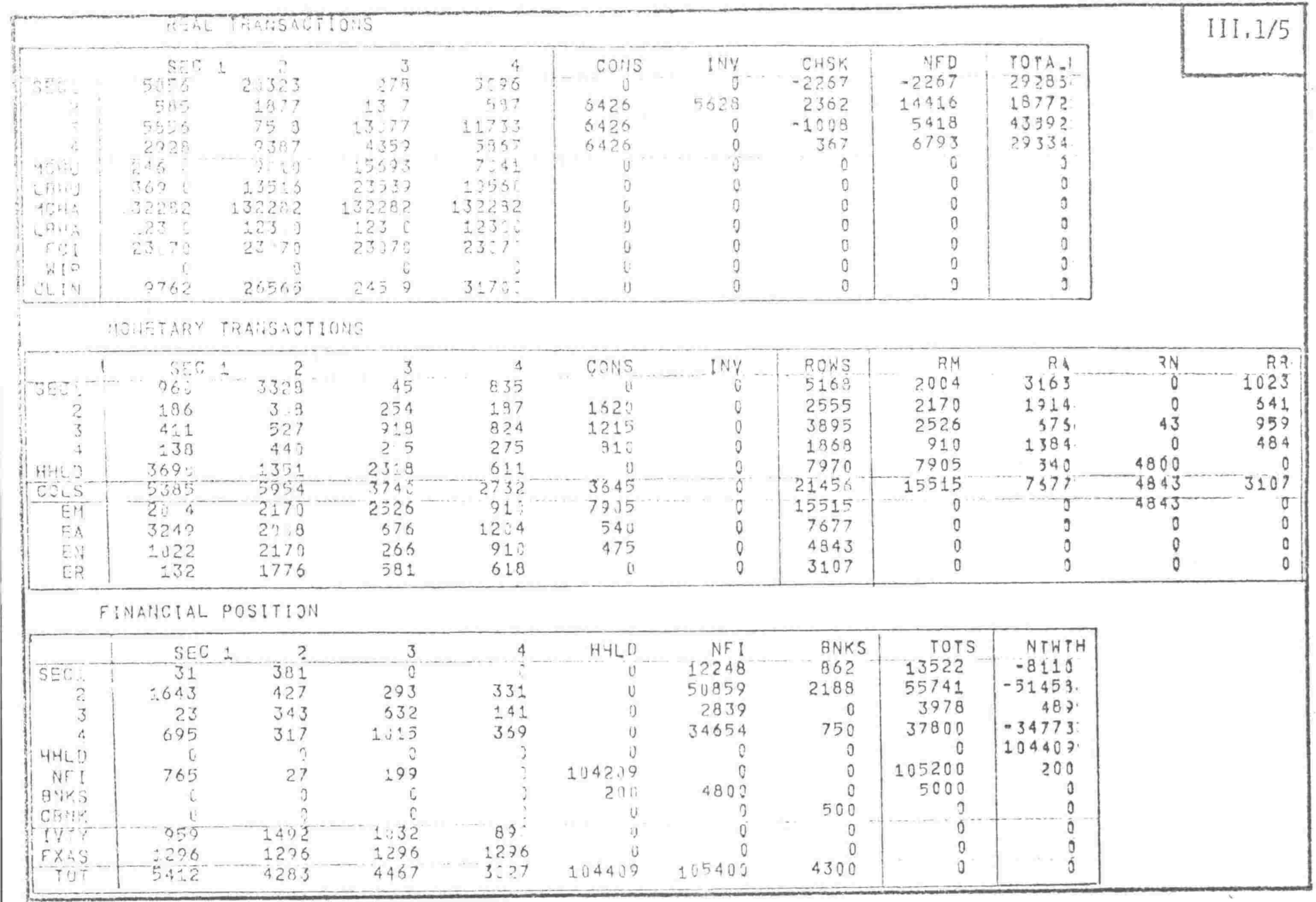

\begin{tabular}{|c|c|c|c|c|c|c|c|c|c|}
\hline \multicolumn{10}{|c|}{ REAL TRANSACTIONS } \\
\hline & SEC & 2 & 3 & 4 & cons & INY & CASK & NFD & TORA-1 \\
\hline istec1 & 5455 & 7829 & 436 & $7: 34$ & U & 0 & 4474 & 4474 & 27273 \\
\hline 2 & 545 & $\frac{1}{4}, 37$ & 137 & 276 & 5366 & 0 & $\begin{array}{l}1815 \\
2738\end{array}$ & $\begin{array}{r}7181 \\
14963\end{array}$ & 10363 \\
\hline $\begin{array}{l}3 \\
4\end{array}$ & $\begin{array}{l}5455 \\
2727\end{array}$ & $\begin{array}{l}4146 \\
66.9\end{array}$ & $\begin{array}{r}13061 \\
4353\end{array}$ & $\begin{array}{l}5913 \\
2957\end{array}$ & 12225 & $\begin{array}{l}0 \\
0\end{array}$ & -1863 & $\begin{array}{l}14963 \\
-1863\end{array}$ & $\begin{array}{l}43333 \\
14783\end{array}$ \\
\hline MCHU & 22913 & $\begin{array}{l}60.9 \\
4976\end{array}$ & $\begin{array}{r}4353 \\
15674\end{array}$ & $\begin{array}{l}2957 \\
3548\end{array}$ & $\begin{array}{l}0 \\
0\end{array}$ & 0 & 0 & $=0$ & -14703 \\
\hline L.BHU & 34370 & 7464 & $235 \div 0$ & 3322 & 0 & 0 & 0 & 0 & $\dot{0}$ \\
\hline$M C H A$ & 17952 & 3816 & 1380 & 10470 & 0 & c & 0 & 0 & 0 \\
\hline LBHA & 1230 & 123 & 1230 & 12300 & 0 & 0 & 0 & 0 & 0 \\
\hline FC! & 2693 & 572 & 2370 & 1571 & 0 & 0 & 0 & 0 & $j$ \\
\hline if $1 p$ & & & 6 & & 0 & 0 & 0 & 0 & 6 \\
\hline CLIN & $29: 6$ & 18774 & $2978 \dot{u}$ & 3476 & 0 & 0 & 0 & 0 & 0 \\
\hline
\end{tabular}

MONETARY TRANSACTIONS

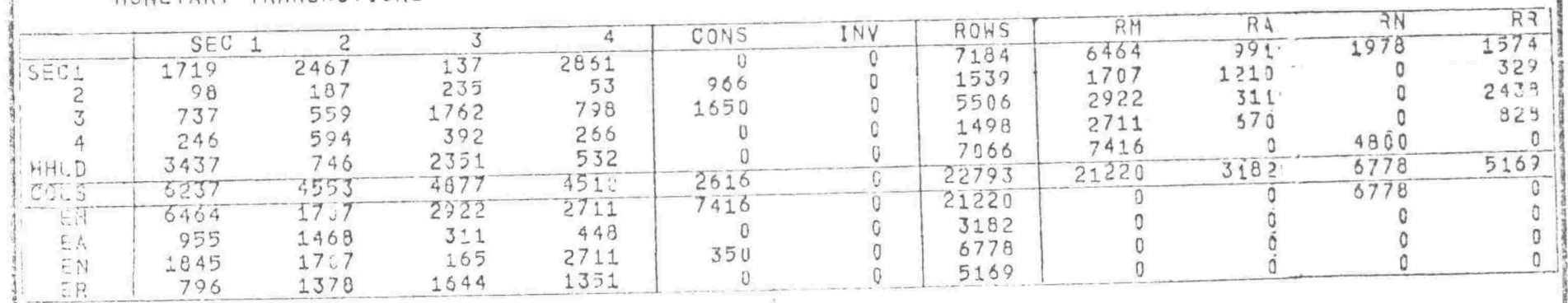

FINANCIAL POSITION

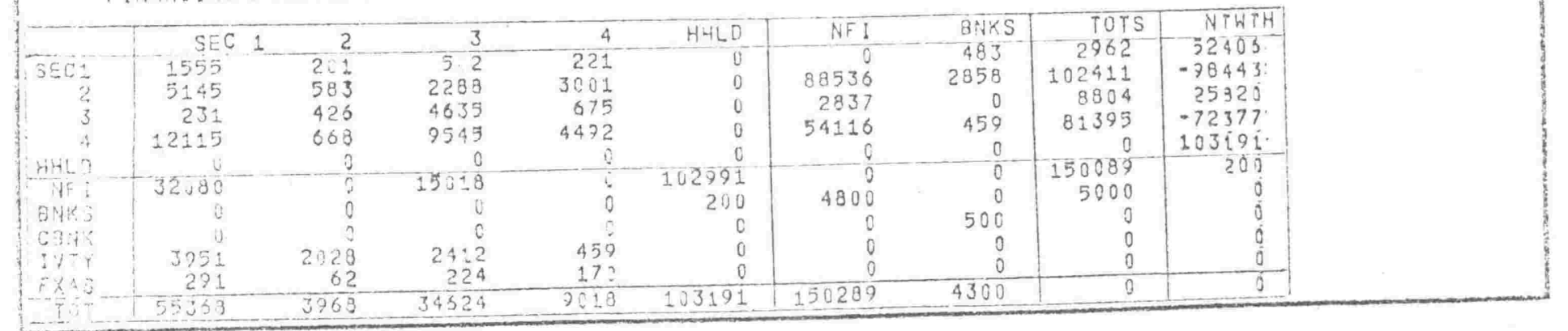




\begin{tabular}{|c|c|c|c|c|c|c|c|c|c|c|c|}
\hline \multicolumn{11}{|c|}{ REAL THENSACTIOUS } & \multirow{2}{*}{ IV. $2 / 4$} \\
\hline & $\frac{\text { SEC }}{235} 1$ & $?$ & 3 & 4 & cois & INY & CHSK & NFD & TOTA. & & \\
\hline SEc: & $\begin{array}{r}235 \\
231\end{array}$ & 2675 & -44 & $25 ? 3$ & 2463 & & 1407 & 3870 & 11323 & & \\
\hline 3 & $\begin{array}{r}231 \\
235\end{array}$ & & $\begin{array}{r}433 \\
4333\end{array}$ & 158 & 1357 & 1407 & $\begin{aligned}-82 \\
432\end{aligned}$ & & $\begin{array}{r}4460 \\
14443\end{array}$ & & \\
\hline & $\begin{array}{l}235 \\
1152\end{array}$ & $\begin{array}{l}1784 \\
2231\end{array}$ & $\begin{array}{r}4333 \\
1444\end{array}$ & $\begin{array}{l}3371 \\
1696\end{array}$ & $\begin{array}{r}1213 \\
379\end{array}$ & 0 & $\begin{array}{l}1432 \\
1334\end{array}$ & $\begin{array}{l}2630 \\
1913\end{array}$ & $\begin{array}{r}14443 \\
842.5\end{array}$ & & \\
\hline acns & 263 & 214 & $5-93$ & 2825 & $\frac{1}{4}$ & 9 & 0 & 0 & 0 & & \\
\hline ILB'U & $245: 9$ & $32: 1$ & 7799 & 3233 & (1) & 0 & 0 & 0 & 0 & & \\
\hline 10,44 & 1.278 & 1554 & 4224 & 3012 & $\mathrm{~b}$ & 0 & 0 & 0 & $j$ & & \\
\hline LGHA & $223:$ & $123 \%$ & 123 & $123 ; 6$ & $\mathrm{v}$ & 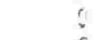 & 0 & 0 & 0 & & \\
\hline $70:$ & $\therefore 542$ & 1497 & 534 & 432 & 6 & 0 & 0 & 0 & 0 & & \\
\hline$H[P$ & 20702 & $=25$ & & 33797 & if & 0 & c & 0 & 3 & & \\
\hline \multirow{2}{*}{\multicolumn{12}{|c|}{ "MHETARY TPAUSACTIONS }} \\
\hline & & & & & & & & & & & \\
\hline & $\sec 1$ & 2 & 3 & 4 & Cans & INV & ROWS & $\overline{R M}$ & $R A$ & $2 N$ & $R ?=$ \\
\hline$\because$ & स196 & 1381 & 76 & 13.5 & 1272 & 0 & 5222 & 3454 & 1769 & 1152 & 0 \\
\hline$\frac{2}{3}$ & 245 & 1957 & 437 & 177 & 1759 & 0 & 4795 & 1170 & 4795 & $\begin{array}{r}0 \\
308\end{array}$ & 01 \\
\hline 3 & $\begin{array}{l}633 \\
540\end{array}$ & $\begin{array}{r}470 \\
1 \quad 46\end{array}$ & $\therefore+\frac{7}{57} 7$ & 927 & $\begin{array}{l}336 \\
273\end{array}$ & 0 & $\begin{array}{l}3577 \\
3326\end{array}$ & $\begin{array}{l}3122 \\
2235\end{array}$ & $\begin{array}{r}453 \\
1591\end{array}$ & $\begin{array}{r}398 \\
0\end{array}$ & $\begin{array}{l}0 \\
0\end{array}$ \\
\hline H:L D ! & 1452 & 321 & $78:$ & 33 & $2 / 3$ & ? & $\begin{array}{l}3320 \\
2856\end{array}$ & 1443 & 2457 & 0 & $\begin{array}{l}0 \\
0\end{array}$ \\
\hline COLS & 4050 & 5195 & 3.73 & $35: \overline{2}$ & $334 !$ & $\overline{0}$ & 19776 & 11424 & 10565 & $1550^{\circ}$ & 0 \\
\hline EN & 3454 & 1177 & $3-22$ & 23.3 & 1443 & $\overline{0}$ & 11492 & 0 & 0 & $1550^{\circ}$ & ㅇ) \\
\hline$E A$ & 1760 & 4.25 & 455 & 1139 & 2397 & 0 & 9844 & 0 & 0 & 0 & c) \\
\hline EN & 0 & 1170 & 6 & & $1: 44$ & 0 & 22.14 & 0 & 0 & 0 & 0 \\
\hline$E B$ & E: & & 0 & & u & & 0 & 0 & 0 & 0 & 요 \\
\hline \multicolumn{12}{|c|}{ FINANCIAL POSITION } \\
\hline & SEC 1 & 2 & 3 & 4 & HULII & NFI & BNKS & ToTs & NPWTH & & \\
\hline SED: & : & 2 & & & u & 6 & 0 & 0 & 29055 & & \\
\hline & u & 0 & & & (1) & 11709 & 2200 & 13909 & 7320 & & \\
\hline 3 & 0 & & i & & $y$ & 0 & 0 & $?$ & 9577 & & \\
\hline 4 & E & & & & 0 & 8275 & 103 & 8383 & 1411 & & \\
\hline HHED. & 6 & & & & (I) & 6.52 & 7 & 6059 & 1357 & & \\
\hline ivf 1 & $1787 i$ & & 3565 & & 7416 & & $\mathrm{c}$ & 28951 & 200 & & \\
\hline BNKS & 2. & & 20 & & u & 3115 & 0 & 3515 & 0 & & \\
\hline conts & & $?$ & & & $J$ & o & 500 & 3 & 0 & & \\
\hline IVTY & 109 & 2.583 & $53: 3$ & 35.3 & 3 & 0 & 0 & 0 & 9 & & \\
\hline$F x+S$ & 976 & 949 & $\therefore \div$ & 236 & $u$ & 0 & 0 & 0 & 0 & & \\
\hline$T O T$ & 29,55 & 21529 & 9377 & 7774 & 7416 & 29151 & 2815 & 0 & $j$ & & \\
\hline
\end{tabular}

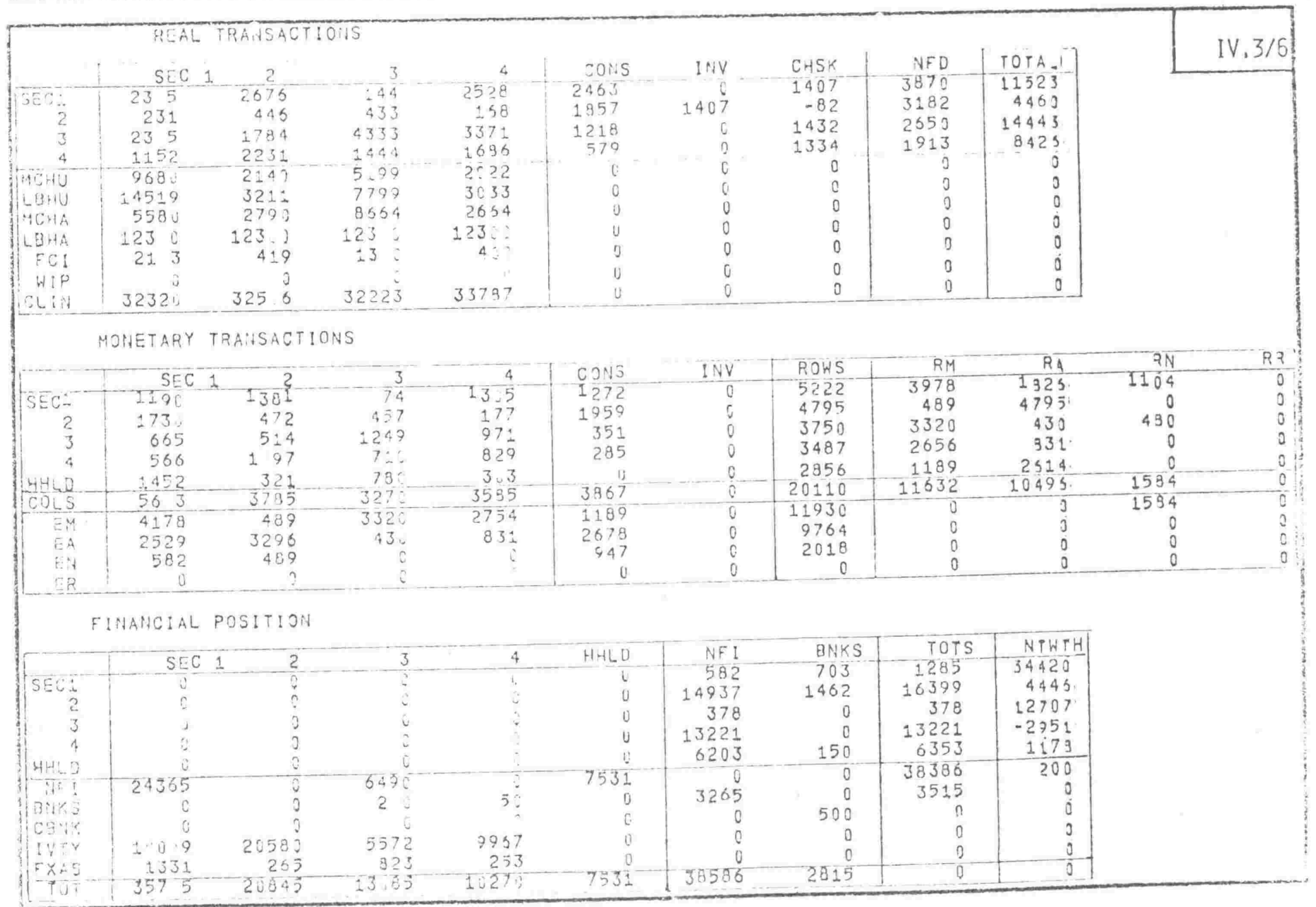




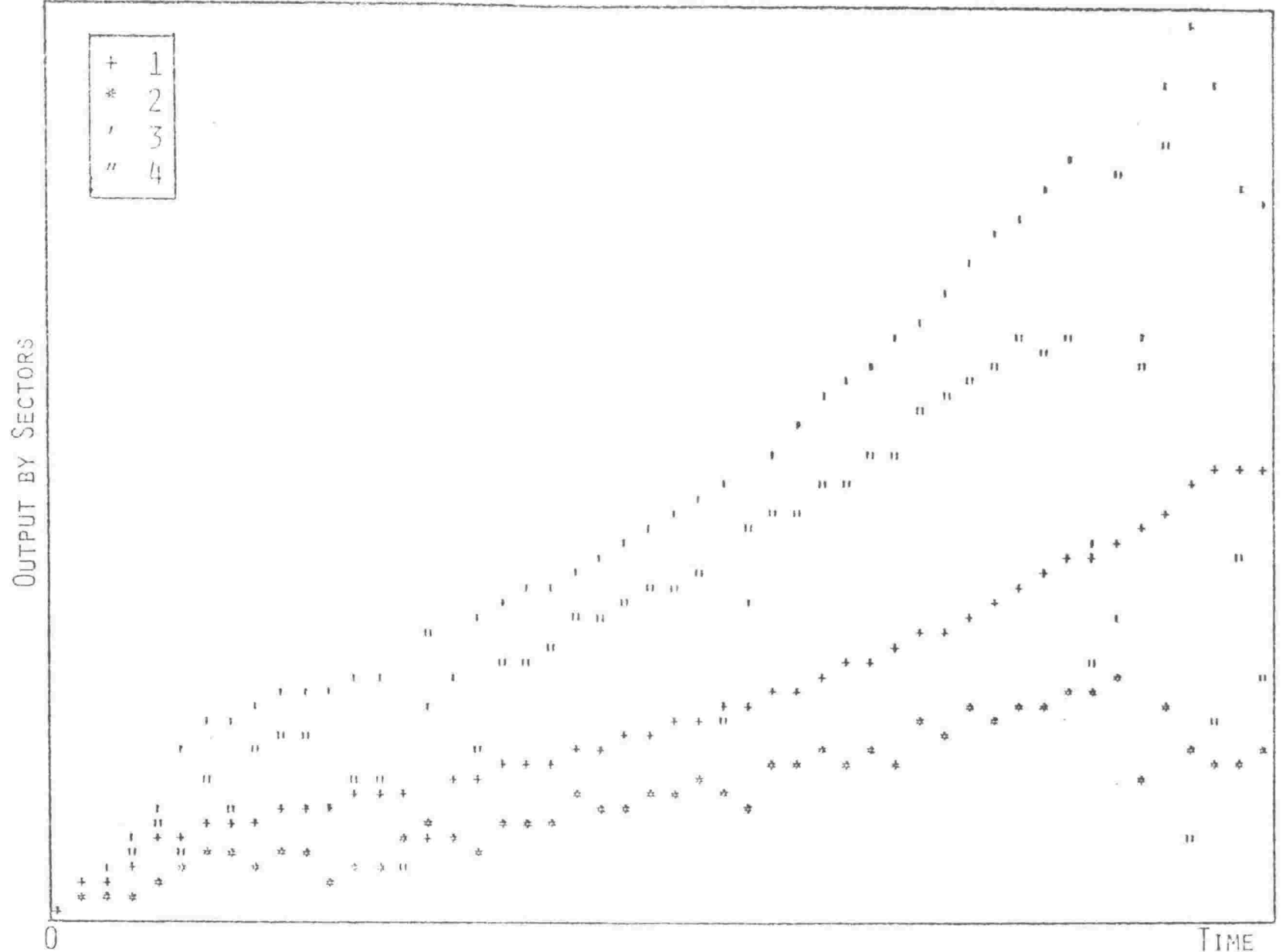

$[\mathrm{V}] /$,

CEILINGS IN SECTOR I

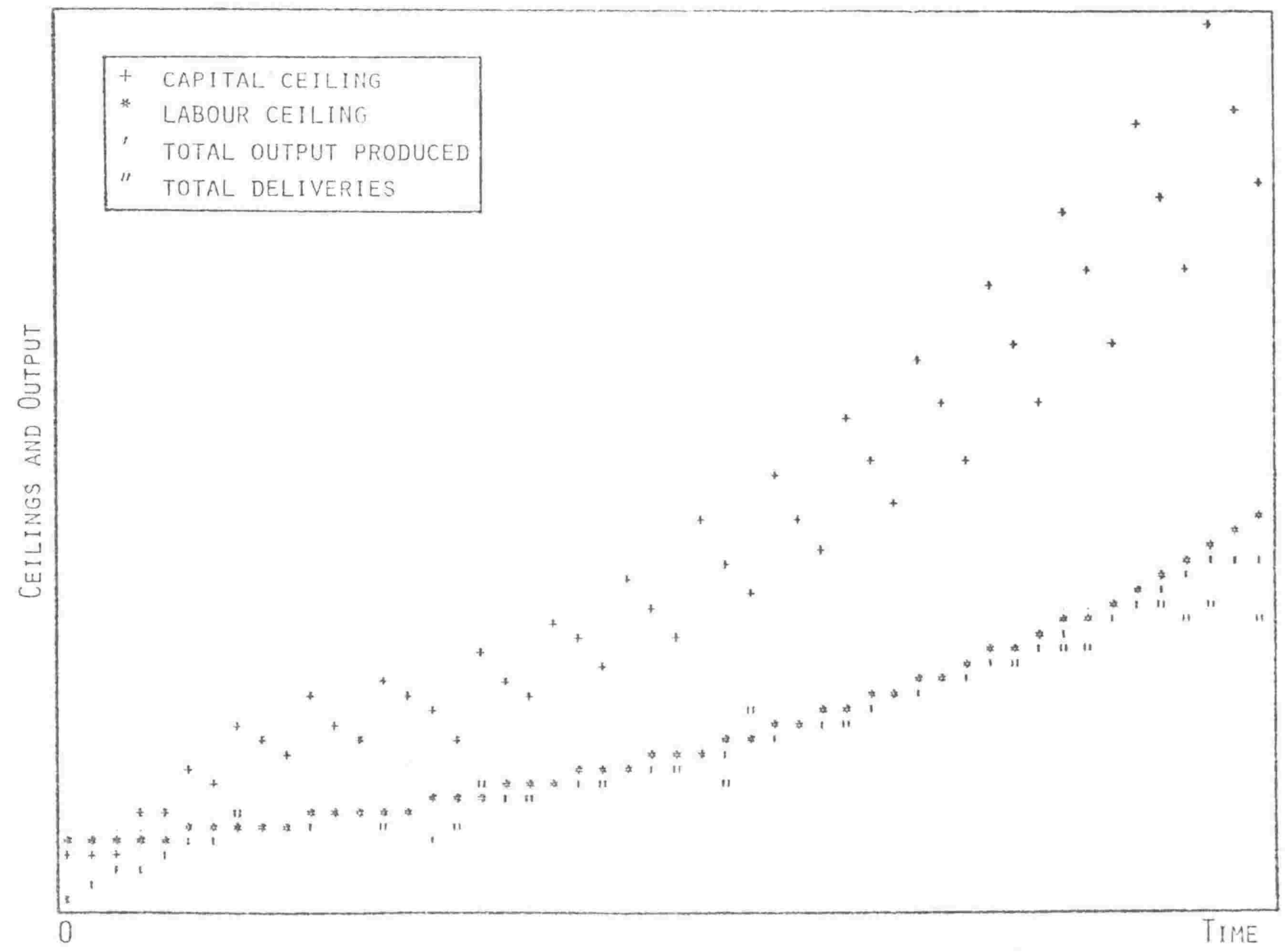




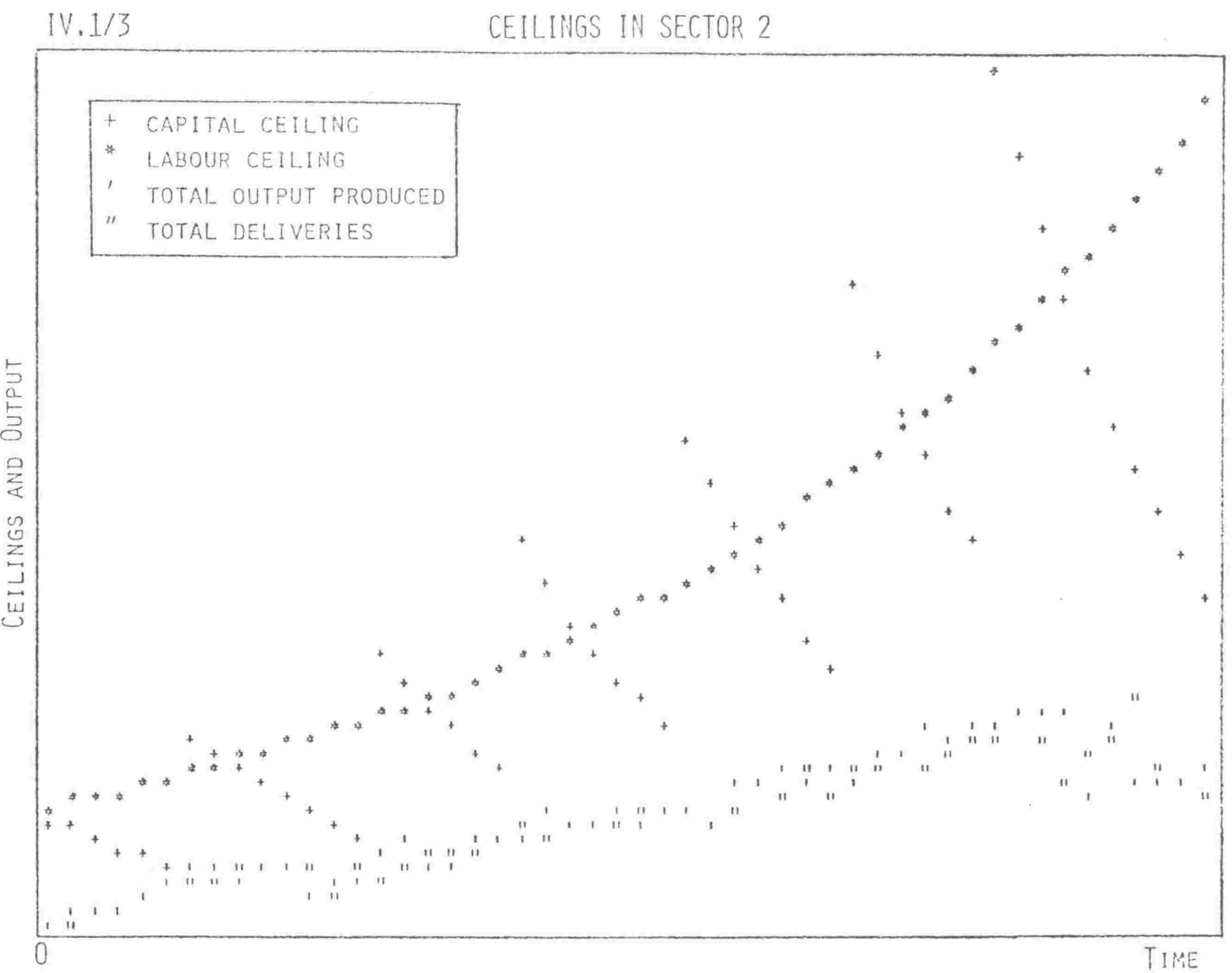

IV. $1 / 4$

CEILINGS IN SECTOR 3

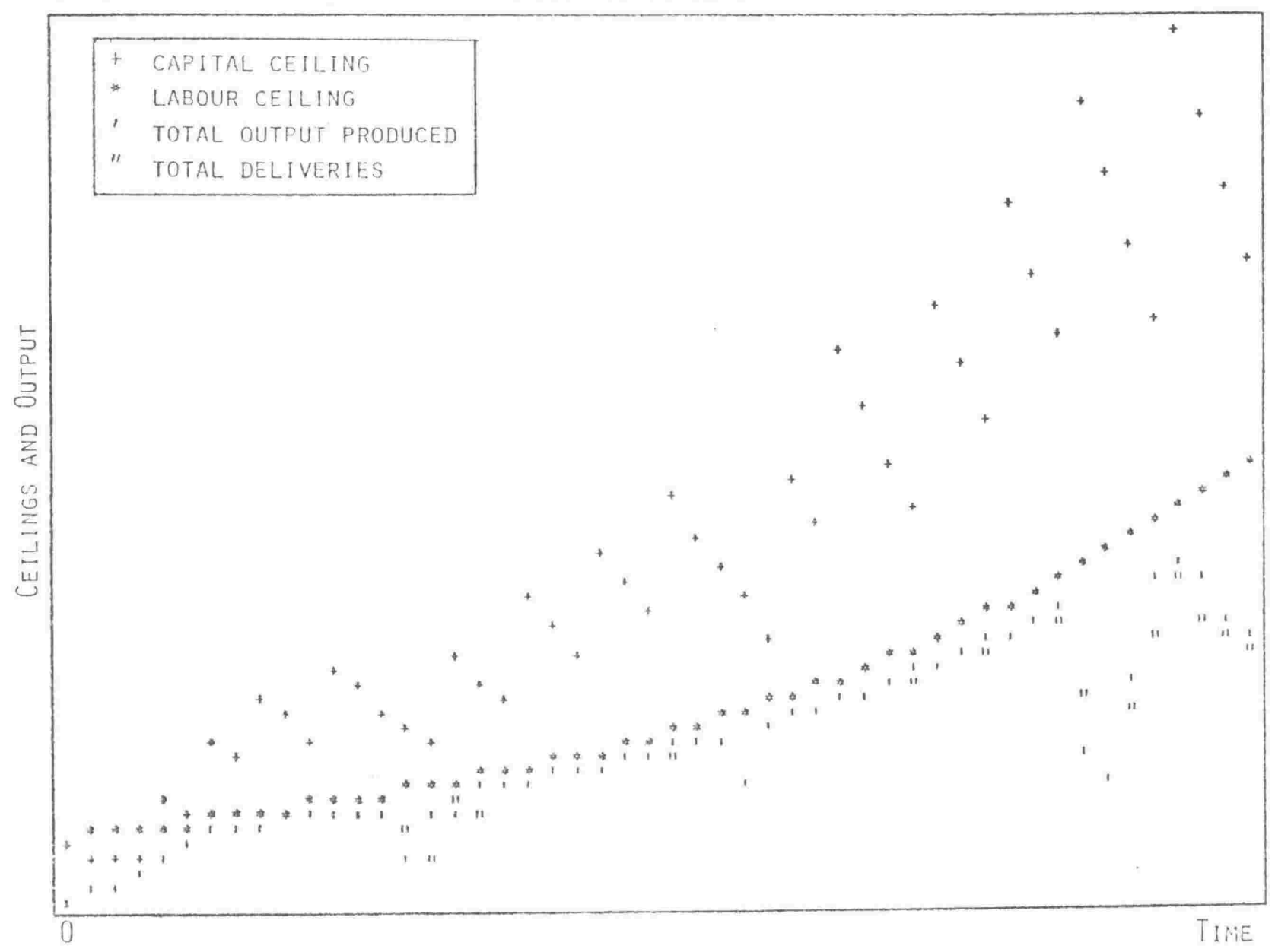



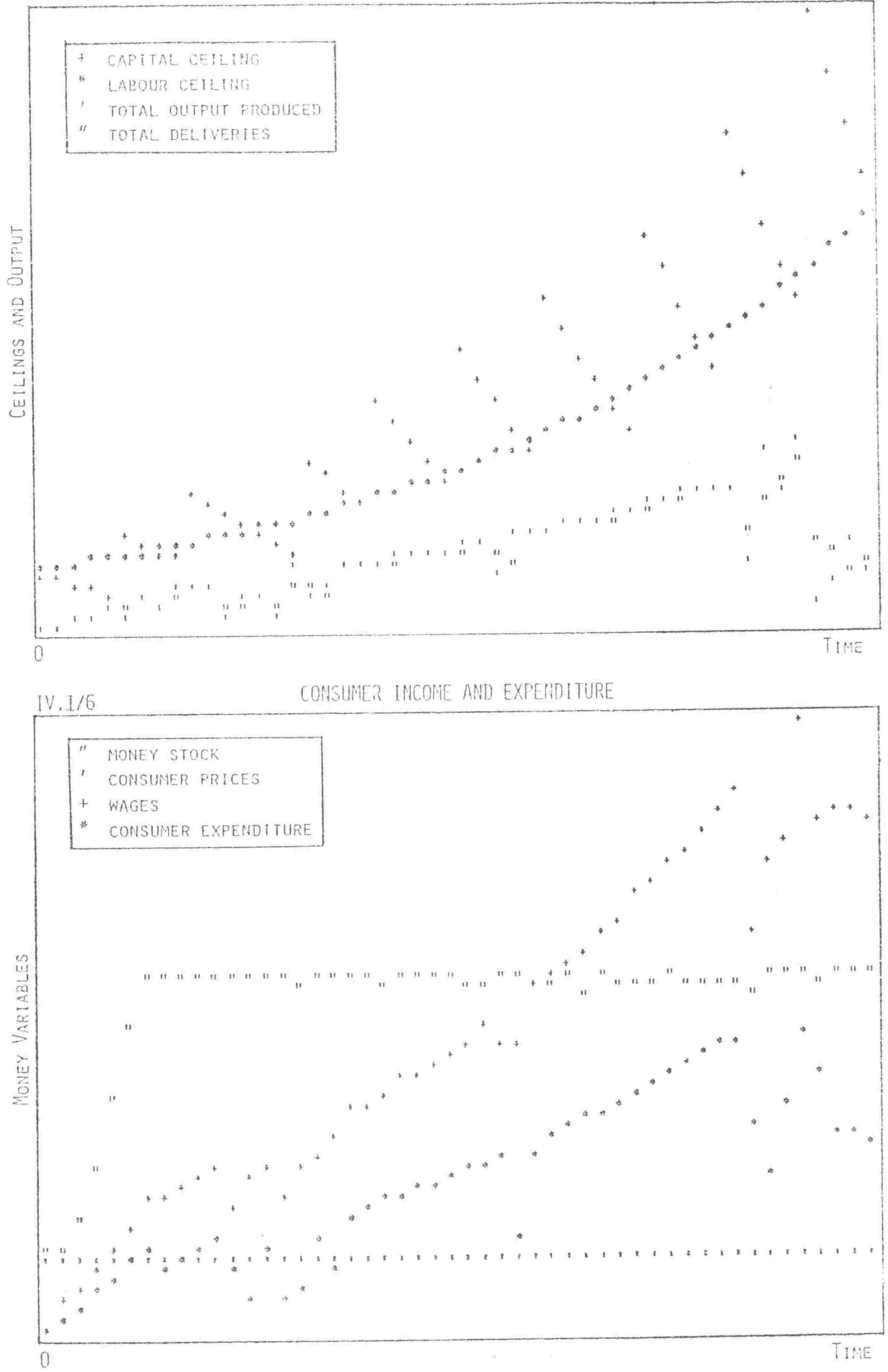

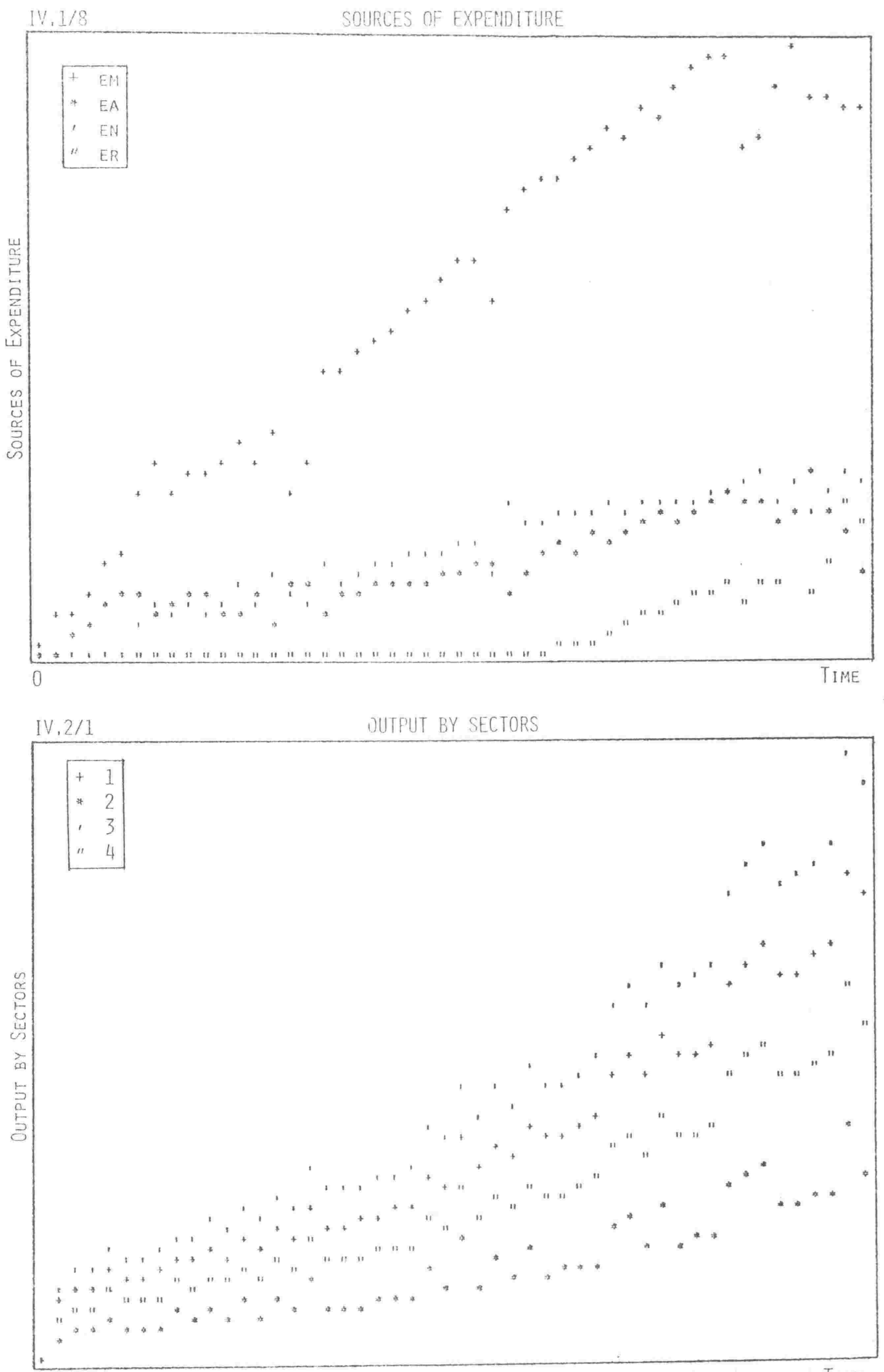
CAPITAL CEILING

* labour ceiling

TOTAL OUTPUT PRODUCED

" total deliveries

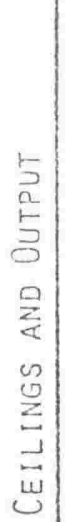

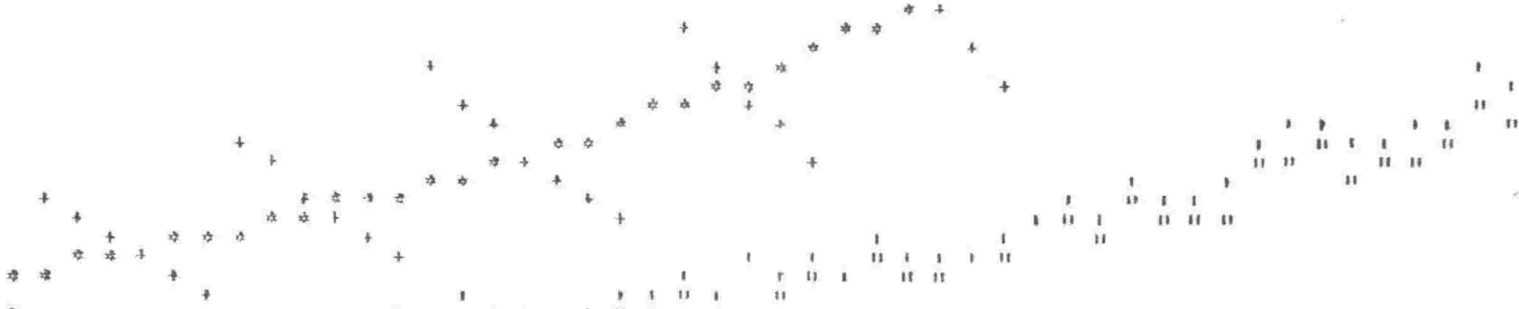

i' i'

0

TIME

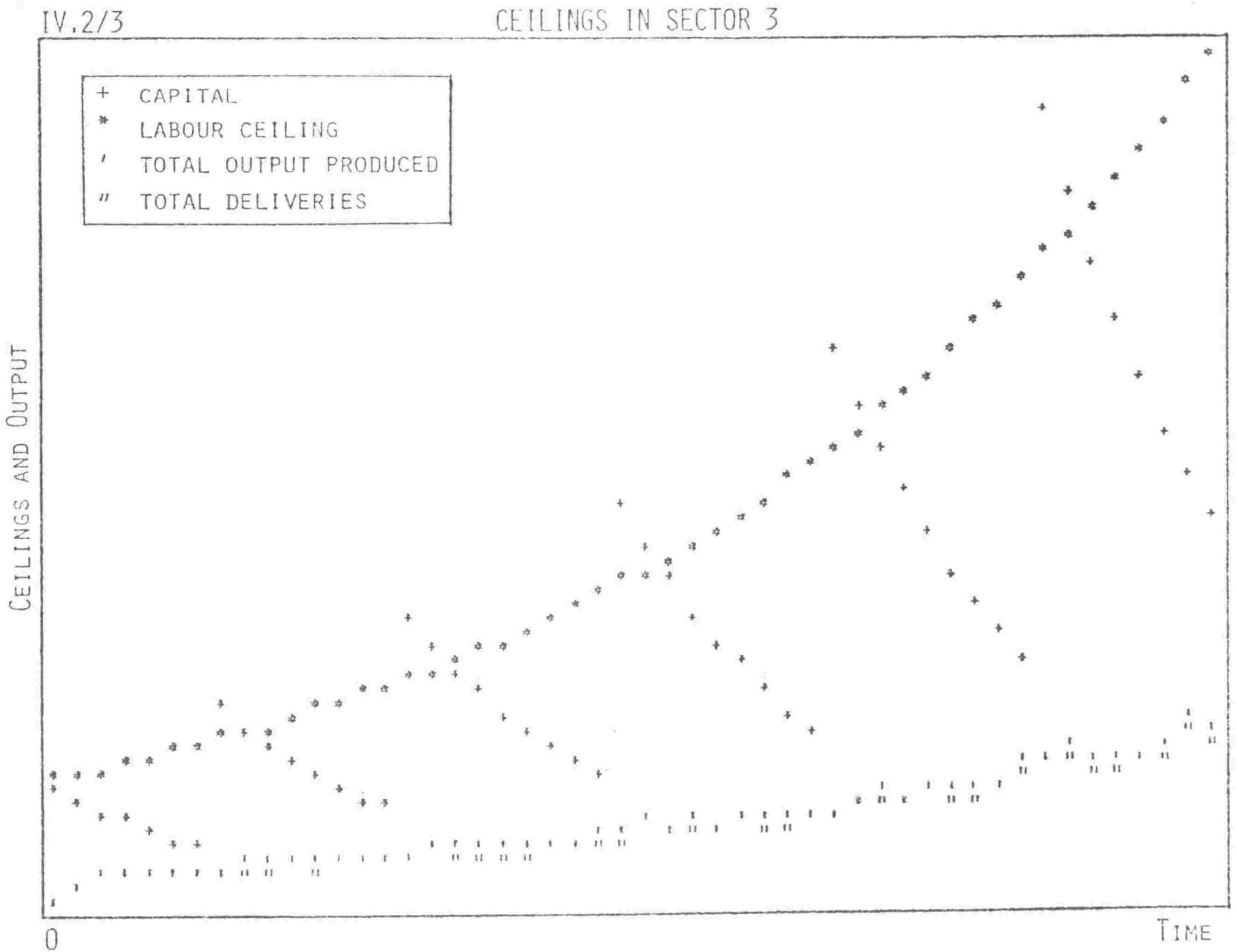




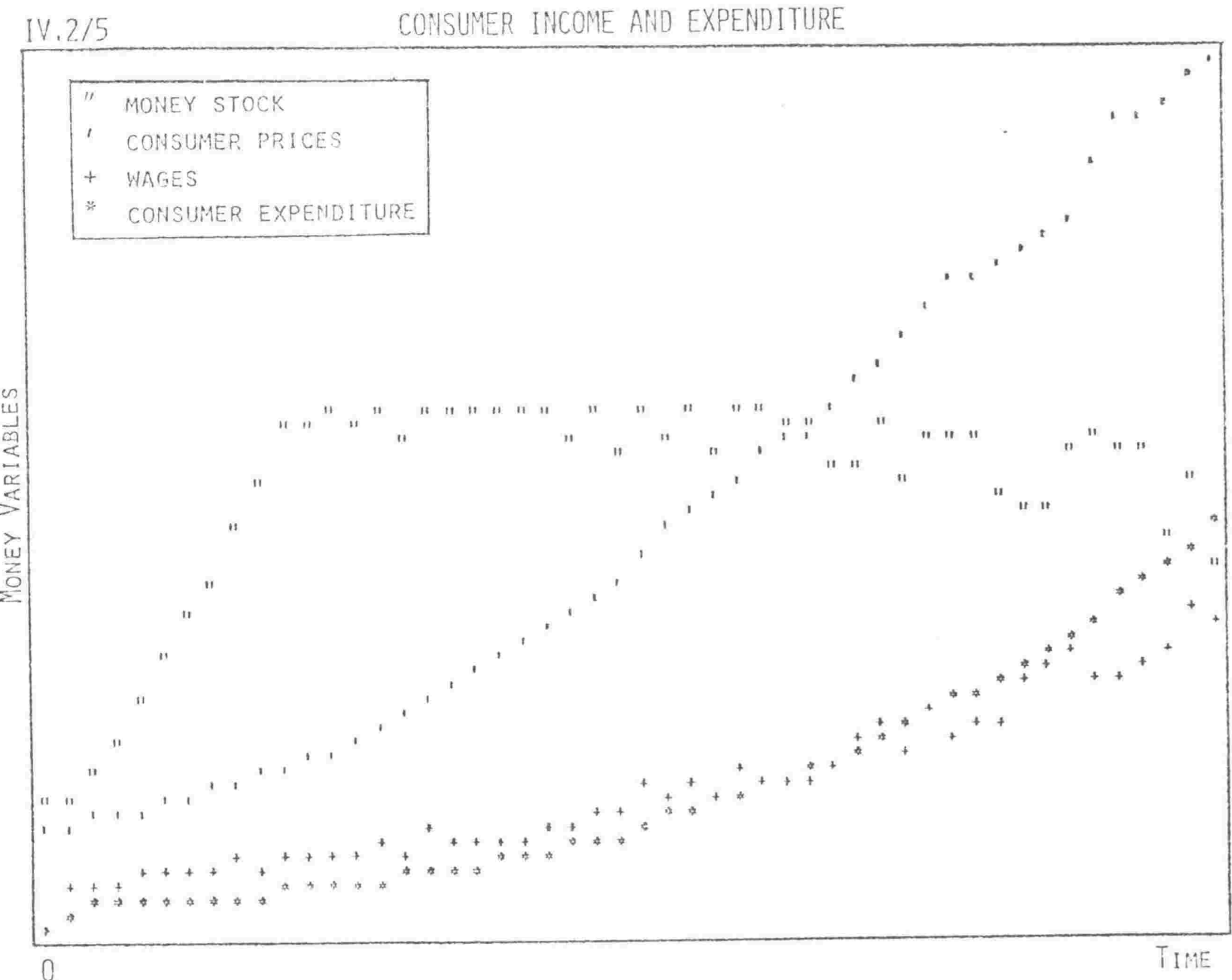

IV. $3 / 1$ GUTPUT BY SECTORS

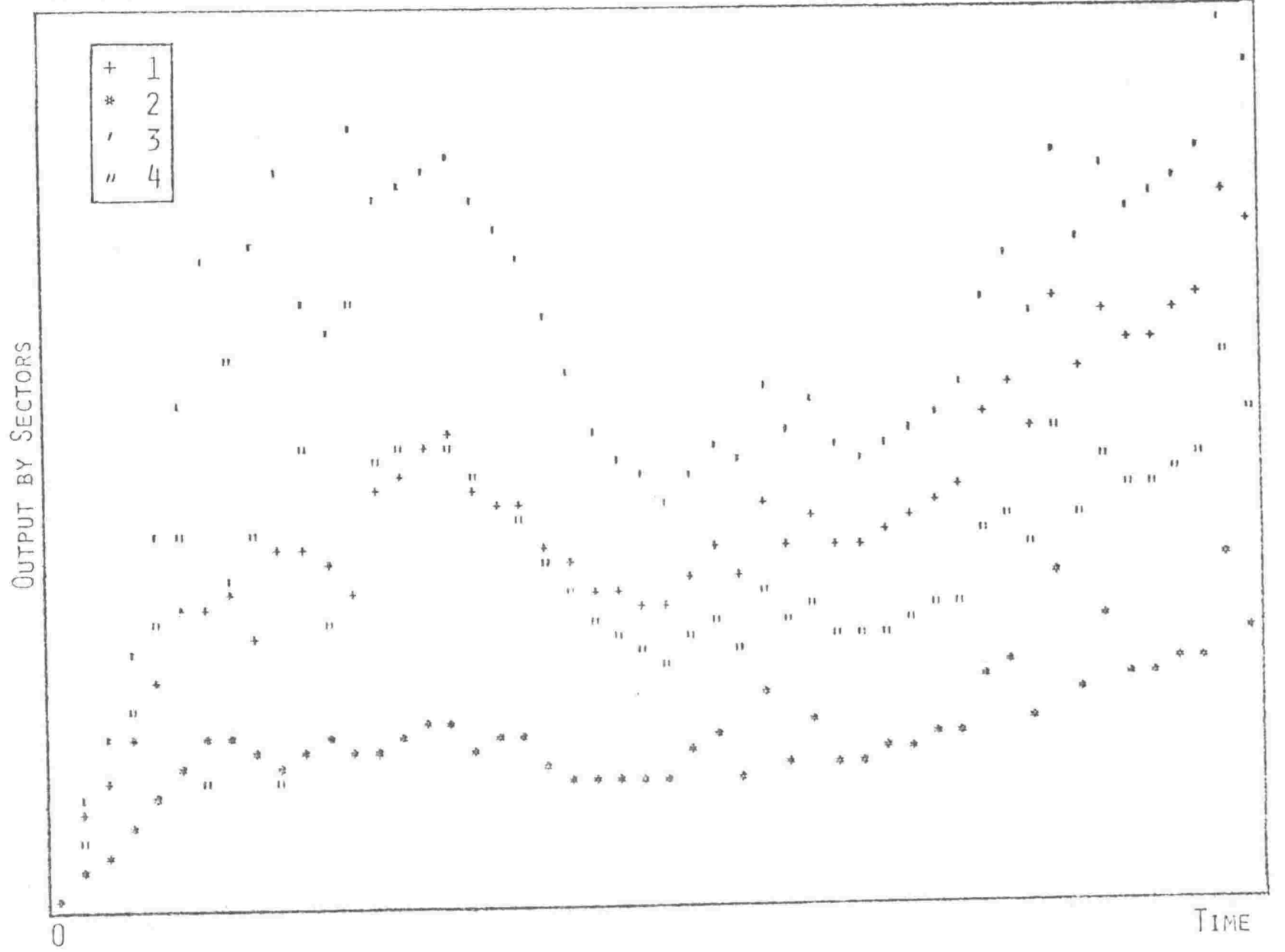



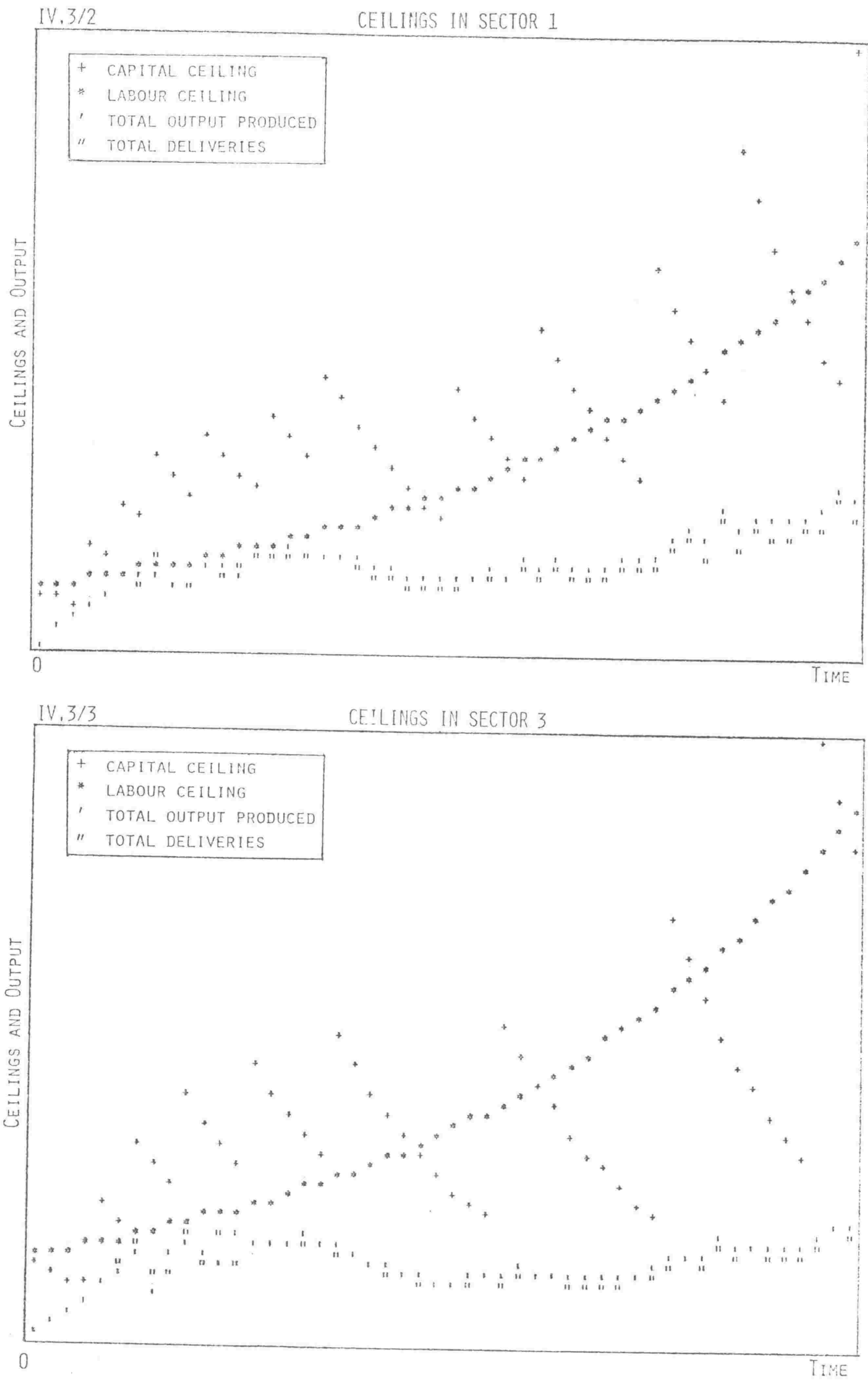

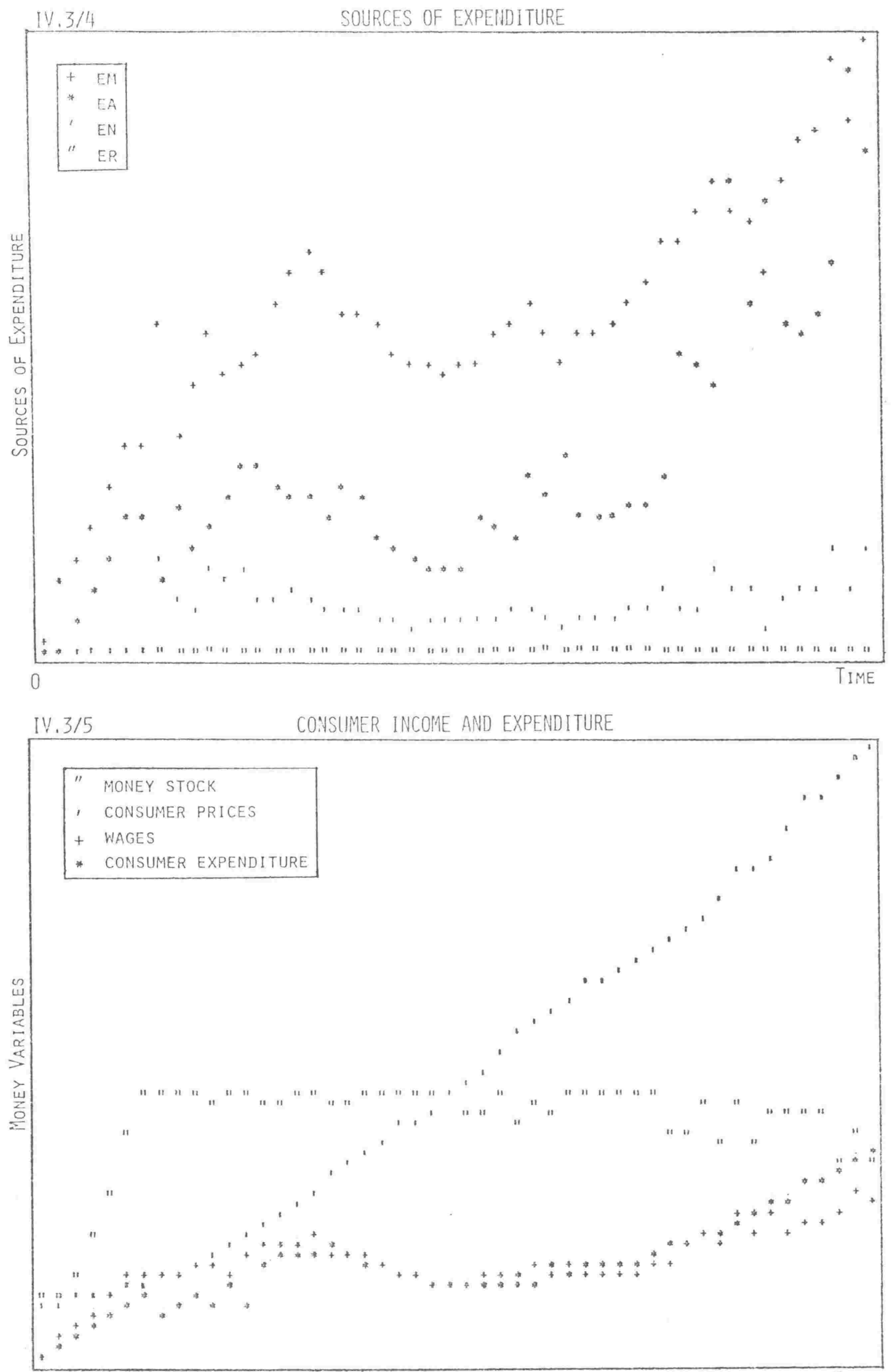


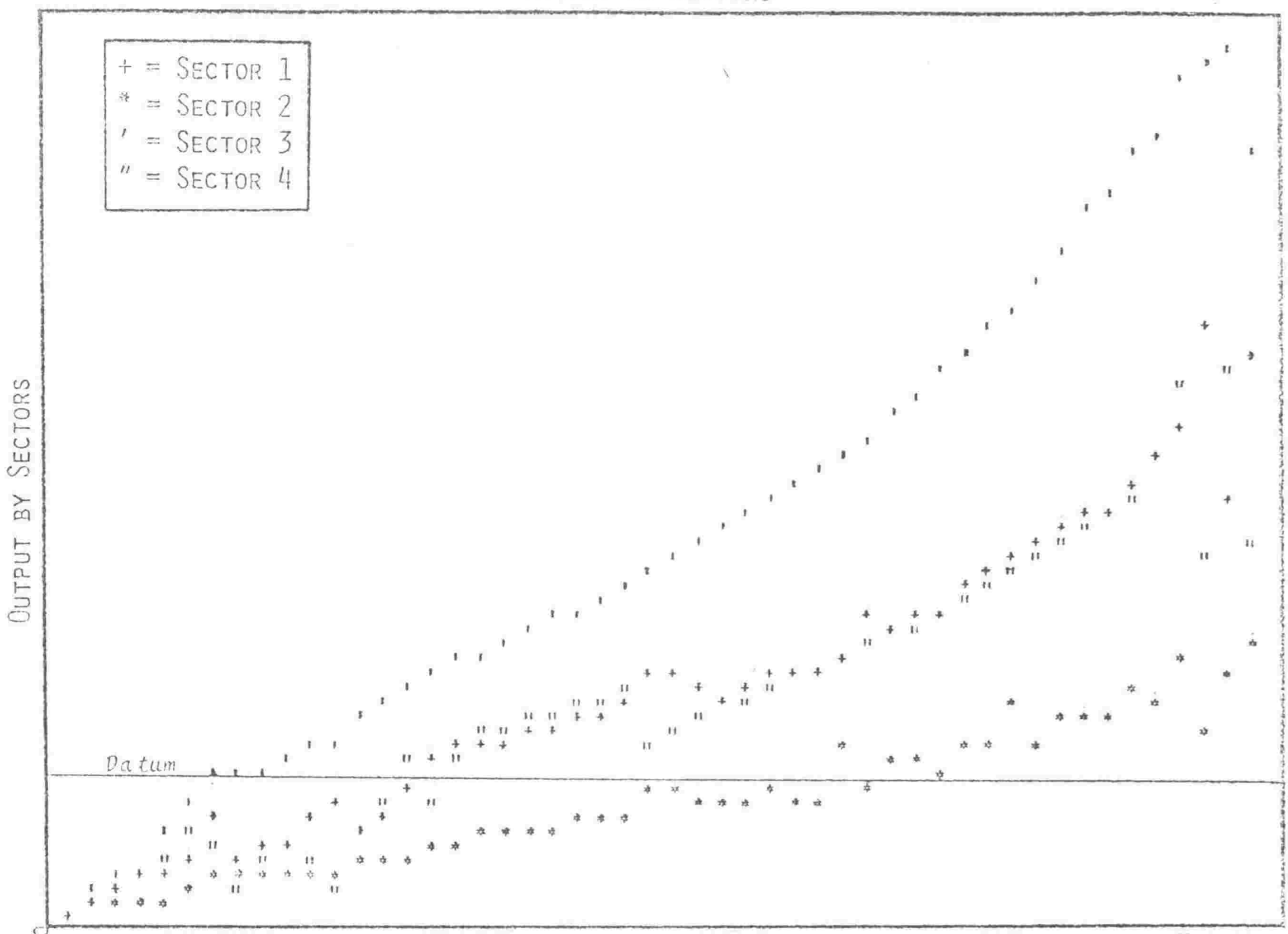

TIME

V. $1 / 2$ CEILINGS IN SECTOR 1

$\begin{aligned}+ & =\text { Capital Ceilling } \\ * & =\text { Labour Ceiling } \\ \prime & =\text { Total Output Produced } \\ " & =\text { Total Deliveries }\end{aligned}$

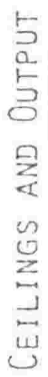




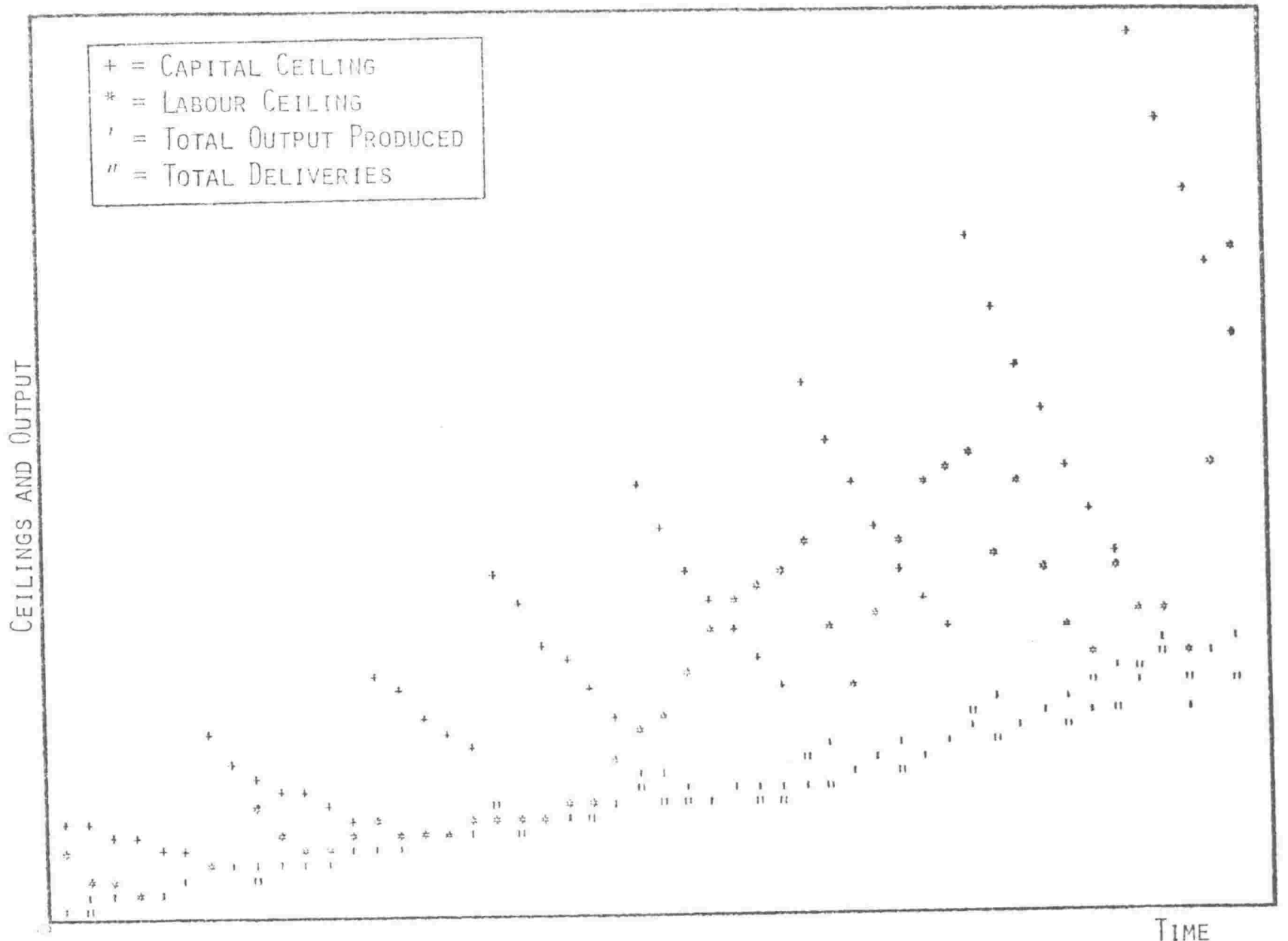

$+=$ CAPITAL CEILING

* labour. Ceiling

' = Total OUtPut Produced

" = TOTAL DELIVERIES

\begin{tabular}{l}
5 \\
5 \\
5 \\
5 \\
0 \\
0 \\
0 \\
0 \\
0 \\
\hline \\
\hline \\
\hline
\end{tabular} 
$+=$ CAPITAL CEILING

* = Labour Ceilling

' = Total OUtPut Produced

" = Total DeLIVERIES

5
5
5
5
0
0
2
0
0
2
-1
4
0

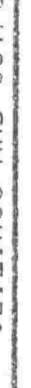

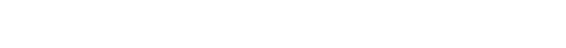

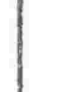

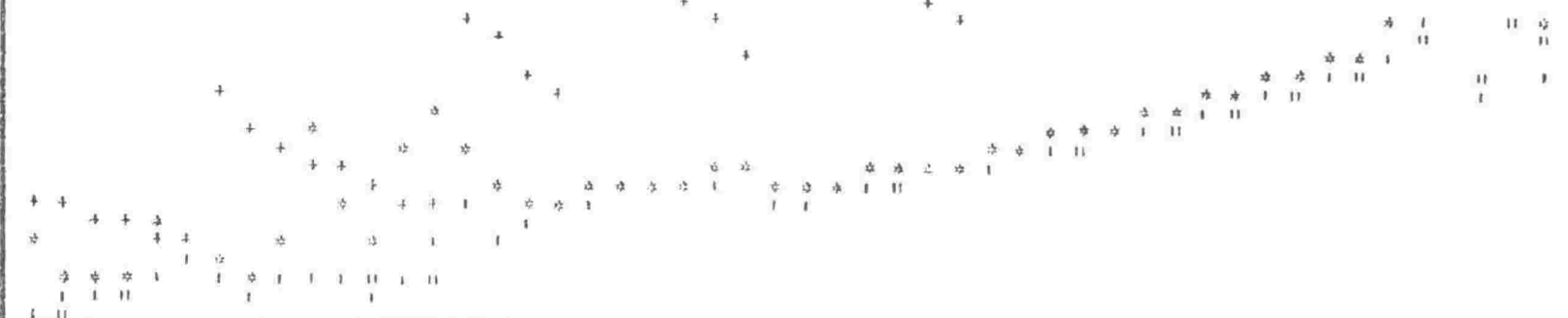

TIME

V.1/6

COASUMER IHCONE AIID EXPEMDITURE

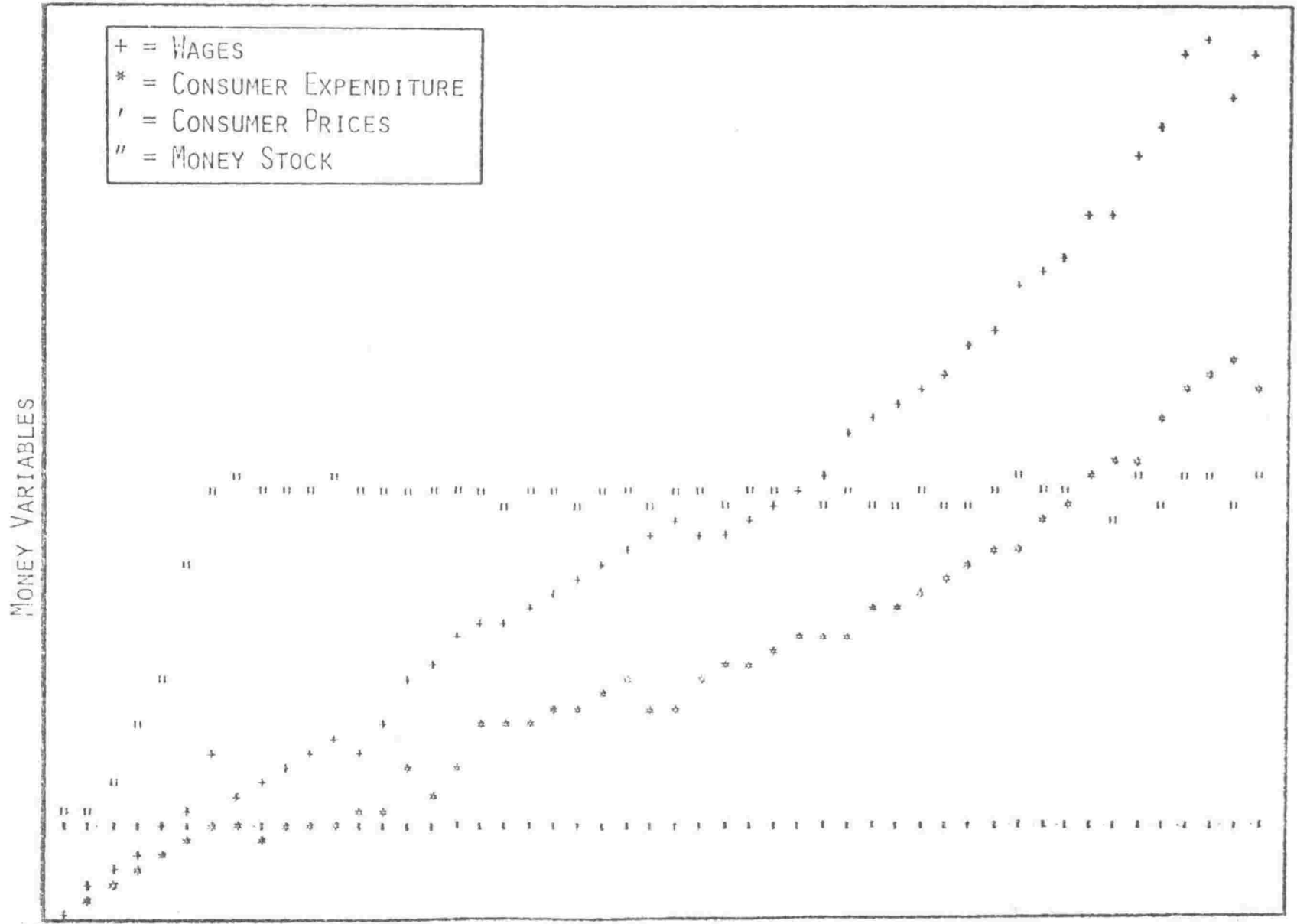




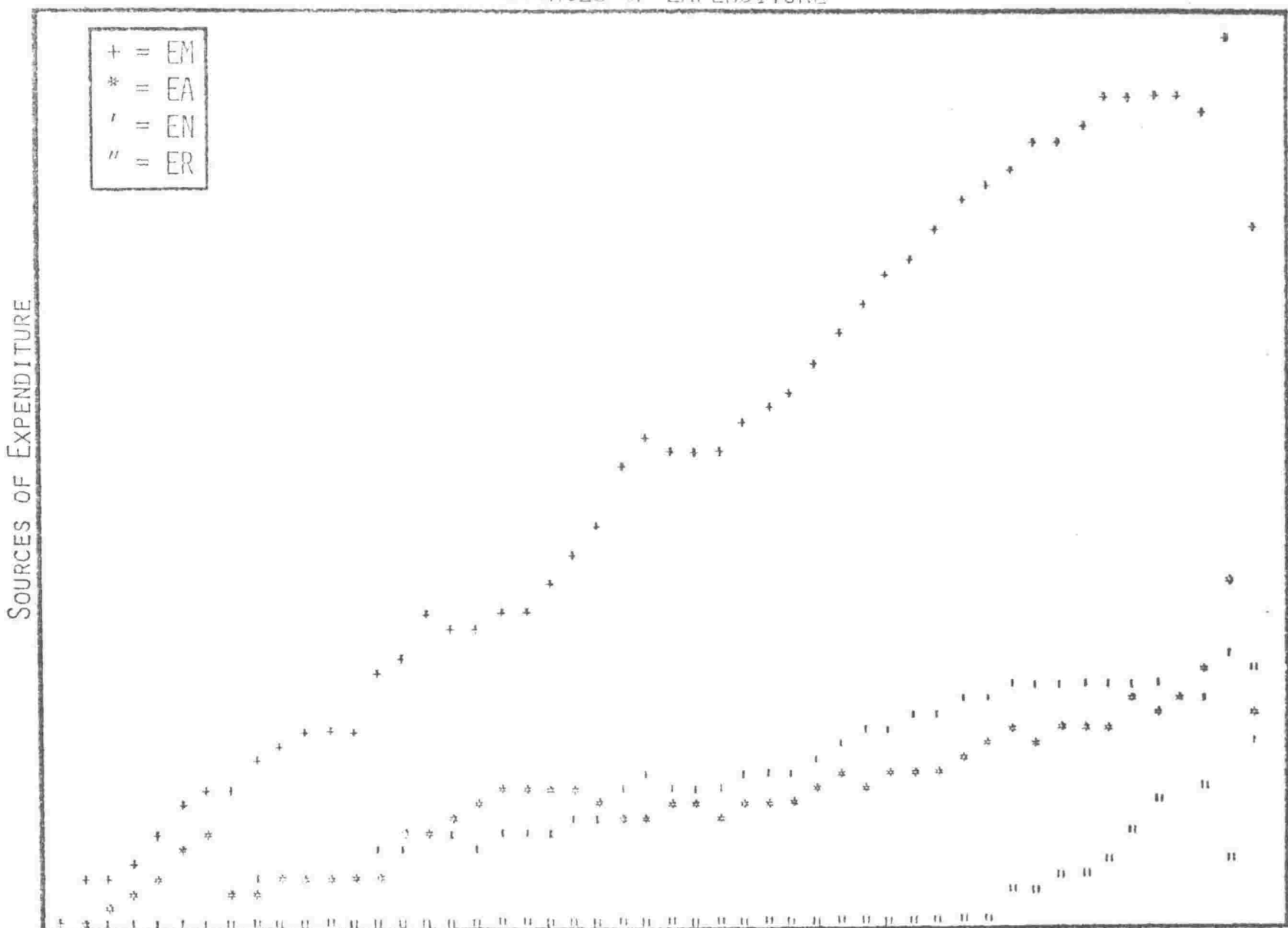

OUTPUT BY SECTORS

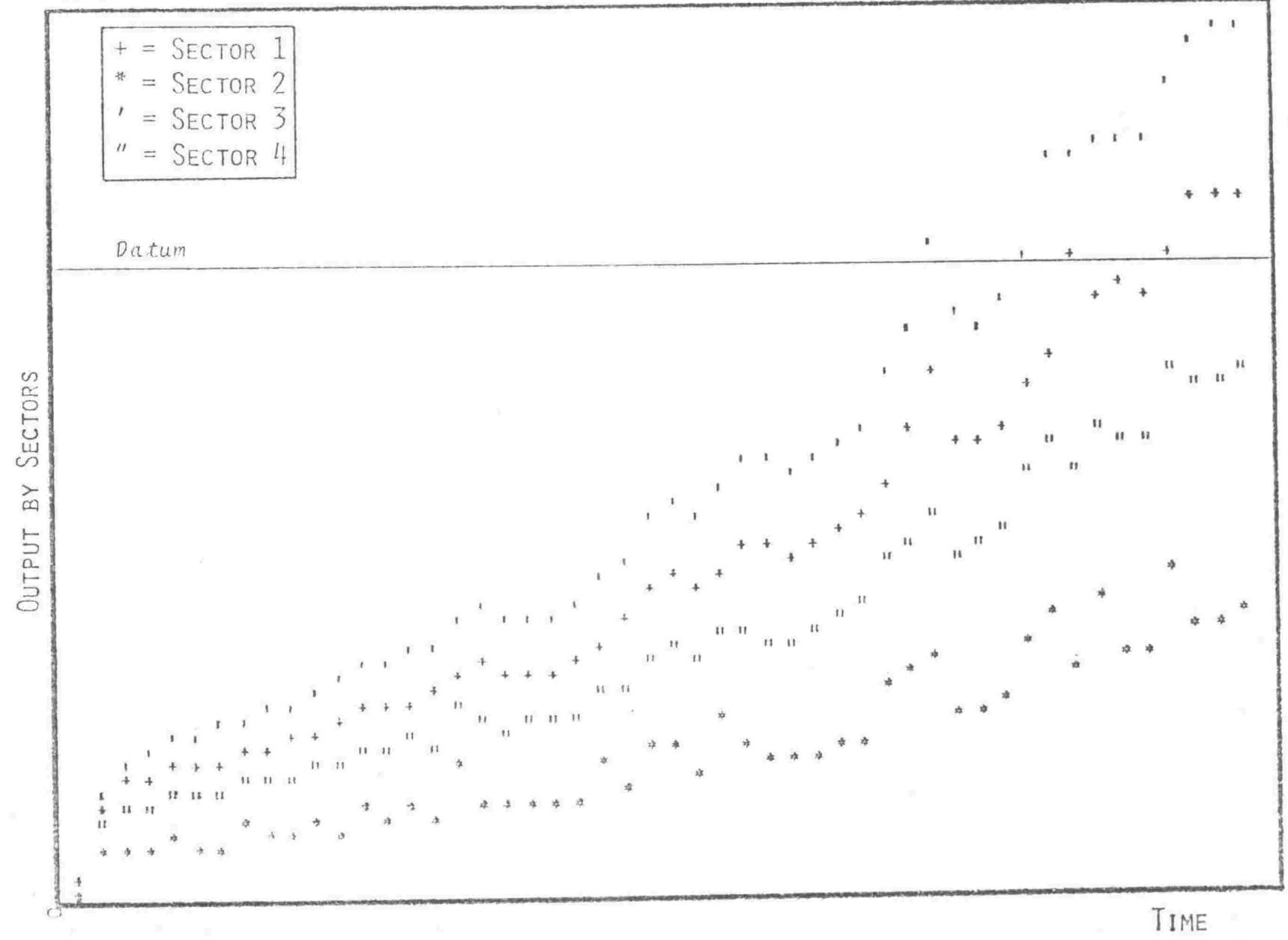



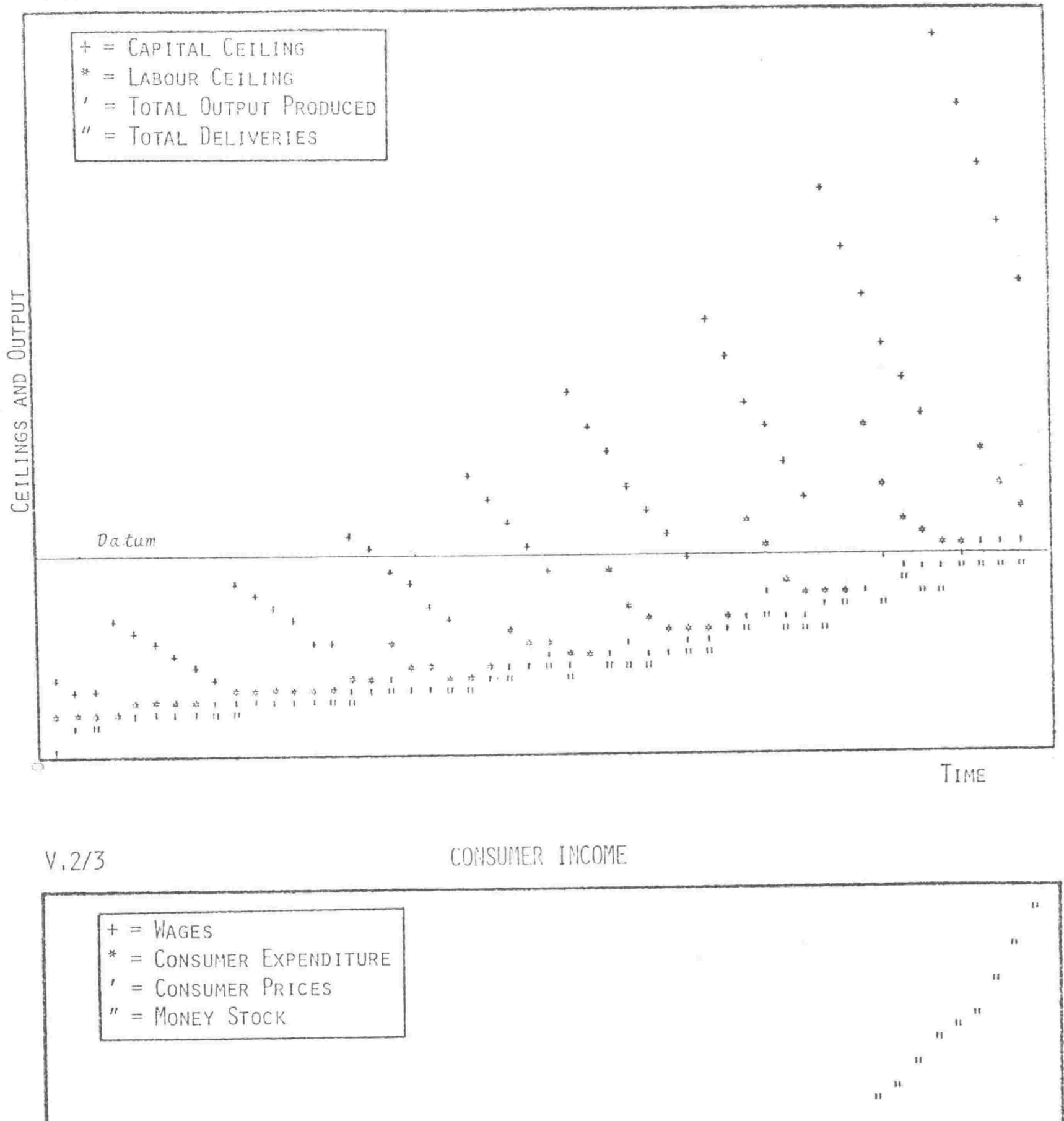

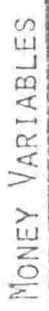

u"

" $"$

" $"$ "

" " " "

" " " " " " " "

if 17

11 

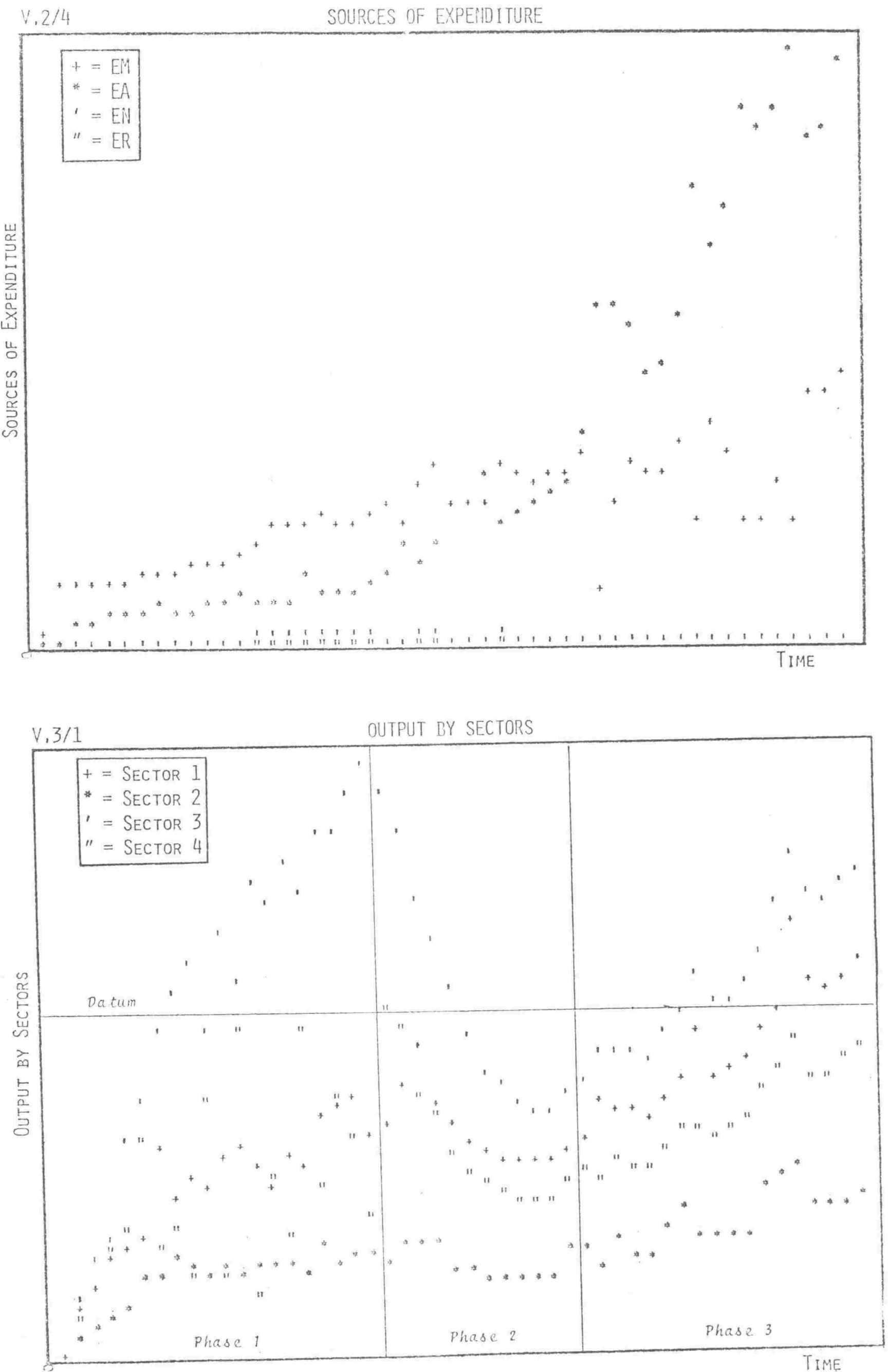


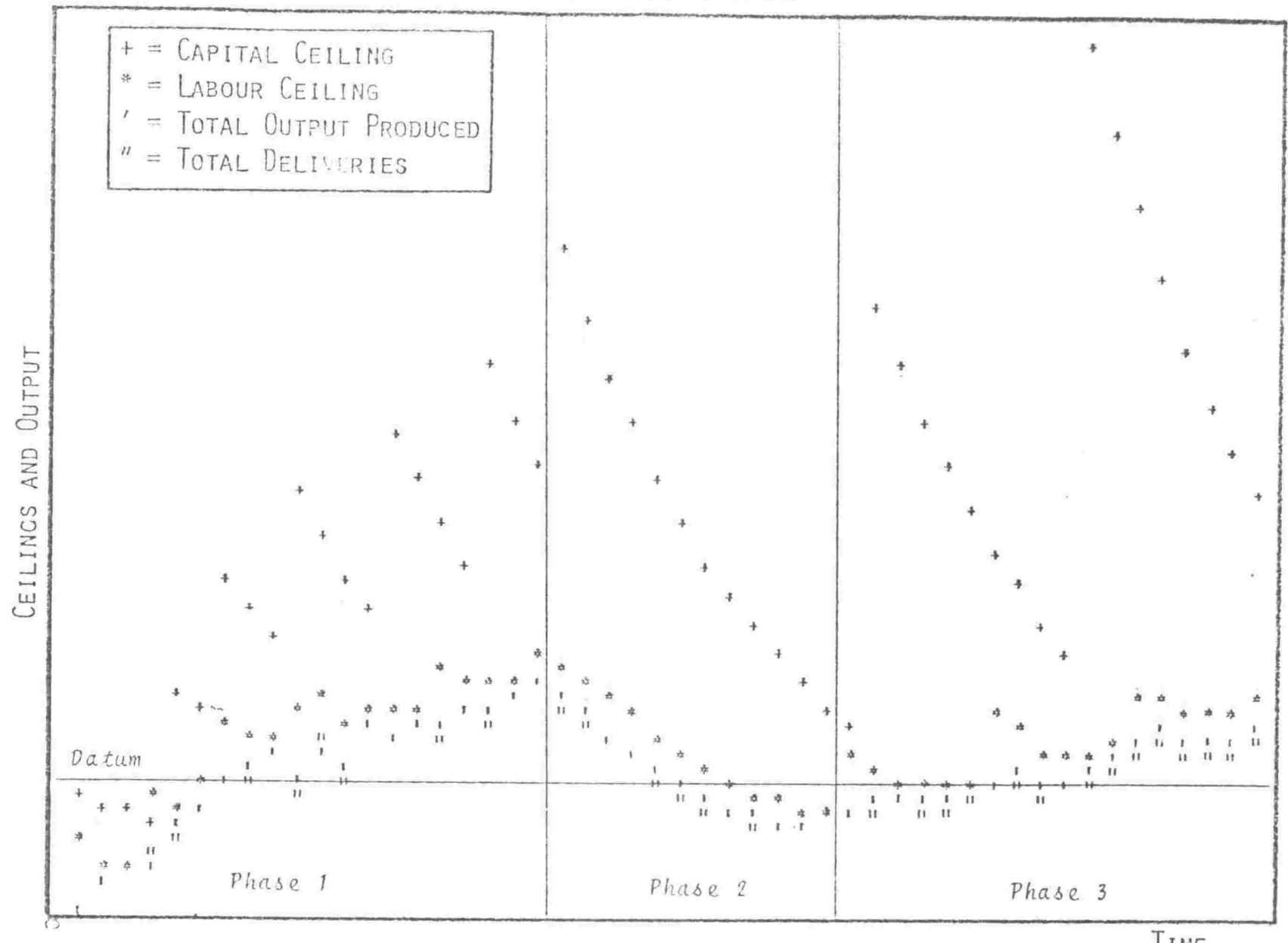

TIME

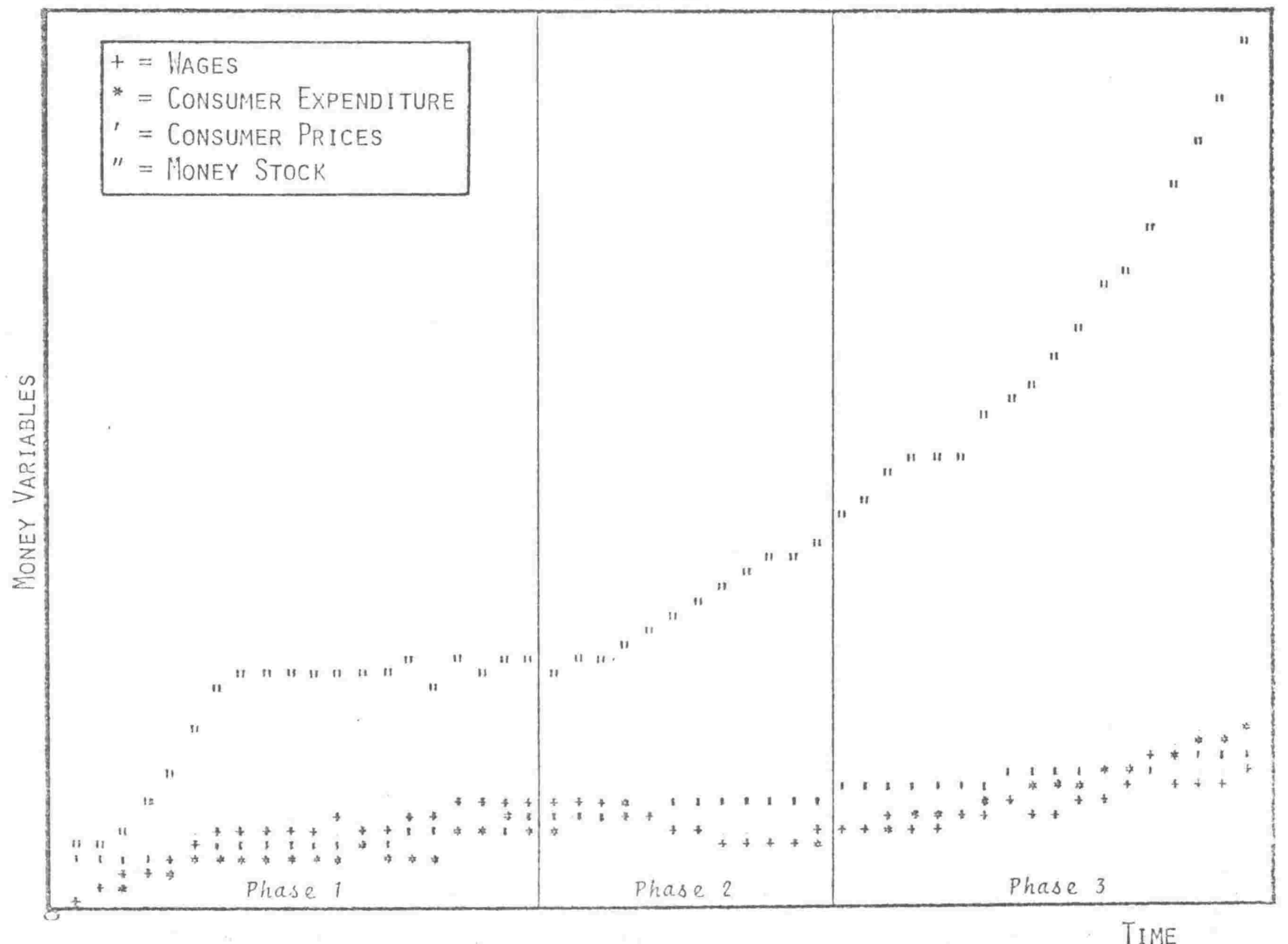


$\begin{aligned}+ & =E M \\ * & =E A \\ \prime & =E N \\ \prime & =E R\end{aligned}$

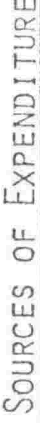

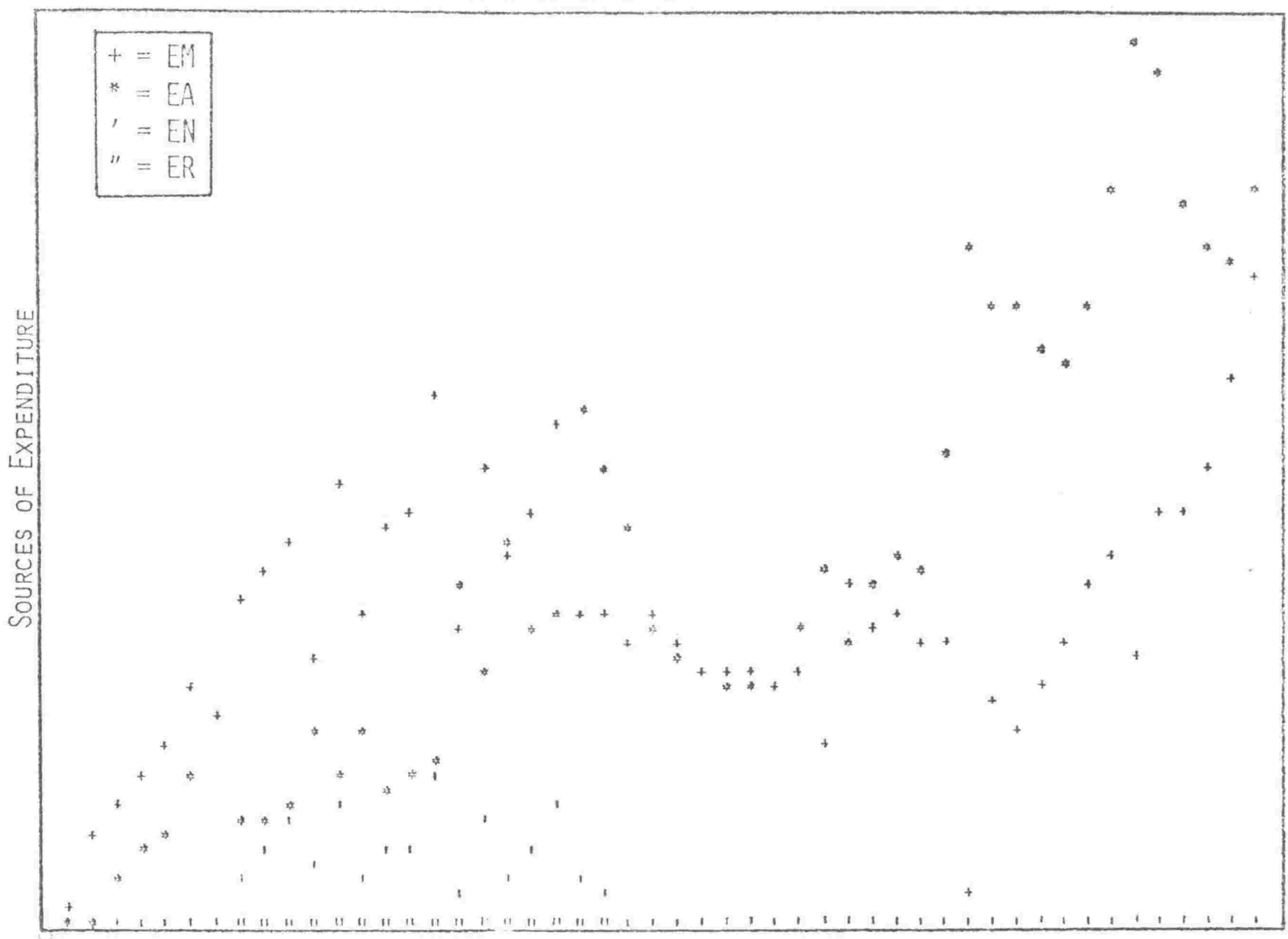

TIME

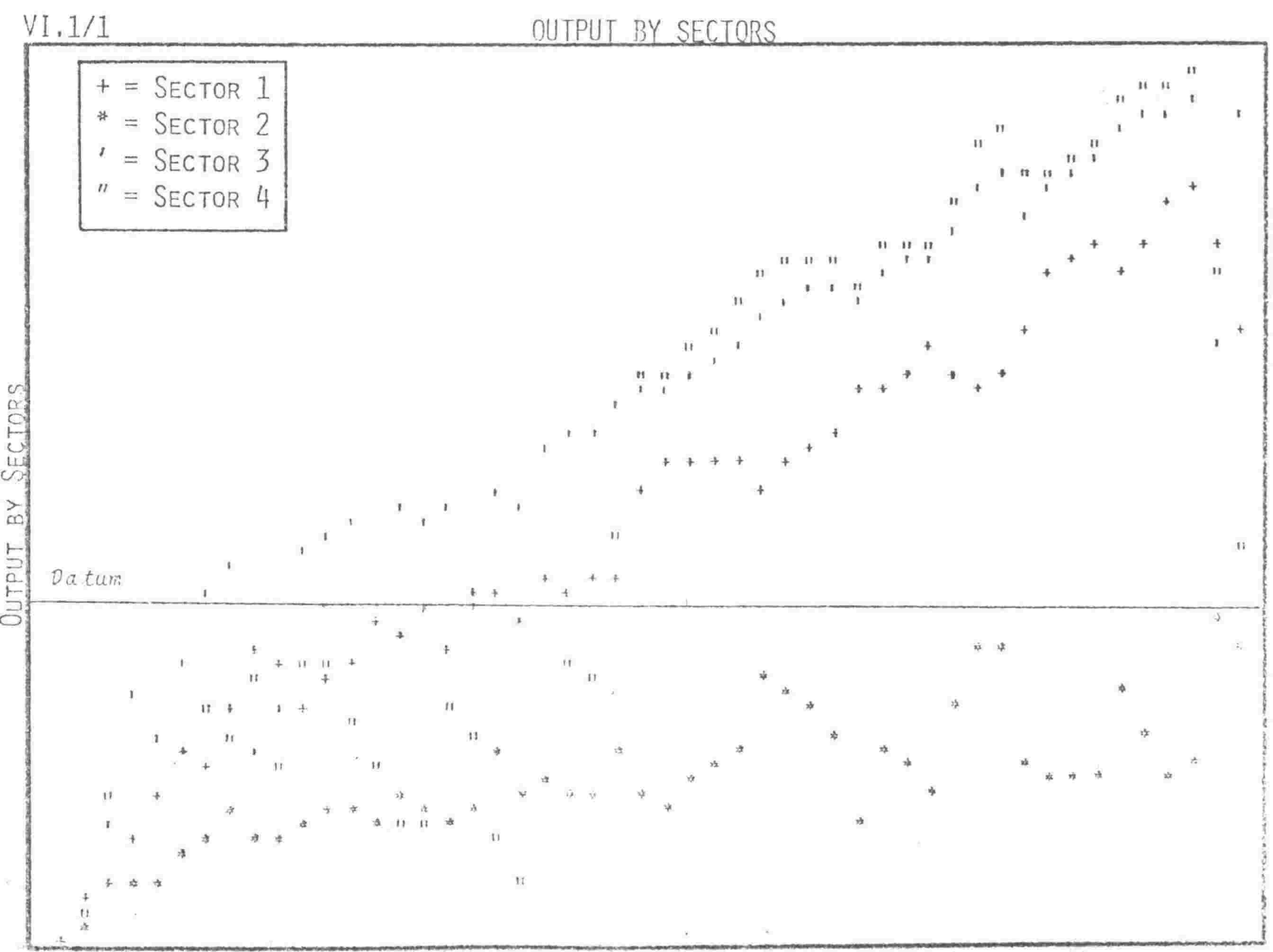




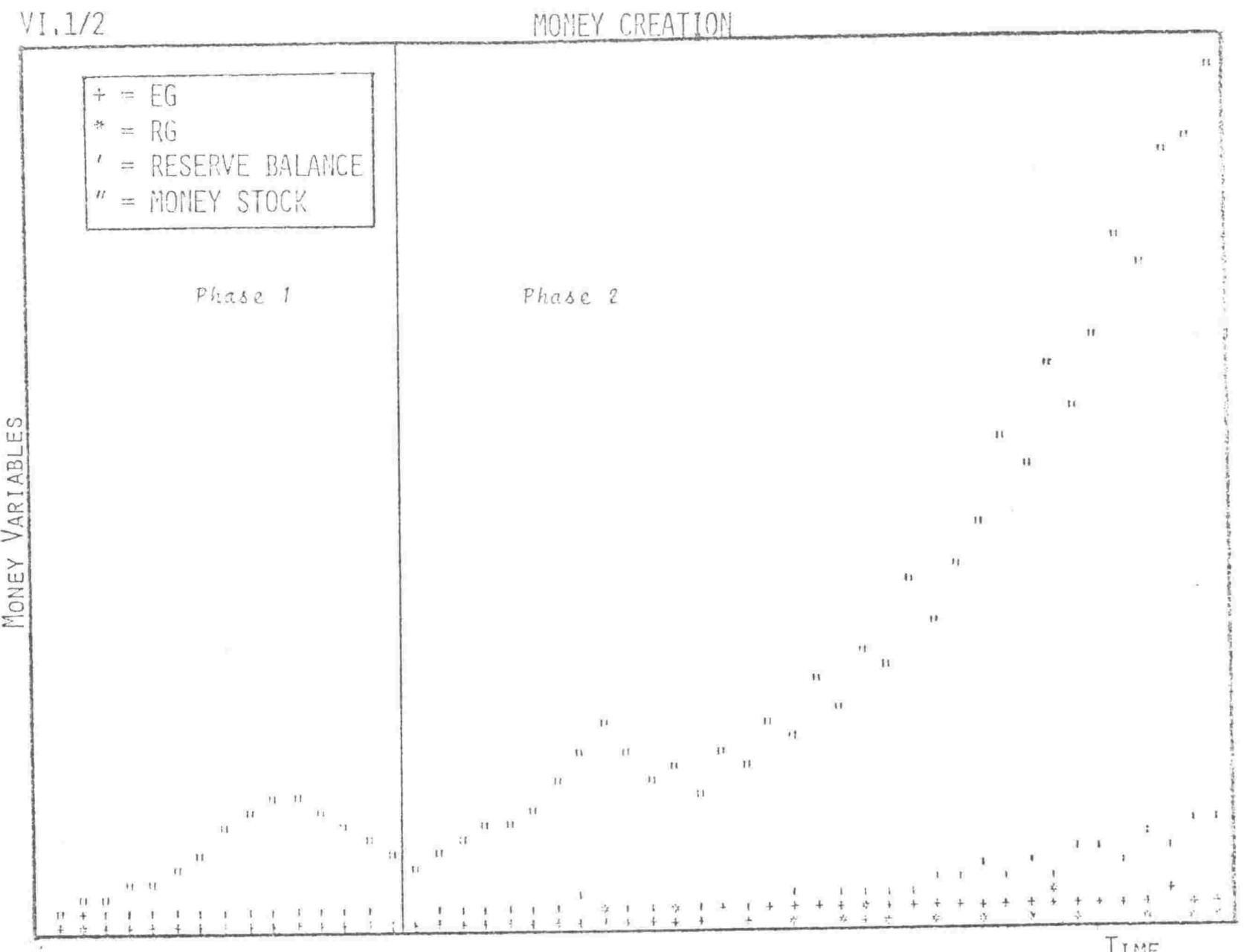

TIME

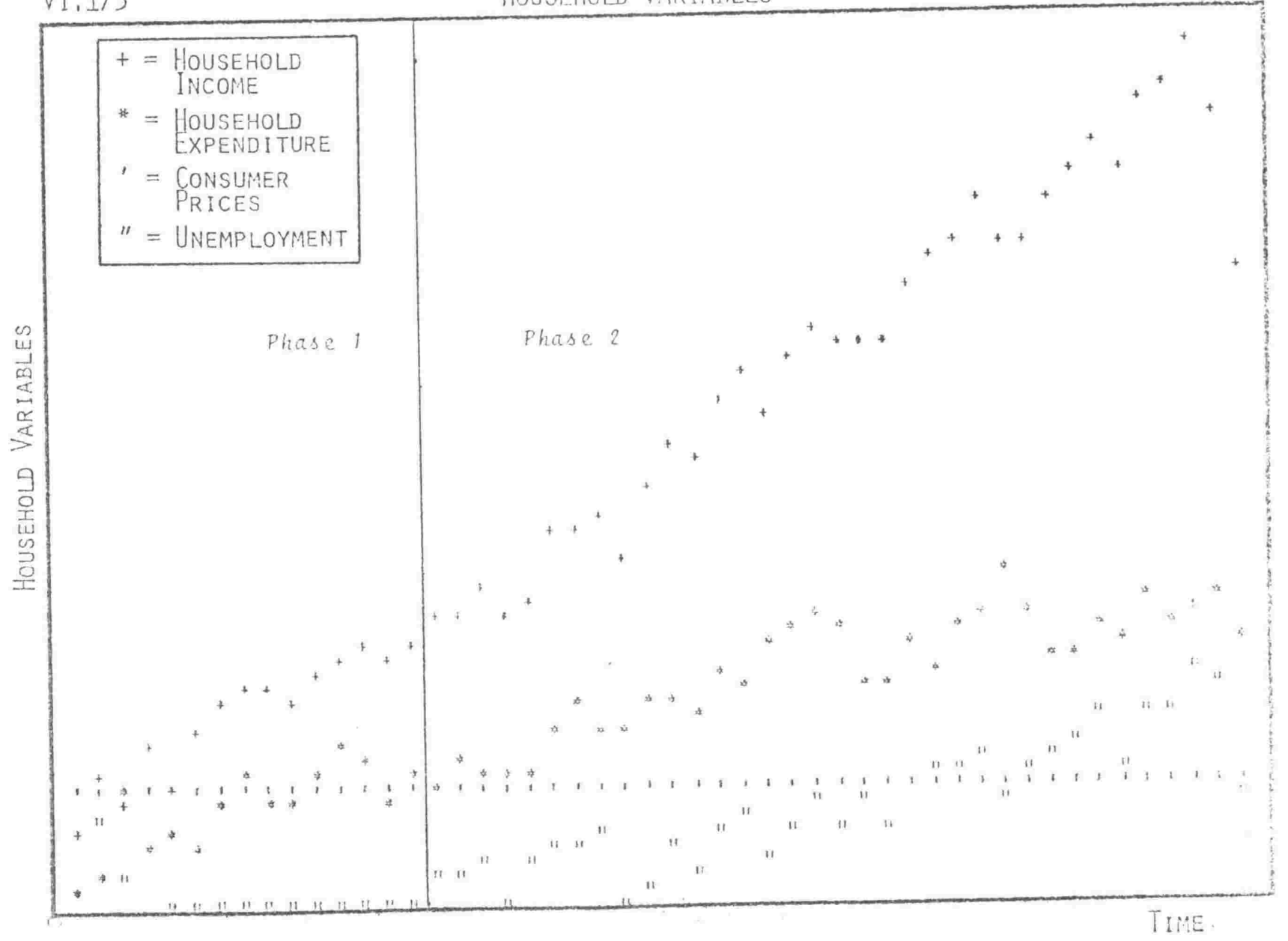



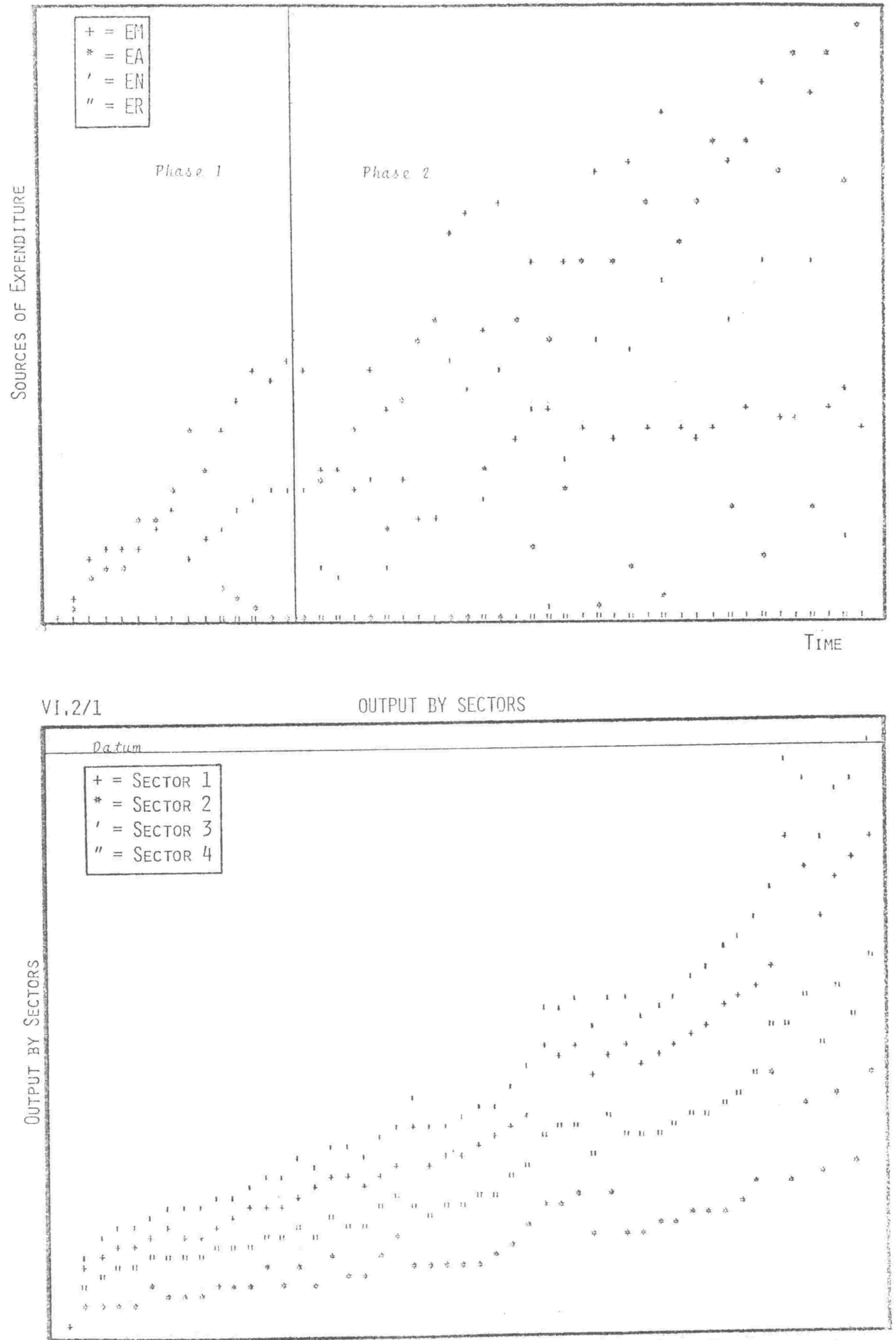

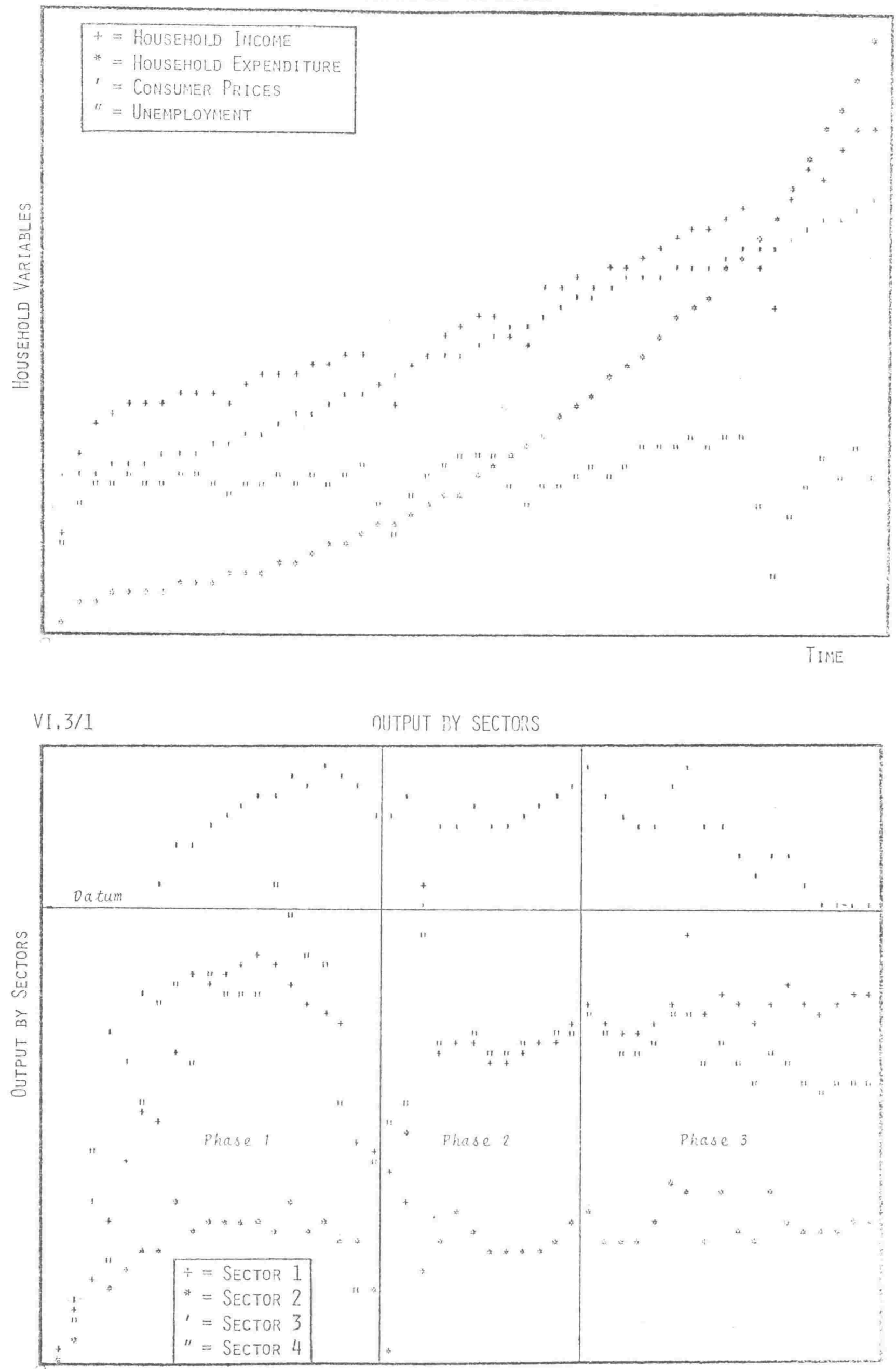


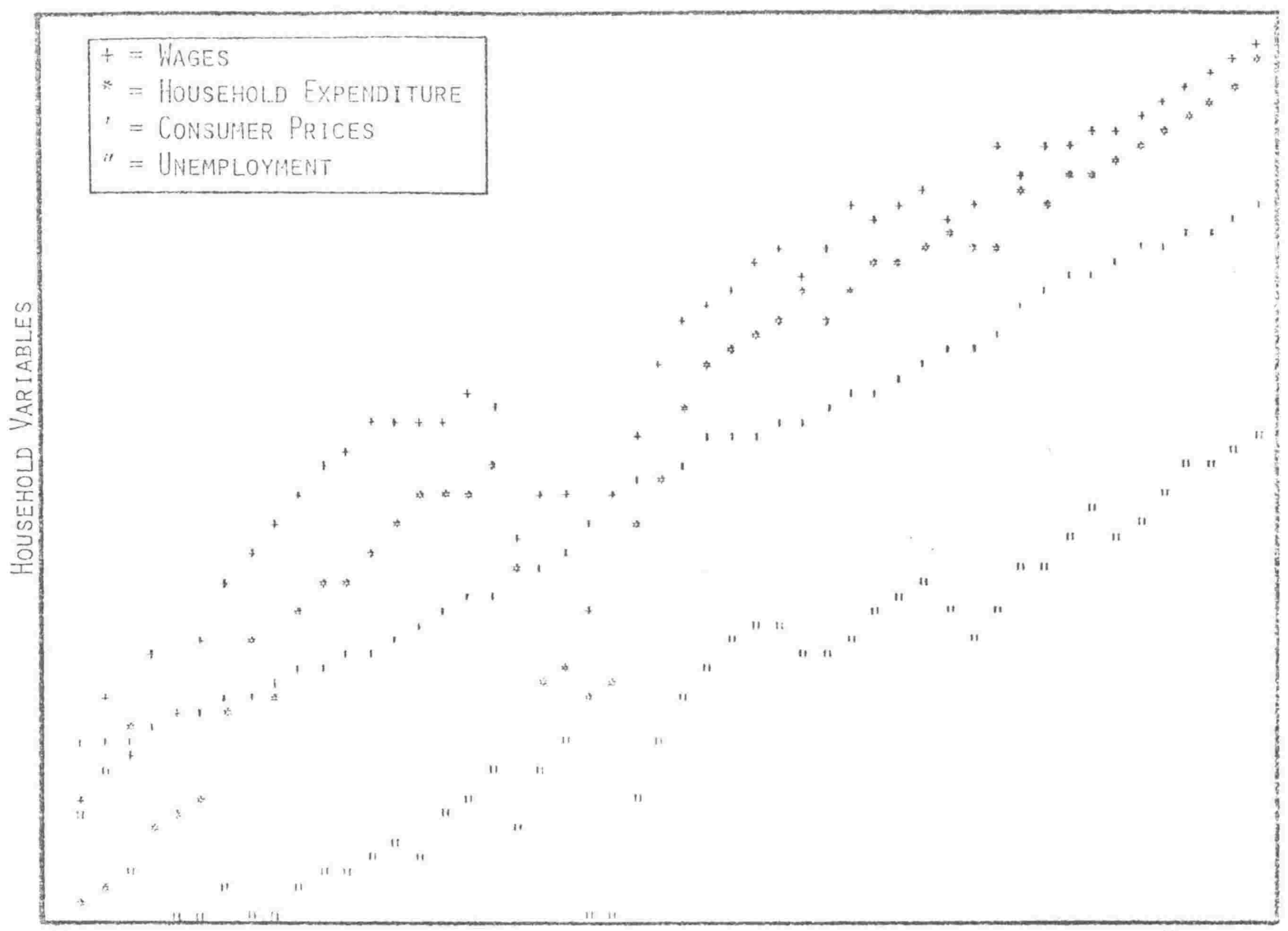




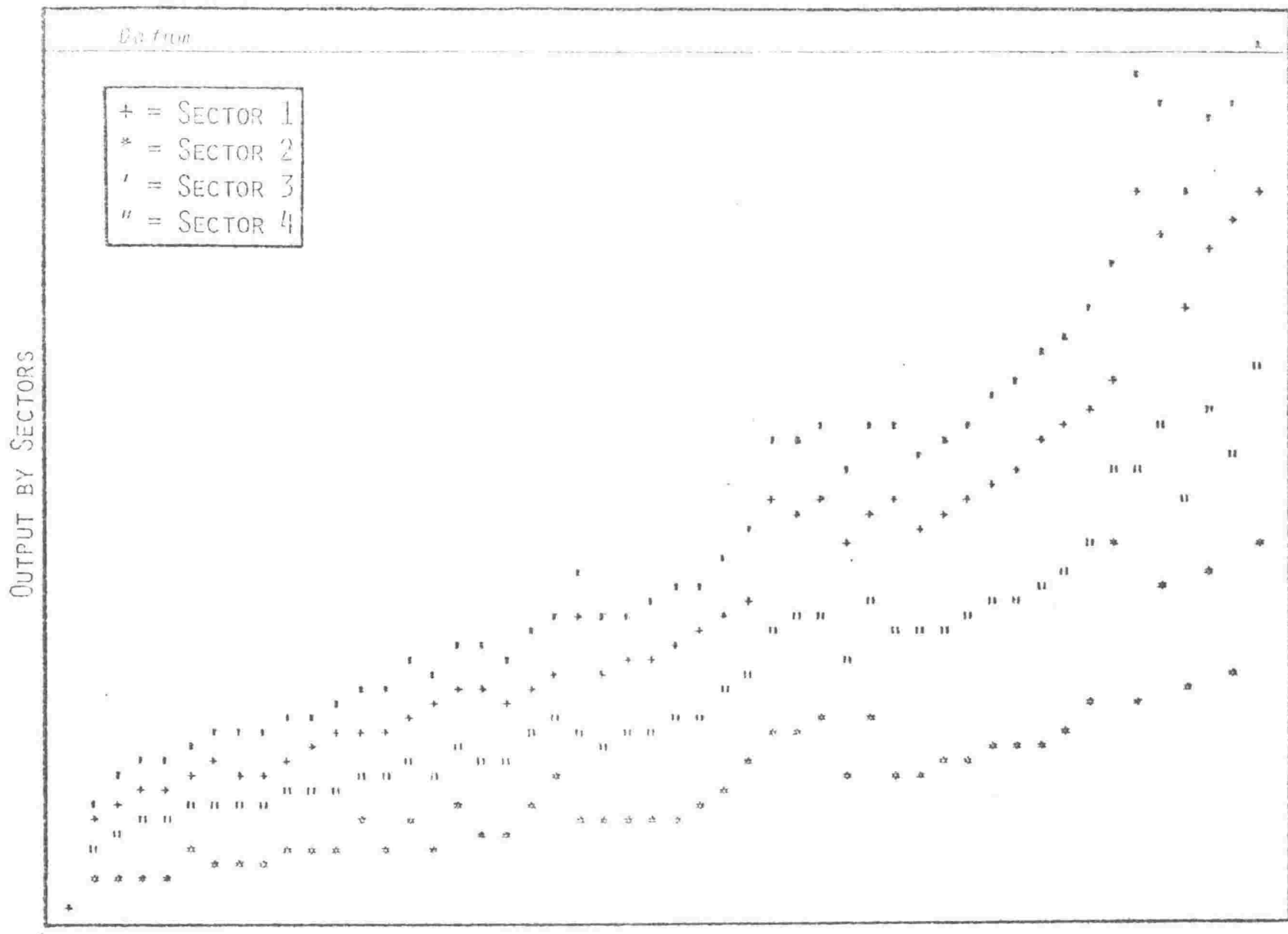

TIME

VII, $1 / 2$

!!UJSEIIILD VARIARLES

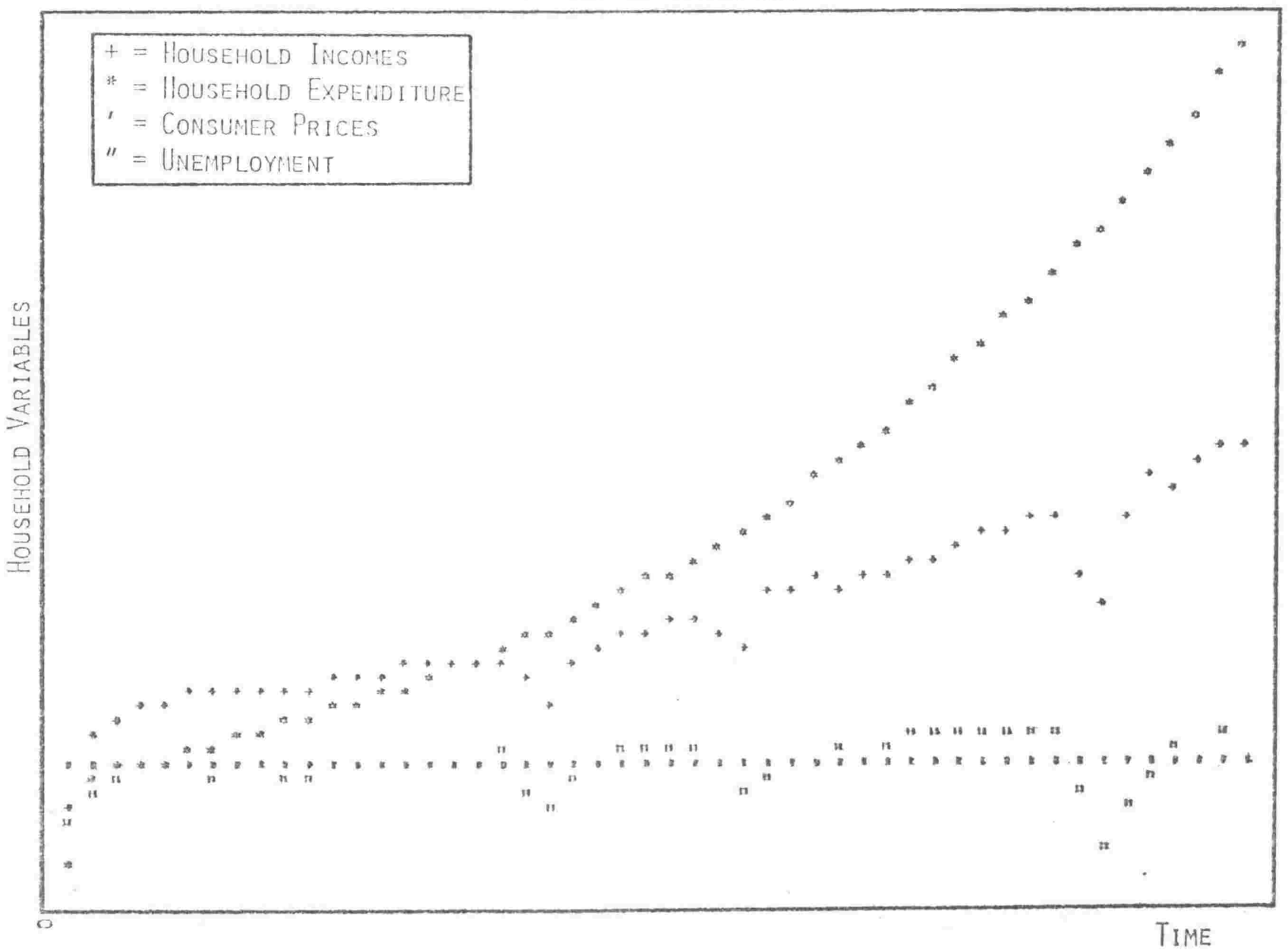




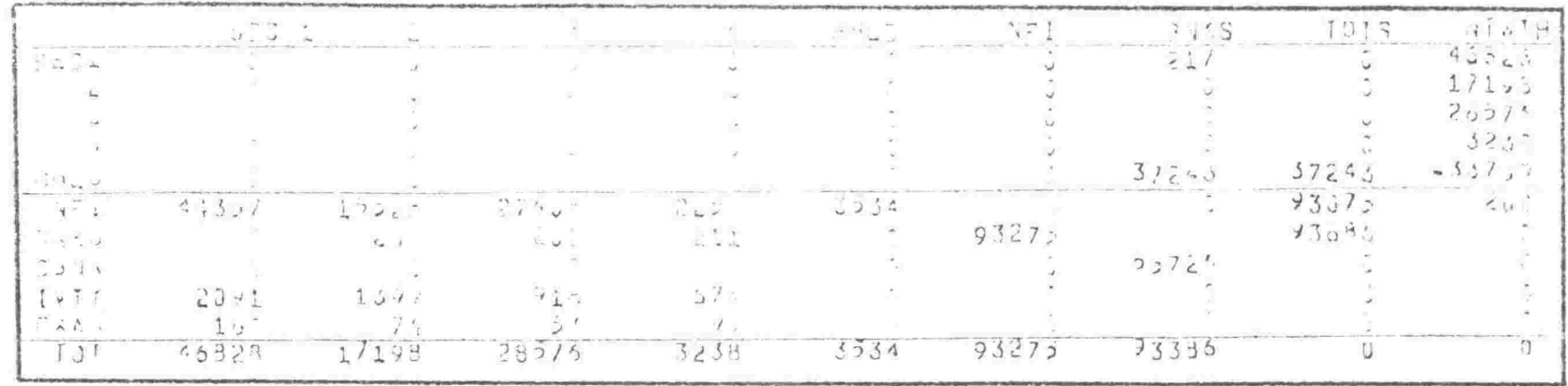

PROFITS BY SECTOR
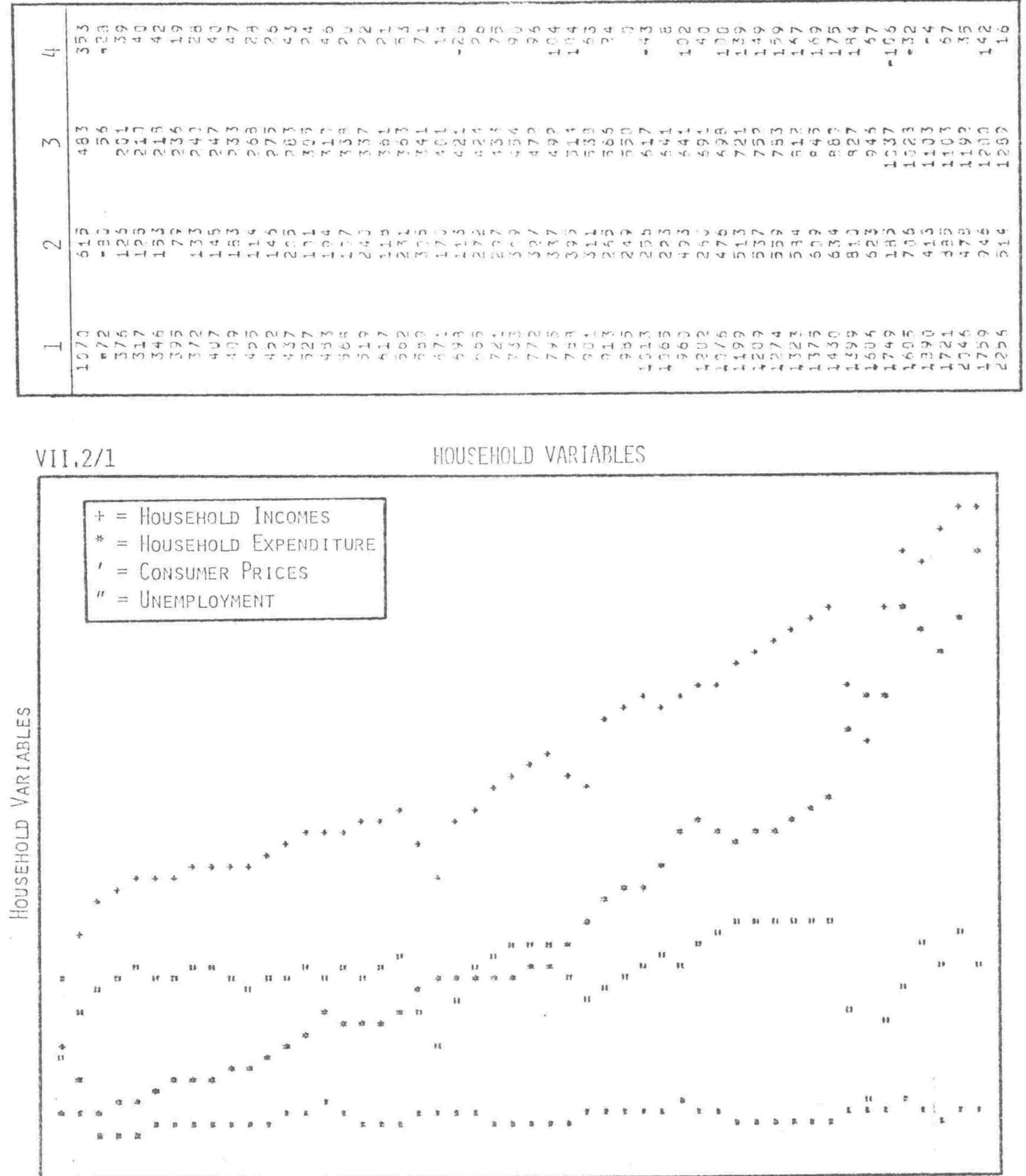


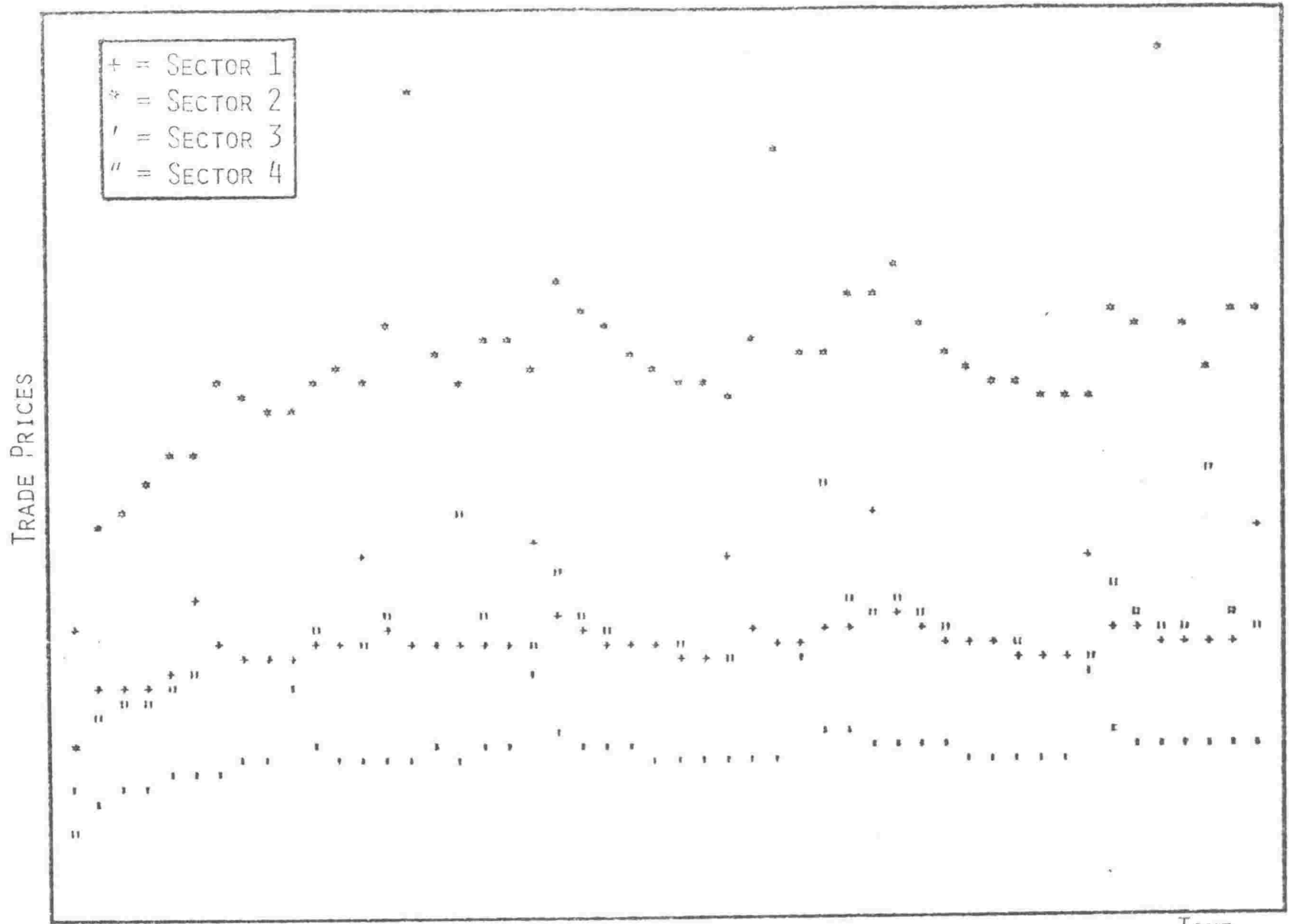

\begin{tabular}{|c|c|c|c|c|c|c|c|c|c|}
\hline & $5=01$ & 2 & 3 & 4 & HHL & $\forall=1$ & $31 \times 5$ & TOTS & NTWTH \\
\hline SECI & 9 & $c$ & 7 & 0 & $n$ & $\bar{j}$ & 79 & 0 & 9552 \\
\hline 2 & i) & 0 & $r$ & 0 & 7 & 0 & $47 \ddot{3}$ & 475 & 7700 \\
\hline$s$ & $?$ & $C$ & 7 & 3 & n & 3 & 0 & 0 & 5189 \\
\hline 4 & 0 & 0 & ) & 0 & ? & 0 & 0 & 0 & 4924 \\
\hline $4+160$ & $?$ & 2 & C. & i) & $\therefore$ & 0 & 0 & 0 & 39430 \\
\hline NF। & 5906 & 3745 & $351 ?$ & 2650 & $x 314$ & 0 & 0 & 22573 & 200 \\
\hline $9 \times 3$ & $n$ & 0 & $? 3$ & 199 & 1297 & 52773 & 0 & 24434 & 0 \\
\hline ç⿰冫 & $?$ & 0 & $n$ & $\mathrm{~J}$ & n & 0 & 33191 & 0 & 0 \\
\hline IVTY & 2755 & 3044 & $1 \geq 35$ & 2333 & n & 0 & 0 & 0 & 0 \\
\hline$F \times \Delta 5$ & 651 & $2+6$ & $1 \times ?$ & 356 & $\therefore$ & 0 & n & 0 & 7 \\
\hline TOT & $755 ?$ & 3253 & 3132 & $43 ? 4$ & 30436 & 52773 & 53234 & 0 & 0 \\
\hline
\end{tabular}

PROFITS BY SECTOR

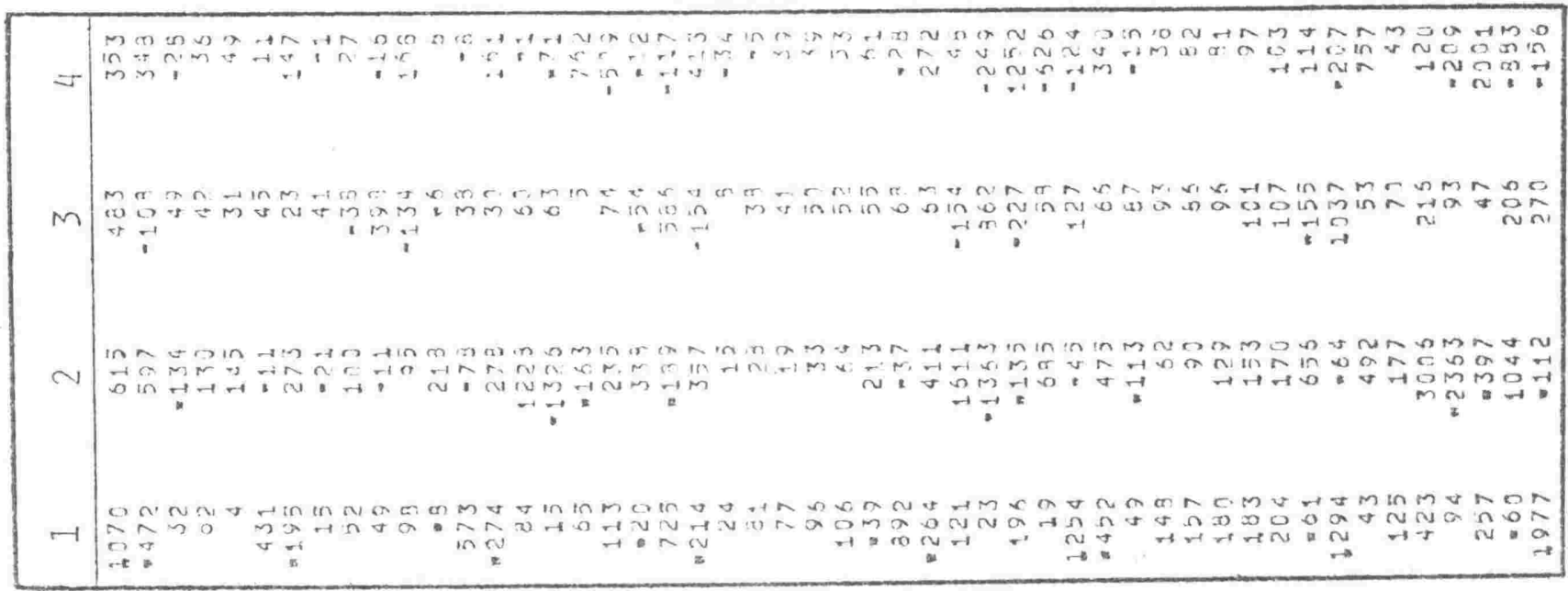




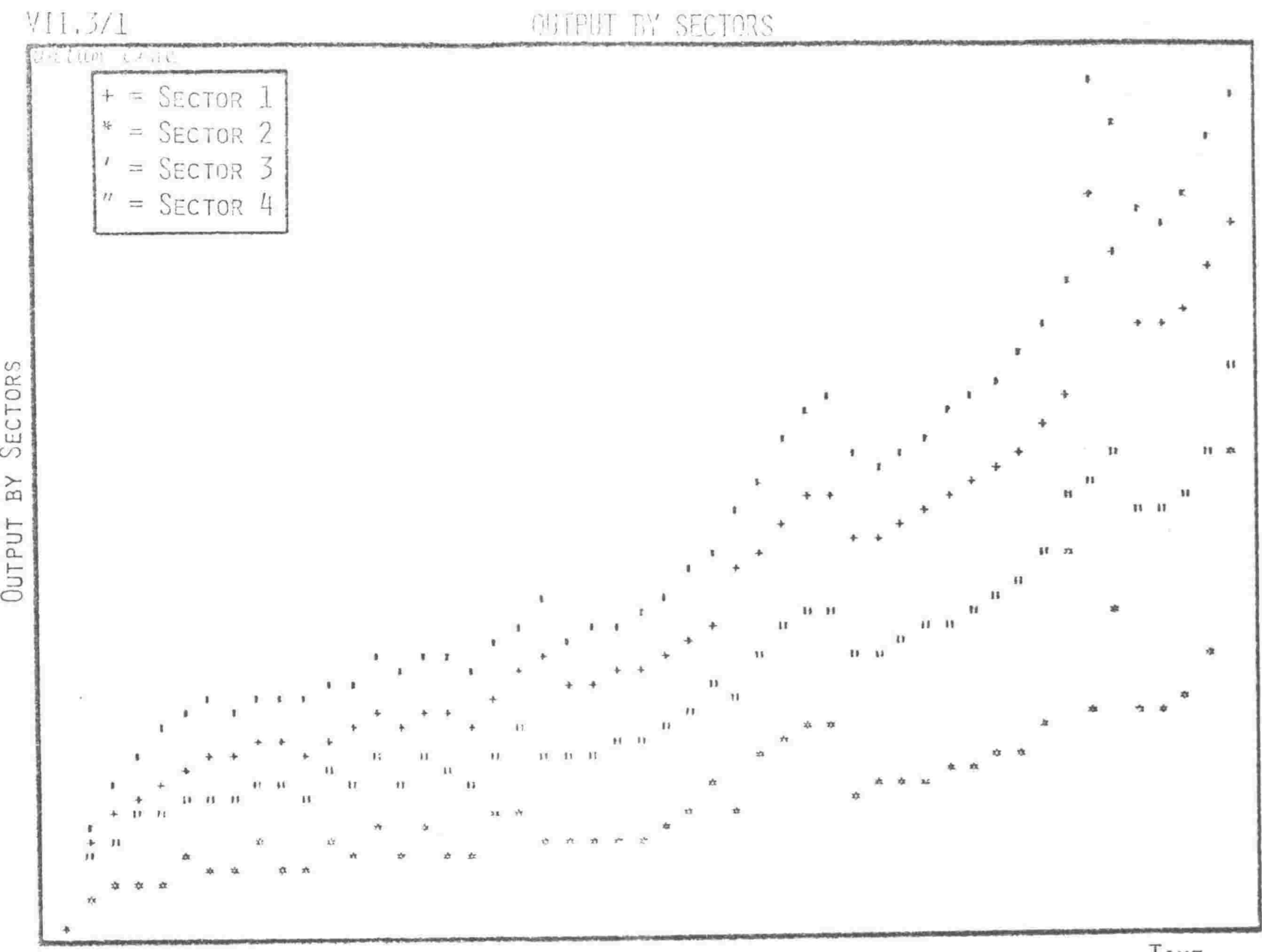

$\begin{aligned}++ & =\text { HOUSEHOLD IHCOME } \\ * & =\text { HOUSEHOLD EXPENSES } \\ \prime & =\text { CONSUMER PRICES } \\ " & =\text { UnEMPLOYMENT }\end{aligned}$

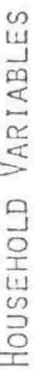

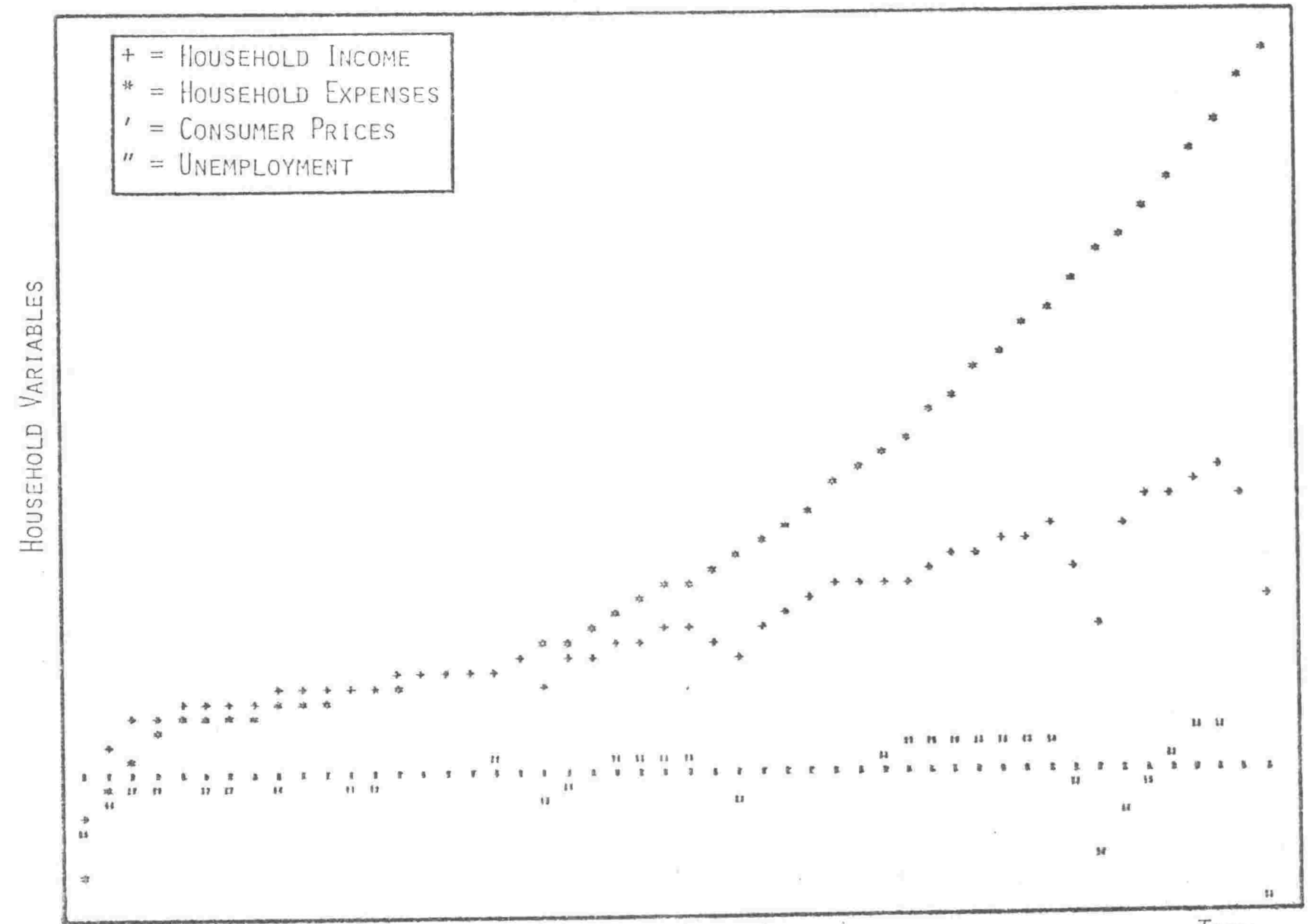




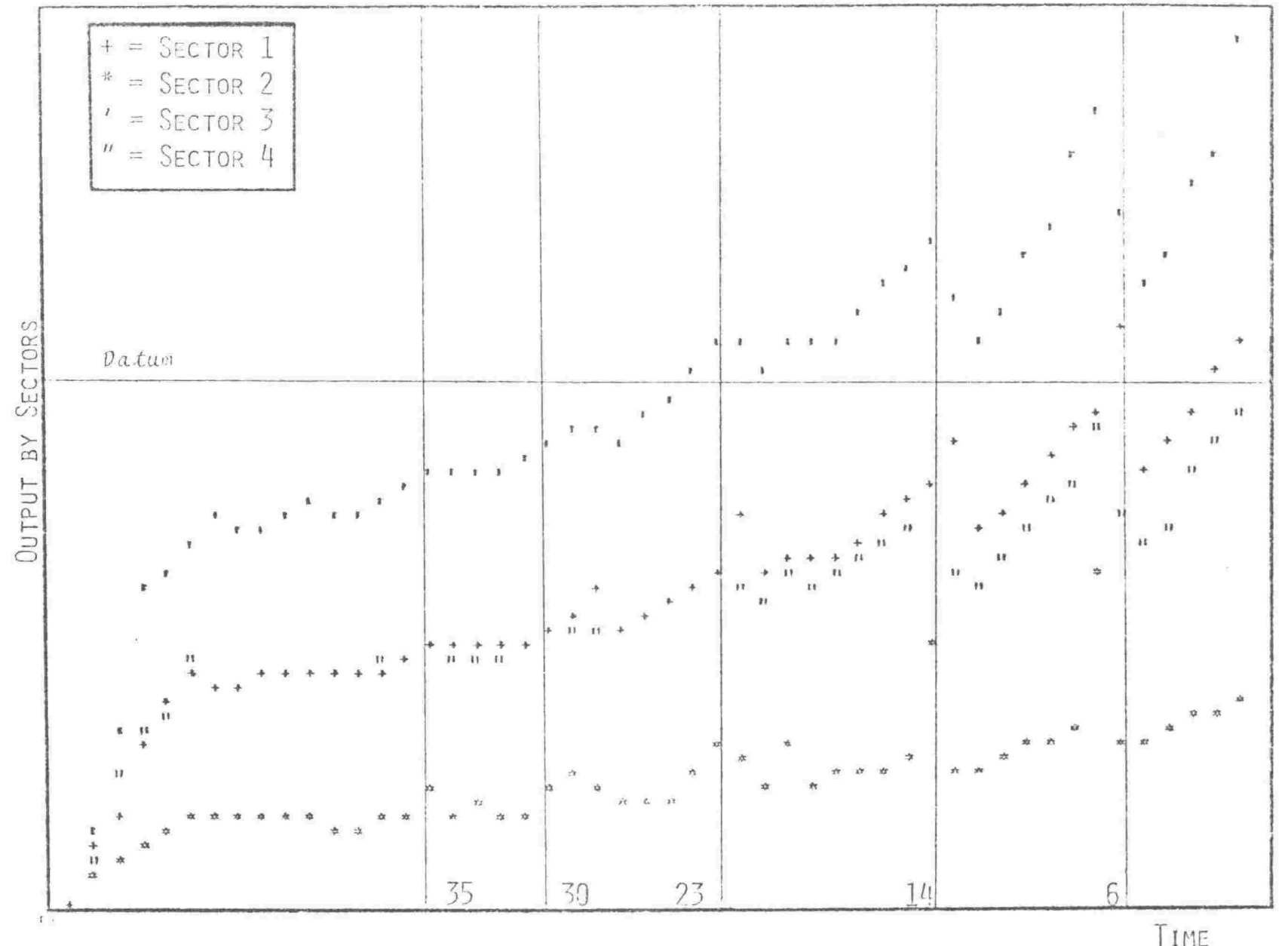

VII. 4/2

IINUSEIIII VARIARLES

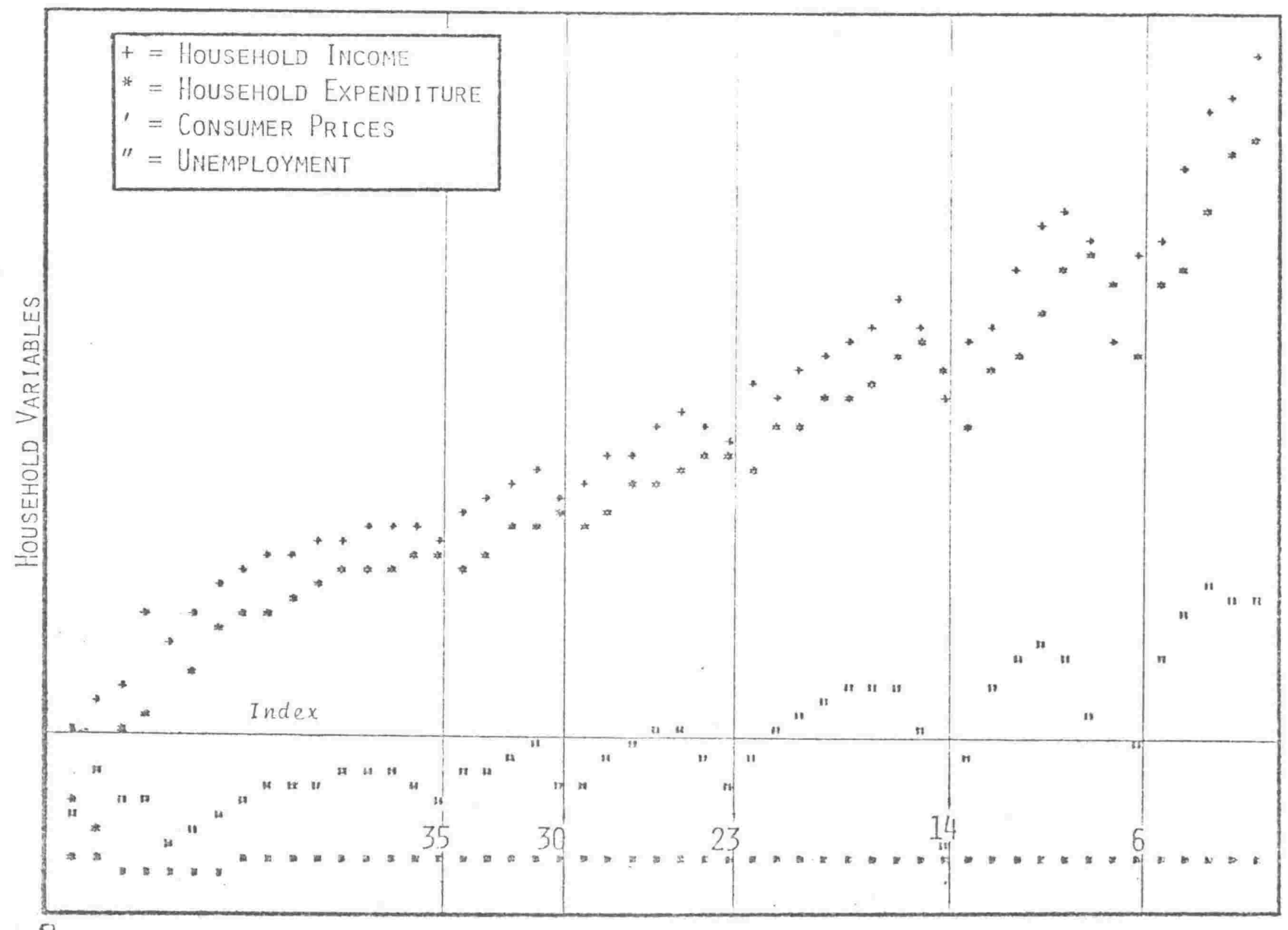




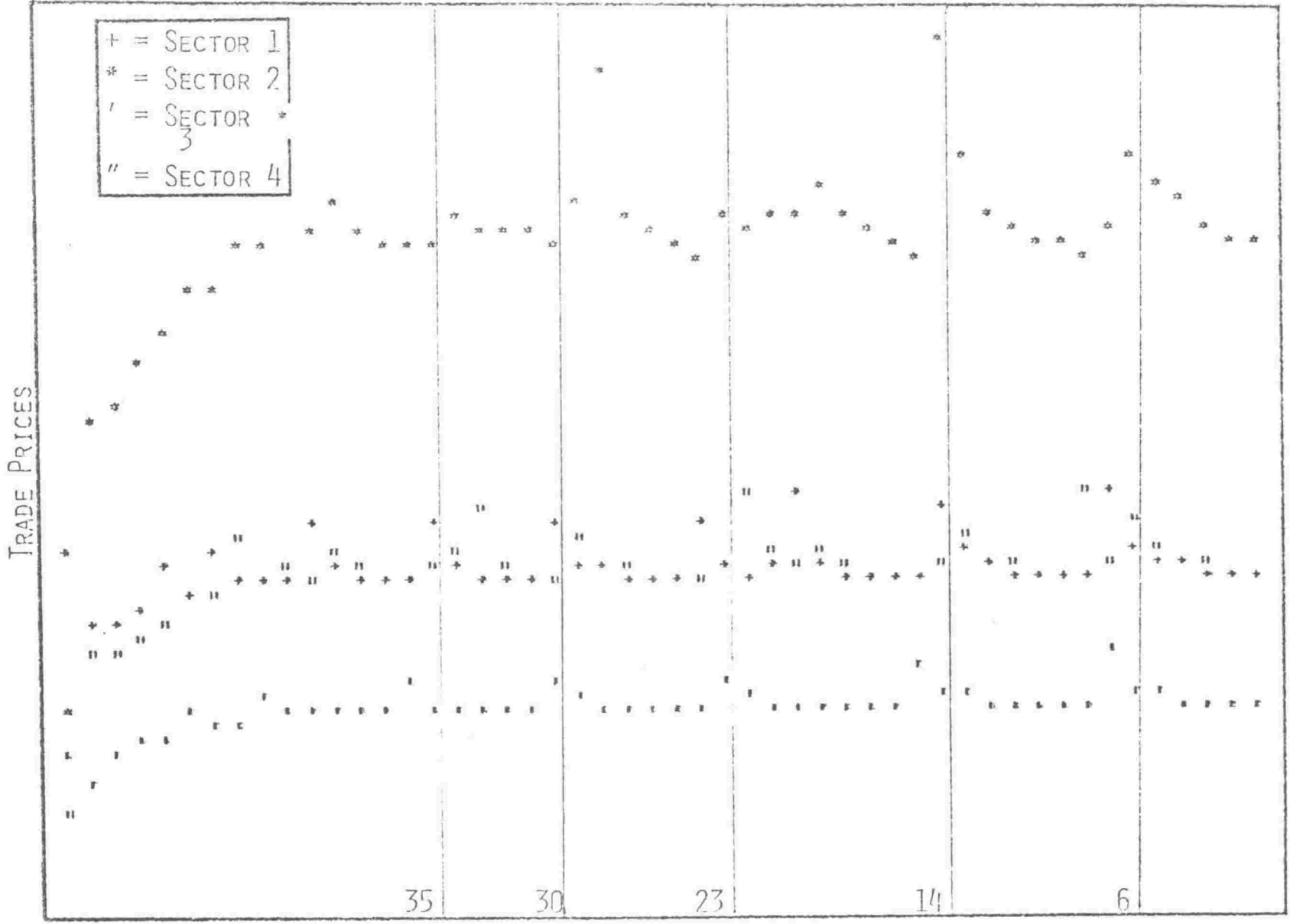

TIME

VII. 4/4

FIIANICIAL POSITINA

\begin{tabular}{|c|c|c|c|c|c|c|c|c|c|}
\hline & $5 \div 2$ & 2 & $?$ & & $\mathrm{H}+\mathrm{C}$ & $v=1$ & $71<3$ & $131=$ & $\because \mathrm{N}^{\top} \mathrm{C}$ \\
\hline SECi & ? & 0 & $n$ & 0 & - & 0 & 601 & 501 & 1.2497 \\
\hline 2 & $n$ & 3 & ก & $j$ & 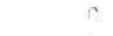 & 0 & 0 & 0 & 12326 \\
\hline$s$ & 3 & U & ? & 3 & $\cap$ & 0 & n & 0 & $1298=$ \\
\hline 4 & ? & 0 & ? & v & $a$ & 0 & 0 & 0 & $1239 ?$ \\
\hline$H-1 L U$ & ? & 2 & $?$ & $=j$ & $?$ & 0 & 3 & 0 & 93330 \\
\hline NFI & $1050 ?$ & 3152 & 10394 & วओ 1 & 11.751 & 0 & i & 20950 & 2.07 \\
\hline GNKS & 0 & $2 n u$ & 200 & $3 ? 2$ & 2010 & 51050 & i) & 23551 & ? \\
\hline çvo & ก & 0 & n & 0 & 0 & 0 & 52550 & 0 & 0 \\
\hline IVTY & $134 ?$ & $3 \ngtr \cap 3$ & 1756 & $2 \pm 17$ & n & 0 & 0 & 0 & $?$ \\
\hline$F \times A S$ & 595 & 55 & $? 3$ ? & 152 & 0 & 2 & C & ก & 7 \\
\hline TOI & 13733 & 12326 & $1275 ?$ & 13372 & 13030 & 51050 & 53131 & 0 & c. \\
\hline
\end{tabular}

PROFITS BY SECTOR

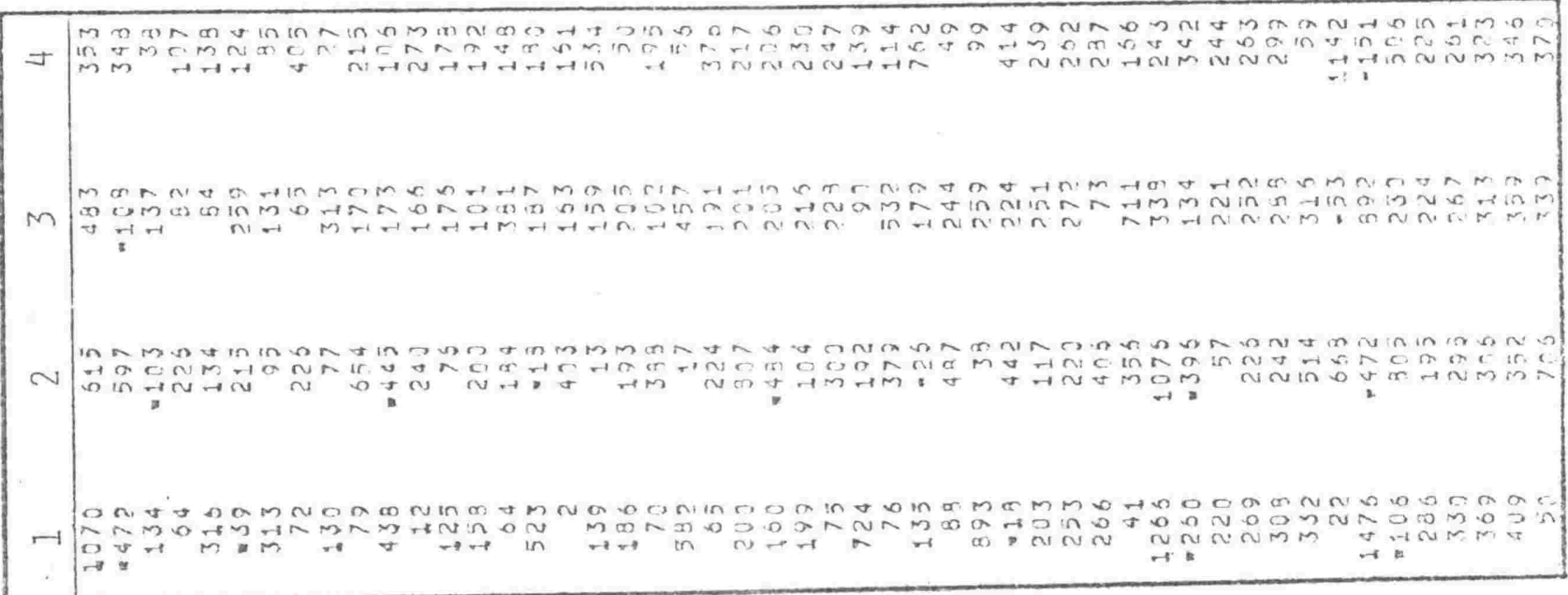




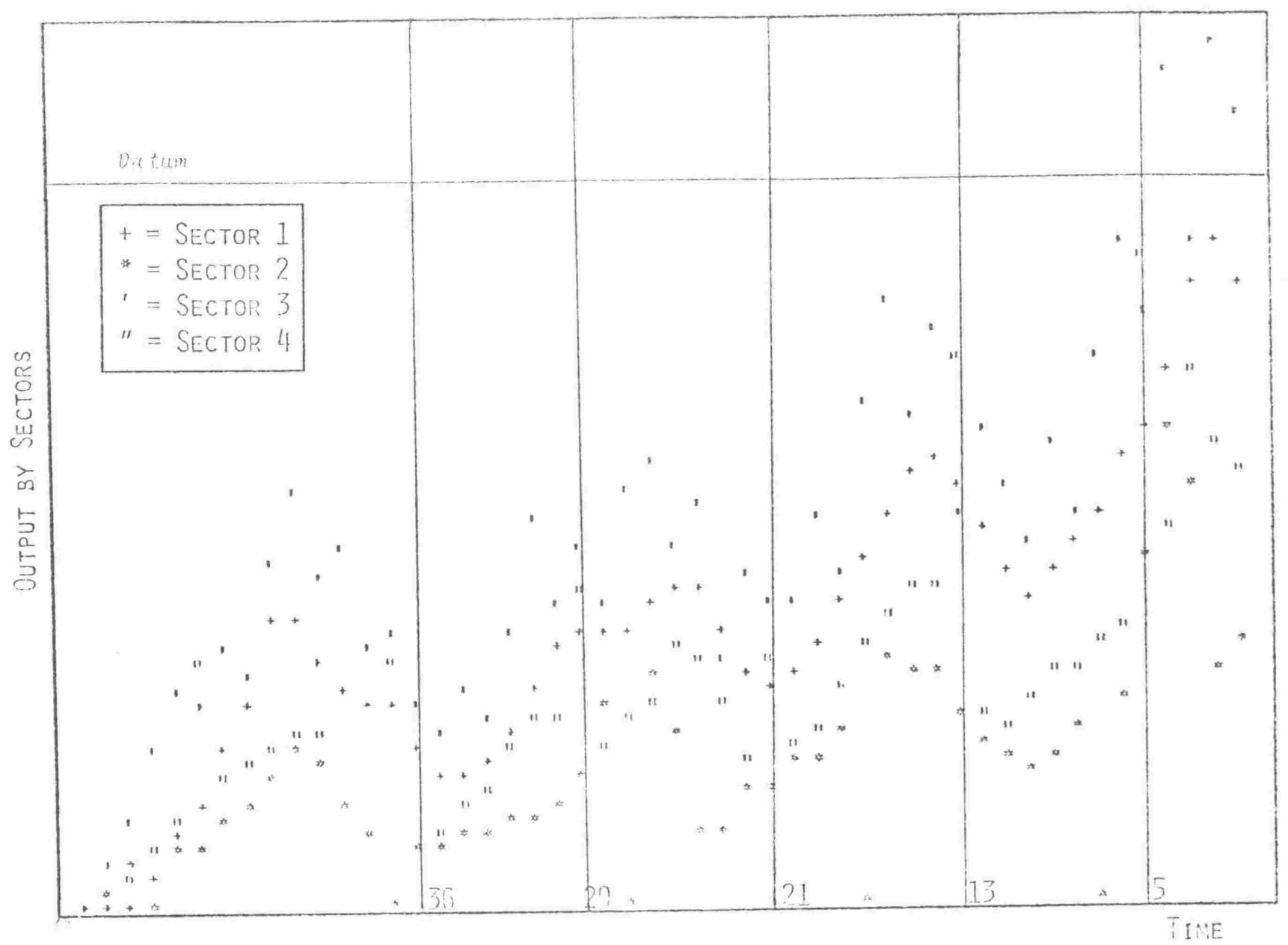

VIII. 1/2

WOUSEHDLI) YARIAPLES

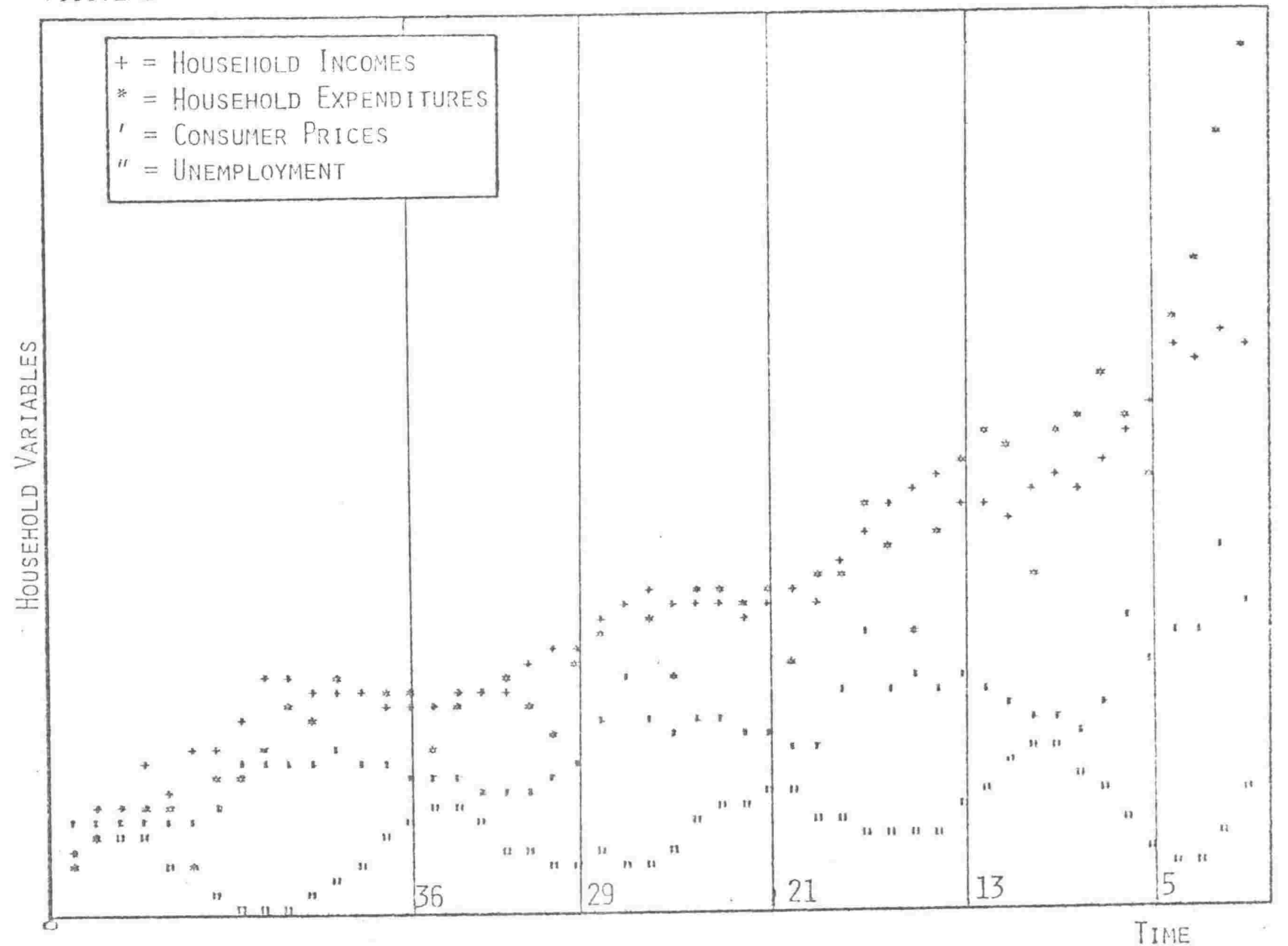



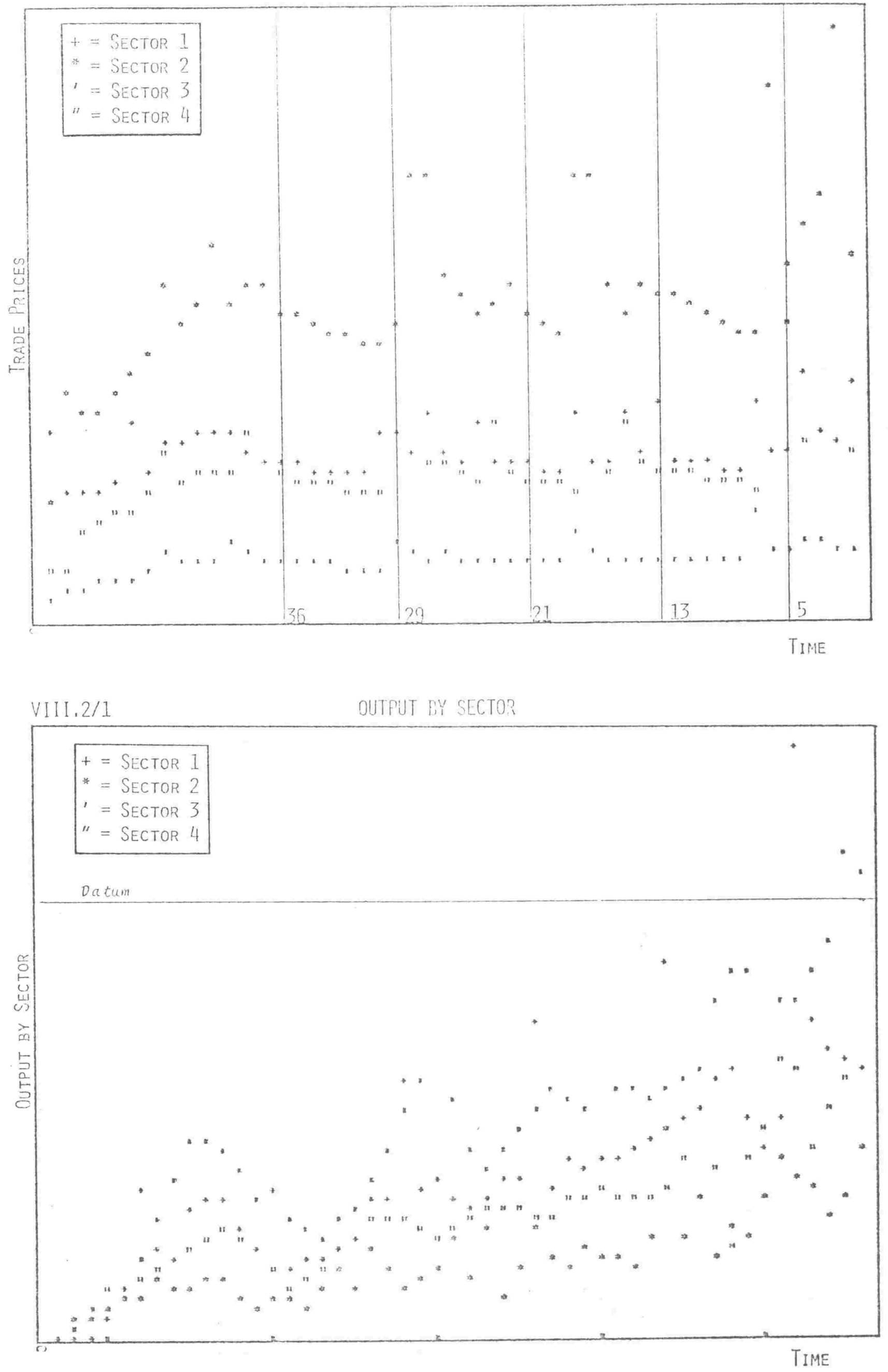


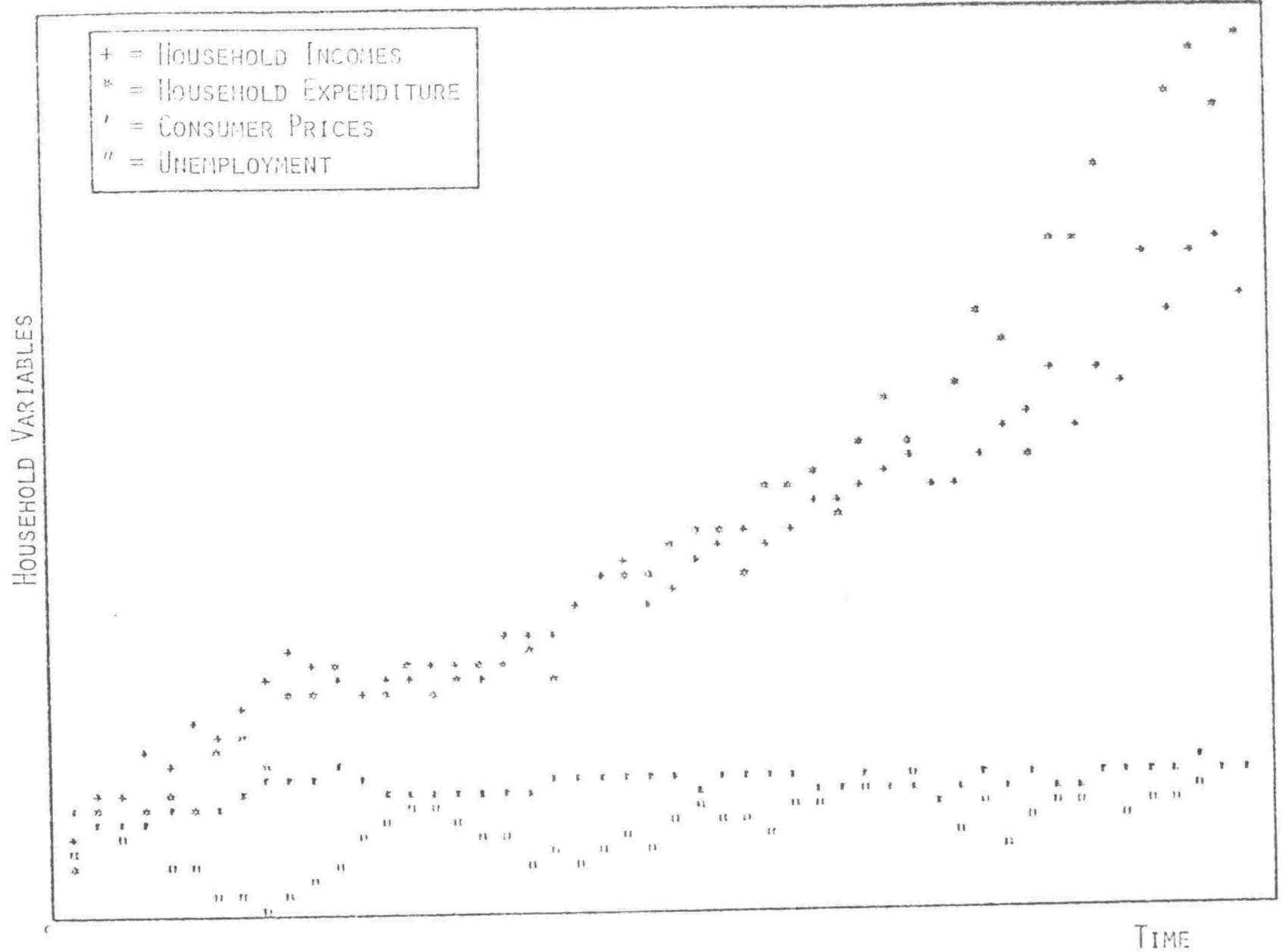

TRADE PRICES BY SECTOR

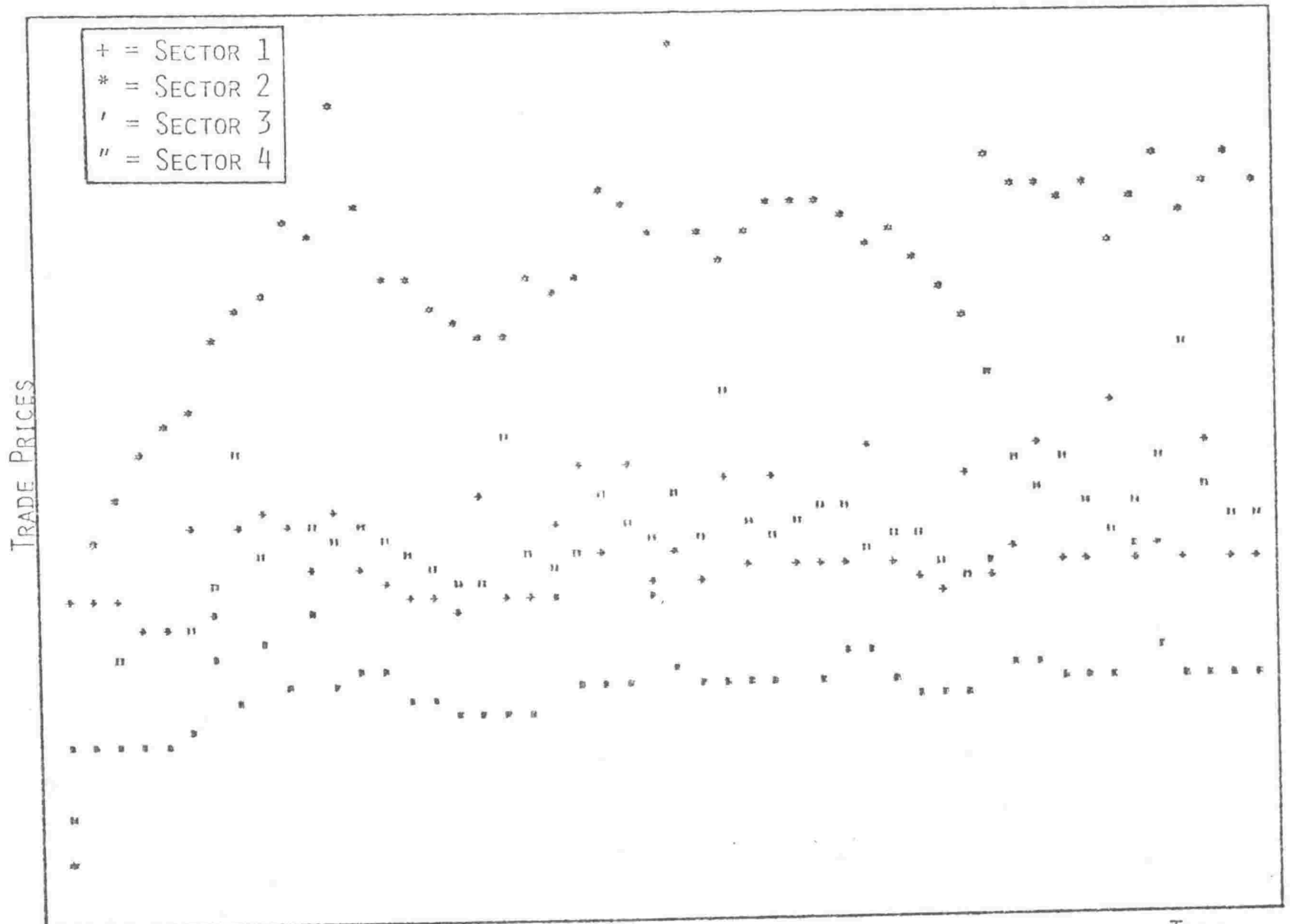



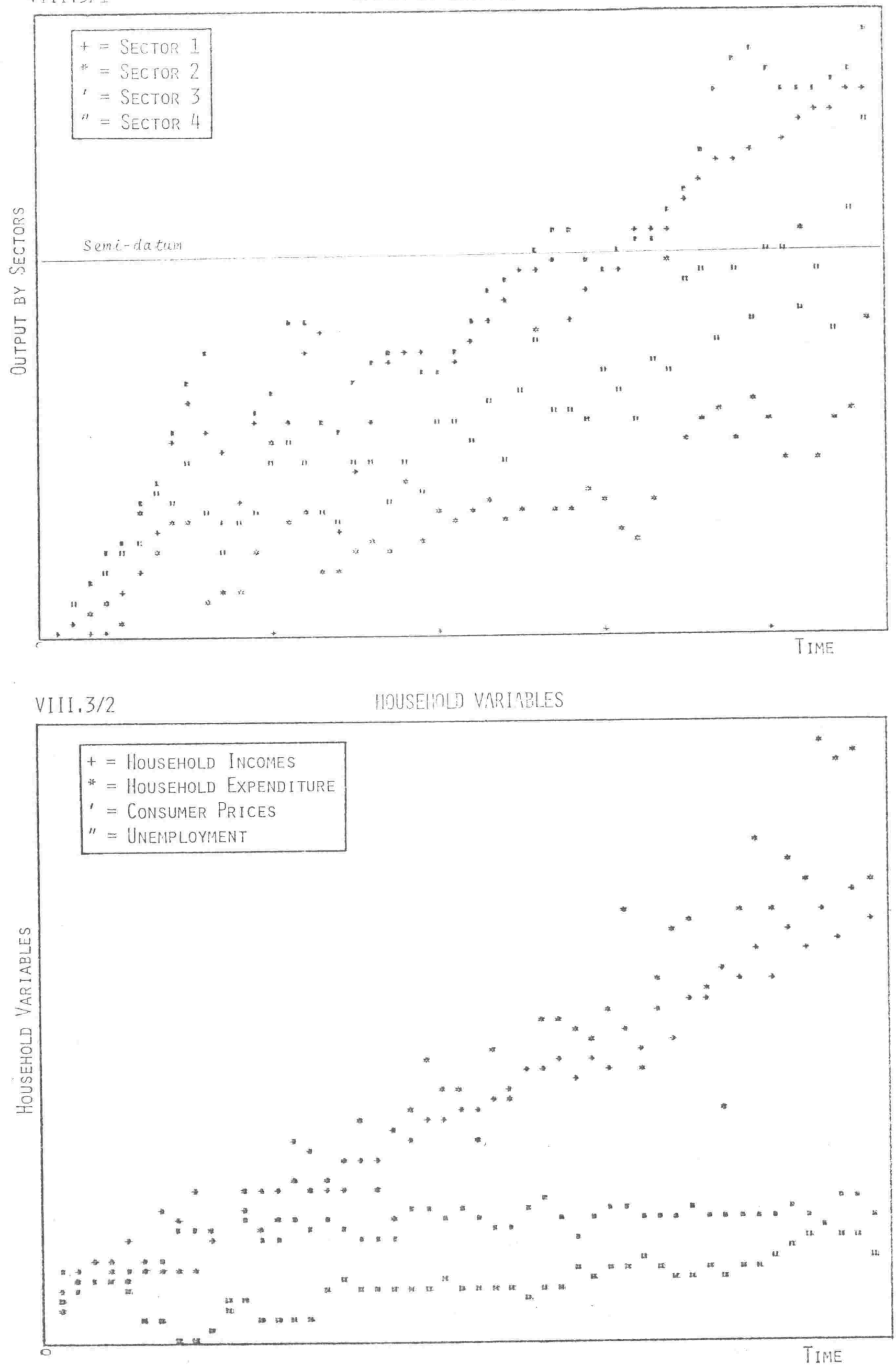


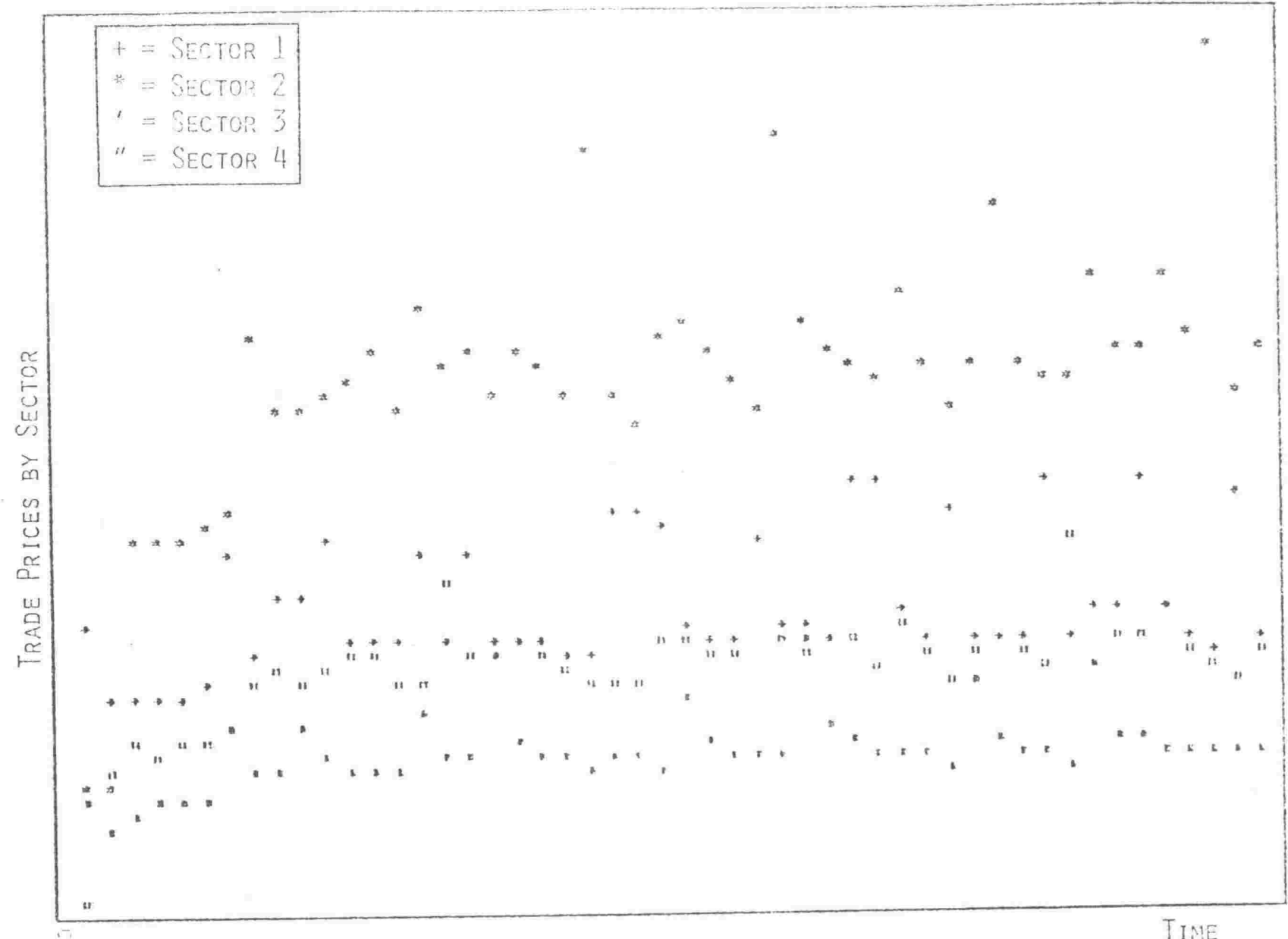

VIII , 4/1

$+=$ SECTOR 1

* = SECTOR 2

$'=$ SECTOR 3

$"=$ SECTOR 4

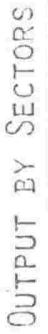
Datum $+{ }^{2}+$

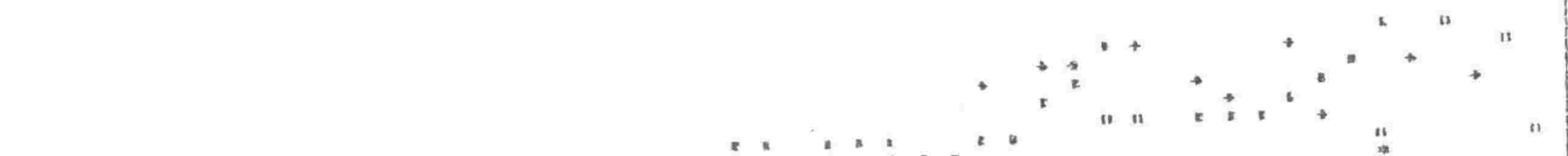
( 


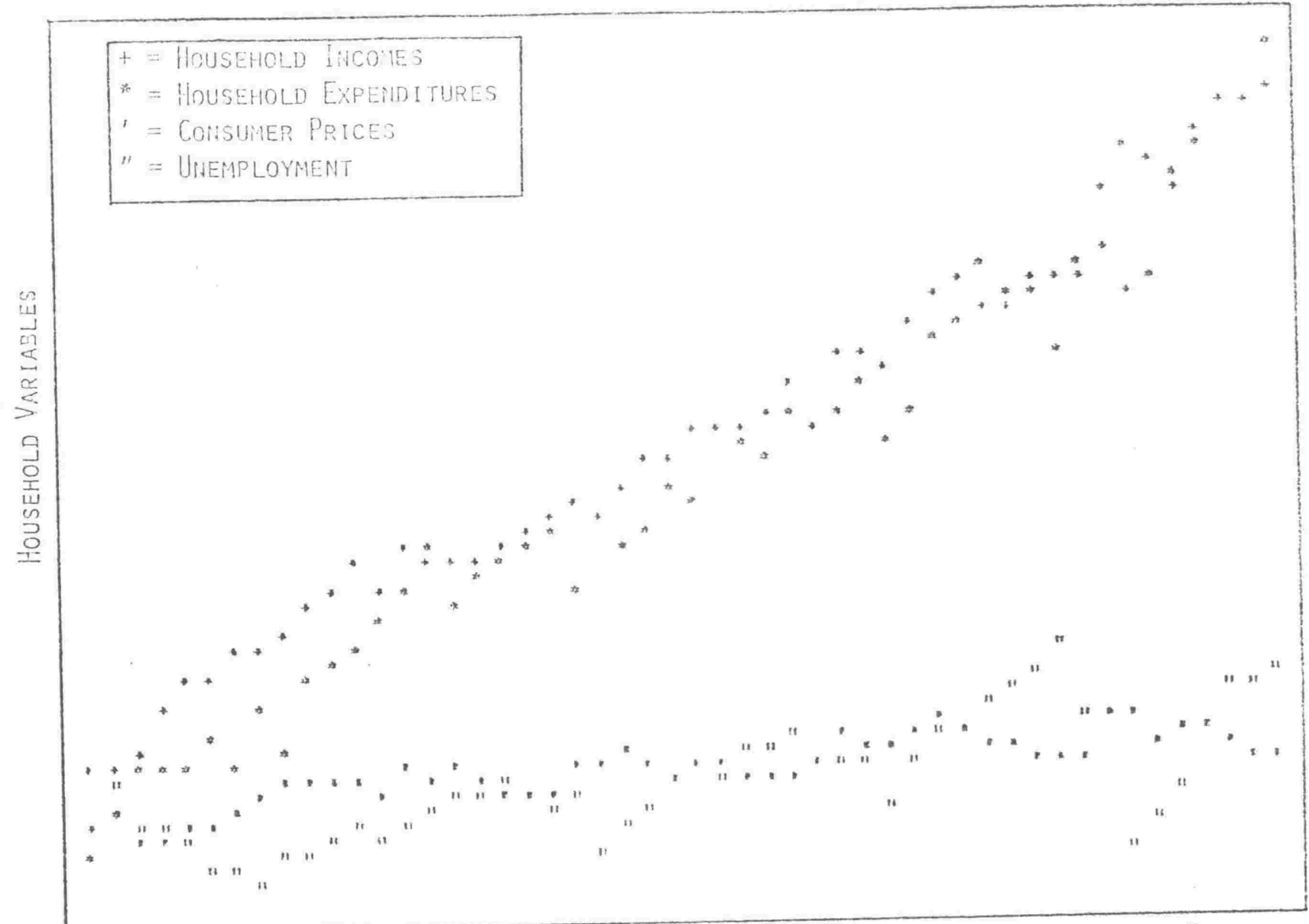

VIII , 4/3

TRADE PRICES PY SECTOR

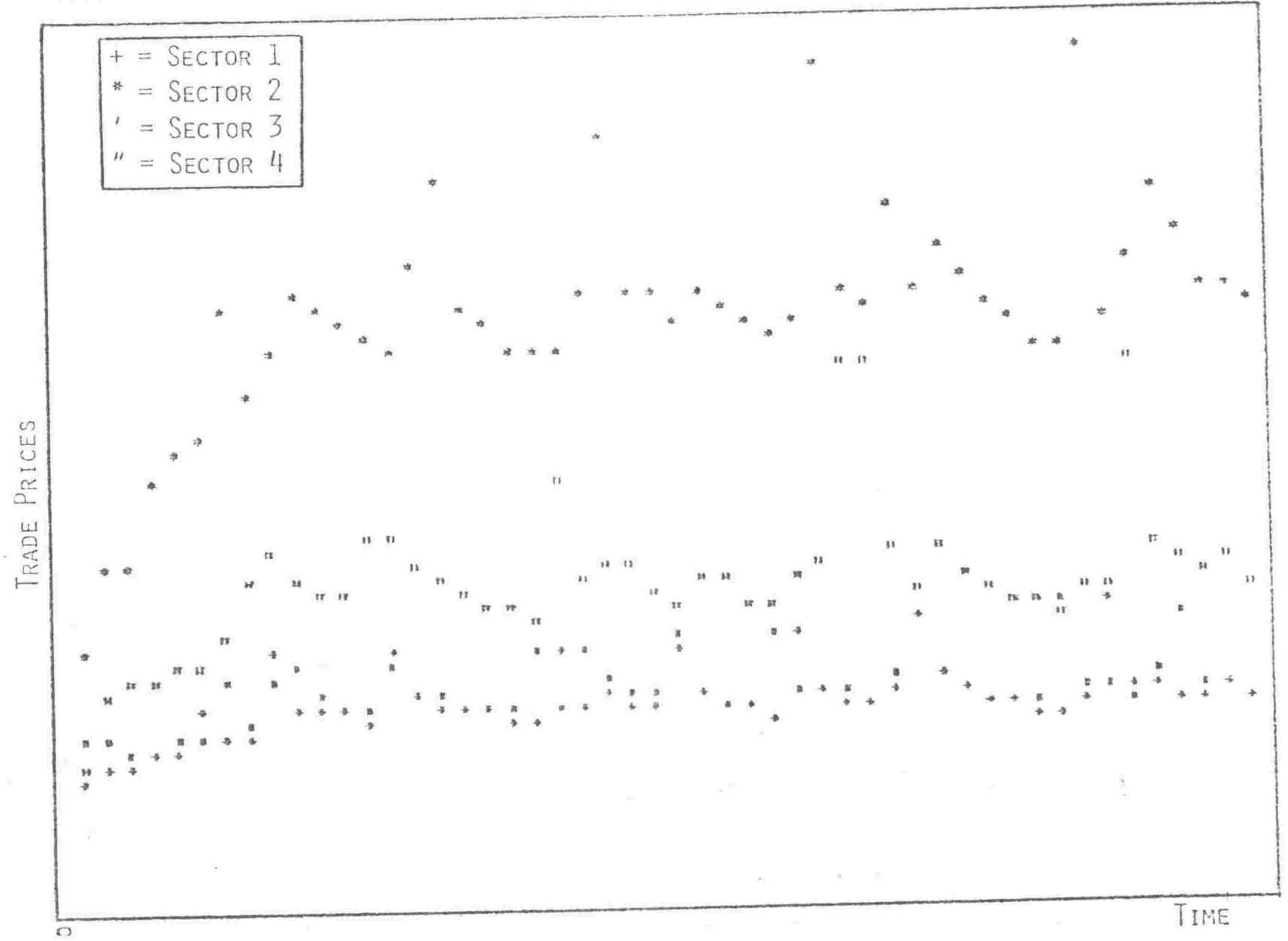




\begin{tabular}{|c|c|c|c|c|c|c|c|c|c|}
\hline & 3521 & 2 & 3 & $A$ & 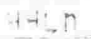 & $V=!$ & $2 y \times 5$ & TOTS & NTWTH \\
\hline$S=C I$ & i & 0 & $n$ & 1) & 0 & $j$ & 1319 & 2151 & $\div 8510$ \\
\hline 2 & A & 15 & a & $3 h$ & n & 0 & 3454 & 9518 & 13360 \\
\hline$S$ & $?$ & j & 0 & 2 & 9 & 0 & ก & 0 & 3740 \\
\hline 4 & $A$ & 2 & 5 & 4 & 0 & 0 & 1330 & 1. 345 & 12122 \\
\hline$H+120$ & $10 ?$ & 149 & 14 & 35 & r & 0 & 9438 & 8746 & 324 \\
\hline NF! & 3451 & $51<1$ & 5635 & 3730 & 9277 & 0 & ก & 35220 & 200 \\
\hline $0 Y<x$ & 0 & g) & s? & i & $?$ & 35428 & 0 & 15476 & 0 \\
\hline 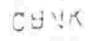 & 7 & 0 & ? & 0 & $n$ & 0 & 13305 & 0 & $n$ \\
\hline IVTY & 9774 & 13794 & 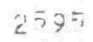 & 6957 & $r$ & 0 & 0 & 0 & 0 \\
\hline$\div \times 45$ & 3119 & 2306 & 116 & 709 & ? & I & 0 & 0 & 0 \\
\hline T. I & 20551 & $\Rightarrow 7179$ & b) 747 & 13465 & 3270 & 35433 & $3490 B$ & 0 & n? \\
\hline
\end{tabular}

PROFITS BY SECTOR

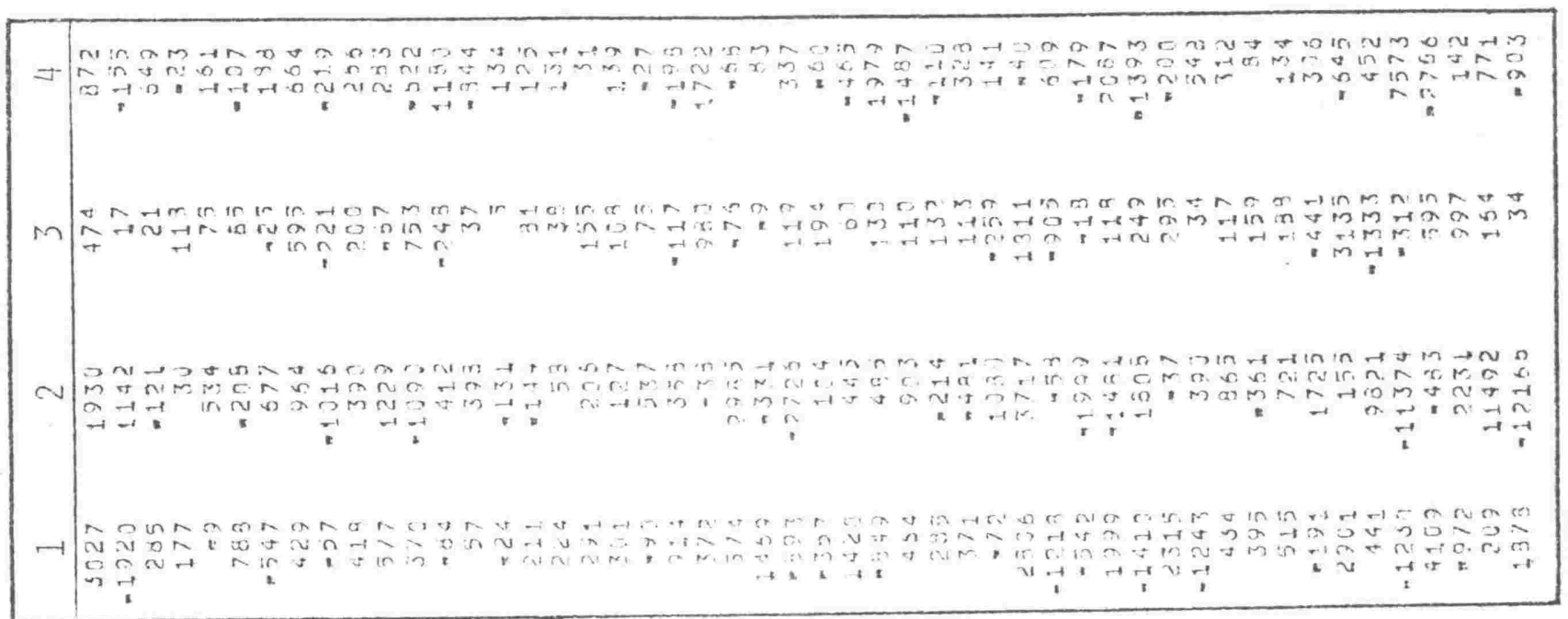

VIII. $2 / 4$

FIIANCIAL POSITIOH

\begin{tabular}{|c|c|c|c|c|c|c|c|c|c|}
\hline & $5=2:$ & 2 & 3 & 4 & $\cdots+\leq$ & $y=1$ & $2 v<S$ & TOT & NTWTH \\
\hline$S E C:$ & i & $\ddot{11}$ & ? & $i$ & 7 & $j$ & 0 & 17 & 21585 \\
\hline c & 143 & 92 & 79 & 1.2. & ? & ju & 711 & 787 & 22773 \\
\hline 3 & $\therefore$ & $i$ & & $j$ & $=$ & 0 & 2199 & 2199 & 11425 \\
\hline 4 & 121 & 13 & :35 & $1: 1$ & $r$ & ก & 752 & 1404 & 13134 \\
\hline HH:! & 165 & 13 & 2) & 10 & $r$ & 0 & 1.7596 & 19170 & -12931 \\
\hline NEI & $1201 \mathrm{~A}$ & 9230 & 0372 & $\therefore 407$ & 5330 & 0 & 0 & 52350 & 200 \\
\hline ANKO & $197 ?$ & i & ก & ij & 5 & $38>60$ & 0 & 40530 & 0 \\
\hline CBVk & $?$ & 0 & 4 & j & ? & 0 & $1338 ?$ & 0 & 0 \\
\hline IVTY & 5223 & 13306 & $422 \%$ & 7311 & n & 0 & 0 & 0 & 0 \\
\hline FXAS & 1323 & 175 & $2+91$ & 1140 & ก & 0 & 0 & 0 & ? \\
\hline T0! & 216.02 & 3550 & 13524 & 14539 & 5230 & 30550 & 37040 & 0 & n \\
\hline
\end{tabular}

\section{PROFITS BY SECTOR}

\begin{tabular}{|c|c|}
\hline$\Rightarrow$ & 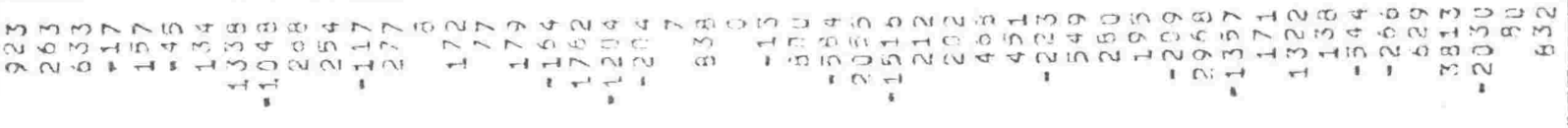 \\
\hline$m$ & 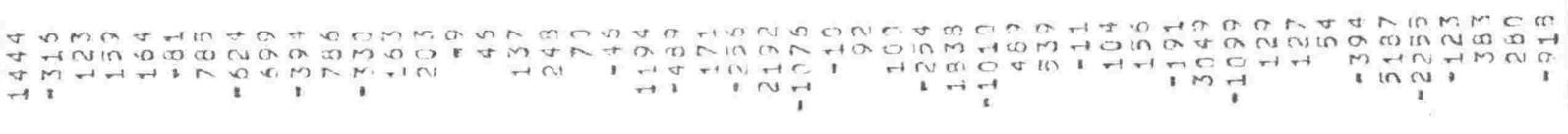 \\
\hline$\sim$ & 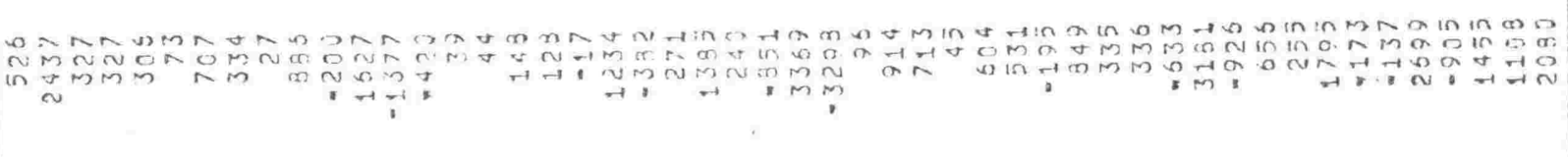 \\
\hline-1 & 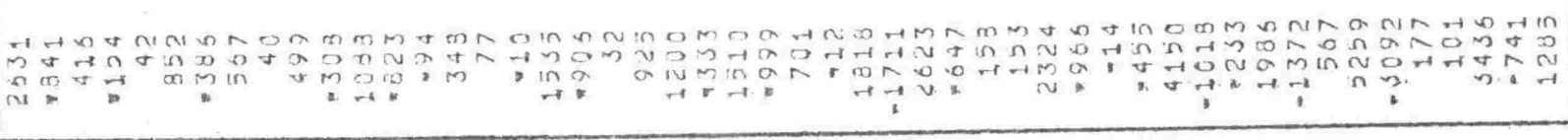 \\
\hline
\end{tabular}




\begin{tabular}{|c|c|c|c|c|c|c|c|c|c|}
\hline & 3: & द & : & $\therefore$ & $\cdots+L^{r}$ & $v=$ : & $74 \times 5$ & Tors & ATNTH \\
\hline 今日; & 1.951 & 37 & $35 \overrightarrow{7}$ & Bn? & $\pi$ & o & n & $35 ? 6$ & 21106 \\
\hline$\therefore$ & $\therefore 12$ & ب27. & $A 14$ & 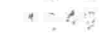 & a & $15 \% 3$ & $176 ?$ & 5683 & 13750 \\
\hline s & ;i & $15: 2$ & 12 & 377 & r & 0 & 776 & $39: 8$ & प्र०14 \\
\hline 4 & 83 & $1: 2$ & $L=37$ & $\therefore 95$ & $\therefore$ & g & $7 \pi$ & 3373 & $103 \overline{7} 4$ \\
\hline $4+t:$. & $?=1$ & $2 \times 4$ & 140 & 214 & n & 5231 & 11364 & 22171 & -15184 \\
\hline$y=T$ & 3504 & 150 & 4237 & 3347 & 7005 & 0 & 0 & 25724 & 200 \\
\hline $0 \times\{0$ & 3054 & a & 9 & ig & $\pi$ & 1476,7 & a & 20023 & 0 \\
\hline Qdus & & $\therefore$ & ? & c & $\mathrm{r}$ & c & 3440 & 0 & 0 \\
\hline$\{V T\}$ & 599 : & $130=?$ & 31,25 & 2085 & ? & 0 & ? & o & ? \\
\hline $5 \times 42$ & $3: 33$ & 1.175 & 2457 & $32 \%$ & a & 0 & c & 0 & n \\
\hline 701 & $=437$ & 21,111 & $1573 ?$ & 1425 & 7005 & 25724 & $1791 ?$ & 0 & 0 \\
\hline
\end{tabular}

PROFITS DY SECTOR

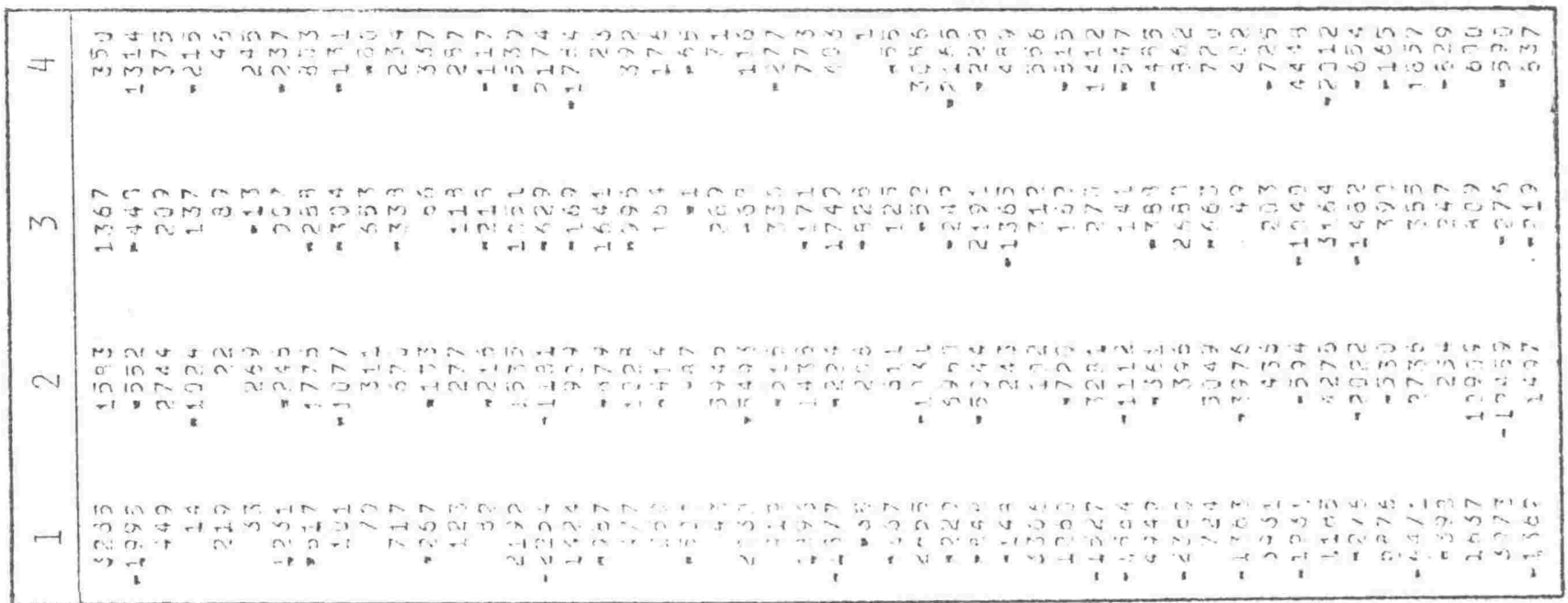

VIII. 4/4

FIHANCINL POSITINA

\begin{tabular}{|c|c|c|c|c|c|c|c|c|c|}
\hline & SF: 1 & 2 & 3 & $\therefore$ & $4+19$ & $v=1$ & $7 \times<5$ & TOT 3 & NTWTH \\
\hline SECl & $n$ & (1) & त & iI & $?$ & 0 & $80 ?$ & 302 & $1071^{\circ}$ \\
\hline 2 & 0 & 0 & $n$ & ce & $\therefore$ & 0 & 0 & 0 & $1360 ?$ \\
\hline s & 7 & 0 & $a$ & 0 & o & 0 & 0 & 0 & 13369 \\
\hline 4 & r & 0 & 7 & j) & ค & 0 & 0 & 0 & 12032 \\
\hline $\mathrm{HHILH}$ & 6? & 59 & 9? & 53 & 0 & 0 & 0 & 255 & 10404 \\
\hline WF! & 7250 & 3343 & 3971 & 3925 & 10704 & 0 & 0 & 55950 & 200 \\
\hline A.VKS & ? & 369 & $1 \mathrm{~d}$ & 413 & 3065 & $3+1=3$ & 0 & 37619 & 0 \\
\hline CHVR & 3 & 0 & ח & 1) & ก & 0 & 35171 & 0 & $n$ \\
\hline IYTY & 3117 & 3923 & $34 \equiv k$ & 5050 & $n$ & 0 & 0 & u & 0 \\
\hline FXAS & 1037 & 393 & 340 & 032 & ก & 0 & 0 & u & 0 \\
\hline Tก & 11521 & 13662 & $1.335 \%$ & 12032 & 10567 & 36153 & 35973 & 0 & n \\
\hline
\end{tabular}

PRDFITS DY SECTOR

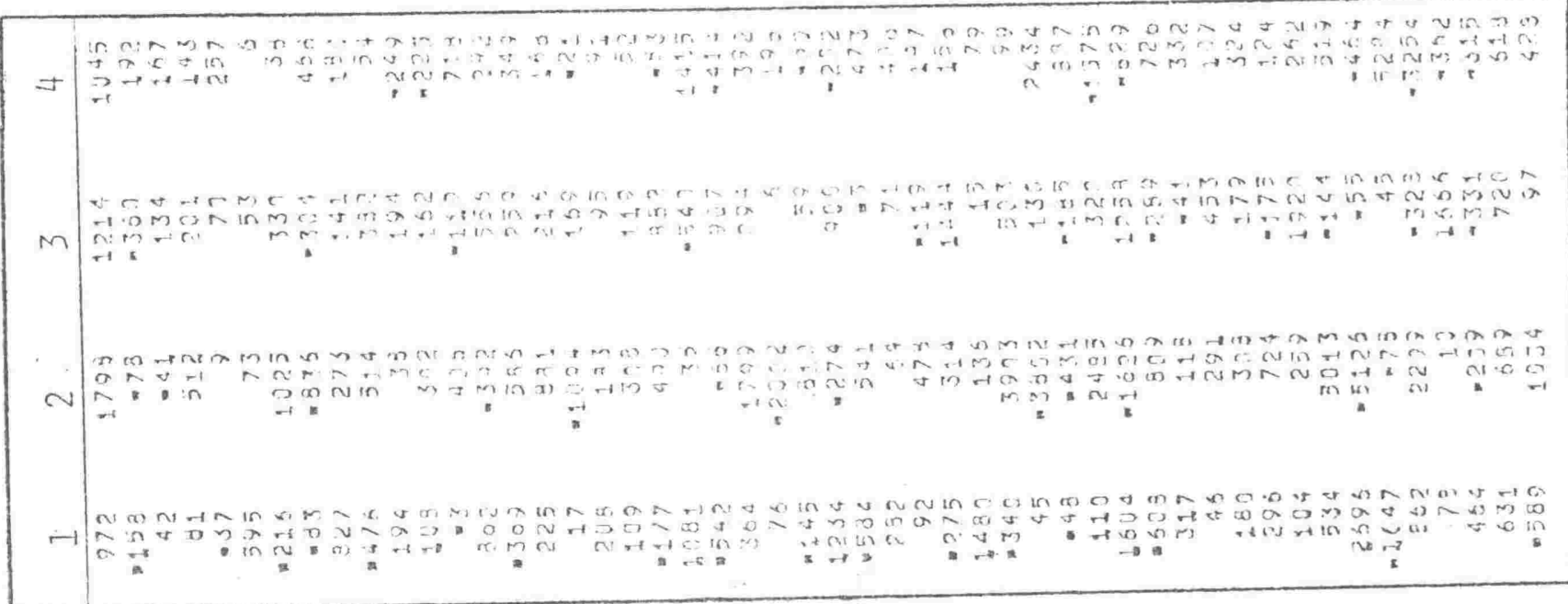



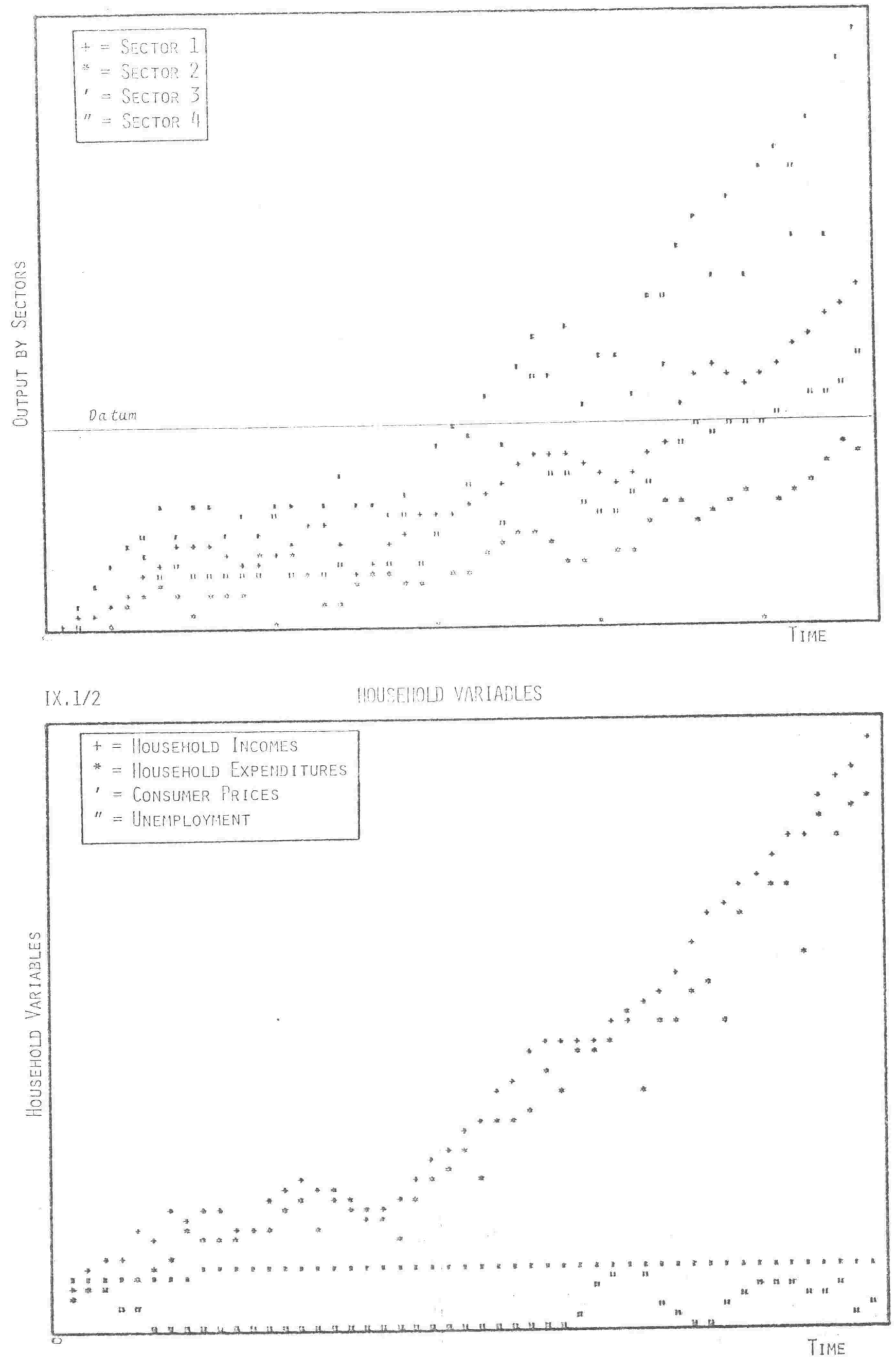


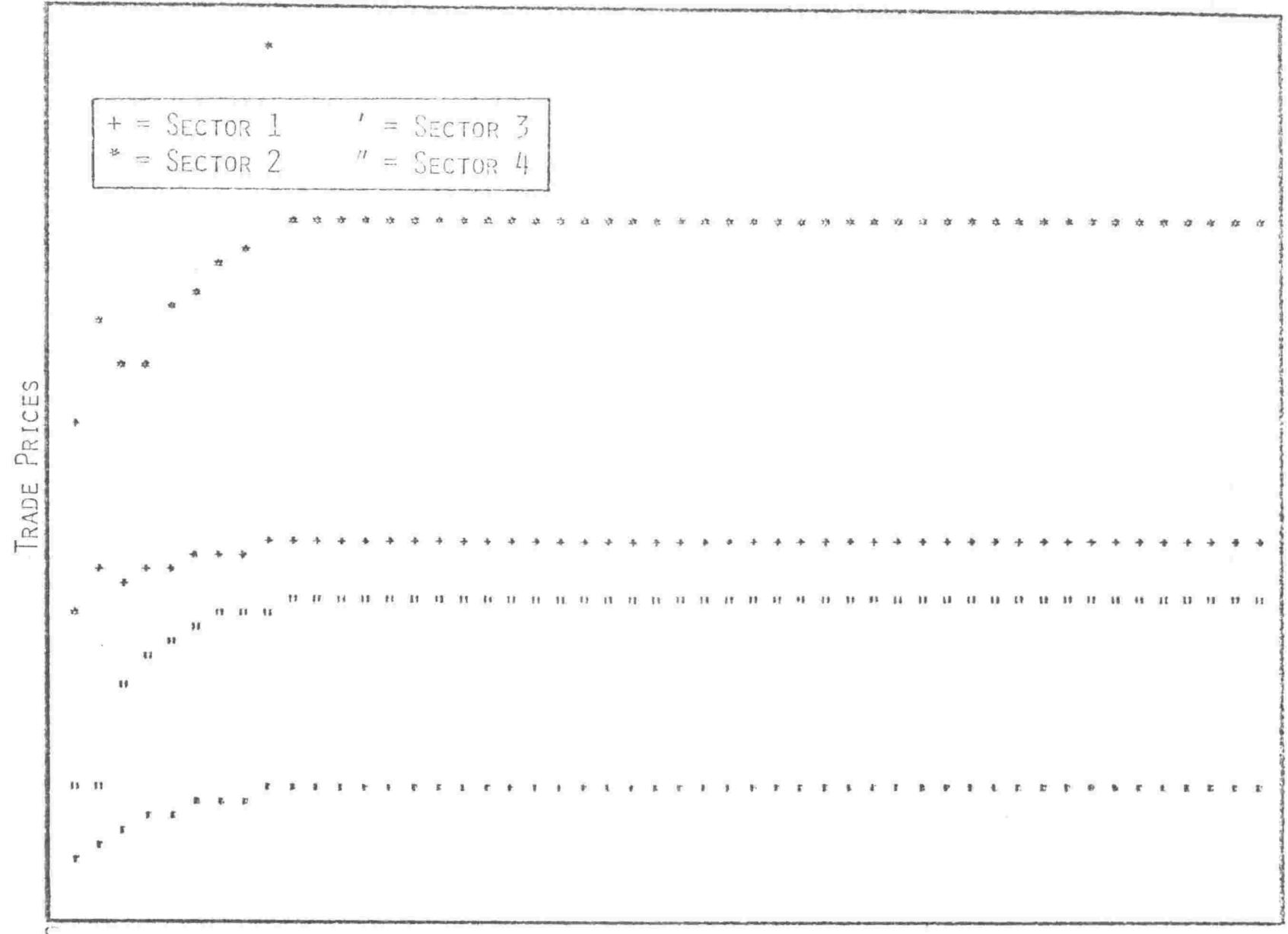

TIME

IN. I/4

SOURCES OF [XPEIIDITURE

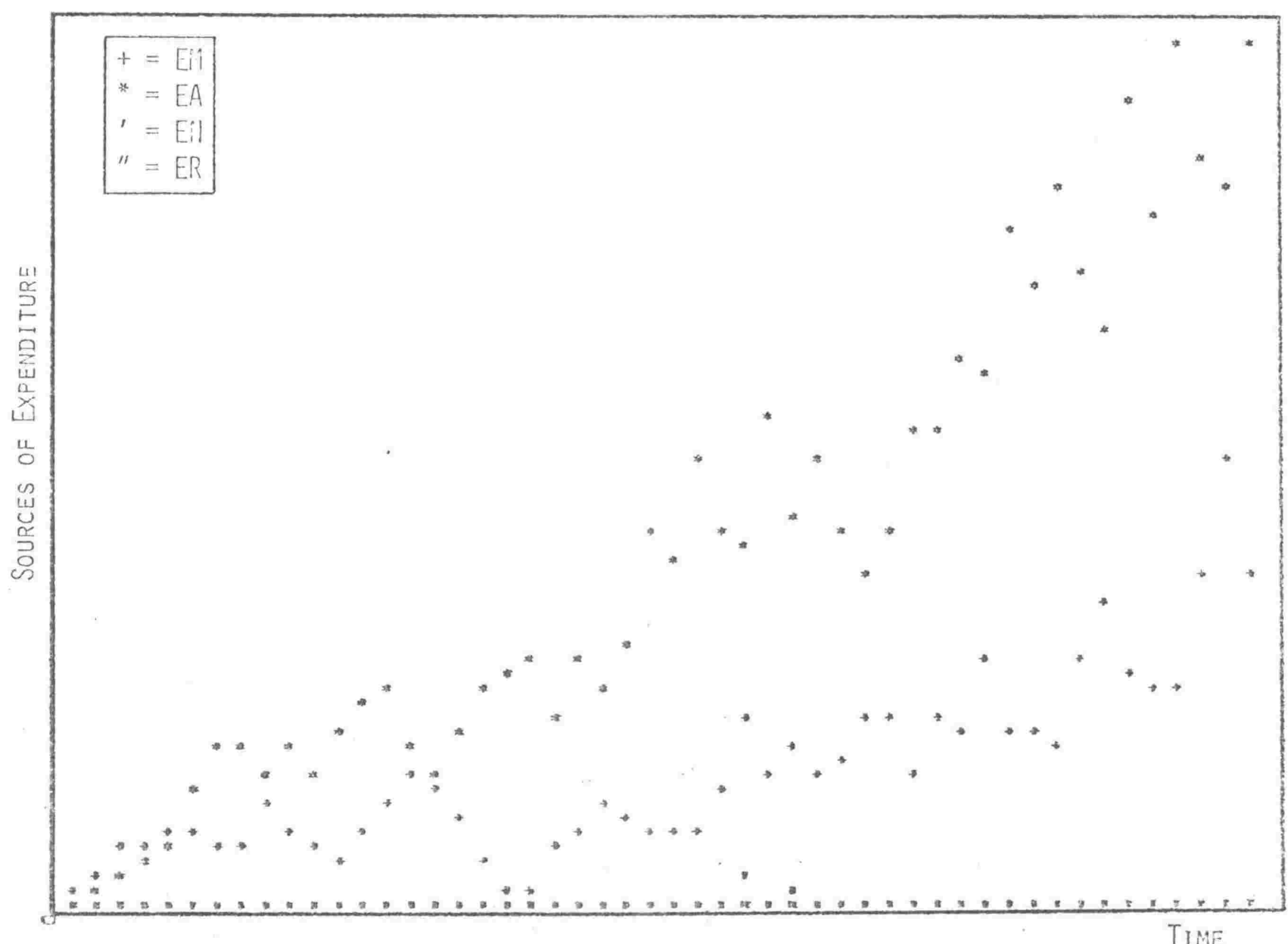




\begin{tabular}{|c|c|c|c|c|c|c|c|c|c|}
\hline & $3 \div 2 \quad 1$ & 2 & 7 & $\therefore$ & $\cdots$ & $1=1$ & $\because 425$ & T215 & $i_{H} T_{r_{1}} T_{H}$ \\
\hline Fa & 3 & & & , & - & 673 & $7=57$ & 3256 & 8550 \\
\hline 2 & , & $\therefore$ & & 1) & $=$ & $7=5$ & 15074 & 16400 & $12 \leq 19$ \\
\hline$s$ & ; & & & & 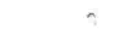 & 0 & 711 & 711 & 10352 \\
\hline 4 & 7 & & & $t_{2}$ & $\because$ & ij & 1142 & $11^{4} 2$ & 15335 \\
\hline 44,6 & $\therefore$ & & & & $\therefore$ & 0 & 0 & C & 29992 \\
\hline Ii 1 & 23 & 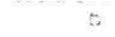 & 354. & $211:$ & $27320^{\circ}$ & 0 & n & 55310 & 200 \\
\hline OVKS & $?$ & 3 & & $\mathrm{~J}$ & $57=$ & $350=5$ & 9 & $352^{\circ} 7$ & 0 \\
\hline CAIS & $?$ & 8 & $r$ & G & 9 & is & 12371 & 6 & ? \\
\hline IVYY & $1331 ;$ & $27+3$ & $235 \pi$ & $2190 ?$ & ᄀ & 0 & 6 & 0 & 7 \\
\hline$F \times A$, & $337^{n}$ & 1231 & $137 ?$ & 651 & - & 0 & 0 & i & $r$ \\
\hline 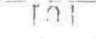 & 16904 & 3254 & 4177 & $i 471$, & 79293 & 37010 & 17925 & 0 & $?$ \\
\hline
\end{tabular}

PROFITS DY SECTOR

\begin{tabular}{|c|c|}
\hline$\Rightarrow$ & 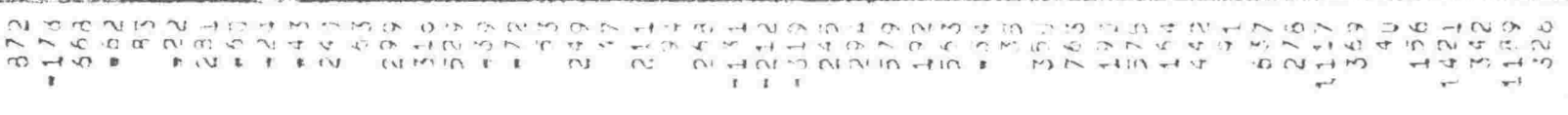 \\
\hline$m$ & 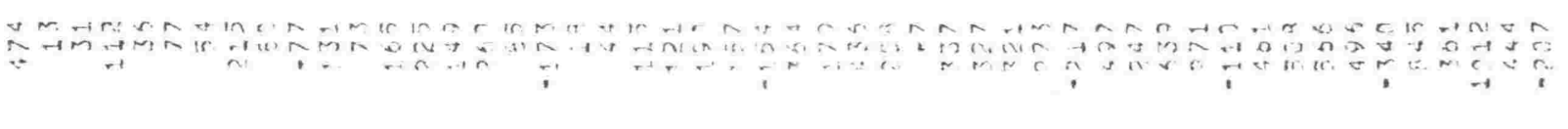 \\
\hline$\sim$ & $\begin{array}{lll} & \\
0 & 0\end{array}$ \\
\hline-1 & 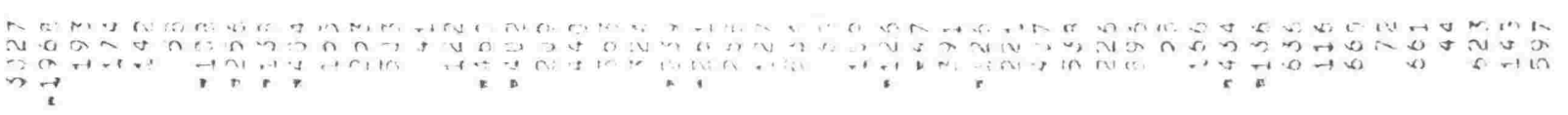 \\
\hline
\end{tabular}


MOVEIARY TPAVSAET! OUS IV THE REAL ECJVOHY(HARRZ); A3EG1

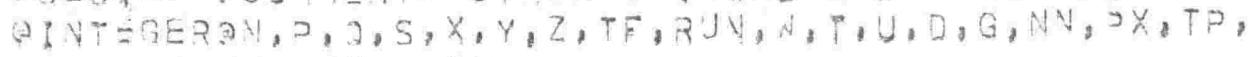
$V V, N, X X ; Y Y, Z Z$, COLSUH, EA,EY,EY,ER, ROA JUM, RA, R4, RN, RR, EG, RG, HHLD, VET G BVKS, CBNK, IVTY,FXAS, TOT, TOTS, VTWTH, YEAR, YOVTH, DAY, YEAPT, LOOOOL,

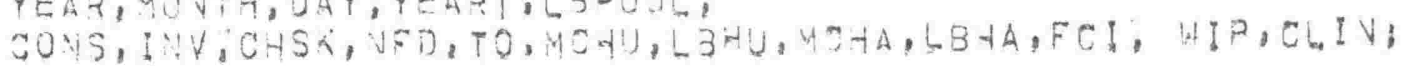
QREAG $2 G W, A C C$, RESRAT, CF! :

it: $=4:$ N $Y:=8$;

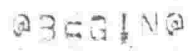

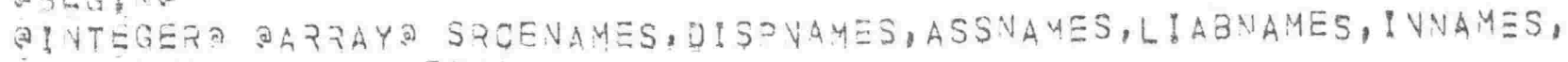
OUTYAMES(/1:30/),

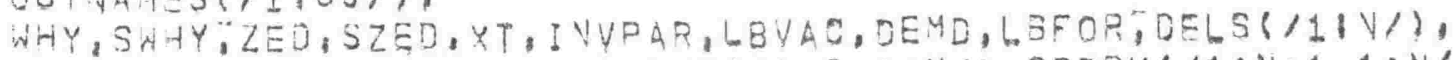
DAR, DA, DY (/1:VV,1:V/), LAGJUT $(1 / 18,1 ; N /), O R O B K(/ 11 N+1,1: V /) ;$ QCOMYENT ICJS! : FIGJRES FOR TIME SER!ESI QINTEGER OARZAYARY, Z,F(11:N+7,1NN+5/),M,MY(111N-7,1:N-3/), A $(11: 8,1: N, 1: 51 /), T$ I YESE(11:N,1:50/)) OREAL OA RRAYOTECH, INTECH(/1/N?2,1:N/), 2RICE(/1:4,1:V/), MAPKIP $(11: 2,1: N /) ;$

QPROCEDUREQ READ TECH:

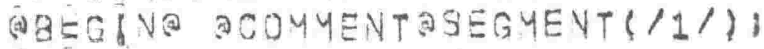

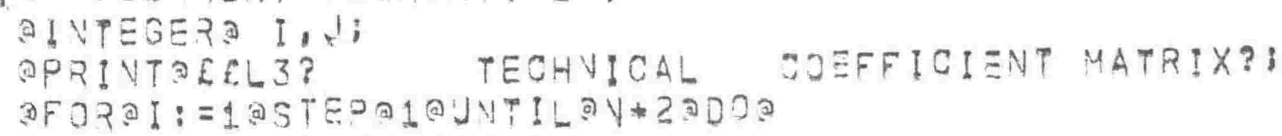

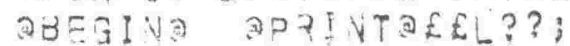
OFTRAJi=12STEPA1 OUNTILON MDOC

aEVก?;

APPIVTAEELZ? IVERSE TECH SOEFF HTR!X?;

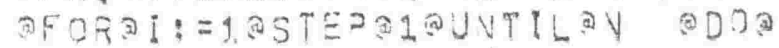

QBEGIVล ADZI YTAEEL??;

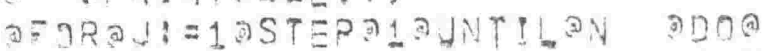
aEV OÁ

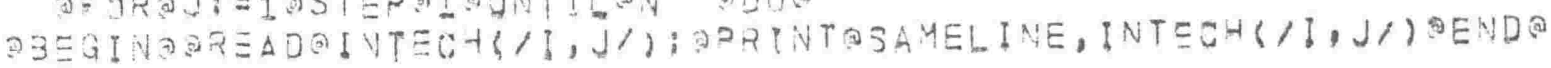

OPRINTAEELZ?DA = FIRST DUE DATES?;

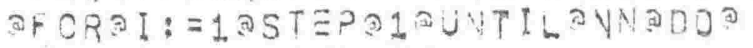

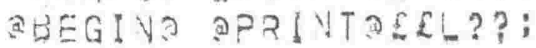

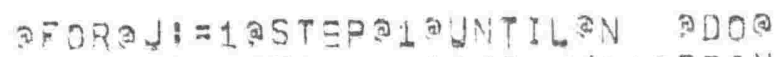

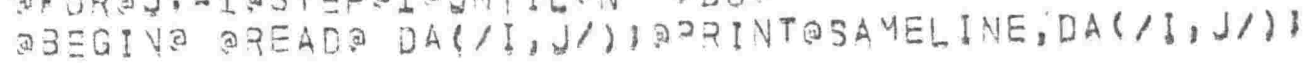

DAR $(/ I, 4 /):=D A(/ 1, J /) ;$

AENDA;

aENDa;

QPPIVTBEEL??TY = ASSIGVED IVTERVALS?

ลF०R ! : =

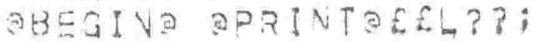

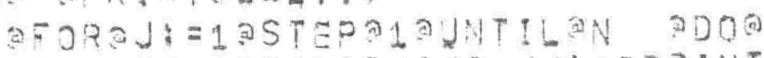

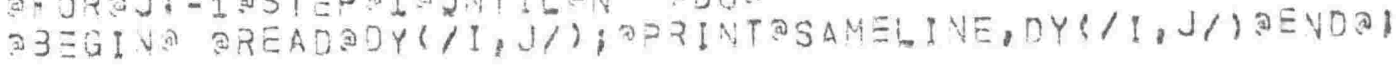

QEVDO;

QENDADRUCEDURE READ TECH

I DEG AREA 1 SIZE 224]

QPROCEUVRED READ MAMES:

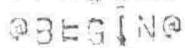

จ INTEGEマลP, З;

$p:=1$;

AFOR

$P:=1 ;$

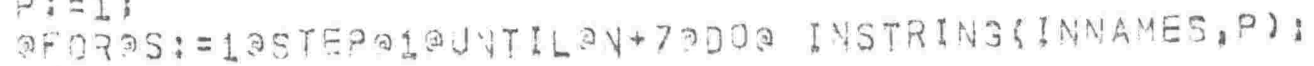




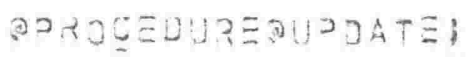

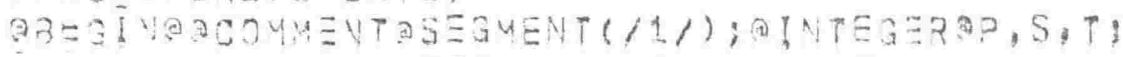

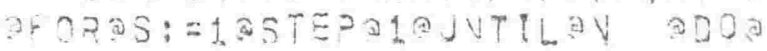

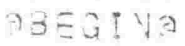

$P(/ 5, G+5 \times /):=R(/ C, I Y, 5 /) \times(6 G \cap U T(14,5 /):$

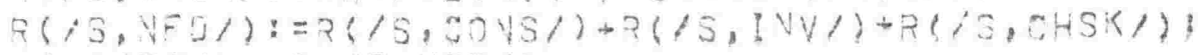

$R(/ S, T O /):=2\{/ 5, Y \cap 0 /) ;$

B⿺辶万人?

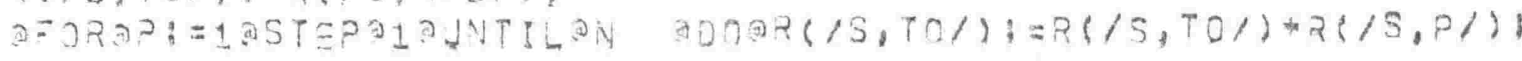

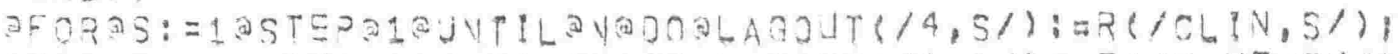

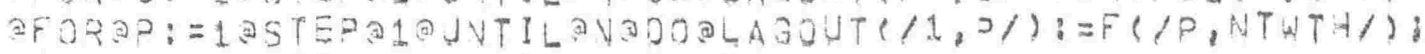

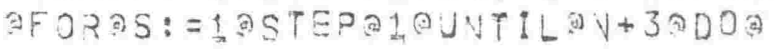

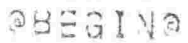

L(1TOT:S/): = ? :

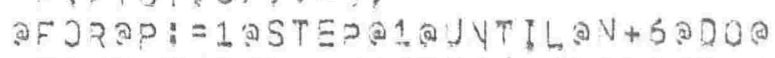

AEVDa;

$F(/ T O T, S /):=F(/ T O T, S /)+F(/ 0, S /)$;

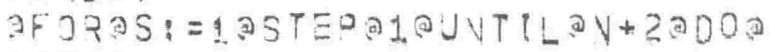

จBEGIVจ

$F(/ S, T O T S /):=0:$

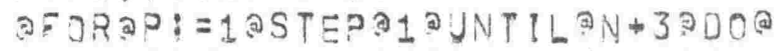

$F(/ S, T O T S /):=F(/ S, T O T S /)+F(/ S, P /) ;$

$F(/ S, V T A T H /):=F($ TOT,S/) F F/S, TOTS/)

QEVDa;

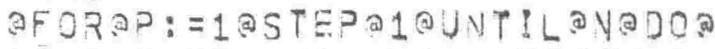

$A(/ B, D, Y \equiv A R /):=F(/ 2, Y T$ NTH/)-LAGOUT $(/ 1,0 /)$;

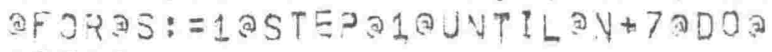

QEEGIN?

$4(, S$, ROASUM $):=0$;

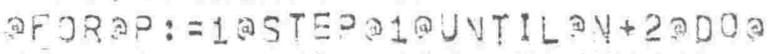

H $(I S, R O N 5 \cup 4 /):=4(15$, RONSUH/ $)+M(13,0 /)$;

(IEบD?;

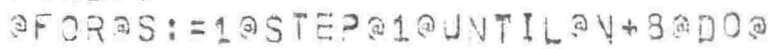

aBEGIVa

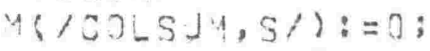

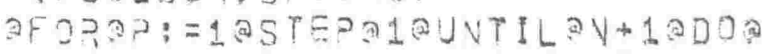

$4(/ 20 L 5 J 4,5 /):=4(/ 20 L 5 \cup 4,5 /)+4(/ 2,5 /) ;$

AEND甶;

Y(IEY, RJASUYf): =M(/EY, ₹JWSUM/)-Y(/EM, RV/);

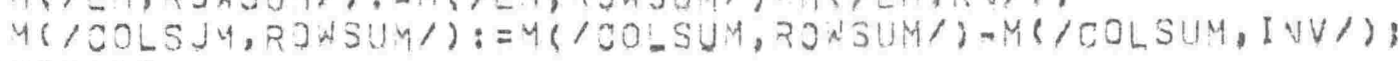
DENDMUPDATE;

[ $S E J$ AREA 1 SIZE 393)

MPROCEDUREA DRT THECKIVG PRODUCTS;

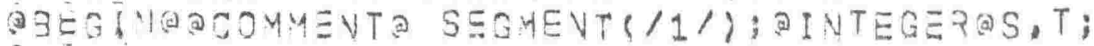

PPRI YTOEELZ? CHECKING JRODUCTS?;

AFORAS:

aBE $\mathrm{a}$ ! ข

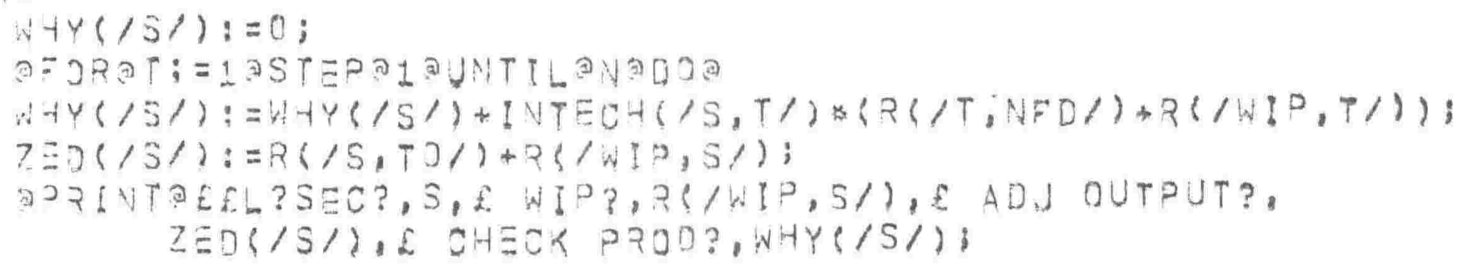

AEVDa

DENDG PRTCHE;

[ SE AREA 1 S!?E 106!

QDROCEDUREARRT TIUE SERIES;

ลB BEGNQ DCOYYENTASEGUENT (/2/);

AIVTEGEPAI, I:

DPF! प ITAERL了? ?

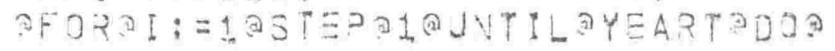

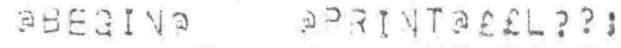

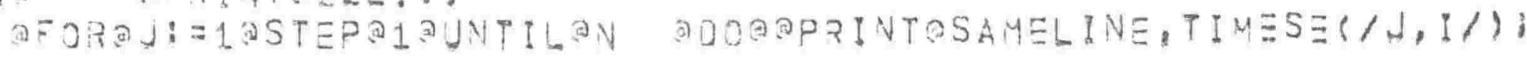

aะกำ

PENDP PRT TIYE SERIES;

[ SEI AREA 2 SIZE 45] 


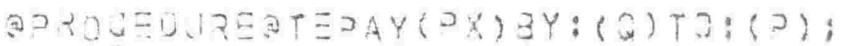

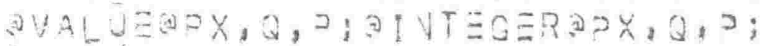

$93=36 \mathrm{~V}$

OSW ITCA TST: = LAST;

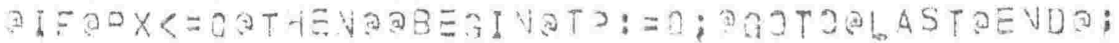

wh: $=F(/ 3 \bigvee k S, Q /)$;

$X X:=F(/ 23 N K$, BVKS/)/RESPAT -F(/BVKS, TOTS/):

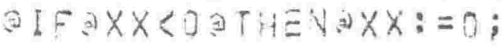

YY: $=F(13 Y K S, Y=I /)$;

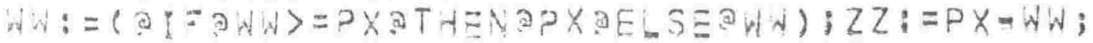

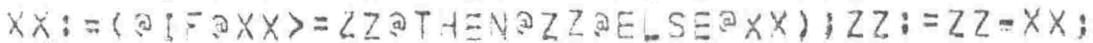

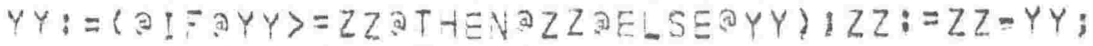

IIF DP=H+DDTHENOZZ:=0;

OIFอP $=R 3 \cong T H \equiv Y$ ล $Z Z:=0 ;$

$T P:=W N+X X+Y Y+Z Z:$

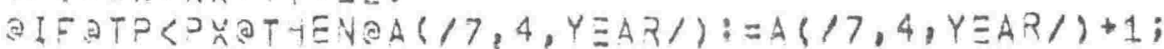

LAST: @EVDQTEDAY;

QPROUEDUREO PAY $(P X, Q, P)$;

QY ALUEAP $, Q, 2$; Q I VTEGER DPX,Q, P;

ล3EG!NO OCOMYENTD SEGMEVT(/1/):

QSNITCHPSP: = $1, P 2,03, P 4, P 5, R 1, ? 2, N E X T, P E C D, L A S T$;

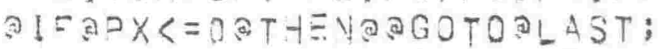

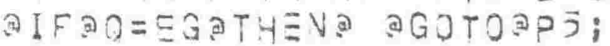

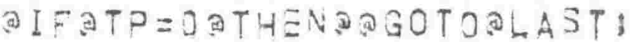

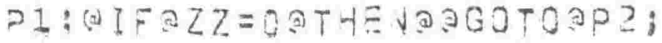

$F(/ 2 ; P /):=F(/ Q ; P /)+Z Z ; M(/ E P, Q /):=M(/ E R, Q /)+Z Z$;

$M(/ P, P R /):=4(/ P, R Q /)+Z Z$ i

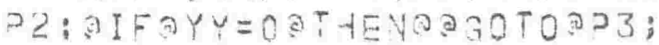

$F(/ 3 Y<S, V F I /):=F(/ 3 Y<S, N F I /)-Y Y: F(/ 3 N K S, 3 /):=F(3 V K S, Q /)+Y Y:$

$F(/ O, V F I /):=F(/ 2, V F I /)+Y Y: M(/ E N, Q /):=4(/ E N, Q /)+Y Y:$

$Y(/ O, Z M /):=4(/ 0, R Y /)+Y Y: T E^{2} A Y(P X, 0, P) ;$

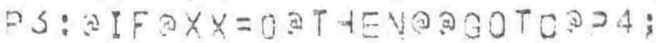

$F(/ 3,3 N<S i):=F(/ 0, B V\langle S /)+X X ; Y S / E A, 0 /):=M(/ E A, 0 /)+X X ;$

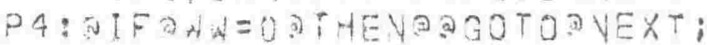

$F(/ B Y K S, Q /):=F(/ B Y K S, O /)$ - W $: F(/ B N K S, T O T S /):=F(/ B Y K S, T O T S /)=W W:$

Y $(/ E Y, 2 /):=M(/ E 4,2 /)+h+$;

人ิธOTว DEXT;

25:F(/C3VK, $3 V K S /):=F(/ C 3 N<, 3 V K S /)+P X$;

$M: / P, I N V /::=Y(/ P, I N V /)+P X:$

H(/EG, IVV/): $=M(/ E G$, I VV/) +PX:

ASTTJ DRECO;

YEXT:PX: =NW $+X X ; \quad M(/ P, Q /):=M(/ P, Q /)+P X+Z Z ;$

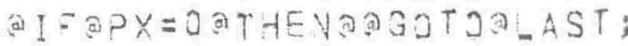

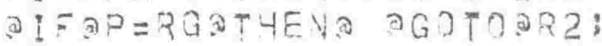

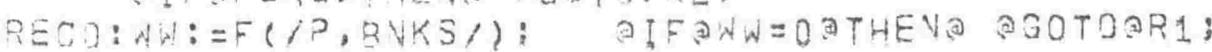

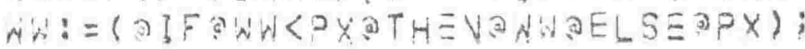

PX: $=2 x-4 y ;$

$F(/ 2, B Y K S /):=F(/ P, 3 N(S /)-4 N i M(/ P, R A /):=M(/ P, R A /)+W N I$

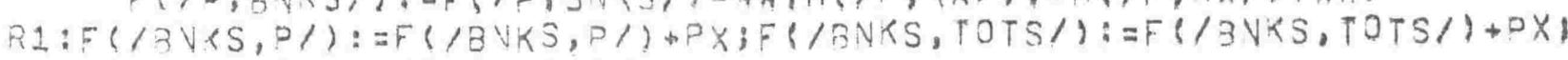

$1(1 / 2, P Y / 7):=4(/ P, R Y /)+P X ;$

aGOT J DLAST;

R2: : (/C3VK, उNRS/): =F(/C3NK, 3NKS/ I-PX;

$M(/ P, 2 G /):=4(/ 2, R 3 /)+P X ;$

LAST: AENDAPRJAEDJPE PAY;

( DES APEA 1 SIZE 3J1] 


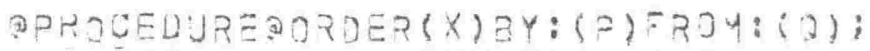

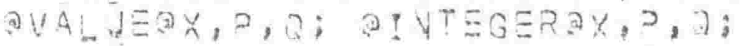

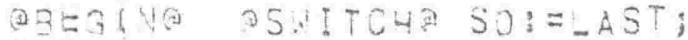

aIFa $=$ COYS THEYO OBEGI HO

$Z:=\{(/ C-3,1 /)-, 5 * I N \cup P A(/ ? /) ;$

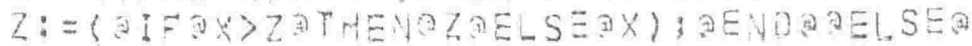

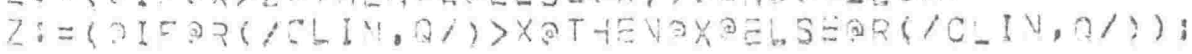

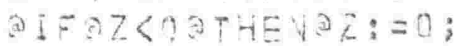

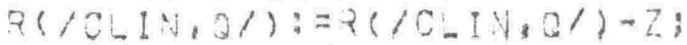

LAST: AEND政DER;

र $(/ 2,2 /):=?(/ 0,2 /)+Z$;

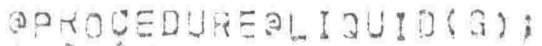

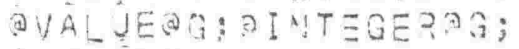

a

অSATTCHOSL: $=1.1$, VOVE;

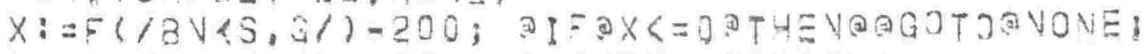

$Y:=F(/ G, V F I /) ;$ a \F a $Y=0$ aTHEVจaGOTOAL1;

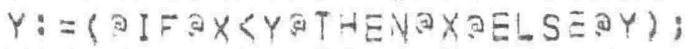

$F(/ G, N F I /):=F(/ G, V F ! /)=Y$;

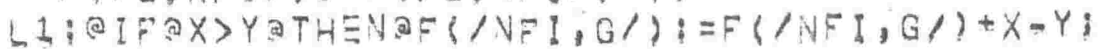

$F(/ B Y K S, Y F I /):=F(/ 3 N K S, Y F I /)+X ;$

$F(/ B N K S, G /):=F(/ B Y K S, G /)=X$;

$M(/: H, G /):=4(/ E M, G /)+X ;$

$M(: G, R N /):=4(/ G, R V /)+X ;$

$M(/ E Y$, RY/ $):=M(/ E M, R N /)+X$ :

NONE: OEVOa!IOU!D;

APROCEDUREARENOMUENCE;

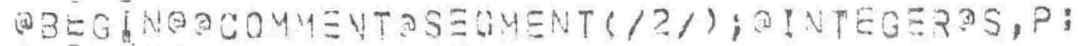

TF: $=$ YOY TA: = YERR: =1:

YEART: $=50 ; \quad$ DAY: $=3941$

RESPAT: : $1 ; \quad$ ACC: $:=0$;

LBPOOL: $=0 ;$

MCHU: = C JYS: = HLOL:=V+1;

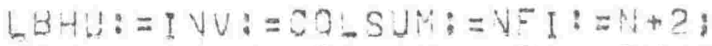

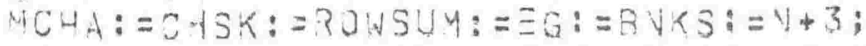

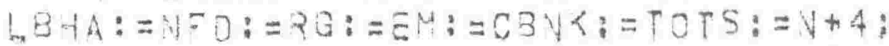

FCI $:=T O:=R M:=\Sigma \Delta:=I \vee T Y:=Y T \wedge T H:=Y+5$;

HIP: $=R A:=E N:=-X \triangle S:=V+5$;

CLIV: = T JT: $=\{V:=E R:=V+7$;

$R R:=N+8$;

SAYELINE!

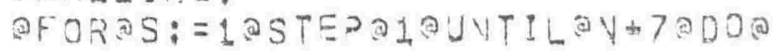

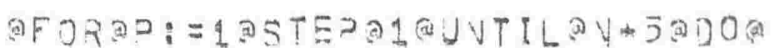

$R(/ 5, P /) !=F(/ S, P /):=P Y(/ 5, P /):=0)$

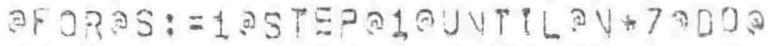

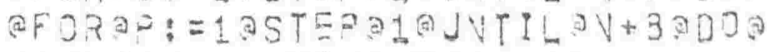

$M(/ S, P /):=4 Y(/ S, P /):=0$;

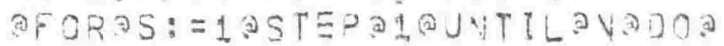

๑

TIMESE $(/ S, P /):=A(/ 7, S, 2 /):=01$

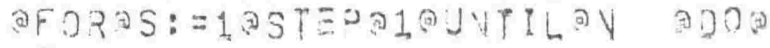

OBESIVI

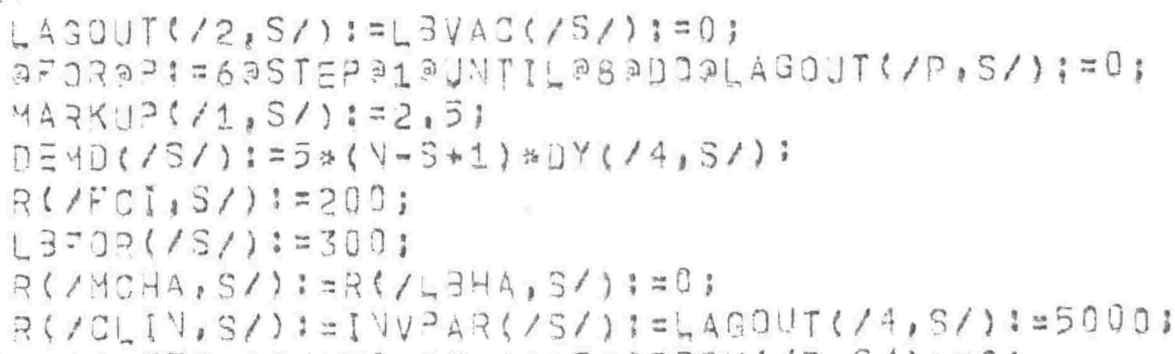

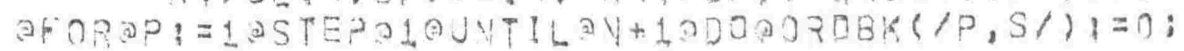

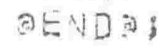

बFDROS: =1 ASTE2312JVTIL

बBEGIV 
$F(/ 3 \cup K S, P O T S /) ;=F(, 3 \vee K S, T O T S /)+F(/$ RNKS,S/):

트묵

F(/03YK, 3YKS/): $=500$ :

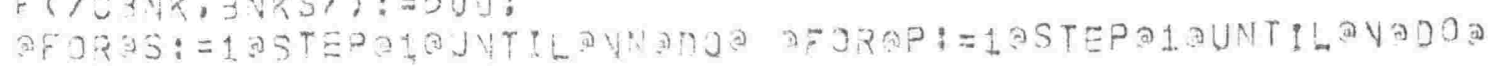

$D A(1, D /):=D A Q(/ S, 3 /)$;

UPDATE;

PRIVT TZAYSACTOONS;

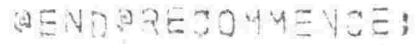

I SEU AREA ? SIBE 3231

MPROCEUUREAEARLIEST;

ABCG!NOQCOY4EVTASE3YENT(12/);

PIVPEGER PSECTOR, ACTIVITY;

$D:=D A(/ 1 ; 1 /) ; B:=S:=1 ;$

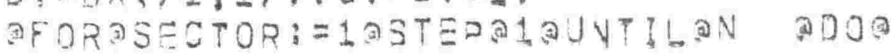

ลBEG! Na

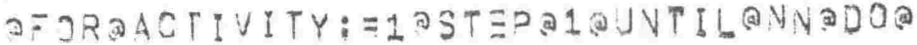

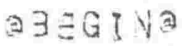

DIFDDA(/ACTIVITY, SESTOR/) $\angle D$ THENO

a $3 \subseteq G[$ ㄴำ ®ENDQ;

วอบดง;

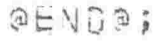

DENDIEARLIESTI

! SEG AREA 2 SIZE 45]

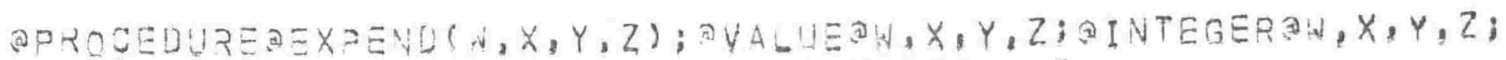

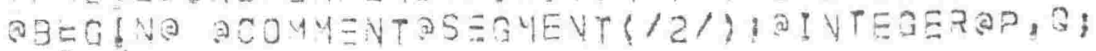

BREALA CC;

OSWITCHOSA: $=11, A 2, A 3, A 4, A 5, L A S T:$

agoroas $5(|X|)$;

A 1:A $(1,1,1,2,1):=1(150,20$ S S $4 /)$;

$A(/ 2,2,2 /):=4(/ E A, 8 G /) \rightarrow 4(/ E 4, R G /:$;

$A(1,1,3,2 /):==: / 00 \mathrm{VK}, 3 \mathrm{~N}\langle 3 /) ;$

$4(/ 1,4,2 /):=0\left(/ 3 \mathrm{~N}<3\right.$, TO $\left.\mathrm{T}^{\top} \mathrm{S} /\right):$

$A(12,1,2):,=4(100-544,00 N 5 /))$

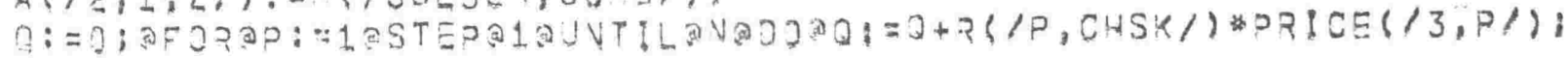

$A(/ 2,2,2 /):=4(/ V-2, \mid V V /)+2$;

$A(/ 2,3, Z /):=4(/ V, I Y V /)+A(/ A H L D, D V V /) !$

$A(/ 2,4, Z /):=A(/ 2,1, Z /)+A(/ 2,2, Z /)+A(/ 2,3, Z /))$

DGOTODLAST;

A2; A $(/ 5,1,2 /):=4(/ H H D, Z 0 \times S \mathrm{JM} /) ;$

$A(13,2, z /):=4(100-5 J 4,30 y S /)$ :

IF $Z=1$ จ

$A(15,4,2):=48000$;

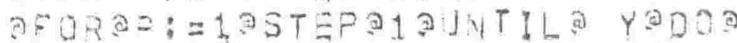

$A(16,2,2 / 1):=1(10+7,204504 /):$

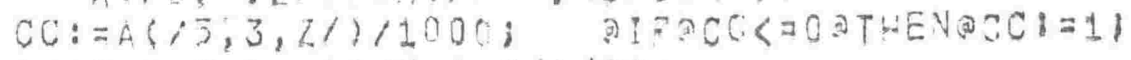

$A(/ 3,1, Z i):=4 ; / 5,1,2 / 1 / 2 C ;$

$A(/ 3,2,2, i):=A(/ 5,2, Z /) / 3 C ;$

$A(/ 3,3,2):,=A(/ 2,4,2 /) / C C$;

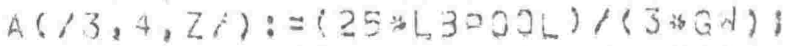

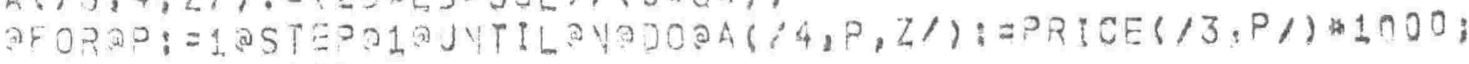

OGOTJA LAST:

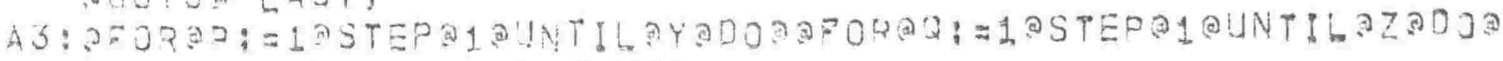

$T ! H E S E(/ P, 2 i):=A(/ 0, x, Q /):$

HGOTJRLAST;

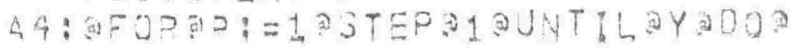

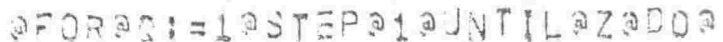

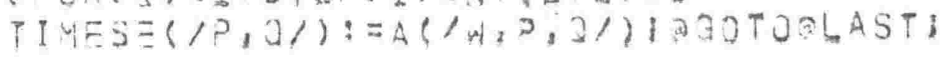

$\operatorname{LASTIMENDOEXOEND;}$

? SEG AREA 2 SIZE 394] 


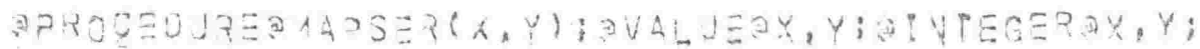

(a)

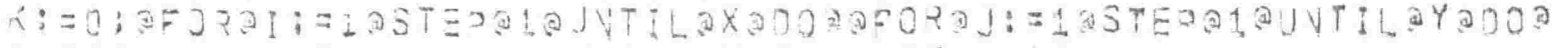

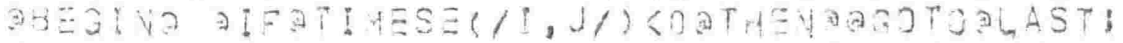

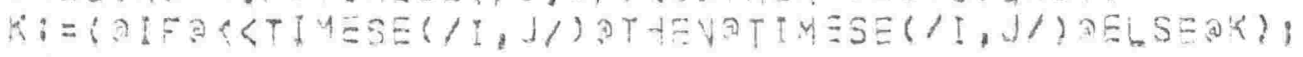

DH⿻上丨?

(1F

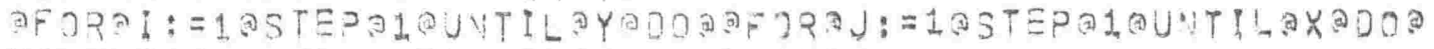

TIHESE(/Je!/): = (TIUESE(/J/I) *6O)/K;

OPPI $0 ? ;$

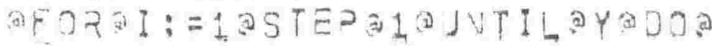

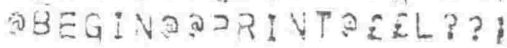

SPรINTDDIGITS(2), A(/7,1, I/), SAMELINE,A(/7,2,1/1, $A(17,3,1 /), A(17,4,1 /)$;

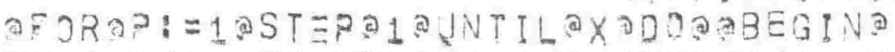

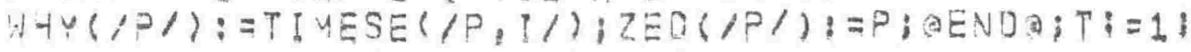

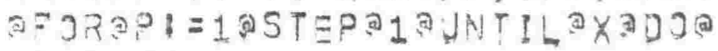

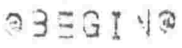

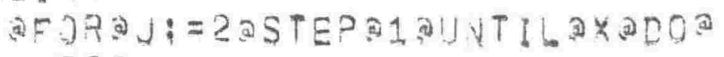

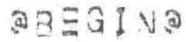

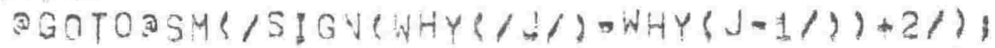

YL:YY: =NHY(/Ja1/); UHY(/J=1/): =LHY(/J/); $Z Z i=Z E D(/ J+1 /) ; Z E D(/ N=1 /) 1=Z E D(/ J /) ;$

WHY $(/ J /):=Y Y ; Z E D(/ J /) ;=Z Z ;$ (DGOTOMMZ:

42; a $F$ OJ

43: จอบดว

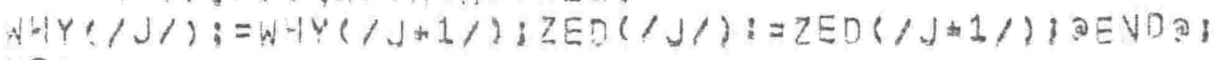

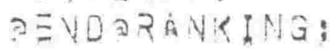

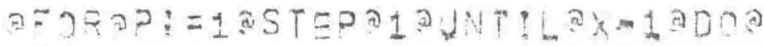

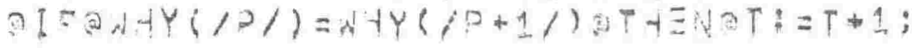

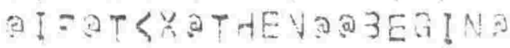

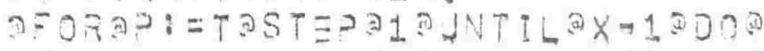

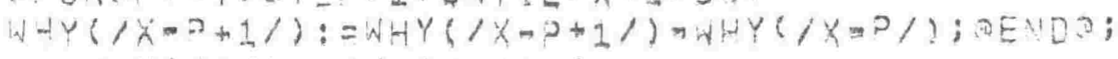

wHY $(/ 1 /) ;=-W y(/ 1 /)+5$;

च

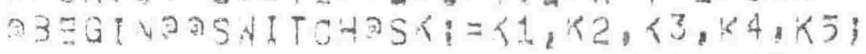

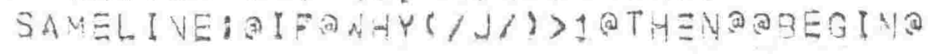

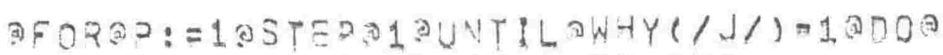

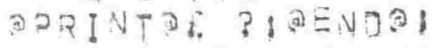

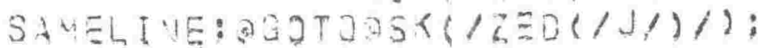

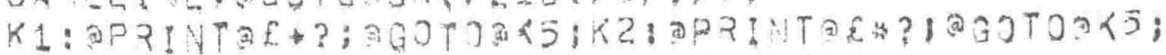

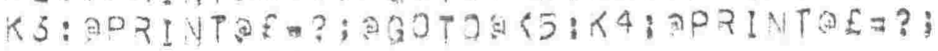

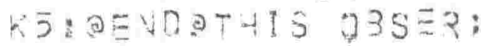

OEvगJOF THIS ROA;

WASTI DEVDOMAOSER;

D SEG APEA 1 SILE AO6I

APROCEDLREQSET PRTDICTIOV THRGET:

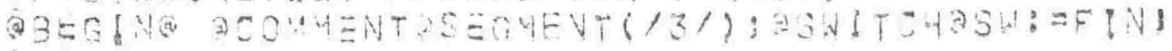

औI $T=2523<; \quad<:=0$;

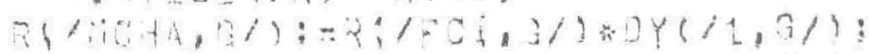

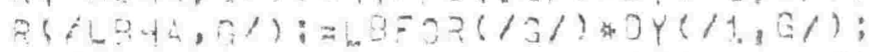

$\times T(/ 3) ;=I$ \%

का

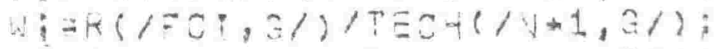

e? IF,

XT(/O/): =, A(/7,1,YEAR/):=A(/7,1,YEAR/)+1;OEVDP;

$A:=63709(13 /) / T \equiv C+(/ 4+2,3 /) ;$

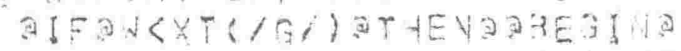

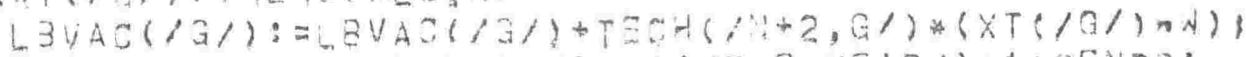

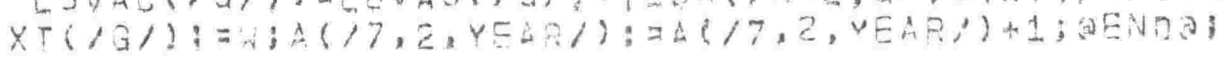




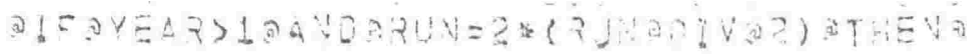

3อำ

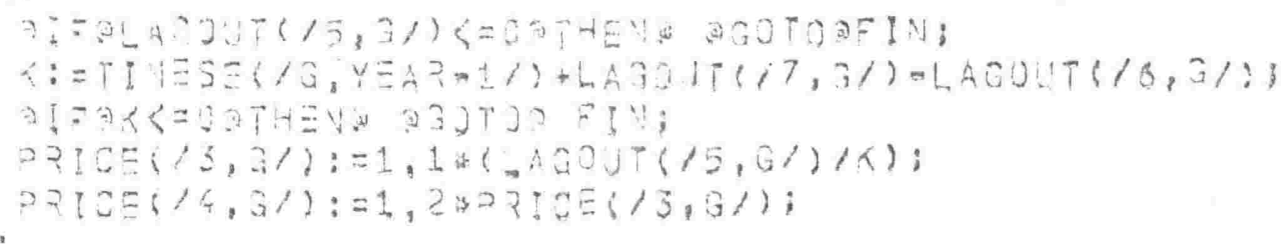

ค.

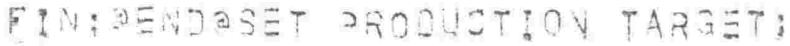

[ SEM AREA 3 SIlE 2361

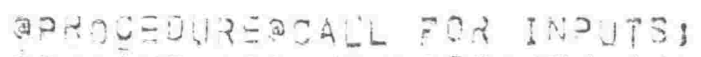

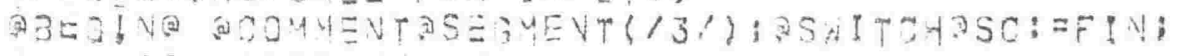

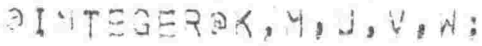

$\times 1=(X T(/) /) \approx D Y(/ 2, G /)) / D Y(/ 3,3 /) ;$

af $F$ a $=0$ aT t

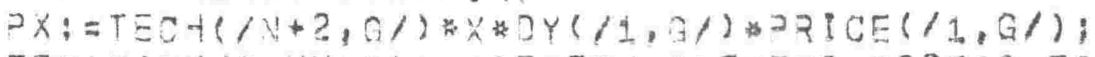

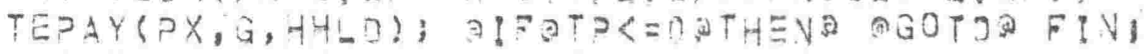

จด

UVi $\quad=0 ;$

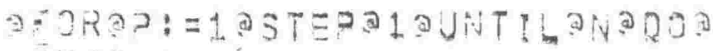

จรEG!Vล

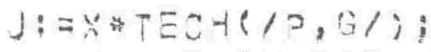

$$
\begin{aligned}
& \because:=, 2 \text { I VУगAR(/ग/); }
\end{aligned}
$$

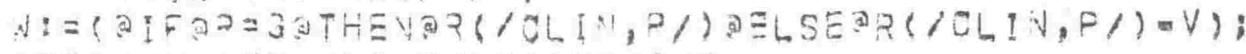

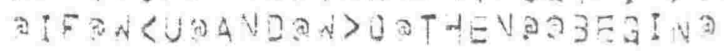

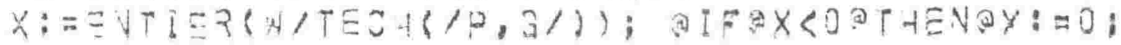

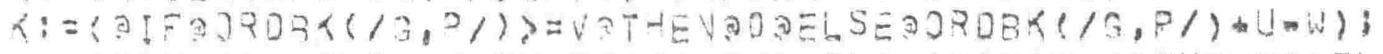

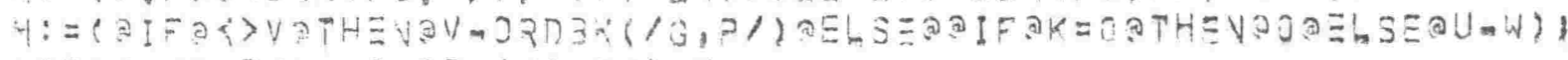

$2203(1 / \mathrm{G}, 0 /):=3203 \times(/ 0,0 /)+4$;

$0703\langle(/ N+1,0 /):=0203(/ / N+1,2 /)+1 ;$

$A, 17,3, Y \leq 42 / 1: 7 A(1,3,1512 /)+1,1$

$2=\forall ว ?$;

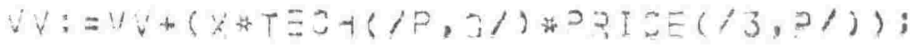

$3=40 ;$

PI

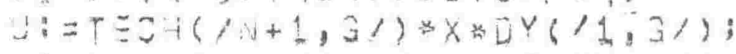

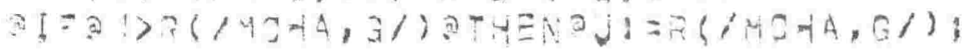

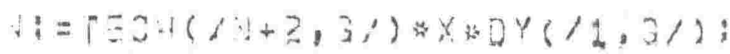

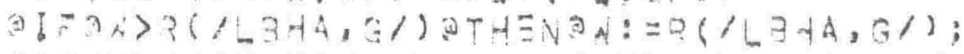

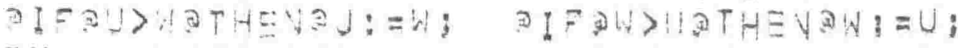

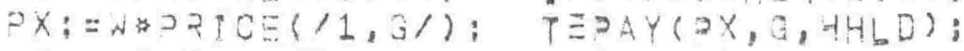

A! =

$V V_{1}=Y V+T=; \quad T=34(V Y, G, 1) ;$

aI

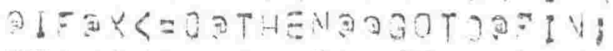

$X T: / 3 /):=(X+0 Y(/ 3,3 /)) / D Y(/ 2, G /:)$

$1:=T E C+(/ 4+2,0 /)=K .0 Y(/ 1,3 /) ;$

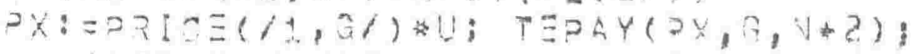

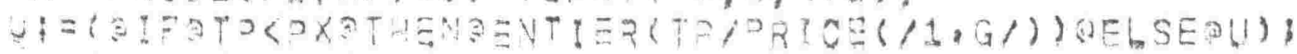

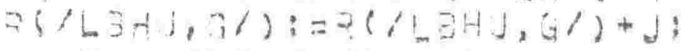

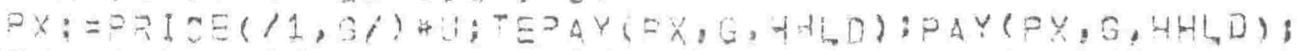

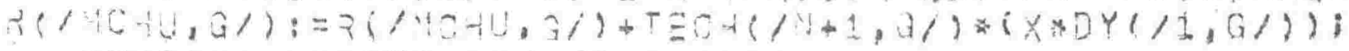

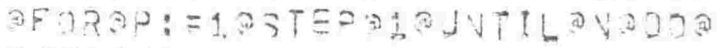

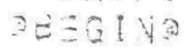

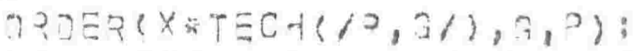

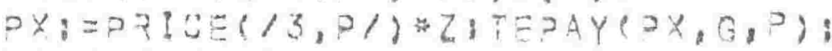

$\supset A Y(P,, U, 2)$;

จENDล;

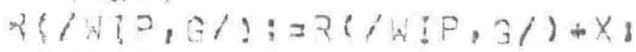

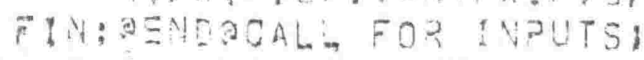

i SEQ AREA 3 SIZE 4D5! 


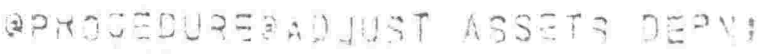

$93=9.4$

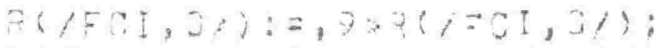

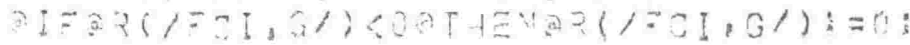

(4) $140 \div 3) ;$

AEVIALOAST ABSETS;

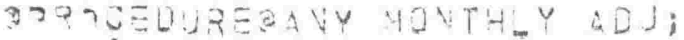

Q 3 LG

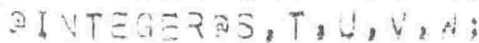

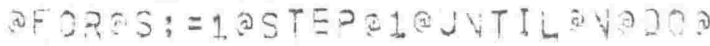

v日Eg!

U: $=Z(/ L 3 H A, S /) / D Y(/ 1,3 /)-Z(/ L 8 H \cup, S /) / D Y(/ N N, V /) ;$

$1:=.5: 4:$

II

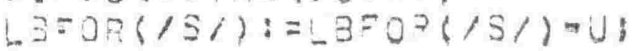

L $3700 \mathrm{~L}=13000 \mathrm{~L}+\mathrm{J}$;

QEND度 $\quad T:=N:=0$;

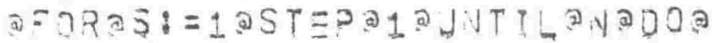

จดES \V

$V:=L \partial H A D(/ S /) ;$

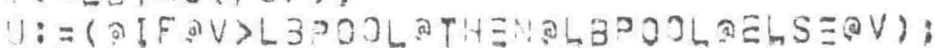

L $8 F O P(/ 5 /):=1.04 *(18 F 02(1 / 3 /)+1) ;$

$A ;=n+\angle 3 F 07(/ 2 /) ;$

L $3300 L:=$ L BPJJL $\rightarrow U:$

จEVD?;

LBVAC(/S!):=-BVAC(/S/)=U; $T:=T+L B V A C(/ S / 1:$

$\mathrm{U}:=A+L \geq 3030$;

$V:=L 3002-T:$

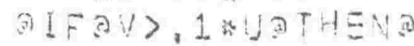

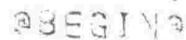

$Y:=100 \approx 3 \mathrm{~B} * \mathrm{~V} / \mathrm{J} ;$

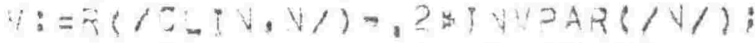

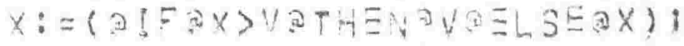

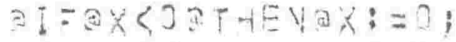

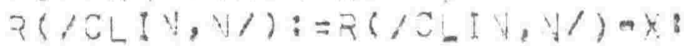

$q(/ 4,[y /):=?(/ N, I y /)+x:$

DX: =XसP I ICE $(/ 4, N /)$;

口४Y(PX, $: G, U)$;

atev?

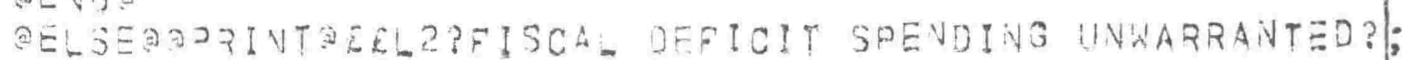
PEATAANY UJUTHLY ADJ

( SES АREA \& SIZE 155$\}$

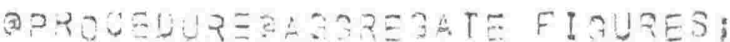

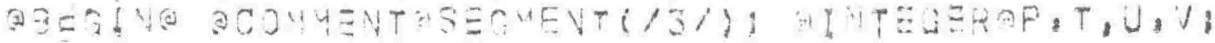

HejID(th):

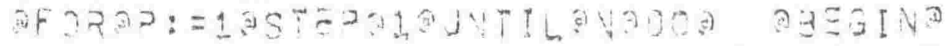

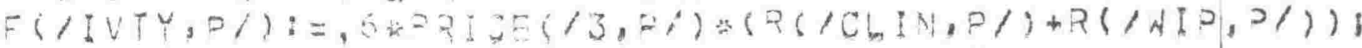

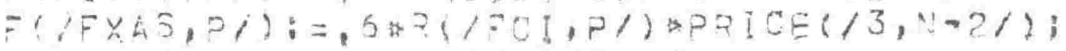

LATOUT $(15,2 /):=$ L $90 \mathrm{JT}(17,2 \mathrm{~T})$

SENDE;

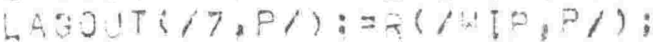

APRIVTEREL2?Rत?, GH:

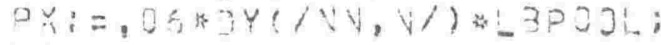

PAY $(\supset x, \equiv\}, y+1-0)$;

UPDLTE:

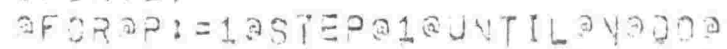

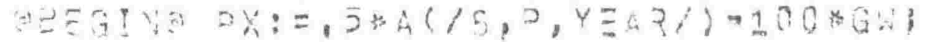

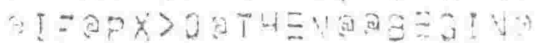

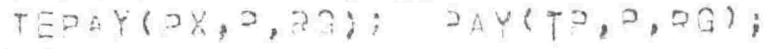

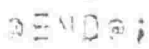

at

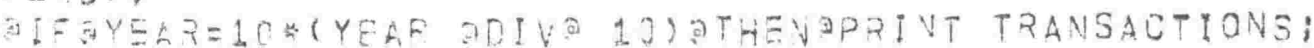

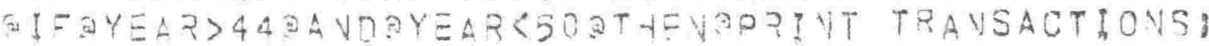

EXPEVD(1.1, Y,YEAR); 
จ เ

U: $:=0 ;$

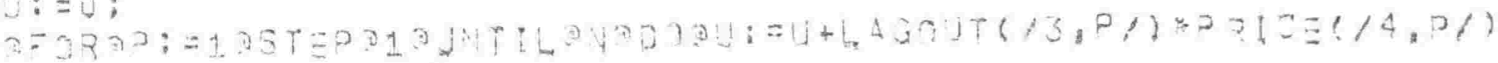

$V:=A(15,2, Y \equiv A P-1 /):$

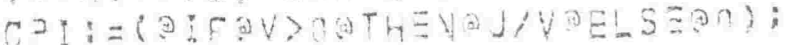

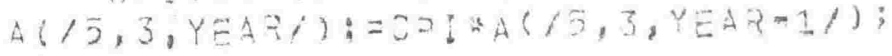

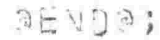

EXPEND(2,2, Y, YEAR);

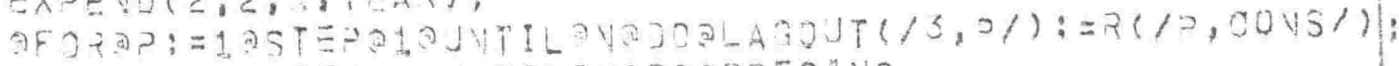

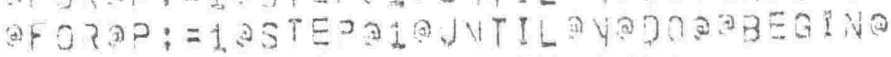

A $30, T(12,0 /):=?(/ 40+1,2 /) ;$

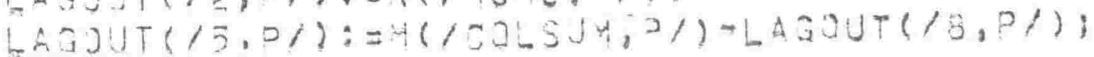

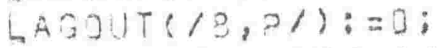

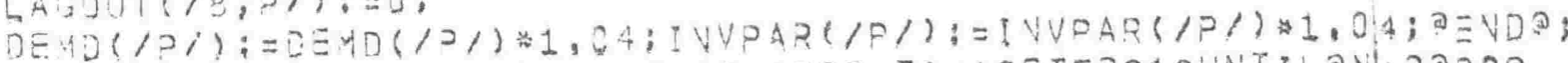

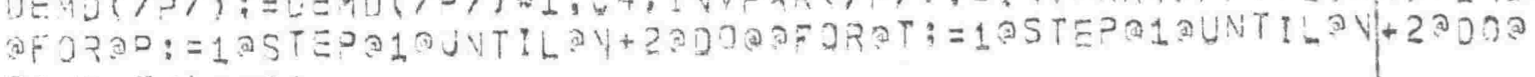

R( /P,T/: : =0:

$M(/ P, T /):=0$;

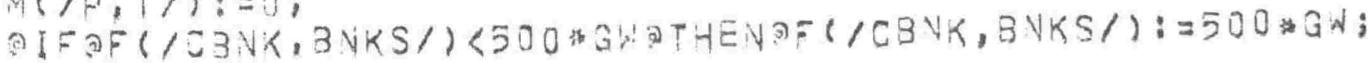

YEAR: $=Y E A R+1 ;$

QENDAAGSREGATE FIGURES;

[ SES AREA 3 SIZE 337]

READ NAYES; READ TECH;

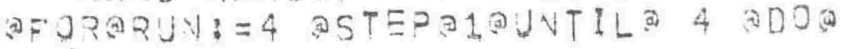

(a) $3=3$ ํㅣㅁ

$$
\text { จว। }
$$

RECOYIEVIE;

LAZUUR GOSTIVG:

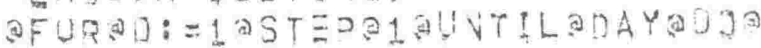

จืEG!

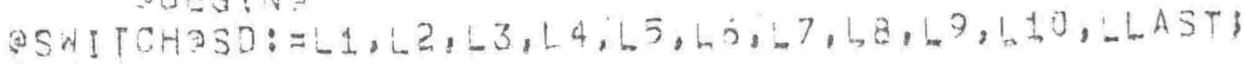

EARL!EST;

$G$ Gi: $=1,04 \% 4 \equiv A$;

बGUTUOSD(/S/)!

L1:SET PRODHITIOV TARGET; จGOYOALLAST;

L2:CALL FOR IYPUTS; AOJTOALLAST:

L3:COMPLETEN DROJUCTIOV TO IVVEYTORY; EGOTOQLLAST:

L4 COUSUYOTIOV PURCHASES YADE: MGOTOMLLAST:

L5:F\$XED CAPITAL IVVESTYEVT; AG JTOMLLASTI

L5:AUJUST HENT LIOUIIIDTY DEPV AVD LABOUR FORIEI DOOTOOLLASTI

LIAYY MONTH Y ADUUSTMEVTS; OAOTOALLAST;

L8:AGGREGATE = IBUPES FOP TIYE SERIES;OGOTDQLLAST;

LLAST:DA $(/ S, G /):=D A(/ S, G /)+D Y(/ S, G /)$;

अEYCo 0 OY ;

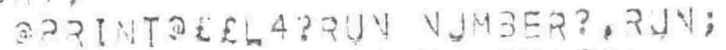

बPR! YTAEEL4?REAL OUTPUT BY SECTOZS?

PरI IIVIE SE?IES;

YAPS $=R(Y, Y E A R T)$;

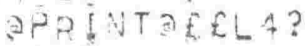

ES

E:PEND(1,4, NEART); गRT

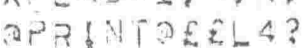

EXPEVD $(2,4, Y, Y E A R T) ; P R T$ TIMESERIES; YA JSER(N,YEART);

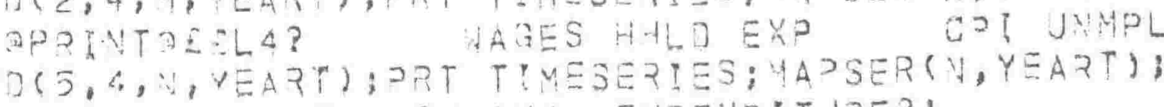

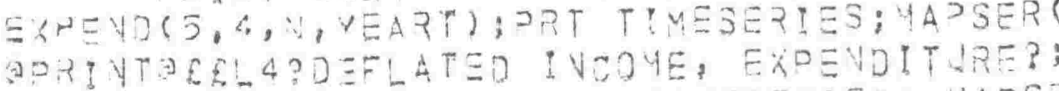

EXPEVD(3,4, V, PEATT); PRT TI ESERIES! HAPSER(N,YEART);

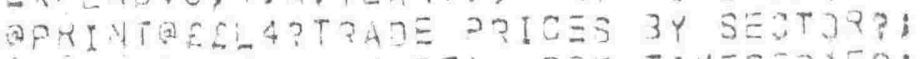

EXPEVU (4, 4, V, YEAरT); PरT TIYESERIES; YAPSER(V,YEAPT);

जPRIVTOŔLA? SUURCES OF EXPEVITURE BY SOURCE?;

EXPEVD $(5,4, Y, Y E A R T) ; P R T$ TIMESGRIES; YA DSER(N, YEART):

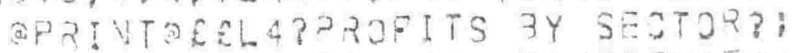

EXPEVI $(8,4, N, Y E A P T)$; PRT TI YESER!ES:

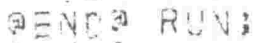

ALVUAMAIV B. OCK: 